\title{
TRUMP-BD: A Computer Code for the Analysis of Nuclear Fuel Assemblies Under Severe Accident Conditions
}
N. J. Lombardo
M. D. White
T. J. Marseille
P. S. Lowery

June 1990

Prepared for the U.S. Department of Energy under Contract DE-AC06-76RLO 1830

Pacific Northwest Laboratory Operated for the U.S. Department of Energy by Battelle Memorial Institute 



\section{ABSTRACT}

TRUMP-BD (Boi1 Down) is an extension of the TRUMP (Edwards 1972) computer procram for the anaiysis of nuclear fuel assemblies under severe accident conditions. This extension allows prediction of the heat transfer rates, metalwater oxidation rates, fission product release rates, steam generation and consumption rates, and temperature distributions for nuclear fuel assemblies under core uncovery conditions. The heat transfer processes include conduction in solid structures, convection across fluid-solid boundaries, and radiation between interacting surfaces. Metal-water reaction kinetics are modeled with empirical relationships to predict the oxidation rates of steam-exposed Zircaloy and uranium metal. The metal-water oxidation models are parabolic in form with an Arrhenius temperature dependence. Uranium oxidation begins when fuel cladding failure occurs; Zircaloy oxidation occurs continuously at temperatures above $1300^{\circ} \mathrm{F}$ when metal and steam are available. From the metalwater reactions, the hydrogen generation rate, total hydrogen release, and temporal and spatial distribution of oxide formations are computed. Consumption of stean from the oxidation reactions and the effect of hydrogen on the coolant properties is modeled for independent coolant flow channels. Fission product release from exposed uranium metal zircaloy-clad fuel is mode ed using empirical time and temperature relationships that consider the releitse to be subject to oxidation and volitization/diffusion ("bake-out") releitse mechanisms. Release of the volatile species of iodine (I), tellurium (Te) cesium (Ce), ruthenium (Ru), strontium ( $\mathrm{Sr})$, zirconium ( $\mathrm{Zr}$ ), cerium $(\mathrm{Cr})$, and barium (Ba) from uranium metal fuel may be modeled.

For vertically oriented flow channels undergoing coolant boiloff, the liquid-vapor dryout interface location is modeled based on coolant properties, coolent mass flow rate, channel geometry, and power generation. The primary limitations of the code are that material properties remain unaltered with oxidation, and molten material relocation is not modeled. Multiple phase changes for single materials are explicitly modeled, however. 


\section{ACKNOWLEDGMENTS}

The authors would like to acknowledge D. M. Ogden, and W. J. Quapp, Westinghouse Hanford Company, for the support of this documentation effort and the modeling enhancements performed in support of the $N$ Reactor Safety Enhancement Program. Additional thanks are extended to F. E. Panisko, Pacific Northwest Laboratory, for the opportunity to incorporate severe fuel damage models into the code in support of the U.S. Nuclear Regulatory Commission's NRU Coolant Boilaway and Damage Progression Program. The efforts of N. C. Waugh, C. D. Rilling, and B. D. Peterson for typing this manuscript, D. K. Hilliard for editing support, and C. L. Bartley for software support are also appreciated.

Finally, we would like to acknowledge the work by A. L. Edwards, the originator of the TRUMP code, who is indirectly responsible for the spin-off code, TRUMP-BD, and to whom we are gratefully indebted. 


\section{NOMENCLATURE}

a

A

Aox

Axs

b

B

C

CBDP

$C_{x}$

$f_{A}$

fps

fpf

$f_{x h}$

$F$

FLHT

GSCS

heff

$\mathrm{h} f \mathrm{~g}$

HLM

$h_{5 C}$

$k$

$K_{p}$

$1 c$

loca

LWR

Itr

luc

$M$

mi

ms

MWR

NRU

Metal-water reaction rate constant

Empirical constant for fission product release

Surface area available for oxidation

Cross-sectional area of boiloff region

Metal-water reaction rate constant

Empirical constant for fission product release

Empirical constant for fission product release

Coolant Boilaway and Damage Progression

Empirical constant for fission product release

Fraction of fuel-cladding surface area debonded

Concentration of fission product in surroundings

Concentration of fission product in fuel

Hydrogen blanketing rate-limiting factor

Fraction of uranium oxidized

Fult-length, high-temperature

Graphite and shield cooling system

Effective heat transfer coefficient for an uncovering node Heat of vaporization

Half-length model

Inlet coolant subcooling

Thermal conductivity

Reaction rate constant

Length of node covered in boiling region

Loss-of-coolant accident

Light-water reactor

Length of node in transition region

Length of node uncovered in dryout region

Molecular weight

Inlet mass flow rate

Exiting steam mass flow rate

Metal-water reaction

National Research Universal 
NOMENCLATURE (contd.)

\begin{tabular}{|c|c|}
\hline NSAC & Canadian Nuclear Safety Advisory Committee \\
\hline P & $\begin{array}{l}\text { Nusselt number } \\
\text { Pressure }\end{array}$ \\
\hline$P(z)$ & Axial power at position $Z$ \\
\hline $\mathrm{Pr}$ & Prandt 1 number \\
\hline $\operatorname{Re}$ & Reynolds number \\
\hline $\mathrm{Rb}_{\mathrm{b}}$ & Fission product release fraction due to bake-out \\
\hline$R_{0}$ & Fission product release fraction due to oxidation \\
\hline$T$ & Temperature \\
\hline t & Time \\
\hline$v$ & Vapor pressure for a fission product \\
\hline$x_{h}$ & Hydrogen/stear mass fraction \\
\hline Z & Axial position \\
\hline \multicolumn{2}{|l|}{ Greek } \\
\hline$\delta$ & Metal or gap thickness \\
\hline$\Delta Q$ & Energy release in a time step \\
\hline$\Delta t$ & Time step \\
\hline$\Delta \mathbf{Z}$ & Node axial length \\
\hline$a$ & Uranium oxidation area multiplier \\
\hline$\Delta \delta$ & Amount of metal consumed in a time step \\
\hline$\Delta H$ & Heat of reaction \\
\hline$\Delta T$ & Incremental temperature increase \\
\hline$\rho$ & density \\
\hline $\bar{\rho}$ & Average liquid density below the dryout front \\
\hline$\lambda$ & Position of liquid-vapor interface (dryout front) \\
\hline$\mu$ & Viscosity \\
\hline
\end{tabular}




\section{CONTENTS}

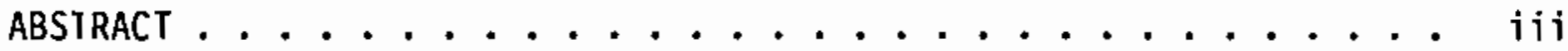

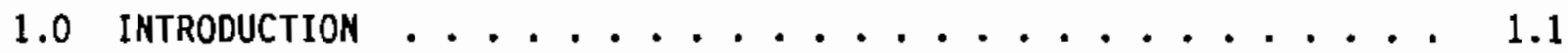

2.0 EXTENDED MODELING CAPABILITIES OF TRUMP-BD $\ldots \ldots \ldots$

2.1 INPUT DATA BLOCKS AND OUTPUT . . . . . . . . 2.2

2.1 .1 BLOCK $1 \ldots \ldots \ldots . \ldots . \ldots . \ldots 2$

2.1 .2 BLOCK $2 \ldots \ldots \ldots \ldots . \ldots \ldots . \ldots . \ldots . \ldots . \ldots$

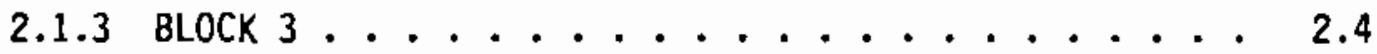

2.1 .4 BLOCK $4 \ldots \ldots . \ldots . \ldots . . \ldots 2 . \ldots$

2.1 .5 BLOCK $5 \ldots \ldots \ldots \ldots \ldots . \ldots \ldots$

2.1 .6 BLOCK $6 \ldots \ldots \ldots \ldots . \ldots \ldots$

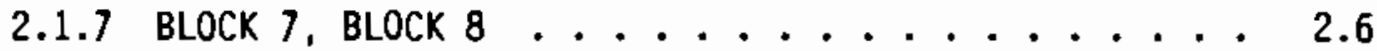

2.1 .8 BLOCK $9 \ldots \ldots \ldots \ldots . \ldots \ldots$

2.1 .9 BLOCK $10 \ldots \ldots \ldots . \ldots . \ldots . . \ldots 2.7$

2.1 .10 BLOCK $11 \ldots \ldots . \ldots . \ldots . \ldots 2 . \ldots$

2.1 .11 BLOCK $12 \ldots \ldots \ldots . \ldots . \ldots 2 . \ldots$

2.1 .12 BLOCK $13 \ldots \ldots \ldots . \ldots . \ldots . \ldots 2 . \ldots$

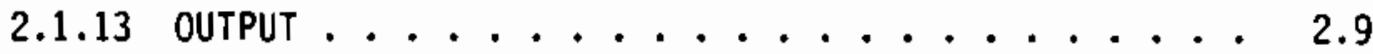

2.2 MODELING RESTRICTIONS AND LIMITATIONS . . . . . . 2.10

2.2 .1 Input Restrictions ............. 2.11

2.2.2 Metal-Water Reaction Modeling ......... 2.12

2.2.3 Simulation of Coolant Boiloffs ......... 2.13

2.2.4 Fission Product Release ........... 2.13

3.0 TRUMP-BD SUBROUTINES $\ldots \ldots \ldots . \ldots \ldots . \ldots . \ldots . \ldots$ 


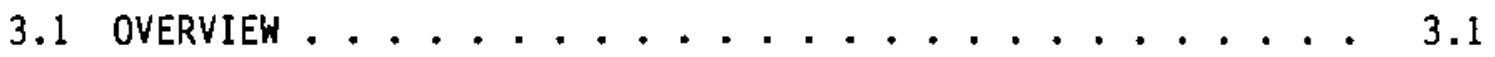

3.2 PROGRAM TRUMP $\ldots \ldots \ldots \ldots . \ldots \ldots . \ldots . \ldots . \ldots . \ldots$

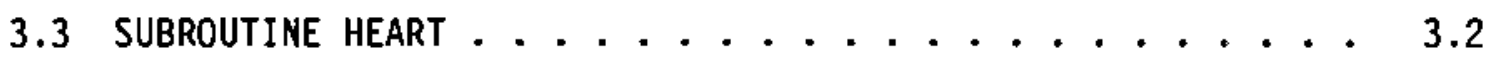

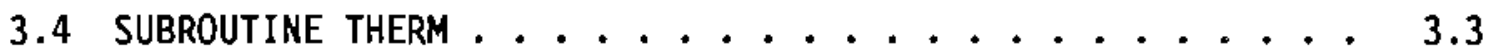

3.5 SUBROUTINE GEN . . . . . . . . . . . . . 3.4

3.5 .1 Input BLOCK $8 \ldots \ldots \ldots . \ldots . \ldots . \ldots . \ldots$

3.5 .2 Metal-Water Reactions .......... 3.5

3.5.3 Node Effective Temperature Rise ........ 3.13

3.6 SUBROUTINE FINK . . . . . . . . . . . . . . 3.13

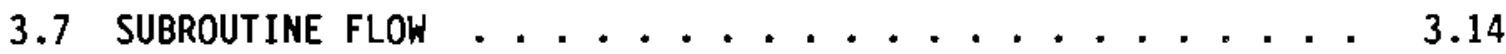

3.7 .1 Input ......................... 3.17

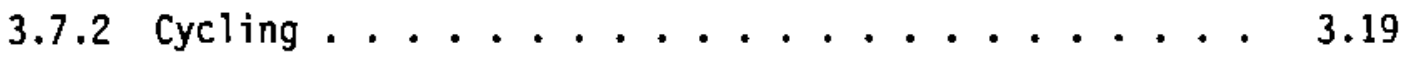

3.7.3 Coolant Boiloff Modeling ......... . 3.20

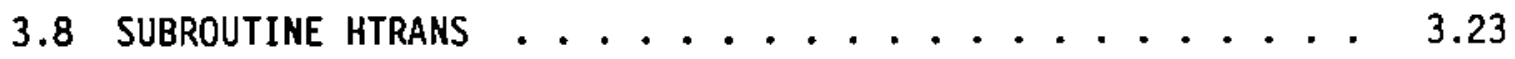

3.8.1 Heat Transfer Correlations and Models ....... 3.24

3.8.2 Severe Accident Heat Transfer Models ....... 3.28

3.9 SUBROUTINE SURE $\ldots \ldots \ldots . \ldots \ldots . \ldots \ldots$

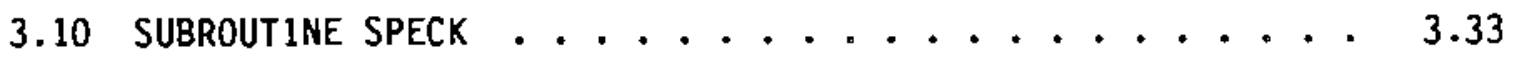

3.11 SUbROUtINE TALLY $\ldots \ldots \ldots \ldots . \ldots \ldots$

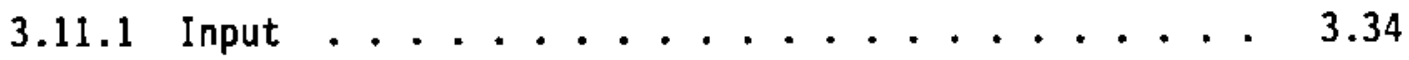

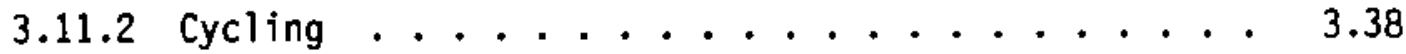

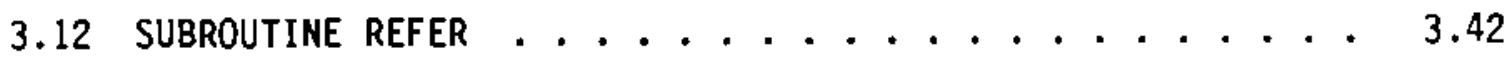

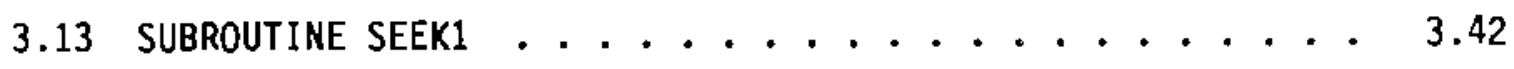

3.14 SUBROUtINE TIMER $\ldots \ldots \ldots . \ldots . \ldots . \ldots . \ldots . \ldots$

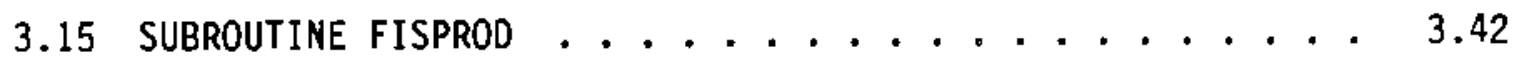


3.15 .1 Input BLOCK $13 \ldots \ldots . \ldots . \ldots 3 . \ldots \ldots$

3.15.2 Fission Product Release from Nuclear Fuel . . . 3.43

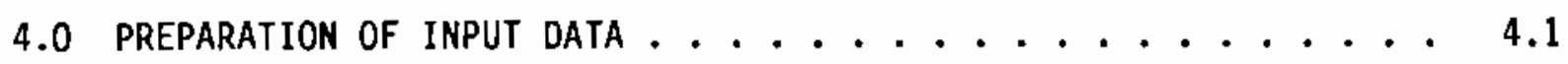

4.1 CARD INPUT FORMATS ....................... 4.1

4.2 DATA DECK ORGANIZATION ..................... 4.1

4.2 .1 Data Decks .............. . 4.1

4.2.2 Problem Name Card ............ 4.1

4.2 .3 BLOCK Number Cards ............. 4.2

4.2 .4 Data End Card .............. 4.3

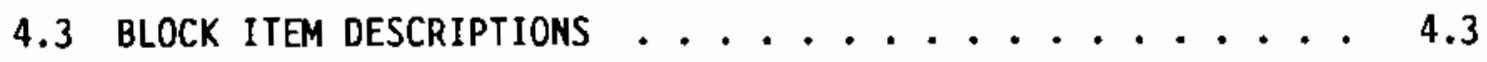

5.0 OUTPUT AND POST-PROCESSING OUTPUT FILES . . . . . . . . 5.1

5.1 OUTPUT FILE $\ldots \ldots \ldots \ldots \ldots \ldots . \ldots \ldots . \ldots \ldots$

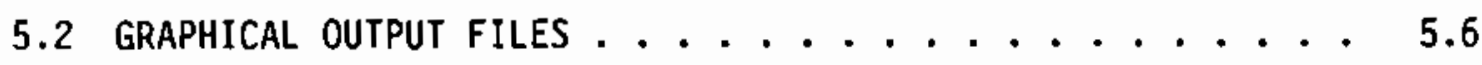

5.2 .1 TAPE3 ............................ 5.6

5.2 .2 TAPE5 $\ldots \ldots \ldots \ldots \ldots \ldots . \ldots \ldots$

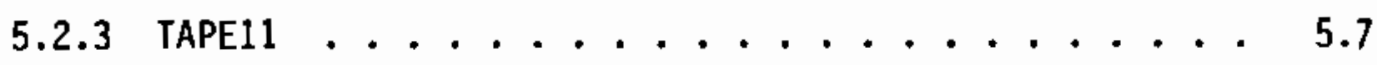

5.2 .4 TAPE12 . . . . . . . . . . . . . 5.8

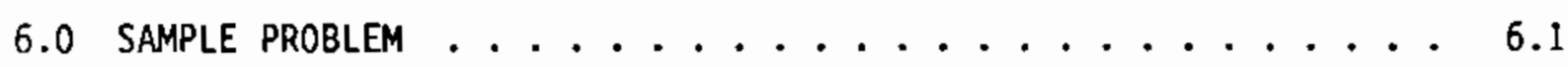

6.1 DESCRIPTION OF N REACTOR . . . . . . . . . 6.1

6.2 MODELING METHODOLOGY ....................... 6.2

6.2 .1 The Half-Length Model .......... 6.2

6.2.2 Station Blackout Accident Scenario Modeling . . . 6.9

6.3 DISCUSSION OF TYPICAL INPUT LINES $\ldots \ldots \ldots . \ldots \ldots$

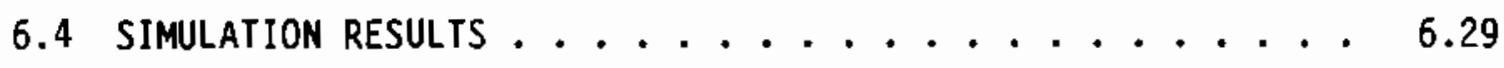

6.4 .1 Inlet Half ................... 6.29 
6.4 .2 Outlet Half ............... 6.32

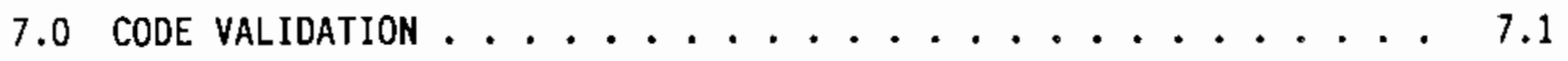

8.0 CODE DIMENSIONING . . . . . . . . . . . . 8.1

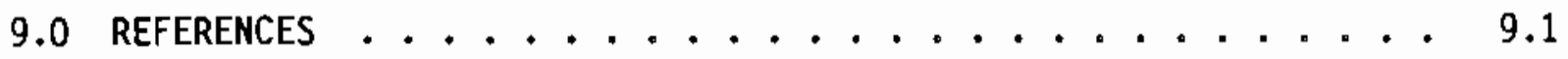

APPENDIX A - VARIABLE GLOSSARY .............. A.1

APPENDIX B - SAMPLE PROBLEM INPUT/OUTPUT FILES . . . . . . . B. 1

APPENDIX C - BOUNDARY CONDITIONS FOR THE TRUMP-BD N REACTOR STATION

BLACKOUT ACCIDENT ANALYSIS: RELAP5 PREDICTIONS . . . . C. C. 


\section{FIGURES}

3.1 Illustration of Fuel Pin Assignments for Fuel Failure

Modeling . . . . . . . . . . . . . 3.12

3.2 Sample Configuration Demonstrating the Relationship between

Flow Regions and Flow Subchannels . . . . . . . . . 3.15

3.3 Illustration of the Node Numbering Scheme for a Multiple Flow

Region Model.................... 3.16

3.4 Key Concepts and Parameters for Modeling a Coolant Boiloff . . 3.21

3.5 Heat Transfer Regimes and Modeling for an Uncovering Node . . . 3.30

3.6 Characteristics and Variable Definitions for a Chopped-Cosine

Axial Power Distribution ............... 3.39

3.7 Cesium Release from Uranium Oxidized in Air . . . . . . 3.45

3.8 Fission Product Release from Uranium Oxidized at $1200^{\circ} \mathrm{C}$. . . 3.45

3.9 Iodine Release from Uranium oxidized in Air . . . . . . . 3.46

3.10 Tellurium Release from Uranium Oxidized in Air at $1200^{\circ} \mathrm{C}$. . . 3.46

6.1 N Reactor Core and Reflector Geometry . . . . . . . . 6.3

6.2 Transverse Cross Section and Nodalization of the Fueled Process Tube ................... 6.4

6.3 TRUMP-BD Nodalization--Cooled Filler Blocks Axial Segment . . 6.5

6.4 TRUMP-BD Nodalization--Uncooled Filler Block Axial Segment . . . 6.6

6.5 Axial Segmentation of the Half-Length Process Tube . . . . . 6.8

6.6 Inner and Outer Fuel Predicted Temperature Histories at Axial Levels 44 and 57--N Reactor Station Blackout . . . . . . . 6.30

6.7 Outer Fuel Predicted Axial Temperature Distribution at 500, 1000, and $2886 \mathrm{~s}-\mathrm{N}$ Reactor Station Blackout . . . . . . . . 6.31

6.8 Peak Inner and Outer Fuel Predicted Temperature Histories-N Reactor Station Blackout . . . . . . . . . . . . 6.33

6.9 Predicted Hydrogen Released--N Reactor Station Blackout . . . 6.34 
6.10 Predicted Hydrogen Release Rate--N Reactor Station Blackout . . 6.35

C.1 RELAP5--Vapor Void Fraction Versus Time--Inner Flow Channel . C.1

C.2 RELAP5--Vapor Void Fraction Versus Time--Middle Flow Channel . C C.2

C.3 RELAP5--Vapor Void Fraction Versus Time--Outer Flow Channel . C C.3

C.4 RELAP5--Mass Flow Rate Versus Time--Inner Channel . . . . C.4

C.5 RELAP5--Mass Flow Rates Versus Time--Middle Channel ..... C.5

C.6 RELAP5--Mass Flow Rate Versus Time--Outer Channet . . . . C.6

C.7 RELAP5--Pressure Versus Time . . . . . . . . c.7

C.8 RELAP5--Void Fraction Versus Time--Inner Channel . . . . C.8

C.9 RELAP5--Void Fraction Versus Time--Middle Channel ...... C.9

C.10 RELAP5--Void Fraction Versus Time--Outer Channel . . . . . . C.10 


\section{$\underline{\text { TABLES }}$}

3.1 Subroutine Calls - Input Phase . . . . . . . . 3.2

3.2 Order of Subroutine Calls - Time Step Phase . . . . . . 3.3

3.3 Illustration of Metal-Water Reaction Node Pointer Array . . . 3.7

3.4 Heat Transfer Models and Correlations - Subroutine HTRANS . . . . 3.23

3.5 Fission-Product Release from Uranium Fuel Irradiated to 1.0-atom

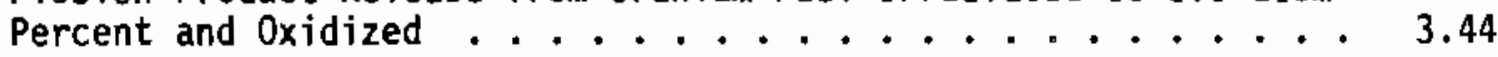

3.6 Oxidation-Induced Fission Product Release Constants . . . . . 3.44

3.7 Fission Product ReJease Data for Metallic Uranium Melted in an Inert Atmosphere ............... 3.48

3.8 Vapor Pressure Equation Coefficients .......... 3.49

4.1 TRUMP Input Data Blocks ................ 4.3

8.1 Parameter Descriptions ............... 8.3 


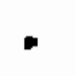


TRUMP-BD: A COMPUTER CODE FOR THE ANALYSIS OF NUCLEAR FUEL ASSEMBLIES UNOER SEVERE ACCIDENT CONDITIONS

\subsection{INTRODUCTION}

TRUMP-BD (Boil Down) is an extension of the TRUMP (Edwards 1972) computer program designed to analyze themal and hydrogen evolution responses during severe temperature transients in a reactor core. The TRUMP-BD program language is FORTRAN $\checkmark$ and simulations characteristic of severe transients are typically executed on super-computer mainframe machines. TRUMP-BD has been successfully adapted to execute on the Los Alamos National Laboratory Central Computing Facility's array of CRAY-1S $S^{T U}$ (a) and CRAY-XMP computers and the Hanford Site CRAY-XMP-14. For limited problem sizes, TRUMP-BD has been executed on an Apple Computer Macintosh II'M(b) at the Pacific Northwest Laboratory (PNL)(c).

TRUMP-BD has retained the majority of the computational capabilities of its fredecessor version of TRUMP. However, this base version of TRUMP lacked those subroutines associated with general chemical reactions. Although TRUMF-BD is capable of solving the same general nonlinear parabolic partial differential equations as its predecessor code, the extended modeling capatilities tailored for reactor accident analys is may render the code cumbersome to use for some applications.

The impetus for developing TRUMP-BD originated with two PNL research programs sponsored by the U.S. Nuclear Regulatory Commission and conducted in the National Research Universal (NRU) Reactor(d): the Materials Tests

(a) Cray-1S is a registered trademark of Cray Research, Inc. Minneapolis, MN.

(b) Apple Computer Macintosh II is a registered trademark of Apple Computer, Inc., Cupertino, CA.

(c) Jperated for the U.S. Department of Energy (DOE) by Battelle Memorial Institute under Contract DE-AC06-76RL0 1830.

(d) Operated by Chalk River Nuclear Laboratories, Chalk River, Ontario, Canada. 
Program (MT) and the Coolant Boilaway and Damage Progression (CBDP) Program(a). These research programs are directly concerned with the behavior of lightwater reactor (LWR) fuel under loss-of-coolant accident (loca) conditions, and have been active for approximately nine years. The TRUMP-BD computer code has been and is currently used for test guidance and to address safety issues relevant to the conduct of these in-reactor tests, providing predictions of hydrogen production rates and integrated release, heatup rates and temperature distributions, radial heat losses, and liquid level position. Although the data from these tests are proprietary, the TRUMP-BD simulation results have been successfully benchmarked against the experimental data (Section 7.0).

Following the incorporation of LWR severe fuel damage models for the NRU CBDP Program, TRUMP-BD was further modified in support of the $N$ Reactor Safety Enhancement Program. N Reactor, located on the U.S. Department of Energy's Hanford site near Richland, Washington, is a $4000 \mathrm{MHt}$ light-water reactor with cylindrical uranium metal fuel clad with Zircaloy. Models for fuel failure, uranium oxidation, multiple phase changes, and multiple flow channels were incorporated into the code for the analysis of core heatup and hydrogen production for the Hydrogen Mitigation Design Basis Accident (HMDBA), a hypothetical loss-of-coolant accident for the graphite-moderated reactor (Heard et al. 1987). More recently(b), algorithms for fission product release were incorporated into TRUMP-BD as part of a concentrated effort to provide an independent benchmark of fission product release/retention behavior in support of probabilistic risk assessment studies for $\mathbf{N}$ Reactor.

The types of geometries that $c$ an be modeled require oxidizing nodes (Zircaloy and/or uranium) to be connected (adjacent) to fluid flow channels.

(a) Partners in this program with NRC include nuclear organizations from the following countries: Belgium, Canada, England, Federal Republic of Germany, Italy, Japan, The Netherlands, Republic of China (Taiwan), Republic of Korea, Spain, Switzerland, and Sweden.

(b) Marseille, T.J., Z.I. Antoniak, and A.W. Cronenberg. 1989. Fission Product Release Hydrogen Production and Thermal Response of Peak Power Process Tubes in the $\mathrm{N}$ Reactor for the Hydrogen Mitigation Design Basis Accident. ESD-89-106, Pacific Northwest Laboratory, Richland, Washington. 
The flow channel and surrounding material geometric configurations may be complex three-dimensional structures. The definition of axial levels along the longitudinal length of the model in the direction of the flow dominates a large portion of the TRUMP-BD logic to determine the location where steamstarved (complete conversion of stean to hydrogen) conditions exist. Metal oxidation is limited to Zircaloy and uranium; however, oxidation of other metals can be added quite readily. The reaction kinetics that ultimately determine hydrogen evolution are modeled with parabolic rate equations; thus, formation of an oxide layer inhibits further oxidation of the surface. For uranium oxidation with steam, the Wilson (1966) correlation is applied, whereas for Zircaloy oxidation, a user-specified correlation is chosen from one of four available correlations: Cathecart et a1. (1977), Urbanic and Heidrick (1978), Prater and Cartwright (1986), or Baker and Just (1962). The multiple phase changes characteristic of uranium metal behavior during loss-of-coolant accidents can also be modeled.

Fission product release from exposed fuel is modeled using empirical time and temperature varying relationships, originally derived by Birney et a1. 1988), for the volatile species of iodine (I), tellurium (Te), and cesium (Ce), as well as the less volatile species of ruthenium (Ru), strontium (Sr), zirconium $(\mathrm{Zr})$, cerium $(\mathrm{Cr})$, and barium $(\mathrm{Ba})$. Subsequent transport and deposition of released fission products are not part of the model, nor is the eventual depletion of inventories due to ongoing nuclear decay.

The code memory requirements can be varied with FORTRAN PARAMETER statements that control the size of arrays (see Section 8.0). Computation time is dependent upon the computer, its memory size and the specific problem, and can vary between seconds and hours of central processing (CPU) time.

TRUMP-BO input and output files are similar in structure to those of TRUMP. The input data files retain their block structure and differ in those areas related to the extended capabilities of TRUMP-BD. The output file maintains the standard TRUMP capabilities and, in addition, provides summaries of the metal-water reactions, hydrogen generation, and fuel failures. 
The primary emphasis of this manual is to describe in detail the theory and application of the extended capabilities of TRUMP-BD. This manual can be used as either an appendix to the TRUMP user's manual for new users, or as a stand-alone document for users experienced with the TRUMP code. With this document, a user will be able to construct an input data file, execute a severe fuel damage simulation, and interpret the output data. To fully appreciate the nonlinear parabolic partial differential equation solution method or the complete capabilities of the code, the TRUMP user's manual should be consulted. 


\subsection{EXTENDED MODELING CAPABILITIES OF TRUMP-BD}

The TRUMP-BD code contains modeling capabilities that extend those of TRUMP for problems concerned with metal-water reactions in flow channels. Because TRUMP-BD was historically developed with the intent of addressing hydrogen evolution in nuclear reactor severe accidents, a number of the extensions were designed for the multiple flow channels and boiloff phenomena of reactor core accidents.

The TRUMP-BD code was created from a standard version of TRUMP code (less the subroutines KITTY, CHEM, PLOT, and PRIME). With the exceptions of general chemical reactants, TRUMP plotting, and a restart option, all of the TRUMP capabilities remain in the TRUMP-BD code.

A considerable portion of TRUMP-BO's extended capabilities are revealed by reviewing modifications in the input and output portions of the code. Because the block structure of the TRUMP input has been maintained in TRUMP-BD, the extended capabilities will be discussed following the block structure of the nput. The extended capabilities that impact the output file will be disclissed separately. Before reviewing the individual input block modifications, a brief overview of the TRUMP-BD extended capabilities is presented.

As previously stated, the TRUMP-BD code was developed to address nuclear reactor core accidents that are characterized by Zircaloy and uranium oxidation with concurrent hydrogen evolution. The chemical energy release for these exothemic reactions and the hydrogen evolution are computed from the mass of metal consumed. The metal oxidation kinetics follow parabolic rate equations. Fission product release from exposed uranium fuel is computed using empirical relationships that consider release to be simultaneously subject to oxidation and volatilization/diffusion ("bake-out") release mechanisms.

The coolant flow regions that supply steam for oxidation are segmented into axial levels in the direction of the flow. Each flow region may be divided into subchannels. In TRUMP-BO terminology, a flow region may be either a grouping of flow subchannels or a single channel. Flow regions may either be oriented verticaliy or horizontally. A vertically orientated flow region with upward coolant flow may undergo a coolant boiloff, with the liquid/vapor dryout interface computed internally or specified. Depletion of the coolant 
by the metal-water reactions occurring at the channel walls is also modeled, as is the effect of hydrogen gas on the convective heat removal.

Beyond these major extensions, the TRUMP-BD code includes modifications to track select node quantities such as temperature, nuclear and chemical heat generation, hydrogen evolution, and metal oxidation. A variety of heat transfer correlations and models have also been incorporated. Because of the elevated temperatures characteristic of severe reactor accidents, the capability to model multiple phase changes is also included in TRUMP-BO.

A complete compilation of the extensions and code modifications will be discussed in the following review of the TRUMP-BD input blocks and output file. The modeling restrictions and limitations of the TRUMP-BD extensions are also presented.

\subsection{INPUT DATA BLOCXS AND OUTPUT}

Described below are the extensions to the standard TRUMP input blocks and output file.

\subsubsection{BLOCK 1}

TRUMP-BD has extended the standard graphics file of standard TRUMP. Graphics files are used to store various output data sets for subsequent graphic processing. Three graphics post-processing files may be generated: 1) a "system summary" file (TAPE3) that contains data on the overall model results, i.e., total nuclear and metal-water reaction power, hydrogen generation rate, fission product release, etc.; 2) a "special node" temperature output file (TAPE5); and 3) an axial profile file that contains data for each axial level, including total heat generation rate, radial heat loss, leaving hydrogen fraction from coolant flow regions, amount of unoxidized metal remaining and user-specified node temperatures (TAPE11). The time intervals between data transfers to these graphic output files is controlled by parameters in BLOCK 1.

Diagnostic printouts added to the output file summarize heat generation, convection, internode heat transfer, oxidation, and heat losses. TRUMP-BD also includes provisions for writing information about user-specified "special output nodes" at different intervals than the normal output. Special output 
nodes permit the user to track the temperatures and information on the current phase change of a few select nodes without having to print the complete normal output block, thus reducing the output file size.

Additionally, TRUMP-BD includes capabilities for suppressing portions of the normal output through input parameters in BLOCK 1 . One option is to suppress the output of node material properties, internal connection properties, node heat content, and node temperature changes during a simulation. Other options suppress output data previously printed in TRUMP, such as indication in the output file when a "regular" node is changed to a "special" node in the calculational scheme, and/or indication in the output file when a repeated cycle (time step) has occurred.

\section{1 .2 BLOCK 2}

Parameters necessary for describing materials comprise the BLOCK 2 input. Because TRUMP-BD was designed with the intent to model the oxidation of uranium and Zircaloy metal in the presence of steam, these materials have been restricted to unique material identification numbers: 1 for uranium, 100 for Zircaloy, 10 for steam or water, and 11 for hydrogen. These material numbers trigger the appropriate oxidation algorithms or property mixture models within the code. Oxidation of the metals yields hydrogen gas that subsequently becomes part of the coolant. Through appropriate inputs in BLOCK 2, the effects of combined steam/hydrogen mixtures can be modeled. Binary gas property mixtures affect the coolant's ability to oxidize meta1, absorb heat, and convect heat away from the channel surfaces. These phenomena are accounted for by allowing the coolant properties to change along the coolant channel in response to depleting steam and evolving hydrogen quantities.

The capability to model multiple phase changes for materials is also an extended capability defined in BLOCK 2 (the original TRUMP code allowed oniy a single phase change). Additionaliy, the effect of temperature on internally calculated convective heat transfer coefficients has been added, requiring specification of coolant density and viscosity. As in the standard TRUMP code, constant density is assumed for convective transport. 


\subsubsection{BLOCK 3}

BLOCK 3 and the associated chemical reaction algorithms (subroutine CHEM) were not included in the version of TRUMP that served as a base for TRUMP-BD.

\section{1 .4 BLOCK 4}

The TRUMP-BD code extensions that pertain to BLOCK 4 include data concerning coolant boiloffs (dryout front position vs. time), the number and length of axial nodes (levels), node fuel "pin" numbers (fuel elements), and node oxidation data (exposed surface area, thickness, and associated flow region). For coolant boiloff problens, the dryout front location may be prescribed as a function of time, with the user having the option of varying the power (BLOCX 9) or coolant mass flow rate (BLOCK 10) to obtain a desired liquid level history.

The concept of axial levels is unique to the TRUMP-BD code and is necessary to calculate the location where fully-consumed conditions exist (complete conversion of stean to hydrogen). Axial levels are defined by structuring the noding scheme into distinct axial segments in the direction of flow along the length of the coolant channels. Up to 99 axial levels may be defined for a given problem. Axial segmenting permits the modeling of dryout fronts, steam depletion, and hydrogen evolution. Axial levels may vary in length from level to level.

Specifications of flow regions and fuel pin numbers are also particular to TRUMP-BD. Flow regions are necessary to associate oxidizing surfaces with a particular steam source. This allows hydrogen evolution and steam depletion to be uniquely calculated for a flow region. A fuel pin is a grouping of fuel nodes that represent a fuel rod or element. Fuel failures are determined for a particular fuel pin and affect all fuel nodes assigned to that fuel pin at a given axial level. Oxidation of uranium nodes can occur only after fuel failure.

For oxidizing nodes, a metal-water reaction material type (1 for uranium, 100 for Zircaloy), a surface oxidation area, and material thickness must be prescribed. Inputs for these nodes are declared in BLOCK 4. Typically, the oxidation area is defined as that area exposed to the coolant. 


\section{1 .5 BLOCK 5}

BLOCK 5 contains the parameters that describe the thermal connections between nodes. TRUMP-BD was extended to allow temperature or time-dependent thermal connections. Additionally, heat transfer between connected nodes can be specified from the following correlations or models:

- The Dittus-Boelter correlation is intended for heat transfer between fully-developed turbulent flow and a channel wall(a).

- The Wong-Hochreiter (1981) correlation describes the heat transfer between the fuel cladding and steam for low Reynolds number, forced convection steam cooling under core dryout conditions(a).

- The $\mathbb{N}$ Reactor gap conductance model computes a heat transfer coefficient between the Zircaloy-2 cladding and uranium metal for $N$ Reactor fuel under clad debonding conditions. The correlation is based on information contained in N Reactor safety analysis documents(b).

- The thermal bridge model is designed to handle irreversible step changes in a heat transfer coefficient dependent on a node temperature. The bridge model has proved valuable in describing the discontinuities that occur when a fuel element fails. Fuel failures are representative of irreversible processes that impact the heat transfer between connected nodes.

- The variable heat transfer option allows the user to specify a temperature or time-dependent heat transfer between two connected nodes. A typical application for this capability is the contact conductance between two solid materials.

(a) The necessary fluid properties are computed within TRUMP-BD and are dependent on the local velocity, coolant temperature, pressure (assumed constant), and gas composition.

(b) UNC 1978, N Reactor Updated Safety Analysis Report: NUSAR, United Nuclear Industries, UNI-M-90, Richland, Washington. 


\section{1 .6 BLOCK 6}

BLOCK 6 contains parameters that describe thermal connections to external nodes. The extended capabilities are limited to heat loss accounting. Heat losses to external heat sinks or sources are accounted for by denoting specific external node numbers. Heat transfer for all connections to external node 1000 are labeled as axial heat losses in the OUTPUT file; similarly all heat transfer through external node 2000 is considered as radial heat losses in the OUTPUT file. Heat transfer to all other external node numbers is labeled as miscellaneous heat losses in the OUTPUT file.

\section{1 .7 BLOCK 7, BLOCK 8}

No extended capabilities are directly associated with BLOCK 7 or BLOCK 8 . The input structure for these blocks remain identical to the base TRUMP code.

\section{1 .8 BLOCK 9}

For TRUMP-BD problems, BLOCK 9 is used to specify information about node initial conditions, heat generation, metal-water reactions, fuel failure, and steam depletion. An extensive number of modifications to this input block were made for reactor applications.

Specification of node heat generation has been considerably revamped. Node internal heat generation is now computed by specifying an average fuel rod power, an axial power distribution, a radial power factor(a), and a timevarying power history. This capability eliminates the need to specify individual power/time histories for each node. The axial power distribution may be user-specified or calculated from a chopped-cosine profile. Time-varying heat generation may be specified either for boiloff or nonboiloff problems.

A significant extension of the BLOCK 9 input involves metal-water reactions. Although the Zircaloy-water reaction is ignored below node temperatures of $1300^{\circ} \mathrm{F}$, several oxidation kinetic equations are available to the user. One of four parabolic kinetic equations can be selected: Cathecart et al. (1977), Urbanic and Heidrick (1978), Prater and Courtwright (1968), or Baker and Just (1967).

(a) The radial direction is defined as perpendicular to the axial direction. 
Uranium oxidation follows the Wilson (1966) parabolic kinetic equation but ' $s$ computed only for times following fuel pin failure. All fuel nodes assigned to a fuel pin will undergo oxidation once its associated fuel surpasses the fuel failure temperature. A uranium oxidation area multiplier (modifying the data specified in BLOCK 4) is used to account for local changes due to fuel relocation and/or swelling, and may be declared as a function of the uranium node temperature. Another control option the user has with respect to metal oxidation is the anount of steam available for oxidation. The user may either declare oxidation based on the amount of local steam available or select the unlimited steam model, which assures unlimited steam availability for metal-water oxidation. 0xidation may also be limited by invoking the hydrogen blanketing model. With this model the presence of hydrogen limits the oxidation reaction rate.

TRUMP-BD allows rapid initialization of node temperatures and phase change concentrations. For multiple phase change materials, the active phase change may be initially declared along with the initial phase change fraction. An axial variation in initial temperature may also be described.

Some miscellaneous extensions associated with BLOCK 9 allow the user to differentiate and uniquely specify gama heating and fission volumetric heat generation rates. An integrated power profile table must also be prescribed in conjunction with the axial power profile for boiloff simulations. Timedeperident power generation and/or time-dependent inlet flow can be selected as a forcing function for coolant boiloff simulations in BLOCKS 9 and 10 , respectively.

\subsubsection{BLOCK 10}

BLOCK 10 contains parameters that describe the flow regions, flow connections, and the necessary variables for a boiloff simulation. Boiloff simulations require a prescription of two out of the following three parameters: 1) energy deposited to the coolant, 2) coolant inlet mass flow rate, and 3) the initial dryout front location. The unspecified parameter is then computed by TRUMP-BD. All three parameters may be declared as a function of simulation time with table inputs: the dryout front position in BLOCK 4, the power generation in BLOCK 9 , and the mass flow rate in BLOCK 10 . 
TRUMP-BD differs from TRUMP with the addition of flow regions and flow subchannels. These concepts have been introduced to facilitate the tracking of steam availability and hydrogen evolved from oxidizing surfaces. Several flow regions may be declared for a single simulation with each flow region composed of multiple flow channels. Only a single flow region undergoes coolant boiloff in a given simulation. The amount of steam available for oxidation and convective heat transfer from solid surfaces is based on the flow for a given flow region. The convective transport is based on subchannel flow, however. Each flow region can have a unique time-dependent mass flow; all subchannel flows within a region are varied similarly.

\section{1 .10 BLOCK 11}

BLOCK 11 in the base version of TRUMP contains output control. Control of output in TRUMP-BD has been transferred to other input blocks previously described, therefore BLOCK 11 is not used in TRUMP-BD and its associated subroutines.

\section{1 .11 BLOCK 12}

BLOCK 12 remains unaltered between TRUMP and TRUMP-BD, therefore retaining the capability for node properties to be dependent on remote temperatures.

\section{1 .12 BLOCK 13}

BLOCK 13 was added to provide user-supplied information about fission products needed to model fission product release during the simulation of a zircaloy-clad uranium fuel nuclear assembly undergoing a severe loss-of-coolant accident.

Among the required input parameters are:

- The number of fission products being modeled

- The whole core initial inventory of each fission product, and the fraction of whole core power generation that occurs in the specific fuel assembly being modeled. (These are used in the computation of initial uranium node fission product inventories during the first time step).

- Four empirical constants for each fission product being modeled. These are used as coefficients in the oxidation and bake-out empirical relationships for fission product release in TRUMP-BD. 
Usiny current inventories, the total fission product release is computed for each failed fuel node at each time step subsequent to failure. Node inventories are then updated before the next time step.

\subsubsection{OUTPUT}

Output unique to TRUMP-BD is typically controlled through input parameters unique to TRUMP-BD. TRUMP-BD also provides control over the standard TRUMP output through the output suppression parameters. These parameters should be used to prevent unwanted output from enlarging the OUTPUT file. TRUMP-BD's extended output is summarized below; a complete discussion of the output and graphics files is presented in Section 5.0.

Output parameters related to boiloff simulations and the restructuring of the BLOCK $g$ (internal heat generation) input of TRUMP-BD include:

- coolant state properties

- integrated axial power at dryout front

- coolant mass flow rate (boiloff region)

- axial location of the dryout front

- rod average power.

With respect to metal-water reactions and maximum metal temperatures, TRUMP-BD output includes:

- maximum Zircaloy (material type 100) and uranium (material type 1) temperatures

- node heat generation from oxidation and other sources

- metal thickness remaining

- coolant hydrogen and steam concentrations

- hydrogen production rate and total hydrogen evolution.

The metal-water reaction data is also detailed by axial level. Comprised in these results are:

- oxidation heat generation uniquely from uranium and Zircaloy

- average uranium and Zircaloy thickness remaining

- hydrogen production rate from uranium and Zircaloy.

The following fission product release results are written for each fission product for each failed fuel node, along with the sum total for the entire model: 
- integral release due to oxidation and bake-out release mechanisms

- release rate due to oxidation and bake-out release mechanisms. TRUMP-BD also prints parameters important for output diagnostics. The extended output includes:

- special output node temperatures

- heat generation by fuel pin

- variable heat transfer coefficient summaries

- radial and axial heat loss values

- phase change status

- detailed heat balance information.

The heat balance information contains quantitative results for numerous heat sources, sinks, and transfer pathways. Each simulation is completed with a final system summary, which reports temperatures, oxidation thicknesses, and heat generation rates for all nodes.

In conclusion, TRUMP-BD modeling capabilities extend those of the base TRUMP code in the area of severe reactor accidents. Although a major portion of the extensions have limited application beyond this class of problems, the code has remained general enough to address a variety of problems. With a little insight, a user can take advantage of the code's extended capabilities beyond the scope discussed here. For example, a passive solar phase change problem could be solved with the multiple phase change and variable heat transfer coefficient capabilities of TRUMP-BD. Conduction problems with expanding and contracting material gaps are also within TRUMP-BD's capacity.

\subsection{MODELING RESTRICTIONS AND LIMITATIONS}

In keeping with the concepts of standard TRUMP, multi-dimensional models with mixed geometry coordinate systems (e.g., Cartesian, polar, and spherical) can be created and the transient and steady-state temperature distributions obtajned. The major limitation of standard TRUMP that carries over to TRUMP-BD is that the mass and momentum conservation equations for the fluid are not part of the solution scheme. Without the coupling of these conservation equations to the fluid energy equation, the fluid flow field must be specified a priori for a model, requiring the user to provide the proper feedback between the temperature and flow distributions. 
Another 1 imitation of both TRUMP and TRUMP-BD is that the model geometry always remains intact; i.e., no material relocation or swelling is accounted for. For horizontally oriented fuel assemblies the effect of this limitation is difficult to accurately assess. However, in vertically oriented fuel assemblies this limitation may actually provide an extra degree of conservatism as fuel will not relocate out of the high temperature regions of the model after mechanical failure or melting temperatures are exceeded.

Inherent with the modeling extensions that are part of TRUMP-BD are several additional modeling restrictions and limitations. These can be categorized into three groups: 1) input, 2) metal-water reaction modeling, and 3) coolant boiloff modeling. The restrictions and limitations of each of these groups are discussed below.

\subsubsection{Input Restrictions}

The major restriction imposed on the input by TRUMP-BD concerns the structuring of the model into axial levels; the current restrictions are that no more than 99 axial levels are included in the model and that no more than 999 uniquely specified nodes reside in an axial level. Additionally, the model noding scheme must be structured such that the axial level number increases along the direction of flow. This requirement enables the code to calculate the onset of steam depletion for problems with metal-water reactions and the position of the liquid-vapor interface for boiloff simulations.

Axial levels are simply defined as the thousandths place of the node number. For example, node 5001 would reside in the fifth axial level; its "base" node number(a) is 001 . The concept of axial levels, although convenient with respect to the code logic structure, also provides the user with an instantaneous picture of the axial position of the node within the model. The axial level designation must be adhered to for metal-water reaction nodes, flow nodes, and boundary heat transfer nodes; other types of nodes and nodes connected to the aforementioned nodes do not necessarily have to follow this naming convention.

(a) Base node numbers can be used to identify different material types or different radial positions in a model. For example, all fuel nodes may be assigned base node numbers of 001-099, cladding nodes 101-199, flow nodes 201-299, etc. 
Other restrictions implicit in any computer code are the array sizes; these restrictions can be eliminated by increasing the array size through the FORTRAN PARAMETER statements in the code. Details of code dimensions and means to vary the existing array sizes are presented in Section 8.0.

Other restrictions include:

- Uranium must have a material identification number of 1, Zircaloy 100 , and steam and hydrogen 10 and 11 , respectively.

- Zero-volume nodes used to specify inlet flow boundary conditions must have an axial level designator of zero; i.e., node 401.

- Temperature units must be entered in degrees Fahrenheit $\left({ }^{\circ} \mathrm{F}\right)$, time in hours $(h)$, mass in pounds-mass ( $1 \mathrm{bm})$, dimensions in inches (in.), and energy in Btu(a).

\subsubsection{Metal-Water Reaction Modeling}

The modeling of the metal-water reactions include the following assumptions/limitations:

- The reactions compute the amount of metal consumed and are modeled as parabolic with an Arrhenius-temperature dependence.

- The growth of the oxygen-stabilized alpha-zircaloy layer is not accounted for.

- In the event of full conversion of available steam at an axial level, the oxidation is reapportioned such that all oxidizing nodes on a level receive some steam. In this scenario, the steam available for oxidation will be based on the node temperature, oxide layer thickness, and surface area; thus, nodes with a greater "appetite" (i.e., higher temperature) for steam will receive more steam than nodes with a less vigorous oxidation rate.

- The oxidation is assumed to take place at isothemal conditions in a time step.

(a) The exception to this is the average rod linear heat generation rate, RODAVE, which must be specified as $\mathrm{kH} / \mathrm{ft}$-rod. 
- Oxidation of uranium fuel nodes is modeled once a user-prescribed failure temperature has been exceeded by the node. Thereafter, the uranium surface area available for oxidation may be specified as a function of temperature. However, the Zircaloy surface area available for oxidation remains constant at $100 \%$ of its intact, exposed surface.

\subsubsection{Simulation of Coolant Boiloffs}

The coolant boiloff model includes the following assumptions/limitations:

- Only one flow region can undergo a coolant boiloff.

- The coolant temperature below the dryout front remains at the userspecified initial temperature until the coolant node is partially uncovered. The initial coolant node temperatures for boiloff problems should therefore be set to the saturation temperature.

- All energy produced within the boiloff channel below the dryout front goes to vaporizing the coolant.

- The system pressure and inlet coolant properties are assumed to be invariant with time.

- Because the boiloff steaming rates are not assumed to vary significantly with time, the time rate of change of the coolant density is not explicitly accounted for.

\subsubsection{Fission Product Release}

The fission product release model for zircaloy-clad uranium fuel includes the following assumptions/limitations:

- Fission product release is based on both oxidation and volatilization/diffusion ("bake-out") release mechanisms, and is assumed to operate continuously subsequent to fuel failure, regardless of whether the uranium is in a solid or liquid phase.

- Fission product inventories are apportioned to individual uranium fuel nodes based on the fraction of whole core fission power generation occurring within the node.

- The deposition and transport of fission products subsequent to release from exposed fuel is not tracked. 
- No depletion of fission product inventories as a result of nuclear decay is considered.

- The heat generation as a function of time is not affected by the fission products released. 


\subsection{TRUMP-BD SUBROUTINES}

\subsection{OVERVIEW}

TRUMP-BD consists of a main program (TRUMP) and several required and optional subroutine, divided according to logical function, the sequence of calculations, and the various modes of heat production and transport. The subroutines required for al1 problems are HEART, THERM, FINK, SPECK, TALLY for the input phase and time step phases of the calculation; SEEK1 and SEEK2 for the input phase only; and REFER for the initialization phase only. The optional subroutines include GEN for problems with internal heat sources, sinks, and/or metal-water reactions, FLOW for problems with convection and/or coolant boiloffs, SURE for problems with boundary conditions, HTRANS for problems which require time or temperature-dependent internal thermal connections, FISPROD for problems in which fission product release from exposed uranium is to be modeled, and TIMER for obtaining the machine time used by each problem. (HTRANS and FISPROD are new subroutines added to TRUMP-BD.) The additional entry points THERM1 and THERM2 in THERM are used for calculation of phase change transitions. The additional entry point TALLY1 in TALLY is for the option of creating a restart file (OUTAPE) containing final values of node temperatures, phase, heat generation, etc. Subroutines CHEM, PLOT, and KITTY, available in the original TRUMP released by Lawrence Livermore National Laboratory, are not included in TRUMP-BD.

Presented below are descriptions of the code's subroutines. Subroutines that were significantly modified from the original TRUMP code are described in greater detail. Definitions for the code variables referenced below are provided in Appendix A.

\subsection{PROGRAM TRUMP}

The TRUMP program opens all required "units", reads and writes (echoes) the input file's "image" to the beginning of the standard output file, rewinds the input file, and calls HEART, the program driver subroutine. 


\subsection{SUBROUTINE HEART}

Subroutine HEART is the logic control center of TRUMP-BD. The majority of calls to other TRUMP-BD subroutines (except PRIME, SEEK1, SEEK2, REFER, HTRANS and FISPROD during time step calculations) are made from HEART. Before any input data are read, several flags are initially set and the machine clock is monitored. Any TRUMP-BD control cards (e.g., ${ }^{\star}$ CHECK, etc.) preceding the "Problem Name Card" are read in, and the appropriate variables are initially set.

The subroutine calls for reading in data from the various input BLOCKs are then made; these calls are presented in Table 3.1.

After the "Data End Card" is read in, the "Problem Name" and integer value on the "Data End Card" are stored in new locations, and subroutines TALLY and SPECK are called to initialize program variables before the first time step $(K C Y C=0)$.

Following the initialization phase, calls are then made to the subroutines required for the time step calculations ( $K C Y C>0)$; this sequence of calls is presented in Table 3.2. After each time step is completed, various tests are made to determine whether the problem should be continued, ended, or interrupted. If the problem is ended, the input file is read again. Assuming

IABLE 3.1. Subroutine Calls - Input Phase

\begin{tabular}{cl} 
DATA BLOCK & SUBROUTINE \\
\cline { 1 - 2 } 1 & TALLY \\
2 & THERM \\
4 & THERM \\
5 & FINK \\
6 & SURE \\
7 & SURE \\
8 & GEN \\
9 & TALLY \\
10 & FLOW \\
12 & THERM \\
$13($ a) & FISPROD
\end{tabular}

(a) Optional call by HEART. 
an end-of-file condition is found, control is returned to the main program TRUMP. If another problem follows in the input file, execution of this next problem begins.

The machine clock is monitored using subroutine TIMER at the beginning of each problem after all data has been read in, and again when the problem is interrupted or ended.

\subsection{SUBROUTINE THERM}

Subroutine THERM is entered to read in the data items in data BLOCK 2 (material properties), BLOCK 4 (node descriptions), and BLOCK 12 (nodes with properties dependent on temperatures of other nodes). All input data and imnediately derived data, such as table slopes, material energy content, and node classifications and volumes, are written to the OUTPUT file. Variable steam and hydrogen density (VISTAB) and viscosity (RHOTAB) tables may be read from BLOCK 2 for TRUMP-BD problems that model temperature and/or concentrationdependent convection within the fuel bundle coolant flow regions. An array

TABLE 3.2. Order of Subroutine Calls - Time Step Phase

Subroutine

THERM

HTRANS (a)

GEN

FINK

FLOW

SURE

THERMI

SPECK

THERM2

TALLY

FISPROD(b)
Function

Update properties.

Update temperature/time dependent internal thermal connections. Temperature change from heat generation. Temperature change from internal thermal connections. Temperature change from convection; computes liquid level. Temperature change from external themal connections. Latent heat absorbed or released by nodes. Final calculation of heat flow across all connections. Final calculation of latent heat absorbed or released by nodes. Current time step accepted or rejected; subsequent time step size determined; node temperatures updated; criteria for ending problem checked; output data written.

Fission product release from failed uranium fuel nodes.
(a) Optional call by THERM.
(b) Optional call by TALLY. 
ZRNOXE is created at the end of the input phase that contains the indices of nodes which can undergo a metal-water reaction (identified in BLOCK 4). Subroutines PRIME, SEEK1, SEEK2, and REFER are called by THERM during the input phase before returning to HEART.

For the first time step (initialization phase, $\mathrm{KCYC}=0$ ), subroutine THERM is entered to initially set cross-reference tables that relate the node list to the material list and relate the remote temperature dependence list to the node list. The node conductivities, masses, densities, heat capacities and heat contents are calculated. The total material volumes, masses, heat capacities, heat contents, and average temperatures are also calculated at this point. Additionally, the phase concentrations in materials with phase transitions involving latent heat are initially set.

For each subsequent time step (KCYC $>0$ ), THERM is entered to recalculate any of the quantities above that are variable. If time or temperaturedependent thermal connections are specified in BLOCK 5 of the input, THERM calls subroutine HTRANS to update the internal thermal connections.

At intervals determined by input data, summary data are written out for each material, listing name, number, heat capacity, heat content, average temperature phase, transition temperature(s), and latent heat(s) of transition. When specified by the user, sumary data are written out for each node, listing node number, material type, classification, location, volume, mass, heat capacity, conductivity, net conductance, and time constant.

If the problem includes nodes having phase changes, THERM is entered at each time step at entry THERMI to estimate the amount of latent heat released or absorbed for each node. THERM is also entered at entry THERM2 after temperature changes are calculated in subroutine SPECK for the final calculation of release or absorption of latent heat.

\subsection{SUBROUTIME GEN}

Subroutine GEN performs three major functions:

- reads and processes input from BLOCK 8 relating to node internal variable heat generation for standard TRUMP problems 
- computes the amount of metal (either uranium or zirconium) consumed and the corresponding energy release and hydrogen production during the time step as a result of chemical reactions

- computes the effective temperature rise of each node due to total heat generation.

Details of each of the three functions are described below.

\subsubsection{Input BLOCK 8}

BLOCK 8 input allows nodes with variable internal heat generation to be specified for standard TRUMP problems. BLOCK 8 input requires that a unique variable heat generation table be entered for each node with varying internal heat generation.

During the input phase, a call to GEN by HEART will occur to read BLOCK 8 variable heat generation data. All nodes with variable heat generation specified are read in. All input and immediately derived data, such as table slopes, are written out.

\subsubsection{Metal-Water Reactions}

Two metal-water reactions are considered in GEN : 1) zirconium-steam $\left(2 \mathrm{r}-\mathrm{H}_{2} \mathrm{O}\right)$, and uranium-steam $\left(\mathrm{U}-\mathrm{H}_{2} \mathrm{O}\right)$. For each reaction, the amount of metal consumed, energy release, and associated production of hydrogen (and depletion of steam) is computed at each time step. The chemical statements for each of these reactions are:

$$
\begin{array}{ll}
\mathrm{Zr}+2 \mathrm{H}_{2} \mathrm{O} \stackrel{\mathrm{K}}{\rightarrow} \mathrm{ZrO}_{2}+2 \mathrm{H}_{2} & \Delta \mathrm{H}_{\mathrm{Zr}}=143 \mathrm{kcal} / \mathrm{mole}-\mathrm{Zr} \\
\mathrm{U}+2 \mathrm{H}_{2} \mathrm{O} \stackrel{\mathrm{K}}{\rightarrow} \mathrm{UO}_{2}+2 \mathrm{H}_{2} & \Delta \mathrm{H}_{U}=55.4 \mathrm{kcal} / \mathrm{mole}-\mathrm{U}
\end{array}
$$

where $X_{p}$ is the reaction rate constant, and $\Delta H$ is the heat of reaction. Since the alloys Zircaloy-2 and Zircaloy-4 used for fuel rod cladding are composed primarily or zirconium, their reaction rates and heat of reactions are assumed identical to that of zirconium. Thus, Zircaloy and zirconium are assumed identical for modeling purposes. 
The axial level concept is critical in the modeling of the metal-water reactions. The node numbering nomenclature must therefore be strictly adhered to so that the location of steam-starved conditions can be determined. An internal pointer array ZRNOXE is constructed in which all oxidizable nodes are arranged by axial level (the order of nodes on a give plane is based on their respective order in the input). Node oxidation is calculated for all metal-water reaction nodes in the order of the ZRNOXE array, computing the oxidation of all nodes in an axial level ( $p$ lanar sweep) before proceeding to the next axial level (axial level sweep); an example of how the metal-water reaction pointer array ZRNOXE is constructed from the BLOCX 4 input is presented in Table 3.3.

For each time step, subroutine GEN scans each flow region and axial level of the model (from $n=1$ to NLEVELS), and every surface on a level [from $i=1$ to $\operatorname{MSURF}(n)]$, to determine which nodes contain oxidizable material (either uranium or Zircaloy). If a positive uranium or Zircaloy thickness has been specified for a node, the possibility of a metal-water reaction is investigated. The uranium or Zircaloy metal thickness for a node is identified by

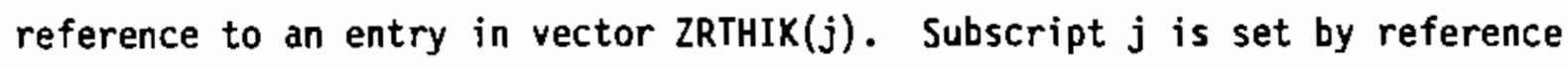
to the entry in vector $\operatorname{ZRNOXE}(a)[j=\operatorname{ZRNOXE}(k)]$ where subscript $k$ is the metal-water reaction node index, defined as:

$$
\begin{array}{ll}
k=i & \text { for } n=1 \text { (axial level } 1) \\
k=i+\operatorname{MHRSURF}(n-1) & \text { for } n \geq 2(\text { axial levels } 2 \text { and above) }
\end{array}
$$

where indices $i$ and $n$ correspond to the current surface and axial level, respectively.

During the oxidation planar sweep, a continual check on the amount of steam remaining is made. If more steam is consumed than is available, the oxidation reactions are allowed to continue assuming steam availability, and a steam-depletion flag is set (NZDEP), indicating the affected flow region and axial level. At the completion of the planar sweep calculations, a damping factor, QDAMP, is computed based on the ratio of steam available to the amount

(a) Vector ZRNOXE relates metal-water reaction index to the node number index. 
TABLE 3.3. Illustration of Metal-Water Reaction Node Pointer Array

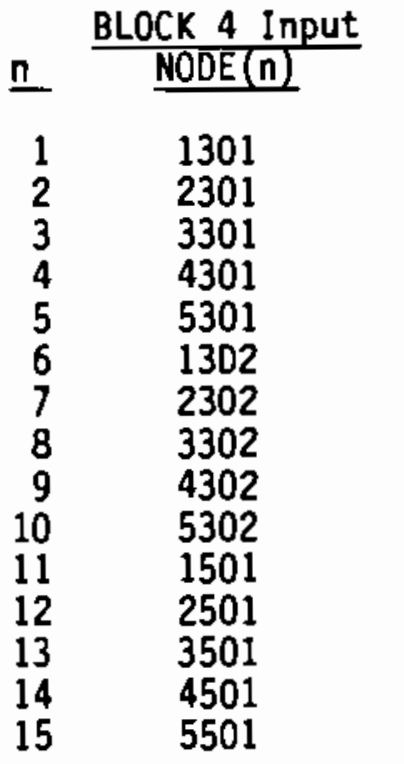

\begin{tabular}{rc}
\multicolumn{2}{c}{ Pointer Array } \\
ZRNOXE(n) & NODE(ZRNOXE(n)) \\
1 & 1301 \\
6 & 1302 \\
11 & 1501 \\
2 & 2301 \\
7 & 2302 \\
12 & 2501 \\
3 & 3301 \\
8 & 3302 \\
13 & 3501 \\
4 & 4301 \\
9 & 4302 \\
14 & 4501 \\
5 & 5301 \\
10 & 5302 \\
15 & 5501
\end{tabular}

of steam consumed (assuming availability) for the steam-depleted axial level. The amount of metal consumed is then recamputed, adjusted by the damping factor. From this revised thickness consumed, new values of energy release and hydrogen production are computed. This procedure prevents the first node in a Jlanar sweep from continually consuming the available steam, resulting in a nore equal apportionment of steam among the oxidizing nodes.

The reacting node material type is identified by the value of vector $\operatorname{NOXMAT}(j)$, where $j$ is as defined above. For material type 100 (NOXMAT $(j)=100)$, the $\mathrm{Zr}-\mathrm{H}_{2} \mathrm{O}$ reaction logic will be used. For material type $1(\operatorname{NOXMAT}(j)=1)$, the $U-H_{2} \mathrm{O}$ logic will be used. Vectors NSURF, MWRSURF, ZRNOXE, ZRTHIK, and NOXMAT are set via input provided in BLOCK 4.

\subsubsection{Zircaloy-Water Reaction}

The $2 \mathrm{r}-\mathrm{H}_{2} \mathrm{O}$ reaction can be modeled with any one of four correlations:

- Cathcart et al. (1977). Chosen by setting MWRCOR =0 (BLOCK 9, Card C)

- Urbanic and Heidrick (1978). Chosen by setting MHRCOR $=1$

- Prater and Courtright (1986). Chosen by setting MNRCOR = 2

- Baker and Just (1962). Chosen by setting MHRCOR $=3$. 
All metal-water reactions can be eliminated by specifying MNRCOR $=-1$. Each of these correlations model the temperature-dependent consumption of metal using a parabolic, Arrhenius-rate relation of the form(a)

$$
\delta=b \sqrt{t} e^{-a / T}
$$

where: $\delta=$ thickness of metal consumed by the reaction, m

$\sigma=$ Arrhenius-rate reaction coefficient, $K$

$b=$ Arrhenius-rate reaction coefficient, $\mathfrak{m} / \sqrt{\mathrm{sec}}$

$T=$ node temperature, $K$

$t=$ time (seconds) for which the metal is exposed to steam at temperature, $T$.

The specific values of the Arrhenius-rate coefficients are determined by the metal-water reaction correlation employed and the temperature of the oxidizing node. Below $1300^{\circ} \mathrm{F}(977 \mathrm{~K})$, the reaction rate is assumed to be negligible and the oxidation logic is skipped; therefore, no metal-water reaction occurs at node temperatures below $1300^{\circ} \mathrm{F}(977 \mathrm{~K})$. At node temperatures above $1300^{\circ} \mathrm{F}$, the following coefficients are used:

- Cathcart et al. correlation

$$
\begin{aligned}
& a=-20070 \mathrm{~K} \\
& b=6.4506(10)^{-6} \mathrm{~m} / \sqrt{\sec }
\end{aligned}
$$

- Urbanic \& Heidrick correlation

- for $1300^{\circ} \mathrm{F} \leq \mathrm{T}<2894^{\circ} \mathrm{F}$

$a=-13553 \mathrm{~K}$

$b=1.169(10)^{-7} \mathrm{~m} / \sqrt{\mathrm{sec}}$

- for $2894^{\circ} \mathrm{F} \leq \mathrm{T}$

$\sigma=-16610 \mathrm{~K}$

$b=2.0868(10)^{-6} \mathrm{~m} / \sqrt{\mathrm{sec}}$

(a) The calculation of metal consumed and energy released is done in units of meters, degrees Kelvin, Joules, and seconds. 
- Prater \& Courtright correlation

- for $1300^{\circ} \mathrm{F} \leq \mathrm{T}<2750^{\circ} \mathrm{F}$

$\sigma=-24460 \mathrm{~K}$

$b=4.481(10)^{-5} \mathrm{~m} / \sqrt{\mathrm{sec}}$

- for $2750^{\circ} \mathrm{F} \leq \mathrm{T}$

$a=-28420 \mathrm{~K}$

$b=1.32496(10)^{-3} \mathrm{~m} / \sqrt{\mathrm{sec}}$

- Baker \& Just correlation

$$
\begin{aligned}
& a=-22899 \mathrm{~K} \\
& b=7.884(10)^{-5} \mathrm{~m} / \sqrt{\mathrm{sec}} .
\end{aligned}
$$

The incremental thickness consumed due to oxidation during the current time step is computed from a modified differential form of the rate equations as:

$$
\delta_{t+\Delta t}=\left[\delta_{t}^{2}+f_{x h} b(\Delta t) e^{-\sigma / T}\right]^{t}
$$

where: $\quad \delta_{t+\Delta t}=$ updated metal thickness

$\delta_{t}=$ old-time metal thickness

$\Delta t=$ time step

$f_{x h}=$ factor to account for hydrogen blanketing of oxidizing node.

The amount of metal consumed is limited to the thickness of the material present in the node and by the availability of steam. The factor $f_{x h}$ is included in Equation (3.2) to account for hydrogen blanketing of the oxidizing node. By specifying HFLAG $=1$ (BLOCK 10, Card $B$ ), the factor $f_{x h}$ will be updated for each node by the linear relation:

$$
f_{x h}=\left(1.0-x_{h}\right)
$$

where: $X_{h}=$ hydrogen fraction in the steam flow region adjacent to the oxidizing node.

When $x_{h}=1.0$, all the steam is consumed and all oxidation is stopped.

The rate of energy release, $\Delta Q$, in time step $\Delta t$ is computed based on the volume of metal consumed and the heat of reaction, as 


$$
\Delta Q=\rho_{Z r^{H}}{ }_{Z r^{\alpha A}} \alpha \mathrm{ZZ \Delta \delta / \Delta t}
$$

where: $\rho_{\mathrm{Zr}}=$ density of zirconium, $6.5 \times 10^{6} \mathrm{~kg} / \mathrm{m}^{3}$

$$
\begin{aligned}
\mathrm{H}_{\mathrm{Zr}}= & \text { heat of reaction of zirconium, } 6.45 \times 10^{6} \mathrm{~J} / \mathrm{kg} \\
\alpha= & \text { oxidation area multiplier (for uranium nodes only) } \\
A_{0 x}= & \text { surface area available for oxidation per unit axial length for } \\
& \text { the node, } \mathrm{m}^{2} / \mathrm{m} \\
\Delta Z= & \text { axial length of node, } \mathrm{m} \\
\Delta \delta= & \text { amount of material consumed in time step } \Delta t, \delta_{t+\Delta t}-\delta_{t} \\
\Delta t= & \text { time step, sec. }
\end{aligned}
$$

The user-specified oxidation area for Zircaloy nodes is assumed constant; an oxidation area multiplier of 1.0 is therefore used for the $\mathrm{Zr}_{-} \mathrm{H}_{2} \mathrm{O}$ reaction.

\subsubsection{Uranium-Water Reaction}

The amount of metal oxidized by the uranium reaction with water is computed in a similar manner with one additional restriction: the associated fuel pin cladding temperature must have exceeded a user-specified "failure temperature" for uranium oxidation to be considered (TFAIL, BLOCK 9, Card C). By restricting the uranium oxidation in this manner, discrete failures of fuel elements (pins) can be modeled. With this feature, uranium oxidation is restricted as long as the accompanying cladding remains intact; upon failure of the cladding, the previously unexposed uranium is assumed to react with the available steam.

The fuel failure model requires that the uranium nodes and Zircaloy nodes that comprise a fuel element be assigned a comnon pin number (NPN, BLOCK 4 , Card D) (a). This convention is illustrated in Figure 3.1, which shows the pin number assignments for a concentric fuel element design. oxidation of uranium nodes will occur only when the minimum temperature of the cladding nodes (NOXMAT $=100$ ) assigned to that pin exceeds the user-specified failure temperature. Pin numbers need only be assigned to the Zircaloy and uranium nodes of

(a) The value of NPN is loaded into the array PINNO(n) where $n$ is the node index. 
a unique fuel element--the fuel element nodes' axial level designation (thousandths place of the node number) is used to identify the axial location of a failed fuel element. For a 20 axial level model with the concentric fuel design shown in Figure 3.1, only two unique pin numbers need to be specified.

The amount of uranium metal oxidized in a time step is computed, as before, using the parabolic Arrhenius-rate relation given in Equation (3.1). The coefficients have the same meaning here as in the Zircaloy-water reaction case. Their values are different, however, and are as follows:

- $\mathrm{T}<2192^{\circ} \mathrm{F}$

$a=9361 \mathrm{~K}$

$b=2.549(10)^{-8} \mathrm{~m} / \sqrt{\mathrm{sec}}$

- $\mathrm{T} \geq 2192^{\circ} \mathrm{F}$

$a=12582 \mathrm{~K}$

$b=2.0784(10)^{-7} \mathrm{~m} / \sqrt{\mathrm{sec}}$

The incremental uranium thickness consumed in time step $\Delta t$ is 1 imited to the available thickness of the material and the available steam. The energy release rate resulting from this reaction is computed as in Equation (3.3) where the volumetric energy release factor $\left(\rho_{u} * \Delta H_{u}\right)$ for the reaction equals $4.7697(10)^{10} \mathrm{~J} / \mathrm{m}^{3}$. To account for a variable uranium oxidation area, $\alpha$ in Equation (3.3) is adjusted by a user supplied, temperature-dependent multiplier used to account for oxidation area changes due to fuel relocation and/or swelling.

\subsubsection{Hydrogen Release from Material Reactions}

The mass of hydrogen generated from the reaction of Zircaloy or uranium with water during the time step is also computed in subroutine GEN for each node. The mass of metal consumed is first computed; the mass of hydrogen gas produced by the reaction is then calculated from the mole fractions of product and reactant identified in the chemical reactions. The hydrogen generated by each reacting surface on an axial level is computed during each time step and is summarized in the axial level sweep. In accordance with the chemistry, each mole of hydrogen produced in these metal-water reactions requires the consumption of one mole of steam. Therefore, the steam mass flow rate associated with each reacting node is correspondingly depleted. The amount 


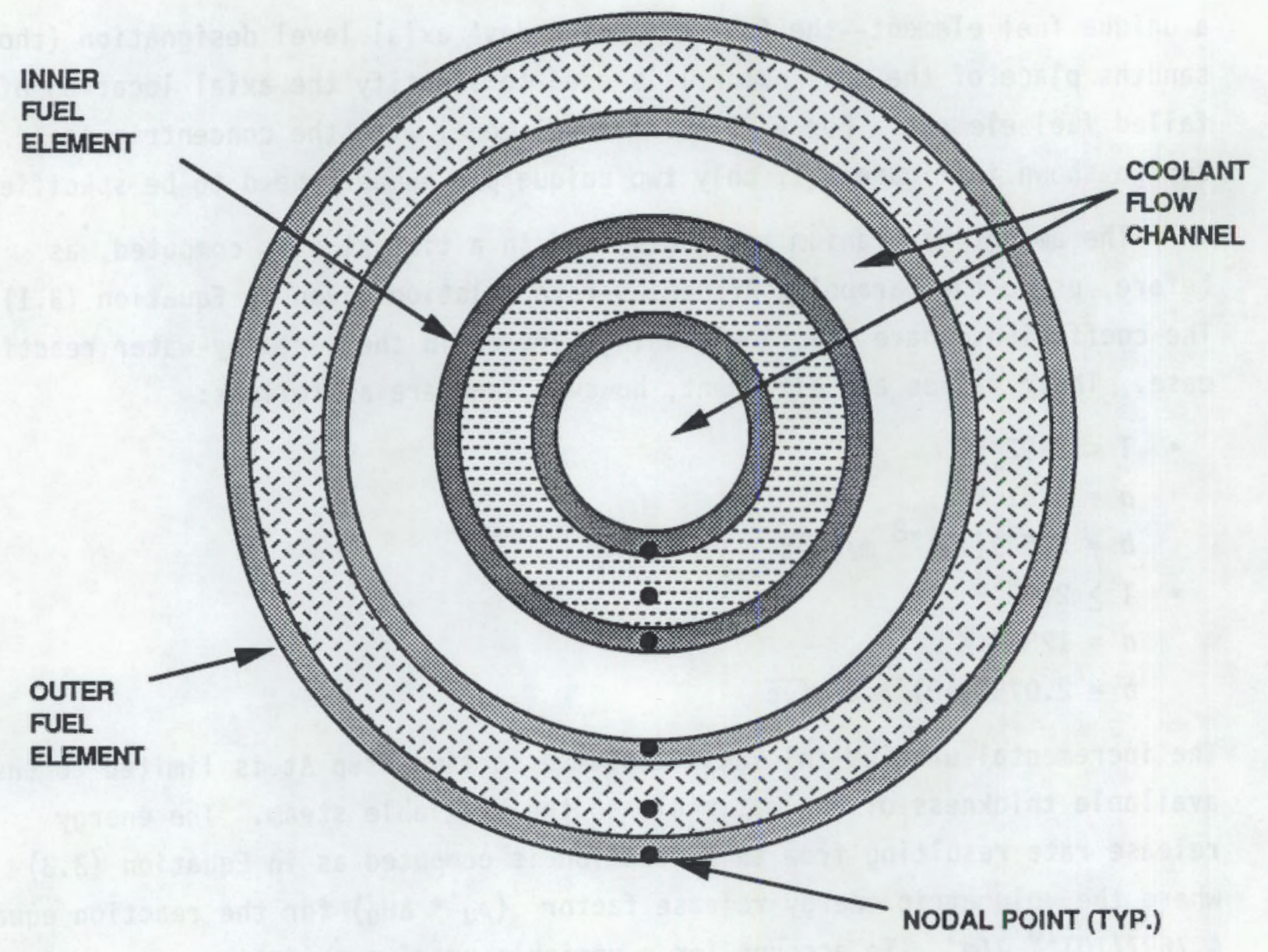

MATERIAL PIN NO.
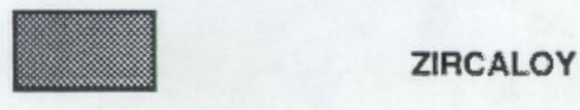

1

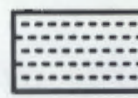

URANIUM

1

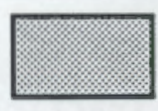

ZIRCALOY

2

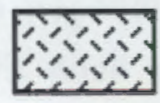

URANIUM

2

FIGURE 3.1. Illustration of Fuel Pin Assignments for Fuel Failure Modeling 
of steam that can be depleted is limited to that available for a flow region at the current axial level. If more steam is required for oxidation than is currently available, the mass of uranium or Zircaloy consumed, the mass of hydrogen produced, and the energy released by the reaction are each reapportioned (reduced) based on the amount of steam available. Because the amount the reaction is reduced is applied uniformly to all oxidizing nodes on a plane (axial level), nodes reacting more vigorously will be allocated more steam than less reacting nodes.

\subsubsection{Node Effective Temperature Rise}

An estimate of the temperature rise in each node resulting from the node's total heat generation is computed just prior to exiting subroutine GEN. For standard TRUMP problems, this is simply the internal heat generation specified in BLOCK 9 (Card B) and BLOCK 8. For TRUMP-BD, total heat generation is the sum of the heat generation associated with metal-water reactions and the internal heat generation specified in BLOCK 9 (Cards C, D, F-H). The net temperature change from the total heat generation is added to the other temperature changes (i.e., from internal thermal connections, flow, etc.) in subroutine TALLY wherein the nodal temperatures are updated. Thermal capacitances used in the computation of this temperature rise in subroutine GEN are based on estimated node temperatures for the current time step (subroutine THERM). The material properties used to make up this capacitance do not reflect the change in composition of the node resulting from the metal-water reaction, i.e., $\mathrm{Zr}$ to $\mathrm{ZrO}_{2}$.

\subsection{SUBROUTINE FINK}

Subroutine FINK is first entered to read in the data items in BLOCK 5, the internal thermal connection list. All input data and immediately derived data, such as connection areas, are written to the OUTPUT file.

If time or temperature-dependent internal thermal connections are specified the thermal connection index and variable heat transfer model type are stored in the variable thermal connection arrays IVARH and IHTCOR for use by subroutine HTRANS. 
For the initialization phase $(K C Y C=0)$, FINK is entered to initially set the cross-reference table that relates thermal connections to the node list (using REFER), and to set the conductances of each connection.

At each time step, FINK is entered to recalculate the overall conductance of the thermal connections and to calculate the amount of heat flow across each connection and the temperature change of each node due to the internal thermal connections. The conductance is calculated based on the temperature difference at the beginning of the time step.

At intervals determined by the input data, summary data for each thermal connection may be written to the OUTPUT file, including the node numbers, area, interface conductance, radiation exchange factor, overall conductance, cumulative heat flow, and average rate of heat flow across the connection.

\subsection{SUBROUTINE FLOH}

Subroutine FLOH is used with problems which model 1) convective heat transport, and 2) coolant boiloffs.

Though standard TRUMP mass flow modeling logic can still be utilized, subroutine FLOW has been rewritten to include modeling capabilities needed for reactor applications. Specifically, the user can now model unique mass flow regions, as well as subchannels within a flow region. This modeling difference allows for a simplification of the flow connections from standard TRUMP and also allows for the modeling of coolant boiloffs. A flow region is defined as any flow area enclosed by solid surfaces; a subchannel can be any unique portion of a flow region. A subchannel's mass flow is defined in the input as some fraction of the total mass flow of the flow region. A diagram illustrating the relationship between flow regions and subchannels is presented in Figure 3.2.

The node numbering scheme for flow problems is somewhat restricted in TRUMP-BD. An illustration of the node numbering scheme for a multiple flow region model is presented in Figure 3.3. Note that connected flow channels differ only by the thousandths place of the node number. This allows the subchannel convective heat removal to be properly calculated and printed in the OUTPUT file convection summary. Also, as in standard TRUMP, a zero volume 


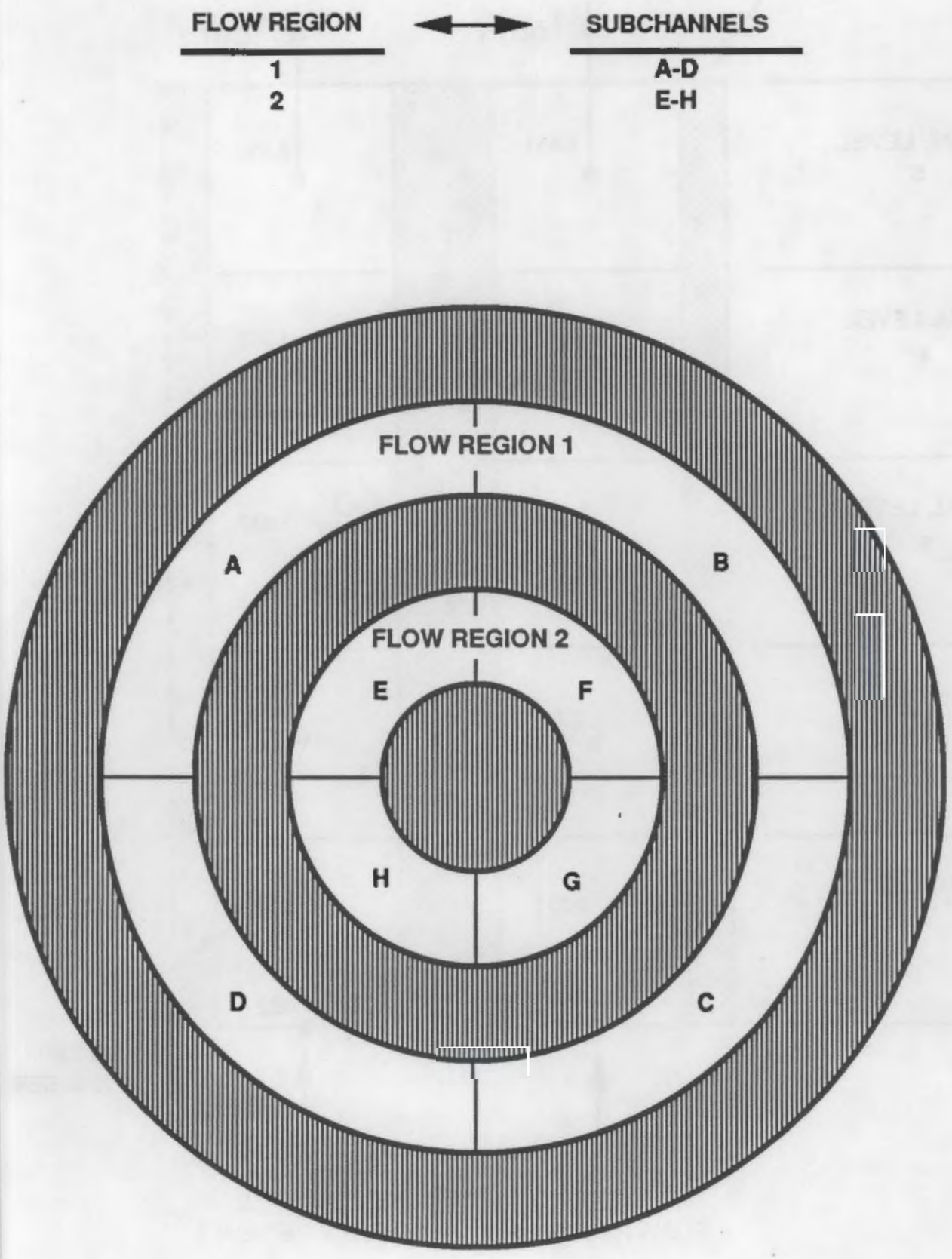

FIGURE 3.2. Sample Configuration Demonstrating the Relationship between Flow Regions and Flow Subchannels 


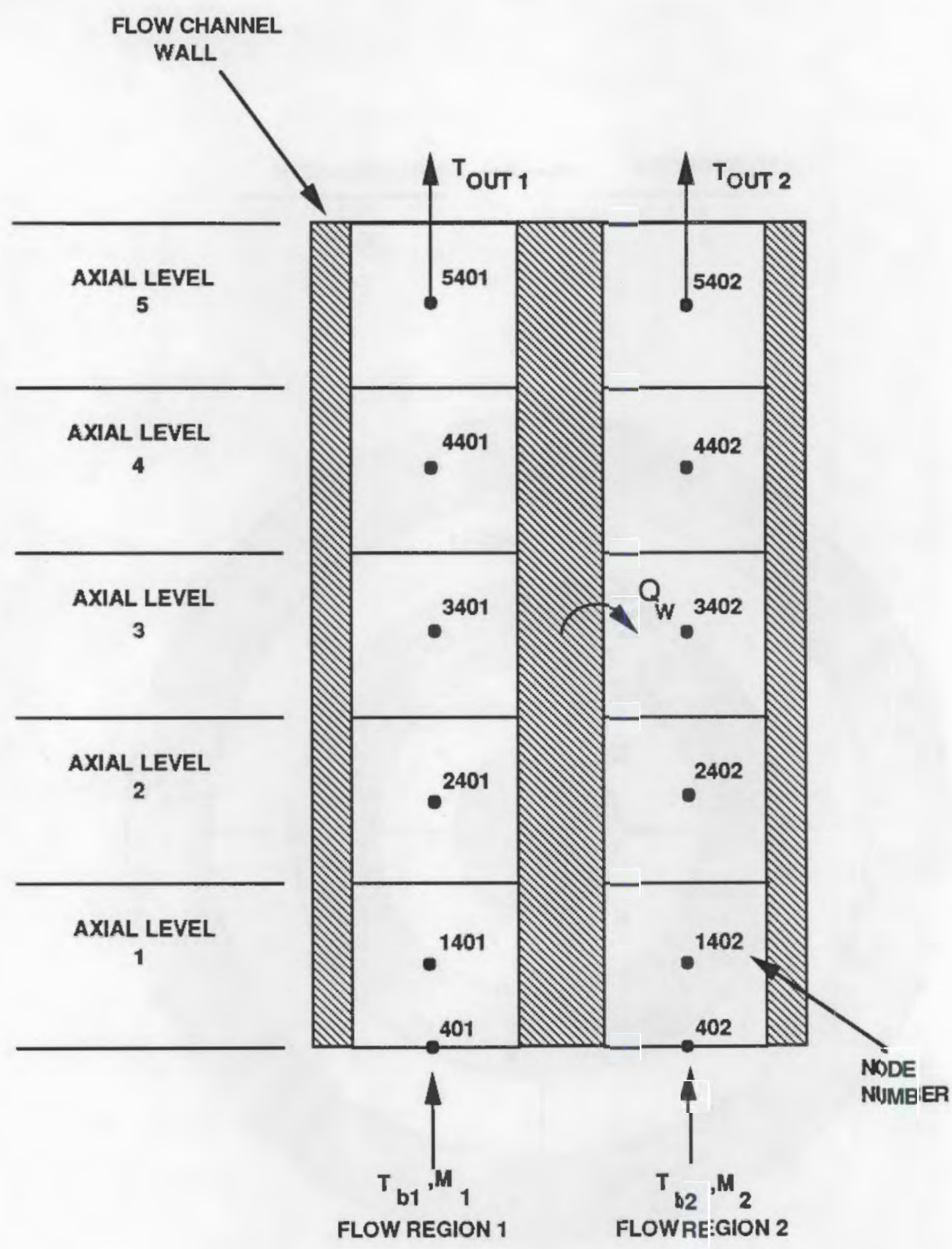

FIGURE 3.3. Illustration of the Node Numbering Scheme for a Multiple Flow Region Model 
node must be specified at the channel inlet; the node number used for this source node and the downstream volume node must differ by 1000 . The zero volume source node number must also be less than 1000 .

Because of the significant modifications made to this subroutine, the logic during both the input and execution phases of the simulation will be discussed in detail.

\subsubsection{Input}

Subroutine FLOW is first accessed by HEART during the input phase of TRUMP-BD to read in the data items in BLOCK 10 of the INPUT file. The BLOCK 10 input is used to define flow regions, mass flow connections, and the characteristics of the boiloff.

The first read statement in FLOW is for Card A, "Auto Noding Parameters". This feature has been removed in the coding; therefore, this card should be blank. Card B, the "Flow Description Card", is then read and is used to describe the overall characteristics of the model flow. The variable IMASFG is a flag used to signal whether the TRUMP-BD time-varying mass flow logic is to be used. If IMASFG $=0$, standard TRUMP logic is used; IMASFG $=-1$ flags that no boiloff simulation is to be performed, but TRUMP-BD time-varying flow logic is to be used; IMASFG $=+1$ indicates that a boiloff of liquid will be simulated and TRUMP-BD time-varying flow logic is to be used. The variable HFLAG is used to flag whether the hydrogen-blanketing model is to be used to 1 imit metal-water reaction rates computed by subroutine GEN. When HFLAG $=0$, no hydrogen blanketing is modeled; when $H F L A G=1$, hydrogen blanketing is assumed and the reaction rate is limited accordingly (Equation 3.3).

Other variables on Card B pertain only to boiloff simulations, and include the setting of fluid properties (heat of vaporization and inlet coolant subcooling) and the initial liquid-vapor dryout interface position, XINTERI.

For each flow region a series of cards are read by FLOW, starting with Card $C$, the "Region Delimiter" card. Because the read statement used in FLOW for Card $C$ is also used for Card $G$ (the "Mass Flow Connections" card), FLOW checks after each execution to see which card has been read. If a new flow region is being input, then NREGON, the flow region counter, is incremented and Card D, the "Flow Region Descriptor" card, is now read. 
Two control variables are read from Card D. The first, IBOLRGN(NREGON), indicates whether the flow region being input is a boiloff $(-1)$ or non-boiloff (0) region. For boiloff simulations the first flow region input must be the region undergoing the coolant boiloff. The second control variable read from Card $D$ is the mass flow rate computation flag, MASFLG. MASFLG $=-1$ indicates the flow region's mass flow rate (XMDOX) is user prescribed directly on Card D. MASFLG $=0$ indicates the mass flow rate will be specified for individual mass flow connections on Card $F$ rather than by flow region. (The MASFLG $=0$ option is used only for standard TRUMP.) MASFLG $=1$ indicates the region flow rate will be computed based on the power generation, liquid-vapor interface, and inlet coolant conditions for a boiloff simulation.

After reading Card $D$, a check is made that HDO, the user-specified length from bulk boiling to dryout conditions, is less than the axial node length (AXDIST(IX), IX $=1$, NLEVELS). If HDO exceeds any node length, KWIT is set to 5 to indicate an input error has occurred. The variable HDO is used by subroutine HTRANS to determine node convective heat transfer coefficients near the dryout front in boiloff simulations (Section 3.8.8).

The ability to specify time-dependent mass flow rates for all flow connections in a flow region can be accomplished by specifying TRUMP-BD flow logic (MASFLG $\neq 0$ ) and by entering a positive value for NTABF (BLOCK 10 , Card D), the number of entries in the flow multiplier-time table (Card E). For positive values of NTABF, the flow region mass flow rate multiplier (FMULT) and corresponding time (FTIME) are read in (Card E). To vary the average coolant density (RHOBAR) below the dryout front during a boiloff simulation, table entries relating the average coolant density below the dryout front (RHOCOL) to the exit steam flow rate (XMS) can be specified (Card F). The actual functional relationship between density and mass flow rate must be determined by the user.

At this point the mass flow connections for the current flow region are read (Card G). The input specified in Card $G$ is used to set up the arrays and other variables detailing the relationship between nodes and flow paths. Subroutine FLOW will continue looping through this section until either: 1) a blank card is read, which tells FLOW all input has been supplied for BL.OCK 
10 and to return control to HEART, or 2) a "Region Delimiter" card (Card C) is encountered, which tells FLOW input cards for another flow region follows.

For TRUMP-BD problems (i.e., MASFLG $=1$ or -1 ), input variable FX (Card G) specifies the fraction of the total flow region flow rate (XMDOX) that applies to the specified connection. When $F X$ is 1.0 , the entire flow region mass flow passes through this convection path; when $\mathrm{FX}$ is less than $1.0 \mathrm{it}$ indicates the region mass flow is defined by multiple subchannels. The mass flow rate for each flow connection (FLOWN) is then calculated by FLOWN $=F X \star X M D O X$.

For standard TRUMP flow problems (MASFLG $=0$ ), FX specifies the actual connection mass flow rate, i.e., FLOWN $=F X$. If in addition $|L T A B F L| \geq 2$ is specified on Card G, FLOW will read Card H, the "Region Subchannel Mass Flow Rate Table". This table provides values of mass flow rate vs. time which are used to update each flow connection at each time step of the problem.

\subsubsection{Cycling}

On the first post-input phase pass $(K C Y C=0)$, subroutine FLOW is entered to cross-reference the flow connection arrays NODF1 and NODF2 with the node array list NODE. FLOW then checks each flow connection to ensure that both nodes are composed of the same materials and that flow paths connected to zero-volume nodes have the appropriate relative flow path lengths. The index pairs representing each flow path are then reordered (if necessary) to produce a positive mass flow between each.

For all subsequent time steps ( $K C Y C>1$ ) mass flow rates are updated, the temperature changes resulting from mass flow are computed, and any consequent changes in the location of the dryout front (when applicable) are computed.

If IMASFG = 0 (standard TRUMP), the mass flow rate FLOWN is reset by interpolation using values from the mass flow (FLOWT) vs. time or temperature (TVARFL) table (BLOCK 10, Card $H$ ) for each connection, and the mass connections are again reordered in the direction of positive mass flow. For IMASFG $=1$ or -1 , i.e., TRUMP-BD logic, a flow region multiplier FXY(NREGON) is interpolated using values from the mass flow table (BLOCK 10, Card E). All flow connections that make up a given flow region are adjusted by the flow multiplier for that region, FXY(NREGON). 
The final computation performed in subroutine FLOW is the temperaturerise associated with convection. The temperature rise is computed based upon the energy loss in the node due to enthalpy transport and the thermal capacitance of the fluid in the node. The resultant $\Delta T$ is added in an accumulator array DT for later use in subroutine TALLY. Program flow is then returned to the calling routine.

\subsubsection{Coolant Boiloff Modeling}

The key concepts and parameters behind the modeling of coolant boiloffs is illustrated in Figure 3.4. As shown, the model can be separated into three distinct regions:

1. the subcooled region where the incoming liquid is brought to saturation conditions,

2. the boiling region, where vapor is generated resulting in a void fraction distribution, and

3. the dryout region, where single-phase vapor is superheated.

Because the dryout region is of primary concern in severe accident modeling, only the heatup of the dryout region is accounted for in TRUMP-BD. Coolant nodes that reside in the subcooled or boiling region remain at their initial temperature until the node becomes partially uncovered. Thus, coolant nodes below the initial dryout front location should be initialized to the coolant saturation temperature. In this manner, boiling in the coolant channel is simulated with the single-phase TRUMP code. The coolant node temperature remains at its initial value by subtracting the temperature rise from heat input from the overall temperature change for the node.

The position of the dryout front (WLEVEL) is calculated from a combination of the mass and energy conservation equations. All energy input to the flow channel is assumed to raise the incoming liquid to saturation conditions and generate steam (Figure 3.4):

$$
\int_{0}^{\lambda} P(z) d z=m_{i} h_{s c}+m_{s} h_{f g}
$$




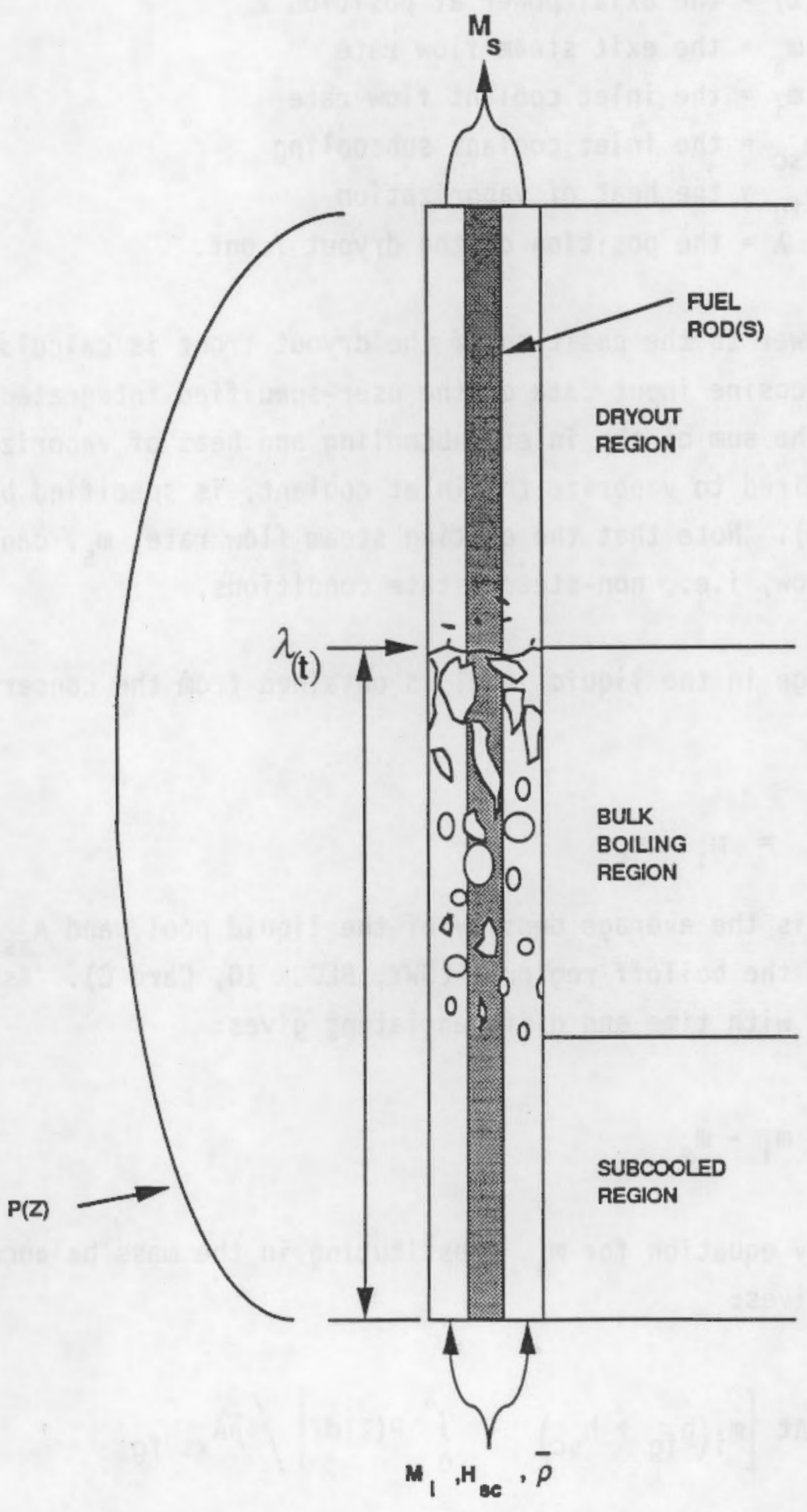

FIGURE 3.4. Key Concepts and Parameters for Modeling a Coolant Boiloff 
where:

$$
\begin{aligned}
P^{\prime}(z) & =\text { the axial power at position } z \\
m_{s} & =\text { the exit steam flow rate } \\
m_{i} & =\text { the inlet coolant flow rate } \\
h_{s c} & =\text { the inlet coolant subcooling } \\
h_{f g} & =\text { the heat of vaporization } \\
\lambda & =\text { the position of the dryout front. }
\end{aligned}
$$

The integrated power to the position of the dryout front is calculated either from the chopped-cosine input data or the user-specified integrated axial power profile. The sum of the inlet subcooling and heat of vaporization, the total energy required to vaporize the inlet coolant, is specified by QBOIL (BLOCK 10, Card B). Note that the exiting steam flow rate, $m_{s}$, can differ from the inlet flow, i.e., non-steady state conditions.

The net change in the liquid level is obtained from the conservation of mass,

$$
\frac{\partial}{\partial t}\left[\rho A_{x s} \lambda\right]=m_{i}-m_{s}
$$

where $\bar{\rho}$ (RHOBAR) is the average density of the liquid pool, and $A_{x S^{\prime}}$ the crosssectional area of the boiloff region (FLOWY, BLOCK 10, Card C). Assuming invariant density with time and differentiating gives:

$$
\bar{\rho} A_{x s} \frac{\partial \lambda}{\partial t}=m_{i}-m_{s}
$$

Solving the energy equation for $m_{s}$, substituting in the mass balance equation and rearranging gives:

$$
\lambda=\lambda_{0}+\Delta t\left[m_{i}\left(h_{f g}+h_{s c}\right)-\int_{0}^{\lambda} P(z) d z\right] / \bar{\rho} A_{x s} h_{f g}
$$

where $\lambda_{0}$ is the old-time position of the dryout front. Thus, the position of the dryout front is a function of coolant properties, the integrated power profile, the channel area, and the coolant density. Variations in the power 
generation rate and/or inlet coolant flow rate can be used to drive the coolant boi off. If a prescribed liquid level history is specified (BLOCK 4, Card C), either the coolant inlet flow rate or the power generation is adjusted to give the desired dryout front position.

Until steady-state conditions are reached, more coolant is boiled away than is being replenished by the inlet coolant flow. This phenomena is accounted for in the code as the boiloff region flow rate is increased by the internally-computed ratio of exit to inlet mass flow rate, STRATIO.

An important parameter in the boiloff calculations that must be specified by the user is RHOBAR, the average density of the liquid pool below the dryout front (Figure 3.4). Because this paraneter can vary considerably over a range of steaming rates, it is possible to enter a flow rate-dependent density (BLOCK 10, Card F). To obtain the relationship between density and flow rate, the void fraction profile must first be computed; several models and constitutive relationships are available to obtain this information (Zuber and Findlay 1965; Wilson et al. 1962; Cunningham and Yeh 1973).

\subsection{SUBROUTINE HTRANS}

Subroutine HTRANS computes the time or temperature-dependent internal thernal connections. The user may choose from among a series of heat transfer models or directly input a user-specified table for each variable thermal connection. The choice is made by specifying unique values of IHEAT for each pair of participating nodes in BLOCK 5 (Card B); the values of IHEAT and the corresponding heat transfer models are presented in Table 3.4.

IABLE 3.4. Heat Transfer Models and Correlations - Subroutine HTRANS

\begin{tabular}{cl} 
IHEAT & \multicolumn{1}{c}{ Heat Transfer Model or Correlation } \\
1 & Wong-Hochreiter correlation \\
2 & Dittus-Boelter correlation \\
3 & N Reactor gap conductance model \\
4 & Thermal bridging mode? \\
5 & User-specified internal thermal connection
\end{tabular}


HTRANS also contains two important models for severe accident simulations: 1) a node uncovery model that determines the convective heat transfer coefficient for solid surfaces in a partially uncovered node, and 2) a binary mixture property model to account for the effect of hydrogen on the convection heat transfer. Each of the different models accessible in HTRANS is described below.

HTRANS is called by subroutine THERM at the beginning of each time step $(\mathrm{KCYC}>0)$ where the heat transfer coefficients of the variable internal thermal connections are updated. The index IVARH is used to identify the current connection index for each pass through HTRANS. A check is made on the value of IHTCOR for each variable internal connection to determine which model to use. Flags are also used to determine whether the node uncovery model and/or the binary mixture property are used. Subroutine HTRANS returns to subrout ine THERM.

\subsubsection{Heat Transfer Correlations and Models}

Described below are the two convective heat transfer correlations and the three heat transfer models of TRUMP-BD.

\subsubsection{Dittus-Boelter Single-Phase Convection Heat Transfer (IHEAT $=1$ )}

A local heat transfer coefficient based on the Dittus-Boelter singlephase heat transfer correlation is computed for an internal thermal connection by specifying IHEAT $=1$ (BLOCK 5, Card B) (a). To use this modeling option, the coolant density and viscosity must be specified (BLOCK 2, Cards $C$ and D). By specifying the coolant properties as a function of temperature, the heat transfer coefficient will be updated as a function of the film temperature, i.e., the average of the wall and coolant temperatures. The effect of two different constituents (i.e., steam and hydrogen) on the overall heat transfer can also be accounted for.

Reynolds (Re) and Prandt] ( $\mathrm{Pr}$ ) numbers are computed for the fluid node using the single or binary mixture properties, the hydraulic diameter, $D$, associated with the fluid node (HIDM, BLOCK 10, Card D), and the characteristic

(a) The value of IHEAT is loaded and used in the array IHTCOR(N) where $N$ is the variable internal thermal connection number $(0 \leq N \leq I J)$, and IJ the total number of variable thermal connections. 
flow velocity of the fluid node. Using these parameters, a convection heat transfer coefficient, $h$, is computed from:

$$
\mathrm{Nu}=\frac{h \mathrm{D}}{\mathrm{k}}=0.023 \mathrm{Re}^{0.8} \operatorname{Pr}^{0.4}
$$

where $\mathrm{Nu}$ is the Nusselt number, and $\mathrm{k}$ is the gas thermal conductivity, evaluated at the film temperature.

\subsubsection{Wong-Hochreiter Correlation (IHEAT $=2$ )}

A local heat transfer coefficient based on the Wong-Hochreiter correlation for low Reynolds number forced convection steam cooling under core-uncovery conditions is computed for an internal thermal connection by specifying IHEAT $=2$. As with the Dittus-Boelter heat transfer option, the coolant density and viscosity must be specified; the option to evaluate the local heat transfer based on properties of a binary mixture is also available. Again, the properties are evaluated at the film temperature.

The overall heat transfer coefficient is computed as:

$$
\mathrm{Nu}=\mathrm{ho} / \mathrm{k}=\quad \begin{array}{ll}
7.86 \mathrm{Pr}^{1 / 3} & \text { for } \mathrm{Re} \leq 2000 \\
(-24.55+0.0162 \mathrm{Re}) \mathrm{Pr}^{1 / 3} & \text { for } 2000<\operatorname{Re} \leq 2500 \\
0.0797 \mathrm{Re}^{0.6774} \mathrm{Pr}^{1 / 3} & \text { for } 2500<\operatorname{Re}
\end{array}
$$

\subsubsection{Neactor Gap Conductance Model (IHEAT $=3$ )}

The temperature-dependent gap conductance model used for modeling the uranium fuel-to-cladding interface resistance is invoked by setting IHEAT $=3$. The model accounts for the postulated separation of the fuel/cladding surfaces of the extruded fuel element as temperatures increase above $1490^{\circ} \mathrm{F}$ and a subsequent decrease in the separation distance as the uranium melt temperature is reached. The overall conductance between the fuel and cladding is evaluated based on the estimated debonded surface area, fuel-to-cladding gap width, and fill-gas (assumed to be xenon). The interface heat transfer coefficient, h (Btu/h-in. $\left.{ }^{2}-{ }^{\circ} \mathrm{F}\right)$, is computed as follows: 


$$
h=\quad \begin{array}{ll}
694 & \text { for } T<1490^{\circ} \mathrm{F} \\
f_{A}{ }^{k} x e^{/ \delta+694\left(1-f_{A}\right)} & \text { for } 1490^{\circ} \mathrm{F} \leq T \leq 2020^{\circ} \mathrm{F} \\
694 & \text { for } I>2020^{\circ} \mathrm{F}
\end{array}
$$

where: $\quad f_{A}=$ the fraction of surface area debonded$$
k_{x e}=x e n o n \text { gas conductivity, Btu/h-in. }-{ }^{\circ} \mathrm{F}
$$$$
\delta=\text { fuel-cladding gap thickness, in. }
$$$$
694=\text { nominal gap conductance, Btu/h-in. }{ }^{2}-{ }^{\circ} \mathrm{F} \text {. }
$$

The fractional debonded surface area, xenon gas conductivity, and fuelclad gap thickness are temperature-dependent quantities. The fractional debonded surface area is computed as:

$$
\begin{array}{ll}
0.0 & \text { for } \mathrm{T}<1490^{\circ} \mathrm{F} \\
\cos [(\pi / 2)(T-1890) / 400] & \text { for } 1490^{\circ} \mathrm{F} \leq \mathrm{T} \leq 1890^{\circ} \mathrm{F} \\
f_{A}= & \text { for } 1890^{\circ} \mathrm{F}<\mathrm{T} \leq 1994^{\circ} \mathrm{F} \\
1.0 & \text { for } 1994^{\circ} \mathrm{F}<\mathrm{T} \leq 2020^{\circ} \mathrm{F} \\
(2020-\mathrm{T}) / 26 & \text { for } 2020^{\circ} \mathrm{F}<\mathrm{T} \\
0.0 &
\end{array}
$$

\begin{tabular}{|c|c|c|}
\hline & 0.0 & for $\mathrm{T}<1490^{\circ} \mathrm{F}$ \\
\hline & $0.1(T-1490) / 400$ & for $1490^{\circ} \mathrm{F} \leq T \leq 1890^{\circ} \mathrm{F}$ \\
\hline$\delta=$ & 0.1 & for $1890^{\circ} \mathrm{F}<T \leq 1994^{\circ} \mathrm{F}$ \\
\hline & $0.1(T-1994) / 26$ & for $1994^{\circ} \mathrm{F}<\mathrm{T} \leq 2020^{\circ} \mathrm{F}$ \\
\hline & 0.0 & for $2020^{\circ} \mathrm{F}<\mathrm{T}$ \\
\hline
\end{tabular}

The temperature used in this computation corresponds to the node representing the uranium material.

The temperature-dependent gap, $\delta$, is computed using the following relationship:

Thus, the gap has a maximum width of $0.1 \mathrm{in}$. 
The temperature-dependent thermal conductivity $\left(\mathrm{Btu} / \mathrm{h}-\mathrm{in},-^{\circ} \mathrm{F}\right)$ of the xenon gas filling the gap is computed as:

$$
k_{x e}=\quad \begin{aligned}
& 0.0 \\
& {\left[1.2633(10)^{-6}\right](T+460)^{0.8616}} \\
& 0.0
\end{aligned}
$$$$
\text { for } \mathrm{T}<1490^{\circ} \mathrm{F}
$$$$
\text { for } 1490^{\circ} \mathrm{F} \leq T \leq 2020^{\circ} \mathrm{F}
$$$$
\text { for } 2020^{\circ} \mathrm{F}<\mathrm{T}
$$

\subsubsection{Thermal Bridging Model (IHEAT $=4$ )}

The thermal-bridging model was implemented to account for a step change in overall heat transfer that may occur due to slumping of components, or step changes in gap sizes. The original user-specified value of heat transfer coefficient (HINT) and area (DLONG*DWIDE) input in BLOCK 5 are replaced by the thermal bridging model variables of HINTV and AREAV once the thermal bridging temperature (TEMPFV) is exceeded. The temperature at which the bridging will occur can be made a function of the uranium node temperature (TEMPFV $<0$ ) or the cladding node temperature (TEMPFV $>0$ ).

This model can also be used to invoke one-time step changes in the internal themal connection for connected components with materials other than uranium or Zircaloy. In this case, the node temperature, which is compared with TEMPFV, is selected from one of the two nodes connected, N1 or N2 (source and sink nodes). If TFAILV is set to a value greater than zero and the material associated with $N 1$ does not represent Zircaloy (i.e., $\operatorname{MOXMAT}(N 1) \neq 100$ ), the temperature of node $N 2$ will be used in the conditional check against TEMPFY. Conversely, if TFAILV is less than zero for this connection and the material of node $N 1$ is not uranium (i.e., $\operatorname{NOXMAT}(N 1) \neq 1$ ), the temperature of node $\mathrm{N} 2$ will be used in the conditional check against TEMPFV.

The bridging model may be invoked only once for an internal themal connection during the execution. The routine sets a flag to prevent resetting the bridging values of HINTV and ARAV any time after this switch is set. The model requires IHEAT $=4$ and non-zero entries of HINTV, AREAV, and TEMPFV (BLOCK 5, Card B). 


\subsubsection{User-Specified Variable Internal Thermal Connections (IHEAT $=5$ )}

This heat transfer option directs subroutine HTRANS to interpolate from tabular values the heat transfer coefficient for the internal thermal connection. Subroutine HTRANS performs a linear interpolation between values in the USERH vs. USERT table using the average film temperature for temperature-dependent specified heat transfer coefficients, or SUMTIM for time-dependent cases. The user-specified variable internal thermal connection is created by specifying IHEAT $=5$ and a non-zero value of NUSERT (BLOCK 5 , Card B) and the appropriate number of entries in the variable heat transfer coefficient table (BLOCK 5, Card C).

\subsubsection{Severe Accident Heat Transfer Models}

Described below are two heat transfer models used in modeling severe reactor accidents: 1) the node uncovery model for boiloff simulations, and 2) a binary gas mixture property model for determining the effect of hydrogen on convective heat transfer.

\subsubsection{Node Uncovery Model}

The node uncovery model allows for a smooth transition from two-phase bulk boiling conditions (node covered) to single-phase vapor/dryout conditions (node uncovered) during a boiloff simulation. This model becomes important in determining the heatup for a node that is being uncovered. The model computes an "average" heat transfer coefficient based on the amount of node covered and the magnitude and profile of the local heat transfer coefficients. This average node heat transfer is updated each time step.

In the vicinity of a dryout front, the heat transfer coefficient used for the affected nodes is a combination of the bulk-boiling heat transfer coefficient for the covered region, HBULK (BLOCK 10, Card B), the single-phase vapor convective heat transfer coefficient computed from one of the above correlations (HSTEAM), and a transition region heat transfer coefficient. This "blend region" heat transfer coefficient is used to make the transition from HBULK (representing that portion of the node still immersed in fluid) to the single-phase vapor heat transfer coefficient (representing that portion of the node above the dryout front). The transition region occurs over a user-specified length HDO (BLOCK 10, Card B). In this region, the heat 
transfer coefficient is assumed to vary from HBULK to the correlation value, HSTEAM, in exponential fashion:

$$
h_{t r}=H B U L K^{\star} \exp ^{X / H D 0^{\star} \ln (H S T E A M / H B U L K)}
$$

where: $\quad x$ is the position in the transition zone, i.e., $\leq$ HDO $h_{t r}$ is the local transition zone heat transfer coefficient.

A schematic illustration of the heat transfer regions and the assumed behavior of the heat transfer coefficient for a node being uncovered is presented in Figure 3.5 .

The node uncovery model considers two cases: 1) when the extent of the dryout region occurs entirely within one node, and 2) when the extent of this region overlaps two (or more) adjoining nodes. When the dryout region occurs entirely within one node, the following relation is used to compute the overall heat transfer coefficient:

$$
h_{\text {eff }}=\frac{1}{\Delta Z}\left\{1_{c}{ }^{* H B U L K}+\left(1_{h c}-\text { HDO }{ }^{* H S T E A M}+\frac{H D O *(\text { HSTEAM }- \text { HBULK })}{\ln (\text { HSTEAMJHBULK) }}\right\}\right.
$$

where: $\Delta Z=$ node axial length

$1_{c}=$ length of node below dryout front in bulk-boiling region

$l_{\text {uc }}=$ length of node above dryout front in dryout region,

$$
1_{u c}=\Delta z-1_{c} \text {. }
$$

A similar expression is used for the case in which the dryout region extends into an adjoining downstream node. The convective heat transfer coefficient used for the node containing the dryout front is computed as:

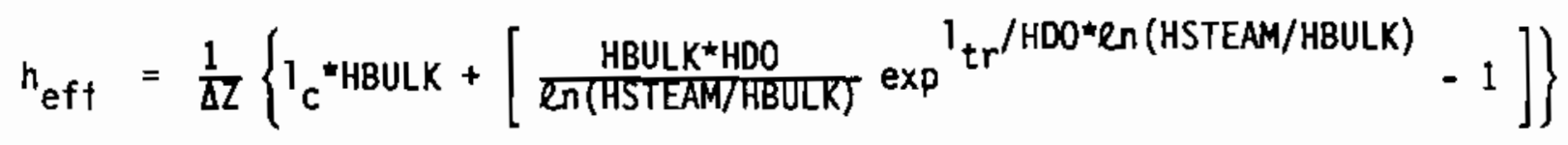



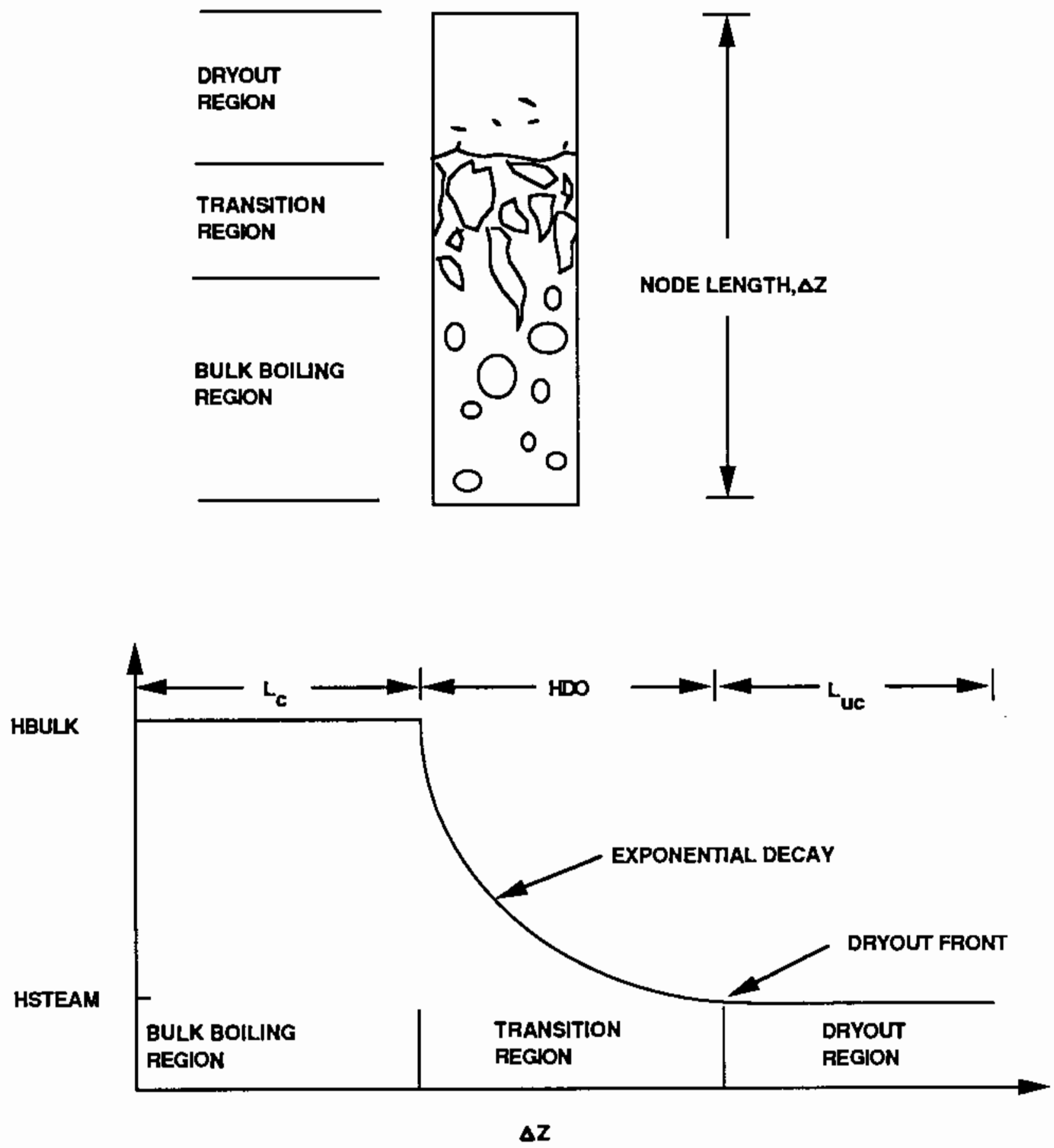

FIGURE 3.5. Heat Transfer Regimes and Modeling for a Node Being Uncovered 
where: $l_{t r}=1$ ength of transition zone in node, $1_{t r}=\Delta z-I_{c}$. In the adjoining node, the convective heat transfer coefficient is computed as:

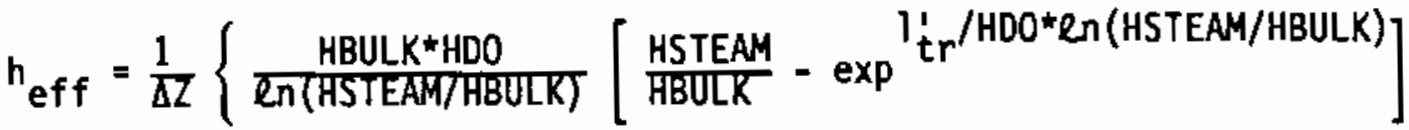

$$
\begin{aligned}
& \left.+I_{u c}{ }^{\star H S T E A M}\right\}
\end{aligned}
$$

where: $I_{t r}=$ length of transition zone in downstream node, $I_{c}+H D O-\Delta Z$

$1_{u c}=$ length of node uncovered in downstream node, $1_{u c}=\Delta z-1_{t r}$.

For nodes completely uncovered, the heat transfer coefficient is computed from either the Dittus-Boelter or Hong-Hochreiter correlations.

\subsubsection{Binary Mixture Property Model}

The optional binary property mixture model can be used to assess the effect of two different gaseous components (normally steam and hydrogen from metal-water reactions) on the convection heat transfer coefficient. In this model, the average density, viscosity, thermal conductivity, and heat capacity of a fluid node are evaluated from the thermophysical properties of the gases according to various mixture laws. The density of each constituent of the fluic mixture is assumed to be a function of temperature only. This temperature dependence is provided in the density-versus-temperature arrays RHOTAB and TRHO (BLOCK 2, Card D). Subroutine HTRANS uses the computed fluid temperature and scans array RHDTAB for the density corresponding to that temperature. Linear interpolation is used between points in the array. If the fluid in the node is a binary mixture (usually composed of steam and hydrogen from the metal-water reactions), the mixture density is computed as a mass-weighted average of the constituents.

The mixture viscosity for the node is computed in a manner similar to the density. Table look-ups for the viscosity of each constituent fluid are performed using the viscosity vs. temperature data provided in arrays VISTAB 
and TVIS (BLOCK 2, Card C). The viscosity for a binary mixture is computed using Wilke's (1950) semiempirical formula:

$$
\begin{aligned}
& \qquad=\sum_{i=1}^{2} \frac{x_{i} \mu_{i}}{\sum_{j=1}^{2} x_{j} \omega_{i j}} \\
& \qquad \begin{aligned}
\phi_{i j}=\frac{1}{\sqrt{8}}\left(1+\frac{M_{i}}{M_{j}}\right)^{-\frac{1}{2}}\left[1+\left(\frac{\mu_{i}}{\mu_{j}}\right)^{\frac{1}{2}}\left(\frac{M_{j}}{M_{i}}\right)^{t}\right]^{2} \\
x_{i}=\text { mass fraction for constituent } i \\
M_{i}=\text { molecular weight of constituent } i \\
\mu_{i}=\text { viscosity of constituent } i
\end{aligned}
\end{aligned}
$$

Constituent and mixture heat capacities are computed in a manner analogous to that done for the density. The heat capacitance of each constituent in the mixture is computed using table look-ups with arrays CAPT and TVARC (BLOCX 2, Card E). As before, the fluid temperature assigned to the node is used for the interpolation process. In the event of the fluid in a node representing a binary mixture, the mass-weighted average of the constituent heat capacitances is used to represent the mixture.

Finally, the constituent and mixture fluid thermal conductivities are computed as was done for the viscosities. The themal conductivity of each constituent is loaded into arrays CONT and TVARK (BLOCK 2, Card F). The node fluid temperature is used to interpolate in these tables and identify the thermal conductivity of each constituent. A mixture thermal conductivity is computed using Wilke's semiempirical formula presented above in the discussion of mixture viscosities (with the constituent viscosities replaced by constituent thermal conductivities).

\subsection{SUBROUTINE SURE}

Subroutine SURE is entered to read in the data items in data BLOCK 6 , the surface-connection list, and in data BLOCK 7, the external temperature (boundary node) list. All input data and immediately derived data, such as connection areas and table slopes, are written out. 
For the first time step, SURE is entered to initially set the crossreference tables that relate the surface-connection list to the node list and boundary node list. The initial values of several quantities are calculated, including the conductance of the surface connections.

At each time step, SURE is entered to calculate the cumulative heat flow across each surface connection, the new boundary node temperatures, the new surface-connection conductances, and the amounts of heat flow across each surface connection. These calculations are based on estimated average conductances during the time step, surface node temperatures at the beginning of the time step, and boundary node temperatures at the end of the time step.

At intervals determined by input data, summary data are written out for each surface connection, including the surface and boundary node numbers, the connection area, the surface conductance, the free-convection exponent, the radiative transfer form factor, the overall conductance, and the net heat flow and average heat flow rate into the surface node from the boundary node. Summary data are written out for each boundary node, including the boundary node number, the external temperature, and the net heat flow and average heatflow rate into the system from the boundary node. The total heat flow and average flow rate into the system for all boundary nodes are also written out.

SURE calls TRUMP subroutines SEEK2 and REFER, and returns to HEART.

\subsection{SUBROUTINE SPECK}

Subroutine SPECK is entered after all input data have been read in, and, for the first time step, to initially set various quantities.

At each time step, SPECK is entered to make the final calculation of heat flow across surface connections and internal thermal and mass flow connections, including nodes classified as special nodes. This calculation is based on interpolated values of special node temperatures during the time step, weighted from 0.57 to 1.00 toward the temperatures at the end of the time step.

When special nodes are connected to each other, an jterative calculation is required, which is done by an accelerated method and imposes strict

convergence criteria on average and individual temperature changes. Diagnostic 
statements are written out if a specified maximum number of iterations are required, and if the problem must be ended because of convergence failure when the smallest time step is being used.

Heat flow into regular nodes connected to special nodes is corrected to maintain an exact heat balance for each connection.

At intervals determined by input data, summary data are written out, including the number of time steps completed; the total, average, and maximum number of iterations used; and the temperature interpolation factor.

SPECK returns to HEART.

\subsection{SUBROUTINE TALLY}

The input and cycling portions of subroutine TALLY are discussed below.

\subsection{1 .1 Input}

Because subroutine TALLY reads in two different input blocks, i.e., BLOCK 1 and BLOCK 9, and changes have been made to both, each of the input blocks are discussed below.

\subsubsection{BLOCK 1}

Within BLOCK 1, several additions and/or modifications have been made from the original TRUMP.

Input variable OUTDISC has been added and is read from Card $A$. OUTDISC acts as a post-processing dump flag. When OUTDISC $=2$, graphics dump files TAPE3 and TAPE5 (see Section 5.0) will be created; when OUTDISC $=0$, these post-processing files are not created.

Card D, the "Bundle Characterization and Special Output Card", has been added. Diagnostic printout flag, IDIAG, controls what TRUMP-BD output sumaries will be created and written to the OUTPUT file (Section 5.0). Variable NSPOUT identifies the number of special output nodes listed on Card $E$ that are read into array NODOUT; node temperatures of the special output nodes at intervals specified by XSPRNT are written to the post-processing output file, TAPE 5. Variable NAXPO identifies the number of special axial output nodes to be entered on Card $F$ and read into array NODEAX. NAXTIM identifies the number of times listed on Card $G$ to be read into array AXTIM; 
the axial temperature profiles at times defined by AXTIM for nodes specified by NOOEAX are written to post-processing output file, TAPE 11 . The last new BLOCK card read by TALLY is Card $H$, the "Output Suppression Card"; this card 1 imits the amount of extraneous standard TRUMP output written in during a simulation.

\subsubsection{BLOCK 9}

Subroutine TALLY is also entered to read in the input items in BLOCK 9, which include heat generation information and the setting initial conditions.

In BLOCK 9 Card $A$, the "TRUMP-BD Logic Card", is read first. When LEVFLG $=0$, standard TRUMP logic is used and TALLY will try to read Card B, the "Initial Conditions Card"; Cards C through I should be omitted in this case. When LEVFLG $=1$, TALLY will route to TRUMP-BD logic and will read Card $C$ through Card I; Card B should be omitted in this case.

Card $C$ is the "Power Generation and Oxidation Description Card". Variable TFAIL, the uranium fuel failure temperature, defaults to $1994^{\circ} \mathrm{F}$ unless specified by the user (Card $C$ ). The metal-water correlation flag, MWRCOR, is then checked by TALLY. If no oxidation is specifjed (MKRCOR $=0$ ), the variable MWR (whose value is the number of metal-water reaction nodes input in BLOCK 4) is reset to zero. MWR is used within TRUMP-BO as a DO-LOOP index limiter; thus resetting this variable to zero causes TRUMP-BD to bypass oxidation logic. Also read from $C a r d ~ C$ is the variable power generation flag. IGENFG. When IGENFG is 1 or -1 , indicating time varying heat generation during boiloff (1) and nonboiloff (-1) simulations, Card D, the "Power Generation-Time Table" is read next by TALLY. Following this, a check is made on NOXVAR, the uranium oxidation area variation flag. If NOXVAR is > 0 , NOXVAR pairs of OXMULT vs. OXTEMP will be read from Card E, the "Oxidation Area Variation Table". This feature was added to provide a means of varying the avajlable uranium oxidation area with temperature to account for changes due to fuel swelling and/or relocation. For problems in which temperature TFAIL is or has been exceeded for a given fuel pin at a discrete axial level, values of OXMULT are linearly interpolated in TALLY from this table at each time step using TPINMAX. For boiloff simulations, AXMG is used to modify the local heat generation rate for nodes above the dryout front, thus accounting for any power change caused due to voiding of the coolant in the flow region. 
The "Axial Power Profile Descriptor Card", Card F, is read next by TALLY. If ICOS, the axial power profile identifier, is found to be 0 , a chopped-cosine axial power profile is used. When ICOS = 1, Card G, the "Axial Power Profile and Integral Table" is read. This card requires that the local peaking factor (PMULT) and integrated power (PINT) be specified at user-specified axial positions (PHIGHT) in the table. Note that the integrated power values (PINT) need only to be input for boiloff simulations.

TALLY next reads Card $H$, the "Node Heat Generation and Temperature Initialization Card". This card is used to specify node axial and radial power factors used by TALLY to derive node heat generation rates, the current phase change mass fractions, and node temperatures to values other than the problem default values read by TALLY in BLOCK 1, Card $C$.

For each Card $H$ read, TALLY first checks ITXY, the initial temperature axial variation flag. When ITXY>0, TALLY will read Card I, the "Initial Temperature Axial Variation Card", for ITXY pairs of node temperatures (TOUM) vs, axial position (ZDUM). The initial temperature, $T T$, of a node is then determined by linear interpolation using the axial position at which the node is located, HEIGHT. When ITXY is zero, TT is set to the value of TXY on Card $H_{;}$if TXY is not specified, the node temperature is defaulted to the value specified by TONE (BLOCK 1, Card C).

For severe accident problems, the model heat generation is normally a combination of fission and/or ganma heating, along with energy release due to metal-water reactions. TRUMP-BD will compute the time-dependent metal-water reaction heat generation component for Zircaloy/uranium nodes in GEN provided: 1) MWRCOR is $\geq 0,2$ ) finite values of node thickness (ZRTHIK) and oxidation area (OXAREA) are specified, and 3) node temperatures are high enough (i.e., $\mathrm{T}>1300^{\circ} \mathrm{F}$ for zirconium, $\mathrm{T}>$ TFAIL for uranium).

To simulate fission and/or gamma heat generation, an average linear heat generation rate for the entire fuel bundle must be specified. This term, RODAVE, is computed by dividing the total fuel bundle heat generation rate (kW) by the total fuel bundle heated length ( $f t)$ and the total number of discrete fuel rods or elements; the units of RODAVE are therefore kW/ft-rod. 
The average volumetric fission heat generation rate, PAVE, is then calculated by

$$
\text { PAVE }=3412 . *(\text { FISAVE } / 12 .) /\left(\mathrm{PI}^{\star} \text { FUELR }{ }^{\star \star 2}\right) \quad\left(\text { Btu } / \mathrm{h}-\mathrm{in} .{ }^{3}\right)
$$

where: FISAVE = the fraction of heat generation by fission, i.e., RODAVE * (1 - PGAMA )

FUELR = effective radius of fuel $\operatorname{rod}(s)(B L O C K \quad 1$, Card $D)$

RODAVE $=$ fuel rod average power $(\mathrm{kW} / \mathrm{ft}$-rod) (BLOCK 9, Card $\mathrm{C})$

PGAMA = fraction of heat generation from ganma heating

(BLOCK 9, Card C)

3412 = conversion from $\mathrm{kW}$ to $\mathrm{Btu} / \mathrm{h}$

12 = conversion from $\mathrm{ft}$ to $\mathrm{in}$.

Note that the total bundle nuclear heat generation rate is composed of a fission and gamma heating contribution; when computing the average volumetric heat generation rate in the fuel (FISAVE), the gamma heat contribution is not included.

The gamna heating volumetric heat generation rate, PGAMMA, is computed from the gamma heating linear heat generation rate (RODAVEःPGAMA) and an effective component cross-sectional area (i.e., cladding) using

$$
\text { PGAMMA }=3412 . \text { * (GAMAVE } / 12 .) / \text { CLADXC } \quad\left(\text { Btu } / \mathrm{h}-\mathrm{in} .{ }^{3}\right)
$$

where: GAMAVE $=$ PGAMMA RODAVE, the average linear heat generation rate due to gamma heating $(\mathrm{kW} / \mathrm{ft}-\mathrm{rod})$

$$
\text { CLADXC = cross-sectional area of fuel cladding }\left(\text { in. }{ }^{2}\right)
$$

For each node specified on Card $H$, the "Node Heat Generation and Temperature Initialization Card," the volumetric heat generation rate defined by either PAVE or PGAMMA is used in conjunction with axial and radial power factors and the node volume to determine the node's initial heat generation rate. If the node is a fuel node, the volumetric heat generation rate is computed based on PAVE, specified by setting NGAM $=0$ (Card $H$ ); for a nonfuel component with 
gamma heating, the volumetric heat generation rate is computed from PGAMMA, specified by setting NGAM $=1$. The axial power factor, PAXIAL, is either computed from the PHULT vs. PHIGHT table (Card G), if ICOS $<1$, or from the chopped-cosine axial profile specified on Card $F$.

The chopped-cosine axial profile is defined by variables PRATIO and EZERO on Card F. PRATIO is the ratio of peak-to-average (RODAVE) power, assumed to occur at the axial midpoint of the bundle length. EZERO is an extrapolated length at which PAXIAL $=0.0$, the imaginary intersection points of the cosine curve at zero (Figure 3.6). An expression for the cosine function defined by extrapolated length and the peak-to-average power ratio is then used by TALLY to calculate a local PAXIAL for each node along the bundle length.

The node radial power factor PRADIL is also input on Card $H$. This factor accounts for the local variation in heat generation due to the radial and/or circumferential position of the node(a). The initial volumetric node heat generation rate is then PAVE^PAXIAL*PRADIL when NGAM $=0$, or PGAMMA*PAXIAL*PRADIL when NGAM $=1$.

When NSEQ $>0$ on Card $H$, an additional MSEQ nodes (where $N 1$ is incremented by NADD each time through the loop) are initialized for this Card. When NSEQ +1 nodes have been initialized, TALLY loops back to read another Card H, continuing until all node initial values have been set, at which point TALLY returns control to HEART.

\subsection{1 .2 Cycling}

After all input data for a problem has been read in, TALLY is entered to write out a sumnary of the number and sizes of input data blocks, data carried over from preceding problems, the number of tables of various types, and the numbers of certain types of input items. Next, the initial conditions from BLOCK 9 are used to set the "current" heat generation rate $(G)$, Temperature $(T)$, and phase mass fraction (A) for each node. The problem time, the size of the first time step and interpolation factor, and other variables are initially set.

(a) PRADIL can also be used to model local variations in the axial power profile. 


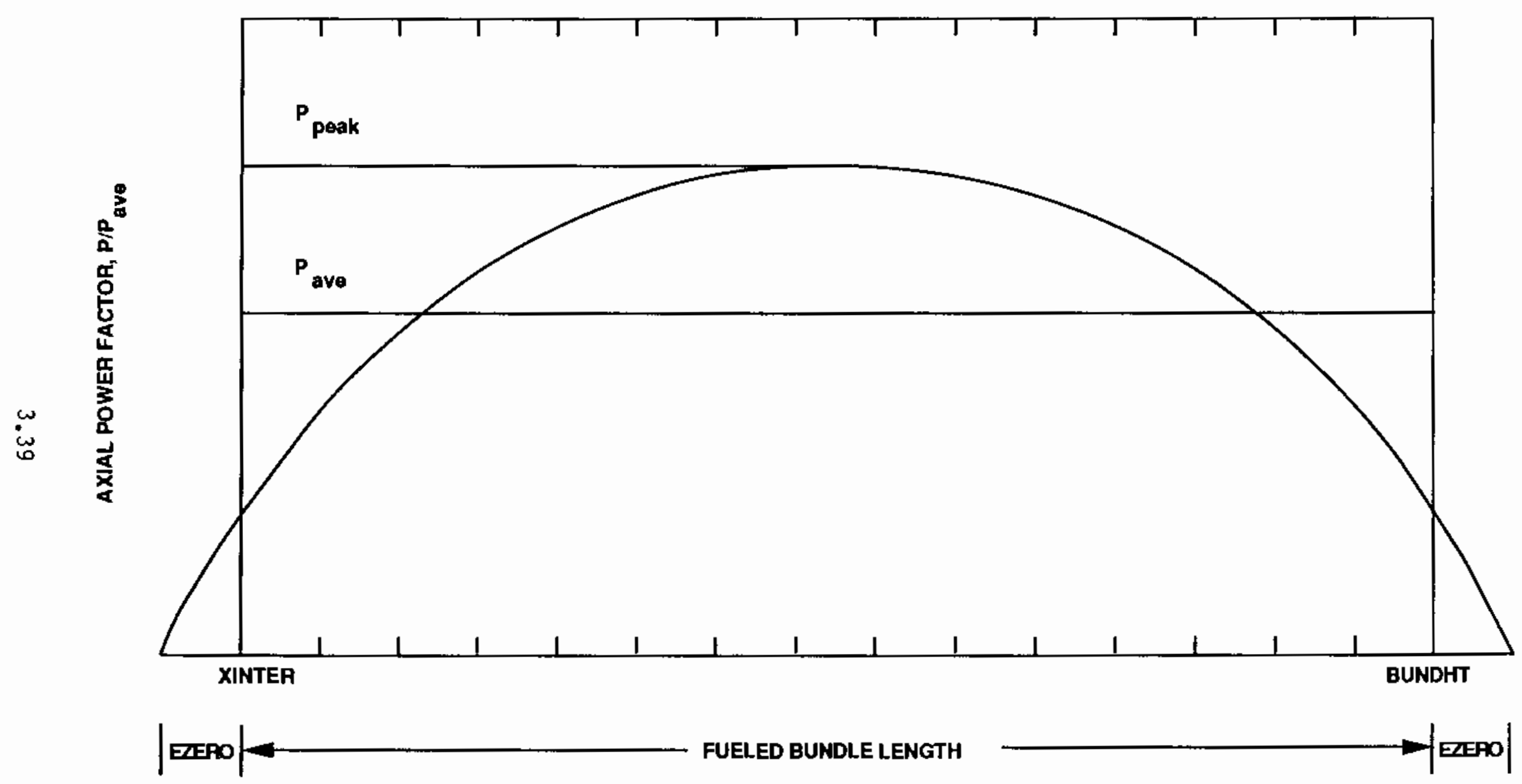

FIGURE 3.6. Characteristics and Variable Definitions for a Chopped-Cosine Axial Power Distribution 
Subroutine TALLY is the time step control center of the program. At the end of every time step the original TRUMP numerics in TALLY are used to determine the maximum stable time step for regular nodes. Nodes may be reclassified as "special" nodes to keep the size of the time step from being limited. The largest temperature change for the time step is found. The results of the time step are accepted or rejected based on input data, the largest temperature change, and changes in tabulated quantities during the time step. The size of the next time step is then determined. The new values of node temperatures, heat contents, fluxes, and maximum and minimum temperatures in the system are computed.

When uranium fuel nodes are designated as belonging to a unique fuel "pin" using NPN (BLOCK 4, Card D), the minimum temperature (TPIN) of each pin for each axial level is computed. A check is made on TPIN to see if it exceeds TFAIL, the fuel failure temperature, and also to see if TPIN exceeds TPINMAX, the maximum temperature for the pin thus far in the transient. When a uranium pin is found to have failed, a uranium oxidation area multiplier (OXAREAM) is computed using linear interpolation of TPINMAX in the OXMULT vs. OXTEMP table. If fission products release is being modeled, subroutine FISPROD is called if any fuel has failed.

The total hydrogen production during the current time step is a result of oxidation of uranium (HFROMU) and Zircaloy (HFROMZ), and is computed based on the conversion of chemical reaction heat generation terms (QZRH20). Additional hydrogen and steam summary information for the model is then also computed, along with FUELMX and CLADMX, the maximum uranium and Zircaloy cladding temperatures in the model, respectively. Special output node temperatures and system summary information is written to TAPE5 and TAPE3 if XSPRNT time has elapsed since they were last written. Special output node temperatures and phase information is also written to OUTPUT, the main output file, after phase concentrations have been updated.

As in the original TRUMP, various criteria for ending the problem are tested. Various criteria for producing output data for the time step are also tested. When required, data for the time step are written to the OUTPUT file. The type and extent of both standard TRUMP and TRUMP-BD output written at this time is discussed in detail in Section 5.0 . 
TALLY is entered at entry point TALLYI when a problem is ended in order to write, if required by the input data, the final conditions of the problem to OUTAPE, which can be used to restart the problem (Section 4.0).

TALLY calls TRUMP-BD subroutines FISPROD, SEEK1, REFER and TIMER. TALLY returns to HEART during normal time step cycling.

\subsection{SUBROUTINE REFER}

Subroutine REFER is entered only during the first time step to produce cross-reference tables relating various input-data item lists. The sequence number in the node list (BLOCK 4) must be found for all nodes listed in data BLOCKs $1,5,6,8,9,10,11$, and 12 . The sequence number in the material list (BLOCK 2) must be found for each material listed in BLOCK 4 . The sequence number in the boundary-node list (BLOCK 7) must be found for each boundary node listed in BLOCK 6 . This procedure makes possible the use of arbitrarily chosen identification numbers for each of the four types of items referenced by other data blocks, allowing flexibility in arranging and modifying data decks. Also, the identification numbers may be chosen to convey additional information to the user, such as composition, spatial location, and function in the problem.

The search for each item referenced is made in reverse sequence, so that the latest item in the list is used. If a referenced identification number is not in the list being searched, a diagnostic statement is immediately written out, an error indicator is set, and the problem is terminated.

REFER returns to the calling routine, which may be THERM, GEN, FINK, FLOW, SURE, or TALLY.

\subsection{SUBROUT INE SEEKI}

Subroutine SEEKI is entered only during the data-input phase of the problem, when a data BLOCK 2, 4, 7, 8, or 9 of type $B$ is being read in. Since the data carryover feature of the code has been deleted, i.e., type B-input, subroutine SEEKI is not used. 


\subsection{SUBROUTINE TIMER}

Subroutine TIMER finds the machine time, in seconds, charged to the program since the last call of TIMER, by means of the system subroutine SECOND. TIMER returns to the calling routine, which may be HEART or TALLY.

\subsection{SUBROUTINE FISPROD}

Subroutine FISPROD performs three major functions:

- reads and processes input from BLOCX 13 relating to initial fission product inventories and release characteristics

- computes fission product release from failed uranium metal zircaloy-clad fuel nodes subsequent to fuel failure after each time step

- writes fission product special output data to TAPE12.

Details of the first two of these three functions are described below; fission product output data written to TAPE12 is described in Section 5.0

\subsubsection{Input BLOCK 13}

By specifying an input BLOCK 13 , subroutine FISPROD is called by HEART during the input phase to read data on those fission products whose release is being modeled. BLOCK 13 input includes:

- the number of different fission products modeled

- a reference vapor temperature needed for the bake-out term of the fission product release empirical relationship (see Section 3.16.2)

- the fraction of whole-core power generation occurring in the fue 1 assembly being modeled (variable FPFRAC)

- initial whole-core inventories of each fission product being modeled (vector FPIT)

- four empirical constants for each fission product which are used in the empirical relationships for fission product release

- variables that control the times at which fission product release sumaries will be written to TAPE 12 (see Section 3.16.3).

Heat generation rates and volumes for all uranium fuel nodes (computed in TALLY and THERM, respectively) are used by FISPROD during problem initialization (i.e., $\mathrm{KCYC}=0$ ), along with BLOCK 13 input FPFRAC and FPIT, to estimate initial node inventories for each fission product by assuming that 
each fuel node's fission product inventory is linearly proportional to the percentage of whole-core decay heat generation occurring in that node.

\subsubsection{Fission Product Release from Nuclear Fuel}

Within FISPROD, the fission product release rate at a given time step from an exposed uranium fuel node is assumed to be the sum total of releases caused by simultaneous mechanisms that account for fuel oxidation and volitization/diffusion, respectively. The overall mass balance equation used by FISPROD for each species can be written as:

$$
(d f p / d t)_{i}=R_{o_{j}}\left(f p_{s_{i}}-f f_{f_{j}}\right)+R_{b_{j}}\left(f p_{s_{i}}-f f_{f_{i}}\right)
$$

where $(d f p / d t)_{i}=$ rate of release of fission product $i$;

$\mathrm{fPs}_{j}=$ concentration of fission product $i$ in surroundings;

$\mathrm{fpf}_{\mathfrak{i}}=$ concentration of fission product $i$ in fuel;

and $R_{O_{j}}$ is a conductance defined as the release fraction due to oxidation and $R_{b_{j}}$ is a conductance defined as the release fraction due to volitization/diffusion. Because accurate determination of surrounding concentrations is not computed by TRUMP-BD, $f P_{s}$ is assumed $=0.0$ as a conservatism. After the rate of release $d f p / d t$ from each fuel node is computed, integral releases are updated by multiplying the node's release rate by the time step, and summing this release with the integral total release for the node accumulated from earlier time steps.

Calculation of the conductances $R_{0 i}$ and $R_{b i}$ is accomplished with relations derived by Birney et al. (1988), based on available data for zircaloy-clad uranium fuel.

Data for fission product release as a result of uranium oxidation in air are shown in Figures 3.7 through 3.10, while that for oxidation in other environments is shown in Table 3.5. The data in the figures indicate that complete fuel oxidation would release about 100 percent of the iodine, tellurium, and about 30 percent of the cesium. Table 3.5 indicates significantly less release for low volatility species. Using these data, Birney et al. formulated the following empirical correlation, where the release 
TABLE 3.5. Fission-Product Release from Uranium Fuel Irradiated to 1.0-atom Percent and 0xidized (Birney, et al. 1988)

\begin{tabular}{|c|c|c|c|c|c|c|c|c|}
\hline \multirow[b]{2}{*}{$\begin{array}{l}\text { Oxidizing } \\
\text { Atmosphere }\end{array}$} & \multirow{2}{*}{$\begin{array}{l}\text { Time } \\
\text { Heated } \\
\text { (min) } \\
\end{array}$} & \multirow{2}{*}{$\begin{array}{l}\text { Percent } \\
\text { Of U } \\
\text { Oxidized }\end{array}$} & \multicolumn{6}{|c|}{ Percent of Total Activity Released } \\
\hline & & & $\underline{I}$ & $\mathrm{Te}$ & Cs & $\mathrm{Ru}$ & $\mathrm{Sr}$ & $\mathrm{Zr}$ \\
\hline Air & 20 & 65 & 57 & 71 & 13 & 1.8 & 0.09 & 0.05 \\
\hline Air & 250 & 100 & 90 & 96 & 24 & 65 & - & 0.01 \\
\hline $\mathrm{CO}_{2}$ & 630 & 100 & 53 & 69 & $1.7(\mathrm{a})$ & 1.0 & $0.01^{(a)}$ & 0.1 \\
\hline $\mathrm{CO}_{2}$-helium & 410 & 90 & 68 & 55 & $0.9^{(a)}$ & -- & $0.01^{(a)}$ & 0.0 \\
\hline Steam-helium & 123 & 65 & 15 & 79 & $0.2^{(a)}$ & 0.01 & $0.02^{(a)}$ & 0.2 \\
\hline Helium & 148 & 4 & 47 & 0.6 & 2.0 & & 0.9 & - \\
\hline
\end{tabular}

fraction $\left(R_{0}\right)$ of a particular species is related to the extent of Uranium oxidation as follows:

$$
R_{0}=C_{X} F
$$

where $F$ is the fraction of uranium oxidized. The release constant $\left(C_{x}\right)$ for each fission product species is given in Table 3.6.

The predicted fraction of uranium oxidized (F) is directly computed by FISPROD; thus, the release fraction ( $R_{0}$ ) for each fission product can be calculated at each time step.

TABLE 3.6. Oxidation-Induced Fission Product Release Constants

$\begin{array}{ll}\text { Iodine } & C_{x}=1 \\ \text { Tellurium } & C_{x}=1 \\ \text { Cesium } & C_{x}=0.3 \\ \text { Ruthenium } & C_{x}=0.05 \\ \text { Strontium } & C_{x}=0.01 \\ \text { Zirconium } & C_{x}=0.01 \\ \text { Cerium } & C_{x}=0.01 \\ \text { Barium } & C_{x}=0.01\end{array}$

(a) Release values probably low because of chemisorption in test apparatus. 


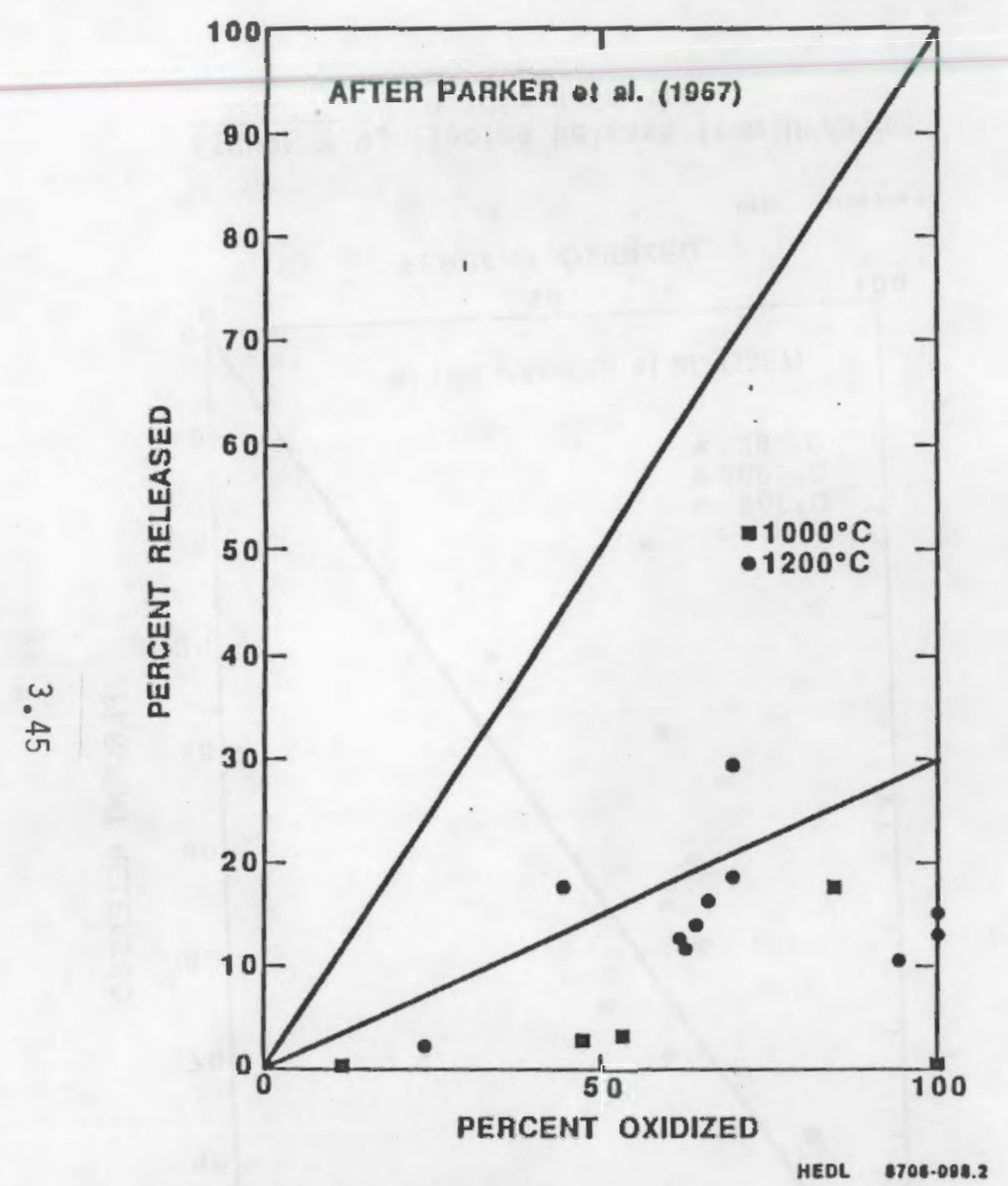

FIGURE 3.7. Cesium Release from Uranium Oxidized in Air

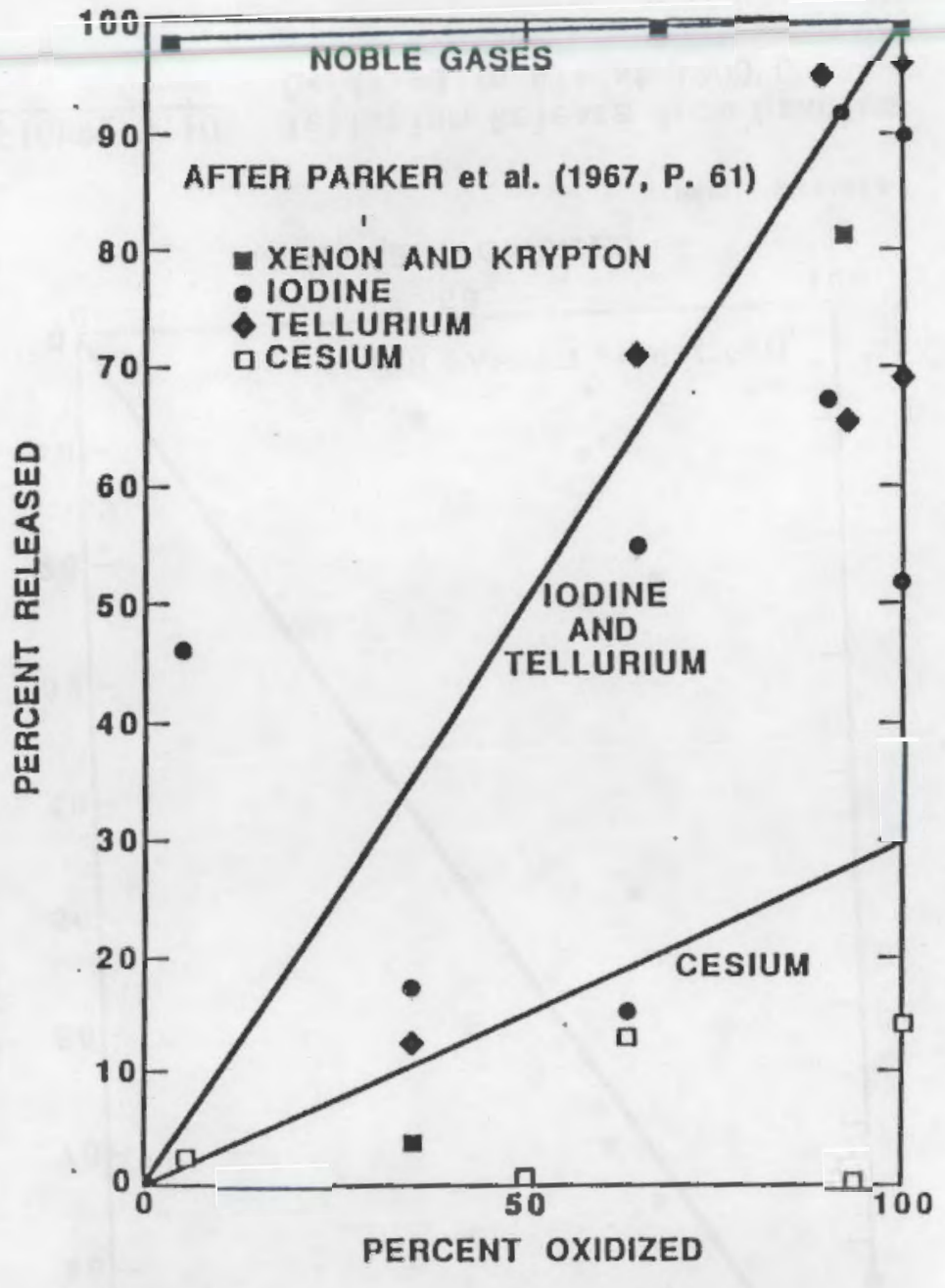

FIGURE 3.8. Fission Product Release from Uranium oxidized at $1200^{\circ} \mathrm{C}$ 


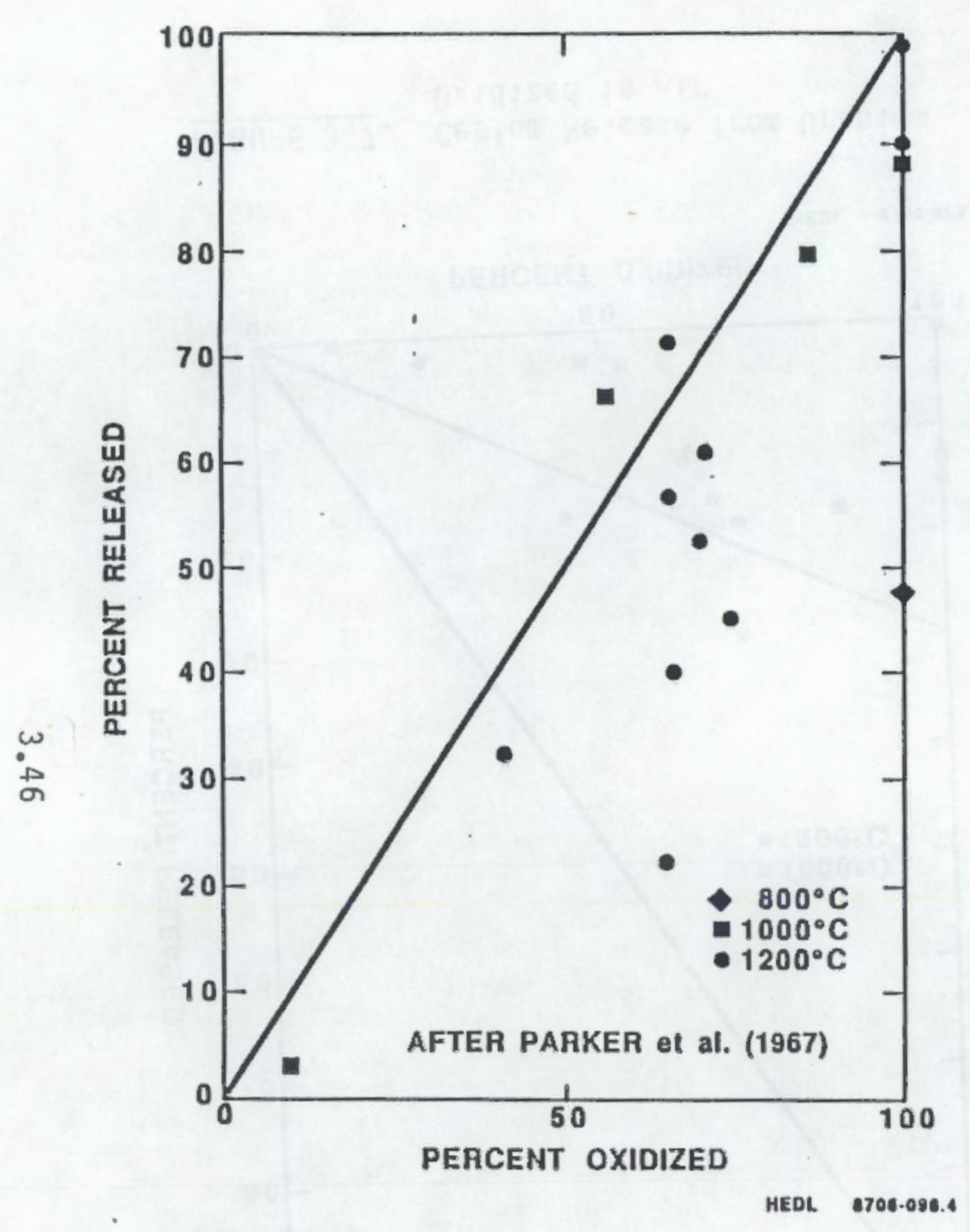

FIGURE 3.9. Iodine Release from Uranium oxidized in Air

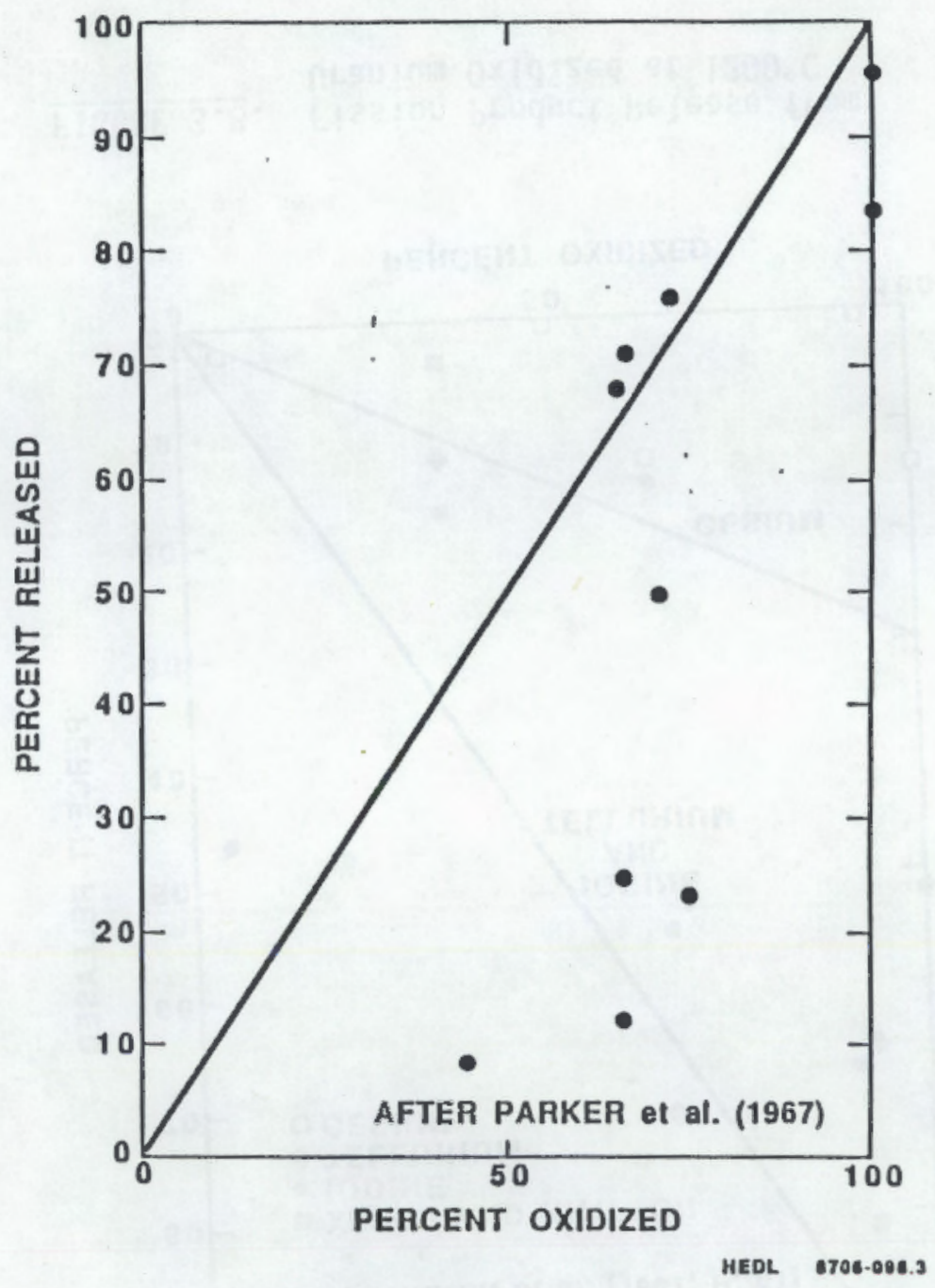

FIGURE 3.10. Tellurium Release from Uranium Oxidized in Air at $1200^{\circ} \mathrm{C}$ 
Available data for fission product release from metallic uranium melted in an inert atmosphere caused by volitization/diffusion (or "bake-out") are shown in Table 3.7.

For each fission product a correlation was developed by Birney et al. that uses the fission products vapor pressures, to formulate a temperaturerelease dependent relationship. The vapor pressures were obtained from Parker and Barton (1975), and fit to the form:

$$
\log P=-0.05223(A / T)+B
$$

where the $\log$ is base $10, P$ is in $\mathrm{mm}-\mathrm{Hg}$ and $\mathrm{T}$ is in $\mathrm{K}$. The $\mathrm{A}$ and $\mathrm{B}$ coefficients are given in Table 3.8 .

Lacking definitive time-dependent release data, the values shown in Table 3.7 were extrapolated linearly with time to 100 percent release. However, to correlate the data, the ratio of the vapor pressures at high temperatures relative to that at $1200^{\circ} \mathrm{C}(1473 \mathrm{~K})$ were raised to the 0.7 -power. Thus, the following release equation was obtained by Birney et al.:

$$
R_{b}=.01 C t\left(V(T) / V_{\text {ref }}\right) 0.7
$$

where

$$
\begin{aligned}
\mathrm{Rb}_{\mathrm{b}}= & \text { fission product release fraction due to bake-out } \\
\mathrm{C}= & \text { constant from Table } 3.8 \\
\mathrm{t}= & \text { time at temperature } T \text { (min) } \\
\mathrm{V}_{\text {ref }}= & \text { vapor pressure for a specific fission product }(\mathrm{mmm}-\mathrm{Hg}) \\
& \text { at the reference temperature of } 1473 \mathrm{~K}\left(2192^{\circ} \mathrm{F}\right) \\
T \quad= & \text { temperature }(\mathrm{K}) .
\end{aligned}
$$


IABLE 3.7. Fission Product Release Data for Metallic Uranium Melted in an Inert Atmosphere

\begin{tabular}{|c|c|c|c|c|c|c|c|c|c|c|}
\hline \multirow[b]{2}{*}{ Reference } & \multirow{3}{*}{$\begin{array}{c}\begin{array}{c}\text { Time at } \\
\text { temperature } \\
\text { (min.) }\end{array} \\
148\end{array}$} & \multirow{2}{*}{$\begin{array}{r}\text { Temperature } \\
\left({ }^{\circ} \mathrm{C}\right) \\
\end{array}$} & & \multicolumn{7}{|c|}{ Percent released } \\
\hline & & & & $\underline{x e-k r}$ & I & $\mathrm{Te}$ & $\mathrm{Cs}$ & Ru & $S r$ & $\mathrm{Ba}$ \\
\hline $\begin{array}{l}\text { Parker et al. } \\
(1967, \text { p. } 61)\end{array}$ & & 1200 & & 98 & $47 *$ & 0.6 & 2.0 & & $0.9 \star$ & \\
\hline $\begin{array}{l}\text { Hflliard } \\
(1959, \text { p. 24) }\end{array}$ & 25 & 1215 & & 10 & 41 & $4.2^{\star}$ & $1.2^{\star}$ & $0.09 *$ & 0.18 & $0.08^{*}$ \\
\hline $\begin{array}{l}\text { Hilliard et al. } \\
\text { (1961, p. 4) }\end{array}$ & 232.5 to & $\begin{array}{l}425 \text { to } \\
1440\end{array}$ & $\begin{array}{l}\text { Min. } \\
\text { Max. } \\
\text { Avg. }\end{array}$ & & & & $\begin{array}{l}0.04 \\
0.17 \\
0.08\end{array}$ & $\begin{array}{l}0.008 \\
0.13 \\
0.05\end{array}$ & $\begin{array}{l}0.008 \\
0.18 \\
0.06\end{array}$ & $\begin{array}{l}0.01 \\
0.23 \\
0.07\end{array}$ \\
\hline $\begin{array}{l}\text { Hilliard et al. } \\
(1961, \text { p. 5-6) }\end{array}$ & $232^{2.5}$ to & $\begin{array}{l}425 \text { to } \\
1440\end{array}$ & & $\sim 50$ & -10 & $<1$ & & & & \\
\hline $\begin{array}{l}\text { H1lliard and Retd } \\
(1962, \text { p. 28) }\end{array}$ & 3 & $\begin{array}{l}1000 \text { to } \\
1400\end{array}$ & & -100 & & & & & & \\
\hline
\end{tabular}

* These data were selected and used to develop Table 4. 
TABLE 3.8. Vapor Pressure Equation Coefficients

\begin{tabular}{|c|c|c|c|}
\hline Element & A & $B$ & $\begin{array}{l}\log \mathrm{pa}^{\circ} \\
\left(1200^{\circ} \mathrm{C}\right)\end{array}$ \\
\hline Iodine & 34175 & 6.740 & 5.53 \\
\hline Tellurium & 120810 & 7.817 & 3.53 \\
\hline Cesiun & 71275 & 6.679 & 4.15 \\
\hline Ruthenium & 611935 & 10.760 & -10.94 \\
\hline Strontium & 141145 & 7.285 & 2.28 \\
\hline Zirconium & 815110 & 15.730 & -13.17 \\
\hline Cerium & 443200 & 12.883 & -2.83 \\
\hline Barium & 176530 & 8.100 & 1.84 \\
\hline $\begin{array}{l}\text { a Log } \\
\text { wher } \\
\text { and }\end{array}$ & $\begin{array}{l}.05223 \\
=\log \text { is } \\
\text { in } K .\end{array}$ & $\begin{array}{l}1973), \\
T+8 \\
\text { ase } 10,\end{array}$ & is in $m \pi n g$, \\
\hline
\end{tabular}





\subsection{PREPARATION OF INPUT DATA}

Described below is the TRUMP-BD input format, data deck organization, and the individual input card function and variable entries. Definitions of code input and processing variables are presented in Appendix $A$, the Variable Glossary.

\subsection{CARD INPUT FORMATS}

All input data for TRUMP are in Hollerith (A), integer (I), or floating point ( $E$ or F) formats.

Hollerith data may consist of any characters in the character set recognized by the computer and available on standard computer terminals.

Integer data may consist of numbers only, preceded by a sign, and rightjustified in the specified data fields.

Floating point data may include numbers, preceded by a sign, and must include a decimal point if the field is not entirely blank. The exponent to the tiase 10 may be included (right-justified in the specified data field), consisting of the letter $E$ or a sign, or both, followed by numbers. Some varicbles used in floating point form in the program are read in with a Hollerith format, converted to floating point if a decimal point is included, or assigned some other value if no decimal point is included.

\subsection{DATA DECK ORGANIZATION}

The structure of the TRUMP-BD input data deck is presented below.

\subsubsection{Data Decks}

Each input data deck must consist of a "Problem Name Card," any number of "BLOCK Number Cards" with their accompanying "BLOCK Item" input cards, and a "Data End Card."

\subsubsection{Problem Name Card}

The first card of each data deck must be a "Problem Name Card." The symbol "ネ" must be in column 1, any desired problem identification and description in columns 2 through 71. The entire contents of the card (NAME) will appear on all output, along with a sequential problem number. Additional cards 
containing comments without "»" in column 1 may precede the name card and will appear on the output.

\subsubsection{BLOCK Number Cards}

There are presently 10 allowed input data blocks as described in Table 4.1. Each block used must begin with a "BLOCK Number Card" and, except for BLOCK 1, must end with a blank card. The specification of data within each data block is described below.

The "BLOCK Number Card" must have the word "BLOCK" in columns 1 through 5 , and the block number right-justified in columns 6 and 7 . Any desired block description may be in columns 9 through 80, which will appear on the printout. Additional cards containing comments may proceed or follow any data block, as Iong as columns 6 and 7 are blank, and will also appear on the printout.

Data BLOCK 1 must follow the "Problem Name Card." Data BLOCK 1 may be used more than once in the data deck to change the values of parameters used for initializing data in the subsequent data blocks, such as SCALE, KO, TONE, ALONE, GONE, FONE, HONE, RONE and PONE. Thus, a data block may be subdivided into sections requiring different values of one or more of the 1 isted parameters, and placed in the data deck with a new BLOCK 1 preceding each section. All other data blocks may be placed in any order. If more than the allowed limit of items are described for a particular block, a diagnostic statement is printed, the excess items each successively stored in the last available memory location, and the value of KWIT, the program termination indicator, set to 11. If any table length exceeds the allowed limit, the data will be incorrectly stored, and the value of KWIT set to 12. In either case, the problem will end after completion of the input and initialization phases.

If the same item is described more than once in a block, the effects will be additive in BLOCKs 5, 6, 10, or 13, but only the last description will be used in BLOCKS 2, 4, 7, 8, 9, or 12 . 
TABLE 4.1. TRUMP Input Data Blocks

\begin{tabular}{|c|c|c|}
\hline BLOCK & Description & $\begin{array}{c}\text { Optiona } 1 \\
\text { Subroutines } \\
\text { Required }\end{array}$ \\
\hline $1(\mathrm{a})(\mathrm{b})$ & Problem controls, Iimits, constants & GEN (c) \\
\hline $2(a)$ & Material properties & \\
\hline $4(a)$ & Node descriptions & \\
\hline 5 & Internal thermal connections & \\
\hline 6 & External thermal connections & SURE \\
\hline 7 (d) & External temperatures (boundary nodes) & SURE \\
\hline 8 & Variable heat-generation rates & GEN \\
\hline 9 & $\begin{array}{l}\text { Initial values of temperature, heat-generation rates, } \\
\text { metal-water reactions }\end{array}$ & GEN $(e)$ \\
\hline 10 & Mass-flow connections, coolant boiloff & FLOW \\
\hline 12 & Nodes with properties dependent on remote temperatures & \\
\hline 13 & Fission Product Inventories & FISPROD \\
\hline
\end{tabular}

\footnotetext{
(a) Required data for all problems.

(b) Must be read in before any other data blocks.

(c) Only if GONE is nonzero.

(d) Required if BLOCK 6 is used.

(e) Only if one or more $G G$ values are nonzero.
}

\subsubsection{Data End Card}

The last card of each data deck must be a "Data End Card" with the word "ENDED" in columns 1 through 5 and " $1 "$ in columns 6 and 7.

\subsection{BLOCK ITEM DESCRIPTIONS}

Input data that may be specified in each data block are summarized in this section. Formats, definitions, options, and suggested uses are described for all input data specified. 
BLOCK 1. PROBLEM CONTROLS, LIMITS, AND CONSTANTS (REQUIRED)

Card A. Format $(1015,2 E 10.3,2$ I5). General Controls.

Column Variable

Description

(1-5) IPRINT

$(6-10) \quad$ NUM

(11-15) KDATA

$(16-20) \quad$ KSPEC

Number of time steps between data output, in addition to output on first, second, and last time steps, and output controlled by TIMEP. IPRINT is not used if negative, zero, or unspecified.

Identification number of a node for which temperature, rate of temperature change, phase, heat-generation rate, and time will be written out after each time step. NUM will not be used if zero or unspecified. Controls options on output data, normal amount ( 0$)$, minimum $(-1)$, or maximum (1).

Node classification and difference-equation control. Normally zero or unspecified. If zero, regular nodes will be reclassified as special nodes only when necessary to maintain the stability limit above the time step, and the interpolation factor in the heat-balance difference equations may vary in the range 0.57 to 1.0. If negative, no nodes may be reclassified. If positive, all nodes will be reclassified as special nodes before the first time step. If 2 , the interpolation factor will be fixed at 1.0 so that the backward difference method will be used. If 3 , the interpolation factor will be fixed at 0.5 so that the central difference method will be used. Node classification may be made individually in BLOCK 4 with KS. All nodes listed in BLOCK 6 are classified as special nodes. DELTO and SMALL must be specified when KSPEC is positive. 


\begin{tabular}{|c|c|c|}
\hline Colurin & Variable & Description \\
\hline$(21-25)$ & MCYC & $\begin{array}{l}\text { Maximum allowed number of time steps. MCYC will not } \\
\text { be used if zero or unspecified. If negative, the } \\
\text { problem will end after the first time step. }\end{array}$ \\
\hline$(26-30)$ & MSEC & $\begin{array}{l}\text { Maximum allowed machine time, in seconds. MSEC will } \\
\text { not be used if zero or unspecified. If negative, the } \\
\text { problem will end after the first time step. }\end{array}$ \\
\hline$(31-35)$ & NPUNCH & $\begin{array}{l}\text { Causes a final system summary of results (see Section } \\
5.0 \text { ) to be written to the main output file when the } \\
\text { problem ends normally, if nonzero. }\end{array}$ \\
\hline$(36-40)$ & NDOT & $\begin{array}{l}\text { Causes all time derivatives to be maintained at zero } \\
\text { during the problem, if nonzero. Not normally used. }\end{array}$ \\
\hline$(41-45)$ & IRITE & $\star \star \star$ NOT USED \\
\hline$(45-50)$ & ITAPE & *\#*NOT USED*\#* \\
\hline$(51-60)$ & TIMEP & $\begin{array}{l}\text { Problem time interval in hours between data output, } \\
\text { in addition to output on first, second, and last time } \\
\text { steps, and output controlled by IPRINT. TIMEP is } \\
\text { ignored if negative, zero, or unspecified. Output } \\
\text { will be written in multiples of TIMEP, if possible, } \\
\text { by adjusting the time steps in the range from SMALL } \\
\text { to DELTO. The adjustment is also limited to a range } \\
\text { from } 2 / 3 \text { to } 3 / 2 \text { of the time step that would otherwise } \\
\text { be used. }\end{array}$ \\
\hline$(61-7))$ & SCALE & $\begin{array}{l}\text { Scale factor. Set to } 1.0 \text { if negative, zero, or } \\
\text { unspecified. Will be applied to all geometric input } \\
\text { data in BLOCKs } 4,5 \text {, and } 6 \text { read in following this } \\
\text { BLOCX } 1 \text { and preceding any other BLOCK } 1 \text { with a } \\
\text { different sCale factor. Lengths will be multiplied } \\
\text { by SCALE, areas by SCALE2, volumes by SCALE3. (a) }\end{array}$ \\
\hline
\end{tabular}




\begin{tabular}{|c|c|c|}
\hline Column & Variable & Description \\
\hline$(71-75)$ & INDISC & $\star \star *$ NOT USED*** \\
\hline$(76-80)$ & Format $(215$ & $\begin{array}{l}\text { Graphics post-processing dump flag: } \\
\text { (0) no graphics dump } \\
\text { (2) graphics dump } \\
\text { 10.3). Symmetry and Limits. }\end{array}$ \\
\hline Column & Variable & Description \\
\hline$(6-10)$ & KT & $\begin{array}{l}\text { Symmetry type indicator: } 1 \text { for nonsymetric, } 2 \text { for } \\
\text { axisymmetric, } 3 \text { for centrisymnetric. Input values } \\
\text { of DRAD in BLOCKs } 4,5 \text {, and } 6 \text { read in after BLOCK } 1 \\
\text { will be replaced with DRAD, } 2 \pi \text { DRAD, and } 4 \pi \text { DRAD2, } \\
\text { respectively. KD is set to } 1 \text { if unspecified or zero. } \\
\text { Temperature scale indicator: This MUST be set to } 3 \\
\text { (for Fahrenheit). }\end{array}$ \\
\hline$(11-20)$ & DELTO & $\begin{array}{l}\text { Maximum allowed time step in hours. May be used with } \\
\text { SMALL to limit range of time step. Not usually needed. } \\
\text { DELTO is set to } 1012 \text { if unspecified or not in the } \\
\text { range from } 10-10 \text { to } 1012 \text {. DELTO must be specified } \\
\text { if KSPEC is positive. }\end{array}$ \\
\hline$(21-30)$ & SMALL & $\begin{array}{l}\text { Minimum allowed time step in hours. May be used with } \\
\text { DELTO to limit range of time step. Not usually needed. } \\
\text { SMALL is set to } 10-12 \text { if less than } 10-12 \text {. If SMALL } \\
\text { is unspecified, the program sets SMALL to } 2 / 3 \text { of } 1 \% \\
\text { of the smallest time constant of any regular node in } \\
\text { the system, if at least } 1 / 4 \text { of the nodes are regular } \\
\text { nodes. }\end{array}$ \\
\hline$(31-40)$ & TVARY & $\begin{array}{l}\text { Desired maximum temperature change in each time step. } \\
\text { TVARY is set to } 5.0 \text { if unspecified or zero. Controls } \\
\text { size of the time step between limits of SMALL and } \\
\text { DELTO. Steady state cannot end the problem until the } \\
\text { maximum temperature change is less than } 0.001 \star \text { TVARY }\end{array}$ \\
\hline
\end{tabular}




\begin{tabular}{|c|c|c|}
\hline Column & Variable & Description \\
\hline & & $\begin{array}{l}\text { for two successive time steps. The convergence } \\
\text { criteria for the iterative calculation for special } \\
\text { nodes are a change in the weighted average temperature } \\
\text { change of all connected special nodes of less than } \\
5(10-5) \star T V A R Y \text {, and in the temperature change of any } \\
\text { finite-volume special node of less than } 5\left(10^{-4}\right) \star \text { TVARY. }\end{array}$ \\
\hline$(41-50)$ & TAU & $\begin{array}{l}\text { Initial problem time. Will be set to zero if } \\
\text { unspecified }(h) \text {. }\end{array}$ \\
\hline$(51-60)$ & TIMAX & $\begin{array}{l}\text { Maximum allowable problem time. TIMAX will not be } \\
\text { used if zero or unspecified. If it is negative, the } \\
\text { problem will end after first the time step }(\mathrm{h}) \text {. }\end{array}$ \\
\hline$(61-70)$ & TMIN & $\begin{array}{l}\text { Minimum allowable problem temperature. Will be set } \\
\text { to }-1012 \text { if equal to or larger than TMAX. HMELT(N) } \\
\text { in BLOCK } 2 \text { will be set to zero for any material for } \\
\text { which TMELT(N) is less than TMIN }\left({ }^{\circ} \mathrm{F}\right) \text {. }\end{array}$ \\
\hline$(71-80)$ & TMAX & $\begin{array}{l}\text { Maximum allowable problem temperature set to } 1012 \text { if } \\
\text { equal to or less than TMIN. HMELT(N) in BLOCK } 2 \text { will } \\
\text { be set to zero for any material for which } \operatorname{TMELT}(\mathrm{N}) \text { is } \\
\text { greater than TMAX }\left({ }^{\circ} \mathrm{F}\right) \text {. }\end{array}$ \\
\hline
\end{tabular}

Card C. Format (2E10.3, 10X, 5E10.3). System Constants. Apply only to data in data blocks read in after BLOCK 1.

Columin Variable

(1-10) TONE

(11-20) ALONE
Description

Initial temperature of all nodes for which TT is either unspecified (left blank or omitted) or set $=0.0$ in BLOCK $9\left({ }^{\circ} \mathrm{F}\right)$.

Initial weight fraction for all nodes for which $A A$ is either unspecified (left blank or omitted) or set = 0.0 in BLOCK 9. 


\begin{tabular}{|c|c|c|}
\hline Column & Variable & Description \\
\hline$(30-40)$ & GONE & $\begin{array}{l}\text { Constant heat generation rate in all nodes for which } \\
\text { GG is either unspecified (left blank or omitted) or } \\
\text { set }=0.0 \text { in BLOCK } 9 \text {, or no table of GT vs. TVARG is } \\
\text { specified in BLOCK } 8 \text { (Btu/h-in.3). }\end{array}$ \\
\hline$(40-50)$ & FONE & $\begin{array}{l}\text { Constant mass flow rate for all mass flow connections } \\
\text { for which FLOWN is either unspecified (left blank) } \\
\text { or set }=0.0 \text { in BLOCK } 10(1 \mathrm{bm} / \mathrm{h}) \text {. }\end{array}$ \\
\hline$(50-60)$ & HONE & $\begin{array}{l}\text { Heat-transfer coefficient for all external connections } \\
\text { for which HSURE or table of HSURT Vs. TVARH is either } \\
\text { unspecified (left blank) or set }=0 \text { in BLOCK } 6 \text { (Btu/h- } \\
\text { in. } 2^{\circ} \mathrm{F} \text { ). }\end{array}$ \\
\hline$(60-70)$ & RONE & $\begin{array}{l}\text { Radiation form factor for all external connections } \\
\text { for which RSURE is either unspecified (left blank) or } \\
\text { set }=0.0 \text { in BLOCK } 6 \text {. }\end{array}$ \\
\hline$(70-80)$ & PONE & $\begin{array}{l}\text { Free convection exponent for all external connections } \\
\text { for which POWER is either unspecified (left blank) } \\
\text { or set }=0.0 \text { in BLOCK } 6 \text {. }\end{array}$ \\
\hline
\end{tabular}

Card D. FORMAT $(215,20 \mathrm{X}, 2 \mathrm{E} 10.0,110, E 10.0,215)$. Bundle Characterization and Special Output Card.

$\begin{array}{ll}\text { Column Variable } & \\ \text { (1-5) IDIAG } & \text { Diagnostic printout flag: } \\ & \text { (1) standard TRUMP output } \\ & \text { (2) heat generation surmary only } \\ & \text { (3) convection summary only } \\ & \text { (4) radial and axial loss summary only } \\ & \text { (5) complete diagnostic summary. }\end{array}$




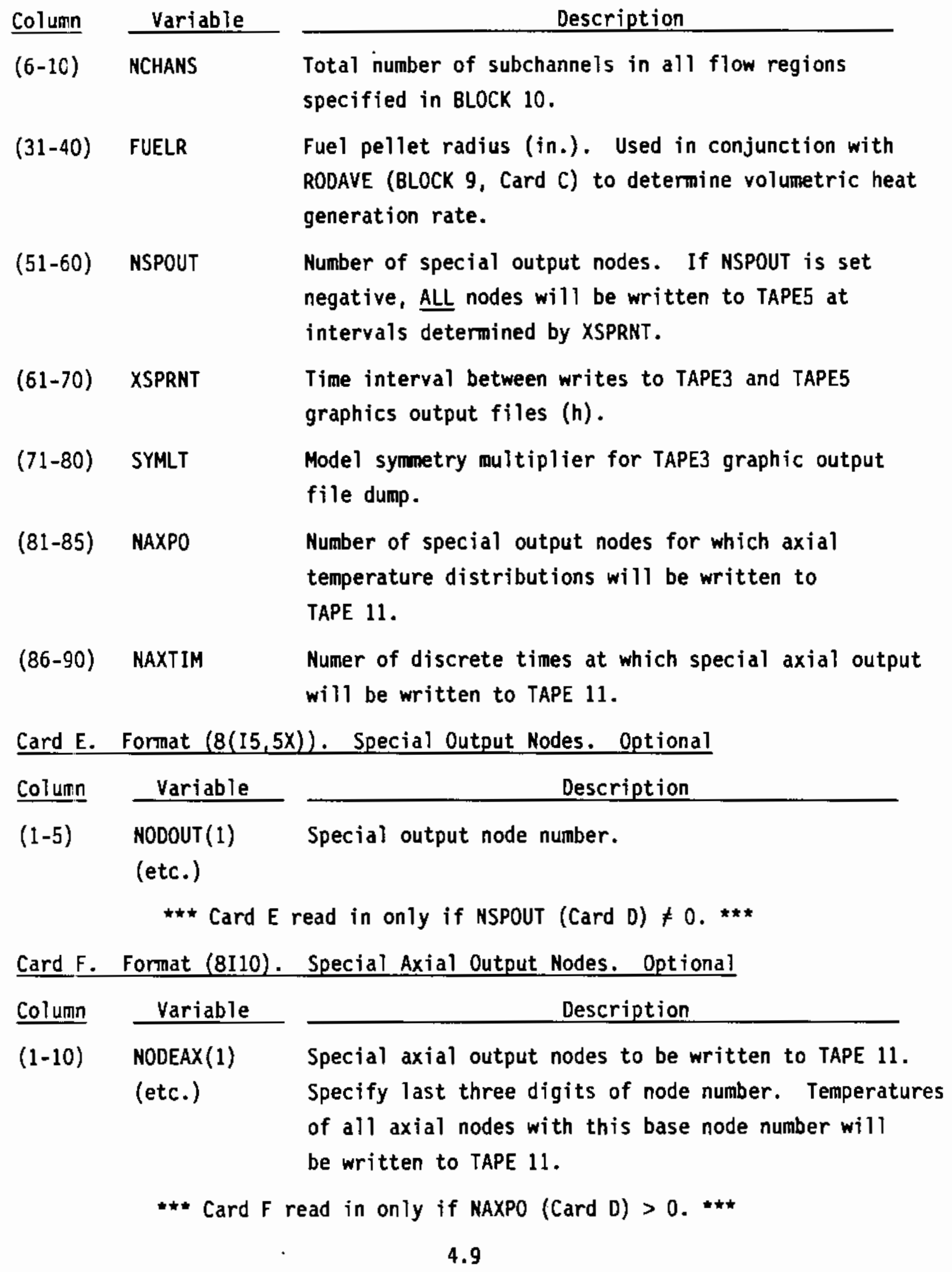

Card E. Format $(8(15,5 x))$. Special Output Nodes. Optional

Column Variable

(1-5) NODOUT(1) Special output node number. (etc.)

Description

*** Card $E$ read in only if NSPOUT (Card D) $\neq 0$. ***

Card F. Format (8I10). Special Axial Output Nodes. Optional

Column Variable

(1-10) NODEAX(1) Special axial output nodes to be written to TAPE 11.

(etc.) Specify last three digits of node number. Temperatures of all axial nodes with this base node number will be written to TAPE 11 .

*** Card $\mathrm{F}$ read in onty if NAXPO (Card $\mathrm{D})>0$. 
Card G. Format (8E10.3). Special Axial Output Times. Optional

Column Variable Description

(1-10) AXTIM(1) Times at which special axial output will be written (etc.) to TAPE $11(\mathrm{~h})$.

*** Card G read in only if NAXTIM (Card D) $>0 . * * \star$

Card H. Format (4A5). Output Suppression Card.

\begin{tabular}{|c|c|c|}
\hline Column & Variable & Description \\
\hline$(1-5)$ & DATA(1) & $\begin{array}{l}\text { Enter "PRT1," to suppress at each output dump: } \\
\text { (1) a node by node material property summary } \\
\text { (2) properties of each internal connection } \\
\text { (3) node current heat content and temperature change } \\
\text { information. } \\
\text { (Note: comma required) }\end{array}$ \\
\hline$(6-10)$ & $\operatorname{DATA}(2)$ & Not used in current version. \\
\hline$(11-15)$ & $\operatorname{DATA}(3)$ & $\begin{array}{l}\text { Enter "PRTS," to suppress message when a node is } \\
\text { changed to a special node. (Note: comma required) }\end{array}$ \\
\hline$(16-20)$ & DATA(4) & $\begin{array}{l}\text { Enter "PRTT," to suppress message indicating a } \\
\text { repeated cycle. (Note: comma required) }\end{array}$ \\
\hline
\end{tabular}


BLOCK 2. MATERIAL DATA.

Card A. Format (A5, I5, 10X, 2I5, 5E10.3). Material Description Card.

Colunin Variable
Description

$(1-5) \quad$ AMAT

Material name. Column 1 must not be blank.

(6-1C) MAT

Material identification number. For TRUMP-BD

problems, uranium $=1$, graphite $=2$, Zircaloy $=100$, steam or water $=10$, hydrogen $=11$.

(21-25) LTABC

Number of points listed on heat-capacity table card (Card E); positive if vs. temperature, negative if vs. time, zero if only one value is specified.

(26-30) LTABK

Number of points listed on thermal-conductivity table card (Card F); positive if vs. temperature, negative if vs. time, zero if only one value is specified.

$(31-40) \quad$ DENS

Density $(1 \mathrm{bm} / \mathrm{in}, 3)$.

(41-50) CAPT

Specific Heat, if constant $\left(\mathrm{Btu} / 1 \mathrm{bm}-{ }^{\circ} \mathrm{F}\right)$.

$(51-60) \quad$ CONT

(61-7D) TMELT

Thermal conductivity, if constant (Btu/h-in..- $\mathrm{F}$ ).

Temperature at which latent heat HMELT is absorbed or released $\left({ }^{\circ} \mathrm{F}\right)$.

$(71-80) \quad$ HMELT

Latent heat effect at TMELT. Difference between heat contents as a result of phase change. HMELT will be set to zero if TMELT is not between TMIN and TMAX. See AX, BLOCK 9, Card H (Btu/1bm).

$(81-85) \quad$ LTABP

Number of points listed on phase-change table card or cards: positive if vs. temperature, zero if only one phase change is specified. Enter LTABP $\geq 2$ and data on Card $G$ if more than one phase change for a material. 
Card B. Format (F10.0, E10.0, 215). Coolant Property Card. Optional.

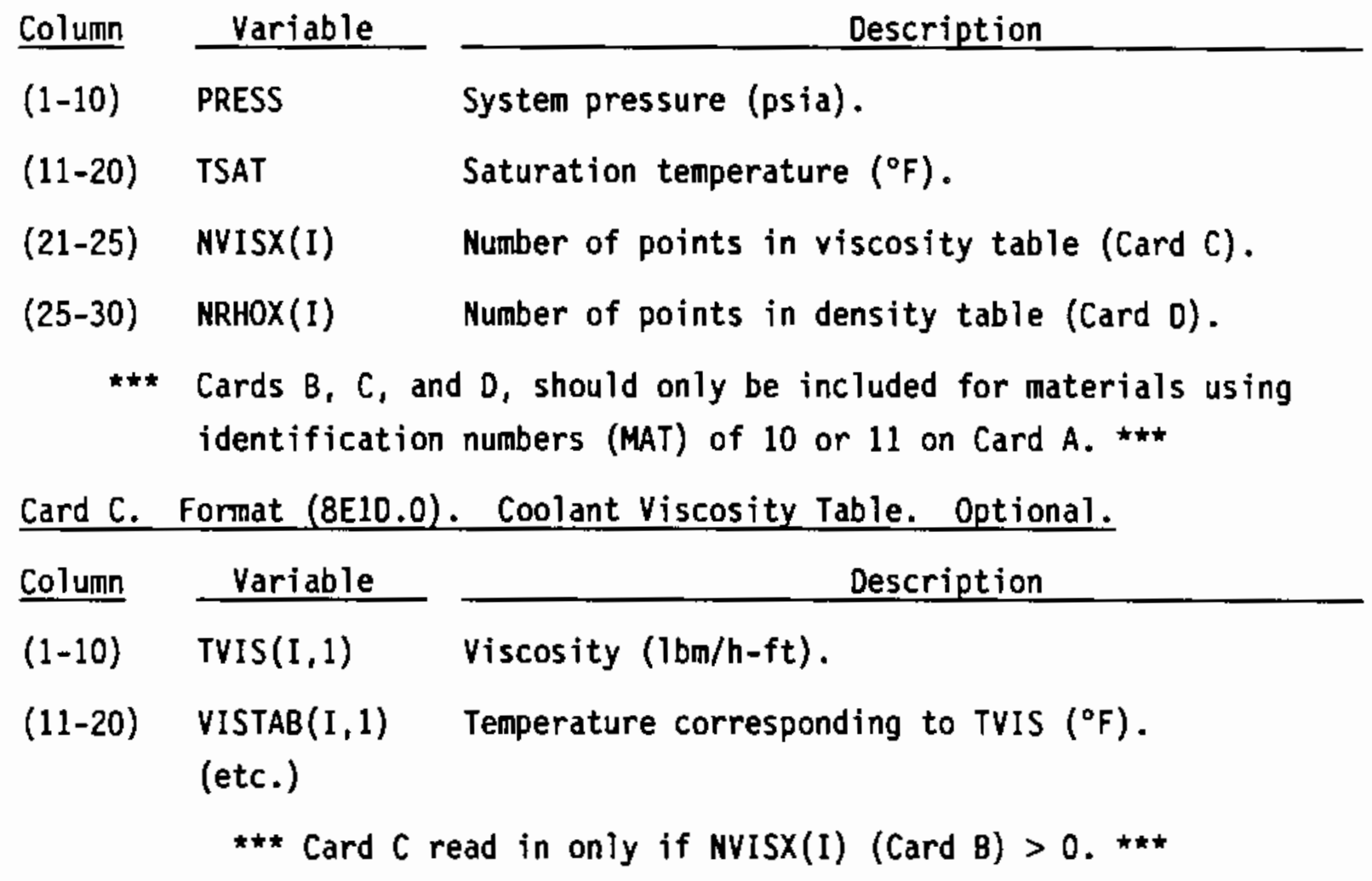

Card D. Format (8E10.0). Coolant Density Table. Optional.

\begin{tabular}{|c|c|c|}
\hline Column & Variable & Description \\
\hline$(1-10)$ & $\operatorname{TRHO}(I, 1)$ & Density $\left(1 \mathrm{bm} / \mathrm{ft}^{3}\right)$. \\
\hline$(11-20)$ & RHOTAB $(I, 1)$ & Temperature corresponding to TRHO $\left({ }^{\circ} \mathrm{F}\right)$. \\
\hline
\end{tabular}

Note: To have coolant properties evaluated as a function of hydrogen concentration, repeat Cards $B, C$, and $D$ (entering hydrogen property data) after specifying material identification number AMAT $=11$ on Card A, BLOCK 2 . 
Card E. Format (8E10.3). Heat Capacity Table. Optional.

\begin{tabular}{|c|c|c|}
\hline Column & Variable & Description \\
\hline$(1-10)$ & CAPT(1) & Heat capacity $\left(B t u / 1 \mathrm{bm}-{ }^{\circ} \mathrm{F}\right)$. \\
\hline$(11-20)$ & $\begin{array}{l}\operatorname{TVARC}(1) \\
\text { (etc.) }\end{array}$ & Temperature or time corresponding to CAPT $(1)\left({ }^{\circ} \mathrm{F}\right.$ or $\left.\mathrm{h}\right)$ \\
\hline
\end{tabular}

Card F. Format (8E10.3). Thermal Conductivity Table. Optional.

Columin Variable
Description

(1-10) $\left.\operatorname{CONT(1)\quad Thermal~conductivity~(Btu/h-in.~}-{ }^{\circ} \mathrm{F}\right)$.

(11-20) TVARK(1) Temperature or time corresponding to CONT(1)

(etc.) ( ${ }^{\circ} \mathrm{F}$ or $\left.\mathrm{h}\right)$.

*** Card $F$ read in only if LTABP (Card A) $\neq 0$. ***

Card G. Format (8E10.3). Phase Change Table. Optional.

Column Variable Description

(1-10) HMELT(1) Latent heat effect at TMELT(1) (Btu/ Ibm).

(11-20) TMELT(1) Teuperature at which tatent heat HMELT(1) is absorbed (etc.) or released $\left({ }^{\circ} \mathrm{F}\right)$.

** Card $G$ read in only if LTABP (Card A) $\geq 2 * \star *$ 
BLOCK 4. NODE DATA

Card A. Format $(10 X, E 10,0,8 X, I 2, E 10,0,2(8 X, I 2), I 10)$. Model Description Card.

$\begin{array}{llll}\text { Column } & \text { Variable } & & \text { Description } \\ (11-20) & \text { XINTER } & \text { Model lower elevation (in.). } \\ (28-30) & \text { NLEVELS } & \text { Number of axial levels in model. } \\ (31-40) & \text { BUNDHT } & \text { Model upper elevation (in.). } \\ (49-50) & \text { ILEVFG } & \text { Dryout front vs. time table flag: }\end{array}$

(0) no table

(1) table supplied.

(59-60) NTABL Number of points in dryout front vs. time table (Card C).

Card B. Format (8E10.0). Axial Noding Descriptor Card.

Column Variable
Description

$\operatorname{AXDIST}(1)$
(etc.)

Axial node length (in.). Repeat up to 8 entries per card for NLEVEL entries.

Card C. Format (8E10.0). Dryout Front-Time Table. Optional.

Column Variable

(1-10) WPOSIT(1)

(11-20) WTIME(1) (etc.)
Description

Dryout front position at time WTIME(1) (in.). Simulation time corresponding to WPOSIT(1) (h).

$$
\text { A) }>0
$$


Card 0. Format $(515,12,13,5 E 10.3)$. Node Descriptor Card.

Column Variable

(1-5) N1

$(6-10) \quad$ NSEQ

(11-15) NADD

$(16-20) \quad N Z$

$(21-25) \quad K S$

$(26-27) \quad$ NPRX

$(28-33) \quad$ NPN

$\left.\begin{array}{ll}(31-40) & \text { DLDNG } \\ (41-50) & \text { DWIDE } \\ (51-60) & \text { DRAD }\end{array}\right\}$
Description

Node identification number.

Number of additional identical nodes, or, if DRAD is preceded by a minus sign, nodes with DRAD values incremented by the difference between DRAD for this node and DRAD for the immediately preceding node. Increment between successive values of NODE in the sequence of NSEQ +1 nodes generated when NSEQ is used.

Identification number of the material of which the node is a part.

Node type indicator. Node will be a special node if KS is nonzero. Only used when KSPEC in BLOCK 1 is negative. Not needed for zero-volume and surface nodes.

Flow region associated with $N 1$ (required for fuel, cladding, and coolant flow nodes only).

Node pin number if part of fuel or cladding. For nodes assigned a pin number, an output summary of the pin heat generation can be obtained (IDIAG $=2$, 5, BLOCK I, Card D). A pin number must be assigned to fuel and cladding nodes that use the fuel failure model.

The product of DLONG, DWIDE, and DRAD with SCALE 3 is equal to the node volume (in. 3 ) if $K D$ is 1 (BLOCK 1 , Card $B$ ). For $K D$ values of 2 or 3 , the input value of DRAD is replaced with $2 \pi$ DRAD, or $4 \pi$ DRAD2, respectively, before calculation of the volume. The progran substitutes 10-24 if NODE is zero volume, which is indicated by setting DWIDE $=0.0$. 


\begin{tabular}{|c|c|c|}
\hline Column & Variable & Description \\
\hline$(61-70)$ & ZRT & $\begin{array}{l}\text { oxidation node thickness (in.). Input only if node } \\
\text { will undergo oxidation. Assigned to array ZRTHIK. }\end{array}$ \\
\hline$(71-80)$ & $0 \times A$ & $\begin{array}{l}\text { Available oxidation area per unit length (in.). } \\
\text { Assigned to array OXAREA. }\end{array}$ \\
\hline
\end{tabular}


BLOCX 5. INTERNAL THERMAL CONNECTION DATA

Card A. Format (2I5). Auto Noding Parameters.

\#* NOT USED--LEAVE BLANK *\#*

Card B. Format $(2 \mathrm{I} 5, \mathrm{I1}, \mathrm{I2}, 2 \mathrm{I} 3, \mathrm{I1}, 4 \mathrm{E} 10.3,20 \mathrm{~A} 1)$ Thermal Connection Descriptor Card.

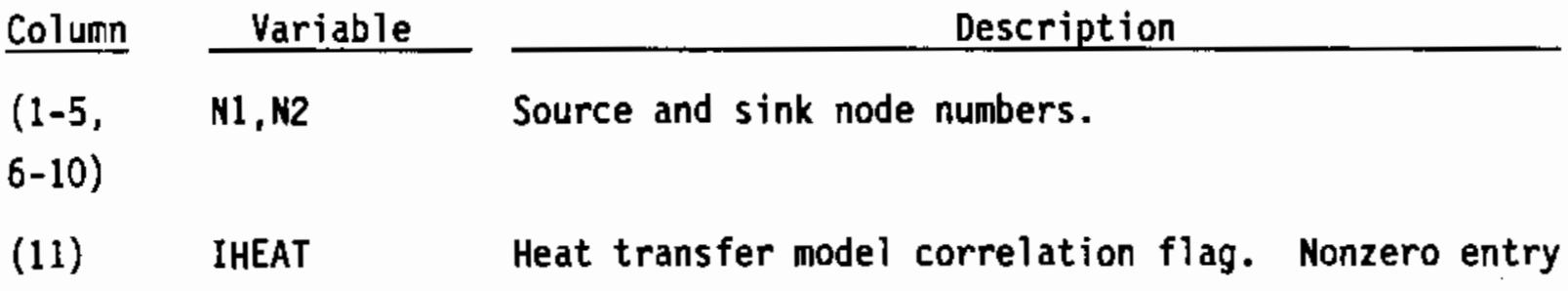
indicates connection type heat transfer determined from the following (see Section 3.8.1):

(1) Dittus-Boelter correlation

(2) Wang-Hochreiter correlation

(3) $N$ reactor gap conductance model

(4) thermal bridge model

(5) user-specified variable heat transfer (HINT).

Note: Zero entry provides constant connection heat transfer specified in HINT.

(12-13) NSEQ

Number of additional identical connections, or if DRAD is preceded by a minus sign, connections with ORAD values incremented by the difference between DRAD for this connection and DRAD for the immediately preceding connection.

$\left.\begin{array}{ll}(14-16) & \text { NAD1 } \\ (17-19) & \text { NAD2 }\end{array}\right\}$

Increments between successive values of $\mathrm{N} 1$ and $\mathrm{N} 2$, respectively, in the sequence of HSEQ + 1 connections generated when NSEQ is used.

(20)

NZ

Indicates NAD1 and NAD2 are each to be multiplied by $10 \mathrm{NZ}$ before use in generating a sequence of connections. 


\begin{tabular}{|c|c|c|}
\hline Column & Variable & Description \\
\hline $\begin{array}{l}(21-30) \\
(31-40)\end{array}$ & $\left.\begin{array}{l}\text { DEL1 } \\
\text { DEL2 }\end{array}\right\}$ & $\begin{array}{l}\text { Lengths, when multiplied by SCALE, of the heat con- } \\
\text { duction paths from the nodal points in } N 1 \text { and } N 2 \text {, } \\
\text { respectively, to the connected interface. Both should } \\
\text { not be zero unless either HINT or RINT is specified. }\end{array}$ \\
\hline $\begin{array}{l}(41-50) \\
(51-60)\end{array}$ & $\left.\begin{array}{l}\text { DLONG } \\
\text { DRAD }\end{array}\right\}$ & $\begin{array}{l}\text { The product of DLONG and DRAD with SCALE2 is the area, } \\
\text { in in. } 2 \text {, of the connected interface if KD is } 1 \text { (BLOCK } \\
1 \text {, Card D). For KD values of } 2 \text { or } 3 \text {, the input value } \\
\text { of DRAD is replaced with } 2 \pi \text { DRAD or } 4 \pi \text { DRAD2, } \\
\text { respectively, before calculating the area. }\end{array}$ \\
\hline$(61-70)$ & HINT & $\begin{array}{l}\text { Heat transfer coefficient between the connected node } \\
\text { surfaces. Can include effects of surface films, gas } \\
\text { gap, or contact resistances. If HINT is not } \\
\text { specified, it will be set to } 10^{12} \text { if RINT is not } \\
\text { specified, or to } 10^{-24} \text { if RINT is specified (Btu/h- } \\
\text { in. }{ }^{2}{ }^{\circ} \mathrm{F} \text { ). }\end{array}$ \\
\hline$(71-80)$ & RINT & $\begin{array}{l}\text { Thermal radiation form factor for the connected } \\
\text { surfaces of the nodes. If RINT is negative, the } \\
\text { absolute value will be used as a free convection } \\
\text { exponent. }\end{array}$ \\
\hline$(81-90)$ & HV & $\begin{array}{l}\text { Heat transfer coefficient for bridge model } \\
\text { (Btu/h-in. } 2^{\circ} \mathrm{F} \text { ). Value assigned into array HINTV. }\end{array}$ \\
\hline$(91-100)$ & AV & $\begin{array}{l}\text { Heat transfer area for bridge model (in.2). Value } \\
\text { assigned into array AREAV. }\end{array}$ \\
\hline$(101-110)$ & TV & $\begin{array}{l}\text { Temperature for onset of bridge model }\left({ }^{\circ} \mathrm{F}\right) . \text { Value } \\
\text { assigned into array TEMPFV. } \\
\text { TV }<0 \text { : uranium node dependent } \\
\text { TV }>0 \text { : Zircaloy node dependent. }\end{array}$ \\
\hline
\end{tabular}


Column Variable

$(111-115) \mathrm{NU}$
Description

Pairs of entries in user-specified variable heat transfer table. When $\mathrm{NU}$ is negative, values are time dependent; when NU is positive, values are temperature dependent. Value assigned into array NUSERT.

Card C. Format (8E10.0). Variable Heat Transfer Coefficient Table. Optiona1. Column Variable

(1-10) USERH $(1, I J)$ User-specified heat transfer coefficient (Btu/h-in. $\left.{ }^{\circ}-^{\circ} \mathrm{F}\right)$.

(11-20) USERT(1,IJ) Temperature or time corresponding to USERH(1,IJ) (etc.) $\left({ }^{\circ} \mathrm{F}\right.$ or $\left.\mathrm{h}\right)$. 
BLOCK 6. EXTERNAL THERMAL CONNECTIONS.

Card A. Format (2I5). Auto Noding Parameters.

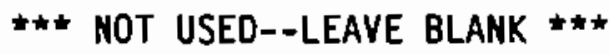

Card B. Format (6I5, 5E10.3). External Thermal Connections.

Column Variable

(1-5) NOOS

(5-10) NODSB

(11-15) NSEQ

$\left.\begin{array}{ll}(15-20) & \text { NADS } \\ (21-25) & \text { NADSB }\end{array}\right\}$

$(26-30) \quad$ LTABH

$(35-40) \quad$ DLONG
area $(41-50) \quad$ DKAD
Description

Surface node identification number. NODS should te either a zero-volume node or a node with the nodal point on its external surface.

External temperature (boundary node) identification number. Set NODSB $=1000$ to get sumary of "axial" boundary heat transfer, or NOOSB $=2000$ for "radial" boundary heat transfer sumary in output file. All other values of NODSB will be grouped into the misceTlaneous boundary heat transfer category.

Number of additional identical connections, or, if ORAD is preceded by a minus sign, connections with DRAD values incremented by the difference between DRAD for the connection and DRAD for the immediately preceding connection.

Increments between successive values of NODS and NOOSB respectively, in the sequence of $\mathrm{NSEQ}+1$ connections generated when HSEQ is used.

Number of tabulated convection coefficient values, negative if vs. time, positive if vs. temperature, zero if no table.

Geometric factors whose product with SCALE2 is the of the external surface of NOOS if KD is 1 . For $K D$ values of 2 or 3 , the input value of DRAD is replaced by $2 \pi$ DRAD or $4 \pi$ ORAD $^{2}$, respectively, before calculating the area. 


\begin{tabular}{|c|c|c|}
\hline Column & Variable & Description \\
\hline$(51-6,0)$ & HSURE & $\begin{array}{l}\text { Convection coefficient, if constant. HSURE is set to } \\
\text { HONE (BLOCK } 1 \text { ) if not specified (left blank) or set } \\
=0.0 \text {. (Btu } / \mathrm{h}-\mathrm{in}^{\circ} \mathrm{2}^{\circ} \mathrm{F} \text { ) }\end{array}$ \\
\hline$(61-70)$ & RSURE & $\begin{array}{l}\text { Thermal radiation form factor. RSURE is set to RONE } \\
\text { (BLOCK 1) if not specified (left blank) or set }=0.0 \text {. }\end{array}$ \\
\hline Card c. & Format (8E10.3) & $\begin{array}{l}\text { Free-convection exponent. POHER is set to PONE } \\
\text { (BLOCK 1, Card C) if not specified or set }=0.0 \text {. } \\
\text { Convection Coefficient Table. }\end{array}$ \\
\hline Column & Variable & Description \\
\hline$(1-10)$ & HSURT (1) & Convection coefficient. (Btu/h-in, $\left.2-^{\circ} \mathrm{F}\right)$. \\
\hline$(11-20)$ & $\begin{array}{l}\text { TVARH(1) } \\
\text { (etc.) }\end{array}$ & $\begin{array}{l}\text { Temperature or time corresponding to HSURT(1) } \\
\left({ }^{\circ} \mathrm{F} \text { or } \mathrm{h}\right) .\end{array}$ \\
\hline
\end{tabular}


BLOCK 7. EXTERNAL TEMPERATURE DATA.

Card A. Format $(215,10 X, 6 E 10.3)$. Boundary Temperatures.

Column

$(6-10) \quad$ LTABT

(21-30) TEMPB (1)

(31-40) TIMEB(1)

$(41-50) \quad$ TEMPB (2)

$(51-60) \quad$ TIMEB (2)

$(61-70) \quad$ (etc.)
Description

External temperature (boundary node) identification number. Set NODB $=1000$ to get sumary of "axial" boundary heat transfer, or NODB $=2000$ for "radial" boundary heat transfer summary in output file. Al1 other values of NODB will be grouped into the miscellaneous boundary heat transfer category.

Number of tabulated external temperature values. To obtain sinusoidal variation of external temperature with time, LTABT must be 100 . Zero if no table.

External temperature. Average value of sinusoidal variation, if LTABT is $100\left({ }^{\circ} \mathrm{F}\right)$.

Time corresponding to TEMPB(1). Period of sinusoidal variation, if LTABT is $100(h)$.

External temperature. Amplitude of sinusoidal variation, if LTABT is $100\left({ }^{\circ} \mathrm{F}\right)$.

Time corresponding to TEMPB(2). Phase advance time of sinusoidal variation, if LTABT is 100 (h). Up to three pairs of values on this card, and four pairs on each additional card required, if LTABT is not zero. Use format (8E10.3) for additional cards. 
BLOCK 8. VARIABLE HEAT-GENERATION DATA.

Card A. Format (4I5, 6E10.3). Variable Heat Generation Card.

Column Variable Description

(1-5) NODG

Identification number of node.

(6-10) NSEQ

Number of additional nodes with identical variation of volumetric heat-generation rate as NODG.

$(11-15) \quad$ NADG

Increment between successive values of NODG in the sequence of NSEQ +1 nodes generated when NSEQ is used.

$(16-20) \quad$ LTABG

Number of tabulated values of heat-generation rate, negative if vs. time, positive if vs. temperature. To obtain exponential decay of heat-generation rate with time, LTABG must be between -1 and 1 , or unspecified, and GT(1) and TVARG(1) specified.

$(21-30) \quad$ GT (1) Volumetric heat-generation rate at TVARG(1), or at zero time (SUMTIM $=0$ ), if exponential decay is specified. See AA (BLOCX 9, Card B), for an additional method to produce an initial pulse of heat at the beginning of a problem. (Btu/h-in.3)

(31-40) TVARG(1) Temperature or time corresponding to GT(1), or half(etc.) life of exponential decay, if the latter is specified $\left({ }^{\circ} \mathrm{F}\right.$ or $\left.\mathrm{h}\right)$. Up to three pairs of values on this card, and four pairs on each additional card required. Use format (8E10.3) for additional cards. 
BLOCK 9. INITIAL CONDITIONS AND CONSTANT HEAT GENERATION DATA.

Card A. Format (I5). TRUMP-BD Logic Card.

\begin{tabular}{|c|c|c|}
\hline \multirow{2}{*}{$\frac{\text { Column }}{(1-5)}$} & Variable & Description \\
\hline & LEVFLG & Logic flag: \\
\hline & & (0) standard TRUMP logic (enter Card B) \\
\hline & & TRUMP-BD logic (enter Cards $C$ through I). \\
\hline
\end{tabular}

Card B. Format (3I5, 5X, 2E10.3, 10X, E10.3). Initial Conditions Card. Optional.

\begin{tabular}{|c|c|c|}
\hline Column & Variable & Description \\
\hline$(1-5)$ & NOTE & Node identification number. \\
\hline$(6-10)$ & NSEQ & $\begin{array}{l}\text { Number of additional nodes with identical initial } \\
\text { conditions. }\end{array}$ \\
\hline$(11-15)$ & NADD & $\begin{array}{l}\text { Increment between successive node numbers in sequence } \\
\text { of NSEQ }+1 \text { nodes generated when NSEQ is used. }\end{array}$ \\
\hline$(21-30)$ & TT & $\begin{array}{l}\text { Initial temperature. TT is set to TONE (BLOCK } 1 \text {, } \\
\text { Card } \mathrm{C} \text { ) if not specified }\left({ }^{\circ} \mathrm{F}\right) \text {. }\end{array}$ \\
\hline$(31-40)$ & AA & $\begin{array}{l}\text { AA is set to ALONE (BLOCK } 1 \text {, Card C) if not specified } \\
\text { or set equal to } 0.0 \text {. AA may be used to specify the } \\
\text { initial weight fraction of low-temperature phase in } \\
\text { nodes of materials with specified values of TMELT and } \\
\text { HMELT, if columns } 67 \text { through } 71 \text { of the Problem Name } \\
\text { Card are "A = BL9." Otherwise, the concentration } \\
\text { will be } 1.0 \text { for initial temperature at or below TMELT } \\
\text { and } 0.0 \text { for initial temperature above TMELT. }\end{array}$ \\
\hline$(51-60)$ & GG & $\begin{array}{l}\text { Heat generation rate. GG is set to GONE (BLOCK } 1 \text {, } \\
\text { Card C) if not specified or equal to } 0.0 \text {. GG is } \\
\text { overwritten if GT vs. TVARG is specified for this } \\
\text { node in BLOCK } 8 \text { (Btu/h-in. }{ }^{3} \text { ). }\end{array}$ \\
\hline
\end{tabular}


Card C. Format (3E10.0, 4I5, 1F5.0, 5X, F5.0, 15). Power Generation and Oxidation Description Card. Optional.

Colurin Variable

$(1-10) \quad$ RODAVE $(a)$

$(11-20) \quad$ PGAMMA

$(21-30) \quad$ CLADXC

$(31-35) \quad$ NPINS
Description

Average fuel rod power (should include ganna heat term) (kw/ft-rod).

Fraction of rod-average power which is a result of ganma heating.

Fuel rod cladding cross sectional area (in.2). Number of fuel pins to be included in heat generation summary and identified in BLOCK 4 , Card $D$.

(a) The volumetric heat generation rate, $G G(N)$, applied to nodes entered on Card $\mathrm{H}$ is computed from:

$$
G G(N)=\frac{\text { RODAVE }}{\pi^{\star}\left(1-P U E L R^{2}\right.} * 284.3 \quad\left(B t u / h-i n .{ }^{3}\right)
$$

for nodes designated as fuel nodes, i.e., NGAM $=0$, Card $H$, or

$$
G G(N)=\frac{\text { RODAVE*PGAMAA }}{\text { CLADXC }} * 284.3 \quad\left(\text { Btu } / \mathrm{h}-\mathrm{in} .{ }^{3}\right)
$$

for nodes designated as gamma-heating nodes, i.e., NGAM $=1$, Card $\mathrm{H}$ (FUELR is defined in BLOCX 1, Card D). The local volumetric heat generation rate for a node is then modified by:

$$
G G(N)=G G(N) \text { *PAXIAL*PRADIL }
$$

where PAXIAL is the local axial power factor determined from the choppedcosine or user-specified power profiles (Card $F$ and Card $G$, respectively) and PRADIL is the radial power factor (Card $H$ ). 
Column

$(36-40)$ IGENFG

$(41-45) \quad$ NTABG

(46-50) MHRCOR

$(51-55) \quad$ AXMG

$(61-65) \quad$ TFAIL
Description

Variable power generation flag:

(1) time-varying heat generation for boilof $f$ simulations

(0) constant heat generation

(-1) time-varying heat generation for non-boiloff simulations.

Number of points in power generation-time table (Card D).

Metal-water reaction correlation flag:

(-1) no oxidation modeled

(0) Cathecart kinetics used for $\mathrm{Zr}-\mathrm{H}_{2} \mathrm{O}$ reactions

(1) Urbanic kinetics used for $\mathrm{Zr}-\mathrm{H}_{2} \mathrm{O}$ reactions

(2) Prater kinetics used for $\mathrm{Zr}-\mathrm{H}_{2} \mathrm{O}$ reactions

(3) Baker-Just kinetics used for $2 \mathrm{r}-\mathrm{H}_{2} \mathrm{O}$ reactions.

NOTE: Wilson kinetics are used for the uraniumoxidation reaction.

Local power multiplier for dryout region. The node heat generation rate is modified by $1+A X M G$ for all nodes above the dryout front. Used for boiloff simulations only.

Uranium fuel failure temperature $\left({ }^{\circ} \mathrm{F}\right)$. Determines start of uranium-water oxidation. Default $=1994.0^{\circ} \mathrm{F}$. 


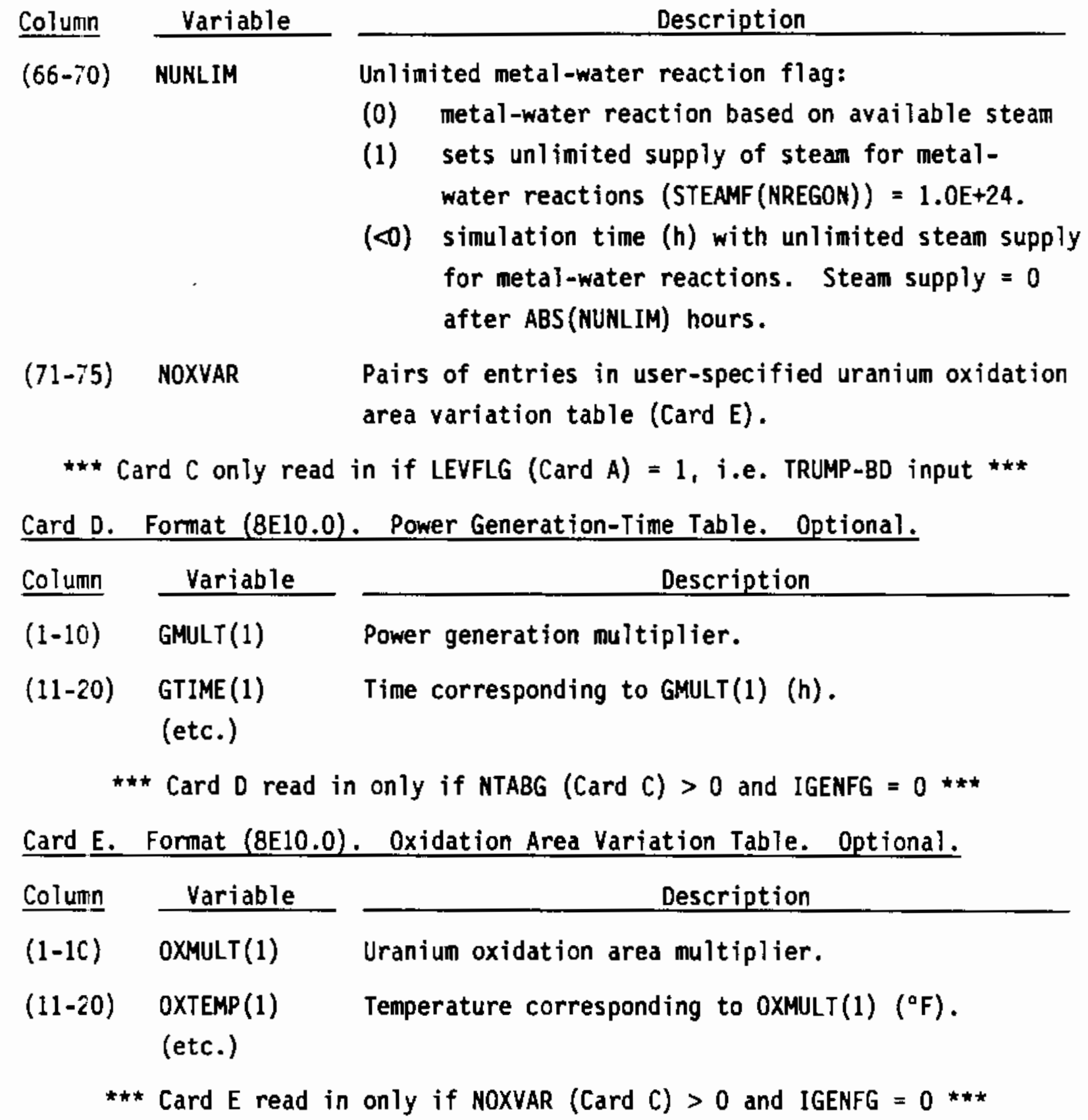


Card F. Format (I10, 3E10.0, I5). Axial Power Profile Descriptor Card. Optional.

Column Variable

Description

$(1-10) \quad$ ICOS

Axial power profile identifier:

(0) power profile user-specified (Card G).

(1) chopped-cosine power profile

(11-20) PRATIO Peak-to-average power ratio used only when $\mathrm{ICOS}=1$.

(21-30) EZERO Extrapolated length (in.) used only when ICOS $=1$.

(31-40) RODTOT Total number of fuel rods in simulation, including rod fractions. Used to determine total heat generation available for coolant boiloff.

(41-45) NTABP Number of points in axial power profile and integral table (Card G).

*** Card $F$ read in only if LEVFLG (Card $A)=1$, i.e., TRUMP-BD input ***

Card G. Format (6E10.0). Axial Power Profile and Integral Table. Optional.

\begin{tabular}{|c|c|c|}
\hline Column & Variable & Description \\
\hline$(1-10)$ & $\operatorname{PHIGHT}(1)$ & Bundle elevation (in.). \\
\hline$(11-20)$ & PMULT(1) & Axial power factor at PHIGHT(1). \\
\hline$(21-30)$ & (etc.) & $\begin{array}{l}\text { Integrated power (in.) at position PHIGHT(1). PINT(1) } \\
\text { is computed by multiplying PHIGHT(1) by the fraction } \\
\text { of total power generated between the inlet (i.e., } \\
\text { bundle elevation }=0.0 \text { ) and bundle elevation } \\
\text { PHIGHT(1). Required for boiloff simulations only. }\end{array}$ \\
\hline
\end{tabular}


Card H. Format $(4 \mathrm{II} 0,2 \mathrm{E} 10.0, \mathrm{I10}, \mathrm{E} 10,0,15)$. Node Heat Generation and Temperature Initialization Card. Optional.

Column Variable

(1-10) N1

$(11-20) \quad$ NSEQ

$(21-30) \quad$ NADD

$(31-40) \quad$ NGAM

(41-50) PRADIL

$(51-60) \quad$ TXY

$(61-70) \quad$ ITXY

$(71-80) \quad A X$

$(81-85) \quad$ NPCX
Description

Node number

Number of additional nodes with identical initial conditions.

Increment between successive node numbers in sequence of NSEQ +1 nodes generated when NSEQ is used. Gamma heating flag. Indicates fuel or non-fue 1 node. NGAM $=0$; heat generation based on RODAVE» (1-PGAMMA) value. $\mathrm{KGAM}=1$; heat generation based on RODAVE^PGAMMA.

Radial power factor.

Node initial temperature. Overwrites value specified by TONE (BLOCK 1, Card C) at each axial lever.

Initial temperature axial variation flag:

(0) uniform initial axial node temperature distribution (set by TONE or TXY)

(>1) number of points in temperature axial variation table. Node axial temperature distribution set by temperature axial variation table card (Card I).

Node initial phase change mass-fraction. Mass fractions must vary between 0.0 and 1.0. Phase change progresses from $A X=1.0$ at start of phase change, to $A X=0.0$ at end of phase change.

Phase change identifier (BLOCK 2, Card G). Use 0 for no active phase change or no phase change. If NPCX does not equal 0 , then TXY must equal TMELT for the active phase change.

*** Card $H$ read only if LEVFLG (Card A) $=1$, i.e., TRUMP-BD input. *** 
Card I. Format (8E10.0) Initial Temperature Axial Variation Card. Optional. Column Variable D__ Description

(1-10) TDUM(1) Node temperature $\left({ }^{\circ} \mathrm{F}\right)$.

(11-20) ZDUM(1) Axial position of TDUM(1) (in.).

(etc.)

** Card G read only if ITXY (CARD H) $>0$. *** 
BLOCK 10. MASS FLOW CONNECTIONS.

Card A. Format (215). Auto Noding Parameters.

*** NOT USED--LEAVE BLANK

Card B. Format $(12,2 X, 11, F 5 \cdot 0,7 E 10.0)$. Flow Descriptor Card.

Column Variable

Description

$(1-2$

IMASFG

Variable flow flag:

(1) boiloff simulation. Boiloff will include time-varying inlet flow rate.

(0) standard TRUMP flow logic used

(-1) non-boiloff simulation; no dryout front assumed. Will include time-varying inlet flow rate for flow regions.

(5) HFLAG Hydrogen-blanketing model flag:

(1) node oxidation limited as a linear function of hydrogen fraction (see Section 3.5.2.1).

(0) no oxidation limiting.

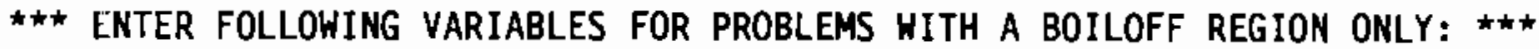

(6-10) QBOIL Sum of inlet subcooling and heat of vaporization (Btu/1bm).

(11-i0) HFG Heat of vaporization $(8 \mathrm{tu} / 1 \mathrm{bm})$.

(21-30) RHOBAR Average density below dryout front (1bm/in.3).

(31-40) HDO Heat transfer length from bulk-boiling to dryout regions. HOO must be less than axial node length (in.).

(41-50) HBULK Value of bulk-boiling heat transfer coefficient below dryout front $\left(B t u / h-i n .-{ }^{\circ} F\right)$.

(51-60) XINTERI Initial position of dryout front (in.). 
Card C. Region Delimiter Card

This card must precede the flow region description card (Card D). A Region Delimiter Card is read for each new flow region. The Region Delimiter Card contains the pattern "888" in columns 3-5 and 8-10.

Card D. Format $(215, E 10,0,15,2 E 10,0,15)$. Flow Region Descriptor Card.

Column Variable

Description

IBOLRGN

Region indicator flag:

$(-1)$ identifies the flow region as a boiloff region. The boiloff region must be the first flow region described in the BLOCK 10 input. Only one boiloff region is allowed in a simulation.

(0) non-boiloff region.

$(6-10) \quad$ MASFLG

Mass flow rate computation flag:

(1) flow rate computed based on initial power, dryout interface and inlet conditions. Computed for boiloff region on Ty.

(0) mass flow specified with standard TRUMP flow logic. Omit remaining items on Card $D_{\text {; }}$ omit Card E.

(-1) flow rate user-prescribed.

(11-20) XMOOX (NREGON) User-prescribed region mass flow rate $(1 \mathrm{bm} / \mathrm{h})$.

(21-25) NTABF (NREGON) Number of entries in mass flow table (Card E).

(26-35) HIDM(NREGON) Flow region hydraulic diameter (in.).

(36-45) FLOWY(NREGON) Flow region cross-sectional flow area (in.2).

(46-50) IRHOCOL Number of pairs of entries in variable density table for coolant density below dryout front (Card F). Enter for boiloff region simulations only. If nonzero, value of RHOBAR (Card B) will be overwritten by variable boiloff region density (Card $F$ ). 
Card E. Format (8E10.) Region Mass Flow Table Card. Optional.

Column Variable Description

(1-10) FMULT(NREGON,1) Region flow rate multiplier

(11-2.0) FTIME(NREGON, 1) Time corresponding to FMULT(NREGON, 1), (h). (etc.)

*** Card $E$ read in only if NTABF (Card D) $>0$.

Card F. Format (8E10.0). Boiloff Region Density Table. Optional

Column Variable

(1-10) RHOCOL(1) Average coolant density below dryout front ( $1 \mathrm{bm} / \mathrm{in} .3$ )

(11-20) XMS(1) Flow region steam flow rate above dryout front $(1 \mathrm{~b} / \mathrm{h})$. (etc.)

*** Card F, Read in only if IRHOCOL (Card D) $>0$ and IBOLRGN $=-1 \star * \star$

Card G. Format $(6 \mathrm{I} 5,10 \mathrm{~A} 1,2 \mathrm{E} 10.3)$ Mass Flow Connections

Column Variable Description

(1-5) NODF1 Identification number of the source node.

(6-10) NODF2 Identification number of the sink node. May not be a zero-volume node. Last three digits of sink node must correspond with last three digits of source node to define unique subchannel.

(11-15) NSEQ Number of additional identical mass flow connections.

(16-z0) NADFI 1 Increments between successive values of NODF1 and

(21-Z5) NADF2 $\}$ NODF2, respectively, in the sequence of NSEQ + 1 mass flow connections generated when NSEQ is used.

(26-30) LTABFL Number of tabulated values of mass flow rate, negative if vs. time, positive if vs. temperature, zero if no table. Used for standard TRUMP (MASFLG) simulations only. 
For TRUMP-BD (MASFLG $=-1$ or 1 ), fraction of region mass flow rate applied to mass flow connections $N 1$ and N2. For standard TRUMP (MASFLG $=0$ ), FX equals actual mass flow rate. $F X$ is set equal to FONE from BLOCK 1.0, Card $C$ if left blank or set equal to 0.0 .

$\left.\begin{array}{ll}(41-50) & \text { DELF1 } \\ (51-60) & \text { DELF2 }\end{array}\right\}$ Lengths of mass flow paths from nodal points of NODFI and NODF2, respectively, to the connected surfaces.

** Use additional Card Gs for any additional mass flow connections for

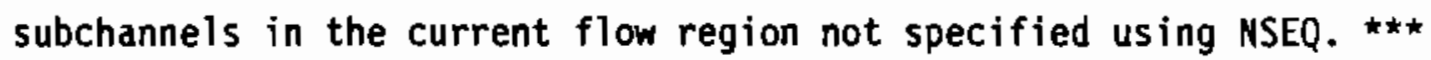
Card H. Format (8E10.3). Mass Flow Rate Table. Optional.

\begin{tabular}{|c|c|c|}
\hline Column & Variable & Description \\
\hline$(1-10)$ & FLOHT (1) & Mass-flow rate. \\
\hline$(11-20)$ & $\begin{array}{l}\text { TVARFL(1) } \\
\text { (etc.) }\end{array}$ & $\begin{array}{l}\text { Temperature or time corresponding to FLOWT(1) } \\
\left({ }^{\circ} \mathrm{F} \text { or } \mathrm{h}\right) \text {. }\end{array}$ \\
\hline
\end{tabular}


BLOCK 12. REMOTE DEPENDENCE DATA

Card 1. Format (7I5). Remote Temperature Dependence Card.

Column Variable

$(1-5) \quad$ NOOP1

$(6-10) \quad$ NODP2

$(11-15) \quad$ NPROP

(16-20) NSEQ

(21-25) NADP1

$(26-30) \quad$ NADP2

$(31-36) \quad$ NADPR
Description

Identification numbers of the node to which the property applies and the node on whose temperature the property depends, respectively, i.e., $P($ NODP1) $=$ $P[T(N O D P 2)]$.

Property indicator: 1 for heat capacity, 2 for thermal conductivity, 6 for variable heat-generation rate, 7 for mass-flow rate, and 8 for surface convection coefficient.

Number of additional nodes with properties dependent on remote temperatures. Node and property numbers are determined by NADP1, NADP2, and NADPR.

Increments between successive values of NODP1, NODP2, and NPROP, respectively, in the sequence of NSEQ + 1 nodes with properties dependent on remote temperatures, generated when NSEQ is used. 
BLOCK 13. FISSION PRODUCT INVENTORIES

Card A. Format $(15,5 \mathrm{X}, 2 \mathrm{E} 10.0,5 \mathrm{X}, \mathrm{I} 5)$. Fission Product Parameters.

Column Variable

(1-5) NFP

(10-20) TREFF

(20-30) FPFRAC Fraction of whole core being modeled in the simulation, in terms of core power.

(36-40) N12WRT Number of discrete times at which fission product release data will be written to TAPE12.

Card B. Format $(A 9,1 \times, 5 e 10.0)$. Fission Product Descriptor Card.

Column Variable
Description ISOTOP

Fission product name.

$(11-20) \quad$ FPIT

$(21-30) \quad A C$

$(31-40) \quad B$

$(41-50) \quad C X$

$(51-60) \quad C$ Total core inventory of fission product $(\mathrm{kg})$. Coefficient used in computing vapor pressure of fission product. (see Section 3.15.2) Coefficient used in computing vapor pressure of fission product. (see Section 3.15.2) Fraction of fission product released per fraction of uranium oxidized. (see Section 3.15.2)

Coefficient used in computing "bake-out" conductance of the fission product. (see Section 3.15.2) ***Card 8 repeated for NFP number of fission products***

Card C. Format $(8 \mathrm{e} 10.0)$. Print Control Table. Optional.

Column Variable

$(1-10) \quad \mathrm{T} 12(1)$

(etc.)
Description

Times at which fission product release output data will be written to TAPE $12(h)$. Times must be read in sequential order.

$\star \star \star$ Card C read in only if N12WRT (Card A) $>0 * \star \star$ 


\subsection{RESTART PROCEDURES}

Not fully verified in TRUMP-BD

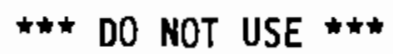




\subsection{OUTPUT AND POST-PROCESSING OUTPUT FILES}

\subsection{OUTPUT FILE}

The TRUMP-BD standard data output file (OUTPUT) differs significantly from the standard TRUMP output, due primarily to TRUMP-BD's extended capabilities.

At the top of the TRUMP-BD output a mirror "image" of the input file is written. This image can be used to check the exact contents of the input files and serves as a user's aid for diagnosing errors that result from incorrect formatting of the input file. The mirror image of the input also provides added traceability for quality assurance purposes.

Following this image is a processed listing of all input-derived quantities such as node volumes, connection areas, fission product inventories, input table slopes, comments concerning special input options, or input errors. Unlike the image input listing, nodes and connections implicitly defined using input variable NSEQ (Section 4.0) are explicitly listed here. The processed input provides confirmation to the user that the input data deck has been entered as intended.

After both the image input and processed input are written to the OUTPUT file, the input parameter list which governs array sizes within the code (Section 8.0) is written. This list can be used as a reference when the user suspects an execution error is due to an undersized array.

As with standard TRUMP, simulation results are written at the first, second, and last time steps, as well as at time intervals TIMEP(a) and time step intervals IPRINT (BLOCK 1, Card A). Also, at time intervals XSPRNT (BLOCK 1. Card D), temperatures (XUTOUT), phase change mass fractions (AOUT), and current phase change indexes (NPCOUT) are written to the output file for each special output node (NODOUT). Input variable KDATA (BLOCK 1, Card A) controls the type and quantity of standard TRUMP data written out, but does not control output unique to TRUMP-BD. The "Output Suppression Card" (BLOCK 1, Card F) provides an additional means of limiting extraneous standard TRUMP output.

(a) See Section 4.0 for information on input variables and Appendix A for definitions of all variables discussed in this section. 
Each standard print interval is preceded by a line identifying the version of TRUMP-BD used, and the input deck title card. The output banner card has been expanded to include:

- coolant pressure (PRESS, pisa) and saturation temperature (TSAT, ${ }^{\circ} \mathrm{F}$ )

- integrated axial power at coolant boiloff interface (PIGRAL, $\mathrm{kW}$ )

- boiloff region mass flow rate multiplier (FFACTR)

- the axial level of dryout front (NBOIL)

- the axial elevation of the dryout front, "x interface" (WLEVEL, in.)

- the model "lower bound", or elevation (XINTER, in.)

- average rod linear heat generation rate (RODAVE, $\mathrm{kW} / \mathrm{ft}$-rod)

Directly beneath each output banner, the current maximum Zircaloy (CLADMX, material 100) and uranium (FUELMX, material 1) temperatures are given, along with the axial level and fuel pin numbers at which they are occurring and the simulation time in seconds (SUMSEC).

For all but the first time step print interval, an oxidation sumanary for each metal-water reaction node is written out. Included for each metal-water reaction node (identified in BLOCK 4 , Card 0 ) are:

- heat generation due to oxidation (QZRH2O, $\mathrm{kW}$ )

- heat generation due to fission or decay heat(a) (QFISON, kW)

- total heat generation (QGEN, $\mathbf{k H}$ )

- node unoxidized metal thickness remaining (ZRLEFT, in.)

- the amount of steam available for oxidation (STEAMF, $\mathrm{kg} / \mathrm{s}$ )

- hydrogen fraction in the adjacent coolant flow region (HFRACT)

- the integrated hydrogen release rate up to that node in the table (HREL, $\mathrm{kg} / \mathrm{s}$ ).

A second oxidation summary, directly following the one described above, prints sumanary information for each axial level. Included are:

(a) Energy production other than metal-water reaction. 
- total heat generation due to oxidation (kW)

- total heat generation due to oxidation of Zircaloy (QZRAX, $\mathrm{kW}$ )

- total heat generation due to oxidation of uranium (QUAX, $\mathrm{KW}$ )

- the average remaining thickness of Zircaloy nodes (AVEDX, in.)

- the average remaining thickness of uranium nodes (AVEUDX, in.).

The total hydrogen release rate (HFLOWR) for the time step and integrated hydrogen release over the transient (HFLOWT) appear at the bottom of this second oxidation sumary.

Additional TRUMP-BD diagnostic sumnary information will be written to the output file depending on the value of IDIAG (BLOCK 1, Card D). The options are:

IDIAG $=1$, no additional diagnostic information

$=2$, pin heat generation summary only

$=3$, variable internal connection and convection summary only

$=4$, radial and axial loss sumary only

$=5$, complete diagnostic sumary (all of above, plus heat balance/heat generation sumary, fission product release summary, and phase change sumnary).

If fuel pins (NPN) are specified (BLOCK 4, Card D) and IDIAG is 2 or 5, a "Pin Heat Generation and State Sumary" is written out during the third print interval and thereafter. In addition, for axial levels at which pin failure has cccurred during the transient, information is written identifying (by pin number):

- the time of failure at each axial level (FAILT, h)

- the oxidation area multiplier applied to fuel node (OXPINM)

- the maximum fuel pin temperature thus far in the simulation (TPINMAX, ${ }^{\circ} \mathrm{F}$ )

- the current pin temperature (TPIN, ${ }^{\circ} \mathrm{F}$ ).

Total heat generation for each pin (QPIN), total fuel node failures (NFAIL), total pin failures (NFAILP), total heat generated by metal-water reactions 
(QZRTOT, $\mathrm{kW}$ ), total heat generated due to nuclear heating (QFISON, $\mathrm{kW}$ ), and the total heat generated (GS, $\mathrm{kW}$ ) are also written.

If variable internal thermal connections between nodes or convection heat transfer is being modeled and IDIAG is 3 or 5, a "Variable Internal Thermal Connection and Convection Surmary" is written to the output file during the third print interval and thereafter. Included in this sumary is the current value of conductance (HINT) for each variable internal thermal, the total losses (QCHAN) in each coolant subchannel, and for boiloff problems, and the energy required for vaporization of liquid coolant (PIGRAV). TRUMP-BD computes subchannel convection losses for source/sink nodes (BLOCK 10, Card F), whose node "base" numbers (three right-most digits) are identical. If this node numbering methodology is not used, the convection summary output may be in error.

If connections to external boundary nodes are specified (BLOCK 6) and IDIAG is 4 or 5, an "Axial and Radial Heat Loss Sumary" is provided, in which each boundary node (NODS) and its associated external node (NODSB) is 1 isted, along with the heat loss or gain attributable to that connection during the current time step. The total axial, radial, and miscellaneous heat losses are written beneath the individual connection heat losses. The axial heat loss (QAXTOT, $k W$ ) is the sum of heat losses to external boundary node 1000 (i.e., NODSB $=1000)$; the radial heat loss (QRADT, $k W$ ) is the sum of heat losses to external boundary node 2000 (i.e., NODSB $=2000$ ); and the miscellaneous heat loss (QMISCT, $\mathrm{kW}$ ) is the sum of heat losses to any other external boundary nodes.

When IDIAG $=5$, a sumnary of all heat generation and heat losses is given, along with a total system energy balance. Items included (in order) are:

- the heat generation due to metal-water reactions (both uranium and Zircaloy) during the time step (QZRTOT, $\mathrm{kW}$ )

- the heat generation due to fission (QFISONT, kW)

- the sum of QZRTOT + QFISON (kW)

- total radial heat loss or gain (QRADT, $\mathrm{kW}$ )

- total axial heat loss or gain (QAXTOT, $\mathrm{kW}$ ) 
- the heat loss due to vaporization of coolant during a boiloff simulation (PIGRAV, $\mathrm{kW}$ )

- total convective heat removal (QCONVT, kW)

- the total system heat loss, i.e., the sum of QRADT + QAXTOT + PIGRAV + QMISCT (kW).

The relative percent of the heat generation and removal terms and an overall system heat balance follow this summary.

Provided IDIAG $=5$ and fission product releases are being modeled the following fission product release data will be written for each fission product:

- fuel node number (NOOE)

- node integral release due to oxidation (FPRELO, $\mathrm{kg}$ )

- node integral release due to bake-out (FPRELB, $\mathrm{kg}$ )

- node total integral release (FPREL, $\mathrm{kg}$ )

- node release rate due to oxidation (FPDTO, $\mathrm{kg} / \mathrm{min}$ )

- node release rate due to bake-out (FPDTB, $\mathrm{kg} / \mathrm{min}$ )

- node total release rate (FPDT, $\mathrm{kg} / \mathrm{min}$ )

- total model integrated release (FPMRL, $\mathrm{kg}$ )

- total model integrated release due to bake-out (FPMRLB, $\mathrm{kg}$ )

- total model integrated release due to oxidation (FPMRLO, $\mathrm{kg}$ )

- total model release rate (FPMDT, $\mathrm{kg} / \mathrm{min}$ )

- total model release rate due to bake-out (FPMDTB, $\mathrm{kg} / \mathrm{min}$ )

- total model release rate due to oxidation (FPMDT0, $\mathrm{kg} / \mathrm{min}$ ).

Finally, when IDIAG $=5$, a phase change summary is given for nodes made of materials that can undergo phase changes during the simulation (BLOCK 2, Card G). Each node is 1 isted, along with its current temperature, change in mass fraction of the lower temperature phase during the time step (DA), time rate of change of mass fraction of the lower temperature phase (DDA), the 
active phase change index (NPC), and the mass fraction of the lower temperature phase (A).

Upon completion of the simulation, a "Final System Summary" is written provided NPUNCH is specified as non-zero in BLOCK 1 , Card A. The final temperatures $\left(T,{ }^{\circ} F\right)$ and heat generation rates $(G X, K W)$ are included in this sumnary for each node (NODE). For metal-water reaction nodes, the final thickness $(\mathrm{THX}, \mathrm{in}$.$) , oxidation area \left(\mathrm{OXA}, \mathrm{in} .^{2}\right)$, and initial thickness are also included.

As with standard TRUMP, at the completion or termination of the problem the following additional data are written out: 1) the problem-end sentinel (KWIT) and its definition, and 2) the elapsed machine time, in seconds, since the beginning of the problem.

Excerpts from a typical TRUMP-BD OUTPUT file, including data through the first time step $(K C Y C=1)$ and the "Final System Sumary" are included in Appendix $B$ as OUT.OD.

\subsection{GRAPHICAL OUTPUT FILES}

In addition to the TRUMP-BD output file described above, the user may specify that graphics "dump" files be created during execution. These additional files contain output data from the simulation formatted so as to be readable by OISPLOT, a post-processing routine(a) that allows $x-y$ plots to be produced on a variety of plotting devices. The graphics dump files are arranged in row/column format; the DISPLDT graphics routine can plot any two columns of data on a plot. Multiple curves on a plot can also be accommodated.

\subsection{1 $\underline{\text { TAPE3 }}$}

When the user specifies OUTDISC $=2$ (BLOCK 1, Card A), a "system summary" file named TAPE 3 is created during execution which contains the following information, written out at each time interval XSPRNT:

- simulation time (SUMSEC, s)

- maximum Zircaloy temperature (CLADHX, ${ }^{\circ} \mathrm{F}$ )

(a) DISPLOT3: An Al1-Purpose, Generalized Plotting Routine. Wildung, $N$. J., Pacific Northwest Laboratories 
- maximum uranium temperature (FUELMX, ${ }^{\circ} \mathrm{F}$ )

- nuclear power heat generation rate (QFISONÆSYMLT, $\mathrm{kW}$ )

- metal-water reaction power (QZRTOT*SYMLT, KW)

- ratio of metal-water reaction power to nuclear power (PER)

- total radial heat losses (QRADT*SYMLT, Btu/h)

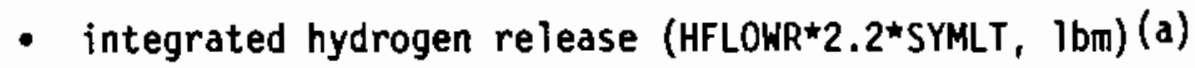

- exit hydrogen fraction (HFRACT)

- exit hydrogen flow rate (HFLOWR*7936.24*SYMLT, $1 \mathrm{bm} / \mathrm{h}$ ) (b)

- integrated hydrogen release from uranium (HFROMUT*2.2*SYMLT, $1 \mathrm{bm}$ )

- integrated hydrogen release from Zircaloy (HFROMZT*2.2*SYMLT, 1bm). When NFP $>0$, values of whole tube fission product release are also written to TAPE3 for each fission product. These data include:

- total tube integrated release (FPMRL*SYMLT*2.2, Ibrin)

- total tube integrated release due to bake-out (FPMRLB*SYMLT*2.2, $1 \mathrm{bm}$ )

- total tube integrated release due to oxidation (FPMRLO*SYMLT*2.2, $1 \mathrm{bm}$ )

- total tube release rate (FPMDT*SYMLT*2.2/60., $1 \mathrm{bm} / \mathrm{h}$ )

- total tube release rate due to bake-out (FPMDTB*SYMLT*2.2/60., 1bin/h)

- total tube release rate due to oxidation (FPMDTO*SYMLT*2.2/60., ibm/h) A copy of a typical TAPE3 is included in Appendix B as TAPE3.0F.

\section{2 .2 TAPE5}

when the user specifies OUTDISC $=2$ (BLOCK 1, Card A) a special output node temperature file named TAPE5 is created that contains either temperatures for each special output node (NODOUT) or all node temperatures (when NSPOUT is specified as negative). This data is written out at each time interval XSPRNT.

4 header to a typical TAPE5, with a portion of the typical data, is included in Appendix B as TAPE5.0D.

\subsubsection{IAPE11}

When the user specifies a positive integer value for NAXTIM (BLOCK 1 , Card $D)$, a TAPEll is created that contains axial information written out at
(a) Conversion from $\mathrm{kg}$ to $1 \mathrm{bm}$.
(b) Conversion from $\mathrm{kg} / \mathrm{s}$ to $\mathrm{lbm} / \mathrm{h}$. 
AXTIM(1),...AXTIM(NAXTIM) times (BLOCX 1, Card 6). For each axial level in the input model, this information includes

- total heat generation rate due to metal-water reactions (QZRAX»SYMLT, KW)

- percent of original total thickness of all Zircaloy nodes (material = 100) that remains unoxidized (PERZLFT)

- percent of original total thickness of all uranium nodes (material $=1$ ) that remains unoxidized (PERULFT)

- radial heat loss (QRADDX*SYMLT, kW)

- leaving hydrogen fraction for each flow region (XH2LEV)

- leaving hydrogen fraction for entire axial level (HFRCLVL).

In addition, temperatures for specified identical nodes (NODEAX) at similar axial levels will also be written to TAPE11 if NAXPO is specified as a positive integer in BLOCK 1 , CARD $D$.

A header to a typical TAPE11, with a portion of the typical data, is included in Appendix B as TAPE11.00.

\section{2 .4 TAPE12}

The TAPE12 output file provides fission product data based on location, written out at T12(1)...T12(N12WRT) times (BLOCK 13, Card C). Among the data provided on TAPE12 is:

- node numbers (NODE) and temperatures $\left(T,{ }^{\circ} \mathrm{F}\right.$ ) for each Zircaloy volume node by order of its axial level and adjacent coolant flow region

- tube integral hydrogen release, by axial level and coolant flow region (HTUBE, kg)

- tube integral release of each fission product due to bake-out, by axial level and coolant flow region (FPRB, $\mathrm{kg}$ )

- tube integral release of each fission product due to oxidation, by axial level and coolant flow region (FPRO, $\mathrm{kg}$ )

- tube integral release of each fission product, by axial level and coolant flow region (FPR, $\mathrm{kg}$ ) 


\subsection{SAMPLE PROBLEM}

This section documents a sample problem using TRUMP-BD to analyze the transient response of $N$ Reactor during a station blackout accident. The model chosen was constructed from a modified version of the half-length process tube model (HLM) developed for the hydrogen mitigation design basis accident scenario of the $\mathbf{N}$ Reactor (Heard et al. 1987). This problem was chosen because numerous features of TRUMP-BD are demonstrated, including metal-water reactions of Zircaloy cladding and uranium fuel, mass flow convective heat transport, and internal heat generation due to fission heating.

A description of the $N$ Reactor is presented in Section 6.1. The model ing methodology employed in developing the HLM is presented in Section 6.2. Section 6.3 describes sample lines from the input, and Section 6.4 briefly discusses results. Appendix B provides copies of the INPUT file and excerpts from the OUTPUT file, along with excerpts from the post-processing files TAPE3, TAPE5, and TAPE11.

\subsection{DESCRIPTION OF N REACTOR}

N Reactor, a $4000 \mathrm{MWt}$, graphite-moderated light-water reactor, employs concentric cylindrical uranium metal fuel that is clad with Zircaloy-2. The reactor core comprises mechanically identical fuel columns arranged horizontally within a cube composed of interlocking graphite blocks. The fuels vary with respect to uranium-235 enrichment; three enrichments are employed throughout the core. Each fuel column is situated in the central $34.8 \mathrm{ft}$ of a Zircaloy-2 process tube that is connected to the manifolds of the reactor coolant system. A total of 1003 horizontally oriented process tubes, arranged in an array of 32 rows and 34 vertical columns, with 21 process tubes omitted from each corner, comprise the core. The cuboid-shaped core is surrounded by a graphite reflector, a borated-steel thermal shield, and a concrete biological shield.

Interlocking graphite blocks form the neutron moderator. The graphite blocks are arranged in alternate horizontal layers with the blocks from alternate layers performing different functions; one layer houses the process tubes, while the next houses the graphite and shield cooling system (GSCS) tubes. The interlocking graphite moderator block arrangement may be more 
clearly understood from the stack configuration shown in Figure 6.1. The graphite matrix voids (approximately $30 \%$ of the volume) are filled with recirculating helium.

The GSCS tubes alternate between filler blocks along the axial length of the process tube. Only the central axial region of the core (73\% of the fuel length) contains provisions for GSCS tubes, whereas no GSCS cooling exists within the end regions of the core. For the station blackout model, the GSCS system was assumed inoperable.

N Reactor's fuel columns are made from individual fuel elements placed end-to-end and seif-supported in the pressure tube. The fuel elements are $20-i n$. to 24.-in. long concentric cylinders that are manufactured by coextrusion of the metallic uranium fuel and Zircaloy-2 cladding, thereby producing a strong metallurgical bond. Welded Zircaloy end closures complete the fuel element encapsulation. The combined fuel and process tube configuration forms three essentially continuous coolant passages; two annular and one cylindrical. A transverse cross section of the fueled process tube is shown in Figure 6.2.

\subsection{MODELING METHODOLOGY}

A description of the TRUMP-BD input model and the modeling of the station blackout accident are presented below.

\subsubsection{The Half-Length Model}

The $N$ Reactor graphite moderator block matrix structure is composed of repetitive substructures, or "unit cells." A unit cell is defined by several planes of symmetry that exist within the moderator configuration. The unit cell encompasses both cooled and uncooled filler blocks, and may be repeated to model the entire heated length of a single process tube. The one-quarter symmetry of the unit cell ignores the slight asymmetries that exist between the top and bottom keyed sections of the GSCS filler blocks. For computational purposes, the unit cell was subdivided into two axial sections along the process tube length: a cooled filler block and an uncooled filler block (Figures 6.3 and 6.4 , respectively). These subdivisions form the building blocks for constructing a model that spans half the process tube length, i.e., 


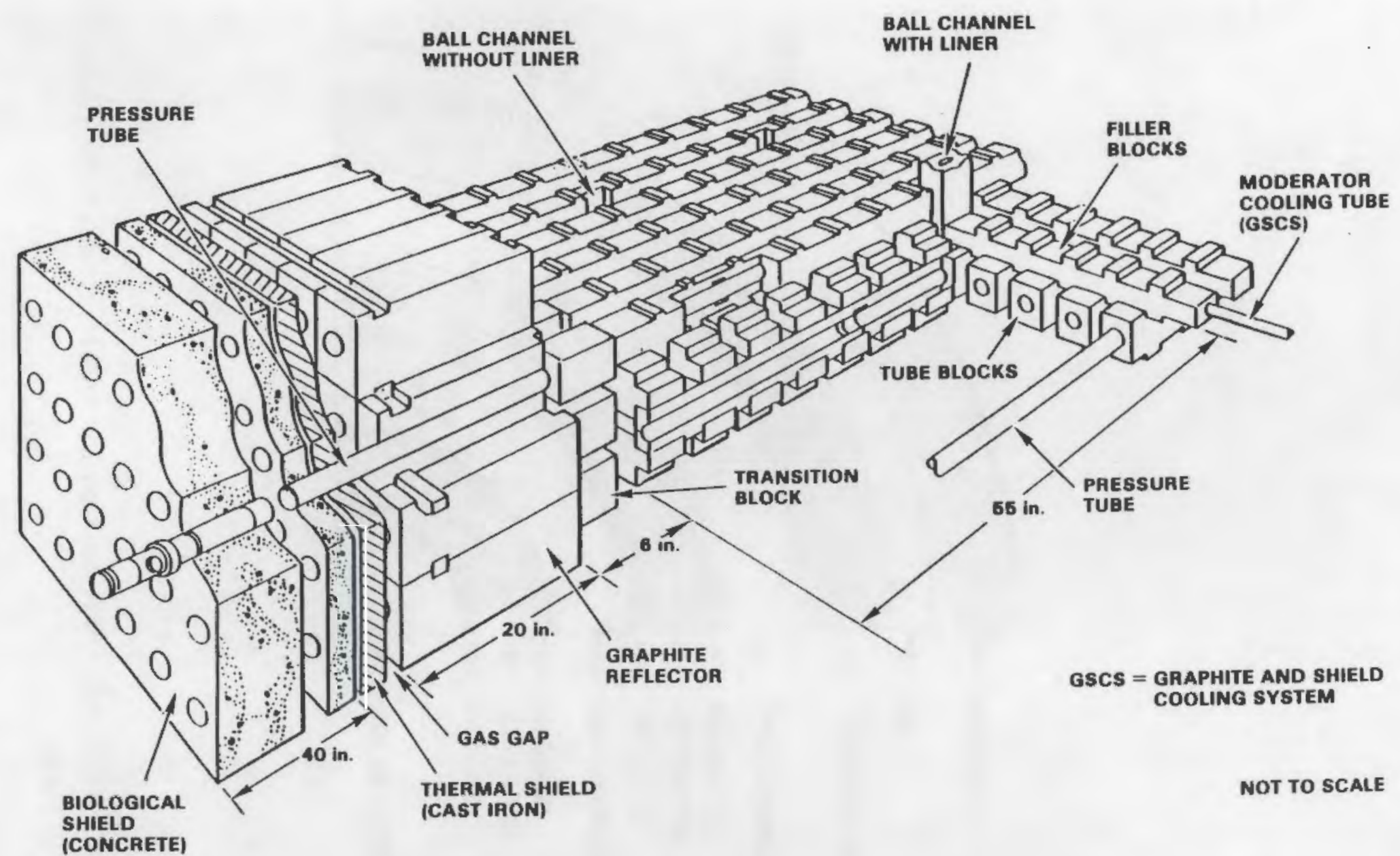

FIGURE 6.1. N Reactor Core and Reflector Geometry 


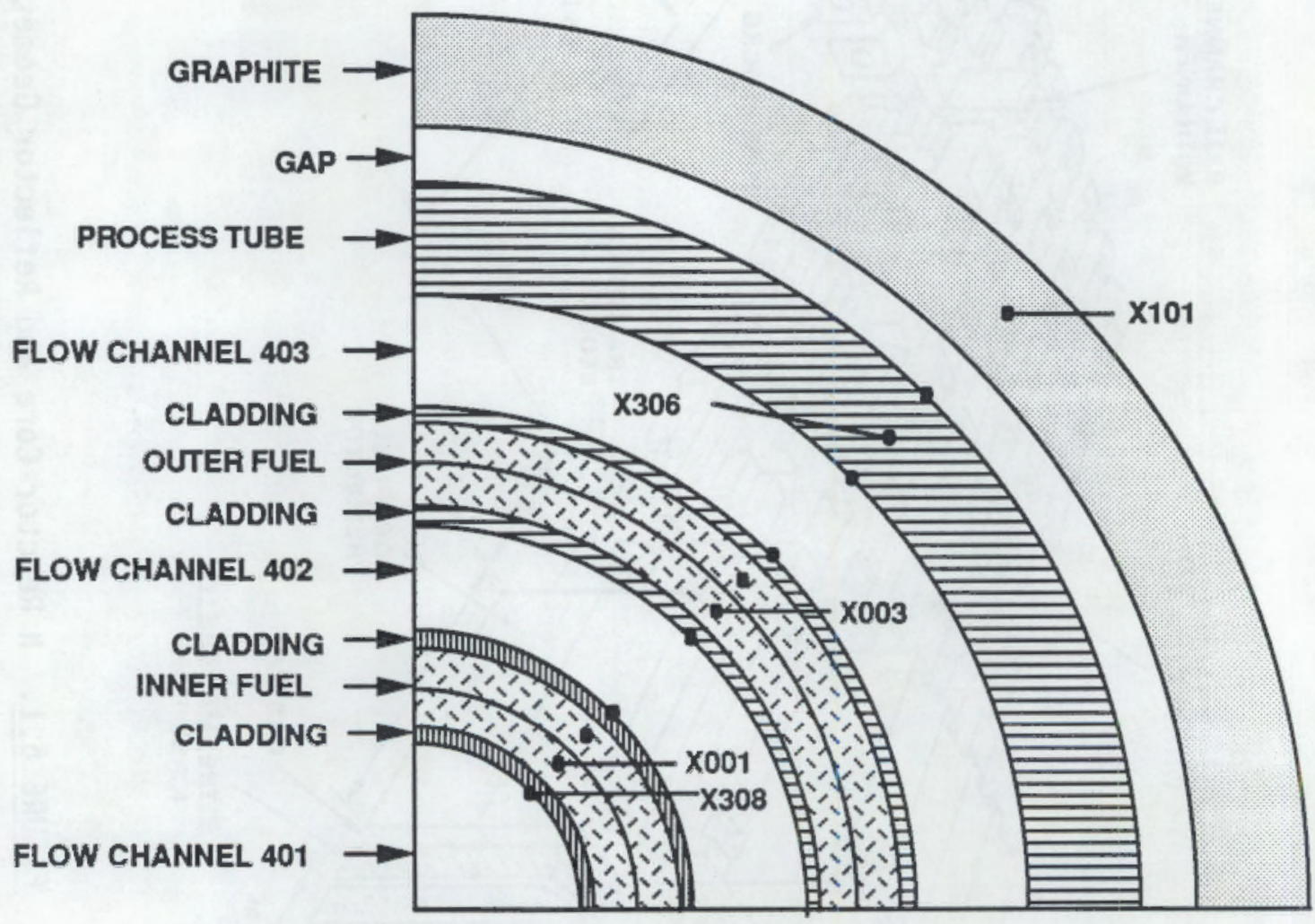

FIGURE 6.2. Transverse Cross Section and Nodalization of the Fueled Process Tube 


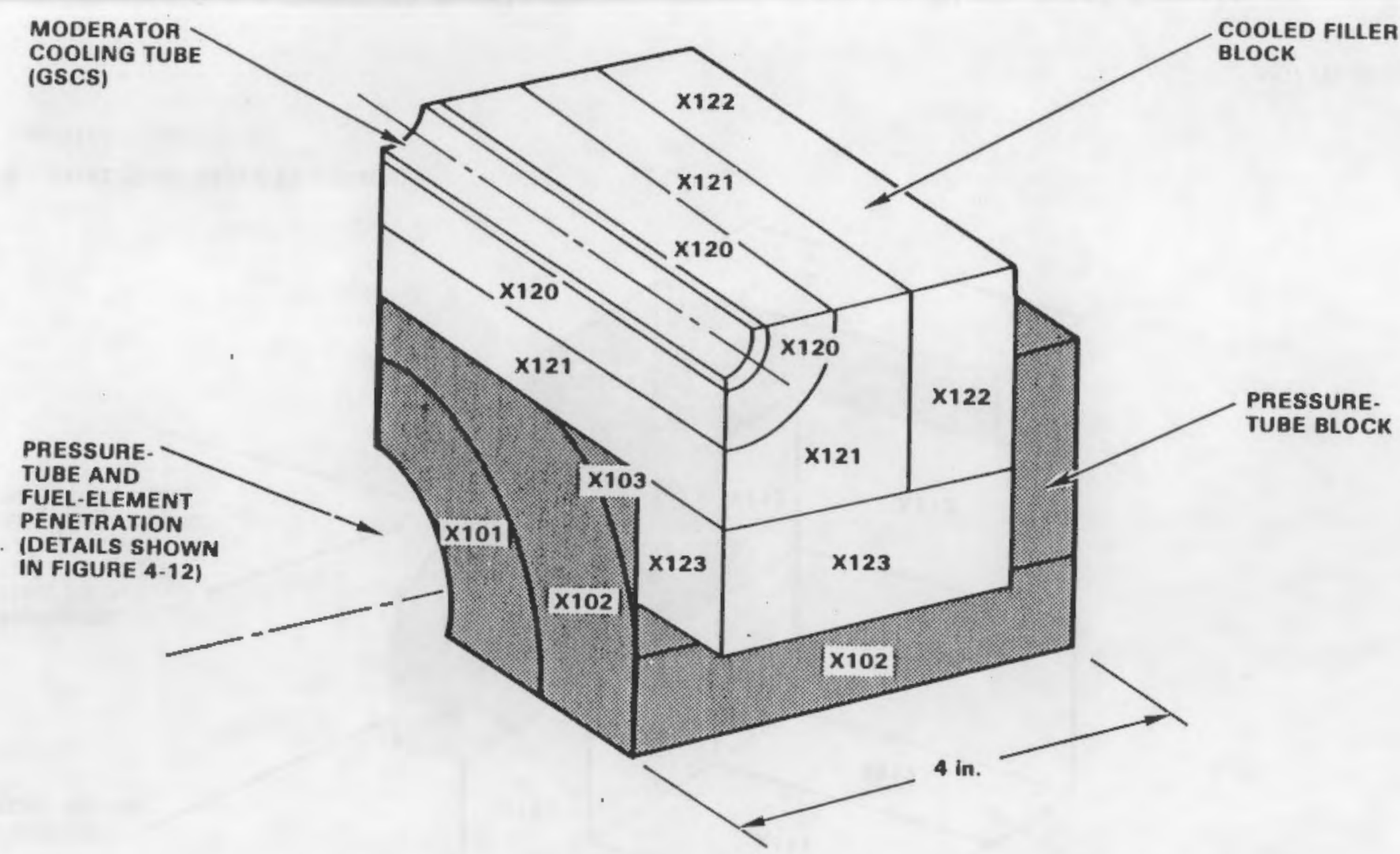

$X=$ AXIAL LEVEL. (NODE ID SHOWN)

NOT TO SCALE

\section{QUARTER SYMMETAY}

GSCS = GRAPHITE AND SHIELD COOLING SYSTEM

FIGURE 6.3. TRUMP-BD Nodalization--Cooled Filler Blocks Axial Segment 


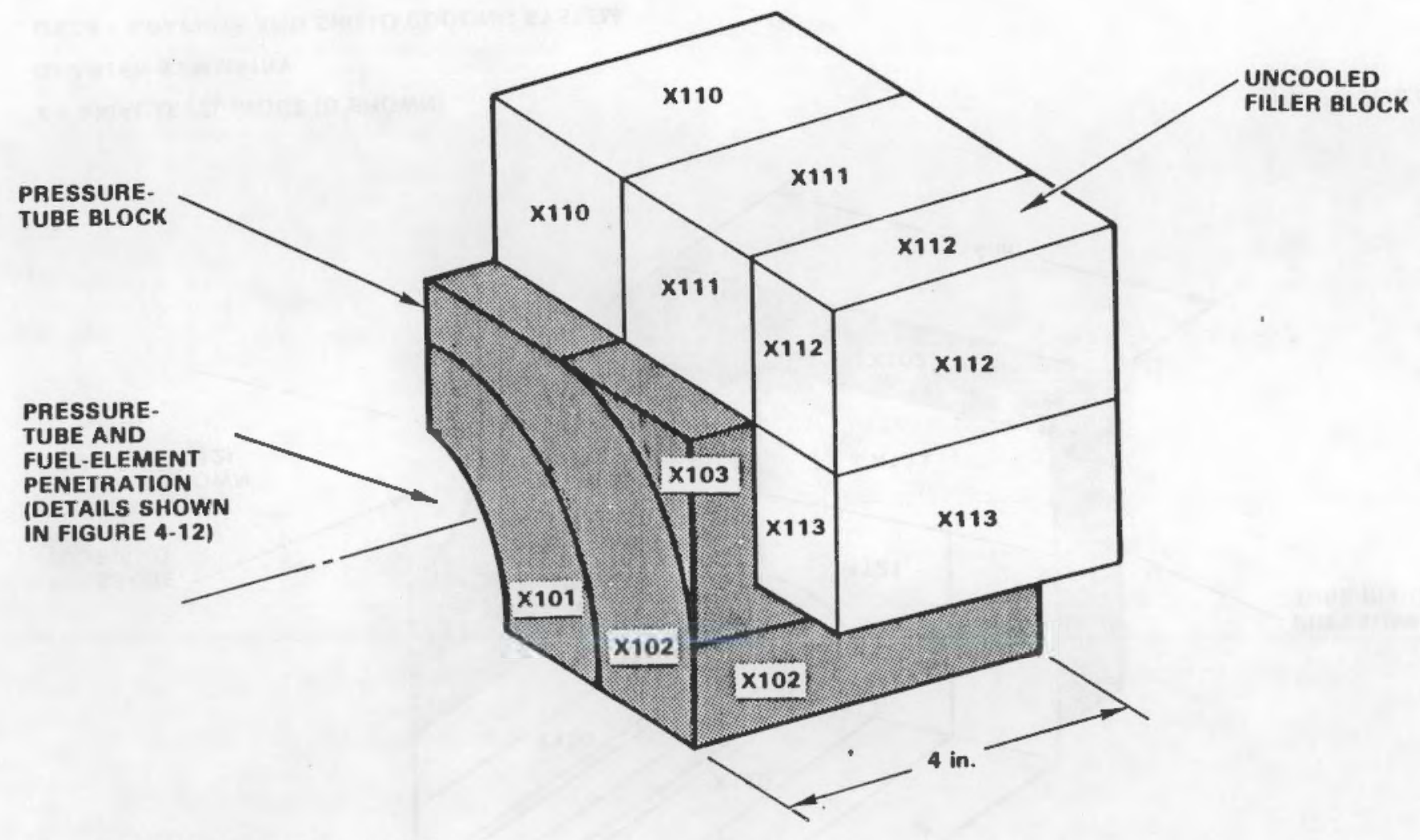

$X$ = AXIAL LEVEL (NODE ID SHOWN)

QUARTER SYMMETRY

FIGURE 6.4. TRUMP-BD Nodalization--Uncooled Filler Block Axial Segment 
half-length model (HLM). The exception to the building-block structure occurs in the transition and reflector regions of the core, where one-quarter symmetry, axial segments were tailored to the graphite geometry. The HLM segmented into unit cell sections, along with the reflector and transition region, appears in Figure 6.5 .

Three-dimensional nodalization of the HLM building blocks entailed specification of node volumes, heat transfer paths, and material properties. Node volumes for the cooled and uncooled filler blocks are indicated in Figures 6.3 and 6.4. The reflector block and transition block nodalizations, while not shown, reflect the degree of node volume refinement shown for the unit cells. In the graphite regions, cylindrical nodes were assigned in regions dominated by radial heat conduction and Cartesian nodes were assigned for the remaining regions. The degree of refinement in nodalization represents a balance between computation effort and accuracy. Adiabatic boundary conditions are applied to the unit cell's planes of symmetry.

The extrusion-fabricated graphite exhibits anisotropic thermal conductivity. Property variations that are dependent on extrusion direction were accounted for by applying a multiplication factor to node themal connection lengths when considering conduction transverse to the extrusion direction. Contact resistances were computed from as-built gap widths and were incorporated into the model for heat transfer between the process tube graphite block and the filler graphite blocks. Temperature-dependent conduction heat transfer coefficients, again based on as-built dimensions, were applied across two helium-filled gaps: between the process tube and graphite and between the GSCS tube and graphite. Radiation heat transfer was explicitly modeled across helium-filled regions between the process tube and the graphite blocks. All surfaces were considered gray and diffuse, and symmetry planes were approximated as diffuse reflectors. The helium was considered optically thin, i.e., a nonparticipating media. Except for the exchange between cooled and uncooled filler blocks, radiation exchange was restricted to radial directions. 


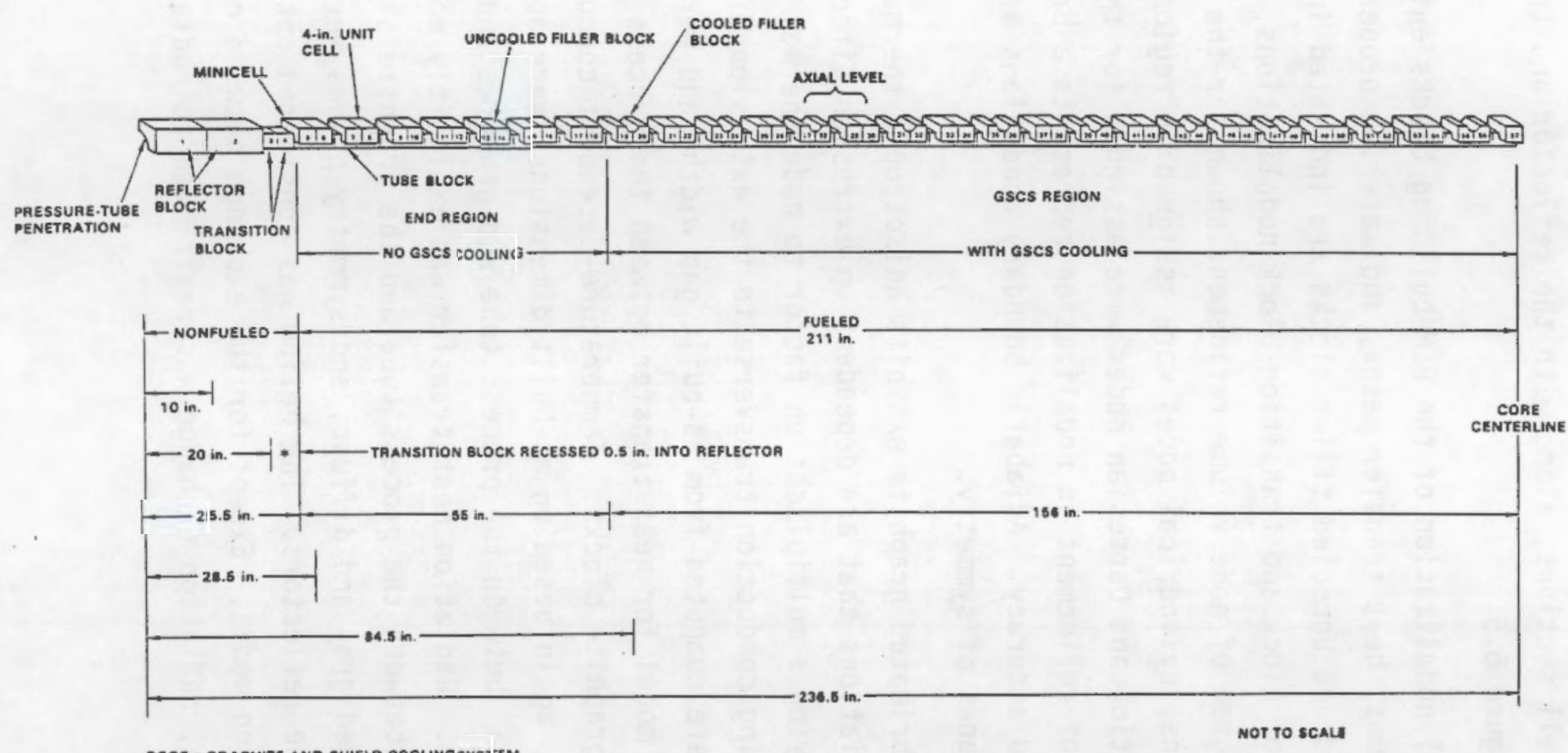

FIGURE 6.5. Axial Segmentation of the Half-Length Process Tube 
Hydrogen evolution was assuned to follow the parabolic kinetics developed by milson et at. (1966) and Baker and Just (1962) for the uranium steam reaction and the Zircaloy steam reaction, respectively. As a conservatism, an unlimited steam supply was assumed available for oxidation. In addition, no convective heat removal was modeled.

Fuel failure, which relates directly to the amount of uranium metal available for oxidation, was determined based on fuel cladding temperatures. A fuel failure temperature of $1900^{\circ} \mathrm{F}$ was chosen based on out-of-pile tests of N Reactor fuel elements. Fuel lengths defined for the HLM corresponded to the node axial lengths, e.9., generally 4 in. N Reactor fuel is actualiy extruded, and cut into 20-in. to 24-in. lengths, however. Fuel failures reported for the HLM, therefore, will not reflect the actual number of ruptured fuel elements. The multitude of fuel loading possibilities complicated the modeling of distinct fuel elements; therefore, the fuel was assumed to be a continuous column with respect to axial conduction, but segmented into axial lengths with respect to fuel failures. Fuel failures of the inner and outer concentric fuel elements were individually tracked. The uranium area accessible for oxidation was maintained at a constant $25 \%$ of the surrounding cladding area.

\subsubsection{Station Blackout Accident Scenario Modeling}

The core coolant system flow transient during the station blackout accident scenario at $N$ Reactor was simulated using RELAP5 (Ranson et al. 1983). The most conservative fluid conditions predicted by the RELAP5 simulation were incorporated into the TRUMP-BD HLM model for the convective modeling of heat transport in the coolant flow passages. The decay heat generation versus time, initial average power, and power deposition were based on a best-estimate data for the "spike region," peak-power tube in the core (the N Reactor fuel loading was segregated into three distinct regions: spike, central, and fringe).

The RELAP5 model predicted three modes of heat removal by the coolant in the flow channel after scram and prior to reflooding of the emergency core cooling system (ECCS); 1) film boiling, 2) nucleate boiling, and then 3) steam cooling. The HLM model was developed to simulate only film boiling and steam cooling; no credit was taken for the temporary return to nucleate boiling. Furthermore, the most conservative conditions predicted by RELAP5 for the 
portions of the transient when steam cooling and film boiling occur were used for the HLM boundary conditions.

The times at which film boiling and steam cooling occur during the transient were determined using RELAP5 plots of vapor void fraction and mass quality for each flow channel of the process tube at the second axial junction. The onset of film boiling (used as time $=0.0$ in the HLM simulation) was assumed to occur at the time at which the void fraction and mass quality initially rise sharply from zero (Appendix C, Figures C.1 through C.3). Using a digitizer, the average time at which this occurred was found to be $114 \mathrm{~s}$. The transition time from boiling to steam cooling was taken as the earliest time at which the void fractions for all three process tube flow channels were simultaneously equal to 1.0. This time was found to be $914 \mathrm{~s}$. after scram.

Mass flow rates predicted by RELAP5 fluctuate dramatically over the transient. Because the HLM models two distinct heat transfer modes (steam cooling and film boiling), constant values of mass flow rates for each channel were obtained from the RELAP5 plots (Figures C.4 through C.6). These mass flow rates were chosen to approximate the value predicted by RELAP5 during the portion of the transient when each flow regime was occurring. Because each process tube in the RELAP5 model is actually equal to 100 tubes, the mass flow rates were first divided by 100 , and then quartered to account for the quarter symanetry used in the HLM.

The least-favorable values of pressure (Figure C.7) and void fraction (Figures C.8 through C.10) were needed for the film boiling portion of the transient. A constant coolant temperature equal to the saturation temperature was used to evaluate fluid properties. These values were used along with the mass flow rate to calculate a single heat transfer coefficient for each flow channel (assumed constant over the process tube length).

Likewise, a least-favorable pressure was used to determine fluid properties needed to calculate stean cooling heat transfer coefficients. It was assumed that the inlet steam temperature was equal to the corresponding saturation temperature. Also, because TRUMP-BO assumes constant fluid density when calculating convective heat transport, steam density was based on the average superheated temperature along the tube length rather than the corresponding saturated value to ensure conservative input. 
Two different film boiling heat transfer correlations (Dougall-Rohsenow 1963, Grenoveld 1969) were examined for application to $\mathbf{N}$ Reactor geometry and thermal-hydraulic conditions. For each correlation, heat transfer coefficients were calculated for each of the three flow channels in the HLM process tube. Film boiling coefficients evaluated from the Dougall-Rohsenow correlation were found to be $\sim 50 \%$ lower than those from Grenoveld. In spite of its less conservative values, the Grenoveld correlation was selected for use in these scoping studies because it was derived in part from horizontal tube data (Dougall-Rohsenow is for vertical orientations only). A sensitivity study was also completed demonstrating that the correlations are most sensitive to the vapor void fraction.

During the steam cooling portion of the transient the Dittus-Boelter correlation was used to calculate a heat transfer coefficient for each channel.

\subsection{DISCUSSION OF TYPICAL INPUT LINES}

Since the model used for the process tube during the station blackout is actually two HLMs, two inputs are used: one for the inlet half, and one for the out let half. The discussion that follows is based on data in the input file (IRSLBOD) that is used for the inlet half of the process tube. A complete copy of this input file is included in Appendix B.

\section{BLOCK 1, Card D}

55
$.989 \dot{2}$

$40 \quad 0.01667$

3

\section{VARIABLE INPUT VALUE COLUMNS \\ IDIAE DESCRIPTION \\ Diagnostic flag; alT TRUMP-BD summary output will be generated and printed to OUTPUT at TIMEP time intervals (Card A).}


VARIABLE INPUT VALUE

$\begin{array}{ll}\text { NCHANS } & 5 \\ \text { FUELR } & 0.9892\end{array}$

NSPOUT $\quad 40$

XSPRNT $\quad 0.01667$

SYMLT $\quad 4$

NAXPO 3

NAXTIM 3
COLUMNS

6-10

$31-40$

$51-60$

$61-70$

$71-80$

$81-85$

$86-90$
DESCRIPTION

The total number of process tube flow regions includes three regions for axial coolant flow channels plus for GSCS flow channels.

The fuel pellet radius is arbitrary as long as PRADIL, the radial power factors for nodes (see typical input in BLOCK 9, Card $H$ below), are computed using the same value for FUELR.

The number of special output nodes is listed on Card $E$.

Every 0.01667 simulation hours summary information and special node temperatures are written to TAPE3 3 and TAPE5, respectively.

The HLM accounts for only one quarter of the process tube. This symmetry multiplier is applied to hydrogen and power generation. variables written to TAPE 3 to give "wholetube" results.

Three special axial nodes, NODEAX(1). NODEAX (2), and NODEAX (3), are listed on Card F. This variable simply tells TRUMP-BD that three are listed.

This variable tells TRUMP-BD that special axial output data, including temperatures of each special axial node in array NODEAX, will be written out at three times,

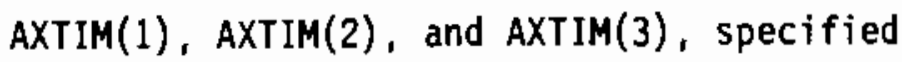
on Card $\mathrm{G}$. 
BLOCK 2, Card A

U-intI I

154

.683

3

VARIABLE INPUT VALUE COLUMMS

AMAT U-MTL

MAT

1

LTABC

15

LTABK

4

LTABP 3

$1-5$

$6-10$
The material identification number for uranium nodes must be 1 for oxidation logic to work.

21-25 Fifteen pairs of values for uranium heat capacity (CAPT) versus temperature (TVARC) are given on Card $\mathrm{E}$. Interpolation between these values will be performed in Subroutine THERM each time step to update uranium heat capacity.

26-30 Four pairs of values of uranium thermal conductivity (CONT) versus temperature (TVARK) are given on Card $F$. Interpolation between these values will be performed in Subroutine THERM each time step to update uranium themal conductivity.

81-85 Three phase changes are specified for uranium on Card $G$. The phase changes will occur at temperatures TMELT, and will have latent heats HMELT. 
BLOCK 4, Card A

$\begin{array}{lllllll}0.00 & 57 & 236.5 & 0 & 0 & 57 & 57\end{array}$

VARIABLE INPUT VALUE COLUMNS

DESCRIPTION

XINTER $\quad 0.00$

11-20

The first axial level is designated to start at $0.00 \mathrm{in}$.

NLEVELS $57 \quad 28-30 \quad$ The total number of axial levels in the HLM is 57 .

BUNDHT $236.5 \quad 31-40 \quad$ The total length of all 57 axial levels is $236.5 \mathrm{in.}$

ILEVFG $0 \quad 49-50$ No boiloff simulation is being modeled; therefore this value is 0 .

NTABL $0 \quad 59-60$ No boiloff simulation is being modeled; therefore this value is 0 .

BLOCK 4, Card D (Reference Figure 6.2)

6200011

.0954

1.0

4. 0

.175

.037

VARIABLE INPUT VALUE COLUMNS

N1

6001

$1-5$

\section{DESCRIPTION}

This is the first node described by this card. Node 6001 is the innermost of two nodes defined for the inner fuel at axial level " 6 ".

NSEQ $\quad 6$

$6-10$

Six additional identical nodes beside 6001 are specified by this card. 


\begin{tabular}{|c|c|c|c|}
\hline VARIABLE & INPUT VALUE & COLUMNS & DESCRIPTION \\
\hline NADD & 2000 & $11-15$ & $\begin{array}{l}\text { The node identification number for each } \\
\text { additional node specified on this card is } \\
\text { incremented by } 2000 \text { over the last value, } \\
\text { i.e., } 8001,10001,12001,14001,16001 \text { and } 18001 \\
\text { are the additional nodes created by TRUMP- } \\
\text { BD after this card. }\end{array}$ \\
\hline NZ & 1 & $16-20$ & $\begin{array}{l}\text { This value identifies nodes described on } \\
\text { this card as being made of uranium, since } \\
\text { the value " } 1 \text { " was used in BLOCK } 2 \text {, Card A } \\
\text { (described above). }\end{array}$ \\
\hline NPRX & 1 & $26-27$ & $\begin{array}{l}\text { Flow region } 1 \text { is the innermost of the three } \\
\text { axial coolant flow regions. In the HLM all } \\
\text { uranium nodes whose identification numbers } \\
\text { end with "001" are for the innermost node } \\
\text { of the inner fuel, and thus are adjacent to } \\
\text { flow region } 1 \text { (see Figure } 6.2 \text { ). } \\
\text { NOTE: BLOCK } 10 \text { input is arranged so the } \\
\text { first flow region read in corresponds to } \\
\text { this one. }\end{array}$ \\
\hline NPN & 1 & $28-30$ & $\begin{array}{l}\text { The inner uranium fuel annulus in the HLM } \\
\text { is defined as pin number "1" (the outer } \\
\text { uranium fuel annulus is pin number "2"). } \\
\text { All fuel and cladding nodes that make up a } \\
\text { given fuel pin should have the appropriate } \\
\text { value of NPN included here. }\end{array}$ \\
\hline DLONG & 0.0954 & $31-40$ & $\begin{array}{l}\text { The node cross-sectional area is } 0.0954 \\
\text { in.2. }\end{array}$ \\
\hline DWIDE & 1.0 & $41-50$ & The assigned node width is $1.0 \mathrm{in}$. \\
\hline DRAD & 4.0 & $51-60$ & $\begin{array}{l}\text { The axial node length } 4.0 \text { in. The product } \\
\text { of DLONG, DWIDE, and DRAD is therefore the } \\
\text { node volume. }\end{array}$ \\
\hline
\end{tabular}




\begin{tabular}{|c|c|c|c|}
\hline VARIABLE & INPUT VALUE & COLUMNS & DESCRIPTION \\
\hline ZRT & 0.175 & $61-70$ & $\begin{array}{l}\text { The oxidation thickness of the node is } \\
\text { measured "radially". }\end{array}$ \\
\hline OXA & 0.037 & $71-80$ & $\begin{array}{l}\text { A geometric factor (in this case, } 10 \% \text { of } \\
\text { the circumferential arc at the cladding- } \\
\text { fuel interface for "001" inner fuel nodes) } \\
\text { used in conjunction with the time-dependent } \\
\text { uranium oxidation area multipliers (BLOCK } \\
\text { 9, Card E) to determine the available } \\
\text { uranium oxidizable area. This area is the } \\
\text { product AXDIST*OXAREAM*OXA. }\end{array}$ \\
\hline
\end{tabular}


BLOCK 5, Card A (Reference Figure 6.2)

\begin{tabular}{|c|c|c|c|}
\hline VARIABLE & INPUT VALUE & COLUMNS & DESCRIPTION \\
\hline NI & 6308 & $1-5$ & $\begin{array}{l}\text { The source node for the first thermal } \\
\text { connection defined by this Card A. }\end{array}$ \\
\hline N2 & 6401 & $6-10$ & $\begin{array}{l}\text { The first sink node (connected to } \mathrm{Nl} \text { ) } \\
\text { described by this Card A. Note that this } \\
\text { card connects the innermost Zircaloy surface } \\
\text { node at a given axial level to its adjacent } \\
\text { innenmost flow channel node. This thermal } \\
\text { connection is used to model heat transport } \\
\text { to the coolant during the steam cooling } \\
\text { portion of the station blackout transient. }\end{array}$ \\
\hline IHEAT & 5 & 11 & $\begin{array}{l}\text { A value of } 5 \text { indicates that HINT for the } \\
\text { thermal connections described on this card } \\
\text { will be variable, with values assigned in } \\
\text { a table in the input (i.e., TRUMP-BD } \\
\text { correlations will not be used to calculate } \\
\text { HINT, as would be the case if IHEAT were 1- } \\
\text { 4). }\end{array}$ \\
\hline NSEQ & 6 & $12-13$ & $\begin{array}{l}\text { Six additional pairs of thermal connections } \\
\text { will be described with this Card } A \text {. }\end{array}$ \\
\hline NADI & 2 & $14-16$ & $\begin{array}{l}\text { The increment between successive values of } \\
\text { NI for each additional thermal connection } \\
\text { described on this card. }\end{array}$ \\
\hline NAD2 & 2 & $17-19$ & $\begin{array}{l}\text { The increment between successive values of } \\
\text { N2 for each additional thermal connection } \\
\text { described on this card. }\end{array}$ \\
\hline
\end{tabular}




\begin{tabular}{|c|c|c|c|}
\hline VARIABLE & INPUT VALUE & COLUMNS & DESCRIPTION \\
\hline NZ & 3 & 20 & $\begin{array}{l}\text { NAD1 and NAD2 will be multiplied by } 10^{N Z} \text {. } \\
\text { Therefore, the six additional thermal } \\
\text { connections described on this card will be } \\
8308-8401,10308-10401, \ldots \text { etc. }\end{array}$ \\
\hline DEL1 & 0.0 & $21-30$ & $\begin{array}{l}\text { Since " } 308 \text { " nodes are Zircaloy surface } \\
\text { nodes, this distance is always zero. } \\
\text { However, because HINT is user specified, } \\
\text { input values of DEL1 and DEL2 are not used. }\end{array}$ \\
\hline DEL2 & 0.0 & $31-40$ & Not used, because HINT is user-specified. \\
\hline DLONG & 0.376 & $41-50$ & $\begin{array}{l}\text { The length of the circumferential arc } \\
\text { described at the interface between the two } \\
\text { nodes is } 0.376 \mathrm{in.}\end{array}$ \\
\hline DWIDE & 4.0 & $51-60$ & $\begin{array}{l}\text { The axial length of the two nodes. The } \\
\text { product of DLONG*DWIDE is the total heat } \\
\text { transfer surface area between the two nodes. }\end{array}$ \\
\hline HINT & 1.e-12 & $61-70$ & $\begin{array}{l}\text { Since film boiling is the heat transfer } \\
\text { mode modeled initially, the HINT for this } \\
\text { connection is initially zero. However, } \\
\text { since zero results in an execution error, } \\
1 . e-12 \text { is used (i.e., a small number). }\end{array}$ \\
\hline NU & -4 & $111-115$ & $\begin{array}{l}\text { HINT values change with time; NU tells TRUMP } \\
\text { to read four pairs of USERH vS. USERT values } \\
\text { from Card } C \text {, which follows this card } \\
\text { inmediately. }\end{array}$ \\
\hline
\end{tabular}


BLOCK 5, Card C

\begin{tabular}{|c|c|c|c|}
\hline $1 . e-12$ & \multicolumn{2}{|r|}{$12=-12$} & \\
\hline
\end{tabular}

As was described in Section 6.2.2, film boiling is modeled during the first portion of the transient (up to $0.220 \mathrm{~h}$ ) in the coolant flow passages. After $0.220 \mathrm{~h}$, steam cooling is modeled. Zircaloy cladding surface nodes are connected in BLOCK 5 to flow nodes for stean cooling phase, and in BLOCK 6 to external boundary nodes for the film boiling phase (see below). Since steam cooling is not modeled at the beginning of the transient, HINT is initially input as zero(a). From the RELAP5 results, steam cooling is predicted to start at 0.220 hours into the transient, and continues for the remainder of the transient (up to 0.801667 hours, the value of TIMAX in BLOCX 1, Card B). HINT during this portion of the transient is therefore reset to the value in the USERH versus USERT table for this time $\left(0.583 \mathrm{Btu} / \mathrm{h}-\mathrm{in} .^{2}{ }^{\circ} \mathrm{F}\right)$.

(a) TRUMP-BD uses a value of $1.0 E-24$ rather than zero to avoid a floating point execution error. 
BLOCK 6, Card B

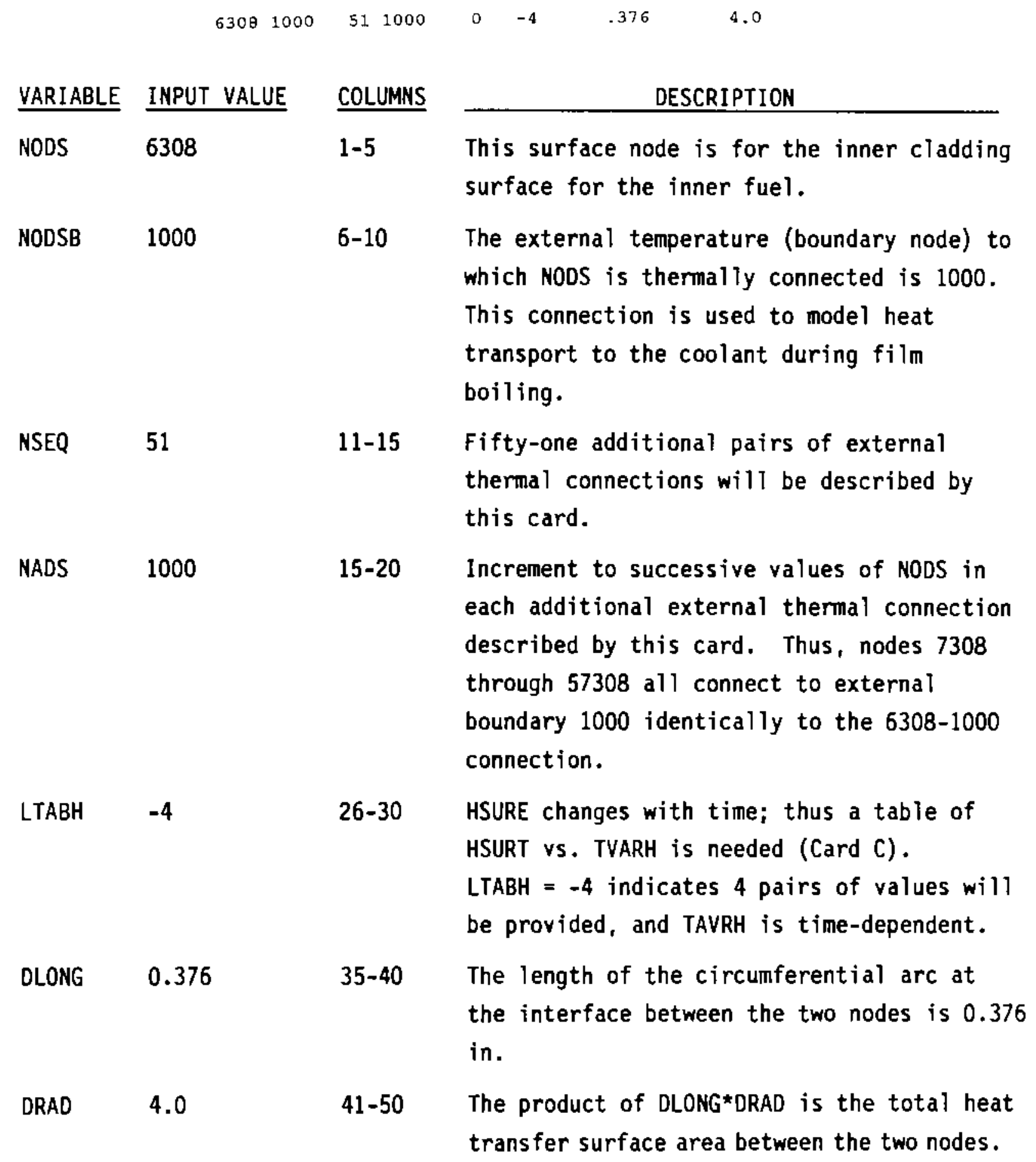


BLOCK 6, Card C

$\begin{array}{llllllll}.172 & 0 . & .172 & .220 & 0 . & .222 & 0 . & 10 .\end{array}$

Film boiling is only modeled during the first portion of the transient by specifying a non-zero HSURT $\left(0.172 \mathrm{Btu} / \mathrm{h}-\mathrm{in} .{ }^{2}{ }^{\circ}{ }^{\circ} \mathrm{F}\right)$ up to $0.220 \mathrm{~h}$, and 0.0 after that time. HSURE is set to these HSURT values at the appropriate times during the simulation. 
BLOCK 7, Card A

External node 3000 is connected to each of zero volume nodes 401,402 , and 403 in BLOCK 6 . These nodes are in turn connected to flow nodes at the first (entering) axial level, 1401, 1402, and 1403, respectively. Through these connections the entering steam temperature into the three HLM coolant flow channels is set at $324.9^{\circ} \mathrm{F}$, the value on the above card. This temperature corresponds to the saturation temperature of the steam at the pressure predicted by RELAP5. 
BLOCK 9, Card C

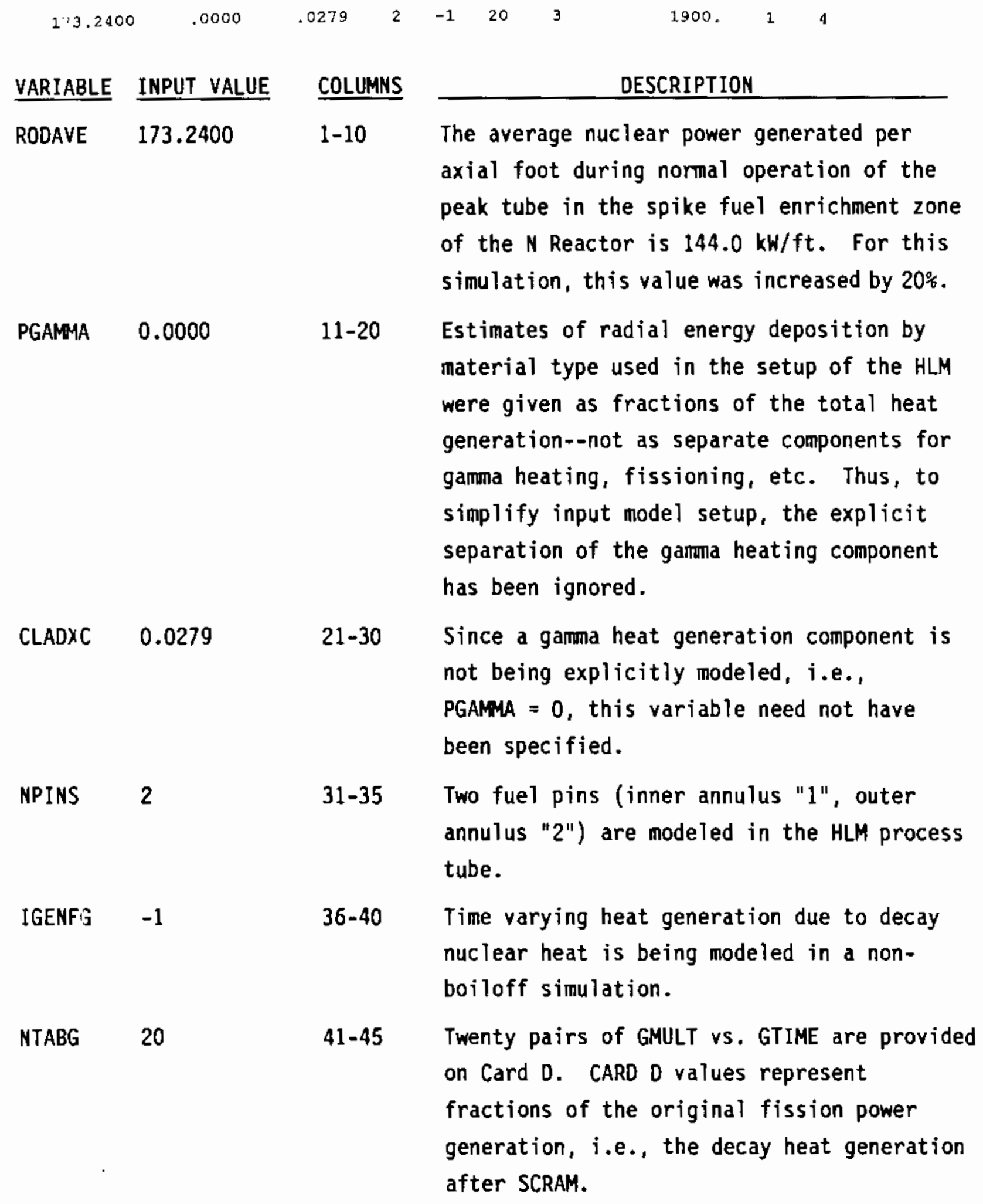




\begin{tabular}{|c|c|c|c|}
\hline VARIABLE & INPUT VALUE & COLUMNS & DESCRIPTION \\
\hline MWCOR & 3 & $46-50$ & $\begin{array}{l}\text { Baker-Just kinetics will be used to model } \\
\text { metal-water reactions of Zircaloy. }\end{array}$ \\
\hline TFAIL & 1900. & $61-65$ & $\begin{array}{l}\text { The assumed failure temperature of fuel } \\
\text { elements is input here. }\end{array}$ \\
\hline NUNL1M & 1 & $66-70$ & $\begin{array}{l}\text { As a conservatism, an unlimited supply of } \\
\text { steam is assumed to be available to any } \\
\text { node undergoing oxidation during the } \\
\text { simulation. }\end{array}$ \\
\hline NOXVAR & 4 & $71-75$ & $\begin{array}{l}\text { Four pairs of OXMULT vs. OXTEMP entries } \\
\text { will be specified on Card } E \text {. Based on the } \\
\text { maximum uranium temperature for each fuel } \\
\text { pin at each axial level, an appropriate } \\
\text { OXMULT value will be interpolated and } \\
\text { applied to uranium nodes after fuel failure } \\
\text { to determine what percentage of the total } \\
\text { available oxidation area for the uranium } \\
\text { node (OXA from BLOCK 4) is available for } \\
\text { oxidation. }\end{array}$ \\
\hline
\end{tabular}

BLOCK 9, Card F

$0 \quad 1.384 \quad 30$

\begin{tabular}{|c|c|c|c|}
\hline VARIABLE & INPUT VALUE & COLUMNS & DESCRIPTION \\
\hline ICOS & 0 & $1-10$ & $\begin{array}{l}\text { Since } I C O S=0 \text {, an axial power profile, } \\
\text { Card } G \text {, must be provided to account for } \\
\text { nuclear heat variation along the axial } \\
\text { length of the HLM process tube. }\end{array}$ \\
\hline PRATIO & 1.384 & $11-20$ & $\begin{array}{l}\text { This variable is only used for problems } \\
\text { with a chopped cosine (ICOS }=1 \text { ) specified } \\
\text { power profile, and could have been omitted } \\
\text { here. }\end{array}$ \\
\hline
\end{tabular}


VARIABLE INPUT VALUE COLUMNS

EZERO -

NTABP $\quad 30$
$21-30$

41-50
DESCRIPTION

This variable is only used for problems with a chopped cosine (ICOS $=1$ ) specified power profile, and therefore has been omitted here.

Thirty points are given in the axial power factor (PMULT) versus axial distance (PHIGHT) table on Card G.

BLOCK 9, Card G
64.50
0.8995
$1.0 \quad 72.50$
1.0358
1.0

The axial distance from each axial level to the HLM inlet is computed using data from BLOCK 4, Card B. By interpolation of these distances in the PMULT versus PHIGHT table specified using Card $G$, the axial power factor for each node is determined(a). Note that variable PINT, given as 1.0 for both locations on the Card $G$ shown above, is used only for boiloff simulations, and could have been omitted here.

BLOCK 9, Card H

$\begin{array}{llllll}5001 & 52 & 1000 & 0 & .8411 & 700 .\end{array}$

\begin{tabular}{|c|c|c|c|}
\hline VARIABLE & INPUT VALUE & COLUMNS & DESCRIPTION \\
\hline NI & 5001 & $1-10$ & Node number. \\
\hline NSEQ & 52 & $11-20$ & $\begin{array}{l}\text { Fifty-two additional inner uranium fuel } \\
\text { nodes have identical initial conditions as } \\
5001 \text {. They are specified using this card. }\end{array}$ \\
\hline NADD & 1000 & $21-30$ & $\begin{array}{l}\text { Increments between successive additional } \\
\text { nodes specified on this card, i.e., nodes } \\
6001,7001 . .57001 \text { will be assigned } \\
\text { conditions identical to } 5001 \text { in this case. }\end{array}$ \\
\hline
\end{tabular}

(a) Shown on the sample input line above are PMULT values of 0.0 (unfueled region) at PHIGHT locations 0.00 and $26.20 \mathrm{in}$. 


\begin{tabular}{|c|c|c|c|}
\hline VARIABLE & INPUT VALUE & COLUMNS & DESCRIPTION \\
\hline NGAM & 0 & $31-40$ & Gamma heating is not explicitly modeled. \\
\hline PRADIL & 0.8411 & $41-50$ & $\begin{array}{l}\text { The radial power factor accounts for the } \\
\text { portion of the total nuclear heat that is } \\
\text { produced in node "001" at each axial level. }\end{array}$ \\
\hline TXY & 700 & $51-60$ & $\begin{array}{l}\text { This initial temperature is based on data } \\
\text { that provide an estimate of inner uranium } \\
\text { fuel temperatures during normal (non- } \\
\text { accident) operating conditions. }\end{array}$ \\
\hline
\end{tabular}

To simplify input file creation, variables AX and NPCX are omitted from Card $H$ because no phase changes have occurred prior to the start of the simulation. Therefore, TRUMP-BD initializes their values as zero.

\section{Calculation of PRADIL}

Using the value of FUELR input in BLOCK 2, Card D, the radial power factor, PRADIL, is calculated using

$$
\text { PRADIL }=\left[P I *\left(F U E L R^{\star \star 2}\right) \star 0.26 \%\right] / A
$$

where $\quad P I=3.141593$

$$
\begin{aligned}
& 0.26 \% \text { fraction of total nuclear heat deposited in the inner fuel } \\
& \text { annulus } \\
& A= \text { radial cross-sectional area of inner fuel }\left(0.9544 \mathrm{in}^{2}\right. \text { ) } \\
&\text { FUELR = fuel pellet radius (specified in BLOCK } 1 \text {, Card } D) .
\end{aligned}
$$


BLOCK 10 , Card B

$\begin{array}{ll}-1 & 0\end{array}$

VARIABLE INPUT VALUE COLUMNS

IMASFG -I

HFLAG 0
$1-2$

5
DESCRIPTION

The problem has no boiloff, and uses TRUMP$B D$ logic to specify flow regions. Thus, IMASFG $=-1$.

Hydrogen blanketing of oxidizing nodes will not be modeled. Because NUNLIM $=1$ in BLOCK 9, Card C and HFLAG $=1$, the supply of steam to fuel oxidizing nodes is assumed continuous and unlimited.

BLOCK 10, Card D

VARIABLE INPUT VALUE

IBOLRGN 0

MASFLG -1

XMDOX $\quad 20.43$
COLUMNS

1-5

$6-10$

$11-20$

\section{DESCRIPTION}

The flow region is a non-boiloff region. A user specified flow rate for this flow region (XMDOX) will be used by TRUMP-BD. From RELAP5 data for the innermost axial coolant flow channel, the average flow rate during the steam cooling portion of the transient is $20.43 \mathrm{lbm} / \mathrm{h}$. 


BLOCK 10, Card F
VARIABLE INPUT VALUE
NODF1 4010001000


VARIABLE INPUT VALUE COLUMNS

DELF2 $\quad 1.0$

The weighting factor for the differencing scheme used by TRUMP-BO for NODF2. As specified here, a central differencing scheme will be employed, since the two are weighted equally.

\subsection{SIMULATION RESULTS}

A brief discussion of the results from the inlet and outlet simulations is presented below.

\subsubsection{Inlet Half}

The primary concern in the station blackout simulation is the peak temperatures. Because of the high heat generation rates in (and relatively slow heat transfer paths from) the fuel annuli, the peak temperatures during the transient were found to always occur in the fuel or its associated cladding. A temperature history of the inlet half of the process tube, generated using data written to TAPE5 during execution (see Appendix B, TAPE5.0D), is given in Figure 6.6 for inner and outer fuel annuli at axial leve's 44 and 57. Axial level 44 corresponds to the location of peak power generation along the length. Because the coolant saturation temperature and heat transfer coefficients remained constant along the entire length of each flow channel during film boiling, the peak temperatures for the first portion of the transient were found to occur at level 44.

Axial level 57 is the exit from the inlet half (i.e., the midpoint of the entire process tube). Nuclear heat generation is lower at this level than at leve 144 , so temperatures at this level are lower during film boiling. During steam cooling, the steam is heated to progressively higher temperatures as it travels down the flow channels. These higher steam temperatures act to shift the location of the peak temperatures to level 57 during the steam cooling.

This shift in peak temperature is better demonstrated by Figure 6.7 , which compares the axial variation in outer fuel node temperature at three different 


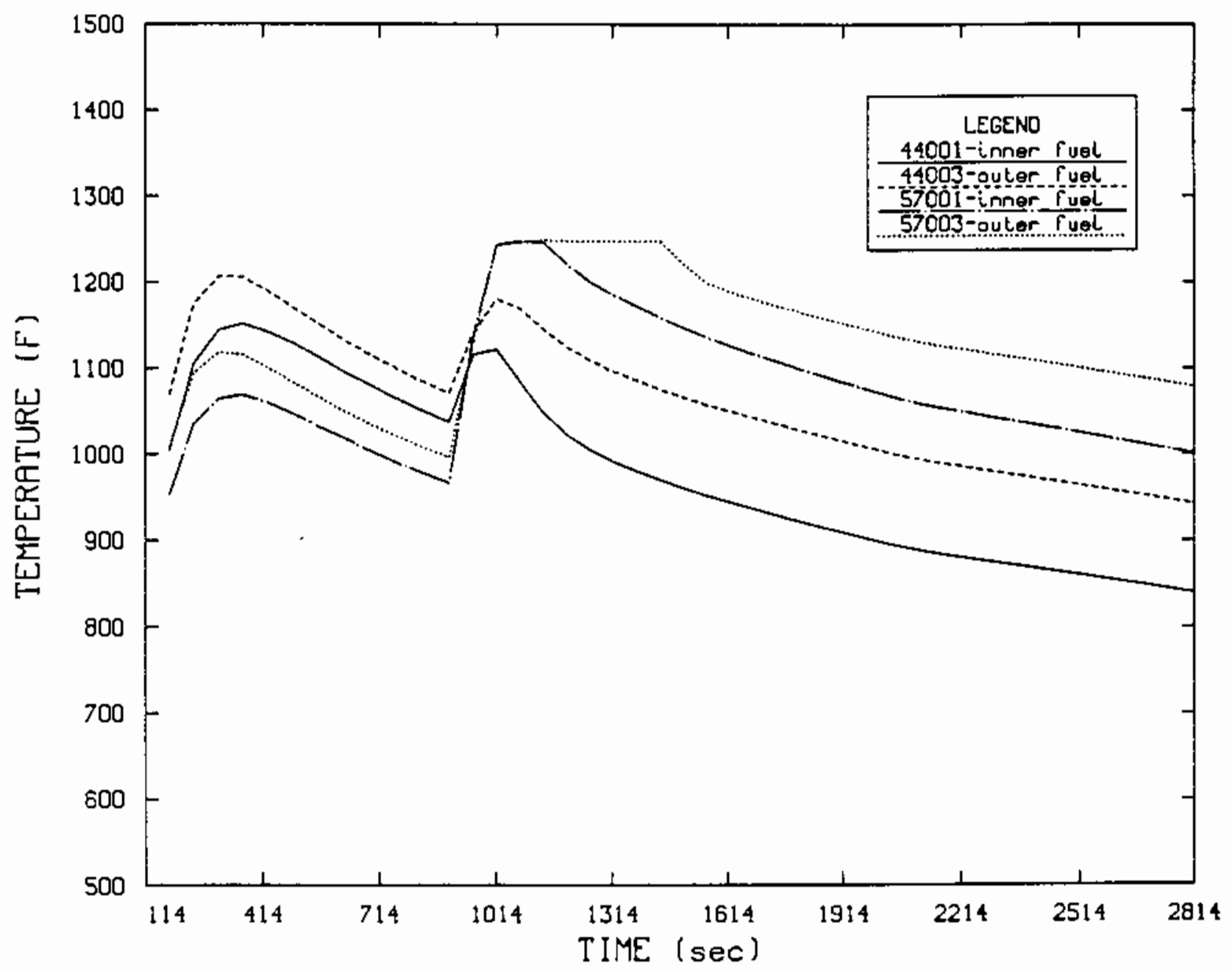

FIGURE 6.6. Inner and Outer Fuel Predicted Temperature Histories at Axial Levels 44 and 57--N Reactor Station Blackout (Inlet Half) 


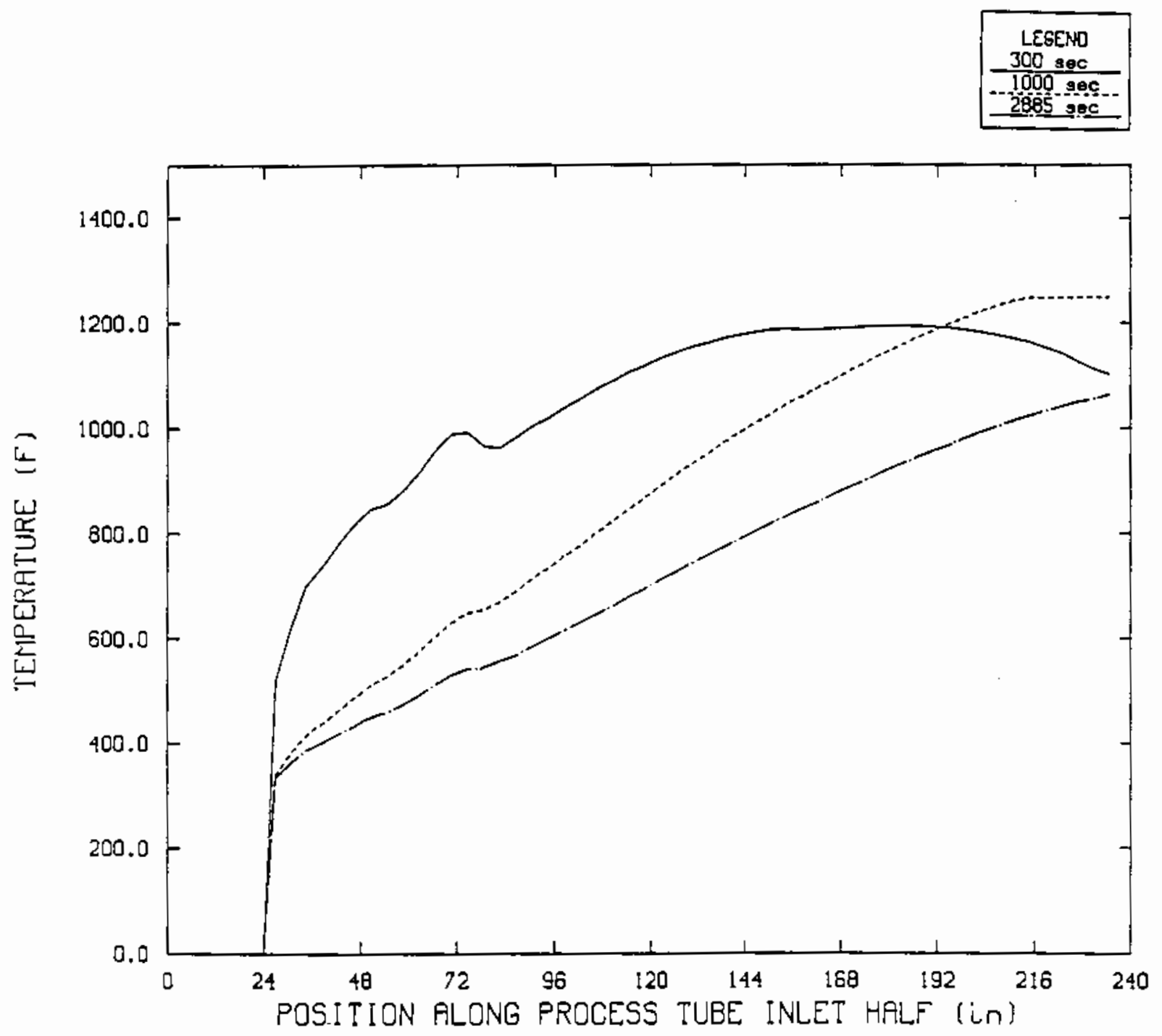

FIGURE 6.7. Outer Fuel Predicted Axial Temperature Distribution at 500, 1000, and $2886 \mathrm{~s}=-\mathrm{N}$ Reactor Station Blackout (Inlet Half) 
times during the transient; $500 \mathrm{~s}$. (film boiling), $1000 \mathrm{~s}$. (just after steam cooling begins), and seconds (end of transient). This plot was generated from data written to TAPE11 during execution, a copy of which is included in Appendix B as TAPE11.0D.

During both film boiling and steam cooling positions of the transient, peak temperatures occur early and then gradualty descend. This rollover occurs because of the continual decay in nuclear heat generation as the simulation progresses.

Excerpts from the OUTPUT file are in Appendix B as OUT.0D. Included in OUTPUT are portions of the processed INPUT from file IRSLBOD, and results for the first time step $(K C Y C=1)$, the final time step and the final system summary.

\section{4 .2 outlet Half}

Inlet steam temperatures during steam cooling for the outlet half of the process tube varied, based on temperatures leaving the inlet half. Thus, the results for the inlet half were inserted directly into BLOCX 6 of file IRSLBOF, used as the INPUT file for the outlet half simulation (see Appendix $B$ for a copy of file IRSLBOF).

Temperature histories for the peak inner and outer fuel elements for the outlet half model (IRSLBOF) are given in Figure 6.8. As can be seen when comparing Figure 6.8 with 6.6 , peak temperatures are higher during steam cooling in the outlet half of the process tube than in the inlet half. This is due to the high temperatures of steam entering the outlet half.

As can be seen in Figure 6.8, fuel temperatures in the outlet half exceed $1300^{\circ} \mathrm{F}$ during much of the steam cooling portion of the transient. Thus, TRUMP-BD metal-water reaction logic is used for this simulation to model Zircaloy oxidation (see Section 3.5.2.1) in the pertinent nodes. Time histories depicting the integrated hydrogen production and the hydrogen production rate (single process tube) associated with this oxidation are given in Figures 6.9 and 6.10 , respectively. These figures were generated using data written to TAPE3 during execution, stored as TAPE3.0F in Appendix B. 


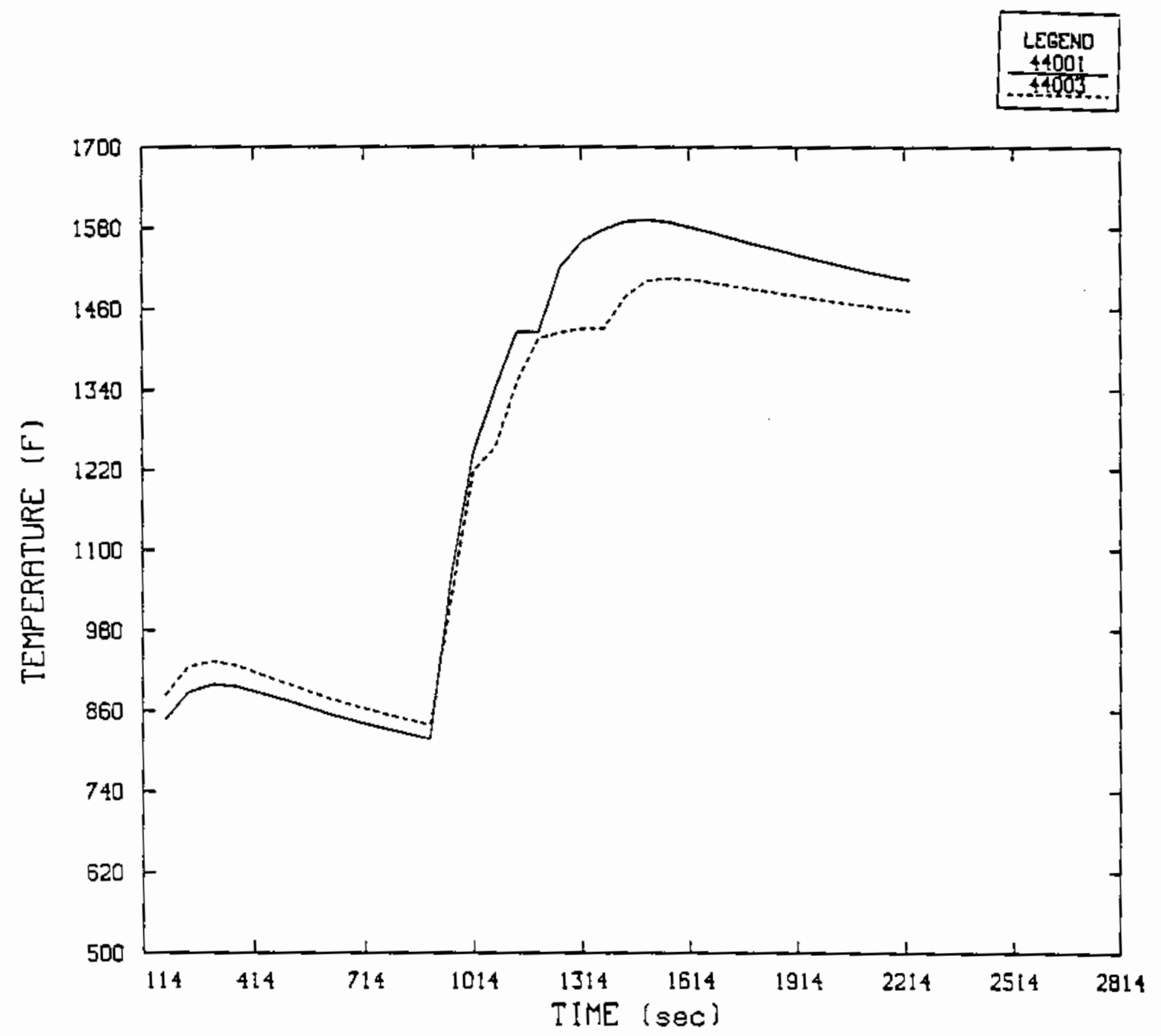

FIGURE 6.8. Peak Inner and Outer Fuel Predicted Temperature Histories-N Reactor Station Blackout (Outlet Half) 


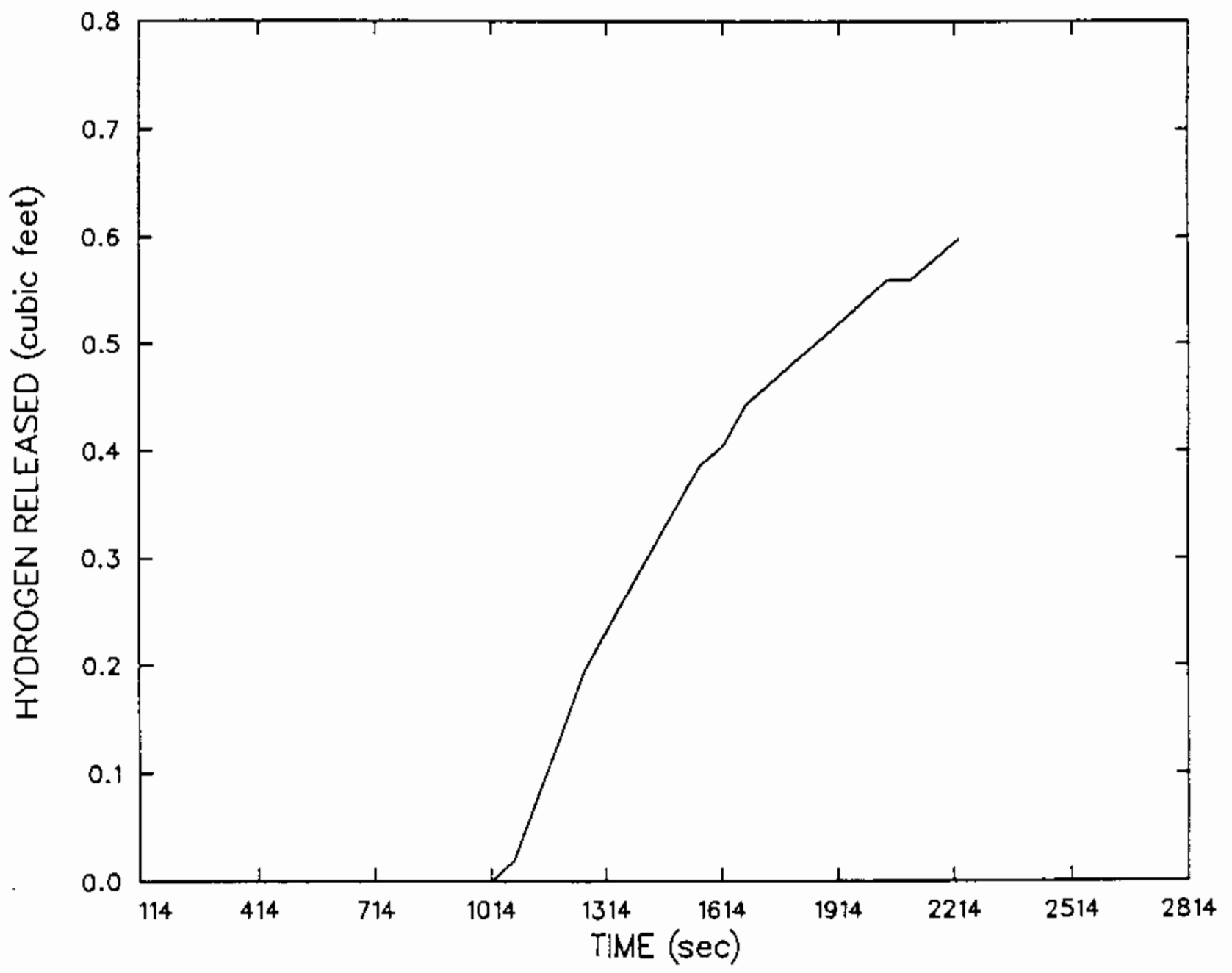

FIGURE 6.9. Predicted Hydrogen Released--N Reactor Station Blackout (Outlet Half) 


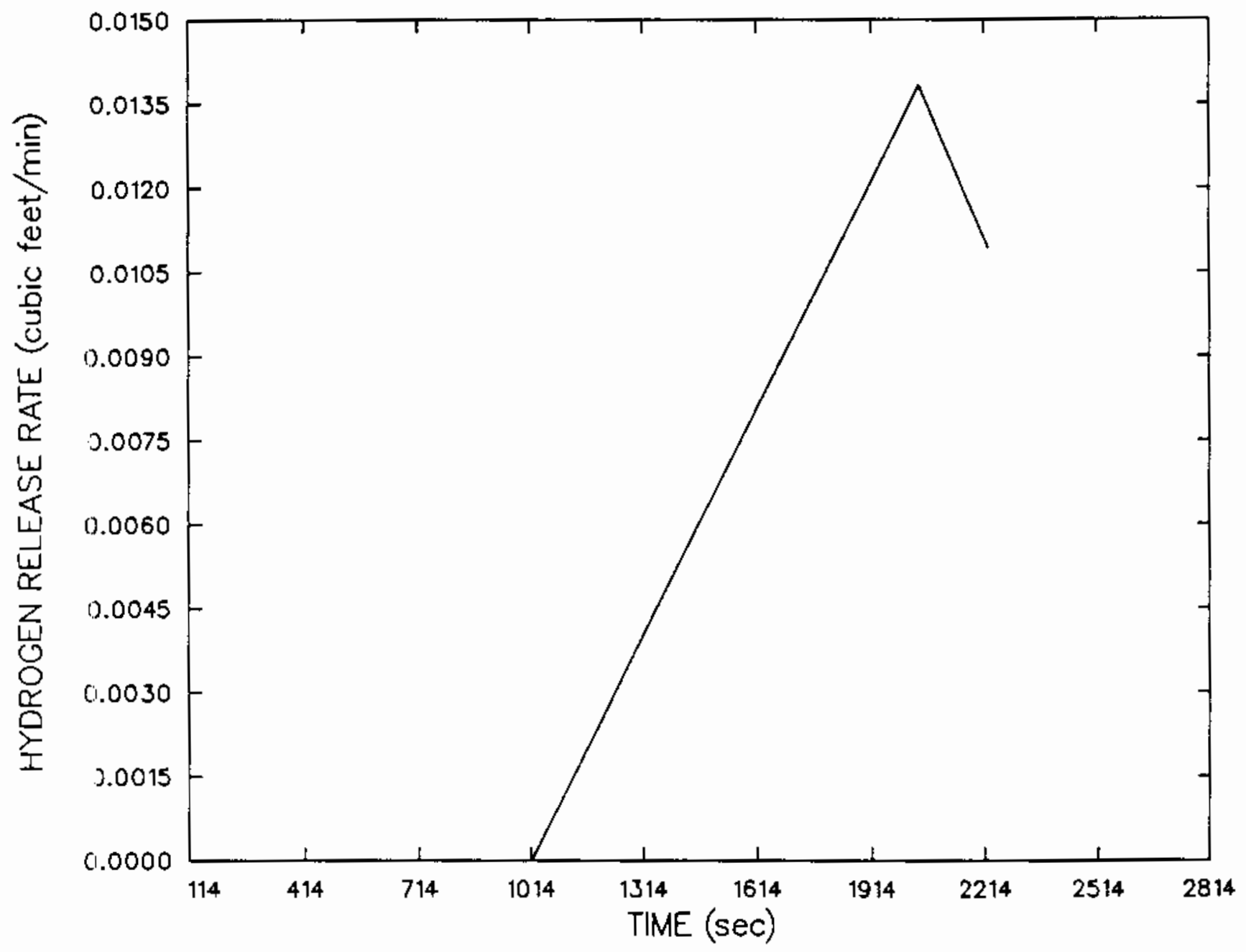

FIGURE 6.10. Predicted Hydrogen Release Rate--N Reactor Station Blackout (Outlet Half) 


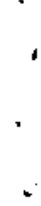




\subsection{CODE VALIDATION}

TRUMP-BD predictions have been assessed against a fairly limited data set; however, the assessment has included key aspects of the code's predictive capabilities. The primary use of the TRUMP-BD code has been for safety analysis and test operational guidance for the Coolant Boilaway and Damage Progression Program (Lanning et a1. 1986 a, b, c; Hesson et al. 1985), an internationally sponsored series of tests investigating the behavior of severe accidents in LWRs. These tests are conducted in the National Research Universal (NRU) Reactor, Nuclear Laboratories, Chalk River, Canada, as part of the U.S. Nuclear Regulatory Commission's Severe Fuel Damage/Source Term Program. The code is currently being used for safety analysis and test operations conducted for Full-Length High-Temperature Experiment 6, expected to be performed in the future, in the NRU Reactor.

The code modifications made to create TRUMP-BD were made as required to perform the thermal-hydraulic and safety analyses for the various programs and were not part of a major effort to develop a code for public release and use. Therefore, there has been no concerted effort to perform extensive validation assessments as might be required for licensing-related programs. The validation assessments that have been performed involve comparisons of several pre- and post-test predictions with actual NRU test data(a). This evaluation is required by the Canadian Nuclear Safety Advisory Committee (NSAC) prior to granting approval for conducting future experiments in the NRU Reactor. In addition, the NSAC committee as well as the staff from the Nuclear Safety and Technology Branch at the Chalk River Nuclear Laboratories, perform a detailed review of the code predictions of the experiment prior to granting approval. This review focuses on several key parameters calculated by the code:

- peak cladding temperature and cladding temperature distributions as a function of time

- hydrogen release rate and integrated release

- chemical energy release

- component temperatures and radial heat loss rate

(a) Tests MT-4A, FLHT-2, FLHT-4. 
- thickness of metal consumed

- bundle exit hydrogen fraction

- coolant boilaway rate and liquid level.

Approval for all proposed tests have been granted by NSAC based on evaluation of the code predictions, which includes the comparison with previous test data, and additional safety analysis. In general, the code pre-test calculations have been successful in predicting the behavior of these complex integral fuel damage tests. Overall, the predictions are conservative relative to the test data. The formal review process required for approval for testing in the NRU Reactor should be considered as part of the validation assessment. 


\subsection{CODE DIMENSIONING}

The TRUMP-BD code, with minor exceptions, is dimensioned with FORTRAN PARAMETER statements. Parameter values are assigned in the main program and every subroutine. The PARAMETER statements precede all array dimension declarations within the main program and subroutines. The variables designated as parameters in TRUMP-BD have short implicit integer variable names (2 to 3 letters/numbers) beginning with the letter " $m$ ". Once assigned within a program or subroutine a parameter value may never be reassigned during execution. To limit the number of parameters to a minimum, arrays with similar dimensioning requirements are sized according to a single comon parameter. For example, the parameter $m 4$ that defines the maximum number of nodes is an appropriate dimension limit for the array that corresponds node index with node number and the arrays that contain the node dimensions. The current version of TRUMP-BD uses the parameters numbered sequentially from $\mathrm{ml}$ to $\mathrm{ml5}$, the parameters alphabetically sequenced from ma to me and $\mathrm{mg}$ to $\mathrm{ml}$, and the parameter $\mathrm{mg}$. Generally, the parameters numbered $m l$ to $m 12$ relate to their respective input block numbers. That is, parameter $m 4$ defines the maximum number of nodes-information read in through BLOCK 4 input.

The size of the entire data field in the current version of TRUMP-BD equals 683,430 words, wherein the dimensioned arrays account for 630,170 words. The dimensioned arrays, therefore, currently occupy $92.2 \%$ of the data memory. Proper selection of parameter sizes to fit the specific problem will result in efficient code execution in terms of memory requirements. Efficient memory declarations translate directly into computer cost savings because most computer billing algorithms include surcharges on excessive memory use.

The following is a brief description of each of the parameters used in TRUMP-BD to dimension arrays. Throughout the TRUMP-BD code, various variables are checked to protect the user from under-dimensioning a problem with respect to the input requirements. These checks are reserved for rather gross dimensioning errors. It is possible to oversize minor parts of the program without being detected by a parameter check. Generally, if a problem size error is found in a parameter check, the parameter, a "KWIT" number, and the input BLOCK number will be written to the output file and the program execution halted. A listing of parameters, their current assigned value, and a sumary 
of the various checks performed with each parameter is presented in Table 8.1. This survey should prove valuable in tracking down dimensioning problems that are identified with a parameter check. the following situation illustrates a parameter check.

Parameter $m 4$, which defines the maximum number of nodes, was assigned a value of 50. An input file was created with 106 nodes in BLOCK 4. The parameter check for $m 4$ in subroutine THERM would find that $106>50$, assign a "KHIT" number of 11, write "MORE THAN ALLOWED--50 ITEMS IN BLOCK 4," and halt program execution. A "KWIT" number of 11 informs the user that there is a problem with the input data. To remedy this particular error, the parameter m4 would need to be increased to at least 106, although some margin, e.g., 20\%, is desirable to prevent the necessity for recompilations for small variations in the problen dimensions. 
TABLE 8.1. Parameter Descriptions

ml: Defines: plot times to a terminal screen; currentiy inactive. Current value: 1

Parameter checks: none

m2: Defines: the maximum number of material types.

Current value: 10

Parameter checks: number of materials $>m 2$

subrout ine THERM, KWIT $=11$, BLOCK 2

$\mathrm{m3}$ : Defines: the maximum number of reactants; currently inactive. Current value: 1

m4: Defines: the maximum number of nodes.

Current value: 1801

Parameter checks: number of nodes $>\mathrm{m} 4$

subroutine THERM, KWIT $=11$, BLOCK 4

number of initial conditions $>\mathrm{m} 4$

subroutine TALLY, KWIT $=11$, BLOCK 9

number of axial levels $>m 4$

subroutine TALLY, KWIT $=11$, BLOCK 9

m5: Defines: the maximum number of internal thermal connections. Current value: 4201

Parameter checks: number of internal thermal connections $>m 5$ subroutine FINK, KWIT $=11$, BLOCK 5

m6: Defines: the maximum number of external themal connections. Current value: 300

Parameter checks: number of external thermal connections > m6 subroutine SURE, KHIT $=11$, BLOCK 6

m7: Defines: the maximum number of boundary nodes.

Current value: 8

Parameter checks: number of boundary nodes $>\mathrm{m} 7$

subrout ine SURE, KHIT = 11, BLOCK 7

m8: Defines: the maximum number of nodes with variable internal

heat generation.

Current value: 200

Parameter checks: number of nodes with variable heat generation $>m 8$ subrout ine GEN, KWIT $=11$, BLOCK 8 
m9: Defines: the maximum table lengths in BLOCKs 2, 3,6, 7, 8, and 10; currently inactive for dimensioning arrays but actively used in parameter checks (see mg below). Current value: 120

Parameter checks: conductivity table length $>m 9$ subrout ine THERM, KWIT $=12$, BLOCK 2

capacitance table length $>m 9$ subroutine THERM, KWIT $=12$, BLOCK 2

internal heat generation table length $>\mathrm{m} 9$ subroutine GEN, KWIT $=12$, BLOCK 8

variable mass flow rate table length $>m 9$ subroutine FLOW, KWIT $=12$, BLOCK 10

variable external convection coefficients table $>\mathrm{m} 9$ subroutine SURE, KWIT $=12$, BLOCK 6

variable external temperature table length $>m 9$ subroutine SURE, KWIT $=12$, BLOCK 7

m10 or ma: Defines: the maximum number of mass flow connections. m10 is used in parameter checks, whereas ma is used for dimensioning arrays. Current value: 251

Parameter checks: number of flow regions $>$ m10 subroutine FLOW, KWIT $=11$, BLOCK 10

m1l or mb: Defines: the maximum number of flow regions. mil is inactive, whereas $\mathrm{mb}$ is used for dimensioning arrays. Current value: 10

Parameter checks: none

m12 or mc: Defines: the maximum number of axial levels and the number of nodes with properties dependent on remote temperatures. $\mathrm{ml} 2$ is related to the nodes with properties dependent on remote temperatures, whereas $\mathrm{mc}$ is related to the number of axial leveis. Current value: 60 Parameter checks: number of nodes with properties dependent on remote temperatures $>\mathrm{ml2}$ subroutine THERM, KWIT $=11$, BLOCK 12 number of axial levels > mc subroutine THERM, KWIT $=5$, BLOCK 4 
m13 or md: Defines: the maximum number nodes with oxidation potential. m13 is used for parameter checks, whereas mo is used for dimensioning arrays. Current value: 700

Parameter checks: number of oxidizable nodes $>$ m13 subrout ine THERM, KWIT = 11, BLOCK 4

m14 or me: Defines: the maximum number of internal connections with variable heat transfer coefficients. m14 is used for parameter checks, whereas me is used to dimension arrays. Current value: 501

Parameter checks: number of variable internal connections $>$ m14 subroutine FINK, KHIT $=11$, BLOCK 5

m9 or $\mathrm{mg}$ : Defines: the maximum number of points in a table (see $\mathrm{mg}$ ). $\mathrm{mg}$ is used strictly for parameter checks, whereas $\mathrm{mg}$ is used to dimension arrays. Current value: 120

Parameter checks: (see $\mathrm{mg}$ for table length checks)

mh: Defines: the maximum number of fuel pins.

Current value: 10

Parameter checks: none

mi: Defines: the maximum number of coolant flow channels.

Current value: 8

Parameter checks: none

mj: Defines: the maximum number of special output nodes.

Current value: 80

Parameter checks: none

mk: Inactive.

Current value: 80

Parameter checks: none

$\mathrm{mn}$ : Defines: the maximum number of fuel fission products.

Current value: 10

Parameter checks: number of fission products $>$ mn subroutine FISPROD, KWIT = 5, BLOCK 13

ml: Defines: the maximum number of either uranium or zircaloy nodes adjacent to each flow region at each axial level.

Current value: 4

Parameter checks: none 



\subsection{REFERENCES}

Baker, L., and L. C. Just. 1962. Studies of Metal-Water Reactions at High Temperature; Experimental and Theoretical Studies of Zirconium-Water Reaction. ANL-6548, Argonne National Laboratory, Argonne, Illinois.

Birney, K. R., and A. H. Cronenberg. 1988. 0xidation of N Reactor Fuel Under High-Temperature Accident Conditions. WHC-SP-0017-2, Westinghouse Hanford Company, Richland, Washington.

Birney, K. R., D. B. Bechtold, and T. B. McCall. 1988. Correlations for Fission Product Release from $N$ Reactor Fuel Under High-Temperature Accident Conditions. WHC-SP-0017-3, Westinghouse Hanford Company, Richland, Washington.

Birney, K. R. and A. W. Cronenberg. 1988. Oxidation of $N$ Reactor Fuel Under High Temperature Accident Conditions. WHC-SP-0017-2, Westinghouse Hanford Company. Richland, Washington.

Cunningham, J. P., and H. C. Yeh. 1973. "Experiments and Void Correlation for PWR Small-Break LOCA Conditions." Trans. Am. NuCl. Soc. 17:269

Cathcart, J. V., et al. 1977. Summary Zirconium Metal-Water Oxidation Kinetics IV. ORNL/NUREG-17, 0ak Ridge National Laboratory, Oak Ridge, Tennessee.

Dougall, R. S., and W. M. Rohsenow. 1963. Film Boiling on the Inside of Vertical Tubes with Upward Flow of the Fluid at Low Qualities. MIT Report Number 9079-26, Massachusetts Institute of. Technology, Cambridge, Massachusetts.

Edward, A. L. 1972. TRUMP: A Computer Program for Transient and SteadyState Temperature Distributions in Multi-Dimensional Systems. UCRL-14754 REV 3, Lawrence Livermore Laboratory, Livermore, California.

Groeneveld, D. C. 1969. An Investigation of Heat Transfer in the Liquid Deficient Regime. AECL-3281.

Heard, F. J., D. M. Ogden, N. J. Lombardo, and M. D. White. 1987. N Reactor Safety Enhancement--Final Report--Hydrogen Generation and Therma I Analysis for the Hydrogen Mitigation Design Bas is Accident. HEDL-TC-2677/UN1-4472, UNC Nuclear Industries, Richland, Washington.

Hesson, G. M., et a]. 1985. Coolant Boilaway and Damage Progression Program Full Length High Temperature Tests--Final Safety Analys is for FLHT-2 Experiment. PNL-5547, Pacific Northwest Laboratory, Richland, Washington.

Lanning, D. D., and N. J. Lombardo. 1987. Final Safety Analysis Report for Full Length High Temperature Experiment 5. PNL-6117, Pacific Northwest Laboratory, Richland, Washington. 
Lanning, D. D., G. M. Hesson and N. J. Lombardo. 1986a. Full-Length HighTemperature Tests--Preliminary Safety Analys is for FLHT-4 Experiment.

PNL-5770, Pacific Northwest Laboratory, Richtand, Washington.

Lanning, D. D., and N. J. Lombardo. 1986b. Final Safety Analysis Report for Fu17-Length High-Temperature Experiment 4. PNL-5869, Pacific Northwest Laboratory, Richland, Washington.

Lanning, D. D., and N. J. Lombardo. 1986c. Preliminary Safety Analys is Report for Full-Length High-Temperature Experiment 5 . PNL-5949, Pacific Northwest Laboratory, Richland, Washington.

Prater, J. T., and E. L. Courtright. 1986. High Temperature 0xidation of Zircaloy 4 in Steam and Steam/Hydrogen Environments. PNL-5558, NUREG/CR-4476, Pacific Northwest Laboratory, Richiand, Washington.

Parker, G. W. and C. J. Barton. 1973. "Fission-Product Release." Chapter 18 of The Technology of Nuclear Reactor Safety, Vo1. 2, "Reactor Materials and Engineering," edited by T. J. Thompson and J. G. Beckerley, the MIT Press, Cambridge, Massachusetts, pp. 525-618.

Ranson, V. H., et al. 1983. RELAP5/M0D2 Code Manual. EG\&G-SAAM-6377, Idaho National Engineering Laboratory, Idaho Falls, Idaho.

Urbanic, V. F., and T. R. Heidrick. 1978. "High Temperature 0xidation of Zircaloy-2 and Zircaloy-4 in Stean." J. Nucl. Mater. 75:251.

Wilke, C. R. 1950. J. Chem. Phys. 18:517-519.

Wilson, J. F., R. T. Grenda and J. F. Patterson. 1962. "The Velocity of Rising Steam in a Bubbling Two-Phase Mixture." Trans. Am. Nucl. Soc. 5:151-152.

Wilson, R. E., et al. 1966. "Geothermal Reaction of Uranium with Steam Between 400 and $1600^{\circ} \mathrm{C}$." Nuclear Science and Engineering. 25(2):109-115.

Wong, S. and L. E. Hochreiter. 1981. Analys is of the FLECHT-SEASET Unblocked Bundle Stean Cooling and Boiloff Tests. NUREG/CR-1533, EPRI NP-1460, Electric Power Research Institute.

Zuber, N., and J. A. Findlay. 1965. "Average Volume Concentration in TwoPhase Flow Systens." ASME J. of Heat Transfer. pp. 453-468. 
APPENDIX A

VARIABLE GLOSSARY 
APPENDIX A

VARIABLE GLOSSARY

\begin{tabular}{|c|c|}
\hline$A(m 4, m 2)$ & Mass fraction of lower temperature phase. \\
\hline $\mathrm{AA}(\mathrm{m} 4, \mathrm{~m} 2)$ & Temporary input value of $A(m 4, m 2)$. \\
\hline$A C(m n)$ & $\begin{array}{l}\text { Constant used in computing vapor pressure for each fission } \\
\text { product. }\end{array}$ \\
\hline ACONST & Oxidation kinetics constant. \\
\hline ADD & $\begin{array}{l}\text { Difference between successive values of DRAD in a sequence } \\
\text { of nodes or connections produced by NSEQ. }\end{array}$ \\
\hline ALONE: & Default input value of $A(m 4, m 2)$. \\
\hline AMAT (m2) & Descriptive name for material with number $\operatorname{MAT}(\mathrm{m} 2)$. \\
\hline AOUT $(\mathrm{mj})$ & Special output of mass fraction of lower temperature phase. \\
\hline AREAim5) & $\begin{array}{l}\text { Interface Area Between } N O D 1(m 5) \text { and } N 002(m 5) \text {, equals } \\
\left(G E O M^{\star} D L O N G^{\star} D R A D^{\star \star K S Y M}\right){ }^{\star S C A L E^{\star *}} 2 \text {. See } K D \text {. }\end{array}$ \\
\hline AREAS $(m 6)$ & $\begin{array}{l}\text { Area of NODS }(m 6) \text { exposed to boundary node } \operatorname{NODSB}(m 6) \text {, equals } \\
\left(G E O M^{\star} D L O N G^{\star} D R A D^{\star \star K S Y M}\right)^{\star} S C A L E^{\star \star 2} \text {. See } K D \text {. }\end{array}$ \\
\hline AREAV (me) & $\begin{array}{l}\text { bridged effective heat transfer area (in. }{ }^{2} \text { ) for a variable } \\
\text { thermal connection. }\end{array}$ \\
\hline $\operatorname{AVEDX}(\mathrm{mc})$ & $\begin{array}{l}\text { Average (mean) thickness of all oxidizing Zircaloy nodes } \\
\text { indexed by axial level (in.). }\end{array}$ \\
\hline AVEUDX (mc) & $\begin{array}{l}\text { Average (mean) thickness of all oxidizing uranium nodes } \\
\text { indexed by axial level (in.). }\end{array}$ \\
\hline$A X$ & Temporary value of $A(m 4, m 2)$. \\
\hline $\operatorname{AXDIST}(m \mathrm{mc})$ & Node axial length (in.). \\
\hline AXDISTM & Node axial length in meters. \\
\hline AXMG & $\begin{array}{l}\text { User defined power multiplier, applied to nodes above the } \\
\text { dryout front, boiloff simulations only. }\end{array}$ \\
\hline $\operatorname{AXTIM}(\mathrm{m} 2)$ & $\begin{array}{l}\text { Times during simulation at which axial plot data is to be } \\
\text { written to TAPE } 11 \text { (see BLOCK 1). }\end{array}$ \\
\hline $\operatorname{AXTIMS}(m 2)$ & Same as $\operatorname{AXTIM(m2).}$ \\
\hline
\end{tabular}




\begin{tabular}{|c|c|}
\hline$B(m n)$ & $\begin{array}{l}\text { Constant used in computing vapor pressure for each fission } \\
\text { product. }\end{array}$ \\
\hline BCONST & Oxidation kinetics constant. \\
\hline BET & Value of a tabulated property, used to find change. \\
\hline BIG & Constant, with value $0.99999999 \mathrm{E} 12$. \\
\hline BUNDHT & Model height (length) (in.). \\
\hline$C(m n)$ & $\begin{array}{l}\text { Constant used in computing bake-out conductance variable } \\
\text { HBAKE }(m 4, m n) \text { for each fission product. }\end{array}$ \\
\hline $\operatorname{CAP}(m 4)$ & Heat capacity of $\operatorname{NODE}(m 4)$ at temperature $T(m 4)$. \\
\hline CAPMS & Total heat capacity of a material. \\
\hline CAPS & Total heat capacity of system. \\
\hline CAPT $(m g, m 2)$ & Heat capacity of MAT(m2) at TVARC $(m g, m 2)$. \\
\hline CCONST & Oxidation kinetics constant. \\
\hline CLADMX & Maximum of all Zircaloy cladding node temperatures. \\
\hline CLADXC & $\begin{array}{l}\text { Clad cross-sectional area (in.), used to compute gamma heating } \\
\text { volumetric heat rate. }\end{array}$ \\
\hline $\operatorname{con}(m 4)$ & Thermal conductivity of $\mathrm{NODE}(\mathrm{m} 4)$ at temperature $T(m 4)$. \\
\hline CONE & Value given a non-decimal $8 C D$ number NXX in PATCH. \\
\hline $\operatorname{CONT}(\mathrm{mg}, \mathrm{m} 2)$ & $\begin{array}{l}\text { Thermal conductivity of material MAT (m2) at temperature } \\
\text { TVARK (mg, m2). }\end{array}$ \\
\hline CORR & Energy content of material at $0 \mathrm{DEG}$, relative to $\operatorname{TVARC}(1)$ \\
\hline $\operatorname{cx}(m n)$ & $\begin{array}{l}\text { Fraction of fission product released per fraction of uranium } \\
\text { oxidized. }\end{array}$ \\
\hline D1 & Temporary value of DELF1(N). \\
\hline D2 & Temporary value of DELF2(N). \\
\hline $\mathrm{DA}(\mathrm{m} 4)$ & Change in mass fraction of lower temperature phase. \\
\hline DAX & Change in $A(m 4, m 2)$ due to phase change. \\
\hline $\mathrm{DDA}(\mathrm{m} 4)$ & $\begin{array}{l}\text { Time rate of change in mass fraction of lower temperature } \\
\text { phase or temporary value of estimated temperature change from } \\
\text { phase change. }\end{array}$ \\
\hline
\end{tabular}


$\operatorname{DDT}(\ln 4)$

DEL1 (m5)

DEL2 (m5)

DELFI (ma)

DELF?(ma)

DELT

DELTG

DELTMX

DELTO

DELTS

DELTSS

DENS (m2)

DEX

DEXA

DF (m4)

DFI (m5)

DFLOT

DFS (m6)

DLONG

DMETAL
Estimated rate of change of $T(m 4)$ in next time step.

Average length of heat flow path from nodal point in NOD1(m5) to interface with NOD2(m5). See SCALE.

Average length of heat flow path from nodal point in NOD2 (m5) to interface with NOD1(m5). See SCALE.

Relative distance from nodal point of NODF1 (ma) to mass flow interface with NODF2 (ma), converted to weight factor DELF2 (ma) / (DELF1(ma) + DELF2 (ma) a fter input.

Relative distance from nodal point of MODF2(ma) to mass flow interface with NODF1(ma), converted to weight factor DELF1 (ma)/(DELF1 (ma) + DELF2 (ma) after input.

Time step, controlled by TVARY, DELTO, DELTMX, TIMEP, and TIMAX. Also see KS, KSPEC.

Last accepted time step completed.

Maximum allowable time step.

Maximum allowable time step. Blank $=1.0 E 12$. Must be specified if KSPEC is positive.

Last time step completed.

Last accepted time step completed before DELTS.

Density of material with number MAT(m2).

Temporary value of DDT(m4).

Temporary value of $\mathrm{DDA}(\mathrm{m} 4)$.

Net heat flow into $\operatorname{NODE}(m 4)$ in time step DELT.

Heat flow from NOD2(m5) to NOD1(m5) in time step DELT.

Time for mass flow into a node to equal the node mass.

Heat flow from $\operatorname{NOOSB}(m 6)$ to $\operatorname{NODS}(m 6)$ in time step DELT.

Average length of a node in BLOCK 4 , an interface in BLOCK 5 , or a surface in BLOCK 6 . See DRAD.

Amount of metal consumed via oxidation $(\mathrm{kg} / \mathrm{s})$. 


\begin{tabular}{|c|c|}
\hline DRAD & $\begin{array}{l}\text { Mean axial length }(K D=1) \text {, or mean radius }(K D=2 \text { or } 3) \text { of } \\
\text { a node in BLOCK } 4 \text {, an interface in BLOCK } 5 \text {, or a surface in } \\
\text { BLOCK } 6 \text {. See NSEQ for use of a negative value. }\end{array}$ \\
\hline DRADS & Value of ORAD for node for connection last read in. \\
\hline DS & Sum of mass flow paths DELF1(ma) and DELF2(ma). \\
\hline $\mathrm{OT}(\pi 4)$ & Change in temperature in $\operatorname{NODE}(\mathrm{m} 4)$ in time step DELT. \\
\hline DT12 & Positive temperature difference between two nodes. \\
\hline DTEMP & Maximum temperature change in time step OELTS. \\
\hline DTHIK(m4) & $\begin{array}{l}\text { Change in a node's oxidation thickness over the last time } \\
\text { step (m). }\end{array}$ \\
\hline DTIME & Time step in seconds. \\
\hline DTMAX & $\begin{array}{l}\text { Maximum change in any tabulated property, in equivalent } \\
\text { temperature or TVARY^ (percent change), or NUTMAX }{ }^{\star} \text { TVARY, if } \\
\text { NUTMAX iterations were done, or } 0.025^{\star} \text { NUTS*TVARY, whichever } \\
\text { is largest, in time step DELTS. }\end{array}$ \\
\hline DTMAXS & Value of DTMAX for time step DELTS. \\
\hline DTX & $\begin{array}{l}\text { Temporary value of the absolute temperature difference between } \\
\text { a node temperature and a phase change temperature. }\end{array}$ \\
\hline DTXP & $\begin{array}{l}\text { Temporary value of the absolute temperature difference between } \\
\text { a node temperature and a phase change temperature. }\end{array}$ \\
\hline DUDT & Fraction of fuel oxidized per minute in a fuel node. \\
\hline DWIDE & Average width of a node in BLOCK 4 . See DRAD. \\
\hline EMAX & 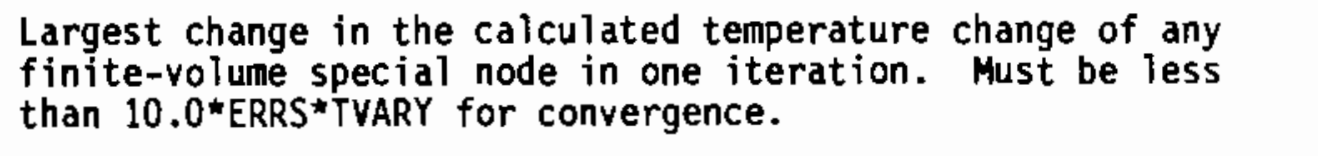 \\
\hline EOF & Indicates an end-of-file has been read, if positive. \\
\hline $\operatorname{ERROR}(m 4)$ & New estimated change in heat flow into $\operatorname{NODE}(\mathrm{m} 4)$. \\
\hline $\operatorname{ERRORX(m4)}$ & Last estimated change in heat flow into $\operatorname{NODE}(\mathrm{m} 4)$ \\
\hline ERRS & $\begin{array}{l}\text { Maximum allowable fraction of TVARY for the change in the } \\
\text { calculated average temperature change of interconnected } \\
\text { special nodes in one iteration, for convergence. }\end{array}$ \\
\hline ESUM & $\begin{array}{l}\text { Change in the calculated total heat content of interconnected } \\
\text { special nodes in one iteration. }\end{array}$ \\
\hline
\end{tabular}


EX

EXHFRAC

EXITSTM

EZERO

$F(m 4)$

$\mathrm{F} 1$ (mg)

F2 (mg)

F3 (mg)

FAILT (mc, mh)

$\mathrm{FB}\left(\mathrm{m}_{7}\right)$

FFACTR

$F I(m 5)$

FIN

FISAV

FIZZ (m4)

FLAPS (ma)

FLEX

FLEX1

FLEX2

FLINT (m4)

FLIPS (m4)

FLOPS (m4)
Extrapolation of temperature or time for table lookup, or a correction to the temperature change of a special node for one iteration step.

Exit hydrogen fraction (mass weighted average over all flow regions).

Exit coolant mass flow rate (sum of all flow regions).

Extrapolated length for chopped-cosine power profiles (in.).

Total heat flow into NODE(m4) at SUMTIM.

Temporary name of first item of input table pair.

Temporary name of second item of input table pair.

Temporary name of slope between input table pairs.

Time in hours at which a uranium fuel pin at a given axial level exceeds TFAIL, the fuel failure temperature.

Total heat added to system from boundary node NODB(m7).

Coolant mass flow rate multiplier used for boiloff flow regions only.

Total heat flow from NOD2(m5) to NOD1(m5) at SUMTIM.

Dumny list argument used for write statements with no list.

Fission power linear heat rate $(\mathrm{kw} / \mathrm{ft})$, excludes gamma heating.

An array that contains array location indexes for fission product variables.

Total mass flow from NODF1(ma) to NODF2(ma) at SUMTIM.

Final correction to heat flux between nodes.

Heat content of mass flow source NODE.

Heat content of mass flow sink NODE.

Net mass flow rate into $\operatorname{NODE}(\mathrm{m} 4)$ during time step.

Net total mass flow into $\operatorname{NODE}(\mathrm{m} 4)$ up to SUMTIM.

Net total mass flow out of NODE (m4) up to SUMTIM. 


\begin{tabular}{|c|c|}
\hline FLOUT (m4) & Net mass flow rate out of $\operatorname{NODE}(\mathrm{m} 4)$ during time step. \\
\hline FLOWN (ma) & $\begin{array}{l}\text { Mass flow rate from NODF1(ma) to NODF2(ma). May be negative } \\
\text { to indicate flow in opposite direction. If not specified, } \\
\text { FONE will be used by program. }\end{array}$ \\
\hline FLOWT (mg, ma) & $\begin{array}{l}\text { Mass flow rate from NODF1(ma) to NODF2(ma) at } \operatorname{TVARFL}(\mathrm{mg}, \mathrm{ma}) \text {, } \\
\text { may be negative to indicate flow in opposite direction. }\end{array}$ \\
\hline FLOWX (ma) & Mass flow from $\operatorname{NODF1(ma)}$ to $\operatorname{NODF2(ma)~during~time~step.~}$ \\
\hline FLOWY (mb) & $\begin{array}{l}\text { Array containing the coolant flow regions' cross-sectional } \\
\text { areas (BLOCK 10). }\end{array}$ \\
\hline FLOWYT & Total model flow area $\left(\right.$ in. $\left.{ }^{2}\right)$. \\
\hline FLUX & Net total heat flow into all nodes in system. \\
\hline FLUXS & Net total heat flow into system from boundary nodes. \\
\hline FONE & $\begin{array}{l}\text { Flow rate for any mass flow connections with FLOWN(ma) blank } \\
\text { in any BLOCK } 10 \text { read in after BLOCK } 1 \text {. }\end{array}$ \\
\hline FOR & $\begin{array}{l}\text { Interpolation factor between temperatures at the beginning } \\
\text { and end of the time step. FOR is set to } 1.0 \text { for the first } \\
\text { time step and after rejected time steps. For other time } \\
\text { steps, FOR is } 1.0 \text { if KSPEC is } 2,0.5 \text { if KSPEC is } 3 \text {, or between } \\
0.57 \text { and } 1.0 \text {, depending on RAST. }\end{array}$ \\
\hline FORD & Factor for estimating changes, $=$ FOR ${ }^{\star} D E L T$ or $0.5^{\star} D E L T$. \\
\hline $\mathrm{FPC}(\mathrm{md}, \mathrm{mn})$ & Current fission product inventories in each fuel node $(\mathrm{kg})$. \\
\hline FPDT (md, mn) & $\begin{array}{l}\text { Total release rate of each fission product from each fuel } \\
\text { node }(\mathrm{kg} / \mathrm{min}) \text {. }\end{array}$ \\
\hline FPDTB (md, mn) & $\begin{array}{l}\text { Release rate of each fission product from each fuel node due } \\
\text { to bake-out }(\mathrm{kg} / \mathrm{min}) \text {. }\end{array}$ \\
\hline FPDTO $(m d, m n)$ & $\begin{array}{l}\text { Release rate of each fission product from each fuel node due } \\
\text { to oxidation }(\mathrm{kg} / \mathrm{min}) \text {. }\end{array}$ \\
\hline FPFRAC & $\begin{array}{l}\text { Fraction of whole core being modeled in TRUMP-BD simulation, } \\
\text { in terms of core power. }\end{array}$ \\
\hline FPI $(m d, m n)$ & Initial fission product inventories in each fuel node $(\mathrm{kg})$. \\
\hline FPIT (mn) & Total inventory of each fission product in the core in $\mathrm{kg}$. \\
\hline PMDT (mn) & Total mode 1 release rate of each fission product $(\mathrm{kg} / \mathrm{min})$. \\
\hline
\end{tabular}




\begin{tabular}{|c|c|}
\hline FPMDTB (mn) & $\begin{array}{l}\text { Model total release rate of each fission product due to bake- } \\
\text { out }(\mathrm{kg} / \mathrm{min}) \text {. }\end{array}$ \\
\hline FPMDTO(mn) & $\begin{array}{l}\text { Model total release rate of each fission product due to } \\
\text { oxidation }(\mathrm{kg} / \mathrm{min}) \text {. }\end{array}$ \\
\hline FPMRL (mn) & $\begin{array}{l}\text { Total model integrated release of each fission product due } \\
\text { to in } \mathrm{kg} \text {. }\end{array}$ \\
\hline $\operatorname{FPMRLB}(m n)$ & $\begin{array}{l}\text { Model integrated release of each fission product due to bake- } \\
\text { out in } \mathrm{kg} \text {. }\end{array}$ \\
\hline FPMRL $0(m n)$ & $\begin{array}{l}\text { Model integrated release of each fission product due to } \\
\text { oxidation in } \mathrm{kg} \text {. }\end{array}$ \\
\hline FPREL (md, mn) & $\begin{array}{l}\text { Total integrated release of each fission product by each fuel } \\
\text { node in } \mathrm{kg} \text {. }\end{array}$ \\
\hline FPREL B (md, mn) & $\begin{array}{l}\text { Integrated release of each fission product by each fuel node } \\
\text { due to bake-out in } \mathrm{kg} \text {. }\end{array}$ \\
\hline FPRELO(md, mn) & $\begin{array}{l}\text { Integrated release of each fission product by each fuel node } \\
\text { due to oxidation in } \mathrm{kg} \text {. }\end{array}$ \\
\hline $\mathrm{FS}\left(m \epsilon_{1}\right)$ & Total heat flow from $\operatorname{NODSB}(m 6)$ to $\operatorname{NODS}(m 6)$ at SUMTIM. \\
\hline FUELMX & Maximum of all uranium fuel node temperatures. \\
\hline FUELF: & $\begin{array}{l}\text { Fuel pellet radius (in.), used to compute volumetric heat } \\
\text { generation rate. }\end{array}$ \\
\hline$F X$ & Average rate of heat flow across a connection. \\
\hline FX1 & Average mass flow rate into $\operatorname{NODE}(m 4)$ up to SUMTIM. \\
\hline FX2 & Average mass flow rate out of $N O D E(m 4)$ up to SUMTIM. \\
\hline FXH2 & $\begin{array}{l}\text { Steam } 1 \text { imiting constant applied to oxidation kinetics, reduces } \\
\text { reaction rate based on hydrogen concentration (HFLAG must be } \\
\text { set }=1 \text { for this model to function). }\end{array}$ \\
\hline $\begin{array}{l}\text { FXY (mb) } \\
G(m 4)\end{array}$ & $\begin{array}{l}\text { Array containing the flow regions flow rate multipliers. } \\
\text { Heat generation rate in } \operatorname{NODE}(m 4) \text {. }\end{array}$ \\
\hline GAMAVE & Gamma heating linear heat rate $(\mathrm{kW} / \mathrm{ft})$. \\
\hline GAP & Fuel-clad gap thickness (in.). \\
\hline & eat generated in system. \\
\hline
\end{tabular}


GEOM

GFACTR

$\mathrm{GG}(\mathrm{m} 4)$

GONE

GS

GX

$H(m 4)$

HBAKE

HBULK

HDO

HEAT

HEFT (m4)

HEFTMS

HEFTS

HEIGHT (mc)

HEX

HFG

HFLAG

HFLOW (mb)
Geometric factor, 1.0 for $K D=1,2.0 \star P I$ for $K D=2$, and 4.0*PI for $K D=3(P I=3.14159265)$.

Heat generation multiplier, used for boiloff flow regions.

Initial heat generation rate in $\operatorname{NODE}(m 4) . \quad$ Blank $=$ GONE.

Constant heat generation rate assigned to all nodes in any BLOCK 4 read in after BLOCK 1 , and substituted for any unspecified GG(mA) in any BLOCK 9 read in after BLOCK 1 . will not be used for nodes listed in BLOCK 8 .

Net total heat generation rate in system.

Temporary value of $\mathrm{GG}(\mathrm{m} 4)$.

Heat added to NODE (m4) up to SUMTIM.

Fraction of each fission product released per minute due to bake-out in a fuel node.

Value of bulk boiling heat transfer coefficient (BLOCK 10), used for boiloff problems.

Heat transfer length from bulk boiling to dryout front regimes (in.). HDO must be less than the minimum node's axial length (BLOCK 10).

Sensible heat content of systen at SUMTIM.

Mass of $\operatorname{NODE}(\mathrm{m} 4)$.

Total mass of a material.

Total mass of system.

Array containing the distance from each axial level's centroid to XINTER.

Heat transferred between NODES in time delt.

Heat of vaporization (Btu/lbm), boiloff simulation only.

Steam limiting model flag; HFLAG:

(0) no steam limiting

(1) oxidation kinetics limited by hydrogen concentration in flow channel adjacent to oxidizing node (1imiting model assumes hydrogen generation rate is also linear function of hydrogen concentration).

Array of mass flow rates of hydrogen at each axial level. 


\begin{tabular}{|c|c|}
\hline HFRACT (md) & $\begin{array}{l}\text { Array of hydrogen partial pressure in values adjacent to } \\
\text { metal-water reaction nodes. }\end{array}$ \\
\hline HFRCLVL(mc) & $\begin{array}{l}\text { Array of hydrogen partial pressures at each axial level based } \\
\text { on the total flow in all model flow regions. }\end{array}$ \\
\hline HFROMU & Total bundle hydrogen flow rate due to uranium oxidation. \\
\hline HFROMUT & Integrated hydrogen release rate from uranium oxidation $(\mathrm{kg})$. \\
\hline HFROMZ & Hydrogen release rate from zirconium oxidation $(\mathrm{kg} / \mathrm{s})$ \\
\hline HFROMZT & $\begin{array}{l}\text { Integrated hydrogen release rate from zirconium oxidation } \\
(\mathrm{kg}) \text {. }\end{array}$ \\
\hline HIDM (mb) & Array of coolant flow regions' hydraulic diameters. \\
\hline HINT (m5) & $\begin{array}{l}\text { Interface conductance between nodes N001 (m5) and NOD2(m5). } \\
\text { Blank }=1.0 \mathrm{E} 12 \text { if RINT is blank, } 1.0 \mathrm{E}-24 \text { if RINT not blank. }\end{array}$ \\
\hline HINTS & Input value of HINT(m5). \\
\hline HINTV (me) & $\begin{array}{l}\left.\text { Bridged effective heat transfer coefficient (Btu/h-in. }{ }^{2}-{ }^{\circ} \mathrm{F}\right) \\
\text { for variable heat transfer connection "me". }\end{array}$ \\
\hline HMELT $(m 2, \mathrm{~m} 2)$ & latent heat of phase change $(B t u / 1 \mathrm{bm})$. \\
\hline HMELTX $(\mathrm{m} 2, \mathrm{~m} 2)$ & Temporary latent heat of phase change $(B t u / 1 \mathrm{bm})$. \\
\hline HMX & Temperature change equivalent to latent heat effect. \\
\hline HONE & $\begin{array}{l}\text { Surface conductance for any external connections with } \\
\text { HSURE(m6) blank, in a BLOCK } 6 \text { read in after BLOCK } 1 \text {. }\end{array}$ \\
\hline HOXD & $\begin{array}{l}\text { Fraction of each fission product released per minute due to } \\
\text { oxidation in a fuel node. }\end{array}$ \\
\hline HREL (md) & $\begin{array}{l}\text { Array containing integrated hydrogen release rates. These } \\
\text { rates represent the sum total integrated release for all." } \\
\text { metal-water reaction nodes up to the one indexed by "md." }\end{array}$ \\
\hline HRELTOT (mc, mb) & Integrated hydrogen release by level and flow region. \\
\hline HSUM & $\begin{array}{l}\text { Total heat capacity of all special nodes which have internal } \\
\text { connections with other special nodes. }\end{array}$ \\
\hline HSURE (m6) & Surface conductance between $\operatorname{NODS}(m 6)$ and $\operatorname{NODSB}(m 6)$ \\
\hline HSURT (mg, m6) & Surf. cond. of $\operatorname{MODS}(m 6)$ at TVARH $(m g, m 6) . \quad B l a n k=$ HONE. \\
\hline
\end{tabular}


IBLOCK

$$
\begin{aligned}
& \text { BLOCK number; IBLOCK: } \\
& \text { (1) for controls, limits, and constants } \\
& \text { (2) for materials } \\
& \text { (4) for nodes } \\
& \text { (5) for internal thermal connections } \\
& \text { (6) for external thermal connections } \\
& \text { (7) for boundary nodes } \\
& \text { (B) for variable heat generation nodes } \\
& \text { (9) for initial conditions and TRUMP-BD heat } \\
& \text { generation } \\
& \text { (10) for mass flow connections } \\
& \text { (12) for nodes with remote property dependence. }
\end{aligned}
$$

IBLOCL Value for IBLOCK on data end card.

IBDLRGN(mb) An array of coolant flow region type indicator flags (BLOCK 10).

$\operatorname{ICOLM}(m 2, m c) \quad$ A "pointer" array used to identify the index for each node at an axial level that is specified as a node whose temperature will be written to TAPE 11 .

IDEPL(mb) Steam depletion flags for each flow region; $0=$ steam available, >0 steam depleted.

IDIAG

Output diagnostic flag.

IFIZZ Variable used to control entry location in subroutine FISPROD when $\mathrm{KCYC}=-1$.

IGENFG Time-dependent heat generation flag.

IHCOMB Binary mixture (hydrogen and steam) property flag.

IHTCOR(me) Variable heat transfer correlation type for variable heat transfer connection index "me".

IJ The index number of a temperature dependent internat thermal connection.

IPRINT

$\star \star \star$ NOT USED $\star \star \star$

IRITE

$\star \star \star$ NOT USED $\star \star \star$

ISOTOP(mn) Descriptive name for fission product, input in BLOCK 13.

$\operatorname{ISTATE}(m c, m h) \quad$ An array of fuel pin states ("intact" or "failed") for each pin at each axial level.

$\operatorname{ITEMS}(n) \quad$ Number of cross-referenced items in data BLOCK $n$. 


\begin{tabular}{|c|c|}
\hline ITST (mb, mc) & $\begin{array}{l}\text { An array of temperatures of coolant flow regions at each axial } \\
\text { level. }\end{array}$ \\
\hline IVARH (me) & $\begin{array}{l}\text { A thermal connection index array for variable heat transfer } \\
\text { connections. } \\
\star \star \star \text { NOT USED }\end{array}$ \\
\hline KCYC & $\begin{array}{l}\text { Indicates problem is in data input phase (if }-1 \text { ), or in } \\
\text { initialization phase, including initial time step of } 1 \text {.E-12 } \\
\text { (if } 0) \text {, or the number of time steps completed. }\end{array}$ \\
\hline KD & $\begin{array}{l}\text { Geometric symmetry indicator; } \mathrm{KD} \text { : } \\
\text { (1) for nonsymmetric } \\
\text { (2) for axisymmetric } \\
\text { (3) for centrisymmetric. } \\
\text { Used to control calculation of node volumes and connection } \\
\text { areas for BLOCKs 4,5, and } 6 \text { read in after BLOCK } 1 \text {. }\end{array}$ \\
\hline KDATA & $\begin{array}{l}\text { Controls amount of standard TRUMP data on printouts, minimum } \\
\text { if negative, normal if zero, and maximum if positive. }\end{array}$ \\
\hline KDATAX & Input value of KDATA. \\
\hline KGOOCI & $\begin{array}{l}\text { Number of successive time steps not repeated, or not involving } \\
\text { changes to special nodes, after } 2 \text { nd. }\end{array}$ \\
\hline KNOCK. & Number of thermal connections between pairs of special nodes. \\
\hline KNOFL & $\begin{array}{l}\text { Number of mass flow connections between pairs of special } \\
\text { nodes. }\end{array}$ \\
\hline KS & Indicates that $\operatorname{NOOE}(m 4)$ is a special node. See KSPEC. \\
\hline KSECS & $\begin{array}{l}\text { Machine time charged to the problem, in seconds, measured } \\
\text { from just before reading the problem name card for each data } \\
\text { deck. }\end{array}$ \\
\hline KSPEC & $\begin{array}{l}\text { Node classification and difference equation control, specified } \\
\text { in BLOCK } 1 \text {. }\end{array}$ \\
\hline KSYM & Symmetry factor, 1 if $K D$ is 1 or 2,2 if KD is 3 . \\
\hline KWIT & $\begin{array}{l}\text { Indicates: } \\
(-1) \text { time step to be repeated } \\
\text { (1) SUMTIM exceeds TIMAX } \\
\text { (2) node temperature over TMAX } \\
\text { (3) node temperature under TIMIN } \\
\text { (5) input error } \\
\text { (6) ॠCHECK card read in } \\
\text { (7) KCYC over MCYC } \\
\text { (8) KSECS over MSEC } \\
\text { (9) missing BLOCK } 2 \text { or } 4\end{array}$ \\
\hline
\end{tabular}


LABEL

LBH

LBR

LIST

LISTR

LISTX

LP

LTAB

$\operatorname{LTABC}(m 2)$

LTABFL(ma)

$\operatorname{LTABG}(\mathrm{mB})$

LTABH (m6)

$\operatorname{LTABK}(\mathrm{m} 2)$

$\operatorname{LTABP}(\mathrm{m} 2)$
(10) iteration convergence failure

(11) number of BLOCK items too large

(12) table length over M9.

Indicates table headings to be rewritten, if nonzero.

Indicates input data field for HINT(m5) is blank if zero.

Indicates input data field for RINT(m5) is blank if zero.

Input array which must be recalculated in subroutine REFER.

Array containing numbers to which array list refers.

Input values of array list.

Temporary special output node counter/controller.

Absolute value of a table length.

Number of pairs of entries in this table of heat capacity CAPT (mg, m2) vs. temperature (or time) TVARC (mg, m2) for material MAT(m2). LTABC is negative for time table, positive for temperature table.

Number of pairs of entries in table of FLOWT(mg,ma) vs. TVARFL (mg, ma), for flow mass connection NOOFi (ma) to NODF2(ma). LTABFL is negative for time table, positive for temperature table.

Number of pairs of entries in this table of GT(mg,m8) vs. TVARG (mg, m8) for NODG (mB). LTABG is negative for time table, positive for temperature table, $-1,0$ or 1 for exponentially decaying heat generation with rate $\mathrm{GT}(1, N)$ at time 0 , halflife $\operatorname{TVARG}(1, N)$.

Number of pairs of entries in table of heat transfer coefficient HSURT (mg, m6) vs. time (or temperature) TVARH ( $m g, m 6$ ) for NODS (m6) -NODSB (m6) connection. LTABH is negative for time table, positive for temperature table.

Number of pairs of entries in table of CONT $(\mathrm{mg}, \mathrm{m} 2)$ vs. TVARK(mg, m2) for MAT(m2). LTABK is negative for time table, positive for temperature table.

Number of temperature-latent heat pairs in phase change table: use 0 to indicate a single-phase change in the input file; for materials with single-phase changes $\operatorname{LTABP}(\mathrm{m} 2)$ is converted to 1 upon code initialization. 


\author{
$\mathrm{LTABT}(m 7) \quad$ Number of pairs of entries in the table of temperature \\ TEMPB ( $m g, m 7)$ vs. time TIMEB $(m g, m 7)$, for external boundary \\ node $\mathrm{NODB}(\mathrm{m} 7)$. \\ M \\ MAR \\ MASFLG \\ $\operatorname{MAT}(m 2)$ \\ $\operatorname{MAVEDX}(\mathrm{mc})$ \\ $\operatorname{MAX}$ \\ MCYC \\ MF \\ MID \\ MIN \\ MOD \\ MODS \\ MS \\ MSEC \\ MSS \\ MWR \\ MWRCOR \\ Unit number used in write statements to OUTPUT. \\ Size of array LISTR in subroutine REFER. \\ Mass flow rate computation flag (BLOCK 10). \\ Array containing the identification numbers for materials \\ defined in BLOCK 2. \\ Array containing the current number of oxidizing uranium nodes \\ for each axial level. \\ Size of arrays LIST and LISTX in subroutine REFER. Highest \\ index of part of table being searched. \\ Maximum allowed number of time steps (limit on KCYC). \\ Negative will stop problem at end of first time step, zero \\ or blank is ignored. \\ Total number of times DTEMP or DTMAX has exceeded TVARY in \\ time steps for which DELT was equal to SMALL. \\ Central index of part of table being searched. \\ Lowest index of part of table being searched. \\ Character in column 8 of BLOCK number card, blank for deleting \\ old items and adding new items, /A/ for saving old $i$ tems and \\ adding new $i$ tems, $/ B /$ for modifying old $i$ tems and adding new \\ items. \\ Indicates $M O D$ is $A(+1)$, B $(-1)$, or neither $(0)$. \\ Number of time steps for which DELT was equal to DELTMX and \\ DTEMP and DTMAX were less than TVARY, since last regular node \\ was reclassified as a special node. \\ Maximum allowed use of machine time, in seconds. Negative \\ will stop problem at end of first time step; zero or blank \\ is ignored. \\ Total number of times DTEMP and DTMAX were less than TVARY \\ in time steps for which DELT was equal to DELTMX. \\ Number of metal-water reaction nodes. \\ Zirconium - hydrogen reaction correlation type.
}


MWRSU(mc, mb, ml) Node index for all fuel nodes adjacent to each flow region at each axial level.

MWRSURF (mc) Array containing the number of metal-water reaction surface nodes at each axial level.

NADD

Difference between successive values of NODE in sequence.

MWRSZ(mc,mb,ml) Node index for all Zircaloy volume nodes adjacent to each flow region at each axial level.

N12WRT

Number of times during simulation at which fission product release data will be written to TAPE12 (BLOCK 13).

NAD1

Difference, after multiplication by $10^{\star \star N Z}$, between values of MAD1 in sequence of connections.

NAD2

Difference, after multiplication by $10^{*} N Z$, between values of NAD2 in sequence of connections.

NADF1

Difference between successive values of NODF1 in sequence.

NADF2

Difference between successive values of NODF2 in sequence.

NADFR

Difference between successive values of NPROP in sequence.

NADG

Difference between successive values of NODG in sequence.

NADP1

Difference between successive values of NODP1 in sequence.

NADP2

Difference between successive values of NODP2 in sequence.

NADS

Difference between successive values of NODS in sequence.

NADSB

Difference between successive values of NOOSB in sequence.

NAME

71-character title on problem name card; must be an *.

NAMES

Problem name at time last data end card was read in.

NAVEDX(mc) Number of zirconium nodes undergoing oxidation in axial level "mc".

NAXPO

Number of nodes (specified in BLOCK 1) for which axial plot information is to be written to TAPE 11 .

NAXTIM

Number of times (specified in BLOCK 1) for which axial plot information is to be written to Tape 11 .

NB

Input unit number for BLOCK items.

NBI

Integer which SEEK1 or SEEK2 is to search for. 
NB2

NBOIL

NBURN

NC

NCHANS

NCHECK

NCOLMS

$\mathrm{NCX} 2(\mathrm{m5})$

NDOT

NEWBL

NEWS

NFP

NFR(m4)

NIT

NLEVELS

NLEVTOT

NMAT

NMELT

NMELT

NOD1 (m5)

N0O2 (m5)

NOOB (m7)

NODBS

NODE (m4)
Integer which SEEK2 is to search for, along with NB1.

Axial level of dryout front.

Number of metal-water reaction nodes fully consumed.

Array subscript of NXX in patch.

Number of channels for convection summary output.

Indicates $/{ }^{*}$ check/ card read in, if non-zero.

The number of columns of data written to TAPE 11 , for each axial level. NCOLMS $=($ NAXPO $+5+$ NREGON $) \star$ NAXTIM +1 .

Input value of $\mathrm{NOD2}(\mathrm{m} 5)$.

1ndicates time derivatives $\operatorname{DDT}(\mathrm{N}), \operatorname{DDA}(\mathrm{N}), \operatorname{DOB}(\mathrm{N})$ will be used $($ NDOT $=0)$, or maintained at 0.0 (NDOT $\neq 0)$.

Number of times data BLOCK has been read in. 1000 is added each time a referenced BLOCK is read in.

Number of regular nodes made special in one time step.

Total number of fission products. maximum $=10$.

An array indexing coolant flow regions with metal-water reaction nodes.

Number of nodes with initial values $\mathrm{TT}, \mathrm{AA}, \mathrm{BB}, \mathrm{GG}$.

Number of axial levels in model.

Total number of axial levels in model.

Number of materials described in input BLOCK 2.

Number of materials with latent heat of phase change.

Number of materials with at least one phase change.

Number of internal or surface node connections to NOD2(m5).

Number of internal or surface node connections to NOD1(m5).

An array containing the node number of each specified boundary node.

Number of boundary nodes.

An array containing the node numbers for each node. 


\begin{tabular}{|c|c|}
\hline NODEAX $(m 2)$ & $\begin{array}{l}\text { Nodes for which axial plot information is to be written to } \\
\text { TAPE } 11 \text {. }\end{array}$ \\
\hline NODER & Number of nodes in restart file. \\
\hline NODES & Number of nodes described in input BLOCK 4 . \\
\hline NODF1 (ma) & Number of node from which mass flows to $N O O F 2(\mathrm{ma})$. \\
\hline NODF2(ma) & Number of node to which mass flows from NOOFI(ma). \\
\hline $\operatorname{NOOG}(m 8)$ & Number of a node with variable heat generation. \\
\hline NOOMAT $(m 4)$ & Identification number of the material in NODE (m4). \\
\hline NODMS & Total number of nodes of a material. \\
\hline NODOUT (mj) & $\begin{array}{l}\text { Number of special output nodes that will have their tempera- } \\
\text { tures written to TAPE } 5 \text {, and temperatures and current phase } \\
\text { change information to OUTPUT at XSPRNT time intervals. }\end{array}$ \\
\hline $\operatorname{NODP} 1(\mathrm{~m} 4)$ & Node for which $\mathrm{T}(\operatorname{NODP} 2(\mathrm{~m} 4))$ determines property $\operatorname{NPROP}(\mathrm{m} 4)$ \\
\hline NODP2 (m4) & $\begin{array}{l}\text { Node whose temperature determines property NPROP }(m 4) \text { of } \\
\text { NODP1 }(m 4) \text {. }\end{array}$ \\
\hline $\operatorname{NODS}(m 6)$ & Number of surface node connected to $\operatorname{NODSB}(m 6)$. \\
\hline $\operatorname{NODSB}(m 6)$ & Number of boundary node connected to $\operatorname{NODS}(m 6)$. \\
\hline NOFLOW & Number of mass flow connections. \\
\hline NOGEN & Number of nodes with heat generation. \\
\hline $\begin{array}{l}\text { NOPOWS } \\
\text { POWER }(m 6)\end{array}$ & Number of surface-boundary connections with non-zero \\
\hline NORAD & Number of node connections with non-zero RINT(m5). \\
\hline NORADS & $\begin{array}{l}\text { Kumber of surface-boundary connections with non-zero } \\
\text { RSURE }(m 6) \text {. }\end{array}$ \\
\hline NOSCON & Number of external connections. \\
\hline NOSPEC & Number of special nodes in system. \\
\hline NOTE $(m 4)$ & $\begin{array}{l}\text { An array containing node numbers for those nodes with initial } \\
\text { conditions specified by } T T, A A \text {, and } G G \text {. }\end{array}$ \\
\hline NOW & $\begin{array}{l}\text { Indicates printouts are being produced for the time step just } \\
\text { completed, if nonzero. }\end{array}$ \\
\hline
\end{tabular}




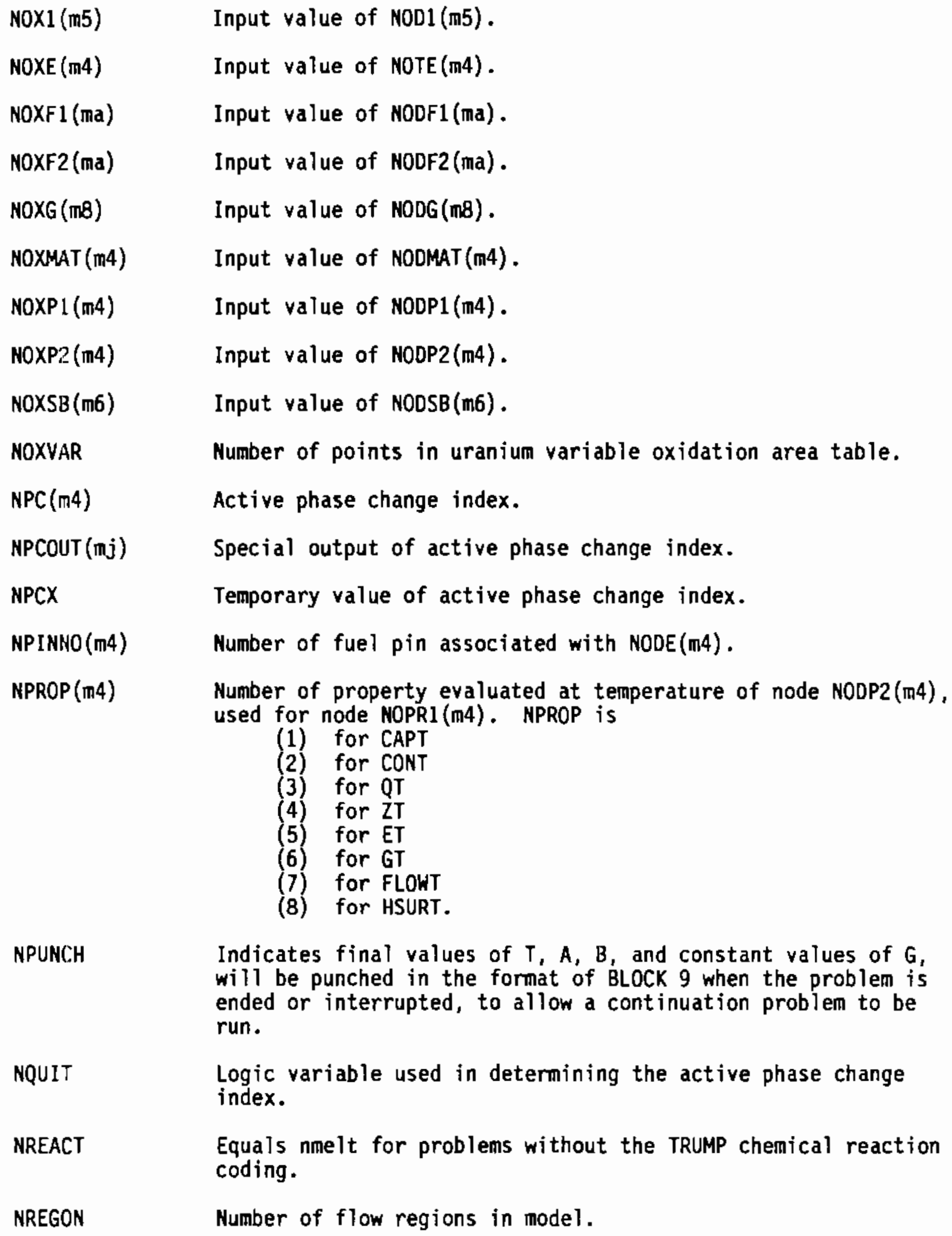

NPUNCH

Indicates final values of $T, A, B$, and constant values of $G$, will be punched in the format of BLOCK 9 when the problem is ended or interrupted, to allow a continuation problem to be run.

NQUIT Logic variable used in determining the active phase change index.

NREACT Equals nmelt for problems without the TRUMP chemical reaction coding.

NREGON

Number of flow regions in model. 
NRHOX

NSEQ

NSPOUT

NSURF (mc)

$\operatorname{NSURFR}(m b, m c)$

$\operatorname{NSURFU}(m c, m b)$

NSURFZ (mc, mb)

$\operatorname{NTABF}(\mathrm{mb})$

NTABG

NTABLE

NTABS

NTYPE (m4)

NUM

NUMX

NUNLIM

NUSERT (me)
Number of points in density table for coolant.

Number of BLOCK items to be generated in addition to the line item described. Node numbers will be incremented by NADD, NAD1, NAD2, NADS, NADSB, etc., as applicable, and if DRAD is preceded by a minus sign, DRAD values will be incremented by the difference between DRAD and the value of DRAD for the preceding BLOCK item.

Number of special output nodes.

Number of metal-water reaction node surfaces at axial level "mc."

An array containing the number of metal-water reaction nodes adjoining each flow region at each axial level.

Number of fuel nodes adjacent to each flow region at each axial leve1.

Number of Zircaloy volume nodes adjacent to each flow region each at axial level.

An array containing the number of entries in coolant mass flow table for each flow connection "mb" (BLOCK 10).

Number of entries in power vs. time table.

Total number of tables in input data.

Number of nodes with remotely dependent properties.

Node type,

(0) regular

(1) surface

(2) zero-volume

(3) special

(4) $\mathrm{KSPEC}=0$ converted special

(5) $\mathrm{KSPEC}=1$ converted special (5).

Number of a node for which T, DDT, A, B, G, and SUMTIM will be written to OUTPUT every time step. This is in addition to the data written out for all nodes at intervals controlled by IPRINT and TIMEP.

Input value of NUM.

Unlimited steam supply for oxidation flag.

Number of pairs of entries in user specified variable heat transfer table. 


\begin{tabular}{|c|c|}
\hline $\begin{array}{l}\text { NUTMAX } \\
\text { NUTS }\end{array}$ & $\begin{array}{l}\text { Maximum allowable number of iterations of the heat balance } \\
\text { equations for inter-connected special nodes }(80) \text {. } \\
\text { Number of iterations completed before convergence. Will cause } \\
\text { next time step to be reduced if more than } 40 \text {. }\end{array}$ \\
\hline NUTSUM & Total number of iterations used in problem. \\
\hline NUTX & Maximum number of iterations used in any time step. \\
\hline NVARC & Number of materials with variable heat capacity. \\
\hline NVARDX & $\begin{array}{l}\text { Axial length noding flag. Equals number of entries in axial } \\
\text { noding descriptor card (BLoCK } 4 \text {, Card } C \text { ). }\end{array}$ \\
\hline NYARFL & Number of mass flow connections with variable flow. \\
\hline NVARG & $\begin{array}{l}\text { Number of nodes with variable heat generation (from BLOCK } 8 \text {, } \\
\text { standard TRUMP). }\end{array}$ \\
\hline NVARH & Number of surface nodes with variable surface cond. \\
\hline NVARK & Number of materials with variable thermal conductivity. \\
\hline NVART $^{\top}$ & Number of boundary nodes with variable temperature. \\
\hline NVISX & Number of points in coolant viscosity table. \\
\hline $\operatorname{NXX}(\mathrm{N})$ & A BCD number to be tested for a decimal point in PATCH. \\
\hline NZ & Indicates NAD1, NAD2 are to be multiplied by $10^{\star * N Z}$. \\
\hline $\operatorname{NZDEP}(\mathrm{mb})$ & $\begin{array}{l}\text { Axial level at which steam used for oxidation has been } \\
\text { completely depleted in flow region mb. }\end{array}$ \\
\hline NZR (nd) & Node number of a fully oxidized node. \\
\hline NZRIDX $(\mathrm{mb}, \mathrm{mc})$ & $\begin{array}{l}\text { Index to keep track of last metal-water reaction node read } \\
\text { in from input for flow region "mb" at axial level "mc." }\end{array}$ \\
\hline OUTDISC & $\begin{array}{l}\text { restart/graphics post-processing dump flag; OUTDISC: } \\
\text { (0) no restart or graphics dump } \\
\text { (1) restart dump only } \\
\text { (2) restart and graphics dump. }\end{array}$ \\
\hline OXAREAM (md) & Uranium node oxidation area multiplier. \\
\hline OXAREM (m4) & $\begin{array}{l}\text { Area containing the available oxidation surface areas for } \\
\text { each metal-water reaction node. }\end{array}$ \\
\hline OXMULT(mg) & Oxide area multiplier applied at temperature 0 XTEMP $(\mathrm{mg})$. \\
\hline $\operatorname{OXPINM}(\mathrm{mic}, \mathrm{mh})$ & Uranium oxidation area multiplier. \\
\hline
\end{tabular}




\begin{tabular}{|c|c|}
\hline $\begin{array}{l}\text { OXTEMP }(\mathrm{mg}) \\
\text { PAXIAL }\end{array}$ & $\begin{array}{l}\text { Temperature at which OXMULT(mg) is applied. } \\
\text { Axial power factor applied to a node. }\end{array}$ \\
\hline $\operatorname{PDUMP}(\mathrm{ma}, \mathrm{mc})$ & $\begin{array}{l}\text { Array into which TAPE } 11 \text { data are stored, used when axial } \\
\text { plots of node temperatures, hydrogen release, oxidation heat } \\
\text { generation, etc. are going to be graphed. PDUMP is dimen- } \\
\text { sioned for "mc" axial levels and "ma" number of columns of } \\
\text { output values for each axial level. See variable NCOLMS. }\end{array}$ \\
\hline PERULFT (mc) & The percent of unoxidized uranium at each axial level. \\
\hline PERZLFT (mC) & The percent of unoxidized Zircaloy at each axial level. \\
\hline PGAMMA & Fraction of rod average power (RODAVE) due to gamma heating. \\
\hline PHIGHT (mg) & $\begin{array}{l}\text { Fuel bundle axial elevations used when specifying axial power } \\
\text { factors (BLOCK } 9) \text {. }\end{array}$ \\
\hline PIGRAL & $\begin{array}{l}\text { Integrated axial power at dryout front, used in boiloff } \\
\text { simulations. }\end{array}$ \\
\hline PIX & $\begin{array}{l}\text { Number of time steps estimated to remain before TIMAX reaches } \\
\text { an integral muItiple of TIMEP. }\end{array}$ \\
\hline $\operatorname{PMULT}(\mathrm{mg})$ & $\begin{array}{l}\text { Power factor at bundle axial elevation PHIGHT(mg), used when } \\
\text { specifying axial power factors (BLOCK } 9 \text { ). }\end{array}$ \\
\hline PONE & $\begin{array}{l}\text { Free convection exponent for any external connection with } \\
\text { POWER(m6) blank, in any BLOCK } 6 \text { read in after BLOCK } 1 \text {. }\end{array}$ \\
\hline POUT & Floating point value given a $B C D$ number $N X X$ in patch. \\
\hline POWER (m6) & 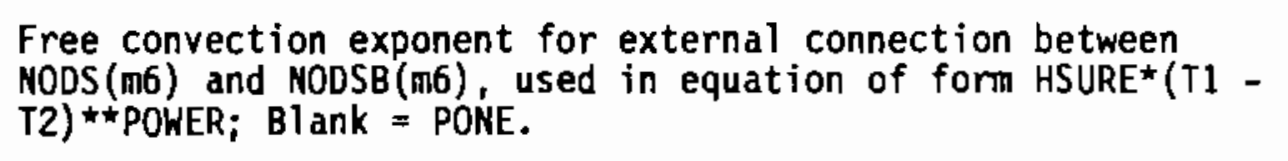 \\
\hline POWTOT & Total initial heat generation rate of fuel nodes. \\
\hline PRATIO & Peak-to-average bundle axial power ratio. \\
\hline PRESS & Pressure corresponding to coolant property data (PSIA). \\
\hline QAXTOT & Total model axial heat loss rate to external nodes. \\
\hline QBOIL & $\begin{array}{l}\text { Energy required to vaporize } 1 \text { lbm of inlet coolant }\left(\mathrm{H}_{\mathrm{fq}}+\right. \\
\left.\mathrm{H}_{\text {subcool }}\right)(\mathrm{Btu} / \mathrm{lbm}) \text {. }\end{array}$ \\
\hline $\operatorname{QCHAN}(m i)$ & $\begin{array}{l}\text { An array of total convective heat transfer rates for each } \\
\text { flow channel }(\mathrm{kW}) \text {. }\end{array}$ \\
\hline
\end{tabular}




\begin{tabular}{|c|c|}
\hline OCONV (ma) & $\begin{array}{l}\text { An array of convection heat transfer rates between each flow } \\
\text { connection }(k W) \text {. }\end{array}$ \\
\hline QCONVT & Total convection heat removal rate $(\mathrm{kW})$. \\
\hline QDAMP & Zirconium-steam reaction damper, based on available steam. \\
\hline QDAMPU & Uranium-steam reaction damper, based on available steam. \\
\hline QFISON & Total fission heat generation rate $(\mathrm{kH})$. \\
\hline QPIN(mh) & An array of total heat generation rates in each fuel pin $(k W)$. \\
\hline QRADCIX (mc) & $\begin{array}{l}\text { The radial heat losses to boundary node } 2000 \text { at each axial } \\
\text { level. }\end{array}$ \\
\hline QRADT & Total radial heat loss $(\mathrm{kW})$. \\
\hline QUAX (mc) & $\begin{array}{l}\text { Energy release from uranium-stean reaction at discrete radial } \\
\text { cross sections along fuel bundle length. }\end{array}$ \\
\hline QUFRAC & $\begin{array}{l}\text { Ratio of uranium oxidation to total oxidation power on a } \\
\text { plane. }\end{array}$ \\
\hline QUPLN (mg, mc) & $\begin{array}{l}\text { Sum of the total uranium oxidation energy release at each } \\
\text { axial level for each flow region. }\end{array}$ \\
\hline QZRAX (mc) & $\begin{array}{l}\text { An array of total heat generation rates due to oxidation at } \\
\text { each axial level. }\end{array}$ \\
\hline $\mathrm{QZRH}_{2} \mathrm{O}(\mathrm{m} 4)$ & $\begin{array}{l}\text { An array of the heat generation rates occurring in each metal- } \\
\text { water reaction node. }\end{array}$ \\
\hline QZRINT & $\begin{array}{l}\text { Integrated metal-water reaction energy release }(k W) \text { over } \\
\text { transient. }\end{array}$ \\
\hline QZRTOT & Total metal-water reaction energy release in a time step. \\
\hline RAD & Radiation coefficient at node connections. \\
\hline RADIUS(m4) & Radius of $N O D E(m 4), D R A D^{\star} S C A L E$ in BLOCK 4 . \\
\hline RAT1 & Value of TVARY/DTEMPT in time step DELTS. \\
\hline RAT2 & Value of TVARY/DTEMPT in time step DELTSS. \\
\hline RATE & Average rate of heat flow into node or system. \\
\hline RATG & Value of TVARY/DTEMPT in time step DELTG. \\
\hline RATIO & $\begin{array}{l}\text { Ratio of DELT to DELTS, before restricting DELT to limits } \\
\text { SMALL and DELTMX. }\end{array}$ \\
\hline
\end{tabular}




\begin{tabular}{|c|c|}
\hline $\mathrm{RHO}(\mathrm{m} 4)$ & Density of node "m4" in $\mathrm{Ibm} / \mathrm{ft}^{3}$. \\
\hline RHOBAR & $\begin{array}{l}\text { Average density of coolant below dryout front in boiloff } \\
\text { simulations. }\end{array}$ \\
\hline RHOTAB & Density value. \\
\hline RINT (m5) & $\begin{array}{l}\text { Radiation view factor for connection between } N 001(m 5) \text { and } \\
\text { NOD2 (m5), including effects of geometry and surface emissiv- } \\
\text { ity. If negative, a positive value used as free convection } \\
\text { exponent, HINT* (T1 - T2)**RINT. }\end{array}$ \\
\hline RINTC & Free convection exponent derived from RINT. \\
\hline RINTR & Radiation transport coefficient derived from RINT. \\
\hline RODAVE & Average nodal power for model $(\mathrm{kW} / \mathrm{ft})$ \\
\hline RODRAD & $\begin{array}{l}\text { Outer radius of a fuel pellet (input in inches, converted to } \\
\text { meters). }\end{array}$ \\
\hline RODTOT & Total number of fuel rods in model (boiloff simulations only). \\
\hline RONE & $\begin{array}{l}\text { Radiation view factor for any external connection with } \\
\text { RSURE(m6) blank, in any BLOCK } 6 \text { read in after BLOCK } 1 \text {. }\end{array}$ \\
\hline $\operatorname{RSURE}(m 6)$ & $\begin{array}{l}\text { Radiation view factor for external connection between NODS (m6) } \\
\text { and NODSB(m6), including effects of geometry and surface } \\
\text { enissivity. Blank = RONE. }\end{array}$ \\
\hline SCALE & $\begin{array}{l}\text { Linear scale factor used in calculating all lengths, areas, } \\
\text { and volumes for BLOCKs } 4,5 \text {, and } 6 \text { read in after BLOCK } 1 \text {. }\end{array}$ \\
\hline SET & Time or temperature for table look-up. \\
\hline SETD & $\begin{array}{l}\text { Factor determining exponential decay of heat generation } \\
\text { (BLOCK } 8 \text { ). }\end{array}$ \\
\hline SETS & $\begin{array}{l}\text { Factor determining exponential decay of heat generation } \\
\text { (BLOCK 8). }\end{array}$ \\
\hline SIGMA & Stephan-Bolzman constant for thermal radiation. \\
\hline $\operatorname{SL1M}(m 4)$ & $\begin{array}{l}\text { Maximum stable time step for a regular } \operatorname{NODE}(m 4) \text {. SLIM equals } \\
\operatorname{CAP}(m 4) / Z \operatorname{IP}(m 4) \text {. }\end{array}$ \\
\hline SLOPS & $\begin{array}{l}\text { Ratio of maximum rates of temperature change in time steps } \\
\left.\text { DELTS and DELTSS, (RAT }{ }^{\star D E L T S}\right) /(\text { RAT2*DELTSS). }\end{array}$ \\
\hline
\end{tabular}


SMALL

SMALT

SPEED

STEAMF (mb)

STEMFLOW (md)

SUMSEC

SUMTIM

SYMLT

$T(m 4)$

T12 (mk)

TB (m7)

TBASE

$\operatorname{TBS}(\mathrm{m} 7)$

TDUM (mg)

TEMPAD

$\operatorname{TEMPB}(2, \mathrm{~m} 7)$

$\operatorname{TEMPB}(m 1, m 7)$

TEMPB (mg, m7)

TEMPER

TEMPFV (me)
Minimum allowable time step. Blank $=1 . E-12$, later replaced with $0.01 *$ DELTMX, as long as at least $1 / 4$ of the nodes are regular nodes.

Input value of SMALL or $1.0 \mathrm{E}-12$, whichever is larger.

Factor controlling acceleration of iteration method (0.2).

The steam flow rates available for oxidation in each flow region $(\mathrm{kg} / \mathrm{s})$.

The local steam flow rates available for oxidation for each metal-water reaction node $(\mathrm{kg} / \mathrm{s})$.

Total problem time in seconds, starting after TAV, going to a maximum of TIMAX.

Total problem time, starting at TAU. Limit is TIMAX.

Symetry factor for model, applied to applicable variables written to TAPE3.

Temperature in $\operatorname{MODE}(m 4)$. See tone, $T T(m 4)$.

Times in hours during simulation at fission product release data will be written to TAPE12 (BLOCK 13).

Temperature at boundary node $\operatorname{NODB}(m 7)$.

Temperature difference between scale in use and absolute scale, 460.0 for $K T=3$ (i.e., Fahrenheit scale--used in all TRUMP-BD simulations).

Average value of $T B(m 7)$ in a time step.

Nodal temperature at bundle axial elevation ZDUM (mg). When axial temperature variation option is selected (BLOCK 9).

Average temperature of system (constant CAP(m4)).

Amplitude of variation of TB(m7), if $\operatorname{LTABT}(\mathrm{m} 7)$ is 100 .

Average value of $T B(m 7)$, if $\operatorname{LTABT}(\mathrm{m} 7)$ is 100 .

Temperature at boundary node $\operatorname{NODB}(m 7)$ at $\operatorname{TIMEB}(m g, m 7)$.

Change in average temperature of a system due to net surface flux.

Temperature criteria for bridging $\left({ }^{\circ} \mathrm{F}\right)$ for variable heat transfer connections with IHEAT $=4$ (BLOCK 5) TEMPFV $<0$; criteria based on uranium temperature TEMPFV > 0; criteria based on zirconium temperature 
TEMPLE

TFAIL

TIM

TIMAX

$\operatorname{TIMEB}(1, \mathrm{~m} 7)$

$\operatorname{TIMEB}(1, m 7)$

$\operatorname{TIMEB}(\mathrm{mg}, \mathrm{m} 7)$

TIMESP

TIMS

TMAX

TMAX1

$\operatorname{TMELT}(\mathrm{m} 2, \mathrm{~m} 2)$

TMIN

TMIN1

TMS

TONE

$\operatorname{TPIN}(m c, m h)$

$\operatorname{TPINMAX}(\mathrm{mc}, \mathrm{mh})$

TRAN (m5)

TRANS (m6)

TREFF
Change in average temperature due to heat generation.

Zirconium cladding melt temperature $\left({ }^{\circ} \mathrm{F}\right)$

Remaining time between SUMTIM and next higher integer multiple of TIMEP for which a printout will be made.

Maximum allowed problen time (upper limit on SUMTIM). A negative value will stop the problem at end of first time step;

a zero or blank is ignored.

Sine wave period of $T B(m 7)$, if $\operatorname{LTABT}(\mathrm{m} 7)$ is 100 .

Sine wave advance time of $\operatorname{TB}(\mathrm{mN})$, if $\operatorname{LABT}(\mathrm{m} 7)$ is 100 .

Time at which boundary node $\operatorname{NODB}(m 7)$ is at $\operatorname{TEMPB}(\mathrm{mg}, \mathrm{m} 7)$.

Elapsed time between special node output/graphics dump

Remaining time between SUMTIM and next higher integer multiple of TIMEP.

Maximum allowable temperature. Replaced with $1.0 \mathrm{E} 12$ if not larger than TMIN.

Maximum temperature in system at SUMTIM.

Temperature of phase change.

Minimum allowable temperature. Replaced with $-1.0 \mathrm{E} 12$ if not less than TMAX.

Minimum temperature in system at SUMTIM.

Average temperature of a material (constant CAP(m4)).

Initial temperature assigned to all nodes in any BLOCK 4 read in after BLOCK 1 , and substituted for unspecified TT(N) in any BLOCK 9 read in after BLOCK 1 .

Minimum temperature of all nodes at an axial level identified as belonging to a fuel pin.

Maximum temperature of TPIN (mc, mh) during transient.

Thermal conductance between NOD1 (m5) and NOD2(m5).

Therma 1 conductance between $\operatorname{NODS}(m 6)$ and NODSB (m6).

Reference temperature used to compute a reference vapor pressure for bake-out fission product correlation $\left({ }^{\circ} \mathrm{F}\right)$. 
TRHO

TSAT

$\operatorname{TSTMAV}(\mathrm{mb}, \mathrm{mc})$

$\mathrm{TT}(m 4)$

TTMEL T (m2, m2)

$\operatorname{TVARC}(m j, m 2)$

TVARFL (mg , ma)

$\operatorname{TVARG}(1, m 8)$

TVARH $(m g, m 6)$

$\operatorname{TVARK}(\mathrm{mg}, \mathrm{m} 2)$

TVARY

TVIS

USERH (mg, me)

USERT (mg , me)

$\operatorname{UTHCON}(m \mathrm{c})$

UTHIC (mc)

VISTAB

Vo(mn)

VOL (m4)

VOLMS

VOLS
Temperature associated with density value RHOTAB $\left({ }^{\circ} \mathrm{F}\right)$.

Saturation temperature $\left({ }^{\circ} \mathrm{F}\right)$.

Average coolant temperature for each axial level in each flow region.

Initial temperature of node NOTE $(m 4) . \quad$ Blank = TONE.

Temperature at which MAT (m2) has latent heat HMELT $(m 2, m 2)$.

Temperature or time at which MAT(m2) has CAPT (mg, m2).

Temperature or time at which FLOWN(ma) is FLOWT(mg,ma).

Half-life of heat generation in $\operatorname{NOOG}(m 8$,$) when \operatorname{LTAGB}(\mathrm{mg}, \mathrm{mB})$ is 0 .

Temperature or time at which $\operatorname{NOOS}(m 6)$ has $\operatorname{HSURT}(\mathrm{mg}, \mathrm{mB})$.

Temperature or time which MAT(m2) has CONT (mg, m2).

Temperature accuracy control. Time steps adjusted to keep maximum temperature change near TVARY, and no more than 2.0^TVARY.

Temperature associated with viscosity value VISTAB $\left({ }^{\circ} \mathrm{F}\right)$.

User specified variable ${ }_{2}$ heat transfer coefficient for variable connections, (Btu/h-in. $\left.{ }^{2}{ }^{\circ} \mathrm{F}\right)$.

User specified temperature (or time) at which corresponding USERH (mg,me) is used for variable heat transfer connections $\left({ }^{\circ} \mathrm{F}\right)$.

Sum total thickness of consumed (oxidized) uranium at each axial level.

Sum total thickness of all uranium oxidation nodes at each axial level.

Coolant viscosity table values.

Reference vapor pressure for each fission product used for bake-out fission product release correlation (mo $\mathrm{Hg}$ ).

Volume of $N O D E(m 4)$, based on input in BLOCKs 1 and 4 , equals $(G E O M * D W I D E * D L O N G * D R A D * \star X S Y M) \star S C A L E \star * 3$.

Total volume of a material.

Total volume of all nodes in system. 

$W(m 4)$
Sensible and latent heat content of NODE $(m 4)$.
WLEVEL
Dryout front elevation during coolant boiloff simulation (in.)
WMS
Total heat content of a material.
$W T(m g, m 2)$
Sens. heat content of MAT(m2) at $\operatorname{TVARC}(\mathrm{mg}, \mathrm{m} 2)$.
$\mathrm{XA}$
Fraction of fuel-clad area debonded.
$\mathrm{XH} 2(\mathrm{mb})$
Partial pressure of hydrogen leaving each flow region.
XH2LEV (mb,mc) Average hydrogen concentrations leaving each flow region at each axial level.
XINQ
Total heat input into system (sum of QZRINT + QFISON).
XINTER
Model starting axial position (e.g., lowest elevation in vertical models, etc.).
XINTERI
Initial dryout front position (boiloff simulations only).
XKXE
Xenon thermal conductivity $\left(B t u / h-i n .-^{\circ} \mathrm{F}\right)$.
$X M D O X(m b)$
Coolant mass flow rates in each flow region.
XOUTQ
XOUTQ
XSPRNT
Total model heat loss rate to external nodes.
Sum of system heat losses (axial, radial, and miscellaneous conduction and convection).
ZDUM(ng)
Special node output/graphics dump print interval (h).
$\operatorname{ZIP}(m 4)$
Bundle axial positions, (distances from XINTER) used when specifying initial node axial temperature variation (BLOCK 9).
Overall conductance for $\operatorname{NODE}(m 4)$, equal to sum of conductances of all internal and external thermal connections to $\mathrm{NODE}(\mathrm{m} 4)$, and conductances of all mass flow connections leading into NODE $(m 4)$.
ZRLEFT(m) Unoxidized metal remaining for each oxidizable node.
ZRNOXE(md) Node index for oxidizable nodes.
ZRTHIC(mC) Sum total thickness of all Zircaloy oxidation nodes at each axiat level.
ZRTHIK(md) Initial thickness available for oxidation for a node, input in inches, converted to meters.
ZTHCON (mc)
Sum total thickness of consumed (oxidized) Zircaloy at each axial level. 


\section{APPENDIX B}

SAMPLE PROBLEM INPUT/OUTPUT FILES 


\section{APPENDIX B}

SAMPLE PROBLEM INPUT/OUTPUT FILES

FILE NAME

IRSLBOD

OUT.OD
DESCRIPTION

Station blackout single process tube inlet half input deck

Excerpts from OUTPUT file for simulation using IRSLBOD input deck

Beginning of processed input (BLOCK 1)

B. 18

BLOCK 2--processed input

B. 19

Top portion BLOCK 4 processed input

B. 21

Top portion BLOCK 5 processed input

B.23

Top of variable internal themal connection portion of Block 5 processed input

Top portion BLOCK 6 processed input

BLOCK 7 processed input

Top portion BLOCK 9 processed input

Top portion BLOCK 10 processed input

Initialization $(\mathrm{kcyc}=0)$ time step

Time step $1($ kcyc $=1)$

Final time step $(k c y c=1610)$

B. 36

Top portion of final system summary

B. $61^{\text {. }}$

B. 62

Header to TAPE5 file from
using IRSLBOD input deck

TAPE 11.00

Header to TAPE11 file from simulation using IRSLBOD input deck

B.76

TAPE3.0F

TAPE3 file from simulation using IRSLBOF input deck 
*ver2.17 trump bd full power spiked hot chansiel reflood station blackout (hygen.tpbd.bnchmrk.sampla) block 1 problem controls, limits and constants

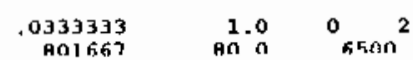

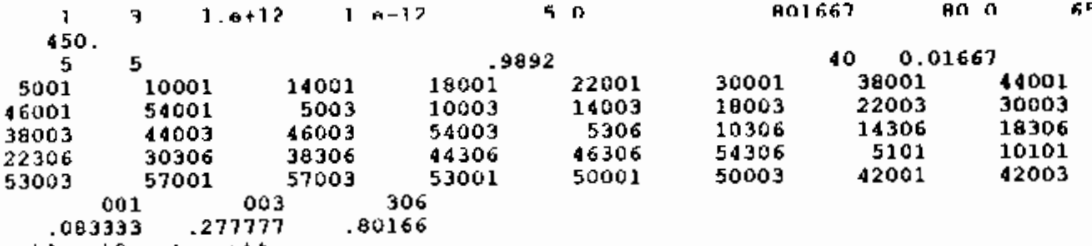

prti, prt2, prta, prtt,

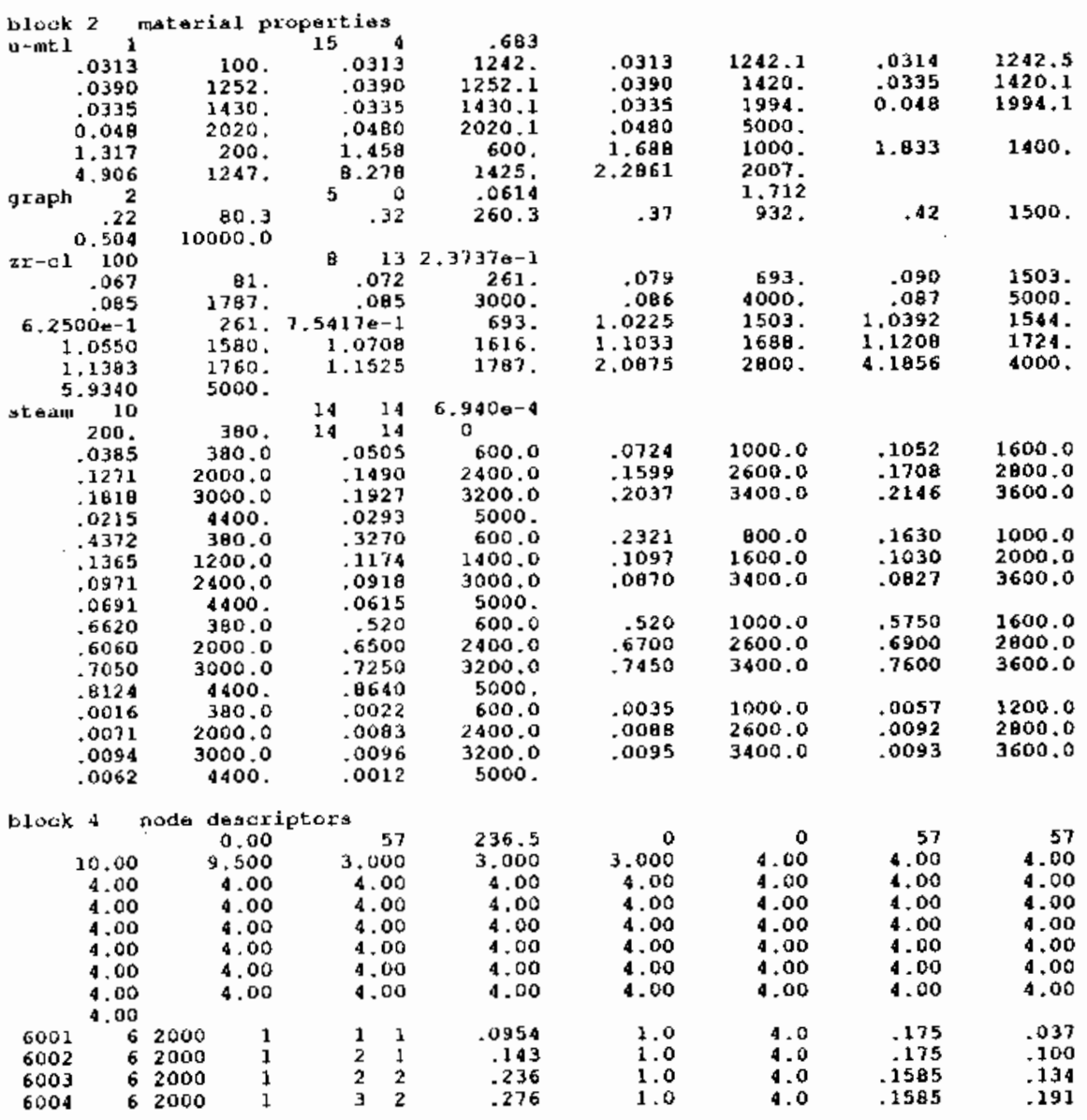




\begin{tabular}{|c|c|c|c|c|c|c|c|c|}
\hline 022 & 62000 & 100 & 2 & .02943 & 3.0 & 4.0 & .03 & 1.005 \\
\hline 304 & $\begin{array}{ll}6 & 2000 \\
6 & 2000\end{array}$ & $\begin{array}{l}100 \\
100\end{array}$ & ${ }_{3}^{2}$ & $\begin{array}{l}.027 \\
.0471\end{array}$ & $\begin{array}{l}1.0 \\
1.0\end{array}$ & $\begin{array}{l}8.0 \\
8.0\end{array}$ & .022 & $\begin{array}{l}1.336 \\
1.905\end{array}$ \\
\hline 006 & $\begin{array}{l}62000 \\
6 \quad 2000\end{array}$ & 100 & & $\begin{array}{r}047 \\
0.0\end{array}$ & $\begin{array}{l}1.0 \\
0.0\end{array}$ & 4.0 & $\begin{array}{l}0.0 \\
0.0\end{array}$ & $\begin{array}{l}1.905 \\
0.0\end{array}$ \\
\hline & $\begin{array}{lll}6 & 2000 \\
6\end{array}$ & 100 & & 0.0 & 0.0 & 4.0 & 0.0 & 0.0 \\
\hline & 62000 & 100 & & $\begin{array}{l}0.0 \\
0.0\end{array}$ & $\begin{array}{l}0.0 \\
0.0\end{array}$ & 4.0 & $\because .0$ & 0.0 \\
\hline & $\begin{array}{l}6 \\
\begin{array}{l}6 \\
6\end{array} 20000\end{array}$ & $\begin{array}{l}100 \\
300\end{array}$ & & $\begin{array}{l}0.0 \\
0.0\end{array}$ & $\begin{array}{l}0.0 \\
0.0\end{array}$ & $\begin{array}{l}4.0 \\
4.0\end{array}$ & & $\begin{array}{l}0.0 \\
0.0\end{array}$ \\
\hline 006 & 62000 & 100 & 3 & .6521 & 1.0 & 4.0 & .27875 & 2.121 \\
\hline $\begin{array}{l}307 \\
407\end{array}$ & $\begin{array}{r}6 \quad 2000 \\
6 \quad 2000\end{array}$ & $\begin{array}{l}100 \\
10\end{array}$ & 1 & $\begin{array}{l}0.0 \\
0.45\end{array}$ & 0 & 40 & & \\
\hline $\begin{array}{l}8402 \\
6402\end{array}$ & $\begin{array}{l}6 \\
62000\end{array}$ & 10 & 2 & $\begin{array}{r}.2469 \\
.2469\end{array}$ & 1.0 & 4.0 & & \\
\hline $\begin{array}{l}6403 \\
6000\end{array}$ & $\begin{array}{l}62000 \\
6 \\
6 \\
6000\end{array}$ & 10 & 3 & .2767 & $\begin{array}{l}1.0 \\
0.0\end{array}$ & $\begin{array}{l}4.0 \\
0.0\end{array}$ & & \\
\hline 6101 & 62000 & 2 & & $4.40=1$ & $2.973 \circ+0$ & 4.0 & & \\
\hline $\begin{array}{l}6102 \\
6103\end{array}$ & $\begin{array}{l}6 \quad 2000 \\
6 \quad 2000\end{array}$ & $\frac{2}{2}$ & & $\begin{array}{l}1.026+0 \\
1.929\end{array}$ & $\begin{array}{l}\begin{array}{l}.66610+0+0 \\
5.283 e-1\end{array}\end{array}$ & $\begin{array}{l}4.0 \\
4.0\end{array}$ & & \\
\hline 6110 & 62000 & 2 & & $\begin{array}{l}1.75 e r 0 \\
7\end{array}$ & .569 & 8.0 & & \\
\hline $\begin{array}{l}6111 \\
6112 \\
612\end{array}$ & $\begin{array}{l}6 \\
\begin{array}{l}6 \\
6\end{array} 20000\end{array}$ & $\frac{2}{2}$ & & $\begin{array}{l}1.75 \mathrm{e}+0 \\
1.75 \mathrm{e}+0\end{array}$ & 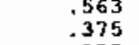 & $\begin{array}{l}8.0 \\
8.0\end{array}$ & & \\
\hline 6113 & $\begin{array}{l}62000 \\
652000\end{array}$ & 2 & & $\begin{array}{r}1.25 e+0 \\
0.0\end{array}$ & $\begin{array}{l}.375 \\
0.0\end{array}$ & $\begin{array}{l}8.0 \\
0.0\end{array}$ & & \\
\hline & 62000 & 2 & & 0.0 & 0.0 & 0.0 & & \\
\hline $\begin{aligned} 22001 \\
2000\end{aligned}$ & 04000 & 1 & $\begin{array}{ll}1 & 1 \\
2 & 1\end{array}$ & .0954 & 1.0 & 4.0 & .175 & .037 \\
\hline 0003 & $\begin{array}{l}0.000 \\
84000\end{array}$ & 1 & & $\begin{array}{l}.143 \\
.236\end{array}$ & $\begin{array}{l}1.0 \\
1.0\end{array}$ & 4.0 & .is5s & \\
\hline 004 & 84000 & 1 & & .276 & 1.0 & 4.0 & .1585 & .191 \\
\hline $\begin{array}{l}301 \\
302 \\
302\end{array}$ & $\begin{array}{l}84000 \\
84000\end{array}$ & $\begin{array}{l}100 \\
100\end{array}$ & $\frac{1}{2}$ & $\begin{array}{l}.007844 \\
0.02434\end{array}$ & 1.0 & $\begin{array}{l}4.0 \\
4.0\end{array}$ & $\begin{array}{r}.02 \\
03\end{array}$ & $\begin{array}{r}.376 \\
1.005\end{array}$ \\
\hline $\begin{array}{l}22302 \\
2203\end{array}$ & 84000 & 100 & 2 & .027 & 1.0 & 4.0 & .02 & 1.336 \\
\hline $\begin{array}{l}223040 \\
2205\end{array}$ & 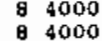 & $\begin{array}{l}100 \\
100\end{array}$ & 3 & $\begin{array}{r}.0471 \\
0.0\end{array}$ & $\begin{array}{l}1.0 \\
0.0\end{array}$ & $\begin{array}{l}4.0 \\
4.0\end{array}$ & $\begin{array}{l}.025 \\
0.0\end{array}$ & $\begin{array}{r}1.905 \\
0.0\end{array}$ \\
\hline 22311 & 8000 & 100 & & 0.0 & 0.0 & 4.0 & 0.0 & 0.0 \\
\hline $\begin{array}{l}22310 \\
2309\end{array}$ & 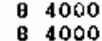 & $\begin{array}{l}100 \\
100\end{array}$ & & $\begin{array}{l}0.0 \\
0.0\end{array}$ & & & $\begin{array}{l}0.0 \\
0.0\end{array}$ & \\
\hline 22308 & 84000 & 100 & & 0.0 & 0.0 & 4.0 & 0.0 & 0.0 \\
\hline $\begin{array}{l}22306 \\
22307\end{array}$ & $\begin{array}{l}8 \\
8 \\
8\end{array} 40000$ & $\begin{array}{l}100 \\
100\end{array}$ & ${ }^{3}$ & $\begin{array}{r}.6521 \\
0.0\end{array}$ & $\begin{array}{l}1.0 \\
0.0\end{array}$ & $\begin{array}{l}8.0 \\
0.0\end{array}$ & & 2.121 \\
\hline 22401 & 84000 & 10 & 1 & .045 & 1.0 & 4.0 & & \\
\hline 22402 & 84000 & 10 & 2 & .2469 & & 4.0 & & \\
\hline $\begin{array}{l}22403 \\
22100\end{array}$ & $\begin{array}{ll}\begin{array}{ll}8 \\
\mathrm{a}\end{array} & 40000 \\
& 4000\end{array}$ & $\begin{array}{r}10 \\
2\end{array}$ & & $\begin{array}{r}.2767 \\
0.0\end{array}$ & $\begin{array}{l}1.0 \\
0.0\end{array}$ & 0.0 & & \\
\hline 22101 & 84000 & 2 & & $4.400-1$ & $2.973 \mathrm{e}+0$ & 4.0 & & \\
\hline 222103 & $\begin{array}{l}4000 \\
4000\end{array}$ & $\begin{array}{l}2 \\
2\end{array}$ & & $\begin{array}{l}1.02 \epsilon+0 \\
1.929\end{array}$ & $\begin{array}{l}3.66100+0 \\
5.2630-1\end{array}$ & 4.0 & & \\
\hline 22110 & & & & $1.750+0$ & & 9.0 & & \\
\hline 22111 & & 2 & & $1.75 e r 0$ & & & & \\
\hline $\begin{array}{l}22112 \\
22113\end{array}$ & $\begin{array}{ll}0 & 4000 \\
8 & 4000\end{array}$ & $\frac{2}{2}$ & & $\begin{array}{l}1.75 e+0 \\
1.25 e 10\end{array}$ & 37 & 8.0 & & \\
\hline 22114 & 84000 & 2 & & 0.0 & 0.0 & 0.9 & & \\
\hline 22104 & & & & 0.0 & & & & \\
\hline & & & & 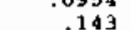 & & & 475 & 100 \\
\hline 7003 & 200 & & & .236 & & & .1585 & :134 \\
\hline 200 & 2000 & 1 & 2 & .276 & & & .2585 & .191 \\
\hline 7301 & 2000 & 100 & $?$ & .00784 & & & .02 & .376 \\
\hline & & 100 & 2 & .037 & & & .02 & $\begin{array}{l}1.005 \\
1.336\end{array}$ \\
\hline 304 & 2000 & 100 & 3 & .0471 & & & .025 & 1.905 \\
\hline 305 & 2000 & 100 & & 0.0 & & & 0.0 & 0.0 \\
\hline 3. & 2000 & 100 & & & & & 0.0 & 0.0 \\
\hline & & 100 & & & & & 0.0 & 0.0 \\
\hline & 2000 & 100 & & & & & 0.0 & \\
\hline 106 & 000 & 100 & 3 & .6521 & & & .27875 & 2.121 \\
\hline
\end{tabular}




\begin{tabular}{|c|c|c|c|c|c|c|c|c|c|}
\hline 7307 & 52000 & 100 & & & 0.0 & 0.0 & 0.0 & & \\
\hline 1901 & $3<$ <ulw & iu & 1 & & .045 & i.u & 4.0 & & \\
\hline 7402 & 52000 & 10 & 2 & & .2469 & 1.0 & 4.0 & & \\
\hline 7403 & 52000 & 10 & 3 & & .2767 & 1.0 & 4.0 & & \\
\hline 7100 & 52000 & 2 & & & 0.0 & 0.0 & 0.0 & & \\
\hline 7101 & 52000 & 2 & & & $4.400-1$ & $2.9730+0$ & 4,0 & & \\
\hline 7102 & 52000 & 2 & & & $1.02 a+0$ & $3.661 \mathrm{e}+0$ & 4.0 & & \\
\hline 7103 & 52000 & 2 & & & 1.929 & $5.283 \theta-1$ & 40 & & \\
\hline 1110 & 52000 & 2 & & & $1.75 e+0$ & .563 & 0.0 & & \\
\hline 7111 & 52000 & 2 & & & $1.75 e+0$ & .563 & 9.0 & & \\
\hline 7112 & 52000 & 2 & & & $1.75 e+0$ & 375 & 8.0 & & \\
\hline 7113 & 52000 & 2 & & & 1.25 a 00 & .375 & B. 0 & & \\
\hline 7104 & 52000 & 2 & & & 0.0 & 0.0 & 0.0 & & \\
\hline 7114 & 52000 & 2 & & & 0.0 & 0.0 & 0.0 & & \\
\hline 21001 & 94000 & 1 & 1 & 1 & .0954 & 1.0 & 4.0 & .175 & .037 \\
\hline $\begin{array}{l}21002 \\
21003\end{array}$ & $\begin{array}{l}94000 \\
94000\end{array}$ & $\begin{array}{l}1 \\
1 \\
\end{array}$ & 2 & $\frac{1}{2}$ & $\begin{array}{l}-143 \\
236\end{array}$ & $\begin{array}{l}1.0 \\
1.0\end{array}$ & $\begin{array}{l}4.0 \\
4.0\end{array}$ & .1585 & $\begin{array}{r}100 \\
.134\end{array}$ \\
\hline 23004 & 94000 & 1 & 3 & 2 & .276 & 1.0 & 4.0 & .1585 & .191 \\
\hline $\begin{array}{l}21300 \\
21301\end{array}$ & 94000 & 100 & 1 & 2 & .00704 & 1.0 & 4.0 & .02 & .376 \\
\hline 21302 & 94000 & 100 & 2 & & .02943 & 1.0 & 4.0 & .03 & 1.005 \\
\hline 21303 & 94000 & 100 & 2 & & .027 & 1.0 & 4.0 & .02 & 1.336 \\
\hline 21304 & 94000 & 100 & 3 & & .0471 & 1.0 & 4.0 & .025 & 1.905 \\
\hline 21305 & 94000 & 100 & & & 0.0 & 0.0 & 4.0 & 0.0 & 0.0 \\
\hline 21311 & 94000 & 100 & & & 0,0 & 0.0 & 4.0 & 0.0 & 0.0 \\
\hline 21310 & 94000 & 100 & & & 0.0 & 0.0 & 4.0 & 0.0 & 0.0 \\
\hline 21309 & 94000 & 100 & & & 0.0 & 0.0 & 4.0 & 0.0 & 0.0 \\
\hline 21308 & 94000 & 100 & & & 0.0 & 0.0 & 4.0 & 0.0 & 0.0 \\
\hline 21306 & 94000 & 100 & 3 & & .6521 & 1,0 & 4.0 & .27875 & 2.121 \\
\hline 21307 & 9000 & 100 & & & 0.0 & 0.0 & 0.0 & & \\
\hline 21401 & 94000 & 10 & 1 & & .045 & 1.0 & 4.0 & & \\
\hline 21402 & 94000 & 10 & 2 & & .2469 & 1.0 & 4.0 & & \\
\hline 21403 & 94000 & 10 & 3 & & .2767 & 1.0 & 4.0 & & \\
\hline 21100 & 94000 & 2 & & & 0.0 & 0.0 & 0.0 & & \\
\hline 21101 & 94000 & 2 & & & $4.400-1$ & $2.973 \mathrm{e}+0$ & 1.0 & & \\
\hline 21102 & 94000 & $\hat{2}$ & & & $1.02 \theta+0$ & $3.66 l e+0$ & 4.0 & & \\
\hline 21103 & 94000 & 2 & & & 1.929 & $5.2630-1$ & 4.0 & & \\
\hline 23104 & 94000 & 2 & & & 0.0 & 0.0 & 0.0 & & \\
\hline 21110 & 94000 & 2 & & & $1.75 e+0$ & .563 & 8.0 & & \\
\hline 21111 & 94000 & 2 & & & $1.750+0$ & .563 & B. 0 & & \\
\hline 21112 & 94000 & 2 & & & $1.75 \theta+0$ & .375 & a. 0 & & \\
\hline 21113 & 94000 & 2 & & & $1.25 \theta+0$ & .375 & a. 0 & & \\
\hline 21114 & 94000 & 2 & & & 0.0 & 0.0 & 0.0 & & \\
\hline 19001 & 94000 & 1 & 1 & 1 & .0954 & 1.0 & 4.0 & .175 & .037 \\
\hline 19002 & 94000 & 1 & 2 & 1 & .143 & 1.0 & 4.0 & .175 & .100 \\
\hline 19003 & 94000 & 1 & 2 & 2 & .236 & 1.0 & 4.0 & .1585 & .134 \\
\hline 19004 & 94000 & 1 & 3 & 2 & & 1.0 & 4.0 & .1585 & .191 \\
\hline 19301 & 94000 & $100^{\circ}$ & 1 & & .00784 & 1.0 & 4.0 & .02 & 3765 \\
\hline 29302 & 94000 & 100 & 2 & & .02943 & 1.0 & $\therefore 0$ & .03 & $i .005$ \\
\hline 19303 & 94000 & 100 & 2 & & 027 & 1.0 & 4.0 & .02 & 1.336 \\
\hline 19304 & 94000 & 100 & 3 & & .0471 & 1.0 & 4.0 & .025 & 1.905 \\
\hline 19305 & 94000 & 100 & & & 0.0 & 0.0 & 4.0 & 0.0 & 0.0 \\
\hline 19311 & 94000 & 300 & & & 0.0 & 0.0 & 4.0 & 0.0 & 0.0 \\
\hline 19310 & 94000 & 100 & & & 0.0 & 0.0 & 4. 0 & 0.0 & 0.0 \\
\hline 19309 & 94000 & 100 & & & 0.0 & 0.0 & 4.0 & 0.0 & 0.0 \\
\hline 19308 & 94000 & 100 & & & 0.0 & 0.0 & 4.0 & 0.0 & 0.0 \\
\hline 19306 & 94000 & 100 & 3 & & .6521 & 1.0 & 4.0 & .27875 & 2.121 \\
\hline 19307 & 94000 & 100 & & & 0.0 & 0.0 & 0.0 & & \\
\hline 19401 & 94000 & 10 & 1 & & .045 & 1.0 & 4.0 & & \\
\hline 19402 & 94000 & 10 & 2 & & 2469 & 1.0 & 4.0 & & \\
\hline 19403 & 94000 & 10 & 3 & & .2767 & 1.0 & 4.0 & & \\
\hline 19100 & 94000 & 2 & & & 0.0 & 0.0 & 0.0 & & \\
\hline 19101 & 94000 & 2 & & & 9. 40 e-1 & $2.973 e+0$ & 4.0 & & \\
\hline 19302 & 94000 & 2 & & & $1.02 \theta+0$ & $3.661 \mathrm{e}+0$ & 4.0 & & \\
\hline 19203 & 94000 & 2 & & & 1.929 & $5.263 e-1$ & 4.0 & & \\
\hline 19104 & 94000 & 2 & & & 0.0 & 0.0 & 0.0 & & \\
\hline 19120 & 94000 & 2 & & & 6.00e-1 & .542 & 0.0 & & \\
\hline
\end{tabular}




\begin{tabular}{|c|c|c|c|c|c|c|c|c|}
\hline 19121 & $\begin{array}{l}94000 \\
0\end{array}$ & 2 & & $8.7500-1$ & 2.310 & 8.0 & & \\
\hline $\begin{array}{l}19122 \\
19123\end{array}$ & $\begin{array}{l}94000 \\
9\end{array}$ & 2 & & $1.75 a+0$ & .625 & 8.0 & & \\
\hline & $\begin{array}{l}94000 \\
94000\end{array}$ & 2 & & & $\begin{array}{l}.809 \\
0.0\end{array}$ & 0.0 & & \\
\hline 19125 & 94000 & 2 & & 0.0 & 0.0 & 0.0 & & \\
\hline 19126 & $\begin{array}{l}94000 \\
0\end{array}$ & 100 & & $\begin{array}{r}0.0 \\
250=2\end{array}$ & & $\begin{array}{l}8.0 \\
8.0\end{array}$ & & \\
\hline $\begin{array}{l}19127 \\
19128\end{array}$ & 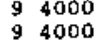 & $\begin{array}{l}100 \\
100\end{array}$ & 4 & $\begin{array}{l}1.250 \mathrm{e}-2 \\
1.250 \mathrm{e}-2\end{array}$ & $\begin{array}{l}2.896 \mathrm{a-1} \\
2.798 \mathrm{g-1}\end{array}$ & $\begin{array}{l}8.0 \\
8.0\end{array}$ & $\begin{array}{l}1.250 e-2 \\
1.250 e-2\end{array}$ & $\begin{array}{l}2.8478-1 \\
2.749 \mathrm{e}-1\end{array}$ \\
\hline 19129 & & 100 & & & & & & \\
\hline $\begin{array}{r}19404 \\
401\end{array}$ & 94000 & $\begin{array}{l}10 \\
10\end{array}$ & 4 & .0962 & 1.0 & 8.0 & & \\
\hline $\begin{array}{l}401 \\
001 \\
022\end{array}$ & $\begin{array}{l}9 \\
9\end{array} 4000$ & 1 & 11 & .0954 & 1.0 & 4.0 & .175 & .037 \\
\hline & $\begin{array}{l}94000 \\
9 \\
9\end{array} 40000$ & $\begin{array}{l}1 \\
1\end{array}$ & $\begin{array}{ll}2 & 1 \\
2 & 2 \\
2\end{array}$ & $\begin{array}{l}.143 \\
.236\end{array}$ & $\begin{array}{l}1.0 \\
1.0\end{array}$ & $\begin{array}{l}4.0 \\
4.0\end{array}$ & .1585 & $\begin{array}{l}.100 \\
.134\end{array}$ \\
\hline & 4000 & & 32 & .276 & 1.0 & 4.0 & .1505 & .191 \\
\hline 20 & $\begin{array}{l}4000 \\
4000\end{array}$ & $\begin{array}{l}100 \\
100\end{array}$ & $\frac{1}{2}$ & $\begin{array}{l}.00794 \\
0.0943\end{array}$ & 1.0 & 4.0 & .02 & 3765 \\
\hline 20303 & $\begin{array}{ll}9 & 9000 \\
9 & 4000\end{array}$ & 100 & 2 & & $\begin{array}{l}1.0 \\
1.0\end{array}$ & $\begin{array}{l}9.0 \\
4.0\end{array}$ & .02 & $\begin{array}{l}1.005 \\
1.336\end{array}$ \\
\hline 304 & 94000 & 100 & 3 & .0471 & 3.0 & 4.0 & .025 & 1.905 \\
\hline & $\begin{array}{l}4000 \\
4000\end{array}$ & $\begin{array}{l}100 \\
100\end{array}$ & & & $\begin{array}{l}0.0 \\
0.0\end{array}$ & $\begin{array}{l}4.0 \\
4.0\end{array}$ & 0.0 & 0.0 \\
\hline & 4000 & 100 & & $\begin{array}{l}\begin{array}{l}0.0 \\
0.0\end{array}\end{array}$ & $\begin{array}{l}0.0 \\
0.0\end{array}$ & 4.0 & $\begin{array}{l}0.0 \\
0.0\end{array}$ & 0.0 \\
\hline & 94000 & 100 & & 0.0 & 0.0 & 4.0 & 0.0 & .0 \\
\hline 20300 & 94000 & 100 & & 0.0 & 0.0 & 4.0 & 0.0 & .0 \\
\hline & 4000 & 100 & 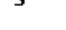 & .6521 & $\begin{array}{l}1.0 \\
0.0\end{array}$ & $\begin{array}{l}8.0 \\
0.0\end{array}$ & .27875 & 2,121 \\
\hline & 4000 & 10 & 1 & .045 & 1.0 & 4.0 & & \\
\hline & 4000 & 10 & 2 & .2469 & 1.0 & 4.0 & & \\
\hline $\begin{array}{l}20403 \\
20100\end{array}$ & $\begin{array}{l}98000 \\
9 \\
9\end{array}$ & $\begin{array}{r}10 \\
2 \\
2\end{array}$ & & $\begin{array}{r}.2767 \\
0.0\end{array}$ & $\begin{array}{l}1.0 \\
0.0\end{array}$ & $\begin{array}{l}4.0 \\
0.0\end{array}$ & & \\
\hline $\begin{array}{l}20101 \\
20102\end{array}$ & $\begin{array}{l}94000 \\
9 \\
9\end{array}$ & $\begin{array}{l}2 \\
2\end{array}$ & & $\begin{array}{l}4.400-1 \\
1.02 e+0\end{array}$ & $\begin{array}{l}2.973 e+0 \\
3.66 l e+0\end{array}$ & $\begin{array}{l}4.0 \\
4.0\end{array}$ & & \\
\hline 20103 & $\begin{array}{l}9 \\
9\end{array}$ & 2 & & $\begin{array}{l}1.929 \\
\end{array}$ & $5.283 e-1$ & 4.0 & & \\
\hline $\begin{array}{l}20104 \\
20120\end{array}$ & $\begin{array}{ll}9 & 4000 \\
9 & 4000\end{array}$ & $\frac{2}{2}$ & & $\begin{array}{r}0.0 \\
6.000-1\end{array}$ & $\begin{array}{r}0.0 \\
.542\end{array}$ & $\begin{array}{l}0.0 \\
8.0\end{array}$ & & \\
\hline 20121 & 94000 & 2 & & $\begin{array}{l}8.7500-1 \\
i .7500\end{array}$ & $\begin{array}{r}1.310 \\
625\end{array}$ & $\begin{array}{l}8.0 \\
80\end{array}$ & & \\
\hline $\begin{array}{l}20122 \\
20123\end{array}$ & $\begin{array}{ll}9 & 4000 \\
9 & 4000\end{array}$ & $\begin{array}{l}2 \\
2\end{array}$ & & $\begin{array}{l}1.75+0 \\
1.00 \mathrm{\theta}+0\end{array}$ & $\begin{array}{l}.625 \\
.469\end{array}$ & $\begin{array}{l}8.0 \\
8.0\end{array}$ & & \\
\hline $\begin{array}{l}20124 \\
20125\end{array}$ & $\begin{array}{ll}9 & 4000 \\
9 & 4000\end{array}$ & 2 & & $\begin{array}{l}0.0 \\
0.0\end{array}$ & $\begin{array}{l}0.0 \\
0.0\end{array}$ & $\begin{array}{l}0.0 \\
0.0\end{array}$ & & \\
\hline 20126 & 94000 & 100 & & 0.0 & 0.0 & 8.0 & & \\
\hline $\begin{array}{l}20127 \\
20128\end{array}$ & $\begin{array}{l}94000 \\
9 \\
9\end{array} 4000$ & $\begin{array}{l}100 \\
100\end{array}$ & ${ }_{4}^{4}$ & $\begin{array}{l}1.2500-2 \\
1.2500-2\end{array}$ & $\begin{array}{l}2.060 \mathrm{Q1} \\
2.79 \mathrm{~B}-1\end{array}$ & $\begin{array}{l}8.0 \\
8.0\end{array}$ & $\begin{array}{l}1.250 \mathrm{a}-2 \\
1.250 \mathrm{e}-2\end{array}$ & $\begin{array}{l}2.8470-1 \\
2.7496-1\end{array}$ \\
\hline & & $\begin{array}{l}100 \\
100\end{array}$ & & 0.0 & 0.0 & & & \\
\hline $\begin{array}{r}20404 \\
5100\end{array}$ & 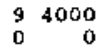 & 10 & 4 & .0962 & $\begin{array}{r}1.0 \\
1.50\end{array}$ & $\begin{array}{l}8.0 \\
0.0\end{array}$ & & \\
\hline $\begin{array}{l}5118 \\
5128\end{array}$ & $\begin{array}{l}0 \\
0\end{array}$ & $\frac{2}{2}$ & & $\begin{array}{l}3.70 \\
1.70\end{array}$ & $\begin{array}{l}1.50 \\
3.00\end{array}$ & 0.0 & & \\
\hline & 0 & 2 & & $\begin{array}{l}1.10 \\
2,30\end{array}$ & 1.50 & 0.0 & & \\
\hline & 0 & $z$ & & 1.70 & 1.50 & 0.0 & & \\
\hline $\begin{array}{l}2128 \\
4108 \\
4\end{array}$ & 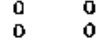 & 2 & & $\begin{array}{l}1.70 \\
2.30\end{array}$ & $\begin{array}{l}\begin{array}{l}.00 \\
5.50\end{array} \\
5\end{array}$ & $\begin{array}{l}0.0 \\
0.0\end{array}$ & & \\
\hline 4118 & 0 & 2 & & 3.00 & 5.50 & 0.0 & & \\
\hline $\begin{array}{l}5001 \\
5002\end{array}$ & $\begin{array}{l}0 \\
0 \\
0\end{array}$ & $\begin{array}{l}1 \\
1\end{array}$ & $\begin{array}{ll}1 & 1 \\
2 & 1\end{array}$ & $\begin{array}{r}.0954 \\
.149\end{array}$ & $\begin{array}{l}1.0 \\
1.0\end{array}$ & 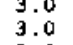 & $\begin{array}{l}-175 \\
: 175\end{array}$ & $\begin{array}{l}.037 \\
.100\end{array}$ \\
\hline & 0 & 1 & $\begin{array}{ll}2 & 2 \\
3 & 2\end{array}$ & $\begin{array}{l}.236 \\
276\end{array}$ & $\begin{array}{l}1.0 \\
1.0 \\
0\end{array}$ & $\begin{array}{l}3.0 \\
3.0\end{array}$ & $\begin{array}{r}1585 \\
.1585 \\
158\end{array}$ & .134 \\
\hline & 0 & 100 & $1^{2}$ & .00784 & $\begin{array}{l}1.0 \\
1.0\end{array}$ & & & .3796 \\
\hline & 0 & 100 & 2 & 02943 & & & .03 & 1.005 \\
\hline & 0 & 100 & 2 & .027 & 1.0 & & .02 & 1.3936 \\
\hline & 0 & $\begin{array}{l}100 \\
100\end{array}$ & & .0471 & 1.0 & 3 & $\begin{array}{r}.025 \\
0.0\end{array}$ & 1.905 \\
\hline 5308 & 0 & 100 & & 0.0 & 0.0 & & 0.0 & $\begin{array}{l}0.0 \\
0.0\end{array}$ \\
\hline & 0 & 100 & & 0.0 & 0 . & 3.0 & 0.0 & 0.0 \\
\hline 5309 & 0 & 100 & & 0.0 & 0.0 & .0 & 0.0 & 0.0 \\
\hline
\end{tabular}




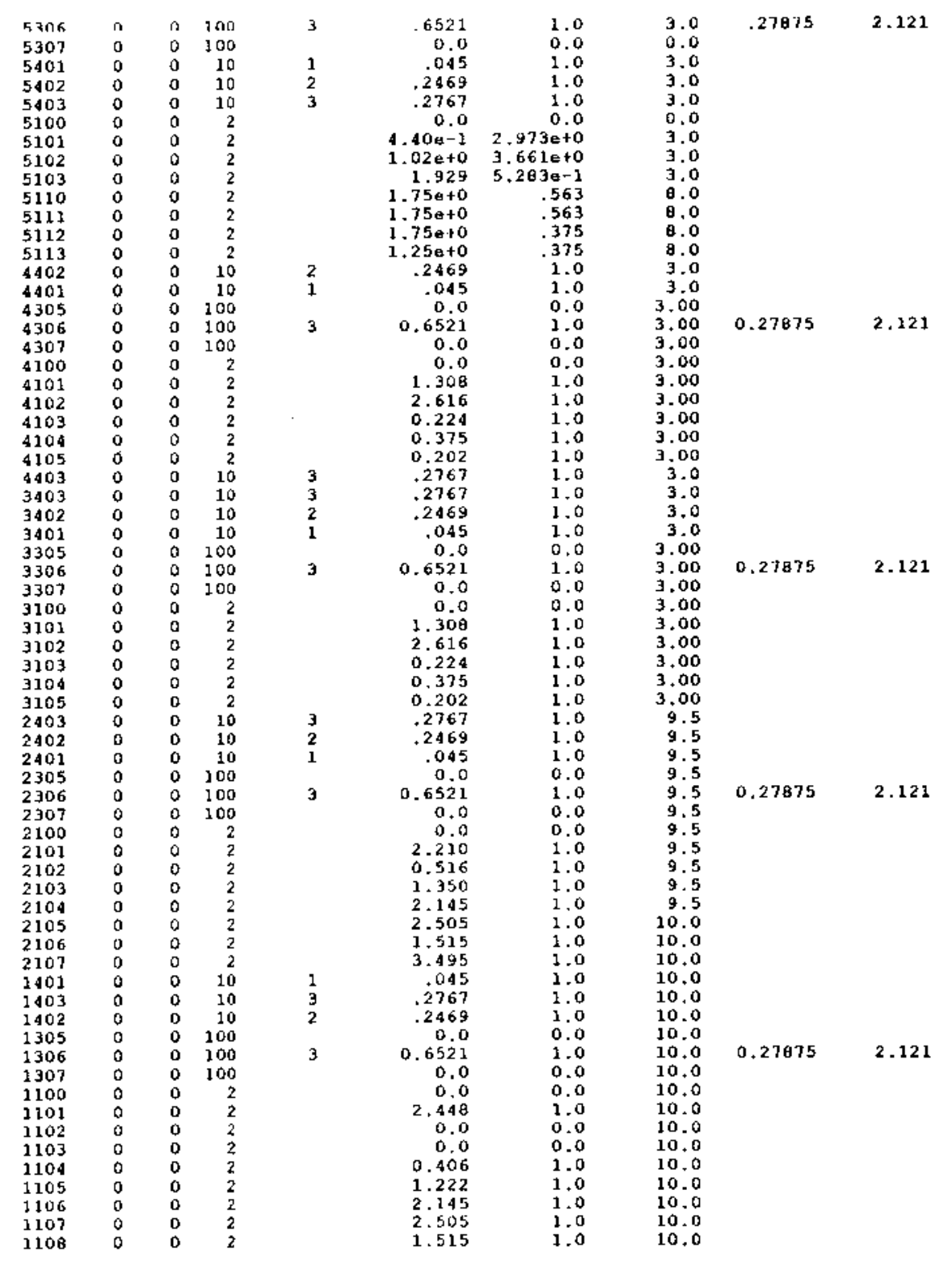




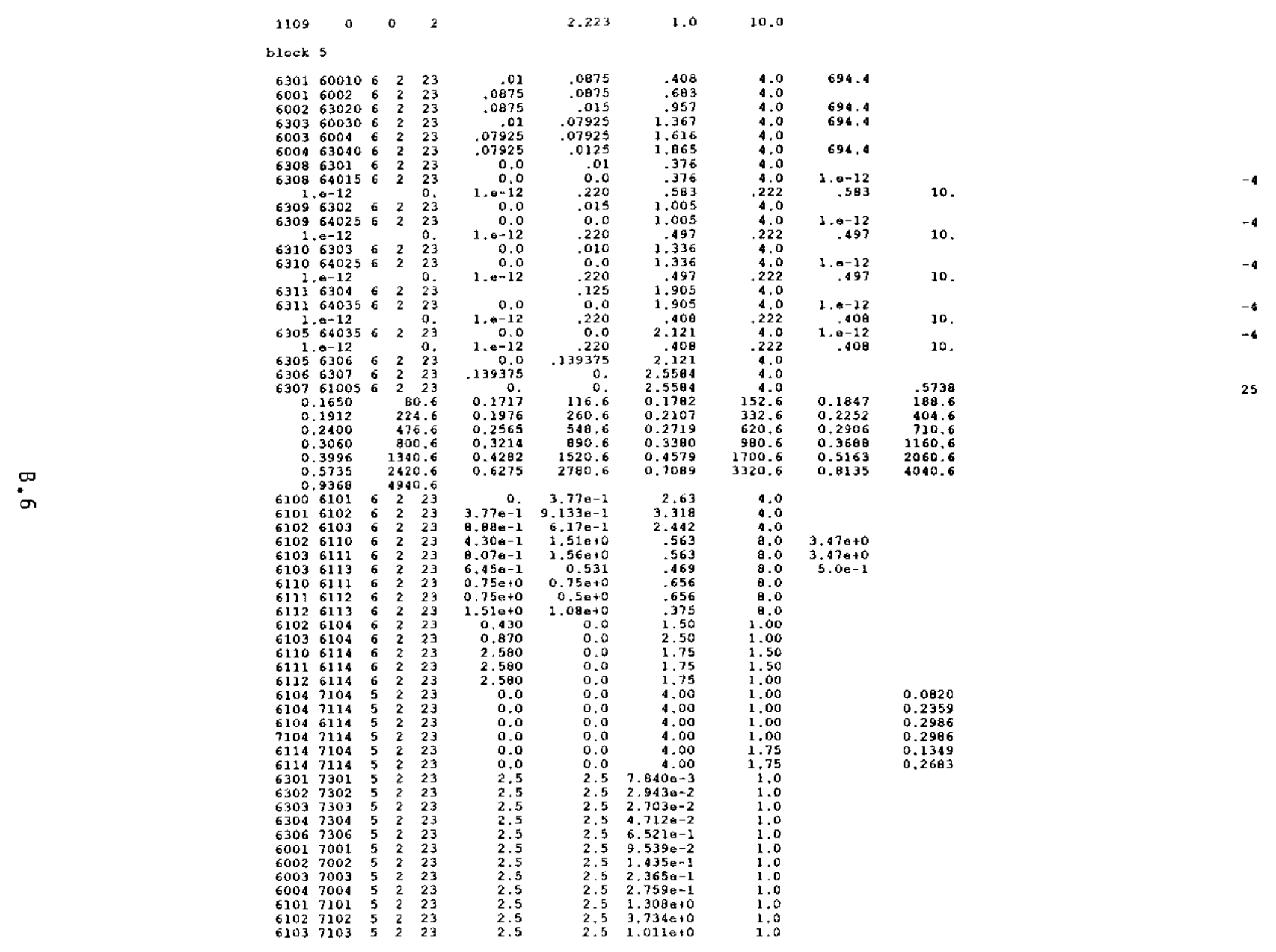




\begin{tabular}{|c|c|c|c|c|c|c|c|c|c|}
\hline 7301 & 70010 & 5 & 2 & 23 & .01 & .0875 & .408 & 4.0 & 694,4 \\
\hline TuNs & ivie & $\vdots$ & 2 & 25 & .0015 & .0013 & .009 & 4,0 & \\
\hline 7002 & 73020 & 5 & 2 & 23 & .0835 & .015 & .957 & 4.0 & 694.4 \\
\hline 7303 & 70030 & 5 & 2 & 23 & .01 & .07925 & 1.367 & 4.0 & 694.4 \\
\hline 7003 & 7004 & 5 & 2 & 23 & .07925 & .07925 & 1.616 & 4.0 & \\
\hline 7004 & 73040 & 5 & 2 & 23 & .07925 & .0125 & 1.865 & 4.0 & 694.4 \\
\hline 7308 & 2301 & 5 & 2 & 23 & 0.0 & +01 & .376 & 4.0 & \\
\hline 7308 & 74015 & 5 & 2 & 23 & 0.0 & 0.0 & .376 & 4.0 & 1. $0-12$ \\
\hline 1. & $e-12$ & & 0 & 0. & $1 . e-12$ & .220 & .583 & .222 & .583 \\
\hline 7309 & 7302 & 5 & 2 & 23 & & .015 & 1,005 & 4.0 & \\
\hline 7309 & $\$ 4025$ & 5 & 2 & 23 & 0.0 & 0.0 & 2.005 & 4.0 & $1.0-12$ \\
\hline & $e-12$ & & & 0. & $1.6-12$ & .220 & .497 & .222 & .497 \\
\hline 7310 & 7303 & 5 & 2 & 23 & 0.0 & .010 & 1.336 & 4.0 & \\
\hline 7310 & 74025 & & 2 & 23 & 0.0 & 0.0 & 1.336 & $\begin{array}{r}4.0 \\
.222\end{array}$ & $1.0-12$ \\
\hline 731. & $\begin{array}{l}\cdot 0-12 \\
7304\end{array}$ & & 2 & 23 & $1.0-12$ & .220 & $\begin{array}{r}-497 \\
1.905\end{array}$ & 4.0 & \\
\hline 7311 & 74035 & 5 & 2 & 23 & 0.0 & 0.0 & 1.905 & 4.0 & $1 .-12$ \\
\hline & $e^{-12}$ & & & 0. & $1 . e-12$ & .220 & .408 & 222 & .408 \\
\hline 7305 & 74035 & 5 & 2 & 23 & & 0.0 & 2.121 & 4.0 & $1.0-$ \\
\hline & $\theta-12$ & & & 0. & $1 . e-12$ & .220 & .400 & & .108 \\
\hline 7305 & 7306 & 5 & 2 & 23 & & .139375 & 2.121 & 4.0 & \\
\hline 7306 & 7307 & 5 & & 23 & .139375 & 0 & 2.5504 & 4.0 & \\
\hline 7307 & 71005 & & & 23 & & 0 & 2.5504 & 4. 0 & \\
\hline & .1650 & & 80. & .6 & 0.1717 & 116.6 & 0.1782 & 152.6 & 0.1847 \\
\hline & .1912 & & 224. & & 0.1976 & 260.6 & 0.2107 & 332.6 & 0.2252 \\
\hline & .2400 & & 476. & & 0.2565 & 548.6 & 0.2719 & 620.6 & 0.2906 \\
\hline & .3060 & & 600. & & 0.3214 & 890.6 & 0.3380 & 980.6 & 0.3688 \\
\hline & .3996 & & $\begin{array}{l}1340 . \\
2420\end{array}$ & & $\begin{array}{l}0.4282 \\
0.6275\end{array}$ & $\begin{array}{l}1520.6 \\
2700.6\end{array}$ & 0.4579 & 1700.6 & 0.5163 \\
\hline & .9368 & & 4940. & & & & & & 0.8135 \\
\hline 7100 & 7101 & 5 & 22 & 23 & 0. & $3.77 e-1$ & 2.63 & 4.0 & \\
\hline 7101 & 7102 & & 2 & 23 & $3.77 \mathrm{e}-1$ & $9,193 \mathrm{e}-1$ & 3.318 & 4,0 & \\
\hline 7102 & 7103 & 5 & 2 & 23 & B.eBe-1 & $6.170-1$ & 2.442 & 4.0 & \\
\hline 7102 & 7110 & 5 & $\overline{2}$ & 23 & $4.30 \mathrm{e}-1$ & $1.510+0$ & .563 & 0.0 & $7.47 e+0$ \\
\hline 7103 & 3111 & 5 & 2 & 23 & $0.07 e-1$ & $1.56 \mathrm{e}+0$ & .563 & 8.0 & $3.47 \mathrm{e}+0$ \\
\hline 7103 & 2113 & 5 & 2 & 23 & 6.45 e- 1 & 0.531 & .469 & 8.0 & $5.0 e-1$ \\
\hline 7110 & 7111 & 5 & 2 & 23 & $0.75 \mathrm{e}+0$ & $0.75 \mathrm{e}+0$ & .656 & 8.0 & \\
\hline 7111 & 7112 & 5 & 2 & 23 & $0.75 e+0$ & $0.5 \theta+0$ & .656 & a. 0 & \\
\hline 7112 & 7113 & 5 & 2 & 23 & $1.510+0$ & $1.080+0$ & .375 & 0.0 & \\
\hline 3102 & 3104 & 5 & 2 & 23 & 0.430 & 0.0 & 1.50 & 1.00 & \\
\hline 7103 & 7104 & 5 & 2 & 23 & 0.870 & 0.0 & 2.50 & 1.00 & \\
\hline 7110 & 7114 & 5 & 2 & 23 & 2.580 & 0.0 & 1.75 & 1.50 & \\
\hline iiji & 7114 & 5 & 2 & 23 & 2.500 & 0.0 & 1.75 & 2.50 & \\
\hline 7112 & 7114 & 5 & 2 & 23 & $2.5 B 0$ & 0.0 & 1.75 & 1,00 & \\
\hline 3301 & 8301 & 5 & 2 & 23 & 1.5 & 1.5 & $7.040 a-3$ & 1.0 & \\
\hline 7302 & 0302 & 5 & 2 & 23 & 1.5 & 1.5 & $2.943 \theta-2$ & 1.0 & \\
\hline 7303 & $\theta 303$ & 5 & 2 & 23 & 1.5 & 1.5 & $2.703 e-2$ & 2.0 & \\
\hline 7304 & 0304 & 5 & 2 & 23 & 1.5 & 1.5 & $4.712 e-2$ & 1.0 & \\
\hline 7306 & 8306 & 5 & 2 & 23 & 1.5 & 1.5 & $6.521 \mathrm{e}-1$ & 1.0 & \\
\hline 7001 & 8001 & 5 & 2 & 23 & 1.5 & 1.5 & $9.539 e-2$ & 1.0 & \\
\hline 7002 & 8002 & 5 & 2 & 23 & 1.5 & 1.5 & $1.4350-1$ & 1.0 & \\
\hline 7003 & 6003 & 5 & 2 & 23 & 1.5 & 1.5 & $2.365 e-1$ & 1.0 & \\
\hline 7004 & 8004 & 5 & 2 & 23 & 1.5 & 1.5 & $2.759 \mathrm{e}-1$ & 1.0 & \\
\hline 7101 & B101 & 5 & 2 & 23 & 1.5 & 1.5 & $1.308 e+0$ & 1.0 & \\
\hline 7102 & 8102 & 5 & 2 & 23 & 1.5 & 1.5 & $3.734 t+0$ & 1.0 & \\
\hline 7103 & 8103 & 5 & 2 & 23 & 1.5 & 1,5 & $1.0110+0$ & 1.0 & \\
\hline 7110 & 8110 & 5 & 2 & 23 & 2.58 & 2.58 & 1.75 & 1.50 & \\
\hline 7111 & Q 113 & $\mathbf{s}$ & 2 & 23 & 2.58 & 2.58 & 1.75 & 1.50 & \\
\hline 1112 & 0112 & 5 & 2 & 23 & 2.59 & 2.58 & 1.75 & 1.00 & \\
\hline 7113 & 8113 & 5 & 2 & 23 & $2+58$ & $\begin{array}{l}2.58 \\
0075\end{array}$ & $\begin{array}{l}3.25 \\
400\end{array}$ & $\begin{array}{l}1.00 \\
4.0\end{array}$ & 694.4 \\
\hline & 220010 & 8 & 4 & 43 & .0875 & .0835 & $\begin{array}{r}.408 \\
.683\end{array}$ & 4.0 & \\
\hline 220022 & 223020 & 8 & 4 & 43 & .0875 & .015 & 957 & 4.0 & 694.4 \\
\hline 223032 & 220030 & 8 & 4 & 43 & .01 & 07925 & 1.367 & & 694.4 \\
\hline & 200 & 8 & 4 & 43 & .07925 & $0 ? 925$ & 1.616 & & \\
\hline 220042 & 223040 & $\mathrm{~g}$ & 4 & 43 & .07925 & .0125 & 1.865 & 4.0 & 694.4 \\
\hline
\end{tabular}




\begin{tabular}{|c|c|c|c|c|c|c|}
\hline 2230822301 & $\theta$ & 4 & 43 & 0.0 & .01 & .376 \\
\hline 22308224015 & B & 4 & ${ }_{0}^{43}$ & 0.0 & $\begin{array}{l}0.0 \\
220\end{array}$ & $\begin{array}{r}376 \\
+583\end{array}$ \\
\hline $\begin{array}{r}1 \cdot e^{-12} \\
23092302\end{array}$ & 8 & 4 & 0 & $1.0-12$ & $\begin{array}{r}220 \\
.015\end{array}$ & $\begin{array}{r}.583 \\
1.005\end{array}$ \\
\hline $2 \angle 309224025$ & 8 & 4 & $\begin{array}{l}91 \\
43\end{array}$ & 0.0 & 0.0 & 7.005 \\
\hline $1.0-12$ & & & o. & 1.e -12 & .220 & .497 \\
\hline 2231022303 & B & 4 & 43 & 0.0 & .010 & 2. 336 \\
\hline 22310224025 & 8 & 4 & 43 & 0.0 & 0.0 & 1.336 \\
\hline $1 . e-12$ & & & 0. & $1 .-12$ & .220 & .497 \\
\hline 2231122304 & 8 & 4 & 43 & & .125 & 1.905 \\
\hline 22311224035 & a & d & $4^{3}$ & $\begin{array}{r}0.0 \\
0-12\end{array}$ & $\begin{array}{l}0.0 \\
220\end{array}$ & $\begin{array}{l}1.905 \\
400\end{array}$ \\
\hline $12=8-12$ & a & 4 & 43 & $\begin{array}{r}1, e-12 \\
0.0\end{array}$ & $\begin{array}{r}220 \\
0.0\end{array}$ & 2.121 \\
\hline $1,-12$ & & & 0. & $1.0-12$ & .220 & .400 \\
\hline 2230522306 & $\theta$ & 4 & 43 & 0.0 & .139375 & 2.121 \\
\hline 230622307 & $\theta$ & & 43 & .139375 & 0 & 2.5584 \\
\hline 2307221005 & 日 & & 43 & & 0. & 2.5584 \\
\hline 0.1650 & & & 0.6 & 0.3717 & 116.6 & 0.1782 \\
\hline 0.1912 & & & 4.6 & 0.1976 & 260.6 & 0.2307 \\
\hline 0.2400 & & & & 0.2565 & 548.6 & 0.2719 \\
\hline 0.3060 & & & 0.6 & 0.3214 & 090.6 & 0.3380 \\
\hline 0.3996 & & 134 & 0.6 & 0.4282 & 1520.6 & 0.4579 \\
\hline 0.5735 & & & & 0.6275 & 2780.6 & 0.7089 \\
\hline 0.9368 & & 494 & & & & \\
\hline $\begin{array}{l}2210022101 \\
221012203\end{array}$ & 8 & 4 & 43 & 3. $37 e^{0}-1$ & $\begin{array}{r}3.77 t-1 \\
9.1330-1\end{array}$ & $\begin{array}{r}2.66 \\
3.318\end{array}$ \\
\hline 2210222103 & a & 4 & $\begin{array}{l}83 \\
43\end{array}$ & $8.80 \mathrm{e}-1$ & $6.17 \mathrm{a}-1$ & 2.442 \\
\hline 2210222110 & $\theta$ & 4 & 43 & $4.30 \mathrm{e}-1$ & $1.516+0$ & .563 \\
\hline 2210322111 & 8 & 4 & 43 & $8.07 \mathrm{e}-1$ & $1.56 e+0$ & .563 \\
\hline 2210322113 & B & 4 & 43 & $6.45 e-1$ & 0.531 & .469 \\
\hline 22111 & $\theta$ & 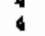 & 43 & $0.750+0$ & $0.75 e+0$ & .656 \\
\hline 2211122112 & 8 & 4 & 43 & $0.750+0$ & $0.5 a+0$ & .656 \\
\hline 2211222113 & 8 & 4 & 43 & $1.510+0$ & $2.08 \mathrm{e}+0$ & .375 \\
\hline 2210222104 & $B$ & 4 & 43 & 0.430 & 0.0 & 1.50 \\
\hline 2210322104 & 8 & 4 & 43 & 0.870 & 0.0 & 2.50 \\
\hline 2211022114 & a & 4 & 43 & 2.580 & 0.0 & 1.75 \\
\hline 2211122114 & 8 & 4 & 43 & 2.580 & 0.0 & 1.75 \\
\hline 2211222114 & 8 & 4 & 43 & 2.580 & 0.0 & 1.75 \\
\hline $\begin{array}{l}1010419104 \\
104\end{array}$ & 9 & 4 & $\begin{array}{l}43 \\
43\end{array}$ & 0.0 & 0.0 & 4.00 \\
\hline $\begin{array}{l}3010439124 \\
3\end{array}$ & 9 & 4 & 43 & 0.0 & 0.0 & 4.00 \\
\hline $\begin{array}{l}30104+6114 \\
3\end{array}$ & 9 & 9 & 93 & 0.0 & 0.0 & 4.00 \\
\hline 1910419124 & 9 & 4 & 43 & 0.0 & 0.0 & 4.00 \\
\hline $\begin{array}{l}1011419104 \\
101\end{array}$ & 9 & 8 & 43 & 0.0 & 0.0 & 4.00 \\
\hline $\begin{array}{l}2811419124 \\
2\end{array}$ & 9 & 4 & 43 & 0.0 & 0.0 & 4.00 \\
\hline $\begin{array}{l}1830119301 \\
\end{array}$ & 9 & 4 & 4 & 2.5 & 2.5 & $7.940 e-3$ \\
\hline 1830219302 & 9 & 4 & 4 & 2.5 & 2.5 & $2.943 \theta-2$ \\
\hline 1830319303 & 9 & 4 & 43 & 2.5 & 2.5 & $2.7030-2$ \\
\hline 1830419304 & 9 & 4 & 43 & 2.5 & 2.5 & $4.712 \theta-2$ \\
\hline 1830619306 & 9 & 4 & 43 & 2.5 & 2.5 & $6.5218-1$ \\
\hline 1800119001 & 9 & 4 & 43 & 2.5 & 2.5 & $9.539 \mathrm{e}-2$ \\
\hline 1800219002 & 9 & 4 & 43 & 2.5 & 2.5 & $1.435 \mathrm{e}-1$ \\
\hline 1800319003 & 9 & 4 & 43 & 2.5 & 2.5 & $2.365 e-1$ \\
\hline 1800419004 & 9 & 4 & 43 & 2.5 & 2.5 & $2.759 \mathrm{a}-1$ \\
\hline 1010119101 & 9 & 4 & 43 & 2.5 & 2,5 & $1.308 e+0$ \\
\hline 1010219102 & 9 & 4 & 43 & 2.5 & 2,5 & $3.734=+0$ \\
\hline 1810319103 & 9 & 4 & 43 & 2.5 & 2.5 & $1,0110+0$ \\
\hline 21301210010 & 9 & 4 & 43 & .01 & .0075 & .408 \\
\hline 2100121002 & 9 & 4 & 43 & .0875 & .0875 & .603 \\
\hline 21002213020 & 9 & 4 & 43 & .0875 & .015 & .957 \\
\hline 21303210030 & 9 & 4 & 43 & .01 & .07925 & 1.367 \\
\hline 2100321004 & 9 & 4 & 43 & .07925 & .07925 & 1.616 \\
\hline 21004213040 & 9 & 4 & 43 & .07925 & .0125 & 1.865 \\
\hline 2130821301 & 9 & 4 & 43 & 0.0 & .01 & .376 \\
\hline 21300214015 & 9 & 4 & 43 & 0.0 & 0.0 & -376 \\
\hline $1, e-12$ & & & 0. & $1 . e-12$ & .220 & -583 \\
\hline 2130921302 & $y$ & 4 & 43 & 0.0 & .015 & 1.005 \\
\hline
\end{tabular}

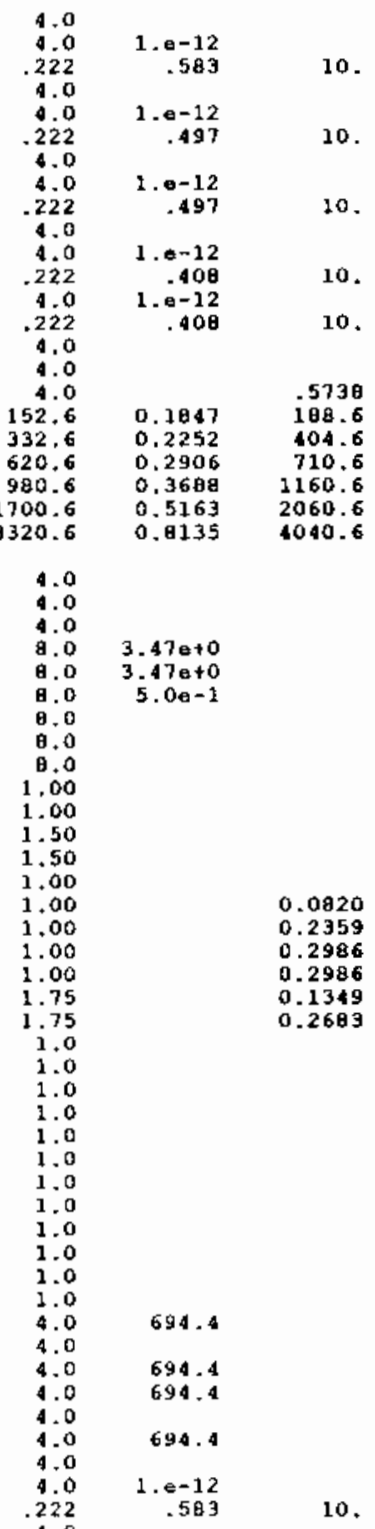




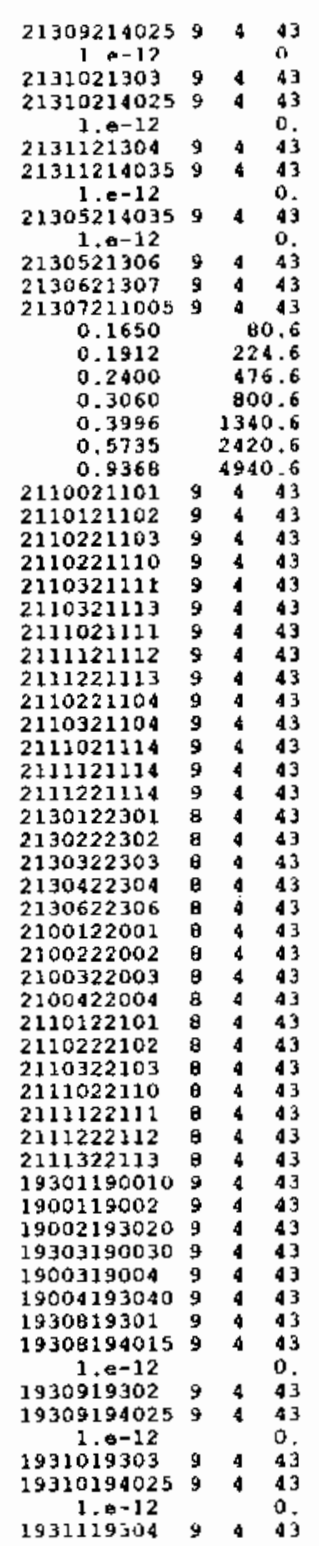

0.0
$1.8-12$
0.0
0.0
$1.8-12$
0.0
$1.0-12$
0.0
$1.0-12$
0.0
.139375
0.17
0.17
0.1976
0.2565
0.3214
0.9282
0.6275

0.0
270
.010
0.0
.220
.125
0.0
.220
.0 .0
.220
.139375
0.
0.0
116.6
26.6
548.6
89.6
150.6
270.6
2790.6

0 .

3. $77 \mathrm{e}-1$

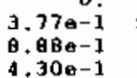

$.133 e-1$
$6.17 e-1$
$1.519+0$

$\begin{array}{ll}8.07 a-1 & 1.560+0\end{array}$

$6.45 \mathrm{e}-1$
$0.75 \mathrm{e}+0$
$0.75+5$

$\begin{array}{ll}0.750+0 & 0.55+0\end{array}$

$\begin{array}{rr}.75 e+0 & 0.5 e+0 \\ .51 e+0 & 1.0 B a+0\end{array}$

0.870

2.580

2.580

1.5
1.5

0.0
0.0
0.0
0.0
0.0

$\begin{array}{rr}0.0 & 1.75 \\ 0.0 & 1.75 \\ 1.5 & 7.8404-3 \\ 1.5 & 2.9438-2 \\ 1.5 & 2.703 e-2 \\ 1.5 & 2.7120-2\end{array}$

4. $712 e-2$

$9.5390-2$

$1.4350-1$

$2.7596-1$

$\begin{array}{rr}1.5 & 3.734 \text { e+o } \\ 1.5 & 1.011 e+0 \\ 2.58 & 1.75 \\ 2.58 & 1.75 \\ 2.58 & 1.75\end{array}$

10.

.

4.0
4.0
4.0

$3.47 e+0$

$3.470+0$
$5.0 *-1$ 


\begin{tabular}{|c|c|c|c|c|c|c|c|}
\hline 19311194035 & 9 & 0,0 & 0.0 & 1.905 & 4.0 & $1.8-12$ & 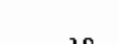 \\
\hline $\begin{array}{r}1 \cdot \theta-12 \\
19305194035\end{array}$ & ${ }_{43}^{0}$ & $\begin{array}{l}4-12 \\
0.0\end{array}$ & $\begin{array}{r}220 \\
0.0\end{array}$ & $\begin{array}{r}.408 \\
2.121\end{array}$ & $\begin{array}{r}.222 \\
4.0\end{array}$ & $\begin{array}{r}.400 \\
1 . e-12\end{array}$ & 10. \\
\hline $\begin{array}{r}1 . \theta-12 \\
1930519306\end{array}$ & $\begin{array}{l}0 . \\
43\end{array}$ & $\begin{array}{r}1 . e-12 \\
0.0\end{array}$ & $\begin{array}{r}.220 \\
.139375\end{array}$ & 2.121 & .222 & & 10. \\
\hline $\begin{array}{l}1930619307 \\
1930719005\end{array}$ & & .139375 & & 2.5584 & 4.0 & & 5738 \\
\hline $\begin{array}{l}27191005 \\
0.1650\end{array}$ & $\begin{array}{r}4 \\
80.6\end{array}$ & 0.1717 & 116.6 & $\begin{array}{l}2.358 \\
0.1782\end{array}$ & $\begin{array}{l}152.0 \\
152.6\end{array}$ & 0.1847 & $\begin{array}{r}.5738 \\
188.6\end{array}$ \\
\hline $\begin{array}{l}0.1912 \\
0.2400\end{array}$ & $\begin{array}{l}224.6 \\
476.6\end{array}$ & $\begin{array}{l}0.1976 \\
0.2565\end{array}$ & $\begin{array}{l}260.6 \\
54.6\end{array}$ & $\begin{array}{l}0.2107 \\
0.2719\end{array}$ & $\begin{array}{l}332.6 \\
620.6\end{array}$ & $\begin{array}{l}0.2252 \\
0.2906\end{array}$ & $\begin{array}{l}404.6 \\
710.6\end{array}$ \\
\hline $\begin{array}{l}0.3060 \\
0.3966\end{array}$ & 900.6 & $\begin{array}{l}0.3214 \\
0.32282\end{array}$ & 890.6 & 0.3380 & 980.6 & 0.3600 & 1160.6 \\
\hline $\begin{array}{l}0.3996 \\
0.5735\end{array}$ & $\begin{array}{l}1340.6 \\
2420.6\end{array}$ & $\begin{array}{l}0.4282 \\
0.6275\end{array}$ & $\begin{array}{l}1520.6 \\
2780.6\end{array}$ & $\begin{array}{l}0.4579 \\
0.7089\end{array}$ & $\begin{array}{l}1700.6 \\
3320.6\end{array}$ & $\begin{array}{l}0.5163 \\
0.0135\end{array}$ & $\begin{array}{l}2060.6 \\
4040.6\end{array}$ \\
\hline $\begin{array}{r}0.9368 \\
10019101 \\
1019107\end{array}$ & & ${ }^{\circ}$ & ${ }^{3}, 770-1$ & & & & \\
\hline $\begin{array}{l}1910119102 \\
1910219103\end{array}$ & & 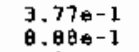 & $\begin{array}{r}9.1330-1 \\
6.17 \mathrm{a}-1\end{array}$ & $\begin{array}{l}3.318 \\
2.442\end{array}$ & $\begin{array}{l}4.0 \\
4.0\end{array}$ & & \\
\hline $\begin{array}{l}1910219104 \\
1910319104\end{array}$ & 43 & $\begin{array}{l}4.300-1 \\
8.070-1\end{array}$ & & $\begin{array}{l}1.50 \\
2.50\end{array}$ & 1.0 & & \\
\hline $\begin{array}{l}1912519120 \\
\end{array}$ & $\begin{array}{lll}9 & 4 & 43 \\
9 & 4 & 3\end{array}$ & 0 & $5.16 e-i$ & .306 & 8. 0 & & \\
\hline $\begin{array}{l}1912019121 \\
1912119122\end{array}$ & $\begin{array}{ll}9 & 4 \\
9 & 4\end{array}$ & $\begin{array}{l}5.16 e-1 \\
1.18 e+0\end{array}$ & $\begin{array}{l}8.600-1 \\
1.00 e+0\end{array}$ & . 778 & 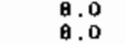 & & \\
\hline $\begin{array}{l}1912219123 \\
\end{array}$ & 43 & $1.516+0$ & $1.00 \varepsilon+0$ & 年. 156 & 8.0 & & \\
\hline $\begin{array}{l}1912219124 \\
192119123\end{array}$ & $\begin{array}{ll}9 \\
9 & 4\end{array}$ & $\begin{array}{l}1.08 a+0 \\
1.16 e+0\end{array}$ & $\begin{array}{l}0.0 \\
1.00 \mathrm{e}+0\end{array}$ & $\begin{array}{l}.819 \\
: 219\end{array}$ & $\begin{array}{l}8.0 \\
\theta .0\end{array}$ & & \\
\hline 1910219121 & 94 & $\begin{array}{l}4.58 E-1 \\
4.58 e-1\end{array}$ & $\begin{array}{l}1.18 \theta+0 \\
1.51 e+0\end{array}$ & .328 & 8.0 & $\begin{array}{l}3.47+0 \\
3.470+0\end{array}$ & \\
\hline $\begin{array}{l}1910219122 \\
1910319121\end{array}$ & $\begin{array}{ll}9 & 4 \\
9 & 4\end{array}$ & $\begin{array}{l}4.79 \mathrm{a}-1 \\
7.79\end{array}$ & $\begin{array}{l}1.18 \mathrm{e}+0 \\
1.18 \mathbf{0}\end{array}$ & .328 & 8.0 & $\begin{array}{l}3.476+0 \\
3.470\end{array}$ & \\
\hline $\begin{array}{l}1910319122 \\
1910319123\end{array}$ & 每3 & $\begin{array}{l}7.79 a-1 \\
6.45 a-1\end{array}$ & $\begin{array}{l}1.51 e+0 \\
5.31 e-1\end{array}$ & $\begin{array}{l}.234 \\
.469\end{array}$ & $\begin{array}{l}8.0 \\
8.0\end{array}$ & $\begin{array}{r}3.47 e+0 \\
5.0 \mathrm{~s}-1\end{array}$ & \\
\hline $\begin{array}{r}19125191265 \\
0.5157\end{array}$ & 94 & $\begin{array}{c}0.0 \\
0.5367\end{array}$ & 116.6 & $\begin{array}{r}3.000-1 \\
0.5570\end{array}$ & $\begin{array}{r}9.0 \\
152.6\end{array}$ & & $\begin{array}{l}0.601 \\
189.6\end{array}$ \\
\hline $\begin{array}{l}0.5975 \\
0.5490\end{array}$ & 224.6 & 0.6175 & $\begin{array}{l}260.6 \\
5.646\end{array}$ & 0.6584 & 332.6 & 0.7038 & 404.6 \\
\hline 0.9563 & 880.6 & $\begin{array}{l}0.8015 \\
1.0045\end{array}$ & 890.6 & 1.0561 & 990.6 & 1.1524 & 1160,6 \\
\hline $\begin{array}{l}1.2488 \\
1.723\end{array}$ & $\begin{array}{l}1340.6 \\
2420.6\end{array}$ & $\begin{array}{l}1.3382 \\
1.9609\end{array}$ & $\begin{array}{l}1520.6 \\
2780.6\end{array}$ & $\begin{array}{l}1.4311 \\
2.2154\end{array}$ & $\begin{array}{l}1700.6 \\
3320.6\end{array}$ & $\begin{array}{l}1.5134 \\
2.5422\end{array}$ & $\begin{array}{l}2060.6 \\
4040.6\end{array}$ \\
\hline $\begin{array}{r}29275 \\
1912619127\end{array}$ & $9 \begin{array}{r}4940 \\
4.63\end{array}$ & 0.0 & $6.250 \mathrm{e}$ & $2.945 \mathrm{e}$ & & & \\
\hline $\begin{array}{l}1912719128 \\
1912819129\end{array}$ & $\begin{array}{l}43 \\
43\end{array}$ & $\begin{array}{l}6.250 \mathrm{e}-3 \\
6.250 \mathrm{e}-3\end{array}$ & 6.25 & $\begin{array}{l}2.847-1 \\
2.749-1 \\
2.74-1\end{array}$ & $\begin{array}{l}8.0 \\
8.0\end{array}$ & & \\
\hline $\begin{array}{l}1930120301 \\
1930220302\end{array}$ & $\begin{array}{ll}9 & 4 \\
9 & 4\end{array}$ & $\begin{array}{l}1.5 \\
1.5\end{array}$ & $\begin{array}{l}1.5 \\
1.5\end{array}$ & $\begin{array}{l}7.8400-3 \\
2.9430-2\end{array}$ & $\begin{array}{l}1.0 \\
1.0\end{array}$ & & \\
\hline 1930320303 & 43 & 1.5 & $\begin{array}{l}1.5 \\
1.5\end{array}$ & $\begin{array}{l}2.7030-2 \\
2.7030-2\end{array}$ & $\begin{array}{l}1.0 \\
1: 0\end{array}$ & & \\
\hline 1930620306 & $\begin{array}{l}43 \\
43 \\
43\end{array}$ & $\begin{array}{l}1.5 \\
1.5\end{array}$ & $\begin{array}{l}1.3 \\
1.5\end{array}$ & $\begin{array}{l}8.521 \mathrm{e}-1 \\
6.52 \mathrm{e}-1\end{array}$ & $\begin{array}{l}1.0 \\
1.0\end{array}$ & & \\
\hline $\begin{array}{l}19000120001 \\
1900220002\end{array}$ & $\begin{array}{l}43 \\
43\end{array}$ & $\begin{array}{l}1.5 \\
1.5\end{array}$ & .5 & $\begin{array}{l}9.539 e-2 \\
1.435 e-1\end{array}$ & $\begin{array}{l}1.0 \\
1.0\end{array}$ & & \\
\hline $\begin{array}{l}1900320003 \\
1900420004\end{array}$ & $\begin{array}{l}43 \\
43\end{array}$ & $\begin{array}{l}1.5 \\
1.5\end{array}$ & $\begin{array}{l}1.5 \\
1.5 \\
\end{array}$ & $\begin{array}{l}2.3658-1 \\
2.7598-1\end{array}$ & $\begin{array}{l}1.0 \\
1.0\end{array}$ & & \\
\hline $\begin{array}{l}1910120101 \\
1910220102\end{array}$ & $\begin{array}{ll}4 & 43 \\
4 & 43\end{array}$ & $\begin{array}{l}1.5 \\
1.5\end{array}$ & $\begin{array}{l}1.5 \\
1.5\end{array}$ & $\begin{array}{l}1.30 \theta e+0 \\
3.734 e+0\end{array}$ & $\begin{array}{l}1: 0 \\
1.0\end{array}$ & & \\
\hline 1910320103 & 43 & 3.5 & 35 & J.011e+o & 1.0 & & \\
\hline $\begin{array}{l}19122020120 \\
1912120121\end{array}$ & ${ }_{43}^{43}$ & $\begin{array}{l}81700 \\
2.064\end{array}$ & $\dot{2}^{81.064}$ & $\begin{array}{r}.6000 \\
.7600\end{array}$ & $\begin{array}{l}\begin{array}{l}4.000 \\
4.000\end{array}\end{array}$ & & \\
\hline $\begin{array}{l}1913320123 \\
20301200010\end{array}$ & $\begin{array}{l}43 \\
43\end{array}$ & $\begin{array}{r}2.560 \\
.01\end{array}$ & $\begin{array}{l}2.560 \\
.0875\end{array}$ & $\begin{array}{l}1.250 \\
.400\end{array}$ & $\begin{array}{r}1.000 \\
4.0\end{array}$ & 694.4 & \\
\hline 2000120002 & 43 & .0075 & .0975 & .683 & 4. & & \\
\hline $\begin{array}{l}2002203020 \\
20303200030\end{array}$ & $\begin{array}{c}43 \\
43\end{array}$ & $\begin{array}{l}.0075 \\
.01\end{array}$ & $\begin{array}{r}0.015 \\
.07925\end{array}$ & $\begin{array}{r}.957 \\
1.367\end{array}$ & $\begin{array}{l}4.0 \\
4.0\end{array}$ & $\begin{array}{l}699.4 \\
694.4\end{array}$ & \\
\hline $\begin{array}{l}200032 \\
200042\end{array}$ & 9 & $\begin{array}{l}.07925 \\
.07925\end{array}$ & $\begin{array}{l}.07925 \\
.0125\end{array}$ & $\begin{array}{l}1.616 \\
1.865\end{array}$ & 4.0 & 694.4 & \\
\hline 2030820301 & 43 & & & .376 & 4.0 & & \\
\hline $\begin{array}{l}20308204015 \\
1.0-12\end{array}$ & & 1.012 & .220 & $\begin{array}{l}.376 \\
.583\end{array}$ & 222 & $\begin{array}{l}1.8-12 \\
583 \\
583\end{array}$ & 10. \\
\hline & & & & & & & \\
\hline
\end{tabular}




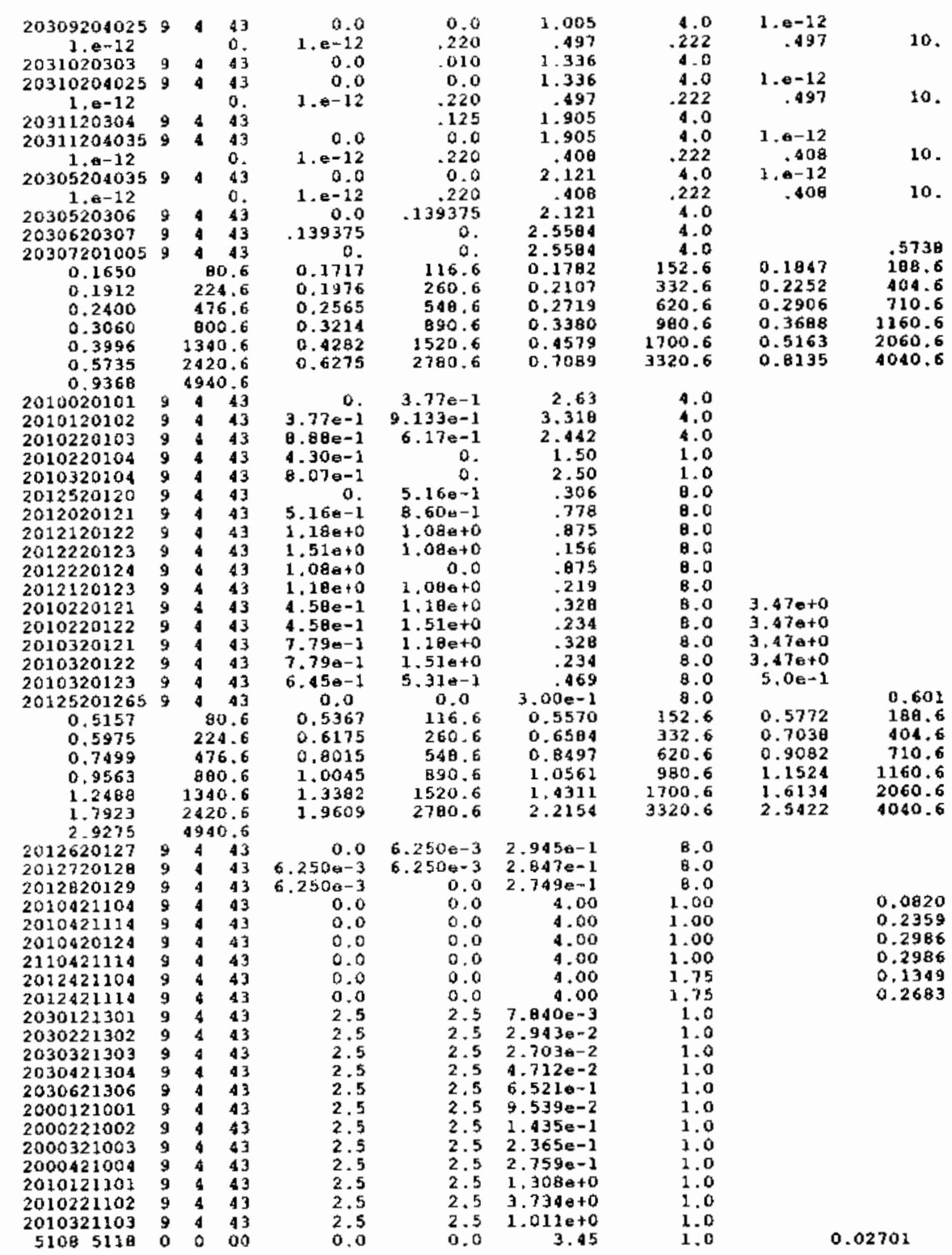




\begin{tabular}{|c|c|c|c|c|c|c|c|c|c|}
\hline 5108 & 5128 & 0 & 0 & 00 & 0.0 & 0.0 & 3.45 & 1.0 & 0.03232 \\
\hline 5108 & 2100 & 0 & 0 & 00 & 0.0 & 0.0 & 3.45 & 1.0 & 0.06099 \\
\hline 5108 & 2118 & 0 & 0 & 00 & 0.0 & 0.0 & 3.45 & 1.0 & 0.03667 \\
\hline 5108 & 2120 & 0 & 0 & 00 & 0.0 & 0.0 & 3.45 & 1.0 & 0.05203 \\
\hline 5108 & 4108 & 0 & 0 & 00 & 0.0 & 0.0 & 3.45 & 1.0 & 0.32735 \\
\hline 5108 & 4110 & 0 & 0 & $\infty$ & 0.0 & 0.0 & 3.45 & 1.0 & 0.11778 \\
\hline 5110 & $512 \theta$ & 0 & 0 & 00 & 0.0 & 0.0 & 2,55 & 1.0 & 0.04971 \\
\hline 5118 & $210 B$ & 0 & 0 & 00 & 0.0 & 0.0 & 2.55 & 1.0 & 0.04962 \\
\hline 5118 & 2118 & 0 & 0 & 00 & 0.0 & 0.0 & 2.55 & 1.0 & 0.04236 \\
\hline 5118 & 2128 & 0 & 0 & 00 & 0.0 & 0.0 & 2.55 & 1.0 & 0.06777 \\
\hline 5118 & 4100 & 0 & 0 & 00 & 0.0 & 0.0 & 2.55 & 1.0 & 0.19575 \\
\hline 5118 & 4118 & 0 & 0 & 00 & 0.0 & 0.0 & 2.55 & 1.0 & 0.22923 \\
\hline 5128 & 2108 & 0 & 0 & 00 & 0.0 & 0.0 & 5.10 & 1.0 & 0.03575 \\
\hline 5128 & 2118 & 0 & 0 & 00 & 0.0 & 0.0 & 5.10 & 1.0 & 0.03386 \\
\hline 5128 & 2128 & 0 & 0 & 00 & 0.0 & 0.0 & 5.10 & 1.0 & 0.07998 \\
\hline 5128 & 4100 & 0 & 0 & 00 & 0.0 & 0.0 & 5.30 & 1.0 & 0.09265 \\
\hline 5128 & 4118 & 0 & 0 & 00 & 0.0 & 0.0 & 5.10 & 1.0 & 0.35417 \\
\hline 2100 & 2118 & 0 & 0 & 00 & 0.0 & 0.0 & 3.45 & 1.0 & 0.02701 \\
\hline 2308 & 2128 & 0 & 0 & 00 & 0.0 & 0.0 & 3.45 & 1.0 & 0.03232 \\
\hline 2108 & 4108 & 0 & 0 & 00 & 0.0 & 0.0 & 3.45 & 1.0 & 0.32735 \\
\hline 2108 & 4118 & 0 & 0 & 00 & 0.0 & 0.0 & 3.45 & 2.0 & 0.11778 \\
\hline 2119 & 2228 & 0 & 0 & $D O$ & 0.0 & 0.0 & 2.55 & 1.0 & 0.04971 \\
\hline 2118 & 4100 & 0 & 0 & 00 & 0.0 & 0.0 & 2.55 & 1.0 & 0.19575 \\
\hline 2118 & 4218 & 0 & 0 & 00 & 0.0 & 0.0 & 2.55 & 1.0 & 0.22923 \\
\hline $212 \theta$ & 4100 & $o$ & 0 & 00 & 0.0 & 0.0 & 5.70 & 1.0 & 0.09265 \\
\hline 2120 & $411 \mathrm{~B}$ & 0 & 0 & DO & 0.0 & 0.0 & 5.10 & 1.0 & 0.35417 \\
\hline 4108 & 4118 & 0 & 0 & 00 & 0.0 & 0.0 & 12.65 & 1.0 & 0.13163 \\
\hline 5110 & 5108 & 0 & 0 & oo & 2.58 & 0.0 & 2.25 & 3.0 & \\
\hline 5111 & 5108 & 0 & 0 & 00 & 2.58 & 0.0 & 1.20 & 1.0 & \\
\hline 5111 & 5118 & 0 & 0 & 00 & 2.58 & 0.0 & 1.05 & 1.0 & \\
\hline 5112 & 5218 & 0 & 0 & 00 & 2.58 & 0.0 & 1.50 & 1.0 & \\
\hline 5111 & 5120 & 0 & 0 & 00 & 2.58 & 0.0 & 0.175 & 1.0 & \\
\hline 5112 & $512 \theta$ & 0 & $\therefore$ & 00 & 2.58 & 0.0 & 0.250 & 1.0 & \\
\hline 5103 & 5128 & 0 & 0 & 00 & 1.5 & 0.0 & 0.789 & 1.0 & \\
\hline $\begin{array}{l}5102 \\
5713\end{array}$ & 5128 & 0 & 0 & 00 & $\begin{array}{r}1.5 \\
2.58\end{array}$ & $\begin{array}{l}0.0 \\
0.0\end{array}$ & 1.136 & 1.0 & \\
\hline 5113 & 5128 & $\stackrel{a}{0}$ & 0 & 00 & 0.215 & $\begin{array}{l}0.0 \\
0.0\end{array}$ & $\begin{array}{l}1.250 \\
1.50\end{array}$ & 1.0 & \\
\hline 4304 & $\begin{array}{l}4108 \\
4108\end{array}$ & $\begin{array}{l}0 \\
0\end{array}$ & $\stackrel{0}{0}$ & $\begin{array}{l}00 \\
00\end{array}$ & 0.215 & 0.0 & $\begin{array}{l}1.50 \\
0.800\end{array}$ & $\begin{array}{l}3.0 \\
3.0\end{array}$ & \\
\hline 4105 & 4218 & 0 & 0 & 00 & 0.694 & 0.0 & 0.25 & $\begin{array}{l}3.0 \\
3.0\end{array}$ & \\
\hline $\begin{array}{l}9105 \\
4103\end{array}$ & 4118 & 0 & 0 & 00 & $\begin{array}{r}0.098 \\
0.0\end{array}$ & 0.0 & 0.632 & 3.0 & \\
\hline $\begin{array}{l}4103 \\
4102\end{array}$ & 4119 & 0 & 0 & 00 & 0.0 & 0.0 & $2 . \mathrm{J1B}$ & 3.0 & \\
\hline $\begin{array}{l}4102 \\
3104\end{array}$ & $\begin{array}{l}4118 \\
4100\end{array}$ & $\begin{array}{l}0 \\
0\end{array}$ & 0 & $\begin{array}{l}00 \\
00\end{array}$ & 0.235 & 0.0 & i.50 & 3.0 & \\
\hline $\begin{array}{l}5104 \\
3105\end{array}$ & 4100 & 0 & 0 & 00 & 0.215 & 0.0 & 0.008 & 3.0 & \\
\hline $\begin{array}{l}3105 \\
3105\end{array}$ & $\$ 118$ & 0 & 0 & 00 & 0.604 & 0.0 & 0.25 & 3.0 & \\
\hline 3103 & 4118 & 0 & 0 & 00 & 0.0 & 0.0 & 0.652 & 3.0 & \\
\hline 3102 & 4118 & 0 & 0 & Do & 0.0 & 0.0 & 2.110 & 3.0 & \\
\hline 5306 & $\begin{array}{l}41106 \\
4706\end{array}$ & 0 & 0 & 00 & 1.50 & 1.50 & 0.6521 & 1.0 & \\
\hline 5101 & 4101 & 0 & 0 & 00 & 1.50 & 1.5 & 1.308 & 7.0 & \\
\hline 5102 & 4102 & 0 & 0 & 00 & 1,50 & 1.5 & 2.599 & 1.0 & \\
\hline 5103 & 4103 & 0 & 0 & 00 & 1.50 & 1.5 & .2241 & 1.0 & \\
\hline 5110 & 4104 & 0 & 0 & 00 & 2.815 & 1,5 & 0.375 & 1.0 & \\
\hline 5111 & 4105 & 0 & 0 & 00 & 2.946 & 1.5 & 0.202 & 1.0 & \\
\hline 4306 & 3306 & 0 & 0 & 00 & 1.5 & 1.5 & 0.6521 & 1.0 & \\
\hline 4101 & 3101 & 0 & 0 & 00 & 1.5 & 1.5 & j.30B & 1.0 & \\
\hline 4102 & 3102 & 0 & 0 & 00 & 1.5 & 1.5 & 2.599 & 1.0 & \\
\hline 4103 & 3103 & 0 & 0 & 00 & 1.5 & 1.5 & .2243 & 1.0 & \\
\hline 4104 & 3104 & 0 & 0 & 00 & 1.5 & 1.5 & 0.375 & 1.0 & \\
\hline 4105 & 3105 & 0 & 0 & 00 & 1.5 & 1.5 & 0.202 & 1.0 & \\
\hline 3306 & 2306 & 0 & 0 & 00 & i.s & 4.750 & 0.6521 & 1.0 & \\
\hline 3102 & 2101 & 0 & 0 & 00 & 1.5 & 4.750 & 1.903 & 1.0 & 3.47 \\
\hline 3103 & 2102 & 0 & 0 & 00 & 1.5 & 4.750 & 0.2241 & 1.0 & 3.47 \\
\hline 3104 & 2101 & 0 & 0 & 00 & 1.5 & 4.750 & 0.307 & 1.0 & 3,47 \\
\hline 3104 & 2102 & $D$ & 0 & ao & 1.5 & 4.750 & 0.068 & 1.0 & 3.47 \\
\hline 3105 & 2102 & 0 & 0 & 00 & 1.5 & 4.750 & 0.208 & 1.0 & 3.47 \\
\hline 2100 & 2103 & 0 & 0 & 00 & 0.0 & 4.75 & 1.350 & 1.0 & \\
\hline 2108 & 2104 & 0 & 0 & 00 & 0.0 & 4.75 & 2.145 & 1.0 & \\
\hline
\end{tabular}




\begin{tabular}{|c|c|c|c|c|c|c|c|c|c|c|}
\hline 2118 & 2105 & 0 & 0 & 00 & 0.0 & 5.000 & 2.505 & 1.0 & & \\
\hline 2128 & 2106 & 0 & 0 & 00 & 0.0 & 5.000 & 1515 & 10 & & \\
\hline 2128 & $210 \%$ & 0 & 0 & 00 & 0.0 & 5.000 & $\exists .495$ & 1.0 & & \\
\hline 2306 & 1306 & 0 & 0 & 00 & 4.750 & 5.000 & 0.652 & 1.0 & & \\
\hline 2101 & 1101 & 0 & 0 & 00 & 4.750 & 5.0 & 0.694 & 1.0 & & \\
\hline 2102 & 2104 & 0 & 0 & 00 & 4.750 & 5.0 & 0.406 & 1.0 & & \\
\hline 2103 & 1105 & 0 & 0 & 00 & 4.75 & 5.0 & 1.222 & 1.0 & & \\
\hline 2104 & 1106 & 0 & 0 & 00 & 4.75 & 5.0 & 2.145 & 1.0 & & \\
\hline 2105 & 1107 & 0 & 0 & 00 & 5.0 & 5.0 & 2,505 & 1.0 & & \\
\hline 2106 & 1109 & 0 & 0 & 00 & 5.0 & 5.0 & 1.515 & 1.0 & & \\
\hline 2107 & 1101 & 0 & 0 & 00 & 5.0 & 5.0 & 0.115 & 1.0 & & \\
\hline 2107 & 1109 & 0 & 0 & 00 & 5.0 & 5.0 & 2.223 & 1.0 & & \\
\hline 4305 & 4306 & 0 & 0 & 00 & 0.0 & 0.139375 & 2.121 & 3.0 & & \\
\hline 4306 & 4307 & o & 0 & 00 & 0.139375 & 0.0 & $\begin{array}{r}2.558 \\
2550\end{array}$ & 3.0 & & \\
\hline 4307 & 41005 & 0 & & 00 & 0.0 & 0.0 & 2.5504 & $\begin{array}{r}3.0 \\
55\end{array}$ & & -5738 \\
\hline 0. & .1650 & & & & 0.1717 & 116.6 & 0.1702 & 152.6 & & 188.6 \\
\hline & .1912 & & & & 0.1976 & $260 \cdot 6$ & 0.2107 & 332.6 & 0.2252 & 404.6 \\
\hline & .2400 & & & & 0.2565 & 548.6 & 0.2719 & $\begin{array}{l}620.6 \\
980.6\end{array}$ & $\begin{array}{l}0.2906 \\
0.3680\end{array}$ & $\begin{array}{r}710.6 \\
1160.6\end{array}$ \\
\hline & .3060 & & 800 & & 0.3214 & 890.6 & 0.3380 & 980.6 & & 1160.6 \\
\hline & .3996 & & 1340 & & 0.4282 & 1520.6 & $\begin{array}{l}0.4579 \\
0.7089\end{array}$ & 1700.6 & 0.5163 & 2060.6 \\
\hline & .5735 & & 2420 & & 0.6275 & 2700.6 & 0.7089 & 3320.6 & 0.0135 & 1040.6 \\
\hline & .9360 & & 4940 & & & & & & & \\
\hline 4100 & 4101 & 0 & 0 & 00 & 0.0 & 0.400 & 2.627 & 3.0 & & \\
\hline 4101 & 4102 & $\therefore$ & 0 & 00 & 0.375 & 0.961 & 3.318 & 3.0 & & \\
\hline 4102 & 4103 & 0 & 0 & 00 & 0.793 & 0.215 & 1.030 & 3.0 & & \\
\hline 4102 & 4104 & 0 & 0 & 00 & 0.321 & 0.215 & 1.500 & 3.0 & & \\
\hline 4103 & 4105 & 0 & 0 & 00 & 0.000 & 0.215 & 0.800 & 3.0 & & \\
\hline 4104 & 4105 & 0 & 0 & 00 & 1.250 & 0.694 & 0.250 & 3.0 & & \\
\hline 3305 & 3306 & 0 & 0 & 00 & $\begin{array}{r}0.0 \\
0.30375\end{array}$ & 0.139375 & 2.121 & 3.0 & & \\
\hline 3306 & 3307 & 0 & 0 & 00 & 0.139375 & 0.0 & $\begin{array}{r}2.558 \\
\quad 5580\end{array}$ & 3.0 & & \\
\hline $\begin{array}{l}3307 \\
0 .\end{array}$ & $\begin{array}{l}31005 \\
.1650\end{array}$ & 0 & & 0.6 & $\begin{array}{r}0.0 \\
0.1717\end{array}$ & $\begin{array}{r}0.0 \\
116.6\end{array}$ & $\begin{array}{l}2.5584 \\
0.1782\end{array}$ & $\begin{array}{r}3.0 \\
152.6\end{array}$ & 0.1047 & $\begin{array}{l}.5736 \\
108.6\end{array}$ \\
\hline & .1912 & & 224 & & 0.1976 & 260.6 & 0.2107 & 332.6 & 0.2252 & 004.6 \\
\hline & 2400 & & 476 & & 0.2565 & 548,6 & 0.2719 & 620.6 & 0.2906 & 710.6 \\
\hline & .3060 & & 000 & & 0.3214 & 990.6 & 0.3380 & 980.6 & $0.368 \mathrm{~g}$ & 1160.6 \\
\hline & 3996 & & 1340 & & $0.42 \mathrm{az}$ & 1520.6 & 0.4539 & 1700.6 & 0.5163 & 2060.6 \\
\hline & .5735 & & 2420 & & 0.6275 & 2780.6 & 0.7009 & 3320.6 & 0.0135 & 4040. \\
\hline & .9368 & & 4940 & & 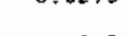 & & & (2) & & \\
\hline 3100 & 3101 & 0 & 0 & 00 & 0.0 & 0.400 & 2.627 & 3.0 & & \\
\hline 3101 & 3102 & 0 & 0 & 00 & 0.375 & 0.961 & 3.310 & 3.0 & & \\
\hline 3102 & 3103 & 0 & 0 & 00 & 0.793 & 0.215 & 1.030 & 3.0 & & \\
\hline 3102 & 3104 & 0 & 0 & 00 & 0.321 & 0.215 & 1.500 & 3.0 & & \\
\hline 3103 & 3105 & 0 & o & 00 & 0.000 & 0.215 & 0.808 & 3.0 & & \\
\hline 3104 & 3105 & 0 & 0 & 00 & 1.290 & 0.694 & 0.250 & 3.0 & & \\
\hline 2305 & 2306 & 0 & 0 & 00 & 0.0 & 0.139 & 2.121 & 9.5 & & \\
\hline 2306 & 2307 & 0 & 0 & 00 & 0.139 & 0.0 & 2.558 & 9.5 & & \\
\hline 2307 & 21005 & 0 & & 00 & 0.0 & 0.0 & 2.558 & 9.5 & & $0.64 \mathrm{E}$ \\
\hline & .0103 & & & 0.6 & 0.0107 & 116.6 & 0.0111 & 152.6 & 0.0115 & 188.6 \\
\hline & .0119 & & 224 & & 0.0123 & 260.6 & 0.0131 & 332.6 & 0,0141 & 404.6 \\
\hline & .0150 & & 476 & & 0.0160 & 548.6 & 0.0170 & 620.6 & 0.0181 & 710.6 \\
\hline & .0191 & & 800 & & 0.0201 & 990,6 & 0.0211 & 980.6 & 0.0230 & 2160.6 \\
\hline & .0249 & & $134 c$ & & 0.0267 & 1520.6 & 0.0286 & 1700.6 & 0.0322 & 2060.6 \\
\hline & .0358 & & 2420 & & 0.0391 & 2780.6 & 0.0442 & 3320.6 & 0.0507 & 4040.6 \\
\hline & .0584 & & 4940 & & & & & & & \\
\hline 2100 & 2101 & 0 & 0 & 00 & 0.0 & 0.640 & 3.660 & 9.5 & & \\
\hline 2101 & 2102 & 0 & 0 & 00 & 0.690 & 0.358 & 1.715 & 9.5 & & \\
\hline 2201 & 2103 & 0 & 0 & 00 & 0.537 & 1.290 & 0.900 & 9.5 & & \\
\hline 2101 & 2107 & 0 & 0 & 00 & 0.640 & 0.307 & 2.093 & 9.5 & & \\
\hline 2102 & 2104 & 0 & 0 & 00 & 0.0 & 1.290 & 1.430 & 9.5 & & \\
\hline 2102 & 2106 & 0 & 0 & 00 & 0.0 & 1.436 & 0.907 & 9.5 & & \\
\hline 2103 & 2104 & a & 0 & 00 & 0.774 & 1.230 & 1.500 & 9.5 & & \\
\hline 2104 & 2105 & 0 & 0 & 00 & 1.230 & 1.436 & 1.500 & 9.5 & & \\
\hline 2205 & 2106 & 0 & 0 & 00 & 1.290 & 0.780 & 1.670 & 10,0 & & \\
\hline 2106 & 2107 & 0 & 0 & 00 & 0.780 & 1,800 & 1.670 & 10.0 & & \\
\hline 1305 & 1306 & 0 & 0 & 00 & 0.0 & 0.139 & 2.121 & 10.0 & & \\
\hline 1306 & 1307 & $a$ & 0 & an & 0.139 & 0.0 & 2.5504 & 10.0 & & \\
\hline
\end{tabular}




\begin{tabular}{|c|c|c|c|c|c|c|c|}
\hline $\begin{array}{c}1307.11005 \\
0.0511 \\
0.0592 \\
0.0743 \\
0.0948 \\
0.1237 \\
0.1776 \\
0.2902\end{array}$ & $\begin{array}{r}0 \quad 000 \\
080.6 \\
224.6 \\
476.6 \\
800.6 \\
1340.6 \\
2420.6 \\
4940.6\end{array}$ & $\begin{array}{c}0.0 \\
0.0532 \\
0.0612 \\
0.0794 \\
0.0996 \\
0.1326 \\
0.1943\end{array}$ & $\begin{array}{r}0.0 \\
116.6 \\
260.6 \\
548.6 \\
890.6 \\
1520.6 \\
27 \theta 0.6\end{array}$ & $\begin{array}{r}2.5584 \\
0.0552 \\
0.0653 \\
0.0042 \\
0.1047 \\
0.1919 \\
0.2196\end{array}$ & $\begin{array}{r}10.0 \\
152.6 \\
332.6 \\
620.6 \\
980.6 \\
1700.6 \\
3320.6\end{array}$ & $\begin{array}{c}0.0572 \\
0.0698 \\
0.0900 \\
0.1142 \\
0.1599 \\
0.2520\end{array}$ & $\begin{array}{l}0.611 \\
188.8 \\
404.6 \\
710.6 \\
1160.8 \\
2060.8 \\
4040 .\end{array}$ \\
\hline $\begin{array}{l}100.2902 \\
101 \\
101 \\
1102\end{array}$ & $\begin{array}{lll}0 & 0 & 0 \\
0 & 0 & 0\end{array}$ & $\begin{array}{r}0.0 \\
0.628\end{array}$ & $\begin{array}{r}0.628 \\
0.0\end{array}$ & $\begin{array}{l}2.7803 \\
3.9466\end{array}$ & $\begin{array}{l}10.0 \\
10.0\end{array}$ & & \\
\hline $\begin{array}{c}110211035 \\
0.0107 \\
0.0124\end{array}$ & 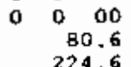 & $\begin{array}{r}0.0 \\
0.0112 \\
0.0129\end{array}$ & $\begin{array}{r}0.0 \\
116.6 \\
260.6\end{array}$ & $\begin{array}{l}3.9 \\
0.0 \\
0.0\end{array}$ & $\begin{array}{r}10.0 \\
1552.6 \\
332.6\end{array}$ & $\begin{array}{l}0.0120 \\
0.0147\end{array}$ & $\begin{array}{l}0.5 \\
189 \\
404\end{array}$ \\
\hline $\begin{array}{l}0.0124 \\
0.0156 \\
0.0199\end{array}$ & $\begin{array}{l}224.6 \\
476.6\end{array}$ & $\begin{array}{l}0.0129 \\
0.0167 \\
0.0709\end{array}$ & $\begin{array}{l}260.6 \\
549.6\end{array}$ & $\begin{array}{l}0.0131 \\
0.0172 \\
0.0220\end{array}$ & $\begin{array}{l}3120.6 \\
620.6 \\
9006\end{array}$ & $\begin{array}{l}0.014 t \\
0.0189 \\
0.0200\end{array}$ & $\begin{array}{l}404 \\
710 \\
160\end{array}$ \\
\hline $\begin{array}{l}0.0260 \\
0.0373\end{array}$ & $\begin{array}{l}1340.6 \\
1320.6\end{array}$ & 0.0279 & $\begin{array}{r}590.6 \\
1520.6 \\
2780.6\end{array}$ & 0.0298 & 1300.6 & 0.0336 & \\
\hline $\begin{array}{l}0.0373 \\
0.0609\end{array}$ & $\begin{array}{r}2420.6 \\
4940.6\end{array}$ & & & & & & \\
\hline $\begin{array}{l}1037104 \\
103105\end{array}$ & $\begin{array}{lll}0 & 0 & 000 \\
0 & 0 & 00\end{array}$ & $\begin{array}{l}0.0 \\
0.0\end{array}$ & $\begin{array}{l}0.344 \\
1.046\end{array}$ & $\begin{array}{l}1.523 \\
1.091\end{array}$ & $\begin{array}{l}10.0 \\
10.0\end{array}$ & & \\
\hline $\begin{array}{l}031109 \\
041106\end{array}$ & $\begin{array}{ccc}0 & 0 & 00 \\
0 & 0 & 00\end{array}$ & $\begin{array}{l}0.0 \\
0.0\end{array}$ & $\begin{array}{l}0.803 \\
1.290\end{array}$ & $\begin{array}{l}2.389 \\
1.260\end{array}$ & $\begin{array}{l}10 \\
10\end{array}$ & & \\
\hline $\begin{array}{l}041106 \\
0451108\end{array}$ & $\begin{array}{ll}0 & 0 \\
0 & 0\end{array}$ & 0.0 & 1.436 & 0.029 & 10.0 & & \\
\hline $\begin{array}{ll}05 & 1106 \\
06 & 1107\end{array}$ & $\begin{array}{ll}0 & 0 \\
0 & 0\end{array}$ & $\begin{array}{c}0.774 \\
1.23\end{array}$ & $\begin{array}{l}1.230 \\
1.436\end{array}$ & $\begin{array}{l}1.445 \\
1.500\end{array}$ & $\begin{array}{l}10.0 \\
10.0\end{array}$ & & \\
\hline $\begin{array}{ll}07 & 1108 \\
08 & 1109\end{array}$ & $\begin{array}{ll}0 & 0 \\
0 & 0\end{array}$ & $\begin{array}{l}1.290 \\
0.790\end{array}$ & $\begin{array}{l}0.780 \\
1.239\end{array}$ & $\begin{array}{l}1.67 \\
1.59\end{array}$ & $\begin{array}{l}10.0 \\
10.0\end{array}$ & & \\
\hline $\begin{array}{l}30150010 \\
0015 \\
0002\end{array}$ & $\begin{array}{ll}0 & 0 \\
0 & 0 \\
0 & 0\end{array}$ & $\begin{array}{l}01 \\
.0875\end{array}$ & $\begin{array}{l}.0875 \\
.0875\end{array}$ & $\begin{array}{l}.408 \\
.683\end{array}$ & $\begin{array}{l}3.0 \\
3.0\end{array}$ & 694.4 & \\
\hline 0253020 & 00 & .0875 & 015 & $\begin{array}{r}.957 \\
.367\end{array}$ & 3.0 & 694.4 & \\
\hline $\begin{array}{l}0355030 \\
035004 \\
0350\end{array}$ & $\begin{array}{ll}0 & 0 \\
0 & 0\end{array}$ & .07925 & $\begin{array}{l}.0795 \\
.07925\end{array}$ & $\begin{array}{l}1.36 \\
1.61\end{array}$ & $\begin{array}{l}\begin{array}{l}3.0 \\
3.0\end{array} \\
\text { 3. }\end{array}$ & 694.4 & \\
\hline $\begin{array}{l}000453040 \\
309 \\
30301\end{array}$ & $\begin{array}{ll}0 & 0 \\
0 & 0\end{array}$ & $\begin{array}{r}.07925 \\
0.0\end{array}$ & .0125 & 1.865 & $\begin{array}{r}3.0 \\
3.0\end{array}$ & 694.4 & \\
\hline $\begin{array}{l}5011 \\
54015\end{array}$ & $\begin{array}{ll}0 & 0 \\
0 & 0\end{array}$ & $\begin{array}{l}0.0 \\
0.0\end{array}$ & 0.0 & $\begin{array}{l}.376 \\
.376\end{array}$ & 3.0 & $1.8-1$ & \\
\hline $\begin{array}{r}1 \cdot \theta-12 \\
53095502\end{array}$ & 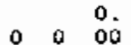 & $\begin{array}{l}1 . e-12 \\
0.0\end{array}$ & .220 & $\begin{array}{r}.583 \\
3.005\end{array}$ & .222 & .583 & \\
\hline 530954025 & & 0.0 & $\begin{array}{l}0.0 \\
220\end{array}$ & 1.005 & 3. & $1.8-12$ & \\
\hline $\begin{array}{r}1 \cdot-0-12 \\
5310 \\
5303\end{array}$ & & $\begin{array}{r}1 . \theta-12 \\
0.0\end{array}$ & $\begin{array}{l}.220 \\
.010\end{array}$ & $\begin{array}{r}.497 \\
1.336\end{array}$ & $\begin{array}{l}.222 \\
3.0\end{array}$ & & \\
\hline $5310 \quad 54025$ & 0 & $\begin{array}{r}0.0 \\
1,0-12\end{array}$ & $\begin{array}{l}0.0 \\
.220\end{array}$ & 1.33 & $\begin{array}{r}3.0 \\
.222\end{array}$ & $\begin{array}{l}1.0-12 \\
.497\end{array}$ & \\
\hline 53115304 & & 0.0 & .125 & $\begin{array}{l}1.905 \\
1.905\end{array}$ & $\begin{array}{l}3.0 \\
3.0\end{array}$ & & \\
\hline $\begin{array}{l}531154035 \\
1 .,-12\end{array}$ & & $1 . \theta-12$ & $\begin{array}{l}.0 .0 \\
.220\end{array}$ & $\begin{array}{l}1.905 \\
.400\end{array}$ & $\begin{array}{l}3.0 \\
.222\end{array}$ & $\begin{array}{l}1 . e^{-1212} \\
.40 \mathrm{~B}\end{array}$ & \\
\hline $\begin{array}{r}530554035 \\
1.0-12\end{array}$ & 0 & $\begin{array}{r}0.0 \\
1 . e-12\end{array}$ & $\begin{array}{r}0.0 \\
.220\end{array}$ & $\begin{array}{r}2.121 \\
.008\end{array}$ & $\begin{array}{l}3.0 \\
.222\end{array}$ & $\begin{array}{r}1.0-12 \\
.408\end{array}$ & \\
\hline $\begin{array}{l}53055306 \\
53065307\end{array}$ & $\begin{array}{l}0 \\
0\end{array}$ & $\begin{array}{r}0.0 \\
.139375\end{array}$ & $\begin{array}{r}.139375 \\
0 .\end{array}$ & $\begin{array}{r}2.121 \\
2.554\end{array}$ & $\begin{array}{l}3.0 \\
3.0\end{array}$ & & \\
\hline 0.1650 & & & & 2.55 & & & \\
\hline $\begin{array}{l}0.1960 \\
0.1912\end{array}$ & & 0.1976 & $\begin{array}{l}260.6 \\
650.6\end{array}$ & 0.2107 & 332.6 & 0.2252 & \\
\hline $\begin{array}{l}0.2400 \\
0.360\end{array}$ & & 0.2565 & $\begin{array}{l}54 \\
89\end{array}$ & & & 0.0 .29 & 110 \\
\hline $\begin{array}{l}0.3966 \\
0.3996\end{array}$ & 1340.6 & 0.4282 & 1520.6 & 0.4579 & 1700.6 & 0.5163 & \\
\hline $\begin{array}{r}0.5735 \\
0.9968\end{array}$ & $\begin{array}{l}2420 \\
4940\end{array}$ & 0.6275 & & & & & \\
\hline $\begin{array}{lll}1016301 & 6301 \\
002 & 6302\end{array}$ & $\begin{array}{lll}0 & 0 & 00 \\
0 & 0 & 00\end{array}$ & $\begin{array}{l}1.5 \\
1.3\end{array}$ & & & $\begin{array}{l}1.0 \\
1.0\end{array}$ & & \\
\hline $\begin{array}{l}2036303 \\
046304\end{array}$ & 00 & 1.5 & 1.5 & & 1. & & \\
\hline $\begin{array}{l}6304 \\
6306 \\
6001\end{array}$ & $\begin{array}{lll}0 & 0 \\
0 & 0 & 0\end{array}$ & 1. & $\begin{array}{l}1.5 \\
1.5\end{array}$ & 6.5212 & 1.0 & & \\
\hline $\begin{array}{l}6001 \\
6002\end{array}$ & 00 & & 1 & & 1. & & \\
\hline $\begin{array}{l}2 \\
3 \\
3 \\
60003\end{array}$ & $\begin{array}{lll}0 & 0\end{array}$ & & & $\begin{array}{l}1.835 e-1 \\
2.365 e-1\end{array}$ & 1.0 & & \\
\hline & & & & & 1.0 & & \\
\hline
\end{tabular}




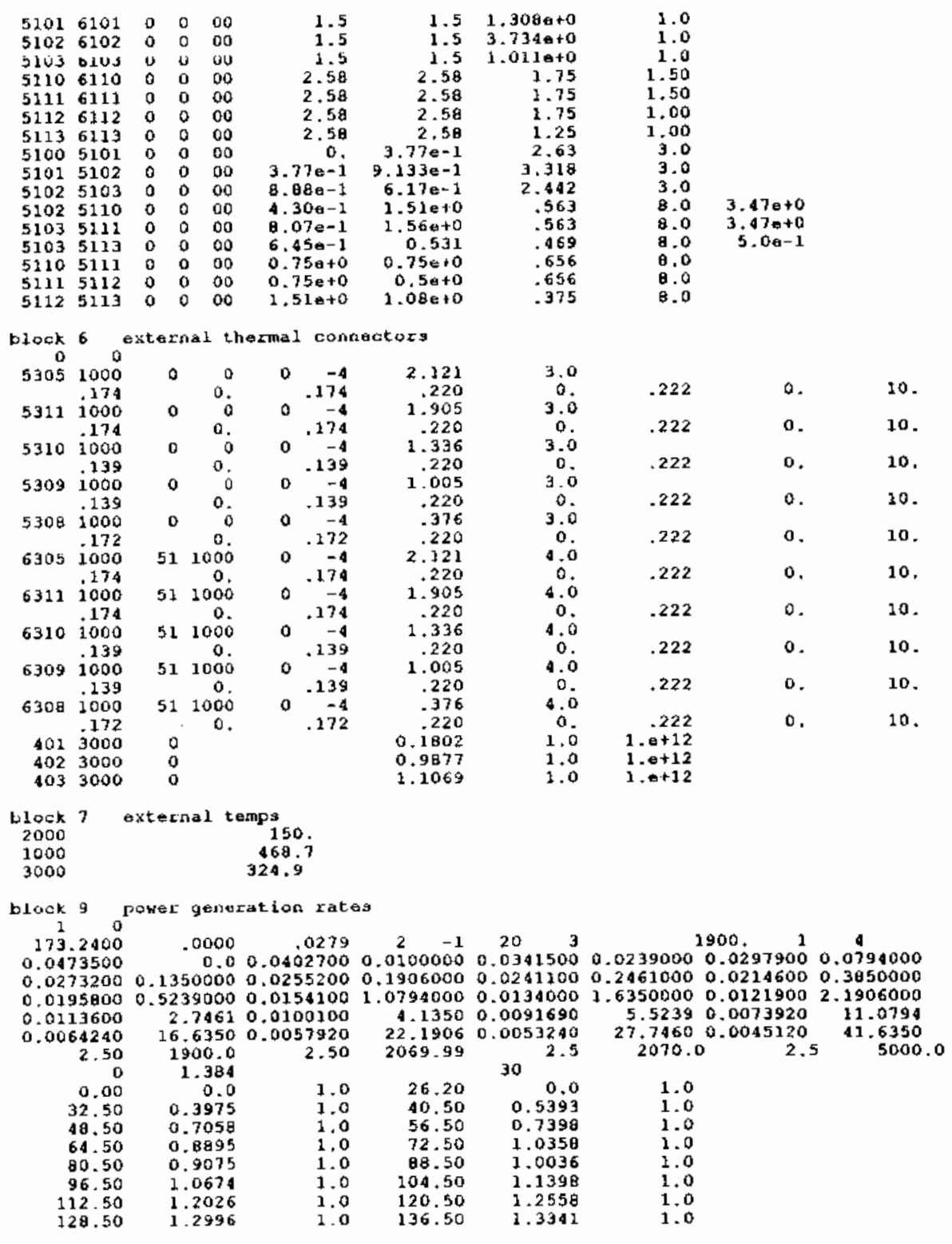




\begin{tabular}{|c|c|c|c|c|c|}
\hline $\begin{array}{l}144.50 \\
160.50\end{array}$ & $\begin{array}{l}1.3596 \\
1.3702\end{array}$ & 1.0 & $\begin{array}{r}152.50 \\
168.50\end{array}$ & $\begin{array}{l}1.3766 \\
1.3779\end{array}$ & 1.0 \\
\hline $\begin{array}{l}160.50 \\
176.50\end{array}$ & $\begin{array}{l}1.3702 \\
1.3836\end{array}$ & $\begin{array}{l}1.0 \\
1.0\end{array}$ & $\begin{array}{r}180.50 \\
184.50\end{array}$ & $\begin{array}{l}1.3854 \\
1.385\end{array}$ & $\begin{array}{l}1.0 \\
1.0\end{array}$ \\
\hline 192.50 & 1.3810 & 1.0 & 200.50 & 1.3691 & \\
\hline $\begin{array}{r}200.50 \\
770\end{array}$ & $\begin{array}{l}1.3490 \\
1.3773\end{array}$ & 1.0 & 716.50 & 1.3195 & 1.0 \\
\hline $\begin{array}{l}\begin{array}{l}224.50 \\
240.50\end{array} \\
20\end{array}$ & $\begin{array}{l}1.2773 \\
1.2070\end{array}$ & $\begin{array}{l}1.0 \\
1.0\end{array}$ & $\begin{array}{l}232.50 \\
248.50\end{array}$ & $\begin{array}{l}1.2109 \\
1.2698\end{array}$ & $\begin{array}{l}1.0 \\
1.0\end{array}$ \\
\hline 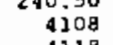 & & 0 & & 0.0 & 450. \\
\hline $\begin{array}{l}4118 \\
4402\end{array}$ & $\begin{array}{l}0 \\
0 \\
0\end{array}$ & $\begin{array}{l}0 \\
0\end{array}$ & $\begin{array}{l}0 \\
0\end{array}$ & $\begin{array}{l}0.0 \\
0.0\end{array}$ & $\begin{array}{l}450 . \\
450 .\end{array}$ \\
\hline 4401 & & 0 & 0 & & \\
\hline 4305 & 0 & 0 & 0 & 0.0 & 450. \\
\hline 4306 & 0 & 0 & 0 & 0.0 & 450. \\
\hline & 年 & $\begin{array}{l}0 \\
0\end{array}$ & $\begin{array}{l}0 \\
0\end{array}$ & 0.0 & 450. \\
\hline 4101 & 0 & 0 & 0 & & \\
\hline 4102 & 0 & 0 & 0 & 0.0 & 450. \\
\hline 4103 & 0 & o & 0 & 0.0 & 450. \\
\hline $\begin{array}{l}4104 \\
4105 \\
4105\end{array}$ & 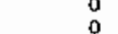 & 0 & $\begin{array}{l}0 \\
0\end{array}$ & $\begin{array}{l}0.0 \\
0.0\end{array}$ & \\
\hline & 0 & 0 & o & 0.0 & 450. \\
\hline & 0 & 0 & 0 & 0.0 & 450. \\
\hline & 0 & 0 & $\stackrel{0}{0}$ & 0.0 & 450. \\
\hline $\begin{array}{l}\begin{array}{r}3401 \\
3305\end{array} \\
3\end{array}$ & 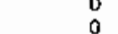 & $\begin{array}{l}0 \\
0\end{array}$ & : & $\begin{array}{l}.0 \\
0.0\end{array}$ & . \\
\hline 3306 & 0 & 0 & a & 0.0 & 450. \\
\hline & 0 & 0 & 0 & 0.0 & 450. \\
\hline & $\stackrel{0}{0}$ & 0 & $\stackrel{0}{0}$ & $\begin{array}{l}0.0 \\
0.0\end{array}$ & ${ }_{450}^{450 .}$ \\
\hline & 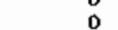 & 0 & 0 & 0.0 & \\
\hline 31 & 0 & 0 & 0 & 0.0 & 450 \\
\hline & 0 & 0 & 0 & 0.0 & 450. \\
\hline $\begin{array}{l}3105 \\
3109\end{array}$ & 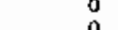 & 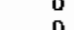 & ${ }_{0}^{0}$ & 0.0 & 450. \\
\hline & 0 & 0 & 0 & 0.0 & \\
\hline & 0 & 0 & 0 & 0.0 & 450. \\
\hline 24 & 0 & 0 & a & 0.0 & 450. \\
\hline 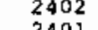 & $a$ & $0_{0}^{0}$ & $a$ & 0.0 & $\begin{array}{l}450 . \\
{ }_{450}\end{array}$ \\
\hline 2305. & 0 & 0 & 0 & 0.0 & 450. \\
\hline & $\stackrel{0}{0}$ & 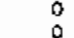 & $\begin{array}{l}0 \\
0\end{array}$ & $\begin{array}{l}0.0 \\
0.0\end{array}$ & $\begin{array}{l}450 . \\
450 .\end{array}$ \\
\hline & 0 & 0 & 0 & 0.0 & 450. \\
\hline & 0 & 0 & 0 & 0.0 & 450. \\
\hline & 0 & 0 & 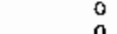 & 0.0 & 450. \\
\hline & 0 & 0 & o & $\begin{array}{l}0.0 \\
0.0\end{array}$ & 450. \\
\hline 2105 & 0 & 0 & 0 & 0.0 & 450. \\
\hline & $\stackrel{0}{0}$ & $\begin{array}{l}0 \\
0\end{array}$ & 要 & 0.0 & $\begin{array}{l}{ }_{450}^{450} . \\
450 .\end{array}$ \\
\hline & 0 & o & 0 & 0.0 & 450. \\
\hline 1403 & 0 & 0 & 0 & 0.0 & 450. \\
\hline & $\therefore$ & 0 & 0 & 0.0 & \\
\hline & & & $:$ & 0.0 & 450 \\
\hline & 0 & o & $a$ & 0.0 & 150. \\
\hline & 0 & 0 & 0 & 0.0 & 450. \\
\hline & . & $0_{0}^{0}$ & 0 & 0.0 & 450. \\
\hline 110 & $a$ & 0 & 0 & 00 & 450 \\
\hline 110 & 0 & 0 & 0 & 0.0 & \\
\hline & 0 & 0 & 0 & 0.0 & 450. \\
\hline & 0 & & 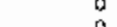 & & \\
\hline & & 0 & 0 & & \\
\hline & & 0 & 0 & 0.0 & $450^{\circ}$ \\
\hline
\end{tabular}




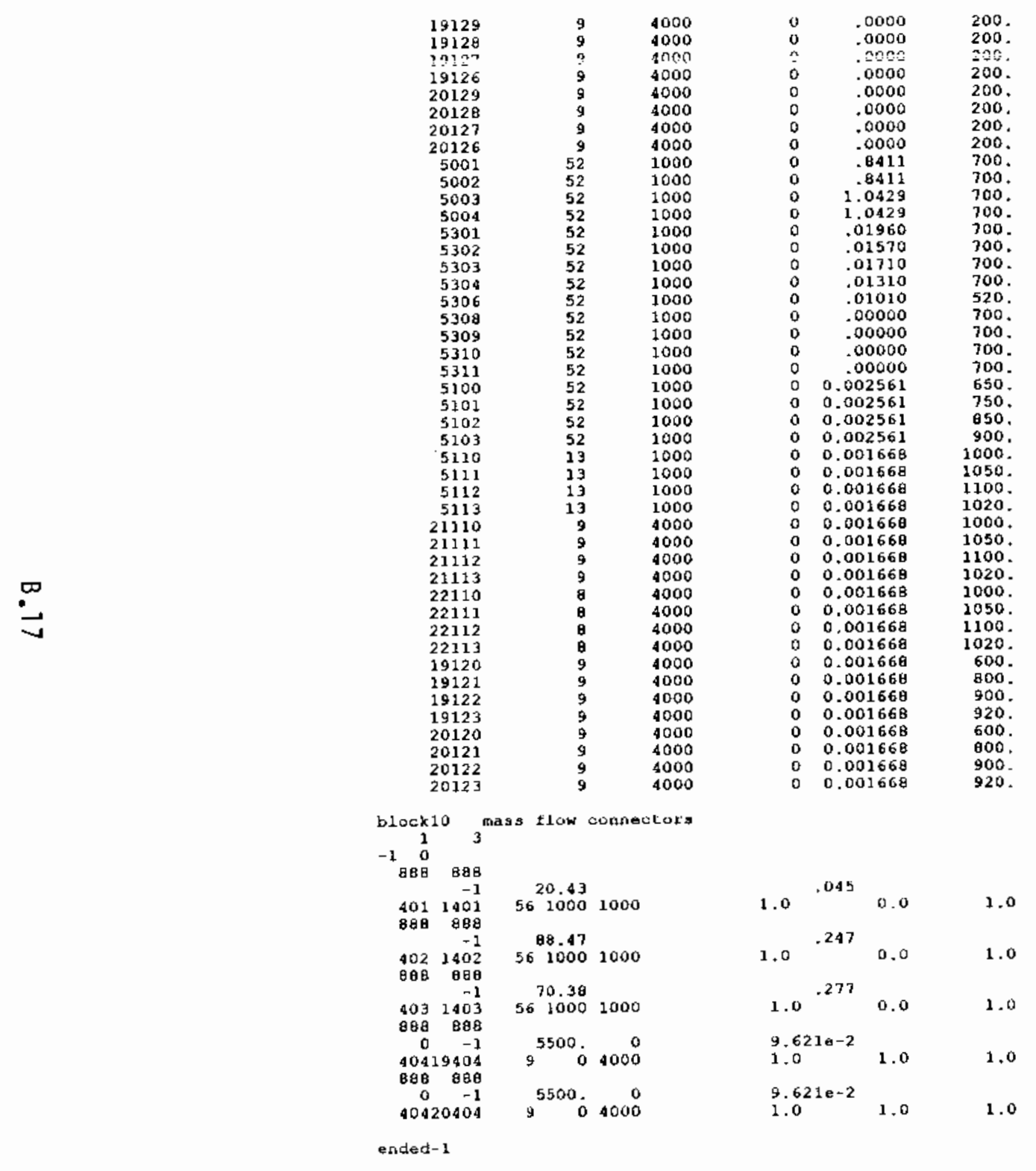




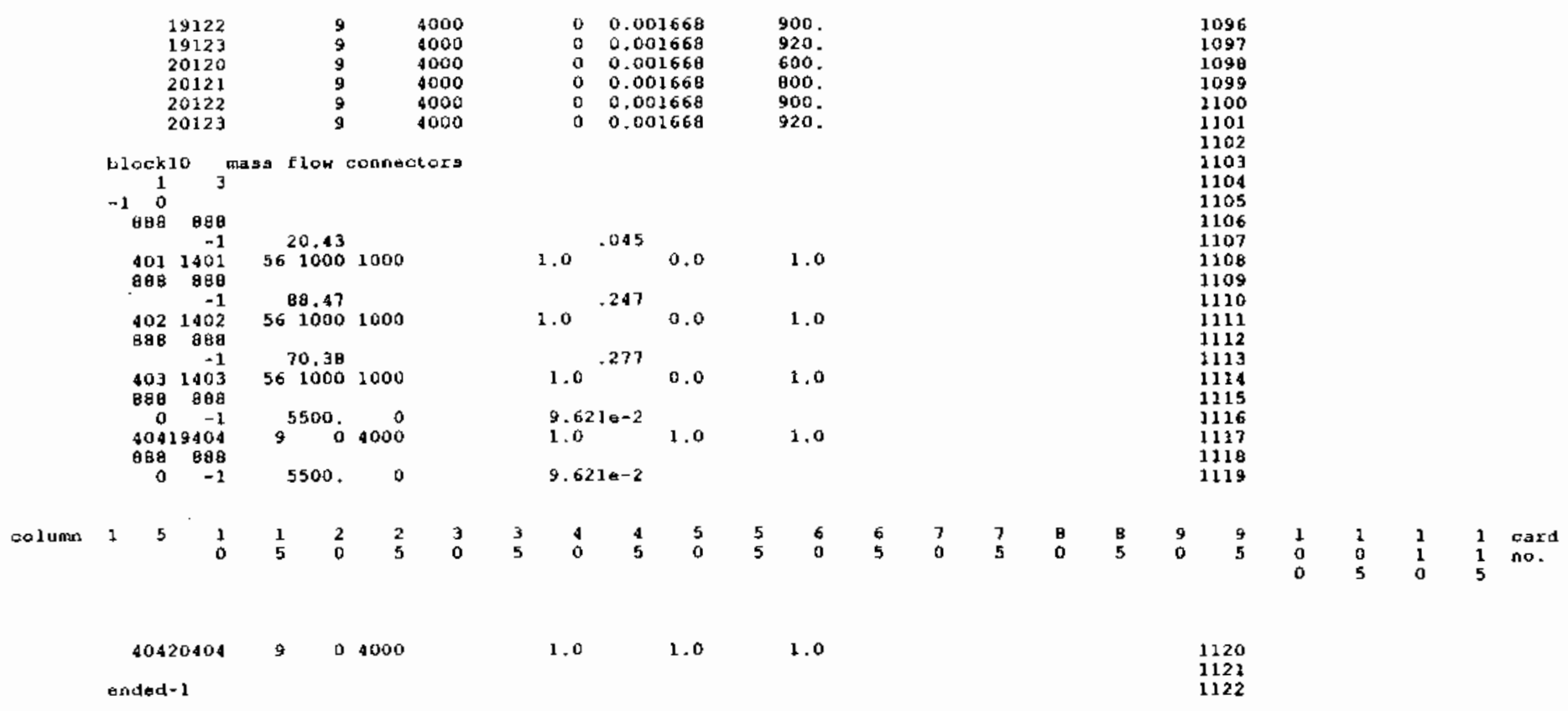

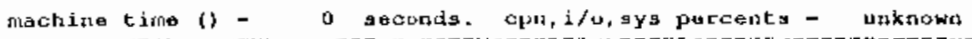

*ver2.27 trump ba full power spiked hot channel reflood station wlackout (hygen,

1 input usit $=5$. autput unit proyrain date 6 data deck 1

*ver2.17 trump bd full power apiked hol charmel reflood station blackout (hygen.

no dita carryover trom preceding problem.

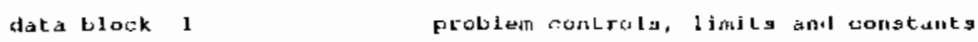

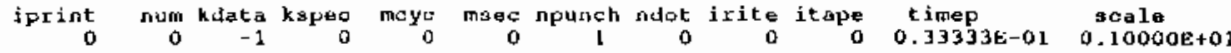




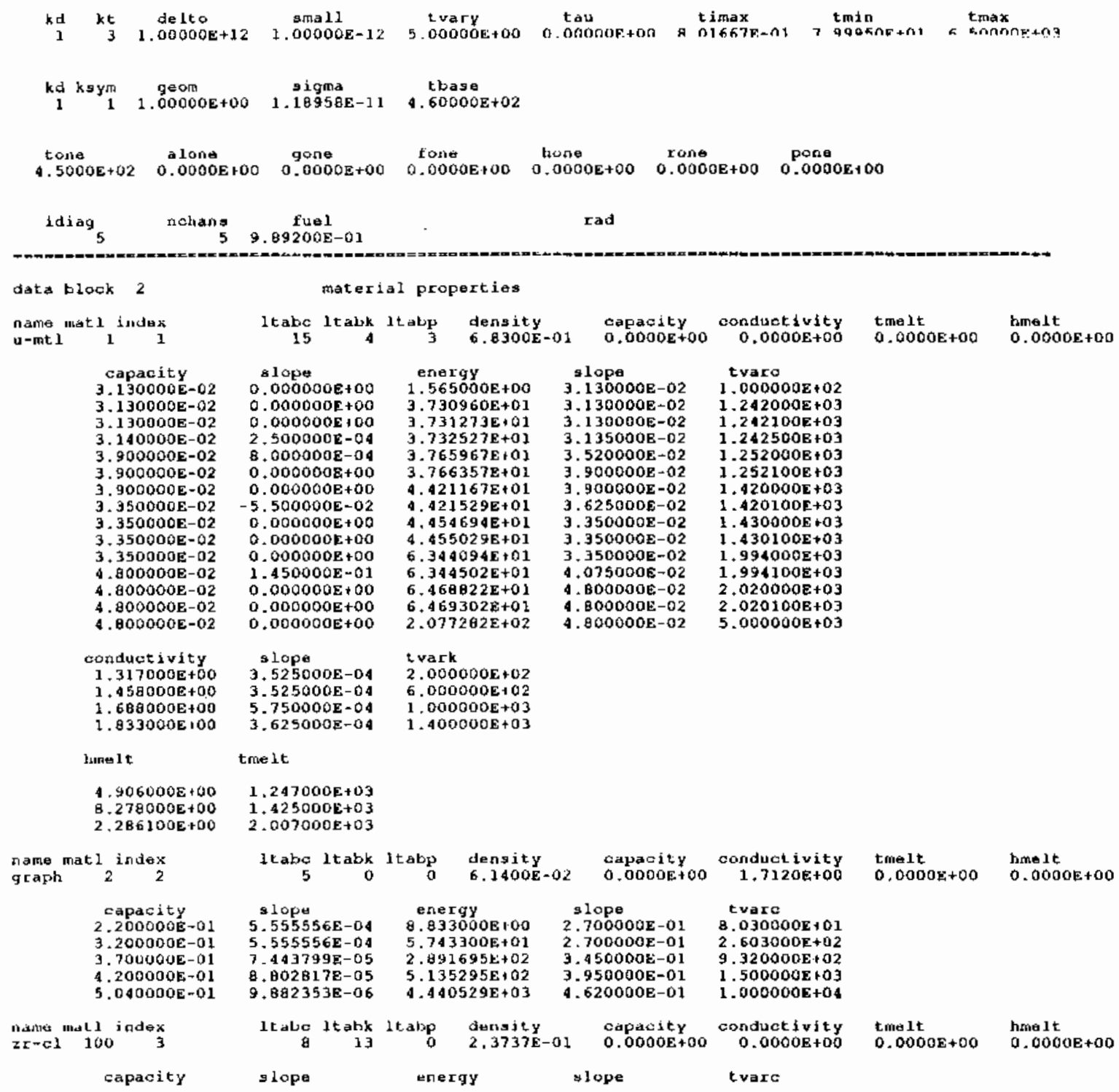

lope

energy

*lope tvarc 


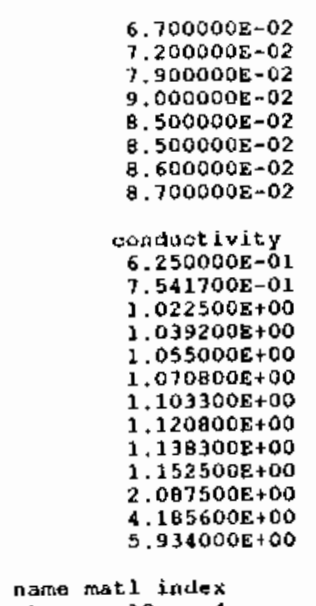

$2.777778 \mathrm{E}-05$
$2.777779 \mathrm{E}-05$
$1.620370 \mathrm{E}-05$
$1.350025 \mathrm{E}-05$
$-1.760563 \mathrm{E}-05$
$0.000000 \mathrm{E}+00$
$1.000000 \mathrm{E}-06$

$2.713500 \mathrm{E} 100$ 1. $3223550 E+01$

$6.950000 \mathrm{E}-02$

6. $950000 \mathrm{E}-02$

$+02 \quad 8.45000$

Q.7500008-02

$\begin{array}{ll}.442395 E+02 & 8.5000008-02 \\ .297395 E+02 & 8.5500000-02\end{array}$

$.930000 \mathrm{E}+02$

$1.503000 \mathrm{E}+03$
$1.767000 \mathrm{E}+03$

3.000000E +03

$\begin{array}{ll}1.000000 \mathrm{E}-06 & 3.297395 \mathrm{E}+02 \\ 1.000000 \mathrm{E}-06 & 4.162395 \mathrm{E}\end{array}$

\section{Mlope trark}

$\begin{array}{ll}.990046 E-04 & 2.610000 E+02 \\ 990046 E-04 & 6.930000 E+02\end{array}$

$\begin{array}{ll}3.99076 \mathrm{E}-04 & 6.930000 \mathrm{E}+02 \\ 3.312716 \mathrm{E}-04 & 1.503000 \mathrm{E}+03\end{array}$

$4.073171 \mathrm{E}-04 \quad 1.544000 \mathrm{E}+03$

$\begin{array}{ll}.380889 E-04 & 1.580000 E+03\end{array}$

$\begin{array}{ll}.313898-04 & 1.616000 \mathrm{E}+03 \\ . & 1.689000 \mathrm{E}+03\end{array}$

$4.861111 \mathrm{E}-04 \quad 1.724000 \mathrm{E}+03$

$4.861111 E-04 \quad 1.760000 E+03$

$\begin{array}{ll}5.259259 \mathrm{E}-04 & 1.767000 \mathrm{E}+03 \\ 9.230010 \mathrm{~A}-0 \mathrm{~A} & 2.600000 \mathrm{E}+03\end{array}$

$\begin{array}{ll}9.230010 \mathrm{E}-0 \mathrm{~A} & 2.000000 \mathrm{E}+03 \\ 1.748417 \mathrm{E}-03 & 4.000000 \mathrm{H}+03 \\ 1.748400 \mathrm{E}-03 & 5.000000 \mathrm{O}+03\end{array}$

name mat1 index

1tabe 1tabk 1tabp density

capacity conductivity
$0.0000 \mathrm{O}+00$

$\begin{array}{ll}\text { tmelt } & \text { hmelt } \\ 0.0000 \mathrm{E}+00 & 0.0000 \mathrm{E}+00\end{array}$

$$
\text { p- } 200.0 \text { psia }
$$

stean viscogity and density tatlo

\begin{tabular}{|c|c|}
\hline $\begin{array}{l}\text { tenp } \\
\text { t. } 60000 \mathrm{E}+02 \\
1.00000 \mathrm{E}+02 \\
1.00000 \mathrm{E}+03 \\
1.60000 \mathrm{E}+03 \\
2.00000 \mathrm{E}+03 \\
2.40000 \mathrm{E}+03 \\
2.60000 \mathrm{E}+03 \\
2.60000 \mathrm{E}+03 \\
3.00000 \mathrm{E}+03 \\
3.20000 \mathrm{E}+03 \\
3.40000 \mathrm{E}+03 \\
3.60000 \mathrm{E}+03 \\
4.40000 \mathrm{E}+03 \\
5.00000 \mathrm{E}+03\end{array}$ & $\begin{array}{r}\text { viscosity } \\
3.85000 \mathrm{E}-02 \\
5.05000 \mathrm{E}-02 \\
7.24000 \mathrm{E}-02 \\
1.05200 \mathrm{E}-01 \\
1.27100 \mathrm{E}-01 \\
1.49000 \mathrm{E}-01 \\
1.59900 \mathrm{E}-01 \\
1.70000 \mathrm{E}-01 \\
1.811000 \mathrm{E}-01 \\
1.92700 \mathrm{E}-01 \\
2.03700 \mathrm{E}-01 \\
2.14600 \mathrm{E}-01 \\
2.15000 \mathrm{E}-02 \\
2.93000 \mathrm{E}-02\end{array}$ \\
\hline
\end{tabular}

temp

Lensity

$.00000 E+02 \quad 3.270008-01$

$2.32100 \mathrm{E}-01$
$.00000 \mathrm{E}+02$

1. $20000 \mathrm{E}+03 \quad 1.36500 \mathrm{E}-01$

$\begin{array}{ll}1.40000 \mathrm{E}+03 & 1.17400 \mathrm{E}-02 \\ 1.60000 \mathrm{0}+03 & 1.09700 \mathrm{E}-01\end{array}$

$2.00000 \mathrm{E}+03 \quad 1.03000 \mathrm{E}-01$

$\begin{array}{ll}2.40000 \mathrm{E} 103 & 9.31000 \mathrm{E}-02 \\ 3.00000 \mathrm{O}+03 & 9.18000 \mathrm{E}-02\end{array}$

3. $40000 \mathrm{E}+03 \quad$. $3.70000 \mathrm{E}-02$

$\begin{array}{ll}3.60000 \mathrm{t} 103 & \text { B. } \\ 4.40000 \mathrm{~T}+03 & 6.91000 \mathrm{E}-02\end{array}$

(6..15000E-02

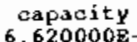

5. $200000 \mathrm{E}-0$

$5.200000 \mathrm{E}-0$

5.750000E-0

$6.500000 \mathrm{E}-01$

6. $700000 \mathrm{E}-01$

$.050000 \mathrm{E}-01$

$7.250000 \mathrm{E}-01$
$7.450000 \mathrm{E}-01$

$7.600000 \mathrm{E}-\mathrm{a}$

$8.1240008-01$
$8.6400008-01$

conduclivity

slope

energy
$1.257800 \mathrm{~B}+02$

5. $5100000 \mathrm{E}-0$.

tuarco

. $454545 \mathrm{E}-04$

$0.000000 E+00$

$9.166667 \mathrm{E}-05$
$7.750000 \mathrm{x}-05$

$1.100000 \mathrm{E}-04$

$1.000000 \mathrm{E}-04$

$7.500000 \mathrm{E}-05$

$1.0000008-04$

$7.500000 \mathrm{E}-05$

$6.550000 \mathrm{E}-05$
$.600000 \mathrm{E}-05$

$2.558000 \mathrm{E}+02$

5. $910000 \mathrm{E}-\mathrm{OL}$

3. $800000 \mathrm{E}+02$

.638000E+02

$1.028500 \mathrm{E}+03$

$1.4117000+03$

$1.547700 E+03$

$5.475000 \mathrm{E}-01$

$6.200000 \mathrm{E}-0$.

.600000 -01

$1.830200 \mathrm{0} 03$.

$1.977200 \mathrm{E}+03$ T. $350000 \mathrm{E}-0 \mathrm{~A}$

$2.127700 \mathrm{E}+03$

$7.350000 \mathrm{E}-010$

$\begin{array}{rr}3.259580 \mathrm{E}+03 & 7.062000 \mathrm{E}-01 \\ 3.2582000 \mathrm{E}-01\end{array}$

$1.600000 E+03$

$.0000000+03$

$2.400000 \mathrm{E}+03$
$2.600000 \mathrm{O}+03$

2. $200000 \mathrm{E}+03$

$3.000000 E+03$
$3.200000 E+03$

$.200000 E+03$

$400000 E+03$

$400000 E+03$
$.000000 E+03$

slope

Lvark 


\begin{tabular}{|c|c|c|}
\hline $\begin{array}{l}1,600000 \mathrm{E}-03 \\
2,200000 \mathrm{E}-03\end{array}$ & $\begin{array}{l}2.7272738-06 \\
2.727273 \mathrm{E}-06\end{array}$ & $\begin{array}{l}3.800000 \mathrm{E}+02 \\
6.000000 \mathrm{E}+02\end{array}$ \\
\hline ? Fnononf na & $\begin{array}{l}3250000 \mathrm{e} \text { ne } \\
1\end{array}$ & nnopone to? \\
\hline $\begin{array}{l}5.700000 \mathrm{E}-03 \\
7.100000 \mathrm{E}-03\end{array}$ & $1,750000 \mathrm{E}-06$ & 1. $000000 \mathrm{E}+03$ \\
\hline 8. $300000 E-03$ & $3,000000 \mathrm{E}-06$ & $2.400000 \mathrm{E}+03$ \\
\hline a. $600000 \mathrm{E}-03$ & $2,500000 \mathrm{E}-06$ & $2.600000 \mathrm{E}+03$ \\
\hline $9.200000 \mathrm{E}-03$ & $2.000000 \mathrm{E}-06$ & $2.800000 \mathrm{E}+03$ \\
\hline $9.400000 \mathrm{E}-03$ & $1.000000 \mathrm{E}-06$ & $3.000000 \mathrm{E}+03$ \\
\hline $9.600000 \mathrm{E}-03$ & $1.000000 E-06$ & $3.200000 \mathrm{E}+03$ \\
\hline $9.500000 \mathrm{E}-03$ & $-5.000000 E-07$ & $3.400000 \mathrm{E} \neq 03$ \\
\hline $9.300000 E-03$ & $-1.0000008-06$ & $3.600000 E+03$ \\
\hline $6.2000005-03$ & $-3.075000 \mathrm{E}-06$ & $4+400000 E+03$ \\
\hline 1. $2000008-03$ & $-8.333333 E-06$ & $5.000000 E+03$ \\
\hline
\end{tabular}

data block 4

node desuriptors

varlable axial length model option

$\begin{array}{rr}\text { level } & \text { length (in) } \\ 1 & 10.0000 \\ 2 & 9.5000 \\ 3 & 3.0000 \\ 4 & 3.0000 \\ 5 & 3.0000 \\ 6 & 4.0000 \\ 7 & 4.0000 \\ 8 & 4.0000 \\ 9 & 4.0000 \\ 10 & 4.0000 \\ 11 & 4.0000 \\ 12 & 4.0000 \\ 13 & 4.0000 \\ 14 & 4.0000 \\ 15 & 4.0000 \\ 16 & 4.0000 \\ 17 & 4.0000 \\ 18 & 4.0000 \\ 19 & 4.0000 \\ 20 & 4.0000 \\ 21 & 4.0000 \\ 22 & 4.0000 \\ 23 & 4.0000 \\ 24 & 4.0000 \\ 25 & 4.0000 \\ 26 & 4.0000 \\ 27 & 4.0000 \\ 28 & 4.0000 \\ 29 & 4.0000 \\ 30 & 4.0000 \\ 31 & 4.0000 \\ 32 & 4.0000 \\ 33 & 4.0000 \\ 34 & 4.0000 \\ 35 & 4.0000 \\ 36 & 4.0000 \\ 37 & 4.0000 \\ 38 & 4.0000 \\ 39 & 4.0000 \\ 40 & 4.0000 \\ 41 & 4.0000 \\ 42 & 4.0000 \\ & \\ & \end{array}$




$$
\begin{array}{ll}
43 & 4.0000 \\
44 & 4.0000 \\
45 & 4.0000 \\
46 & 4.0000 \\
47 & 4.0000 \\
48 & 4.0000 \\
49 & 4.0000 \\
50 & 4.0000 \\
51 & 4.0000 \\
52 & 4.0000 \\
53 & 4.0000 \\
54 & 4.0000 \\
55 & 4.0000 \\
56 & 4.0000 \\
57 & 4.0000
\end{array}
$$

this gimulation is pexformed usizng a5? axial level rodel with a lower boundary of 0.000 in.

the ovarall model length is $236.50 \mathrm{in}$.

\begin{tabular}{|c|}
\hline 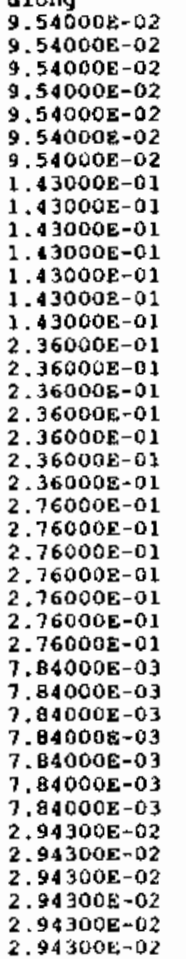 \\
\hline
\end{tabular}

\begin{tabular}{|c|c|}
\hline $\begin{array}{l}1.00000 E+00 \\
1.00000 E+00 \\
1.00000 E+00 \\
1.00000 E+00 \\
.00000 E+00 \\
.00000 E+00 \\
.00000 E+00 \\
.00000 E+00 \\
.00000 E+00 \\
1.00000 E+00 \\
.00000 E+00 \\
.00000 E+00 \\
.00000 E+00 \\
.00000 E+00 \\
.00000 E+00 \\
.00000 E+00 \\
1.00000 E+00 \\
.00000 E+00 \\
.00000 E+00 \\
1.00000 E 100 \\
.00000 E+00 \\
0000\end{array}$ & 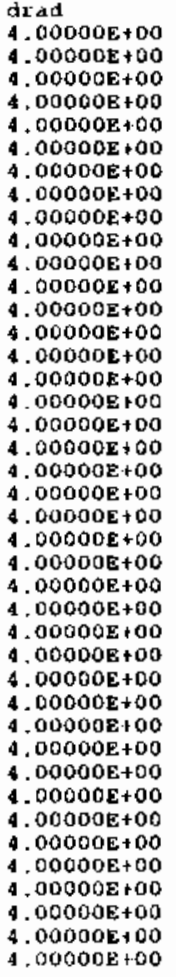 \\
\hline
\end{tabular}

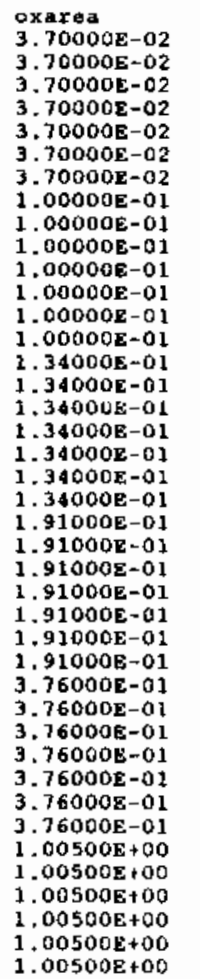

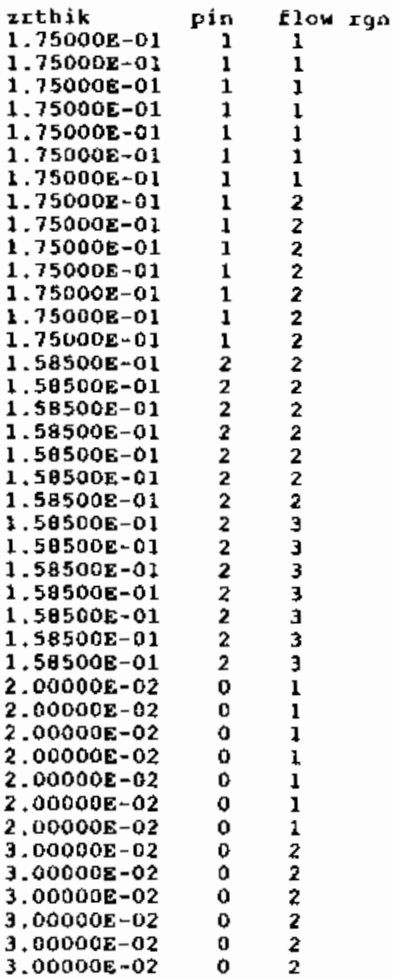

$3.00000 \mathrm{E}-02$
$3.00000 \mathrm{E}-02$

$\begin{array}{rrrr}\text { noda } & \text { index } & \text { inat l } & \text { intypo } \\ 60001 & 1 & 1 & 0 \\ 8001 & 2 & 1 & 0 \\ 10001 & 3 & 1 & 0 \\ 12001 & 4 & 1 & 0 \\ 14001 & 5 & 1 & 0 \\ 14001 & 6 & 1 & 0 \\ 16001 & 6 & 1 & 0 \\ 19001 & 7 & 1 & 0 \\ 6002 & 8 & 1 & 0 \\ 8002 & 9 & 1 & 0 \\ 10002 & 10 & 1 & 0 \\ 12002 & 11 & 1 & 0 \\ 14002 & 12 & 1 & 0 \\ 16002 & 13 & 1 & 0 \\ 18002 & 14 & 1 & 0 \\ 6003 & 15 & 1 & 0 \\ 8003 & 16 & 1 & 0 \\ 10003 & 17 & 1 & 0 \\ 12003 & 18 & 1 & 0 \\ 14003 & 19 & 1 & 0 \\ 16003 & 20 & 1 & 0 \\ 18003 & 21 & 1 & 0 \\ 6004 & 22 & 1 & 0 \\ 8004 & 23 & 1 & 0 \\ 10004 & 24 & 1 & 0 \\ 12004 & 25 & 1 & 0 \\ 14004 & 26 & 1 & 0 \\ 16004 & 27 & 1 & 0 \\ 18004 & 29 & 1 & 0 \\ 6301 & 29 & 100 & 0 \\ 8301 & 30 & 100 & 0 \\ 10301 & 31 & 100 & 0 \\ 12301 & 32 & 100 & 0 \\ 14301 & 33 & 100 & 0 \\ 16301 & 34 & 100 & 0 \\ 18301 & 35 & 100 & 0 \\ 6302 & 36 & 100 & 0 \\ 0302 & 37 & 100 & 0 \\ 10302 & 38 & 100 & 0 \\ 12302 & 39 & 100 & 0 \\ 14302 & 40 & 100 & 0 \\ 16302 & 41 & 100 & 0 \\ & & & \end{array}$

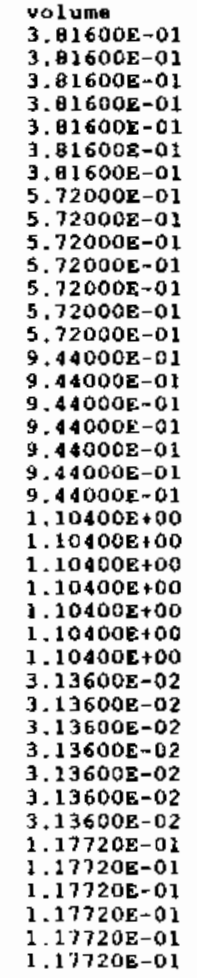


data block 5

\begin{tabular}{|c|c|c|c|c|c|c|c|c|c|c|}
\hline & & & & & & & & & & \\
\hline & & & $\varepsilon-02$ & $0 E-02$ & & & $9440 E+02$ & $0.0000 \mathrm{z}+00$ & $6320 E+00$ & \\
\hline & & & & & & & $\mathrm{DE}+02$ & $0.0000 \mathrm{E}+00$ & $6320 E+00$ & \\
\hline & & & $0 \Sigma-02$ & $100 \mathbf{E}$ & & $8+00$ & $E+02$ & $0,0000 \mathrm{E}+00$ & $6320 E+00$ & \\
\hline & & 4 & $1.0000 \mathrm{E}-02$ & $7500 E-02$ & $4.0800 E-01$ & $4.0000 \varepsilon+00$ & $9440 \mathrm{E}+02$ & $0.0000 \mathrm{z}+00$ & $6320 \mathrm{E}+00$ & \\
\hline & & & $1.0000 \mathrm{E}-02$ & a. $7500 \mathrm{E}-02$ & $4.0800 \mathrm{E}-01$ & $4.0000 \varepsilon+00$ & $6.9440 \mathrm{E}+02$ & $0,0000 \mathrm{E}+00$ & $6320 \mathrm{E}+00$ & \\
\hline & 16001 & & $1.0000 E-02$ & $8.7500 \mathrm{E}-02$ & $4.0000 \mathrm{E}-01$ & $4.0000 E+00$ & $6.9440 \mathrm{E}+02$ & $0.0000 \mathrm{z}+00$ & $1.6320 E+00$ & \\
\hline $\begin{array}{l}\text { Tos. } \\
18301\end{array}$ & 18002 & & $1.0000 \mathrm{E}-02$ & $0.75008-02$ & $4.0800 \mathrm{E}-01$ & $\therefore$ DOO0E r00 & $6.9440 E+02$ & $0.0000 \mathrm{E}+00$ & $1.6320 \mathrm{E}+00$ & 0 \\
\hline 6001 & 6002 & & 8.7500z-02 & B. 7500E-02 & $6.8300 \mathrm{E}-01$ & $4,0000 E+00$ & $1.0000 \mathrm{E}+12$ & $0.0000 \mathrm{E}+00$ & $2.7320 \mathrm{E}+00$ & 0 \\
\hline Bool & 6002 & & $8.75008-02$ & G.7500E -02 & $6,8300 \mathrm{E}-01$ & 4.0000 + +00 & $1,0000 \mathrm{E}+12$ & $0.0000 \mathrm{~B} 100$ & $2.7320 \mathrm{E}+00$ & 0 \\
\hline 10001 & 10002 & 10 & Q $7500 \mathrm{E}-02$ & $8.7500 \mathrm{E}-02$ & $6.0300 \mathrm{E}-01$ & $4.0000 E+00$ & $1.0000 \mathrm{E}+12$ & $0.0000 \mathrm{E}+00$ & $2.7320 \mathrm{E}+00$ & 0 \\
\hline 12001 & 12002 & 11 & $0,7500 \mathrm{E}-02$ & $9.7500 \mathrm{E}-02$ & G.B300E-01 & A.0000E $\$ 00$ & $1.0000 \mathrm{E}+12$ & $0.0000 \mathrm{E}+00$ & $2.7320 \mathrm{E}+00$ & 0 \\
\hline 14001 & 14002 & 12 & $0.7500 \mathrm{E}-02$ & B.7500E-02 & $6.8300 \mathrm{E}-01$ & $4.0000 \mathrm{E}+00$ & $1.0000 E+12$ & $0.0000 \mathrm{E}+00$ & $2,7320 \mathrm{E}+00$ & \\
\hline 16001 & 16002 & 13 & $0.7500 \mathrm{E}-02$ & 0.7500E-02 & $6.0300 \mathrm{E}-01$ & $4.0000 E+00$ & $1.00000+12$ & $0.0000 E+00$ & $2.7320 \mathrm{E}+00$ & \\
\hline 19001 & 18002 & 14 & 0.7500E-02 & $8.7500 \varepsilon-0 z$ & $\begin{array}{l}6.8300 \mathrm{E}-01 \\
\end{array}$ & $4.0000 \mathrm{E}+00$ & $1.0000 \mathrm{E}+12$ & $0,0000 \mathrm{E}+0 \mathrm{D}$ & $2.7320 \mathrm{E}+00$ & \\
\hline 6002 & 6302 & 15 & G. $3500 \mathrm{E}-02$ & $1.5000 \mathrm{E}-02$ & $9.5700 z-01$ & $4.0000 \mathrm{E}+00$ & $6.9440 \mathrm{E}+02$ & $0,0000 E+00$ & $3 . \theta 2 \theta 0 \varepsilon+00$ & 0 \\
\hline 8002 & 9302 & 16 & $8,7500 E-02$ & $1.5000 E-02$ & $9.5700 \mathrm{E}-01$ & $4.0000 \mathrm{E}+00$ & $6.9440 \mathrm{~B}+02$ & $0.0000 E+00$ & . OZ208 + & \\
\hline 10002 & 10302 & 17 & a. $7500 \mathrm{E}-02$ & $1.5000 E-02$ & $9.5700 \mathrm{E}^{\mathrm{N}} \mathrm{Ol}$ & $4.0000 \mathrm{E}+00$ & $6.9440 \mathrm{E}+02$ & $0.0000 E+00$ & $3.92808+00$ & \\
\hline 12002 & 12302 & 18 & $8.7500 \mathbf{E}-02$ & $1.5000 \mathrm{E}-02$ & $9.5700 \mathrm{E}-01$ & $4.0000 E+00$ & $6.9440 E+02$ & $0.0000 E+00$ & $3.8280 z+00$ & 0 \\
\hline 14002 & 14302 & 19 & $8.7500 \mathrm{E}-02$ & $1,5000 \mathrm{E}-02$ & $9.5700 \mathrm{E}-01$ & $4.0000 \mathrm{E}+00$ & $6.9440 \mathrm{E}+02$ & $0.0000 \mathrm{E}+00$ & $3,0280 \mathrm{E}+00$ & \\
\hline 16002 & 16302 & 20 & $9.7500 \mathrm{E}-02$ & $1.5000 E-02$ & $9.5700 \mathrm{E}-01$ & $4.0000 \mathrm{E}+00$ & $6.94408+02$ & $0.0000 \varepsilon+00$ & $3.8280 \mathrm{E}+00$ & \\
\hline 18002 & 18302 & 21 & g.7500E-02 & $1.5000 \mathrm{E}-02$ & $9.5700 \mathrm{E}-01$ & $4.0000 \mathrm{E}+00$ & $6.9440 E+02$ & $0.0000 E+00$ & $3.8280 E+00$ & 0 \\
\hline 6303 & 6003 & 22 & $1.0000 \mathrm{E}-02$ & $7.9250 \mathrm{E}-02$ & $1.3670 \mathrm{E}+00$ & $4.0000 \varepsilon+00$ & $6.9440 E 102$ & OOE +00 & $0 E+00$ & 0 \\
\hline 8303 & 8003 & 23 & $1.0000 \mathrm{E}-02$ & $7.9250 \mathrm{E}-02$ & $1.3670 z+00$ & 4.0000E +00 & $6,9440 E+02$ & & +00 & \\
\hline 10303 & 10003 & 24 & $1.00000-0 z$ & $7.9250 \mathrm{E}-02$ & $1.3670 \bar{z}+00$ & & & & & \\
\hline 12303 & 12003 & 25 & $1.0000 \mathrm{E}-02$ & $7.9250 \mathrm{E}-02$ & 1. $36702+00$ & 4.0 & & 0.0 & $O E+O O$ & \\
\hline 14303 & 14003 & 26 & $1.0000 \mathrm{E}-02$ & $7.9250 \mathrm{E}-02$ & $1.3670 \mathrm{E}+00$ & & & & +00 & \\
\hline 16303 & 16003 & 27 & $1.0000 \mathrm{E}-02$ & $7.9250 \mathrm{E}-02$ & $1.36700+00$ & 00 & 6.9 & & $+\infty 0$ & \\
\hline 18303 & 18009 & 28 & $1.0000 \mathrm{E}-02$ & $7.9250 \mathrm{E}-02$ & 1.3670 & 00 & & & & 0 \\
\hline 6003 & 6004 & 29 & $7.9250 \mathrm{E}-02$ & $7.9250 \mathrm{E}-02$ & 1.616 & & & & & 0 \\
\hline 8003 & 8004 & 30 & 7.9250 & $7.9250 \mathrm{E}-02$ & 1.61 & & & & & 0 \\
\hline 10003 & 10004 & 31 & 7.9250 & $7.9250 \mathrm{E}-02$ & 1.61 & & & & & 0 \\
\hline 12003 & 12004 & 32 & 7.925 & 7.92 & & & & & & 0 \\
\hline 14003 & 14004 & 33 & 7.925 & 7.92 & & & & & & 0 \\
\hline 16003 & 16004 & 34 & $E-02$ & 7.92 & & & & & & 0 \\
\hline 18003 & 18004 & & $0 E-02$ & 7.92 & & & & & & 0 \\
\hline 6004 & 6304 & 36 & $50 E-02$ & 1.25 & 1.8 & & & & & 0 \\
\hline & 04 & 37 & 7.92 & 1.25 & & & & & & 0 \\
\hline 10004 & 10304 & 38 & 7.92 & & & & & & & 0 \\
\hline 12004 & 12304 & 39 & 7.92 & 1.250 & & 4.0 & 6.94 & & & 0 \\
\hline$\$ 4004$ & 14304 & 40 & $0 E-02$ & 1.250 & $1.0650 E 100$ & $4.0000 E$ & 6.9 & & & 0 \\
\hline 16004 & 16304 & 41 & $7.9250 \mathrm{E}-02$ & 1.250 & $1.8650 E+00$ & 4.000 & 6.944 & & & 0 \\
\hline 18004 & 18304 & 42 & $7.9250 \mathrm{E}-02$ & 1.250 & 1.6650 & 4.00 & & & & 0 \\
\hline 6308 & 6301 & 13 & $0.0000 E+00$ & 1.000 & $3.7600 \mathrm{E}$ & 4.000 & 1.0 & & & o \\
\hline 8308 & 8301 & 4 & 0.00 & 1.00 & 3.7 & 4.0 & & & & 0 \\
\hline $\begin{array}{l}10308 \\
12308\end{array}$ & 10301 & 5 & 0.00 & 1.000 & 3.768 & 4.00 & $E+12$ & & bo & $a$ \\
\hline $\begin{array}{l}12308 \\
14308\end{array}$ & 12301 & 7 & 0.000 & 1.000 & 3.76 & 4,00 & & & 00 & 0 \\
\hline $\begin{array}{l}14308 \\
26308\end{array}$ & $\begin{array}{l}14301 \\
16301\end{array}$ & 47 & $0.0000 E+00$ & 1.000 & 3.7 & 4.00 & & & 1.50 & 0 \\
\hline $\begin{array}{l}16308 \\
10308\end{array}$ & $\begin{array}{l}16301 \\
18301\end{array}$ & $\begin{array}{l}48 \\
49\end{array}$ & $\begin{array}{l}0.0000 \mathrm{Q}+00 \\
0.0000 \mathrm{0} \neq 00\end{array}$ & $\begin{array}{l}1.0000 \mathrm{E}-02 \\
1.0000 \mathrm{E}-02\end{array}$ & $\begin{array}{r}3.7600 \mathrm{E}-01 \\
3.7600 \mathrm{E}-01\end{array}$ & $\begin{array}{l}4.0000 \mathrm{E}+00 \\
4.0000 \mathrm{O}+00\end{array}$ & $\begin{array}{l}1.0000 \mathrm{E}+12 \\
1.0000 \mathrm{E}+12\end{array}$ & $\begin{array}{l}0.0000 \mathrm{E}+00 \\
0.0000 \mathrm{E}+00\end{array}$ & $\begin{array}{l}1.5040 E+00 \\
1.5040 E+00\end{array}$ & $\begin{array}{l}0 \\
0\end{array}$ \\
\hline 6308 & 6401 & so & $0.0000 E+00$ & $0.0000 \mathrm{E}+00$ & $3.7600 E-01$ & $4.0000 \varepsilon+00$ & $1.0000 \mathrm{~B}-12$ & $0.0000 \mathrm{E}+00$ & $15040 \mathrm{E}+00$ & 5 \\
\hline 8308 & 0401 & 51 & $0.0000 \varepsilon+00$ & $0.0000 \mathrm{E}+$ & $3,7600 \mathrm{E}-$ & 4.000 & 1.00 & $0.0000 E+00$ & 1. $5040 \mathrm{E}+$ & 5 \\
\hline 10308 & 10401 & 52 & $0.0000 \Sigma+00$ & $0.0000 \mathrm{E}+$ & $3.7600 \mathrm{E}-$ & $E+00$ & $1.0000 \mathrm{E}-12$ & $0.0000 E+00$ & $1.5040 E+$ & 5 \\
\hline 12308 & 12401 & 53 & $0.0000 \mathrm{E}+00$ & $0.0000 \mathrm{E}+00$ & $3.7600 \mathrm{E}-01$ & 4.0 & $1.0000 E_{-12}$ & $0.0000 \mathrm{E}+00$ & 1. $5040 \mathrm{E}+00$ & 5 \\
\hline 14308 & 14401 & 54 & $0.0000 \mathrm{E}+00$ & $0.0000 E+00$ & $3.7600 \mathrm{E}-$ & $4,0000 E+00$ & $1.00000-12$ & $0.0000 E+00$ & $1.5040 \mathrm{E}+00$ & 5 \\
\hline 16308 & 16401 & 55 & $0.0000 E+00$ & $0.0000 E+00$ & $3.7600 \mathrm{E}-01$ & $4,0000 \mathrm{E}+00$ & $1.0000 \mathrm{E}-12$ & $0.0000 \mathrm{E}+00$ & $1.5040 E+00$ & 5 \\
\hline 19300 & 18401 & 56 & $0.0000 E+00$ & $0.0000 E+00$ & $3.7600 \mathrm{E}-$ & $4.0000 \mathrm{E}+00$ & $1.0000 \mathrm{E}-12$ & $0.0000 \varepsilon+00$ & $1.5040 E+00$ & 5 \\
\hline 6309 & 6302 & 57 & $0.0000 E+00$ & $1.5000 \mathrm{E}-02$ & $1.0050 E+00$ & $4.0000 E+00$ & $1.0000 E+12$ & $0.0000 E+00$ & $4.0200 \mathrm{E}+00$ & \\
\hline
\end{tabular}

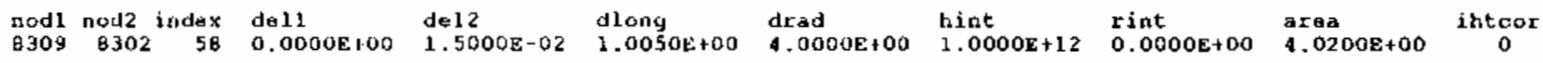


$.0000 E+01 \quad 1.0000 E+12 \quad 0.0000 E+00 \quad 2.7803 E+03$ $.0000 E+01 \quad 1.0000 E+12 \quad 0.0000 E+00 \quad 3.9466 E 10$ $0000 \mathrm{E}+01 \quad 1.0000 \mathrm{E}-24 \quad 5.6600 \mathrm{E}-0 \mathrm{~L} \quad 3446 \mathrm{E}+01$ $\begin{array}{llll}1.0000 E+01 & 1.00008+12 & 0.0600 E+00 & 1.5230 \mathrm{E}+01\end{array}$ 1.000EEt12 $0.0000 \mathrm{E}$ TOO $1.0910 \mathrm{E} 1 \mathrm{O}$ 1.0000eti2 $0.0000 \mathrm{E}+00 \quad 2.3890 \mathrm{E}+01$ . $0000 \mathrm{E}+01$ 1.000E $0000 \mathrm{E}+01 \quad 1.0000 \mathrm{E}+12 \quad 0.0000 \mathrm{E}+00 \mathrm{O} \quad \mathrm{A} 450 \mathrm{E}+0$ $\begin{array}{llll}.0000 \mathrm{E}+01 & 1,0000 \mathrm{E}+12 & 0.0000 \mathrm{E}+00 & 1.5000 \mathrm{E}+0\end{array}$ $1.0000 \mathrm{E}+01 \quad 1.0000 \mathrm{E}+12$ 0.0000E+00 $1.6700 \mathrm{E}+01$ .0000E+01 1.0000Et12 0.0000E+00 $1.5990 E+01$ $0000 \mathrm{E}+00$ 1. $0000 \mathrm{E}+12$ o.0000E 100 1.2240E+00 $0000 E+00 \quad 6.9440 E+02 \quad 0.0000 E+00 \quad 2.8710 E+00$ $.0000 \varepsilon+00 \quad 6.9440 \varepsilon+02 \quad 0.0000 E+00 \quad 4.1010 E+00$ .0000E+00 $1.0000 E+12 \quad 0.0000 E+00 \quad 4.8400 E+00$ .0000E $6.9440 \mathrm{E}+02$ 0.0000E+00 $5.5950 \mathrm{E}+00$ $0000 \mathrm{E}+00 \quad 1.0000 \mathrm{E}-12 \quad 0.0000 \mathrm{E}+00 \quad 1.1280 \mathrm{E}+00$ $0000 E+00 \quad 1.0000 E+12 \quad 0.0000 E+00 \quad 3.0150 E+00$ $.0000 \mathrm{E}+00 \quad 1.0000 \mathrm{E}-12 \cdot 0.0000 \mathrm{E}+00 \quad 3.0150 \mathrm{E}+00$ $.0000 E+\infty 0$ 1.0000E+12 $0.0000 E+00$ A.0000E 100 $\begin{array}{llll}.0000 z+00 & 1.0000 E-12 & 0.0000 E+00 & 4.0000 E+00\end{array}$ $0000 \mathrm{t}, 00,0000 \mathrm{E}-12 \quad 0.0000 \mathrm{E}+00 \quad 5.7150 \mathrm{E}+00$ , $0000 E+00 \quad 1.0000 E-12 \quad 0.0000 E+00 \quad 6.3630 E+00$ $.0000 E+00 \quad 1.0000 E+12 \quad 0.0000 E+00 \quad 6.3630 E+00$ $0000 \mathrm{E}+00$ 1.0000E $5.200 \mathrm{E}+00 \mathrm{~T}$

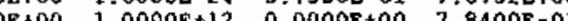
$.0000 \mathrm{E}+00 \quad 3.0000 \mathrm{E}+12 \quad 0.0000 \mathrm{E}+00 \quad 2.9430 \mathrm{E}-0.2$

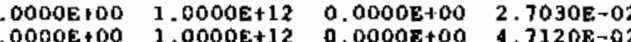

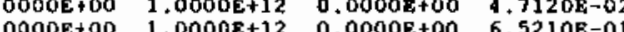
$0000 E+00 \quad 1.00000+12 \quad 0.0000 \mathrm{E}+00 \quad 9.52108-01$

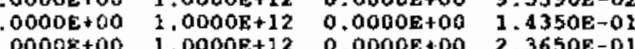

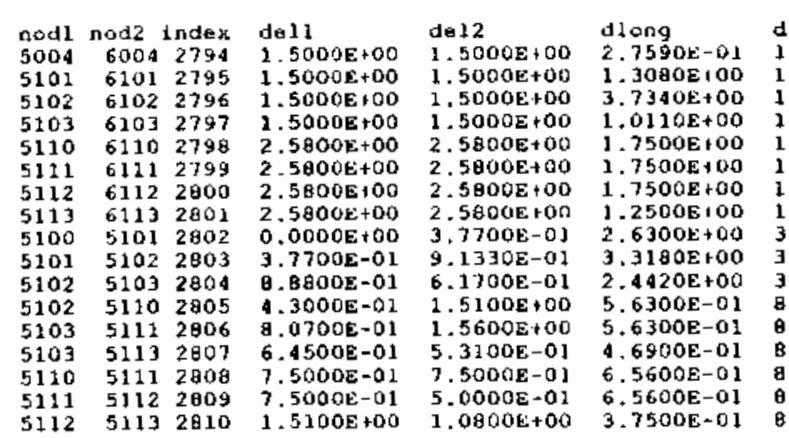

hint

\section{rint}

$.0000 \mathrm{E}+00$

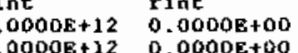

$\begin{array}{lll}0.0000 \mathrm{E}+00 \quad 3.7340 \mathrm{E}+00 & 0\end{array}$ $\begin{array}{llll}1.0000 E+00 & 1.0000 E+12 & 0.0000 E+00 & 1.0110 E+00 \\ 1.5000 E+00 & 1.0000 E+12 & 0.0000 E+00 & 2.6250 E+00\end{array}$ $\begin{array}{llll}.5000 E+00 & 1.0000 E+12 & 0.0000 E+00 & 2.6250 E+00\end{array}$ $\begin{array}{llll}.0000 E+00 & 1.0000 \varepsilon+12 & 0.0000 E+00 & 1.7500 E+00\end{array}$ $1.0000 \varepsilon+00 \quad 1.0000 \varepsilon+12 \quad 0.0000 E+00 \quad 1.2500 \varepsilon+00$ $\begin{array}{lllll}3.0000 E+00 & 1.0000 E+12 & 0.0000 E+00 & 7.8900 E+00 \\ 3.0000 E+00 & 1.0000 E+12 & 0.0000 E+00 & 9.9540 E+00\end{array}$ $\begin{array}{llll}.0000 E+00 & 1.0000 E+12 & 0.0000 E+00 & 9.9540 E+00\end{array}$ .000E+00 1.00700E+12 a.0000 $00008+00 \quad 3.47008+00 \quad 0.00008+00 \quad 4.50408+00$ $\begin{array}{llll}.0000 \mathrm{E}+00 & 5.0000 \mathrm{E}-01 & 0.0000 \mathrm{E}+00 & 3.7520 \mathrm{E}+0.0\end{array}$ $\begin{array}{llll}.0000 x+00 & 1.0000 E+12 & 0.0000 E+00 & 5.2480 E+00\end{array}$ $\begin{array}{llll}.0000 E+00 & 1.0000 E+12 & 0.0000 E+00 & 5.2480 E+00 \\ .0000 E+00 & 1.0000 E+12 & 0.0000 E+00 & 3.0000 E+00\end{array}$

itilox
0
0
0
0
0
0
0
0
0
0
0
0
0
0
0
0
0

variable internal thermal connections

nodl nod2 ncon $1 j$ inteor 
hint (btu/hr-in*k2-f) time (hr)

$\begin{array}{lr}1.00000 E-12 & 0.0000 \\ 1.00000 E-12 & 0.2200 \\ 5.83000 E-01 & 0.2220\end{array}$

$\begin{array}{rr}5.83000 E-01 & 0.2220 \\ 5.83000 \mathrm{E}-01 & 10.0000\end{array}$

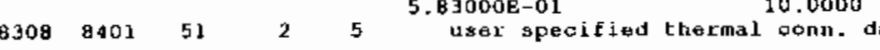

Hint (btu/hr-in**2-f) tjma (hr)

$1.00000 \mathrm{E}-12 \quad 0.0000$

$\begin{array}{ll}1.00000 E-12 & 0.0000 \\ 5.000000-12 & 0.2200\end{array}$

$\begin{array}{rr}5.03000 \mathrm{E}-01 & 0.2220 \\ 5.83000 \mathrm{E}-01 & 10.0000\end{array}$

$103091040152 \quad 355$ user specified therinal conn. da

$0.00000 \mathrm{E}+00 \quad 0.00000 \mathrm{E}+00$

hint (btu/lur-in**2-f) Lime (hr)

$\begin{array}{ll}1.00000 \mathrm{E}-12 & 0.0000 \\ 1.00000 \mathrm{E}-12 & 0.2200\end{array}$

$1.00000 \mathrm{E}-12$
$5.83000 \mathrm{E}-01$

$.83000 \mathrm{E}-0$

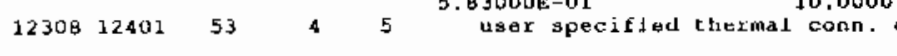

hint (btu/hr-in**2-f) time (hx)

$\begin{array}{ll}1.00000 E-12 & 0.0000 \\ 1.00000 E-12 & 0.2200 \\ 5.03000 E-01 & 0.2220\end{array}$

$5.83000 \mathrm{E}-01 \quad 0.2220$

.

$1430814401 \quad 54 \quad 5 \quad 5$

$0.00000 \mathrm{E}+00 \quad 0.00000 \mathrm{E}+00$

Lint (btu/hre-in**2-f) thme (bis)

$\begin{array}{lr}1.00000 \mathrm{E}-12 & 0.0000 \\ 1.00000 \mathrm{~L}-12 & 0.2200 \\ 5.83000 \mathrm{D}-01 & 0.2220 \\ 5.83000 \mathrm{E}-01 & 10.0000\end{array}$

$5.83000 \mathrm{E}-01 \mathrm{10}$

$163001640155 \quad 6 \quad 5$ user specis

hint (btu/hr-intk2-f) time (hx)

$\begin{array}{ll}1.00000 \mathrm{E}-12 & 0.0000 \\ 1.00000 \mathrm{E}-12 & 0.2200 \\ 5.63000 \mathrm{E}-01 & 0.2220\end{array}$

$1830818401 \quad 56 \quad 7$

uger spucified thermal conn, data

hint (btu/hr-in**2-f) time (hr)

$1.00000 \mathrm{E}-12 \quad 0.0000$

$\begin{array}{ll}1.00000 E-12 & 0.2200 \\ 5.83000 \mathrm{E}-01 & 0.2220\end{array}$

5. B3000E-01
5.83000E-01

$6309640264 \quad 8 \quad 5$ user specified thermal conn, data

$0.000008+00 \quad$ 0.00000E+00 


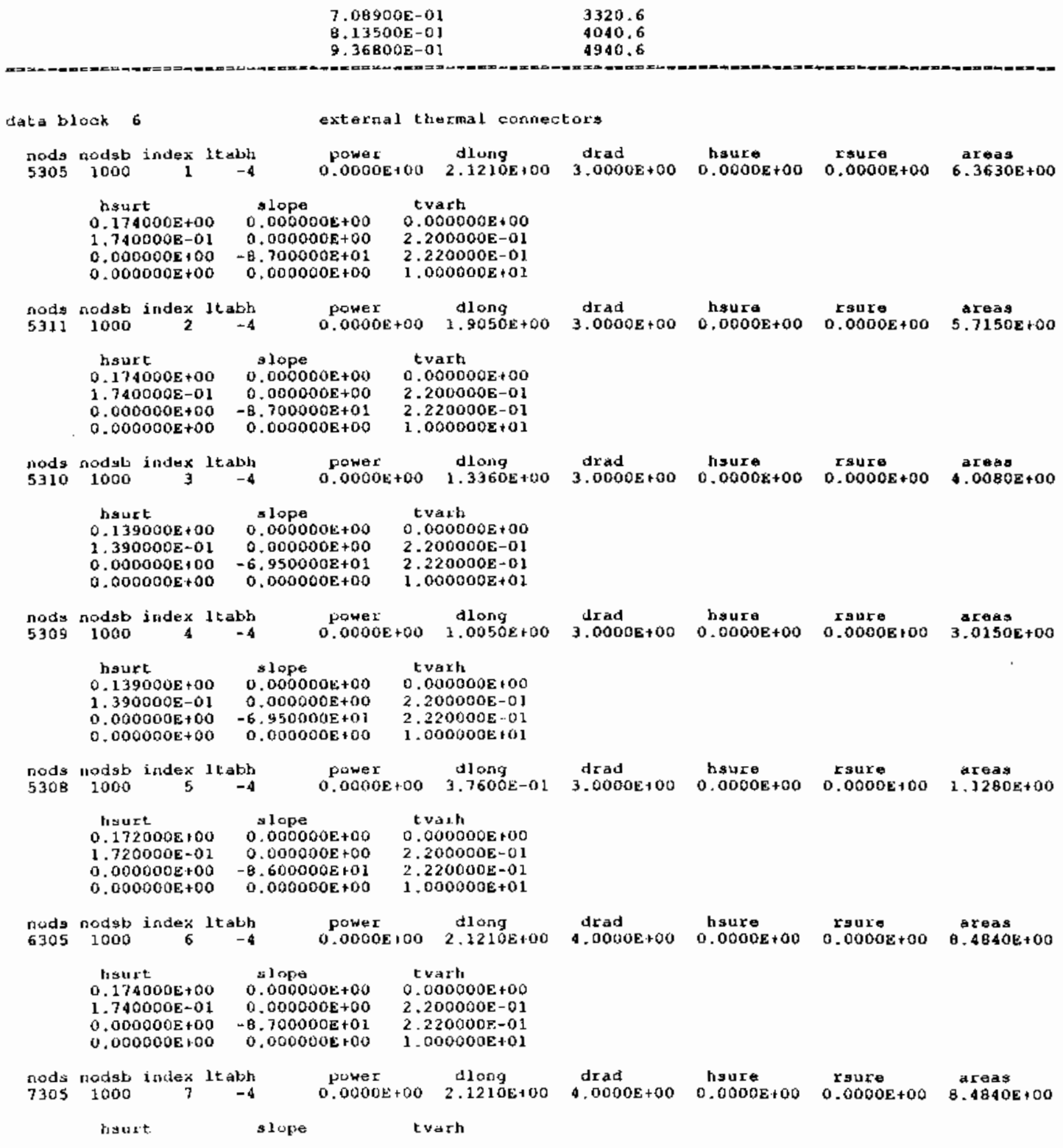




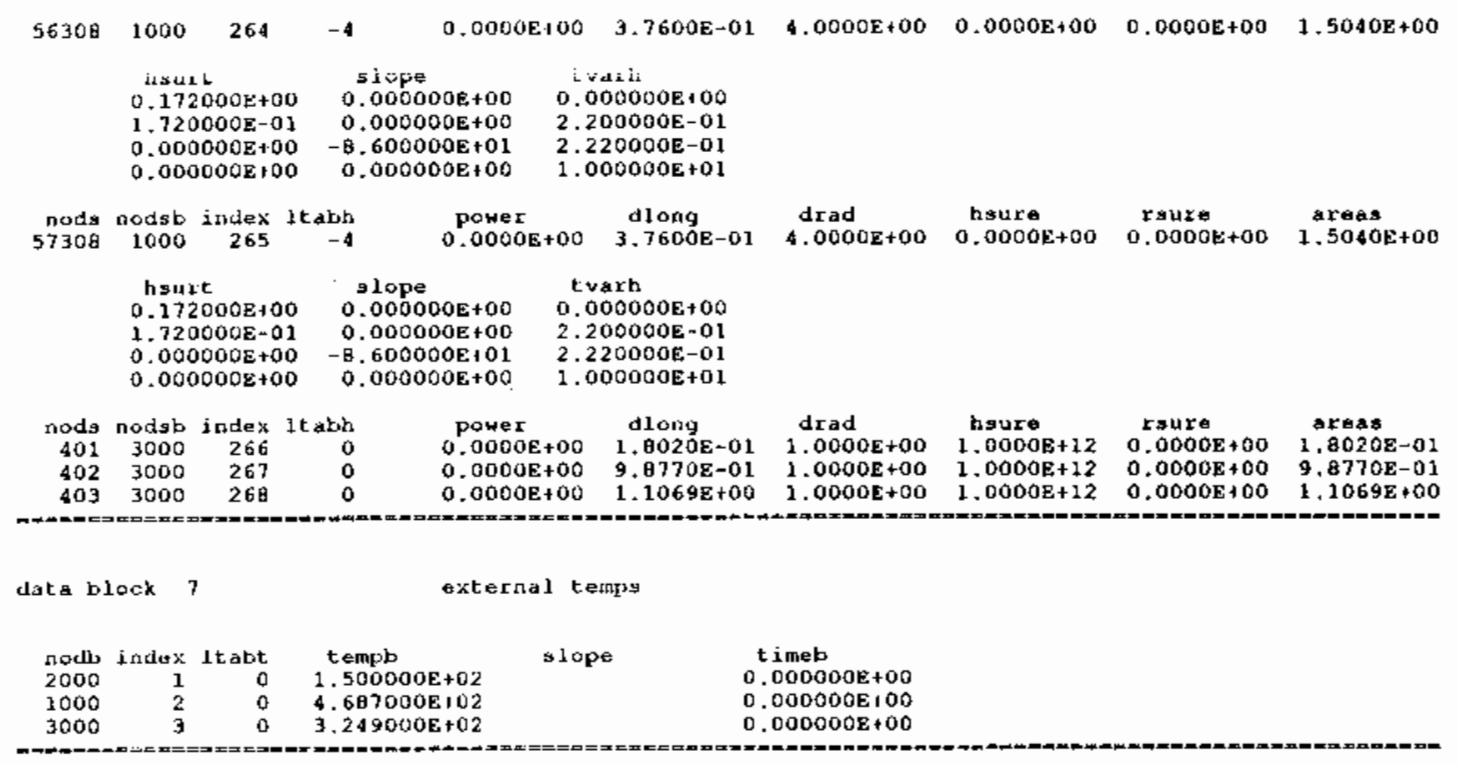

power generation rates

data block 9

bakur metal-water foation modol uged
tfail - $1.900 \mathrm{~g}+03$

power - tjme Lablo

\begin{tabular}{|c|c|}
\hline \multirow{2}{*}{$\begin{array}{c}\text { Pmult } \\
43500 E-02\end{array}$} & \\
\hline & $\begin{array}{l}\text { time }(\mathrm{hrs}) \\
0.00000 \mathrm{E}+00\end{array}$ \\
\hline $4.02700 \varepsilon-02$ & $1.00000 \mathrm{E}-02$ \\
\hline $0.41500 E-02$ & $2.39000 \mathrm{E}-02$ \\
\hline $.97900 E-02$ & $7.94000 \mathrm{E}-02$ \\
\hline $.73200 \mathrm{a}-02$ & $1.35000 \mathrm{E}-01$ \\
\hline $.55200 \mathrm{E}-02$ & $1.90600 \mathrm{E}-01$ \\
\hline $.41100 E-02$ & $2,46100 \mathrm{E}-01$ \\
\hline $.146008-02$ & 3. $85000 \mathrm{E}-01$ \\
\hline $.958000-02$ & $5.23900 \mathrm{E}-01$ \\
\hline $1.54100 \mathrm{E}-02$ & $1.07940 \mathrm{E}+00$ \\
\hline $1.34000 \mathrm{E}-02$ & $1.63500 E+00$ \\
\hline $1.21900 \mathrm{E}-02$ & $2.19060 \mathrm{E}+00$ \\
\hline $1.13600 \mathrm{E}-02$ & $2.74610 \mathrm{E}+00$ \\
\hline $1.00100 \mathrm{E}-02$ & $4.13500 E+00$ \\
\hline $9.16900 \mathrm{E}-03$ & $5.52390 \mathrm{E}+00$ \\
\hline $.39200 \mathrm{E}-03$ & $1.10794 E+01$ \\
\hline $5.42400 \mathrm{E}-03$ & $1.66350 E+01$ \\
\hline $.79200 \mathrm{E}-03$ & $2,21906 \mathrm{E}+01$ \\
\hline $5.32400 E-03$ & $2.77460 \mathrm{E}+01$ \\
\hline $4.51200 \mathrm{E}-03$ & A. $16350 E+01$ \\
\hline
\end{tabular}




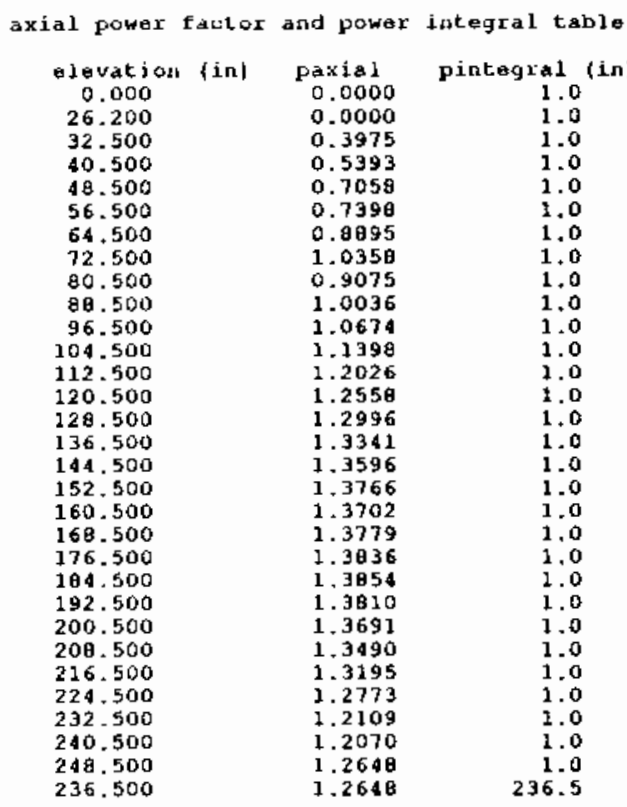

urarium oxide ares varbation table

$$
\begin{array}{lr}
\text { oxenuit } & \text { oxtemp }(\mathrm{f}) \\
2.50000 \mathrm{E}+00 & 1.90000 \mathrm{E}+03 \\
2.50000 \mathrm{0}+00 & 2.06999 \mathrm{E}+03 \\
2.50000 \mathrm{0}+00 & 2.07000 \mathrm{0}+03 \\
2.00000 \mathrm{0}+00 & 5.50000 \mathrm{0}+04
\end{array}
$$

A* power generation sumnary **

rod average power (fission and gallwh heat) $173.240 \mathrm{kw} / \mathrm{ft}$

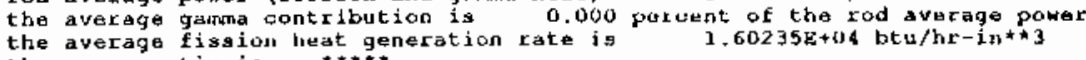

$\begin{array}{lccc}\text { note } & \text { inder } & \text { paxial } & \text { pradial } \\ 4100 & 1 & 0.00000 \mathrm{E}+00 & 0.00000 \mathrm{E}+00 \\ 4110 & 2 & 0.00000 \mathrm{E} 100 & 0.00000 \mathrm{E}+00 \\ 4402 & 3 & 0.00000 \mathrm{E}+00 & 0.00000 \mathrm{E}+00\end{array}$

Pfact 1
$.00000 \mathrm{E}+00$

$0.00000 \mathrm{p}+00$ $0.00000 \mathrm{E}+00$ tt 4402 I $0.00000 \mathrm{E}+00$ $0.00000 \mathrm{E}+00$ $0.00000 \mathrm{E}+00$ 0.00000E+00 $\begin{array}{cccc}99 & h / z & \text { ad } & \text { npo } \\ 0.00000 \mathrm{z}+00 & 0.101 & 0.000 & 0 \\ 0.00000 \mathrm{E}+00 & 0.101 & 0.000 & 0\end{array}$ $\begin{array}{llll}0.00000 \mathrm{E}+00 & 0.101 & 0.000 & 0 \\ 0.00000 \mathrm{E} 100 & 0.101 & 0.000 & 0\end{array}$ 


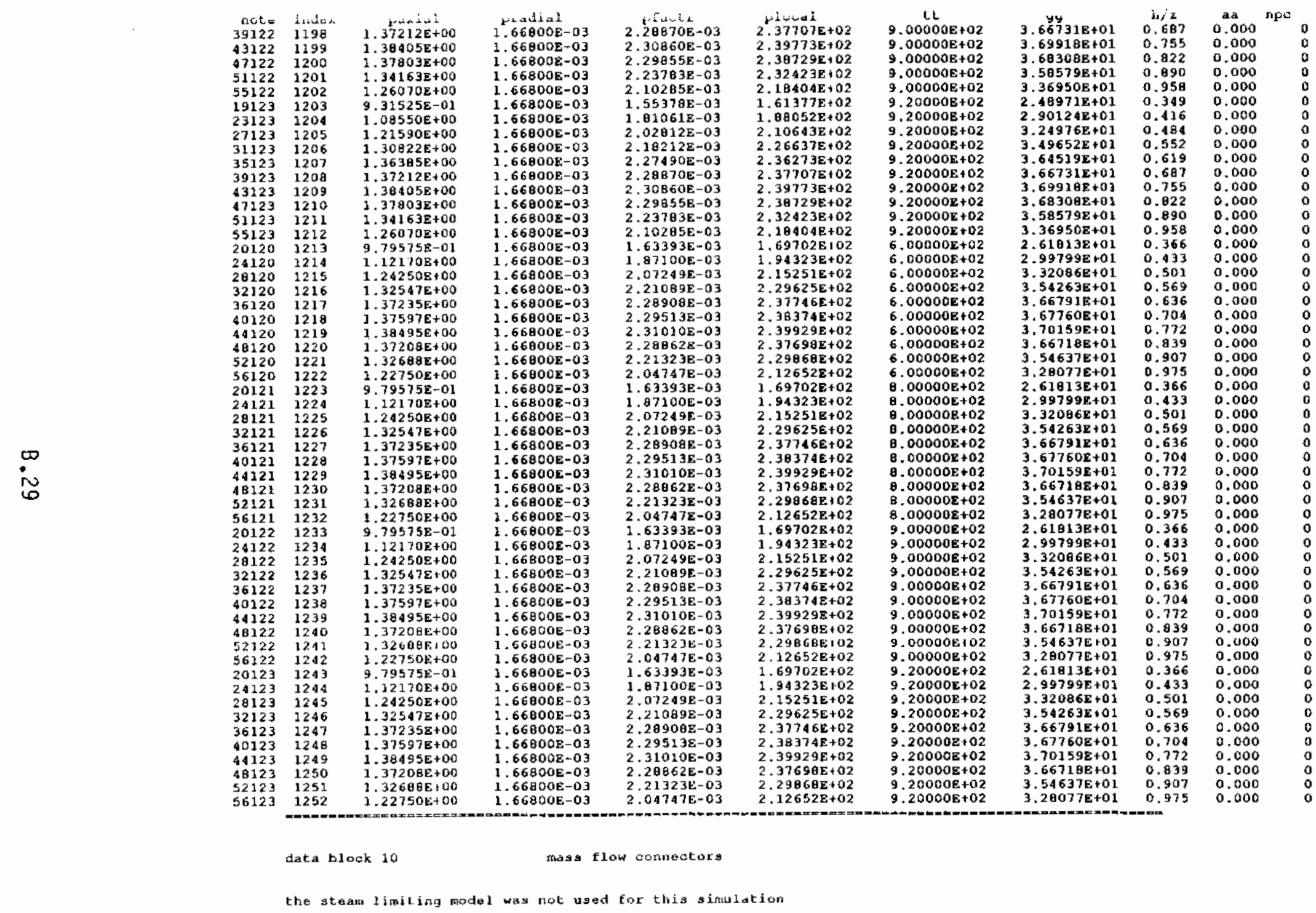


an initial flow rate of $2.043000 \mathrm{e}+01 \mathrm{kgm} / \mathrm{hr}$ was uger prescribed for flow regton 1

flow region hydraulic diameter $=0.00000$ too in; flow region cross-sectional area- 4.50000 -02 in**2

nodf1 nodf2 index ltabfl

$\begin{array}{ll}401 & 1401 \\ 1401 & 2401\end{array}$

24013401

$3401 \quad 4401$

$\begin{array}{ll}4401 & 5401 \\ 5401 & 6401\end{array}$

$\begin{array}{ll}5401 & 6401 \\ 6401 & 7401\end{array}$

7401 B401

(201 9401

9401
20401
210401

1140112401

1340114401

1440115401

1540116401

1740110401

1840119401

204012140

2140122401
22402
23401

2340124401

2640127401

2740128401

294013040

3140132401

324013340

3440135401

354013640

3740138401

3940139401

404014140

4140142401

4340144401

4540146401

4640147401

484014940

494015040

5140152401

524015340

5440155401

5540156401

Howt stofl trarft

.

$2.043000 \mathrm{e}$ to

$2.043000 E+01$

$2.043000 \mathrm{E} 101$

$2.043000 \mathrm{E}+01$

.043000E + 01

$2.043000 E+01$

$2.043000 \mathrm{E}+01$

$2.043000 \mathrm{E}+01$

$2.043000 \mathrm{E}+01$

$2.043000 \mathrm{E}+01$

$2.043000 \mathrm{E} \vdash 01$

$2.043000 \mathrm{E}+01$

$2.043000 \mathrm{E}+\mathrm{O}$

.

$2.043000 E+01$

$2.043000 \mathrm{Et} 01$

2.043000

$2.043000 \mathrm{E}+01$

$2.043000 E+01$

2.04300E

$2.043000 \mathrm{E}+01$

$2.0430008+0$

$2.043000 \mathrm{E}+0$

$2.0030000^{2}$

2. $043000 \mathrm{E} 10$

$2.043000 \mathrm{E}+02$

$2.043000 E+0$

$2.043000 E+01$

$2.043000 E_{10}$

2.043000E+O1

$2.043000 \mathrm{E}+01$

$2.043000 \mathrm{E}+01$

$2.043000 \mathrm{E}+01$

$2.043000 \mathrm{E}+0$.

2.043000EiO

$2.043000 \mathrm{E}+01$

$2.043000 \mathrm{E}+01$

$2.043000 \mathrm{E}+\mathrm{O}$

$2.043000 \mathrm{in} 1$
$2.043000 \mathrm{0}+01$
delE1

$0.000000 \mathrm{E}+00$

$0.000000 \mathrm{E}+00$

$0.000000 E+00$

$0.00000 \mathrm{E}+00$

$0.000000 \mathrm{E}+00$

$0.000000 \mathrm{E}+00$

$0.000000 \mathrm{E}+00$

.000000 +00

$0.000000 \mathrm{E}+00$

$0.00000 \mathrm{E}+00$

$0.00000 \mathrm{~B}+00$

$0.000000 \mathrm{E}+00$

$.000000 \mathrm{E}+00$

$0.000000 \mathrm{E}+a 0$

$0.000000 \mathrm{z}+00$

$0.000000 E+00$

.

$.000000 \mathrm{E}+00$

Q.000000E +00

$0.000000 \mathrm{~B}$

$0.00000 \mathrm{~B}+0$

.000000+00

.000000E+co

$0.000000 \mathrm{a}+00$

.

$.000000 \mathrm{E}+00$

.

$0.00000 \mathrm{E}+00$

$000000 \mathrm{E}+00$

.

$000000 \mathrm{E}+80$

.000000E+00

.000000E+00

$.000000 \mathrm{E}+00$

..000000E+00

.000000E+00

$.000000 \mathrm{E}+00$

.000000E+00

$0.000000 \mathrm{t}+00$

000000 E 100

(152

$000000 \mathrm{E}+00$

$000000 \mathrm{E}+00$

$.000000 \mathrm{E}+00$

$.000000 \mathrm{E}+00$

$0000008+00$

$000000 \mathrm{E}+00$

$0000000+00$

$000000 \mathrm{E}+00$

$000000 \mathrm{E}+00$

$.000000 \mathrm{E}+00$

$000000 \mathrm{E}+00$

$.000000 \mathrm{~B}+00$

$.000000 \mathrm{E}+00$

$.000000 \mathrm{E}+00$

$.000000 \mathrm{E}+00$

$000000 \mathrm{E}+00$

OOD0000E+00

$00000 \mathrm{E}+00$

$000000 \mathrm{E}+00$

$.000000 \mathrm{E}+00$

$.000000 \mathrm{E}+00$

$.000000 \mathrm{E}+00$

.00000E+00

$000000 \mathrm{E}+00$

$0000008+00$

$000000 \mathrm{E}+00$

$1.000000 \mathrm{E}+00$

$1.000000 \mathrm{E}+00$

$1.000000 E+00$

$1.000000 \mathrm{E}+00$

$1.000000 \mathrm{E}+00$

$1.000000 \mathrm{E}+00$

$1.000000 \mathrm{E}+00$

$.000000 \mathrm{E}+00$

. $000000 \mathrm{a}+00$

$1.000000 \mathrm{E}+00$

$1.000000 \mathrm{E}+00$

$1.000000 \mathrm{E}+00$

1. $000000 \mathrm{E}+00$

$1.0000008+00$

$1.000000 \mathrm{E}+00$

$1.000000 \mathrm{E}+00$

$1.000000 \mathrm{E}+00$

$.000000 \mathrm{E}+00$

$1.000000 \mathrm{~K}$
1.00000000 
flow region hydraulic diameler = 0.00000 to 00 in; flow region cross-sectional area- $9.621008-02$ in** 2

$\begin{array}{rrrr}\text { nodf1 nodf2 } & \text { index } & \text { itabf } 1 \\ 404 & 19404 & 172 & 0 \\ 40423404 & 173 & 0 \\ 40427404 & 174 & 0 \\ 40431404 & 175 & 0 \\ 40435404 & 176 & 0 \\ 40439404 & 177 & 0 \\ 40443404 & 178 & 0 \\ 404 & 47404 & 179 & 0 \\ 40451404 & 170 & 0 \\ 404 & 55404 & 181 & 0\end{array}$

fluwt
$5.500000 \mathrm{E}+03$
$5.500000 \mathrm{E}+03$
$5.500000 \mathrm{E}+03$
$5.500000 \mathrm{E}+03$
$5.500000 \mathrm{E}+03$
$5.500000 \mathrm{E}+03$
$5.500000 \mathrm{E}+03$
$5.500000 \mathrm{E}+03$
$5.500000 \mathrm{0}+03$
$5.500000 \mathrm{0}+03$

slof 1

tvarf 1

deles

$1.000000 \mathrm{E}+00$

delf2 $1,00000 \mathrm{E}+00$

$1.000000 \mathrm{E}+00$

$1.000000 \mathrm{E}+00 \quad 1.000000 \mathrm{E}+000$

1.000008+00

$1.000000 \mathrm{E}+0000000 \mathrm{2}+00$

$1.0000008+00$

.000000E 100 $1.000000 \mathrm{E}+00$

$1.000000 \mathrm{E}+00 \quad 1.000000 \mathrm{E}+00$

an initial flow rate of $5.500000 \mathrm{E}+03 \mathrm{lbm} / \mathrm{hr}$ was user prescribed for flow region 5

flow region hydraulic diameter $=0.00000 \mathrm{E}+00$ in: flow region cross-sectional aroa- $9.62100 \mathrm{E}-02$ in**2

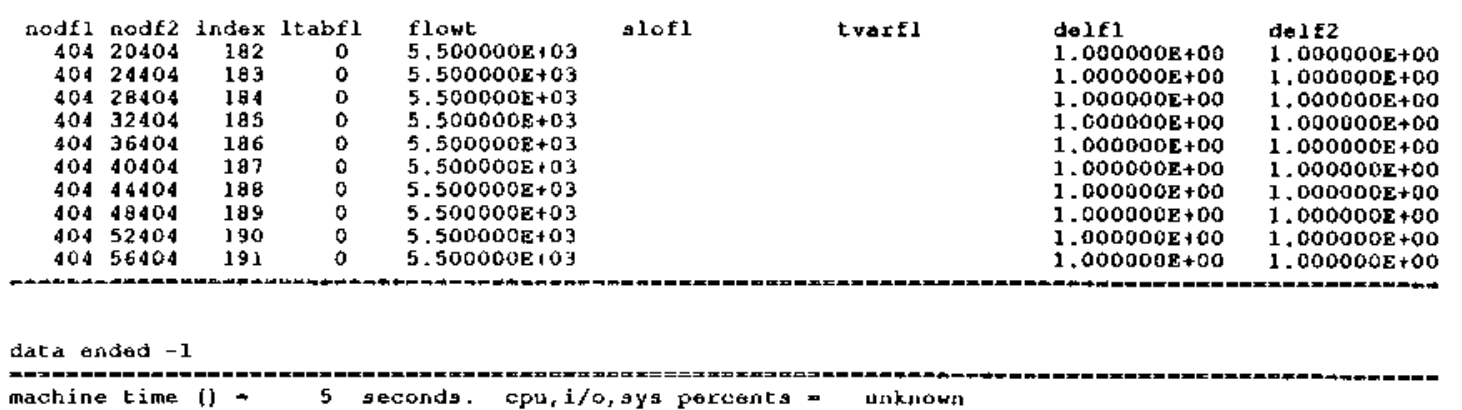

machine time 0 - 5 seconds.

24* trump input parameter list: *a*

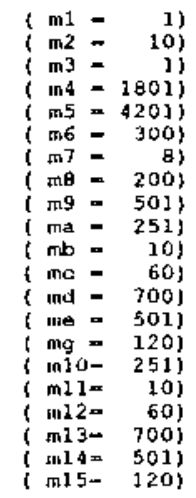




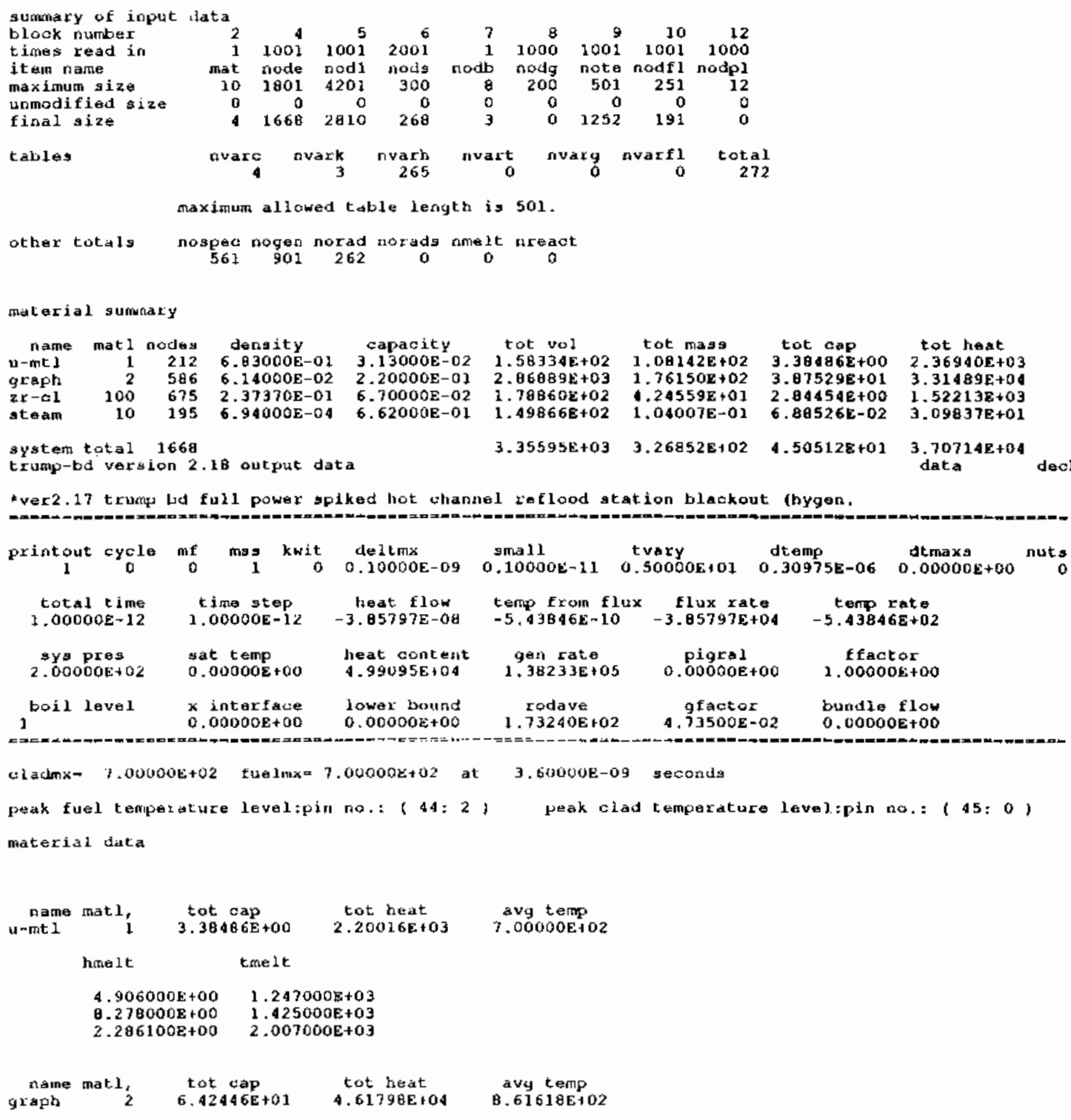




\begin{tabular}{|c|c|c|c|c|}
\hline $\begin{array}{c}\text { name } \\
\mathbf{z} \times \rightarrow 1\end{array}$ & $\begin{array}{l}\text { mat } 1^{\prime} \\
100\end{array}$ & $\begin{array}{c}\text { tot } \operatorname{cap} \\
3.24510 \mathrm{E}+00\end{array}$ & $\begin{array}{l}\text { tot heat } \\
1.51] \theta 3 E+03\end{array}$ & $\begin{array}{l}\text { avg temp } \\
5.36207 \mathrm{E}, 02\end{array}$ \\
\hline $\begin{array}{l}\text { name } \\
\text { stean }\end{array}$ & $\begin{array}{r}\text { mat } 1, \\
10\end{array}$ & $\begin{array}{l}\text { tat cap } \\
6.41534 \mathrm{E}-02\end{array}$ & $\begin{array}{c}\text { tot heat } \\
1.77372 \mathrm{E}+01\end{array}$ & $\begin{array}{l}\text { avg temp } \\
4.50000 \mathrm{E}+02\end{array}$ \\
\hline
\end{tabular}

boundary node data

\begin{tabular}{|c|c|c|c|}
\hline $\begin{array}{l}110015 \\
2000 \\
1000 \\
3000\end{array}$ & $\begin{array}{l}\text { tempb } \\
1,50000+02 \\
4.6 \theta 70 E+02 \\
3.24900+02\end{array}$ & $\begin{array}{r}\text { heat flow } \\
0.0000 \mathrm{E}+00 \\
-3.85 \mathrm{~B} 1 \mathrm{E}-0 \mathrm{~g} \\
1.3642 \mathrm{E}-12\end{array}$ & $\begin{array}{r}\text { avg rate } \\
0.0000 \mathrm{E}+00 \\
-3.8561 \mathrm{E}+04 \\
1.3642 \mathrm{E}+00\end{array}$ \\
\hline & & $-3.9580 \mathrm{-}-0 \mathrm{~B}$ & $-3.8580 E+D$ \\
\hline
\end{tabular}

system total

\begin{tabular}{|c|c|c|c|c|c|}
\hline 5005 & & & & & \\
\hline & 1000 & $6.3630 \mathrm{E}+00$ & 1.7400E-01 & $0.0000 \mathrm{E}+00$ & \\
\hline $\begin{array}{l}5311 \\
5310\end{array}$ & $\begin{array}{l}1000 \\
1000\end{array}$ & $\begin{array}{l}5.7150 \mathrm{E}+00 \\
4.0080 \mathrm{E}+00\end{array}$ & $\begin{array}{l}1.7400 E-01 \\
1.3900 E-01\end{array}$ & $\begin{array}{l}0.0000 \mathrm{E}+00 \\
0.0000 \mathrm{t}+00\end{array}$ & \\
\hline & 1000 & $.0150 E+00$ & 1. $3900 \mathrm{~g}-01$ & $0.0000 \mathrm{E}+00$ & \\
\hline & 1000 & $1280 E+00$ & $00 \mathrm{E}-01$ & $.0000 E+00$ & $E+00$ \\
\hline & 1000 & & & $00 E+00$ & \\
\hline 7305 & 1000 & 48408 & & & \\
\hline 8305 & 1000 & $4840 E+00$ & & $0.0000 E+00$ & \\
\hline 9305 & 1000 & & & & \\
\hline 0305 & & & & & \\
\hline & & & & & \\
\hline & 1000 & & & & \\
\hline & 1000 & & $008-01$ & & \\
\hline & & & & & \\
\hline & & & 1.74 & & \\
\hline & & & & & \\
\hline 5 & & & & & \\
\hline 83 & & & 1.7 & & \\
\hline 93 & & $4 \theta$ & 1.7 & & \\
\hline 5 & & .48 & 1.7 & & \\
\hline & & & 1.7 & & \\
\hline 23 & & & & & \\
\hline 33 & & 4 & & & \\
\hline 243 & & & 1.7 & & \\
\hline & & & 1.7 & & \\
\hline & & & & & \\
\hline & & & & & \\
\hline 283 & 10 & & & & \\
\hline & 10 & & & & \\
\hline & 10 & a. & 1.7 & & \\
\hline & 100 & 8.48 & 1.7 & & \\
\hline & 100 & & & & \\
\hline 39305 & 100 & & 1 . & & \\
\hline & & & & & \\
\hline 353 & 100 & 8 & 1.74 & & \\
\hline 5 & 100 & & & & \\
\hline & 100 & $\begin{array}{l}8.48 \\
8.48\end{array}$ & 170000 & & \\
\hline & & 48 & & & \\
\hline & & .48 & 1.7 & & \\
\hline & & & & & \\
\hline & & & & & \\
\hline & 10 & & & & \\
\hline & 10 & 日 & 1.74 & 00 & \\
\hline & 1000 & $+4840 E+00$ & $1.7400 \mathrm{E}-01$ & $0.0000 \mathrm{E}+00$ & \\
\hline & & $4840 E+00$ & $1.7400 \mathrm{E}-01$ & $0.0000 E+00$ & $000 E+00$ \\
\hline
\end{tabular}

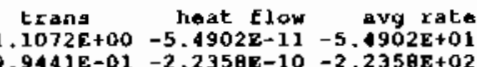

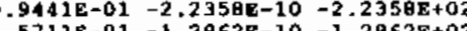

$5.5711 E-01-1,2062 \mathrm{E}-10-1.2062 \mathrm{E}+02$

$1.1909 \mathrm{E}-01-9.666 \mathrm{EE}-11-9.6668 \mathrm{E}+01$
$1.9402 \mathrm{E}-01-6.4774 \mathrm{E}-11-4.4774 \mathrm{E}+01$

$1.4762 \mathrm{E}+00-7.3203 \mathrm{E}-11-7.3203 \mathrm{E}+01$

$4762 E+00-7.3203 E-11-7.3203 E+01$

$.4762 E+00=7.3203 E-11-7.3203 E+01$

$.4762 \mathrm{E}+00-7.3203 \mathrm{E}-11-7.3203 \mathrm{E}+01$

$.4762 E+00-7.3203 \mathrm{E}-11-7.3203 \mathrm{E}+01$
$4762 \mathrm{E}+00-7.3203 \mathrm{E}-11-7.3203 \mathrm{E}+01$

$.4762 \mathrm{E}+00-7.3200 \mathrm{E}-11-7.3203 \mathrm{E}+01$
.4701

$4762 \mathrm{E}+00-7.3203 \mathrm{E}-11-7,3203 \mathrm{E}+03$

$.4762 \mathrm{E}+00-7.3203 \mathrm{E}-11-7.3203 \mathrm{E}+01$

4762E+00-7.3203E-11 -7.3203E +01

$4762 \mathrm{E}+00-7.3203 \mathrm{E}-11-7.3203 \mathrm{z}+01$

$.4762 \mathrm{E}+00-7.3203 \mathrm{E}-11-7.3203 \mathrm{E}+01$

$.4762 \mathrm{E}+00-7.3203 \mathrm{E}-11-7.3203 \mathrm{E}+01$

.4762E+00 $-7.3203 \mathrm{E}-11-7.3203 \mathrm{E}+01$

$.4762 E+00-7.3203 E-11-7.3203 E+01$

$4762 \mathrm{E}+00-7.3203 \mathrm{E}-11-7.3203 \mathrm{E}+01$

$.4762 E+00-7.3203 E-11-7,3203 E+01$

$462 E+00-7.3203 E-11-7.3203 E+01$
$4762 E+00-7.3203 E-11-7.3203 E$ $47625+00-7.3203 \mathrm{E}-11-7.3203 \mathrm{E} 101$ $4762 \mathrm{E} 100-7.3203 \mathrm{E}-11-7.3203 \mathrm{E}+01$ $-4762 \varepsilon+00-7.3203 E-11-7.3203 E+01$ $.4762 E+00-7.3203 E-11-7.3203 E+01$ $4762 \mathrm{E}+00-7.3203 \mathrm{E}-11-7.3203 \mathrm{E}+01$ $4762 E+00-7.3203 E-11$
$.4762 E+00-7.3203 E+01$ $4762 \mathrm{E}+00-7.3203 \mathrm{E}-11-7.3203 \mathrm{E}+01$ $.4762 \mathrm{E}+00-7.3203 \mathrm{E}-11-7.3203 \mathrm{E}+01$ $1.4762 \mathrm{E}+00-7.32038-11-7.3203 \mathrm{E}+01$ $.4762 \mathrm{E}+00-7.3203 \mathrm{E}-11-7.32038+01$ $4762 \mathrm{E}+00-7.3203 \mathrm{E}-11-7.32038+01$ $.4762 \mathrm{E}+00-7.3203 \mathrm{E}-11-7.3203 \mathrm{E}+01$ $.1762 E+00-7.3203 E-11-7.3203 E+01$ $1.4762 \mathrm{E}+00-7.3203 \mathrm{E}-11-7.3203 \mathrm{E}+01$ $4762 E+00-7.3203 E-11-7.3203 E+01$ $4762 E+00-7.3203 E-11-7.3203 E+01$
$4762 E+00-7.3203 E-11-7.3203 E+01$ 


\begin{tabular}{|c|c|c|c|c|c|c|c|c|}
\hline 29308 & 1000 & $1.5040 E+00$ & $1.7200 \mathrm{E}-01$ & $0.0000 E+00$ & & $2.5869 \mathrm{E}-01$ & $-5.9699 z-11$ & $99 E+01$ \\
\hline 30308 & 2000 & $1.5040 \mathrm{E}+00$ & $1.7200 \mathrm{E}-01$ & $0.0000 E+00$ & $0.0000 E+00$ & & & \\
\hline 31308 & 1000 & $1.5040 E+00$ & $1.7200 \varepsilon-01$ & $0.0000 E+00$ & $0.0000 E+00$ & $.5869 z-01$ & $-5,9699 \mathrm{E}$ & $.9699 E+01$ \\
\hline 32308 & 1000 & $1.5040 \mathrm{E}+00$ & $1.7200 \mathrm{E}-01$ & $0.0000 E+00$ & $0.0000 \mathrm{E}+00$ & $2.5869 E-01$ & -5.9699 & $-5.9699 \mathrm{E}+01$ \\
\hline 33308 & 1000 & $1.5040 E+00$ & $1.7200 \mathrm{E}-01$ & $0.0000 E+00$ & 0.0000 & $2.5869 \mathrm{~B}-01$ & $6998-11$ & ta1 \\
\hline 34300 & 1000 & $\$ .504$ & $1.7200 \mathrm{E}-01$ & $0.0000 \mathrm{E}+00$ & $0.0000 \varepsilon+00$ & $2.5069 \mathrm{E}-01$ & 11 & $\varepsilon+01$ \\
\hline 35308 & 1000 & 1.5040 & $1.72008-01$ & $0.0000 E+00$ & $0.0000 \varepsilon+00$ & $2.5069 \mathrm{E}-01$ & & \\
\hline 36308 & 1000 & 1.504 & 1. $7200 \mathrm{E}-01$ & $0.0000 \mathrm{E}+00$ & $0,0000 \mathrm{E}+00$ & 01 & & +01 \\
\hline 37308 & 1000 & & $1.7200 E-01$ & 0.00 & & & & \\
\hline 38308 & 1000 & & $1.7200 \mathrm{E}-01$ & $0.00008+00$ & 0.0 & $5069 E-01$ & & \\
\hline 39300 & 1000 & $1.5040 \mathrm{R}+00$ & & & & & & \\
\hline 40308 & 1000 & $1.5040 E+00$ & $1.7200 \mathrm{E}-01$ & & $0.0000 E+00$ & & & \\
\hline 41308 & 1000 & & & & & & & \\
\hline 42300 & 1000 & & & & & & & \\
\hline $4330 \theta$ & 1000 & $1.5040 E+00$ & $1.7200 \mathrm{E}-0 \mathrm{r}^{\circ}$ & 0.00 & & & & \\
\hline 44309 & 1000 & $1.5040 \mathrm{E}+00$ & $1,7200 \mathrm{E}-01$ & $0.0000 E+00$ & 0.0 & & & \\
\hline 45308 & 1000 & $1.5040 \mathrm{E}+00$ & $1.7200 E-01$ & $0,0000 E+00$ & $0.0000 E+00$ & & & \\
\hline 46308 & 1000 & $1.5040 \varepsilon+00$ & $1,7200 z-01$ & $0.0000 \mathrm{E}+00$ & $0.00002+00$ & & & $\mathrm{E}+01$ \\
\hline 47300 & 1000 & $1.5040 \mathrm{E}+00$ & $1.7200 \mathrm{E}-01$ & 0.0000 & 0.005 & & & \\
\hline 48308 & 1000 & $1.5040 E 100$ & $1.7200 \mathrm{E}-01$ & $0.0000 E * 00$ & & 01 & & \\
\hline 49308 & 1000 & $1.5040 E+00$ & $1.7200 E-01$ & $0.0000 \varepsilon+00$ & $0.0000 E+00$ & 1 & 11 & $699 \mathrm{E}+01$ \\
\hline 50308 & 1000 & $1.5040 E+00$ & $1.72008-01$ & $0.0000 E+00$ & $0.0000 z+00$ & $5869 z-01$ & $-5.9699 \mathrm{E}-11$ & $-5,9699 \mathrm{E}+01$ \\
\hline & 1000 & $\begin{array}{l}1.5040 \mathrm{E}+00 \\
1.5040 \mathrm{O}\end{array}$ & $\begin{array}{l}1.7200 \mathrm{E}-01 \\
1.7200 \mathrm{E}-01\end{array}$ & $0.0000 E+00$ & $0.0000 \mathrm{E}+00$ & $5869 \mathrm{E}-01$ & $-5.9699 \mathrm{E}-11$ & $-5,96998+01$ \\
\hline 53308 & $\begin{array}{l}1000 \\
1000\end{array}$ & $\begin{array}{l}1.5040 E+00 \\
1.5040 E+00\end{array}$ & $\begin{array}{l}1.7200 \mathrm{E}-01 \\
1.7200 \mathrm{0}-01\end{array}$ & $\begin{array}{l}0.0000 \Sigma+00 \\
0.0000 \varepsilon+00\end{array}$ & $\begin{array}{l}0.0000 E+00 \\
0.0000 E+00\end{array}$ & & & $\left\{\begin{array}{r}9699 \mathrm{E}+01 \\
9699 \mathrm{E}+01\end{array}\right.$ \\
\hline & 1000 & $1.5040 E+00$ & $1.72008-$ & $0.0000 \mathrm{E}$ & $0,0000 E+00$ & .5869 & $95-11$ & $\begin{array}{l}-5.9699 \mathrm{E}+01 \\
\end{array}$ \\
\hline & & $1.5040 E+00$ & $1.7200 \varepsilon-01$ & $0.0000 \mathrm{E}$ & $0.0000 E+00$ & $2.5069 \mathrm{E}-01$ & & \\
\hline & 300 & & $0 E-01$ & $000 \mathrm{E}$ & $0.0000 \mathrm{E}+00$ & $5069 E-0$ & & \\
\hline & 1000 & 00 & 1 & $00 \varepsilon+0$ & $100 \mathrm{E}+00$ & $069 \mathrm{E}-01$ & 6 & \\
\hline & 3000 & $0 \bar{E}-01$ & 12 & & & $0 E+11$ & & \\
\hline & 3 & & & & & & & \\
\hline & 3000 & & $1.0000 \mathrm{E}+12$ & $000 \varepsilon+00$ & & $1069 \mathrm{E}+12$ & $0.0949 \mathrm{E}-13$ & \\
\hline
\end{tabular}

kcyo- o, iterations... total $=0$, average -0, maximum -0. Eor $=0.570$
trump-bd vergion 2.19 output data

*ver2 17 trump bd full power spiked hot chanel reflood gtation blackout (hygen.

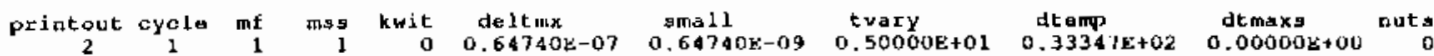

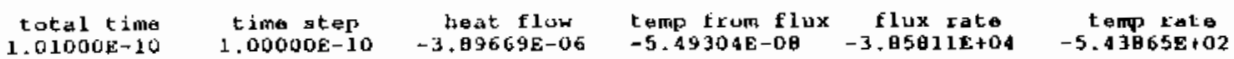

$\begin{array}{llllll}\text { sysprus } & \text { sat Lemp } & \text { heat content } & \text { gen rat. } & \text { pigral } & \text { ffactor } \\ 2.00000 \mathrm{E}+02 & 0.00000 \mathrm{E}+00 & 4.99095 \mathrm{E}+04 & 1.3 \mathrm{H} 33 \mathrm{E}+05 & 0.00000 \mathrm{E}+00 & 1.00000 \mathrm{E}+\infty 0\end{array}$

$\begin{array}{llllll}\text { boil level } & x \text { interface } & \text { lower bound } & \text { rodave } & \text { gfactor } & \text { bundle flow } \\ 1 & 0.00000 \mathrm{E}+00 & 0.00000 \mathrm{E}+00 & 1.73240 \mathrm{E}+02 & 4.73500 \mathrm{E}-02 & 0.00000 \mathrm{E} 100\end{array}$

c. admx-7.00000E t02 fuelmx=7.00000e+02 at $3.63600 \mathrm{E}-07$ seconds

peak fuel temperature levelipin no.: $(44: 2$ ) peak clad temperature leval:pin no.: (44: 0 )

material data

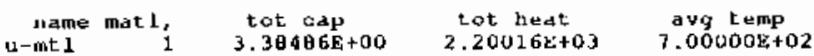

lonelt theit 


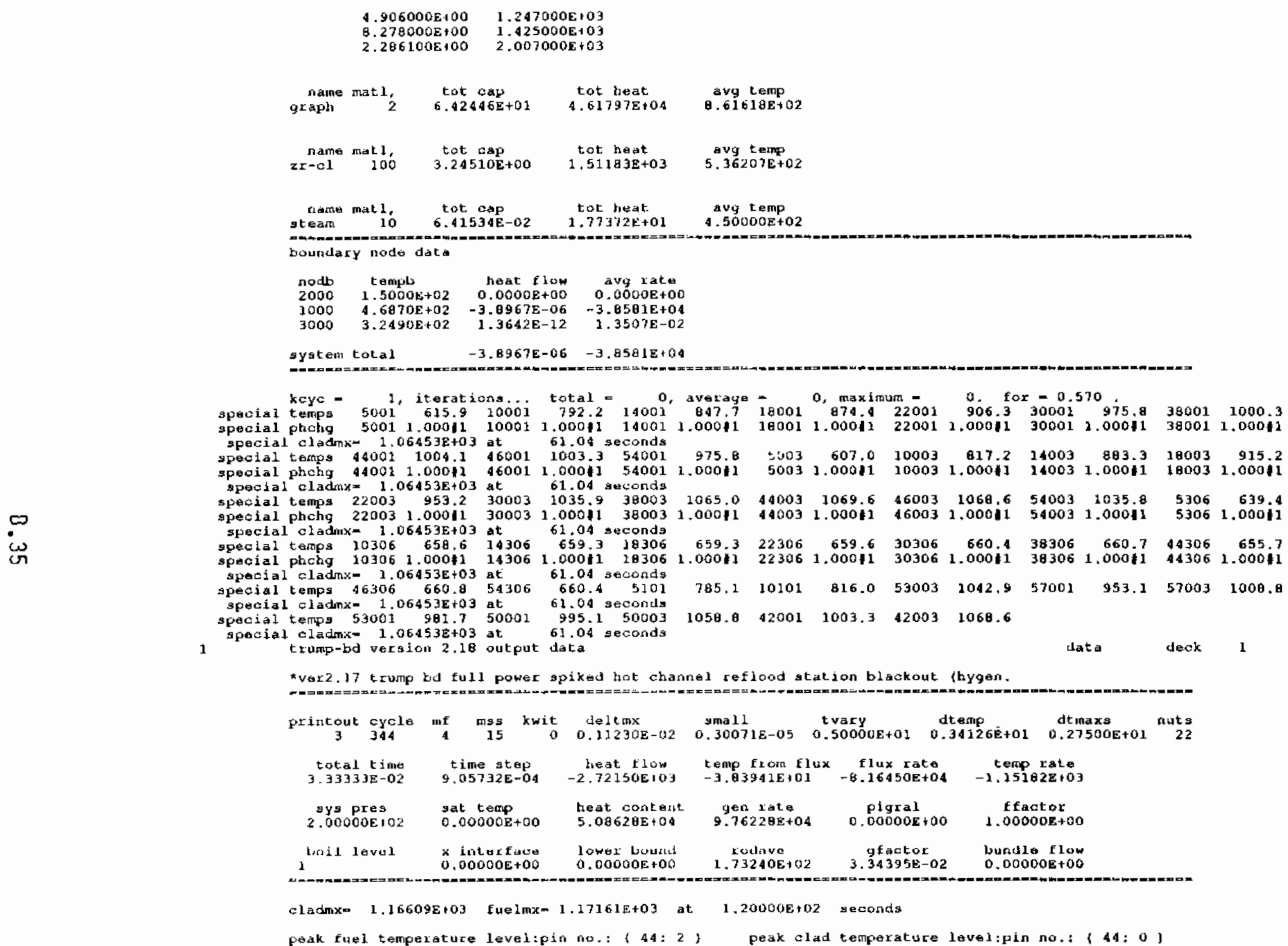


*ver2.17 trump bd full power spiked thot channel reflood station blackout fbygen.

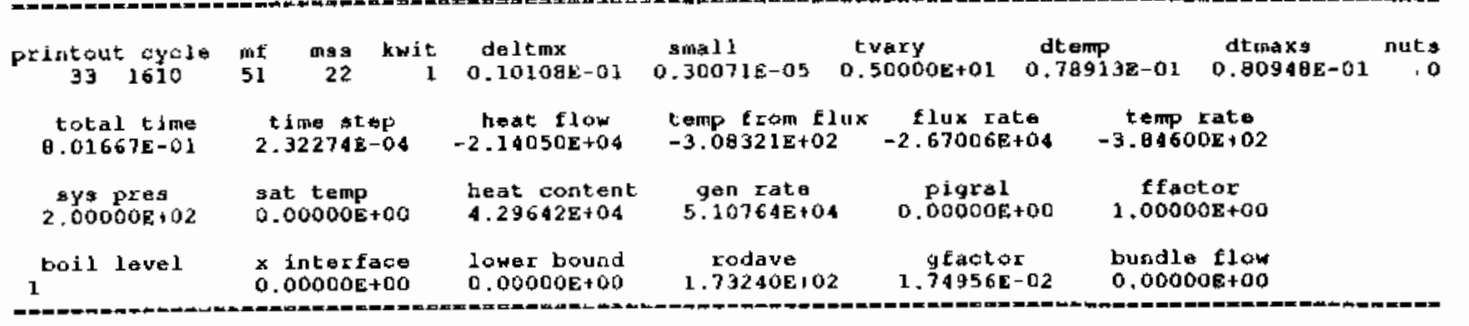

cladmx= $1.06231 \mathrm{E}+03$ fue $1 \mathrm{mx}=1.06514 \mathrm{E}+03$ at $2.88600 \mathrm{E}+03$ geconds

peak fuel temperature level:pis no.: $\{57: 2$ )
final

\begin{tabular}{|c|c|c|c|c|c|c|c|c|c|}
\hline $\begin{array}{l}\text { node } \\
66001\end{array}$ & $349456 E+02$ & node & $7757565+0$ & & & & & & \\
\hline $\begin{array}{l}6001 \\
6001\end{array}$ & $\begin{array}{l}3.49456 E+02 \\
4.64305 E+02\end{array}$ & $\begin{array}{r}8001 \\
18001\end{array}$ & $\begin{array}{l}3.75356 \mathrm{E}+02 \\
4,75465 \mathrm{E}+02\end{array}$ & $\begin{array}{r}10001 \\
6002\end{array}$ & $\begin{array}{l}3.98081 E+02 \\
3.49222 E+02\end{array}$ & $\begin{array}{r}12001 \\
0002\end{array}$ & $\begin{array}{l}4.147078+02 \\
3.75365 E+02\end{array}$ & $\begin{array}{l}14001 \\
10002\end{array}$ & $\begin{array}{r}371600+02 \\
97631 \mathrm{E}+02\end{array}$ \\
\hline & $14299 E+02$ & & & & & & & 6003 & \\
\hline 1003 & $01060 \varepsilon+02$ & 10003 & $1704 E+02$ & 1200 & $9932 \varepsilon+02$ & & +02 & 16003 & 3651 \\
\hline 003 & $44370 E+02$ & 6004 & $172 \mathrm{QE}+02$ & 800 & $1573 E+02$ & & $E+02$ & & \\
\hline 004 & $1326 \mathrm{E}+02$ & 16004 & $6769 \mathrm{E}+02$ & & $48 E+02$ & 6301 & & & \\
\hline 301 & $95642 \varepsilon+02$ & 12301 & $1 E+02$ & 1430 & $5 E+02$ & & & & \\
\hline 6302 & $1 E+02$ & 8302 & $5 E+02$ & & +02 & & & & \\
\hline 6302 & & 18302 & $3 E+02$ & & $E+02$ & & & & \\
\hline 12303 & & 14303 & & & 02 & & $E+02$ & & \\
\hline & & 10304 & $43 E+02$ & & $9 \mathrm{E}+02$ & 1430 & $E+02$ & & \\
\hline 830 & $1 E+02$ & 6305 & & & & & & & \\
\hline 305 & $551 \mathrm{E}+02$ & 16305 & & & & & & & \\
\hline 1031 & $8+02$ & 12311 & & & & & & & \\
\hline 631 & 02 & & & & & & & & \\
\hline 1631 & & 183 & & & & & & & \\
\hline 1236 & & 143 & & & & & & & \\
\hline 83 & & 103 & & & & & & & \\
\hline 183 & & & & & & & & & \\
\hline 143 & 5,2 & 163 & & & & & & & \\
\hline & 4.8 & & & & & & & & \\
\hline & 3.2 & & & & & & & & \\
\hline 164 & & & & & & & & & \\
\hline & & & & & & & & & \\
\hline & 3.5 & & & & & & & & \\
\hline 184 & 4.59 & & & & & & & & \\
\hline 141 & & & & & & & & & \\
\hline & 6.0 & & & & & & & & \\
\hline & 5.28 & & & & & & & & \\
\hline $\begin{array}{ll}161 \\
101\end{array}$ & 6.68 & & & & & & & & \\
\hline 121 & 6.4 & & & & & & & & \\
\hline & & & & & & & & & \\
\hline $\begin{array}{l}103 \\
141\end{array}$ & $\begin{array}{l}6.969 \\
6.815\end{array}$ & $\begin{array}{r}6111 \\
16111\end{array}$ & 2 & 181 & & & $\begin{array}{l}8.4 .2 \\
5.48\end{array}$ & & $\begin{array}{l}6.66512 \\
6.2369\end{array}$ \\
\hline 101 & 6.53 & 12112 & & & & & & & \\
\hline & 5.4 & & & & & & 6.6 & & \\
\hline 161 & 6.9 & 181 & & & & & & & \\
\hline 121 & 6.65 & & & & & & & & \\
\hline & & & & & & & 6.5 & & \\
\hline & & 2200 & & & & & 6.2 & & \\
\hline & & 420 & 2 & 460 & & & & & \\
\hline & & & & & & 34002 & $6.926568+02$ & & \\
\hline & & & .55014 E.ro2 & 50002 & $9.08241 E+02$ & 54002 & $9.557 ه 9 E+02$ & 22003 & 5.9913 \\
\hline
\end{tabular}


$7.25963 \mathrm{E}+02 \quad 34003 \quad 7.80406 \mathrm{E}+02 \quad 38003$ 0
$.00172 E+03$ 54003

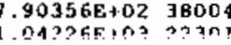
$.33460 \mathrm{E}+024230$ $7.94849 E+02 \quad 46302$ $6.56422 \mathrm{E}+02 \quad 30303$ $9.49060 \mathrm{E}+02 \quad 50303$ $7.25236 \mathrm{E}+02 \quad 34304$ $7.29520 \mathrm{t}+02 \quad 39305$ $9.21106 \mathrm{E}+022231$ 8. $38450 E+02 \quad 42311$

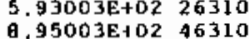
$5.65409 E+0230309$ Q. $50952 \mathrm{E}+0250309$ $6.17741 E 102 \quad 34308$ $9.00253 E+02$
$7.33310 E+02$
38306 $9.21305 E+02 \quad 22307$ $6.23550 \mathrm{E}+02 \quad 46401$ $\begin{array}{ll}4.857375+02 & 30402 \\ 7.66078 E+02 & 50402\end{array}$ $6.230035+0234403$ $8.76435 E+0254403$ $7.813478+02 \quad 39100$
$9.20400 E+02 \quad 22101$ 9.20400E+02 22101
$8.15785 E_{102}$
62101 $6.97458 \mathrm{BE}+02 \quad 26102$ $7.34555 \mathrm{E}+02 \quad 3010$ Q. $76733 \mathrm{E}+0250103$ $7.74901 E+02$ 3N110 $0.99378 E+025411$ $9.17799 E+022211$ Q. $32607 E+0242112$ $7.19093 \mathrm{E}+02$
$8.56225 \mathrm{E}+02 \quad 4611$ $0.56225 \mathrm{E}+02$
$7.46906 \mathrm{E}+02 \quad 3011$ B. $79106 E+02 \quad 50110$ $7.63012 E+0234104$

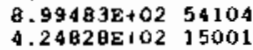
$4.07403 E+02 \quad 13002$ 3. $86828 \mathrm{~B}+021100$ $5.42507 E+02 \quad 7301$ $4.47377 E+02 \quad 37301$ 4.21849E+D2 15302 $4.16962 \mathrm{E}+0211304$ $4.33405 E 1029305$ 5.05005E102 1731 $4.70251 \mathrm{E}+021531$ 3. $04173 E+02 \quad 11308$ $4.40078 E+02 \quad 9306$ $5.53324 E+02$
$5.40104 E+02$
37307 3. $50410 \mathrm{E}+02$ I 15401 Q. $48167 \mathrm{E}+02 \quad 42004$ $7.91190 \mathrm{E}+02 \quad 4630$ $.517378+0250302$ $7.20084 \mathrm{~B}+02 \quad 3430$ $9.96660 \mathrm{E}+0254303$ $.039308+0322305$ . $933118+0226311$ 8. $93450 \mathrm{E}+024631$ (6.5) 6.20436E +02 34309 $.04361 \mathrm{E}+0254309$ $.40124 E+02 \quad 2230$ $7.75963 E+0242306$ G. $17823 E+0246307$ . $37478 E+0230401$ 3. $35906 \mathrm{E}+0234402$ $6.21649 \mathrm{E}+02$ 5402 .18193E402 22100 8.13144E+02 42100 6. $84999 E+02 \quad 261 a 1$ ?. $291518+023010$ 8. $75550 \mathrm{~g}+0250102$ $7.66052 \mathrm{E}+0234103$ $8.99605 E+0254103$ $.18000 \mathrm{E}+022211$ . $20810 \mathrm{~B}+02$ 2611 o. $56743 \mathrm{E}+024611$ .79094E+02 5011 . $7.946265+023810$ $9.19325 E+02 \quad 3001$ $4.50983 E+021300$ $4.49439 \mathrm{E}+021300$ $4.185338+021300$ $3.64809 \mathrm{E}+02 \quad 9301$ $4.68942 \mathrm{E}+02 \quad 7302$ $4.47557 z+0217302$ $4.71022 E+02$
$4.48504 E+02$
43304 $4.61472 \mathrm{E}+02+130$ $3.82630 \mathrm{E}+02 \quad 9311$
$5.34622 \mathrm{E}+02$ $.05979 \mathrm{E}+02 \quad 37310$ $4.21211 \mathrm{E}+02 \quad 1530$ $4.69537 \mathrm{E}+0211306$ $4.468 \theta^{\prime} \mathrm{E}+02 \quad 9307$ 5. $58868 \mathrm{E}+02 \quad 7401$ $6.78948 \mathrm{E}+025040$
9. $46372 x+02 \quad 42003$ $.03350 E+0246004$ Q. $48037 E+0250301$ $6.21296 E+02 \quad 34302$ $.05109 E+0254302$ $7.02458 \varepsilon+02 \quad 38303$
$1.036548+03$
22304 $\begin{array}{lll}1.03664 \Sigma+03 & 22304 \\ 45222 E+02 & 42304\end{array}$ $8.45222 E+02$
$5.923012+02$
86305 $8.13961 \mathrm{E}+0246305$ $6.55472 \mathrm{E}+0230311$ $.18892 E+0234310$ $.9548 E+0254310$ $.52153 E+0222300$ 7. 32224E+02 12300 S. $98683 \mathrm{~B}+02 \quad 26306$ $6.46916 \mathrm{E}+0230307$ $.75720 E+02 \quad 34401$ $7.34175 E+02 \quad 54401$ 9.74126E+02 22403 $416005+0242403$ $.79667 \mathrm{E}+0226100$ $.43087 \mathrm{E}+02$
$.17972 \mathrm{E}+02 \quad 30101$ .72670E r02 50101 $9.99255 \mathrm{E}+02 \quad 54102$ $7.964292+02 \quad 38103$ $9.19473 \mathrm{E}+02 \quad 22110$ .10222E102 26111 $.55982 E+0246111$ $.79374 \varepsilon+02 \quad 50112$ $7.77540 E+02 \quad 34113$
$9.99821 E+02 \quad 54113$ $.04817 E+0238114$ $.10129 \mathrm{E}+0222104$ $.66349 \mathrm{E}+029001$ $4.72921 E+02 \quad 7002$ .5057)+02 17002 $4.50346 \mathrm{E}+02$ 13004 $3.04611 \mathrm{E}+0211301$ $.69396 \mathrm{E}+02 \quad 7303$ $.06082 \mathrm{E}+0217303$ $837885+0213305$ $4.1322 \exists E+02$
31311 $5.35264 E+027309$ $4.46815 E+0217309$ $.91809 \mathrm{E}+0213306$ $4.75993 \mathrm{E}+02$
$3.28691 \mathrm{E}+02$
3407

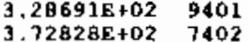

$9.0173 \mathrm{gE}+02$ $6.63953 \mathrm{E}+02$
$9.55945 \mathrm{E}+02$ $10072 \mathrm{E}: \mathrm{O}^{2}$ $.01429 \mathrm{E}+02$
$6.7908 \mathrm{E}+02$ . $52 \theta 45 E+02$ .05 $2 a+02$ . . $37568 \mathrm{~B}+02$ $.527998+02$ . $18896 \mathrm{BE}+02$ (92929E+02 $07518+03$ 36128 + $7.89957 \mathrm{E}+02$ $6.02847 E+02$ . $92137 \mathrm{E}+02$ 5. . . $.92296 \mathrm{E}+02$ $0.71414 \mathrm{E}+02$ 7. $7.92669 \mathrm{E}+02$ $9.1992 \mathrm{aE}+02$ 0.24940E+02 $7.15540 \mathrm{E}+02$ $7.47445 E+02$ $7.78006 \mathrm{E}+02$ $8.99872 \mathrm{E}+02$ 8.056312+02 9. $.50696 z+02$ . $66740 E+02$ . $5.11269 \mathrm{E}+02$ $75874 E+02$ $4.05381 \mathrm{E}+02$ $3.84304 \mathrm{E}+02$ $5.36239 \mathrm{E}+02$ (2) $\mathrm{E}+02$ $4.44143 \mathrm{E}+02$ 4. $64058 \mathrm{E}+02$ 4. $68614 \mathrm{E}+02$ $4.46642 E+02$ $5.12682 \mathrm{E}+02$ 3. $34389 \mathrm{E}+02$ 3. $30769 E+02$ 


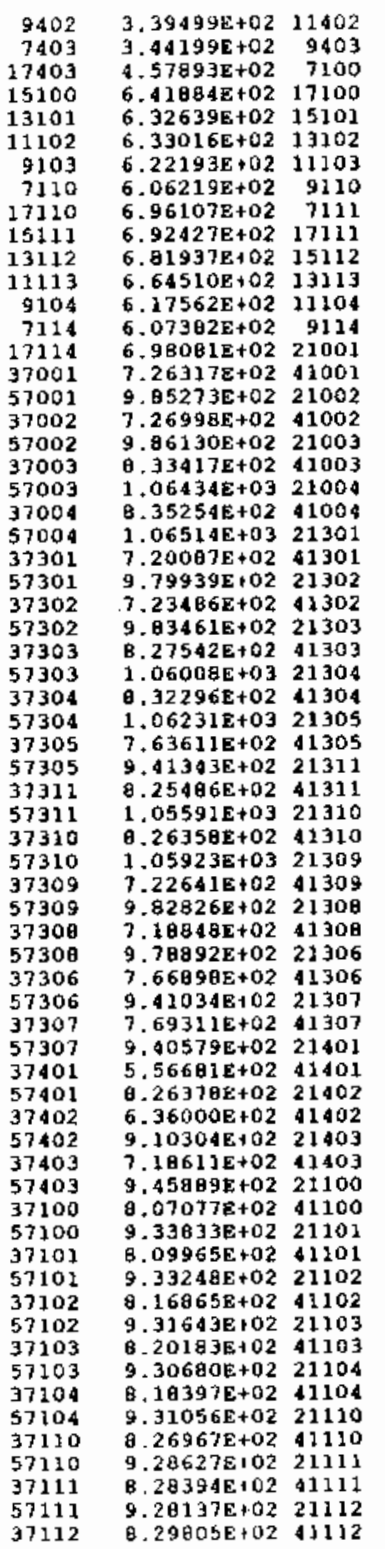

$3.50838 E+02 \quad 13402$ $5.55303 E+0211403$ $6.52746 \mathrm{E}+02 \quad 7101$ $6.483678+02 \quad 17101$ $6.41515 \mathrm{E}+02 \quad 13103$ $6,10341 \mathrm{E}+02 \quad 9111$ $6.99390 \varepsilon+027112$ $6.95958+02$ 171 6. $39573 \mathrm{E}+021511$ $6.42938 \mathrm{E}+02$ 21114 $5.06922 \mathrm{E}+02 \quad 25001$ $7.03426 \mathrm{E}+02 \quad 45001$ $3.06836 \mathrm{E}+02 \quad 25002$ . $44930 \mathrm{E}+022500$ .9852 E +0245003 $5.866872+02 \quad 25004$ 8.901age+02 45004 $7.77179 \mathrm{E} .02 \quad 45301$ 7. BOEl1E+02 45302 $5.79961 \varepsilon+02 \quad 25303$

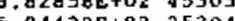
.044102502 25304 $5.832158+0225305$ 8.05096E+02 45305 5. $79210 E+02 \quad 25311$ $5.7894 \theta E+02 \quad 25310$ $5.029796+02 \quad 25309$ $7.79995 E+02 \quad 45309$ $5.01767 E+0225300$ $7.75941 E+02 \quad 45300$ $5.83405+02 \quad 25306$ $5.94\} 31 E+02 \quad 25307$ B. $094262+0245307$ 3. $98082 \mathrm{E}+02 \quad 25401$ $6.09814 E+02$ 45401 6.32401850225402 $5.05213 \mathrm{E}+02 \quad 25403$ 3.69056E+02 45403 $6.79049 \mathrm{E}+0225100$ 8. $37272 \mathrm{E}+02$ 25100 9. $39454 E+02 \$ 5101$ $6.92324 E_{102} 25102$ Q.44644E+0z 45102 6. $98801 E 10225103$ $6.95408 E+022510 \mathrm{~A}$ 8. $45736 \varepsilon+0245106$ $7.1227 \mathrm{BE}+0225110$ Q.52014E+02 45110 \%. $8.53039 k+02$
$7.16017 E+02$
0.51112 6.540548102 45112
$9.636778+02 \quad 15402$ $3.05896 E+02$
$5.89017 \mathrm{E}+02$
11100 $6.58816 \mathrm{E}+02 \quad 7102$ $6.642378+02 \quad 17102$ $6.59345 \mathrm{E}+0213110$ 6. $44981 E+0211111$ $7.02598 \mathrm{E}+02711$ $6.93682 E+02 \quad 27113$ $6.61475 x+0213114$ $5.56 \mathrm{~B} 09 \mathrm{E}+0229001$ $5.566 \mathrm{BOE}+0229002$ $.41569 E+02 \quad \$ 9002$ $46630 E+022900$ $9.421918+0249003$ $9.43654 E+02 \quad 49004$ $1633 E+022930$ $5.53495 E+02 \quad 29302$ 0.38249E+02 99302 $6.41139 E+0229303$ 6.46041E+02 29304 $.27252 E+0229305$ B.44420E+02 49305 $6.40218 E+0229311$ 6.40023E+02 29310 5. 526$) 3 E+02 \quad 29309$ 8. $374548+02 \quad 49309$ . $33334 E+02 \quad 49308$ $6.32778 \mathrm{E}+02 \quad 29306$ $6,33040 E+02 \quad 29307$ 9.474338+02 49307 $6.65090 \mathrm{E}+02 \quad 49401$ $4.74202 E+02 \quad 29402$ $5.55715 E+02 \quad 29403$ Q.18930E+02 49403 . $7.11725 E+0229101$ $.67459 \mathrm{E}+0249101$ $7.23449 \mathrm{E}+0229102$ 0.72489E+02 49103 . $.715 B 1 E+0249104$
$.41447 E+02 \quad 29130$ 0.75611E+02 49110 $.44041 E+022911$ $8.76239 E+02$
$7.46602 \mathrm{E}+02$
9 29112 B. $76865 E+0249112$
3. $79016 \mathrm{E}+0217402$ . $6.73629 \mathrm{E}+02 \quad 7103 \quad 5.05959 \mathrm{E}+02$ $6.72231 \mathrm{E}+0217103$ 6.01011E+02 $6.745618+0215110 \quad 6.898418+02$ $6.40944 E+0211112 \quad 6.782818+02$ $6.11933 E+02 \quad 9113 \quad 6.46402 E+02$ $6.68081 \mathrm{E}+02$ 27104 $6.77252 \mathrm{E}+02$ $6.76625 E+0215114 \quad 6.90005 E+02$ $6.11016 \mathrm{E}+02 \quad 33001 \quad 6.68003 \mathrm{E}+02$ $6.11270 \mathrm{a}+0233002$ G. $94154 \mathrm{E}+02$ $0.95040 \mathrm{E}+0253002$. $7.10676 E+0233003 \quad 7.73579 E+02$ $9.90959 \mathrm{E}+0253003 \quad 1.03260 \mathrm{E}+03$ $9.9206 \mathrm{E}+0233004 \quad 7.7558 \mathrm{E}+02$ 6.05447E+02 33301

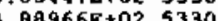
$6.077138+02 \quad 33302$ $7.04794 \mathrm{E}+02 \quad 3330$ $9.05002 \mathrm{E}+025330$ $9.89347 \mathrm{E}+025330$ $6.73677 \mathrm{E}+02 \quad 33305$ $7.03647 \mathrm{E}+02 \quad 3331$ 9.82159E+02 53311 9.84770E+02 53310 $6.06053 E+02$
8.93309 $6.04336 \mathrm{E}+023330$ $6.78504 \mathrm{E}+0253306$ $82150 E+0253306$ $\begin{array}{ll}6.821790+02 & 33307 \\ 8.82794 x+02 & 53307\end{array}$ $4.656198+02 \quad 33401$ $5.22 \mathrm{B17E+02} 3340$ (1) $6.10019 E+02$
0.65355402 53403 $7.4124 B E+0233100$ $7.45418+0253100$ 8.933408+02 $\$ 3101$ $7.55735 E+0233102$ 8.951082 0253102 $9.950058+0253103$ $8.95325 \mathrm{E}+0253104$ ?.71274E+02 33110 $7.73503 \mathrm{E}+02 \quad 33111$ $8.97392 \mathrm{E}+02531: 1$ व.97625E+02 53112 
$75025 E+02$
$0.76566 E+02$
99113 $.76566 E+02$
.49113 0.75272E+02 4911 $.30905 \mathrm{E}+022700$ $30096 \mathrm{E}+022300$ (1) $9.15811 \mathrm{E}+02 \quad 47000$ $6.16767 \mathrm{E}+02 \quad 27004$ $9.17375 E+02$
2627004 $.06103 E+02 \quad 47301$ $.27657 E+02 \quad 27302$ $.09679 \mathrm{E}+02 \quad 23303$ $9.10242 E+02$
$6.14394 E+02$ 27303 $.143948+02 \quad 27304$ 6. $03895 E+02$ 2730 $8.24212 \mathrm{E}+02$ 47305 $6.08205 \mathrm{E}+02$ 27311 $9.0739 \mathrm{BE}+02 \quad 47311$ $.0 B 614 E+0227310$ $268685+0227309$ 8. $08967 \mathrm{E}+02 \quad 4730$ $5.25345 \mathrm{E}+02 \quad 2730$ 0. $04870 \mathrm{E}+02 \quad \$ 730$ . $26316 \mathrm{E}+02 \quad 2730$ $6.14131 E+02 \quad 2730$ 0,277735402 4730? $4.1272 \mathrm{aE}+02 \quad 2740$ 47401 $7.23207 \mathrm{E}+02 \quad 47402$ $5.29953 E+0227403$ $7.94667 \mathrm{E}+02 \quad 47403$ $6.89211 E+0227100$ $6.93722 \varepsilon+02 \quad 2710$ $6.519628+02 \quad 47101$ $7.05377 \varepsilon+02 \quad 2710$ 8.56102E+02 47102 G $57800 \mathrm{0}+02$. . $09160 \mathrm{E}+02$ 2710 $.56922 E+0247104$ .26091E.02 27120 $8.62395 \mathrm{E}+0247120$ $8.61535 \mathrm{E}+0247121$ $7.23595 \mathrm{E}+0227122$ 8.61115E+02 47122
$7.23949 \mathrm{E} 102$
27123 a. $61516 E+02 \quad 47123$ 8. $60004 \mathrm{E}+0247324$ $7.26314 \mathrm{E}+02 \quad 27129$ 9.62413E102 47125 9.27101E+02 27126 $7.27106 \mathrm{E}+02 \quad 27127$
$7.74376 \mathrm{E}+0233113 \quad 9.02576 \mathrm{E}+02$

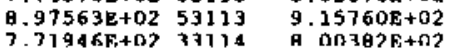
$0.96619 \mathrm{E}+0253114 \quad 9.15197 \mathrm{E}+02$

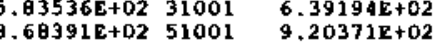

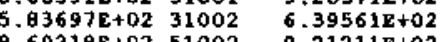
$6.78584 E+0231003 \quad 7.42352 E+02$ \begin{tabular}{ll}
$1.01287 E+03$ \\
\hline
\end{tabular} $9.68673 \mathrm{E}+0251004 \quad 1.01400 \mathrm{E}+\mathrm{a} 3$ . $6.33394 \mathrm{E}+02$ $5.00202 \mathrm{E}+02 \quad 31302 \quad 6.35966 \mathrm{E}+02$ $6.72992 \mathrm{E}+0231303$ $9.62004 \mathrm{E}+0251303 \quad 1.00769 \mathrm{E}+03$ $9.65613 E+0251304 \quad 1.01097 E+03$ (9416E+02 $31305 \quad 6.95935 E+02$ $6.71855 \mathrm{E}+0231311 \quad 7.35115 \mathrm{E}+02$ $9.58603 E+0251311 \quad 1.00404 E+03$ $9.60939 \mathrm{E}+0251310 \quad 1.00699 \mathrm{E}+03$ $8.65174 E+0251309 \quad 9.17373 E+02$ $5.771845+02 \quad 31300 \quad 6.32238 \mathrm{E}+02$ $8.61049 \mathrm{E}+0251300 \quad 9.13286 \mathrm{E}+02$ $6.54542 \mathrm{E}+0231306 \quad 7.00319 \mathrm{E}+02$ $6.58469 \mathrm{E}+02 \quad 31307 \quad 7.03629 \mathrm{E}+02$ $\begin{array}{lll}.64545 E+02 & 51307 & 0.982 \theta 4 \Sigma+02 \\ .46496 \varepsilon+02 & 31401 & 4.86221 \Sigma+02\end{array}$ $6.928348+0251401 \quad 7.47934 E+02$ . $80205 \mathrm{E}+0251402 \quad 5.49397 \mathrm{E}+02$ $.82459 \mathrm{E}+0231403 \quad 6.37604 \mathrm{E}+02$

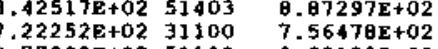
$7.77902 E+0251100 \quad 9.031238+02$

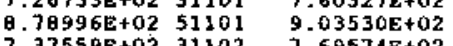
$\begin{array}{lll}.37559 \mathrm{E}+02 & 31102 & 7.69574 \mathrm{E}+02 \\ 9.81427 \mathrm{E}+02 & 51102 & 9.04265 \mathrm{E}+02\end{array}$ $7.42468 \mathrm{E}+02 \quad 31103 \quad 7.73720 \mathrm{E}+02$ .40013E+02 $31104 \quad 7.71644 E+02$ 0.81825E+02 $51104 \quad 9.04246 E+02$ $\begin{array}{lll}.04026+02 & 31120 & 7.04996 E+02 \\ 51120 & 9.04507 \mathrm{E}+02\end{array}$ $.53869 \mathrm{E}+02$
01121

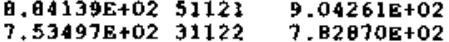
$\begin{array}{lll}0.03732 \mathrm{E}+02 & 51122 & 9.03903 \mathrm{E}+02 \\ 7.53902 \mathrm{E}+02 & 31123 & 7.83294 \mathrm{E} 102\end{array}$ $.04103 E+0251123 \quad 9.04229 \mathrm{E}+02$ $\begin{array}{lll}.53140 E+02 & 31124 & 7.82529 \mathrm{E}+02 \\ 8.03553 \mathrm{E}+02 & 51124 & 9.03789 \mathrm{E}+02\end{array}$ $7.56050 E+02 \quad 31125 \quad 7.85147 E_{102}$ $\begin{array}{lll}0.0469 \theta \mathrm{E}+02 & 51125 & 9.04502 \mathrm{E}+02\end{array}$ $7.56713 \mathrm{E}+0231126 \quad 7.85659 \mathrm{E} r 02$ $\begin{array}{lll}0.046 \mathrm{BgE}+02 & 51126 & 9.04484 \mathrm{E}+02 \\ 7.56717 \mathrm{E}+02 & 31127 & 7.85662 \mathrm{E}+02\end{array}$ 
$7.01118 \mathrm{a}+02 \quad 23128$ 9. $38568 E+02 \quad 43128$ $438565+02 \quad 43129$ $4.50000 E+02 \quad 23404$ $500008+0243404$ $\begin{array}{rr}3.24900 \mathrm{E}+02 & 402 \\ 5.43319 E+02 & 28001\end{array}$ $5.43319 E+02 \quad 28001$ . $61192+02 \quad 40001$ B. $26933 \mathrm{E}+02 \mathrm{02} 48002$ . $30126 E+0228003$ $9.285938+0246003$ $6.32010 \mathrm{E}+0220004$ . $3104 \mathrm{E}+02$ 48004 G. $1991 \theta E+02 \quad 48301$ $.40050 \varepsilon+02 \quad 28302$ 8. $23606 \mathrm{E}+02 \quad 48302$ . $247712+0228303$ $6.23092 \varepsilon+02$ a 303 27071E+02 43304 $6.13820 E+0228305$ 8. $329992+0246305$ 6.23936E+02 28311 $6.23683 E+0228310$ $9.21980 E+0240310$ $5.39248 E+0228309$ B.22809E+02 48309 . $6.19352 E+02 \quad 28306$ B. $34861 E+02 \quad 48306$ $6.23637 \mathrm{E}+02 \quad 28307$ . $36131 E \div 02 \quad 4830$ ? 6. $51202 E+0248401$ $63040 \mathrm{~F}+02 \quad 28402$ 7. $375608+02 \quad 48402$ $5.42598 \varepsilon+0228403$ 8.06777E+02 48403 6.55625E+02 48100 $6.99204 E+02 \quad 28\} 01$ 0.57189E+02 48101 $7.10834 \mathrm{E}+0228102$ 3.6075650249102 0.6209BE+02 4B103 $7.13600 E+02 \quad 28104$ $8.61586 \mathrm{E}+02 \quad 49104$ $7.27 \theta 40 E+02 \quad 28120$ . $63869 \mathrm{E}+02 \quad 48120$ $8.63979 \mathrm{E}+02 \quad 48121$ $7.276998+02 \quad 20122$ 日. $64661 \mathrm{E}+02 \quad 4 \mathrm{~B} 122$ $7.27106 \mathrm{E}+0228123$ $7.277718+0228124$ $0.64 \mathrm{Ba} 2 \mathrm{E}+02 \quad 4 \mathrm{B124}$ 7. $28062 E+0228125$ $8.63886 E+02$
$7.28844 E+02 \quad 28126$

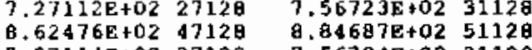
.62476E+02 47128 . $24768+02$ (7) .50000E+02 27404 .50000E+02 47404 $4.24900+02$
$96725 E+02 \quad 32001$ G.81356E+02 52001 $5.96939 \mathrm{E}+0232002$ $6.93992 \mathrm{E} 102 \quad 32003$ $9.78839 \mathrm{E}+0252003$ $6.95984 \mathrm{E}+0232004$ 5.913018402 32301 $.75261 \mathrm{E}+02 \quad 52301$ 5. $789775+0232302$ $6.80234 \bar{E}+0232309$ . $9.77084 \mathrm{E}+02 \quad 52304$ $6.598628+02 \quad 32305$ $8.70461 \mathrm{E}+0252305$ 6.97165E+02 32311 $6.87066 \mathrm{E}+02 \quad 33310$ G.72564E+O2 52310 $5.92570 \mathrm{E}+0232309$ $5.902198+02 \quad 32300$ a. $74003 E+0252308$ $6.64727 E+0232306$ B. $71616 \mathrm{E}+02 \quad 52306$ 9.7231BE+02 52307 .55057Et02 32401 $5.20052 \mathrm{E}+02 \quad 32402$ $7.94158 \mathrm{E}+0252402$ $5.96053 \mathrm{E}+0232403$ $7.28600 E+02 \quad 32100$ $969 E+0252100$ B. $839468+02 \quad 32103$ $.43184 E+0232102$ 0.65725E+02 52102 $.86280 E+0252103$ Q. $86134 \mathrm{E}+02 \quad 52104$ $7.57650 \mathrm{E}+02 \quad 32120$ B. $86058 \mathrm{E}+02$
$7.56830 \mathrm{E}+02$
32121 $57723 E+02 \quad 32121$ $8.87009 \mathrm{E} 10252122$ . $57216 E+0232123$ $7.57823 E+02 \quad 32124$ Q.87262E+02 52124 $7.57 \mathrm{a} 39 \mathrm{E}+0232125$ $0.06055 E+02$
72225
$7.58496 E 102 \quad 32126$ $0.84687 \mathrm{E}+0251129$ $4.50000 \mathrm{E}+023140$ 4. $50000 \varepsilon+025140$ $\begin{array}{ll}4.24900 E+02 & 404 \\ 6.53030 \Sigma+02 & 3600\end{array}$ $9.32058 \mathrm{E}+02 \quad 56001$ 9. $32905 \mathrm{E}+0256002$ 7.57407210236003 $1.02265 \mathrm{E}+035600 \mathrm{~J}$ $1.023738+0356004$ $6.471468+02 \quad 36301$ $6.49874 E+0236302$ $9.29874 E+0256302$ $1.0177 \mathrm{\theta E}+0356303$ $56508 \mathrm{E}+023630$ $1.06182 \mathrm{E}+0236305$ $7.5083 E+02 \quad 3631$ , $50265 \mathrm{E}+023631$ $.016818+0356310$
$.49011 E+02 \quad 36309$ $9.29150 E+02 \quad 56309$ (2) $9.05130 \mathrm{E}+0256306$ 9.13397810236307 $7.613498+0256401$ a. $48374 E+0256402$ . $7.627 \mathrm{agE}+02 \quad 36100$ $9.078518+02 \quad \begin{array}{ll}56101 \\ 9\end{array}$ $7.75052 E+0236102$ $9.08066 \mathrm{E}+0256102$ $9.07 \mathrm{BSOE}+02 \quad 56203$ $9.08054 \mathrm{E}+02 \quad 56104$ $.06230 E+0256121$ $7.86995 E+02 \quad 36122$ 56124 .86818E+02 36125

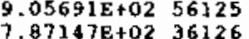

$.05667 E+02$ $85668 \mathrm{~B}+02$ 04484 . $.50000 \mathrm{E} \div 02$ . .7. $7.121768+02$ 9.357318 $0.18600 \mathrm{E}+\mathrm{O} 2$ $1.05620 \mathrm{k}+03$ $1.057055+03$ $7.05352 \mathrm{E}+\mathrm{C}$ $7.08646 \mathrm{E}+02$ . $330058+02$ 1.051日38+03 8.175388+0 $1.05420 \mathrm{E}+03$ $7.500715+02$ . B. $115048+02$ $7.07796 \mathrm{E}+02$ $7.04121 \mathrm{E}+02$ $9.60376 \mathrm{E}+02$ 9.339948 $5.44072 \mathrm{E}+02$ $8.13787 \mathrm{E}+02$ $6.21245 E+02$
$\theta .98554 E+02$ $7.05274 \varepsilon+02$ $7.955918+02$ $9.28205 \mathrm{E}+02$ $7.96536 \mathrm{E}+02$ $9.2773 \mathrm{E}+02$ $9.2633 \mathrm{BE}+02$ $9.25903 \mathrm{E}+02$ 9. $11750 \mathrm{E}+02$ $8.13994 \mathrm{E}+02$ 9.14380E+02 . $22760 \mathrm{a}$ $9.22500 \mathrm{E}+02$ $8.14934 E+02$
$9.22994 E+02$ 日. $14364 \mathrm{E}+02$ $9.21685 E+02$
$8.14482 E+02$ 


\begin{tabular}{|c|c|c|c|c|c|c|c|c|c|}
\hline $\begin{array}{l}40126 \\
20127 \\
40127\end{array}$ & $\begin{array}{l}8.39919 E+02 \\
7.02262 E+02 \\
\text { a. } 39920 E+02\end{array}$ & $\begin{array}{l}44126 \\
24127 \\
14127\end{array}$ & 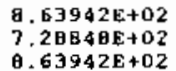 & $\begin{array}{l}48126 \\
28127 \\
48127\end{array}$ & $\begin{array}{l}\text { B. } 96044 \mathrm{E}+02 \\
7.58500 \mathrm{E}+02 \\
8.06044 \mathrm{E}+02\end{array}$ & $\begin{array}{l}52126 \\
32127 \\
52127\end{array}$ & $\begin{array}{l}9.05674 E+02 \\
7.07149 E+02 \\
9.05673 E+02\end{array}$ & $\begin{array}{l}56126 \\
36127 \\
56127\end{array}$ & $\begin{array}{l}9.21463 E+02 \\
8.14483 E+02 \\
9.21462 E+02\end{array}$ \\
\hline 40127 & & & $\begin{array}{l}0.63942 E+02 \\
7\end{array}$ & & & & & & \\
\hline 128 & $8399200+02$ & 128 & $863942 E+02$ & 48128 & $8.86044 \mathrm{E}+02$ & 52128 & $9.05673 \mathrm{E}+02$ & 56120 & $21460 \mathrm{E}+02$ \\
\hline 2 & $02271 \mathrm{E}+02$ & 24129 & $7.28056 \mathrm{E}+02$ & 28129 & $758507 \mathrm{E}+02$ & 32129 & $7.87152 \mathrm{E}+02$ & 36129 & $8.1448<E+0$ \\
\hline 4 & $0 E+02$ & 44129 & $53943 E+02$ & 48129 & $86044 \mathrm{E}+02$ & 52129 & $9056738+02$ & 56129 & $9214598+02$ \\
\hline 4 & $2+02$ & & $50000 \mathrm{E}+02$ & 20404 & $4,50000 E+02$ & 32404 & 4.50000 e roz & 16404 & $4.500000+02$ \\
\hline 4 & & & & & 4.5000 & 52404 & & & $\mathrm{E}+02$ \\
\hline & $22912 \mathrm{E}+02$ & $511 \theta$ & $26990 \mathrm{O}+02$ & 512 & $5,12608 \mathrm{E}+02$ & 21 & $54512 \mathrm{E}+02$ & & \\
\hline & $54527 \mathrm{~B}+02$ & $410 B$ & 4. $50367 \mathrm{E}+02$ & 411 & $4.49941 \mathrm{E}+02$ & & & & \\
\hline & $34427 \mathrm{E}+02$ & 5004 & $3,34510 E+02$ & 530 & 3.3 & & $2 \theta 2 E_{-1}$ & & \\
\hline & $34349 \mathrm{E}+02$ & 5305 & $3.95259 \mathrm{E} \cdot 02$ & 530 & $3.30293 \mathrm{E}+02$ & 5311 & $935 E+02$ & & A5E \\
\hline & $3.30225 \mathrm{E}+02$ & 5306 & $4.00936 E+02$ & 530 & $4.05324 E+02$ & 5401 & $25138 \mathrm{E}+02$ & & $3.25302 \mathrm{E}$ \\
\hline 403 & $28677 \mathrm{E}+02$ & 5100 & 4. 67990E+02 & 510 & $4.92386 \mathrm{E}+0$ & 5102 & $04515 E+02$ & & 2 \\
\hline 5110 & $5.24211 E+02$ & 5111 & $23995 \mathrm{E}+02$ & 511 & $5.31003 \mathrm{E}+02$ & 5113 & $5.27623 E+02$ & 140 & 24900 \\
\hline 4401 & $3.24900 \mathrm{E}+02$ & 4305 & $4.48277 \mathrm{E}+02$ & 4306 & $4.48277 \mathrm{E}+02$ & 4307 & $.48440 E+02$ & 4100 & $51604 E+02$ \\
\hline 4101 & $517 \mathrm{BEE}+$ & $\$ 102$ & $4.49941 \mathrm{E}+02$ & 410 & $49941 E+$ & 4104 & $4.50461 E+02$ & $\$ 105$ & $4.50296 \mathrm{E}+02$ \\
\hline 4403 & $24900 E+02$ & 3409 & 3. $24900 E+02$ & 3402 & $.24900 E+02$ & 3401 & $3.24900 z+02$ & 3305 & $4.50061 \mathrm{E}+02$ \\
\hline 3306 & $50061 E+02$ & 3307 & $.500605+02$ & 3100 & $4.50049 \mathrm{E}$ & 3101 & $4.50049 \mathrm{E}+02$ & 3102 & $4.499412+02$ \\
\hline 3103 & $4.49941 E+02$ & 3104 & $51 E+02$ & 3705 & $4.501500+02$ & 2403 & $3.24900 \mathrm{E}+02$ & 24 & $3.24900 \mathrm{z}+02$ \\
\hline 2401 & $24900 E+$ & 2305 & $4.53251 \mathrm{E}$ & 2306 & $4.53251 E+02$ & 2307 & 4. $53254 \mathrm{E}+02$ & 2100 & $4+53548 \mathrm{Q}+02$ \\
\hline 210 & $.53551 E+$ & 2102 & 4.53 & 2103 & 4.535 & 2104 & $4.53601 E+02$ & 2105 & $4.5363308+02$ \\
\hline 2106 & $4.53607 \mathrm{E}$ & 2307 & 4.535 & 1401 & $3.24900 \mathrm{E}+02$ & 1403 & $3.24900 E+02$ & 1402 & $3.249000 \mathrm{E}+02$ \\
\hline 1305 & $4.51013 E+02$ & 1306 & $4.51013 E+02$ & $\begin{array}{l}1307 \\
1307\end{array}$ & $4.51014 E+02$ & 1100 & $4.51050 \mathrm{E}+02$ & 1101 & $4.51052 E+02$ \\
\hline 1102 & 4.51057E+02 & 1103 & 4.514518+02 & 1104 & 4. $51454 E+02$ & 1105 & $4.51458 E+02$ & 1106 & $4.51462 \mathrm{E}+02$ \\
\hline 1107 & $4.51468 \mathrm{E}+02$ & 1108 & $4.51462 E+02$ & 1109 & $4.51455 E+02$ & & & & \\
\hline
\end{tabular}

$\underbrace{\square}$

*** oxidation summary ***

\begin{tabular}{|c|c|c|c|c|}
\hline node & qzkhzo(kw) & gffison ( KW) & qgen $(\mathbf{k H})$ & 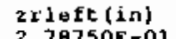 \\
\hline & & & & $2.78750 \mathrm{E}-01$ \\
\hline 2306 & $0.00000 E+00$ & $0.00000 \varepsilon+00$ & $0.000008+00$ & $2.787505-01$ \\
\hline 3306 & $0,00000 E+00$ & $20 E+00$ & $0.00000 \mathrm{E}: 00$ & $2,787500-01$ \\
\hline 4306 & $0.00000 E+00$ & $0.00000 E+00$ & $0.00000 \mathrm{E}+00$ & $2.78750 \mathrm{E}-01$ \\
\hline 5001 & $0.00000 z+00$ & $9.98348 \mathrm{E}-04$ & $9.98340 \mathrm{E}-04$ & $1.75000 E-01$ \\
\hline & 0.0 & $1.49648 \mathrm{E}-03$ & $1.49648 \mathrm{E}-03$ & \\
\hline 5003 & $0.00000 \mathrm{E}+00$ & $3.062258-03$ & $225 E-03$ & $1.595008-01$ \\
\hline 5004 & 100E:100 & $3.5 B 126 \mathrm{E}-03$ & $3.58328 \mathrm{E}-03$ & $58500 E-01$ \\
\hline 5301 & $0.00000 \mathrm{E}+00$ & $1.91187 E-06$ & $1.91187 E-06$ & 2. $000000-02$ \\
\hline 5302 & $0.00000 \mathrm{E}+00$ & $5.74070 \mathrm{E}-06$ & $5,74678 \mathrm{E}-06$ & $00000 \mathrm{E}-02$ \\
\hline 5303 & $0.00000 E+00$ & $5.74442 E-06$ & $5.74442 E-06$ & $2.00000 E-02$ \\
\hline 5304 & $0.00000 \mathrm{E}+00$ & $7.67676 \mathrm{E}-06$ & $7.67676 \mathrm{E}-06$ & $2.50000 \mathrm{E}-02$ \\
\hline 5306 & $0.00000 \mathrm{E}+00$ & & 8.19448E-05 & $2.387505-01$ \\
\hline $\begin{array}{l}6001 \\
6002\end{array}$ & $\begin{array}{l}0.00000 E+00 \\
0.000008+00\end{array}$ & $\begin{array}{l}7.154938-03 \\
1.07247 E-02\end{array}$ & $\begin{array}{l}7.15483 \mathrm{E}-03 \\
1.07247 \mathrm{E}-02\end{array}$ & $\begin{array}{l}1.75000 \mathrm{E}-11 \\
1.75000 \mathrm{E}-01\end{array}$ \\
\hline & $0.00000 \mathrm{E}+100$ & $2,19461 \mathrm{E}-02$ & 2.79461E-02 & $1.58500 \mathrm{E}-01$ \\
\hline & & $2.566588 \mathrm{E}-02$ & $2.56658 \mathrm{E}-02$ & $1.58500 \mathrm{E}-01$ \\
\hline & $E+00$ & $1.37017 \mathrm{E}-05$ & $1.37017 \mathrm{E}-05$ & $0 \mathrm{E}-02$ \\
\hline & $D E+00$ & $4.11996 \mathrm{E}-05$ & $4.11996 \mathrm{E}-05$ & $3.00000 E-02$ \\
\hline & $100 E+00$ & 4.11683E-05 & $4.11603 \mathrm{E}-05$ & $2.00000 \mathrm{E}-02$ \\
\hline & $E+00$ & $5.50160 \mathrm{E}-05$ & $.50168 \mathrm{E}-05$ & $2.50000 \mathrm{E}-02$ \\
\hline & & $5.87271 \mathrm{E}-$ & $07271 \mathrm{E}-\mathrm{C}$ & $2.79750 E-01$ \\
\hline & $100 E+00$ & $1.14175 E-c$ & $.14175 E-02$ & $1.75000 \mathrm{E}-01$ \\
\hline & OOOE $\div 00$ & $1.711438-02$ & $1.71143 E-02$ & 1. $75000 \mathrm{E}-01$ \\
\hline & $00000 E: 00$ & $3.50212 E-02$ & $.50212 \mathrm{E}-02$ & 1. $58500 \mathrm{E}-01$ \\
\hline & $E+\infty 0$ & $9570 \mathrm{E}-02$ & $.09570 \mathrm{E}-02$ & $1.58500 \mathrm{E}-01$ \\
\hline & & 86498 & $E-05$ & \\
\hline & $00 E: 100$ & 5 & $5 E-05$ & \\
\hline & b0: 100 & $.56955 \mathrm{E}-05$ & $56955 E-05$ & \\
\hline & no & $947 \mathrm{E}-05$ & $77947 E-05$ & \\
\hline 7306 & $0.00000 E+00$ & $37155 \mathrm{E}-04$ & $.37155 \mathrm{E}-04$ & $2.78750 \mathrm{E}-01$ \\
\hline
\end{tabular}

\begin{tabular}{|c|c|c|}
\hline & 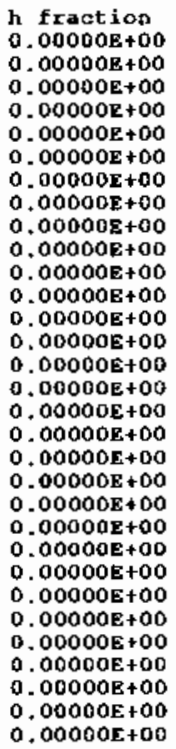 & 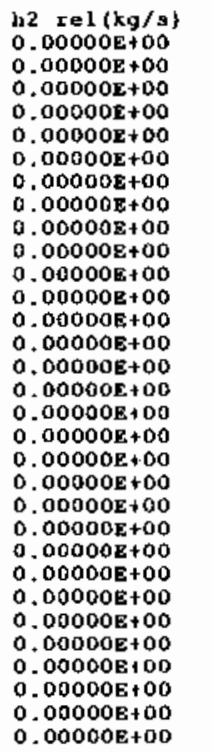 \\
\hline
\end{tabular}


$0.00000 \mathrm{E}+00$
$0.00000 \mathrm{E}+00$

(.0000E+2

$0.00000 \mathrm{E}+00$

(2)

$0.00000 \mathrm{E}+00$

. $00000 \mathrm{E}+00$

$0.00000 \mathrm{E}+00$

$.00000 \mathrm{E}+24$

$0.000 \mathrm{E}$

.00000E+24

$.00000 \mathrm{~B}+00$

$0.00000 \mathrm{E}+00$

$0.00000 E+00$

$1.00000 \mathrm{x}+24$

(a)

$.00000 \mathrm{E}+00$

$0.00000 \mathrm{E}+00$

$0.00000 E+00$
$0.00000 E+00$

00000E+24 0.000

$0.00000 E+00$

$\begin{array}{ll}0.00000 \mathrm{E}+00 & 0.00000 \mathrm{E}+00 \\ 0.00000 \mathrm{E}+00 & 0.00000 \mathrm{E}+00\end{array}$

.0000E+2 $0.00000 \mathrm{R}+00$

$0.00000 \mathrm{E}+00$

$.00000 \mathrm{E}+00$

$0.00000 \mathrm{R}+00$
$0.00000 \mathrm{E}+00$

$0.00000 \mathrm{E}+00$

$0.00000 \mathrm{E}+00$

$0.00000 \mathrm{E}+00$
$0.00000 \mathrm{E}+00$

$0.00000 \mathrm{E}+00$

$0.000008+00 \quad 0.00000 \mathrm{E}+00$

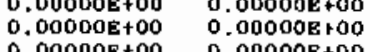

$0.00000 \mathrm{E}+00$
$0.00000 \mathrm{E}+00$

$0.00000 \mathrm{E}+00$
$0.00000 \mathrm{E}+00$

$0.00000 \mathrm{E}+00 \quad 0.00000 \mathrm{E}+00$

$0.00000 \mathrm{E}+000.00000 \mathrm{E}+00$

$0.00000 E+00 \quad 0.00000 E+00$

$\begin{array}{ll}0.00000 E+00 & 0.00000 E+00 \\ 0.00000 E+00 & 0.00000 E+00\end{array}$

$0.00000 E+00$ D. $00000 E+00$

$0.00000 \mathrm{E}+00 \quad 0.00000 \mathrm{E}+00$

$0.00000 \mathrm{E}+00 \quad 0.0000 \mathrm{O}+00$

$0.00000 \mathrm{E}+00 \quad 0.00000 \mathrm{E}+00$

$\begin{array}{ll}0.00000 E+00 & 0.00000 E+00 \\ 0.00000 E+00 & 0.00000 E+00\end{array}$

$0.00000 E+00 \quad 0.00000 \mathrm{~B}+00$

$0.00000 E+00 \quad 0.00000 E+00$

$0.00000 E+00 \quad 0.00000 E+00$

$0.00000 E_{100} 0.000000$ +00

$0.00000 \mathrm{E} 100 \quad 0.00000 \mathrm{E}+00$

$0.00000 \mathrm{E}+00 \quad 0.00000 \mathrm{E}+00$

$0.00000 \mathrm{E}+00 \quad 0.00000 \mathrm{E}+00$

$0.00000 \mathrm{E}+000.00000 \mathrm{E}+00$

$\begin{array}{ll}0.00000 E+00 & 0.00000 E+00 \\ 0.00000 E+00 & 0.00000 E+00\end{array}$

$.00000 \mathrm{E}+2$

$1.00000+24$

$0.00000 \mathrm{E}+00$

$0.00000 E+00$
$0.00000 E+00$

$00000 \varepsilon+24$

$0.00000 \mathrm{E}+00 \quad 0.00000 \mathrm{E}+00$

$0.00000 \mathrm{E}+0 \mathrm{OA} \quad 0.00000 \mathrm{E}+00$

$0.00000 \mathrm{E}+000.00000 \mathrm{E}+00$

$0.00000 \mathrm{E}+00$

$0.00000 \mathrm{E}+00$

$0.00000 \mathrm{E}+00$

$0.00000+000$

$000005+24$

$0.00000 \mathrm{E}+00$

$0.00000 \mathrm{E}+00$

$1.00000 \mathrm{E}+2$

$0.00000 \mathrm{E}+00$

$\begin{array}{lll}1.00000 E+24 & 0.00000 E+00 & 0.00000 E+00\end{array}$

$\begin{array}{lll}1.00000 E+24 & 0.00000 E+00 & 0.00000 E+00 \\ 1.00000 E+24 & 0.00000 E+00 & 0.00000 E+00\end{array}$ 
$\begin{array}{ll}1.00000 \mathrm{E}+24 & 0.000008+00\end{array}$ $00000 \mathrm{E}+24 \quad 0.00000 \mathrm{E}+00$ $.00000 k+24$ D. $00000 \mathrm{~B}+00$ D.00000E+00 (1.00000000000 E+24 0.00000E+00 $00000 \mathrm{E}+24 \quad 0.00000 \mathrm{z}+00$ .00000E+24 $0.00000 E+00$ $00000+24 \quad 0.00000 E+00$ $0000 \mathrm{O} 240000 \mathrm{E}$ $0.00000 \mathrm{E}+00$ $.00000 \mathrm{E}+24 \quad 0.00000 \mathrm{E}+00$ $00000 \mathrm{E}+24 \quad 0.00000 \mathrm{E}+00$ $0.0000 \mathrm{E}+00$ $00000 E+240.00000 E+00$ $0.00000 E+00$ 1.00000E+24 $0.00000 \mathrm{E}+00$ 0.00000 e+o $.00000 \mathrm{E}+24 \quad 0.00000 \mathrm{E}+00$ $00000 E+24 \quad 0.00000 E+00$ $.00000 E+24 \quad 0.000002+00$ $0.00000 \varepsilon+00$ $.00000 \mathrm{E}+240.00000 \mathrm{E}+00$ $0.00008+00$ $00000 E+24 \quad 0.00000 E+00$ $00000 \mathrm{E}+24 \quad 0.00000 \mathrm{E}+00$ $.00000 \mathrm{E}+24 \quad 0.00000 \mathrm{E}+00$ (1.00000 $0.00000 \mathrm{E}+0$ $.00000 \mathrm{E}+24 \quad 0.00000 \mathrm{E}+00$ $0.00000 \mathrm{E}+00$ $1.00000 \mathrm{E}+24 \quad 0.00000 \mathrm{E}+00$ $00000 E+24 \quad 0.00000 E+00$ $00000+24 \quad 0.00000 E+00$ $00000 \mathrm{E}+24 \quad 0.00000 \mathrm{E}+00$ $.00000 \mathrm{E}+24 \quad 0.00000 \mathrm{z}+00$ .0000E+24 $0.00000 \mathrm{E}+00$ $000008+24 \quad 0.00000 E+00$ $00000 \mathrm{E}+24 \quad 0.00000 \mathrm{E}+00$ $.00000 \mathrm{E}+24 \quad 0.00000 \mathrm{E}+00$ .00000E+24 $0.00000 \mathrm{E}+00$ $0.00000+00$ $00000 \mathrm{R}+24 \quad 0.00000 \mathrm{E}+00$ $.00000 E+24 \quad 0.00000 E+00$ $.00000 \mathrm{E}+24 \quad 0.00000 \mathrm{E}+00$ $0.00000 \mathrm{E}+00$ $00000 \mathrm{E}+240.00000 \mathrm{E}+00$ $00000 E+24 \quad 0.00000 E+00$ $.00000 \mathrm{E}+24 \quad 0.00000 \mathrm{E} 100$ $.00000 \mathrm{E}+24 \quad 0.00000 \mathrm{E}+00$ $000008+24$ $00000+240.00000 E+00$ $\begin{array}{ll}.00000 \mathrm{E}+24 & 0.00000 \mathrm{E}+00 \\ 00000 \mathrm{E}+24 & 0.00000 \mathrm{E}+00\end{array}$
$0.00000 \mathrm{E}+00$ $0.00000 \mathrm{E}+00$ $0.00000 \mathrm{E}+00$ $0.00000 \mathrm{E}+00$ $0.00000 \mathrm{z}+00$ $0.00000 \mathrm{z}+00$ $0.00000 \mathrm{0}+00$ $0.00000 \mathrm{E}+00$ $0.00000 \mathrm{E}+00$ $0.00000 \mathrm{E}+00$ $0.00000 \mathrm{E}+00$ 0. $-00000 \mathrm{~B}+00$ $0.00000 \mathrm{z}+00$ $0.00000 \mathrm{E}+00$ $0.00000 \mathrm{E}+00$ $0.00000 \mathrm{E}+00$ $0.00000 \mathrm{E}+00$ $0.00000 \mathrm{E}+00$ $0.00000 \mathrm{E}+00$ $0.000008+00$ $0.000008+00$ $0.00000 E+00$
$0.00000 E+00$ $0.00000 E+00$ $0.00000 \mathrm{E}+00$ $0.00000 \mathrm{E}+00$ $0.00000 \mathrm{E}+00$ $0.00000 \mathrm{E}+00$ $0.00000 \mathrm{E}+00$ $0.000008+00$ $0.00000 \mathrm{E}+00$ $0.00000 \mathrm{E}+00$ $0.00000 \mathrm{E}+00$ $0.00000 \mathrm{E}+00$ $0.00000 E+00$ $0.00000 \mathrm{E}+00$ $0.00000 \mathrm{E}+00$
$0.00000 \mathrm{E}+00$ $0.00000 \mathrm{E}+00$ $0.00000 \mathrm{E}+00$ $0.00000 \mathrm{E}+00$ $0.00000 E+D 0$ $0.00000 E+00$
$0.00000 E+00$ $0.00000 \varepsilon+00$ $0.00000 \mathrm{E}+00$ $0.00000 \mathrm{E}+00$ $0.00000 \mathrm{E}+00$
$0.00000 \mathrm{E}+00$ $0.00000 \mathrm{E}+00$ $0.00000 \mathrm{E}+00$ $0.00000 \mathrm{E}+00$ $0.00000 E+00$
$0.00000 \mathrm{E}+00$ $0.00000 \mathrm{E}+00$
$0.00000 \mathrm{E}+00$ $0.00000 \mathrm{E}+00$ 


\begin{tabular}{|c|c|c|c|c|c|c|c|}
\hline & $0.00000 \mathrm{E}+00$ & 8. $50514 \mathrm{E}-02$ & 0.50514E-02 & $3.585008-01$ & $1,00000 \mathrm{E}+24$ & $0.000008+00$ & $0.00000 \mathrm{E}+00$ \\
\hline & $0,00000 E+00$ & & $9.94669 \mathrm{E}-02$ & 1. $58500 \mathrm{E}-01$ & $1.00000 \mathrm{E}+24$ & $0.00000 \mathrm{E}+00$ & $0.00000 E+00$ \\
\hline 22301 & $0.000000+00$ & $5.310058-05$ & $5.31005 E-05$ & $2,00000 \mathrm{E}-02$ & $1.00000 \mathrm{E}+24$ & $D E+00$ & $000 \mathrm{E}+00$ \\
\hline 22302 & $0.00000 E+00$ & $1,5966 \mathrm{BE}-04$ & $1.5966 \mathrm{BE}-04$ & $3.000008-02$ & $1.00000 \mathrm{E}+24$ & $0.00000 E+00$ & $00 \mathrm{E}+00$ \\
\hline 22303 & $0.00000 \mathrm{E}+00$ & $1,59546 \mathrm{E}-04$ & $1.59546 E-04$ & $00000 \mathrm{E}-02$ & $000 E+24$ & 0.00000 R +00 & $000 \mathrm{R}+00$ \\
\hline 22304 & $0,00000 \mathrm{E}+00$ & $2.13216 \mathrm{E}-04$ & $2.13216 \mathrm{E}-04$ & $50000 \mathrm{E}-02$ & $1.00000 \mathrm{E}+24$ & $000 E+00$ & $100 \mathrm{R}+00$ \\
\hline 2306 & $0,00000 E+00$ & $2.27595 \mathrm{E}-03$ & $2.27595 \mathrm{E}-03$ & $2.78750 \mathrm{E}-01$ & $1.00000 \mathrm{E}+24$ & $00 \mathrm{E}+00$ & $000 \mathrm{E}+00$ \\
\hline 23001 & $0.00000 \mathrm{E}+00$ & $2,06262 \mathrm{E}-02$ & $2.06262 \mathrm{E}-02$ & $1.75000 \mathrm{E}-01$ & $1.00000 \mathrm{E}+2 \mathrm{~A}$ & $200 E+00$ & $00 \mathrm{E}+00$ \\
\hline 23002 & $0.00000 E+100$ & $4.29093 \mathrm{E}-02$ & $4.29093 \mathrm{E}-02$ & $1.75000 \mathrm{E}-01$ & $1.00000 \mathrm{E}+24$ & $000 \mathrm{E}+00$ & $0005+00$ \\
\hline 3003 & $0,00000 E+100$ & $8.70057 \mathrm{E}-02$ & 0.78057E-02 & $1.585008-01$ & $1,00000 \mathrm{E}+24$ & $000 \varepsilon+00$ & $0.00000 \mathrm{E}+00$ \\
\hline 3004 & $0.00000 E+00$ & $1,02689 \mathrm{E}-01$ & $1.0260 \mathrm{aE}-01$ & $1.50500 \mathrm{E}-01$ & $1.00000 \mathrm{E}+24$ & $0000 \mathrm{E}+00$ & $0.00000 \mathrm{E}+00$ \\
\hline 3301 & $0.00000 \mathrm{E}+00$ & $5.48201 \mathrm{E}-05$ & $5.48201 E-05$ & $2.00000 \mathrm{E}-02$ & $1.00000 \mathrm{E}+24$ & $000 \mathrm{z}+00$ & $000 E+00$ \\
\hline & $0.00000 E+00$ & $1.64838 \varepsilon-04$ & $1.64838 \mathrm{~B}-04$ & $3,00000 \mathrm{E}-02$ & $1.00000 \mathrm{~B}+24$ & $00 E+00$ & $0000 E+00$ \\
\hline 3303 & $0.00000 \mathrm{E}+00$ & $2.64713 \mathrm{E}-04$ & 1. $64713 \mathrm{E}-04$ & $2,00000 \mathrm{E}-02$ & $00000 E+24$ & $0000 E+00$ & $0000 E+00$ \\
\hline 304 & $0.00000 E+00$ & $2.20120 \mathrm{E}-04$ & $2.20120 E-04$ & $2.50000 \mathrm{E}-02$ & $000 z+24$ & $000 \mathrm{E}+00$ & $0000 E+00$ \\
\hline 306 & $0.000008+00$ & $2.34965 E-03$ & 2. $34965 E-03$ & $2.78750 E-01$ & $1.00000 E+24$ & $0 \mathrm{OE}+00$ & $00 E+00$ \\
\hline & $0.00000 E+00$ & $0.00000 \mathrm{E} r 00$ & $0.00000 \mathrm{E}+00$ & $1008-02$ & $00 E+21$ & & $00 E+00$ \\
\hline 128 & $0.00000 \mathrm{E}+00$ & $0,00000 E+00$ & $00000 \mathrm{E}+00$ & 22 & $00 E+24$ & & $000 \mathrm{E}+00$ \\
\hline 1001 & $0.00000 E+00$ & $2.95009 \mathrm{E}-02$ & $2.95809 \mathrm{E}-02$ & $1.75000 \mathrm{E}-\mathrm{D1}$ & & & $100 E+00$ \\
\hline 002 & $0.00000 \mathrm{E}+00$ & 4. $434038-02$ & $4.43403 E-02$ & $1.75000 E-01$ & & & $0.80000 E+00$ \\
\hline 003 & $0.00000 \mathrm{E}+00$ & $9.07339 \mathrm{E}-02$ & $9.07339 \mathrm{E}-$ & & & & \\
\hline 004 & $0.00000 \mathrm{E} \div 00$ & $1,06113 \mathrm{E}-01$ & $.06113 E-01$ & & & & \\
\hline 301 & $0.00000 \varepsilon+00$ & $5.66483 \varepsilon-0.5$ & 5.664 & & & & \\
\hline & $0.00000 \mathrm{E}+00$ & 1.703 & & & & & \\
\hline & $0.00000 \mathbf{E}+$ & & & & & & \\
\hline 04 & 0.0000 & 2.2746 & 2.27 & & 1.0 & & \\
\hline 06 & 0.0 & & & & & & \\
\hline & 0.0 & & & & & & \\
\hline 28 & 0.000 & & & & & $0.00000 \varepsilon+00$ & \\
\hline $\begin{array}{l}25001 \\
25002\end{array}$ & $0.00000 \mathrm{E}$ & & $\begin{array}{r}3.047228-02 \\
4.567648-02\end{array}$ & $\begin{array}{l}1.750008-01 \\
1.75000 E-01\end{array}$ & $\begin{array}{l}1.00000 E+24 \\
1.000008+24\end{array}$ & $\begin{array}{l}0.00000 \mathrm{E}+00 \\
0.00000 \mathrm{E}+00\end{array}$ & $\begin{array}{l}0.00000 E+00 \\
0.00000+00\end{array}$ \\
\hline 02 & & $\begin{array}{l}4.56764 \mathrm{E}-0 \mathrm{O} \\
9.346 \mathrm{~B} 0 \mathrm{E}-02\end{array}$ & $\begin{array}{l}4.567648 \mathrm{E}-02 \\
9.346 \mathrm{BOE}-02\end{array}$ & $\begin{array}{l}1.15000 \mathrm{E}-01 \\
1.58500 \mathrm{D}-01\end{array}$ & $1.00000 \mathrm{E}+24$ & $00 \mathrm{D}+00$ & $0.00000 E+\infty 0$ \\
\hline & 0 & $1.09310 E-01$ & & & & & \\
\hline & 0.0 & & & & & & \\
\hline & 0.0 & & & & & & \\
\hline & 0.0 & & & & & & \\
\hline 25304 & 0.0 & & & & & & \\
\hline & & & & & & & \\
\hline 26001 & & & & & & & \\
\hline 26002 & & & & & & & \\
\hline 26003 & & & & & & & \\
\hline 26004 & & & & & & & \\
\hline & & & & & & & \\
\hline & & & & & & & \\
\hline & & & & & & & \\
\hline & & & 4 & & & & \\
\hline & & & 3 & & & & \\
\hline & & & 2 & & & & \\
\hline & 0.0 & 4.806 & 4 & & & & \\
\hline & & & & & & & \\
\hline 270 & & & & & & & \\
\hline 273 & 0.00 & & & & & & \\
\hline 273 & 0.00 & 8464 & $84640 E$ & & & & \\
\hline 2730 & 0.00 & $.04500 \mathrm{E}$ & $84500 E$ & & & & $0 E+00$ \\
\hline 2730 & 0.00 & $2.46563 \mathrm{E}-$ & $46563 \mathrm{E}$ & & & & $0 \mathrm{E}+00$ \\
\hline 273 & 0.00 & & & & & 00 & \\
\hline $2 \geqslant 1$ & 0.00 & 0 & & & & & 00 \\
\hline $2 ? 1 ?$ & 0.00 & & & & & & $0 E+00$ \\
\hline 280 & 0.00 & & & & & & $0 \mathrm{E}+00$ \\
\hline $2 \mathrm{BO}$ & 0.00 & 4.911 & 4.9 & 1.7 & & Do & 0.0 \\
\hline 280 & & & & & & 0 & 0.0 \\
\hline 280 & & 1.1 & & & 4 & & oo \\
\hline 283 & 0.000 & 6.274 & 6. & & & po & \\
\hline 283 & $.00000 E+00$ & $1.08679 \mathrm{E}-$ & J. $\theta$ & 3.0 & & 00 & \\
\hline 2830 & $0.00000 z+00$ & $1.80536 \mathrm{E}-$ & 1. $88536 \mathrm{E}-04$ & $2.00000 \varepsilon-02$ & & $0.00000 E+00$ & $0000+00$ \\
\hline 28304 & $0.00000 \mathrm{E} 100$ & $2.51957 E-04$ & $2.519578-04$ & $2.50000 \mathrm{E}-02$ & $1.00000 E+24$ & $0.00000 E+00$ & $0.00000 E+00$ \\
\hline
\end{tabular}




\begin{tabular}{|c|c|c|c|c|c|c|c|}
\hline 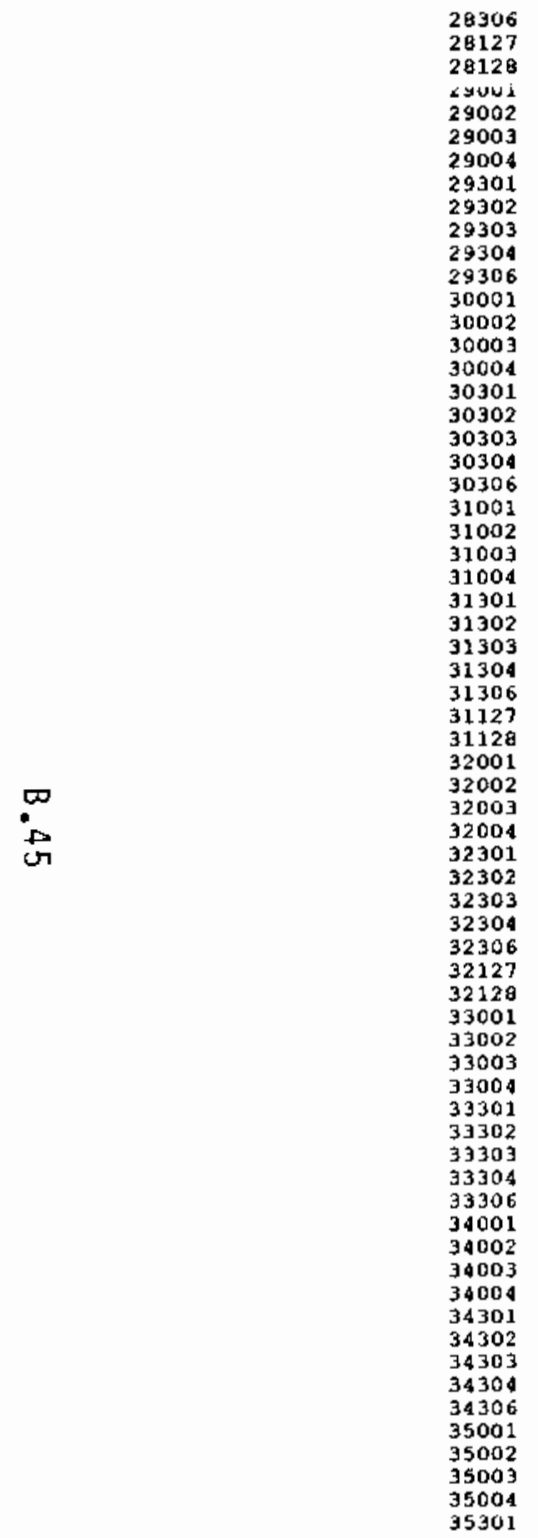 & 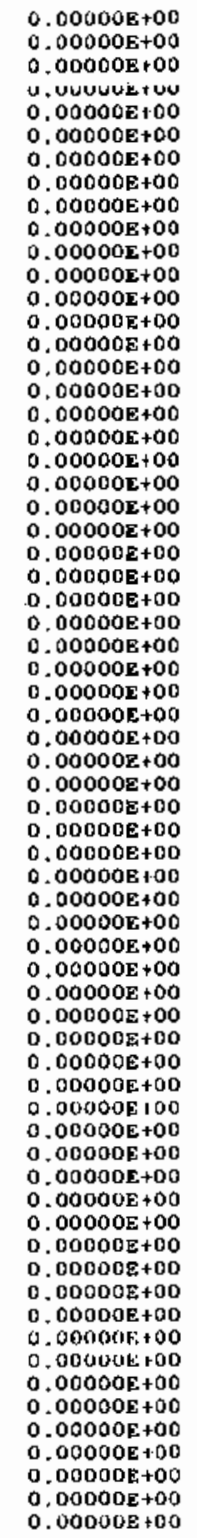 & 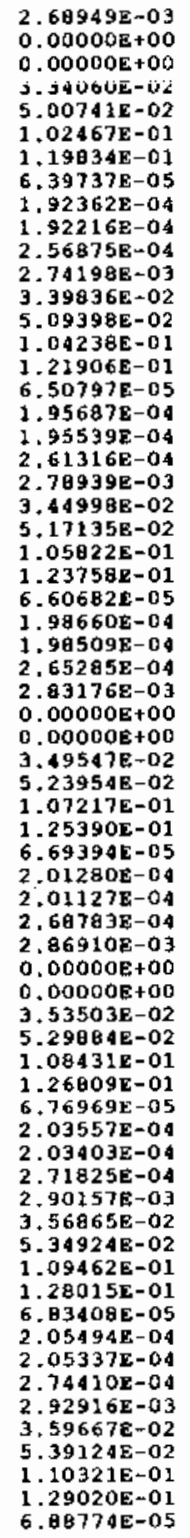 & 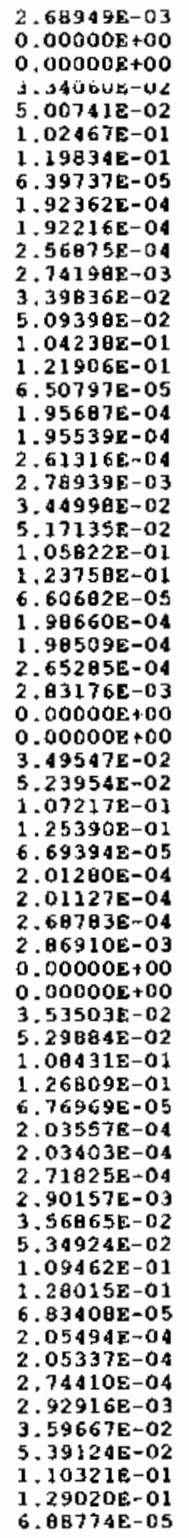 & 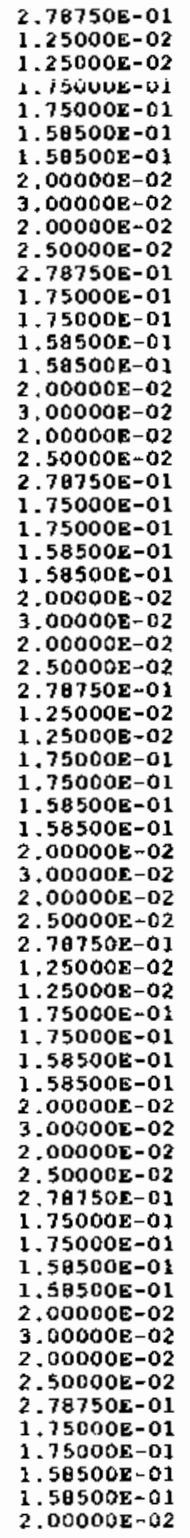 & 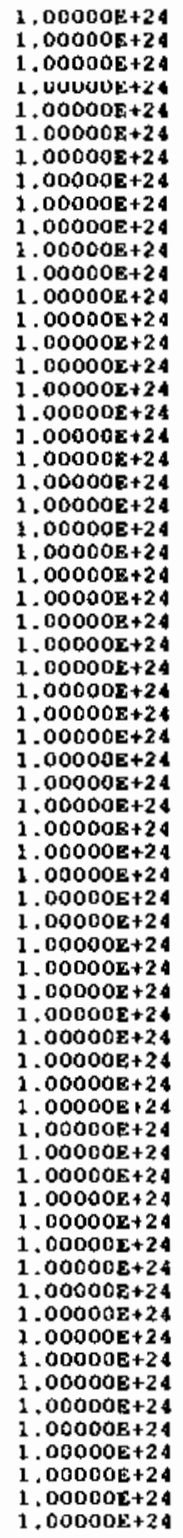 & 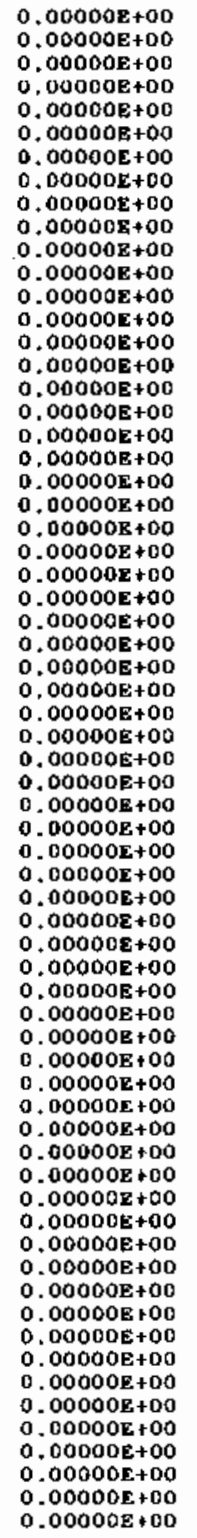 & 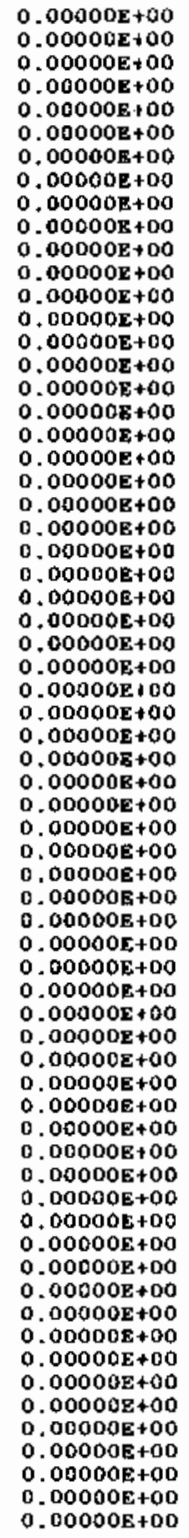 \\
\hline
\end{tabular}




\begin{tabular}{|c|c|c|}
\hline & $0.00000 E+00$ & $2.071078-0 \mathrm{~A}$ \\
\hline & $0,00000 \mathrm{E}+00$ & $2.06950 \mathrm{E}-04$ \\
\hline 30 & $0.00000 \mathrm{E}+00$ & $2,76565 \mathrm{E}-04$ \\
\hline 530 & $0.00000 \mathrm{E}+00$ & $2.95216 \mathrm{E}-03$ \\
\hline 512 & $0.00000 \mathrm{E}+00$ & $0.00000 \mathrm{E}+00$ \\
\hline 15$] 2$ & $0.00000 \mathrm{E}+00$ & $0.00000 \Sigma+00$ \\
\hline $\begin{array}{l}56001 \\
0602\end{array}$ & $0.00000 \mathrm{E}+00$ & $3,61909 \mathrm{E}-02$ \\
\hline $\begin{array}{l}36002 \\
36003\end{array}$ & $0.00000 E+00$ & $5.42484 E-02$ \\
\hline $\begin{array}{l}36003 \\
36004\end{array}$ & $0.00000 \mathrm{E}+00$ & $1.11009 \mathrm{E}-01$ \\
\hline $\begin{array}{l}36004 \\
36301\end{array}$ & $0.00000 \mathrm{E}+00$ & $1.29124 \mathrm{E}-01$ \\
\hline $\begin{array}{l}\begin{array}{l}36301 \\
36302\end{array} \\
3630\end{array}$ & $\begin{array}{l}0.00000 E+00 \\
0.00000 E+00\end{array}$ & $\begin{array}{c}\mathrm{C} .930678-05 \\
2\end{array}$ \\
\hline 36303 & $\begin{array}{l}0.00000 E+00 \\
0.00000 E+00\end{array}$ & $\begin{array}{l}2.0839 \mathrm{BE}-04 \\
2.00239 \mathrm{E}-04\end{array}$ \\
\hline 304 & $0.00000 \mathrm{E}+00$ & $2.782295-04$ \\
\hline 36127 & $0.00000 \varepsilon+00$ & $2.97056 \mathrm{E}-03$ \\
\hline $\begin{array}{l}36127 \\
3612 \theta\end{array}$ & $0.00000 E+00$ & $0.00000 E+00$ \\
\hline $\begin{array}{l}3612 \theta \\
37001\end{array}$ & 0.00000 E +00 & $0,00000 \mathrm{E}+00$ \\
\hline 37002 & $\begin{array}{l}0.00000 \mathrm{E}+00 \\
0.00000 \mathrm{0}+00\end{array}$ & $3.62600 \mathrm{E}-02$ \\
\hline 37003 & $\begin{array}{l}0.00000 \text { r } 00 \\
0.00000 \text { r.00 }\end{array}$ & $\begin{array}{l}5.43531 \mathrm{E}-02 \\
1.1223 \mathrm{E}-01\end{array}$ \\
\hline 37004 & $\begin{array}{l}0.000000+00 \\
0.00000 E+00\end{array}$ & $\begin{array}{l}1.12223 \mathrm{E}-01 \\
1.30075 \mathrm{E}-01\end{array}$ \\
\hline 37301 & $0.00000 \mathrm{E}+00$ & $6.944058-05$ \\
\hline 37302 & $0.00000 \mathrm{E}+00$ & $2.088000-04$ \\
\hline 37303 & $0.00000 \mathrm{E}+00$ & $2.08642 \mathrm{E}-04$ \\
\hline 37304 & $0.00000 \mathrm{E}+00$ & $2.78926 \mathrm{E}-04$ \\
\hline 37306 & $0.00000 \mathrm{E}+00$ & $2.97630 \mathrm{E}-03$ \\
\hline 38001 & $0.000008+00$ & $3.61764 \mathrm{E}-02$ \\
\hline 38002 & $0.00000 \mathrm{E}+00$ & $5.422668-02$ \\
\hline 38003 & $0.00000 E+00$ & 1. $10964 \mathrm{E}=01$ \\
\hline 38004 & $0.00000 E+00$ & $1.29772 \mathrm{E}-01$ \\
\hline 38301 & $0.00000 E+00$ & $6.92789 \mathrm{E}-05$ \\
\hline 38302 & $0.00000 z+00$ & $2.0831 \mathrm{dE}-04$ \\
\hline 38303 & $0.00000 E+00$ & $2.00156 \mathrm{E}-04$ \\
\hline 36304 & $0.00000 \mathrm{E}+00$ & $2.78177 \mathrm{E}-04$ \\
\hline 38306 & $0.00000 \mathrm{E}+00$ & $2.96937 \mathrm{E}-03$ \\
\hline 39001 & $0.00000 \mathrm{E}+00$ & $3.61049 \mathrm{E}-02$ \\
\hline 39002 & $0.00000 \mathrm{E}+00$ & $5.42395 E-02$ \\
\hline 39003 & $0.00000 E+00$ & $1.10991 \mathrm{E}-01$ \\
\hline 39004 & $0.00000 E+00$ & $1.29803 \mathrm{E}-01$ \\
\hline 39301 & $0.00000 E+100$ & $6.92953 \mathrm{E}-05$ \\
\hline 39302 & $0.00000 E+00$ & $2.08364 \mathrm{E}-04$ \\
\hline 39303 & $0.00000 E+00$ & $2.09205 E-04$ \\
\hline $\begin{array}{l}39304 \\
39306\end{array}$ & $\begin{array}{l}0.00000 \mathrm{E}+00 \\
0.00000 \mathrm{E}+00\end{array}$ & $\begin{array}{l}2.70243 \mathrm{E}-04 \\
9000 \mathrm{E}-0 \mathrm{~J}\end{array}$ \\
\hline $\begin{array}{l}39306 \\
39127\end{array}$ & $\begin{array}{l}0.00000 E+00 \\
0.00000 E+00\end{array}$ & $\begin{array}{l}2.97000 \mathrm{E}-0 \mathrm{~J} \\
0.00000 \mathrm{E}+00\end{array}$ \\
\hline 39128 & $0.00000 \mathrm{E}+00$ & $0,00000 \mathrm{E}+00$ \\
\hline 40001 & $0.00000 \mathrm{E}+00$ & $3.62065 \mathrm{E}-02$ \\
\hline 40002 & $0.00000 \mathrm{E}+00$ & $5.43911 \mathrm{E}-02$ \\
\hline & $0.00000 \mathrm{E}+00$ & $1.11302 \mathrm{E}-01$ \\
\hline & $0.00000 E+00$ & $1.30167 \mathrm{E}-01$ \\
\hline 40301 & $0.00000 E+00$ & $6.94498 \mathrm{E}-05$ \\
\hline 40302 & $0.00000 \mathrm{E}+00$ & $2.00948 \mathrm{E}-04$ \\
\hline 10303 & $0.00000 E+00$ & $2.08789 \mathrm{E}-04$ \\
\hline 10304 & $0.00000 E+00$ & $2.79024 E-04$ \\
\hline 40306 & $0.00000 \varepsilon+00$ & $2,97841 E-03$ \\
\hline & $0.00000 E+00$ & $0.00000 \mathrm{E}+00$ \\
\hline 10128 & $0.00000 \mathrm{E}+00$ & $0.00000 \mathrm{E}+00$ \\
\hline 1001 & $0.00000 \mathrm{t}+00$ & $3.63748 \mathrm{E}-02$ \\
\hline 1002 & $0.00000 \mathrm{E}+00$ & $5.45241 \mathrm{E}-02$ \\
\hline 41003 & $0.00000 \mathrm{E}+00$ & $1.115338-01$ \\
\hline 41004 & $0.00000 \mathrm{k}+00$ & $1.30464 \mathrm{E}-01$ \\
\hline 41301 & $0.00000 \mathrm{E}+00$ & $6.96589 \mathrm{E}-05$ \\
\hline 41302 & $0,00000 \mathrm{E} * 00$ & $2.09457 \mathrm{E}-04$ \\
\hline 41303 & $0.00000 E+00$ & $2.09298 \mathrm{E}-04$ \\
\hline 43304 & $0.00000 \mathrm{~b}+00$ & $2.79703 \mathrm{E}-04$ \\
\hline 41306 & $0.00000 E+00$ & $2.985668-03$ \\
\hline
\end{tabular}

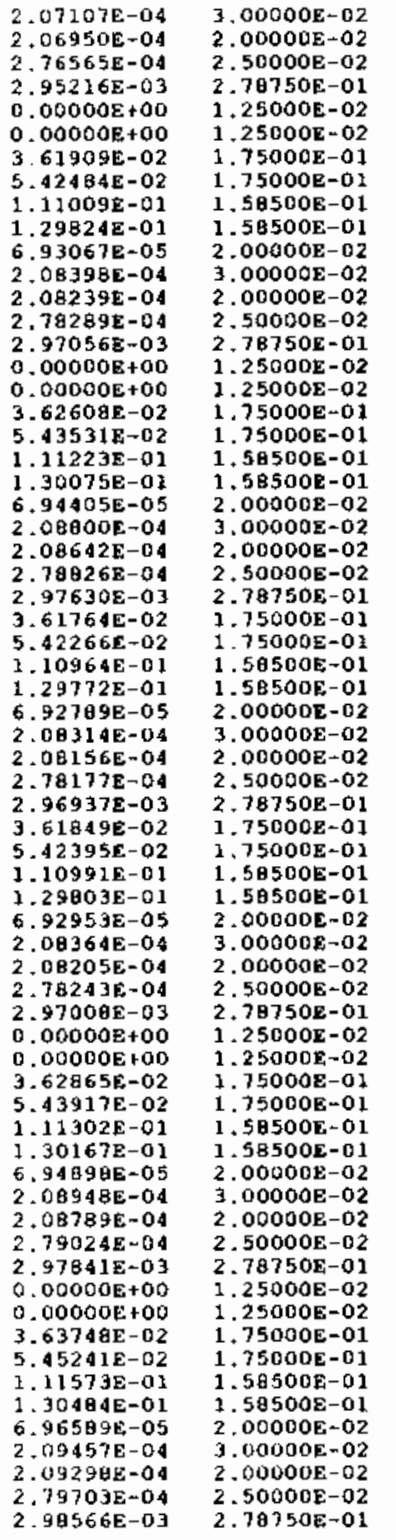

$1.00000 E+24$
$1.00000 E+24$
$1.00000 E+24$
$1.00000 E+24$
$1.00000 E+24$
$1.00000 E+24$
$1.00000 E+24$
$1.00000 E+24$
$1.00000 E+24$
$1.00000 E+24$
$1.00000 E+24$
$1.00000 E+24$
$1.00000 E+24$
$1.00000 E+24$
$1.00000 E+24$
$1.00000 E+24$
$1.00000 E+24$
$1.00000+24$
$1.00000 E+24$
$1.00000 E+24$
$1.00000 E+24$
$1.00000 E+24$
$1.00000 E+24$
$1.00000 E+24$
$1.00000 E+24$
$1.00000 E+24$
$1.00000 E+24$
$1.00000 E+24$
$1.00000 E+24$
$1.00000 E+24$
$1.00000 E+24$
$1.00000 E+24$
$1.00000 E+24$
$1.00000 E+24$
$1.00000 E+24$
$1.00000 E+24$
$1.00000 E+24$
$1.00000 E+24$
$1.00000 E+24$
$1.00000 E+24$
$1,00000 E+24$
$1.00000 E+24$
$1.00000 E+24$
$1.00000 E+24$
$1.00000 E+24$
$1.00000 E+24$
$1.00000 E+24$
$1.00000 E+24$
$1.00000 E+24$
$1.00000 E+24$
$1.00000 E+24$
$1.00000 E+24$
$1.00000 E+24$
$1.00000 E+24$
$1.00000 E+24$
$1.00000 E+24$
$1.00000 E+24$
$1.00000 E+24$
$1.00000 E+24$
$1.00000 E+24$
$1,00000 E+24$
$1.00000 E+24$
$1.00000 E+24$
$1.00000 E+24$
$1.00000 E+24$

$0.00000 E+00$ 0.0000E+00 $0.00000 \mathrm{E}+00$ $0.00000 \mathrm{E}+00$
$0.00000 \mathrm{E}+00$ $0.00000 E+00$ $0.00000 E+00$ $0.00000 \mathrm{E}+00$ $0.00000 \varepsilon+00$ $0.00000 \mathrm{E}+00$ $0.00000 E+00$ $0.00000 \mathrm{~K}+00$ $0.00000 \mathrm{E}+00$ $0.00000 \mathrm{E}+00$ $0.00000 \mathrm{E}+00$ $0.00000 \mathrm{E}+00$
$0.00000 \mathrm{E}+00$ $0.00000 \mathrm{E}+00$ $0.00000 \mathrm{E}+00$ $0.00000 \mathrm{E}+00$ $0.00000 \mathrm{E}+00$ $0.00000 \mathrm{E}+00$ $0.00000 \mathrm{~B}+00$ $0.00000 \mathrm{z}+00$ $0.00000 \mathrm{E}+00$ $0.00000 \mathrm{E}+00$ 0.0000 tod $0.00000 \mathrm{E}+0$ $0.00000 \mathrm{E}+00$ $0.00000 \mathrm{E}+00$ $0.0000 \mathrm{E}+00$ $0.00000 z+00$ $0.00000 \mathrm{E}+00$ $0.00000 \mathrm{E}+00$ $0.0000 \mathrm{E}+00$ $0.00000 \mathrm{E}+00$ 0.00000 t +00 $0.00000 \mathrm{r}+00$ $0.000008+00$ 0.000005100 $0.00000 \mathbf{x}+00$ $0,00000 \mathrm{E}+00$ $0.00000 E+00$ 0.00000 E t0O $0.0000 \mathrm{x}$ $0.00000 \mathrm{E}+00$ 0.00000 e +00 $0.00000 \mathrm{E}+00$ 0.00000 EOo $0.00000 \mathrm{E}+00$ $0.00000 \mathrm{E}+\mathrm{C}$

$0.00000 \mathrm{E}+00$ $0.00000 E+00$

$0.00000 \mathrm{E}+00$ . $0.00000 \mathrm{E}+00$ $0.00000 \mathrm{E}+00$ $0.00000 \mathrm{E}+00$
$0.00000 \mathrm{E}+00$ $0.00000 \mathrm{E}+00$ $0.00000 E+00$ $0.00000 \varepsilon+100$
$0.00000 z+00$ $0.00000 \mathrm{E}+00$ $0.00000 \mathrm{E}+00$ $0.0000 \mathrm{D}$ $0.000008+00$ $0.00000 \mathrm{E}+00$ $0.00000 \mathrm{E}+00$ $0.0000 \mathrm{E}+00$ $0.00000 \mathrm{E}+00$ $0.00000 \mathrm{E}+00$ $0.00000 \mathrm{E}+00$ $0.00000 \mathrm{E}+00$ $0.00000 \mathrm{t}+00$ D. $00000 \mathrm{E}+00$ 0.000002100 $0.00000 \mathrm{E}+00$ $0.00000 \mathrm{E}+00$ $0.00000 \varepsilon+00$ $0.000008+00$ $0.00000 \mathrm{E}+00$ $0.0000 \mathrm{E}+00$ $0.00000 \mathrm{E}+00$ $0.00000 \mathrm{E}+00$ $0.00000 \mathrm{E}+00$ $0.00000 \mathrm{x}+00$ $0.00000 \mathrm{t}+00$ $0.00000 \mathrm{E}+00$ $0.00000 \mathrm{E}+00$ $0.000008+00$ $0.00000 \mathrm{E}+00$ $0.00000 E+00$
$0.00000 E+00$ $0.00000 E+00$ $0.00000 \mathrm{E}+00$ $0.00000 \mathrm{E}+00$ $0.00000 \mathrm{E}+00$ $0.00000 \mathrm{t}+00$ $0.00000 \mathrm{E}+00$ $0.00000 E+00$ $0.00000 E+00$ $0.00000 \mathrm{E}+00$ $0.00000 \mathrm{E}+00$ $0.000008+00$ $0.00000 \mathrm{E}+00$ $.00000 \mathrm{E}+0$ 


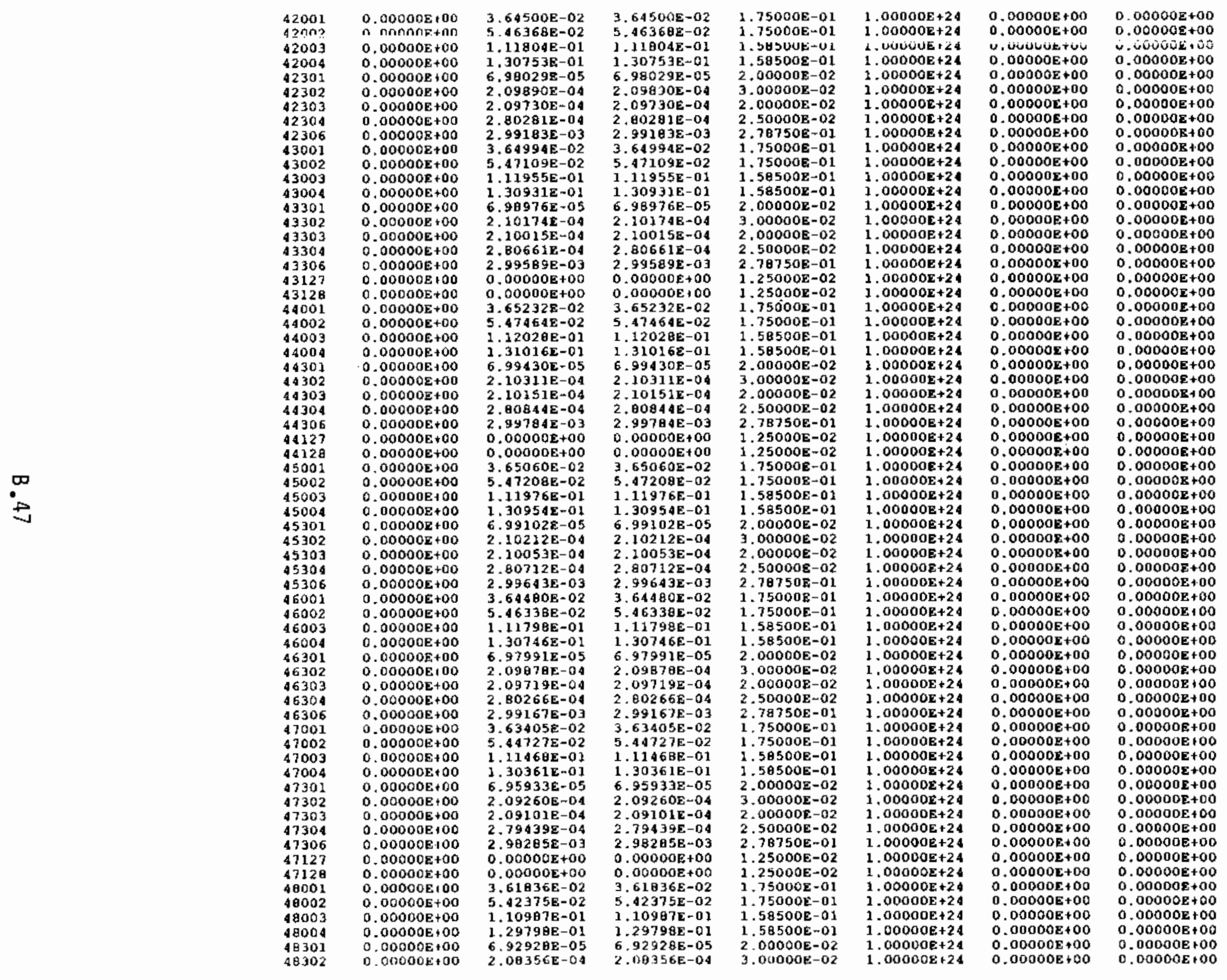




\begin{tabular}{|c|c|c|c|c|c|c|c|}
\hline 18303 & $0.00000 E+00$ & $2.0819 \mathrm{aE}-04$ & $2.0819 \mathrm{dE}-04$ & $2.00000 \mathrm{E}-02$ & $1.00000 E+24$ & $0.00000 E+00$ & $0.00000 E+00$ \\
\hline 18304 & $0.00000 E+00$ & $2.78233 E-04$ & $2.78233 \mathrm{E}-04$ & $2.50000 \mathrm{E} \cdot 02$ & $1.00000 \mathrm{E}+24$ & $0.00000 \mathrm{E} * 00$ & $100 E+00$ \\
\hline 10306 & $0.00000 \mathrm{E}+00$ & $2.96997 \mathrm{E}-03$ & $2.96997 \mathrm{E}-03$ & $2.78750 \mathrm{E}-01$ & $1+24$ & 0.00 & $O E+00$ \\
\hline 40127 & $0.00000 \mathrm{E}+00$ & $0.00000 E+00$ & $0.00000 E+00$ & 1.25 & 1.00 & $+\infty 0$ & $\bar{E}+00$ \\
\hline $6012 \theta$ & $0.00000 E+00$ & $0.00000 E+00$ & $0.000008+00$ & $1.25000 \mathrm{E}-02$ & +24 & +00 & $0 \mathrm{E}+\infty 0$ \\
\hline 49001 & $0.00000 E+00$ & $3.59726 \mathrm{E}-02$ & 3. $59726 \mathrm{E}-02$ & $1.75000 \bar{E}-01$ & $00 \mathrm{z}+2 \mathrm{i}$ & $000 \mathrm{z}+00$ & $0 E+00$ \\
\hline 49002 & $0.00000 \mathrm{E}+00$ & 5. $39213 \mathrm{E}-02$ & $5.39213 \mathrm{E}-02$ & $1.75000 \bar{E}-01$ & $1.00000 E+24$ & $200 \bar{E}+00$ & $000 \mathrm{E}+00$ \\
\hline 49003 & $0.00000 E+00$ & $1.10340 E-01$ & $1.10340 \mathrm{E}-01$ & $1.58500 \mathrm{E}-01$ & $1.00000 \varepsilon+24$ & $0.00000 \mathrm{E}+00$ & $00000 \varepsilon+00$ \\
\hline 49004 & $0.00000 E+00$ & $1.29041 \mathrm{E}-01$ & $1.29041 \mathrm{E}-01$ & 1. $58500 \mathrm{E}-01$ & $1.00000 E+24$ & $0.00000 E+00$ & $00000 \mathrm{E}+00$ \\
\hline 49301 & $0.00000 E+00$ & $6.08089 \mathrm{E}-05$ & $6.080885-05$ & $2.00000 \mathrm{E}-02$ & $1.00000 \mathrm{E}+24$ & $0.00000 \mathrm{E}+00$ & $0000 E+00$ \\
\hline 49302 & $0.00000 E+00$ & $2.07141 \mathrm{E}-04$ & $2.071418-04$ & $3.00000 \mathrm{E}-02$ & 1. $00000 \mathrm{E}+24$ & $0.00000 \mathrm{E}+00$ & $000 \mathrm{E}+00$ \\
\hline 49303 & $0.00000 E+00$ & $2,06984 \mathrm{E}-04$ & $2.06984 \mathrm{E}-04$ & $2.00000 \mathrm{E}-02$ & $00000 E+24$ & $0.000002+00$ & $00 \mathrm{E}+00$ \\
\hline 49304 & $0.00000 \mathrm{E}+00$ & $2.76610 \mathrm{E}-04$ & $2.76610 \mathrm{E}-04$ & $2.50000 \mathrm{E}-02$ & $1.00000 \mathrm{E}+24$ & $0.00000 E+00$ & $00 \mathrm{E}+00$ \\
\hline 49306 & $0.00000 E+00$ & $2.95265 E-03$ & $2.952658-03$ & $2.78750 \mathrm{E}-01$ & $1.00000 \mathrm{E}+2 \mathrm{~d}$ & $0.00000 \mathrm{E}+00$ & $000+00$ \\
\hline 50001 & $0.00000 \mathrm{E}+00$ & $3.57076 \mathrm{E}-02$ & $3.57076 \mathrm{E}-02$ & $1.75000 \mathrm{E}-01$ & $1.00000 E+24$ & $0.00000 \mathrm{E}+00$ & $00000 \mathrm{E}+00$ \\
\hline 6002 & $0.00000 E+00$ & $5.35240 \mathrm{E}-02$ & $5.35240 \mathrm{E}-02$ & $1.75000 \mathrm{E}-01$ & $1.00000 E+24$ & $0.00000 \mathrm{E}+00$ & $.00000 E+00$ \\
\hline 50003 & $0.00000 E+00$ & $1.09527 \mathrm{E}-01$ & $1.09527 E-01$ & $1.58500 \mathrm{E}-01$ & $1.000008+24$ & $0.00000 \mathrm{E}+00$ & $00000 \bar{z}+00$ \\
\hline 50004 & $0.00000 E+00$ & 1. $28090 \mathrm{E}-01$ & $1.20090 \mathrm{E}-01$ & 1. $58500 \mathrm{E}-0 \mathrm{l}$ & $3.00000 E+24$ & $0.00000 \mathrm{E}+00$ & $00000 E+00$ \\
\hline 50301 & $0.00000 E+00$ & $6.83812 \mathrm{E}-05$ & 6. $63812 \mathrm{E}-05$ & $2.00000 E-02$ & 1. $00000 \mathrm{E}+24$ & $0.00000 \mathrm{E}+00$ & $00000 E+00$ \\
\hline 50302 & $0.00000 E+00$ & $2.05615 \mathrm{E}-04$ & $2.05615 \mathrm{E}-04$ & $3.00000 \mathrm{E}-02$ & $1.00000 \mathrm{~B}+2 \mathrm{~A}$ & $0.00000 E+00$ & $0.00000 E+00$ \\
\hline 50303 & $0.00000 E+00$ & $2.05459 E-04$ & $2.05459 \mathrm{E}-04$ & $000 \mathrm{E}-02$ & $1.00000 \mathrm{E}+24$ & $0.00000 \mathrm{E}+00$ & $0.00000 E+00$ \\
\hline 50304 & $0.00000 E+00$ & $2.74573 E-04$ & $2.74573 \mathrm{E}-04$ & $2.50000 \mathrm{E}-02$ & $1.00000 \mathrm{E}+24$ & $0.00000 \mathrm{E}+00$ & $0000 E+00$ \\
\hline & $0.00000 E+00$ & $2.930908-03$ & $2,93090 \mathrm{E}-03$ & $2.78750 \mathrm{E}-01$ & $1.00000 E+24$ & $0.00000 \mathrm{E}+00$ & $00000 \times 00$ \\
\hline 51001 & $0.00000 \varepsilon+00$ & $3.53806 \mathrm{E}-02$ & $3.53806 \mathrm{E}-02$ & $1.75000 \mathrm{E}-01$ & 1. $60000 E+24$ & $0.00000 E+00$ & $0000 \Sigma+00$ \\
\hline 51002 & $0.00000 \varepsilon+00$ & $5.30330 \mathrm{E}-02$ & $5,3033 \mathrm{BE}-02$ & $1.75000 \mathrm{E}-01$ & $1.00000 E+24$ & $0.00000 \mathrm{E}+00$ & $00 \mathrm{E}+00$ \\
\hline 51003 & $0.00000 E+00$ & $1.08524 \mathrm{E}-0 \mathrm{~J}$ & $1.00524 \mathrm{E}-01$ & & $1.00000 E+24$ & $000 \mathrm{E}+00$ & $00 \mathrm{E}+00$ \\
\hline 51004 & $0.00000 \mathrm{E}+100$ & $1.26917 \mathrm{E}-01$ & $1.26917 \mathrm{E}-01$ & & & $100 E+00$ & $10 \mathrm{E}+00$ \\
\hline 51301 & $0.00000 E+00$ & $6.77550 \mathrm{E}-05$ & $6.77550 \mathrm{E}-05$ & 32 & & & $0 \mathrm{E}+00$ \\
\hline 51302 & $0.00000 E+00$ & $2.03732 \mathrm{E}-04$ & $2.03732 \mathrm{E}-04$ & & & & $E+00$ \\
\hline & $0.00000 \mathrm{E}+00$ & $2.03577 \mathrm{E}-04$ & & & & & \\
\hline 51304 & $0.00000 \mathrm{E}+00$ & 2.72058 & & & & & \\
\hline 51306 & $000 \mathrm{E}+00$ & 2.96 & & & & & \\
\hline $5 \div 127$ & $0 \varepsilon+00$ & 0.00 & & & & & \\
\hline 51128 & $0 \Sigma+00$ & $0.00000 \mathrm{E} t$ & & & & & \\
\hline & 0.00 & & & & & & \\
\hline 520 & 0,00 & 5.26 & & & & & \\
\hline 520 & 0.00 & 1,07 & & & & & \\
\hline & 0.00 & & & & & & \\
\hline 52301 & 0.0 & 6.70101 & 6.7010 & & & & \\
\hline & & 2.01492 & & & & & \\
\hline 523 & 0.00 & & & & 1.0 & & \\
\hline 52304 & $0.000008+00$ & $2.69067 \varepsilon-04$ & & & & & \\
\hline & 0.00000 E 100 & $2.87213 E-03$ & 2.87213 & & & & \\
\hline & $.00000 \mathrm{E}+00$ & $0.00000 \mathrm{E}+$ & 0.00000 & & & & \\
\hline 521 & & & & & & & \\
\hline & & & & & & & \\
\hline & & & 2 & & & & $\mathrm{E}+00$ \\
\hline & & 1 & 3.05 & $1.5 \mathrm{E}$ & 1.000 & 0.00 & $\mathrm{OE}+00$ \\
\hline & & & & & & & $0 E+00$ \\
\hline 533 & 0.00 & 6.61 & 6.6104 & & & & $+\infty$ \\
\hline 5330 & 0.00 & 1.98 & 1.98770 & 3.0 & & & \\
\hline 5330 & 0.00 & 1.98 & 1.90619 & & & & $0 z+00$ \\
\hline 533 & 0.00 & & 2,65432 & & & & \\
\hline 5330 & 0.00 & 2.833 & 2.033 & & 1.00 & & $000 \mathrm{E}+00$ \\
\hline 5400 & 0.00 & $3,39625 \mathrm{E}$ & 3.396 & 1.750000 & $1,00000 \mathrm{E}$ & & 0.00 \\
\hline 5400 & 0.000 & 5.090 & 5.09 & 1.750 & 1.000 & & 0.0 \\
\hline & 0.0000 & 1.0427 & 3.0417 & ]. $58500 \mathrm{E}$ & & & 0.00 \\
\hline 54004 & $0.00000 E+c$ & $1.21830 \mathrm{E}$ & 1.21030 & $1.58500 \mathrm{E}$ & & 0 & $100 \varepsilon+00$ \\
\hline 5430 & 0.00 & 6.503931 & $6,50393 E$ & 2.00 & 1.00 & 0.0 & 0.0000 \\
\hline 54302 & 0.000 & $1.95566 \mathrm{E}$ & $1.95566 \mathrm{E}$ & & 1.00 & 0.0 & 0.00 \\
\hline 54303 & 0.00 & 1.95 & $1.95417 \mathrm{E}$ & & 1.0 & 0 & $00 E+00$ \\
\hline & 0.00 & $2.61153 \mathrm{E}$ & $2.61153 \mathrm{E}$ & 2.5 & 1.0 & $00 \mathrm{E}$ & $100 E+00$ \\
\hline 5430 & 0.0000 & $2.78766 \mathrm{E}$ & $2.78766 \mathrm{E}-$ & 2.7 & 1.0 & 0.0 & $100 E+00$ \\
\hline 5500 & $0.000008+00$ & $3.32465 \mathrm{E}-02$ & $3.32465 \mathrm{E}-$ & $1.75000 E-$ & 1.0 & 00 & $1008+00$ \\
\hline 5500 & $0.00000 \mathrm{E}+00$ & 4. $98349 \mathrm{E}-02$ & $4.98349 \mathrm{E}-$ & $1.75000 \mathrm{E}-01$ & $1.00000 \mathrm{z}+24$ & $000 \mathrm{E}+00$ & $00 E+00$ \\
\hline 55003 & $0,00000 E+100$ & $1.01970 \mathrm{E}-01$ & $1.01978 E-01$ & $1.58500 \mathrm{E}-01$ & $1.00000 E+24$ & $0.00000 \mathrm{e}+00$ & $0.00000 E+00$ \\
\hline
\end{tabular}




\begin{tabular}{|c|c|c|c|c|c|c|c|c|c|c|}
\hline 55004 & $0.00000 \mathrm{E}+00$ & & $1.19262 E-01$ & \multicolumn{2}{|c|}{$1,19262 \mathrm{E}-01$} & & & 0 \\
\hline 55301 & $0.00000 \mathrm{E}+00$ & \multicolumn{2}{|c|}{$6.36681 \mathrm{E}-05$} & \multirow{2}{*}{\multicolumn{2}{|c|}{$6.36681 \mathrm{E}-05$}} & \multirow{2}{*}{\multicolumn{2}{|c|}{$\begin{array}{l}2.00000 \mathrm{E}-02 \\
3.00000 \mathrm{E}-02\end{array}$}} & \multirow{2}{*}{\multicolumn{2}{|c|}{$\begin{array}{l}1.00000 \mathrm{E}+24 \\
1.00000 \mathrm{E}+24 \\
1.00000 \mathrm{2}+24\end{array}$}} & 0 \\
\hline 55302 & $0.00000 \mathrm{E}+00$ & \multirow{2}{*}{\multicolumn{2}{|c|}{$\begin{array}{l}1.91443 E-04 \\
1.91298 E-04\end{array}$}} & \multirow{2}{*}{\multicolumn{2}{|c|}{$\begin{array}{l}1.91443 \mathrm{E}-04 \\
1.9129 \mathrm{BE}-04\end{array}$}} & & & & & \\
\hline 35094 & $0.00000 \mathrm{E}+00$ & & & & & & $\begin{array}{l}3.00000 \mathrm{E}-02 \\
2.00000 \mathrm{E}-02\end{array}$ & \multicolumn{2}{|c|}{$\begin{array}{l}1.00000 E+24 \\
1.00000 E+24\end{array}$} & $.00000 \mathrm{E}$ \\
\hline 55304 & $0.00000 \mathrm{E}+00$ & \multirow{2}{*}{\multicolumn{2}{|c|}{$\begin{array}{l}2.55648 \mathrm{E}-04 \\
2.72689 \mathrm{E}-03\end{array}$}} & 2.5 & $6488-04$ & 2.5 & $000 \mathrm{E}-02$ & $1.00000 \mathrm{E}$ & & 0 \\
\hline 55306 & $0.000008+00$ & & & 2.7 & $809 E-03$ & 2.7 & $750 \mathrm{E}-01$ & 1.000008 & & 0 \\
\hline$\$ 5127$ & $0.00000 E+00$ & & $10000 E+00$ & 0.0 & $000 E+00$ & 1.2 & $200 \mathrm{E}-02$ & 1.00000 & & .000001 \\
\hline 55128 & 0.000008100 & & $10000 E+00$ & 0.0 & $000 \mathrm{E}+00$ & 1.2 & $00 \mathrm{E}-02$ & 1.00000 & & $.00000 \mathrm{E}$ \\
\hline 560 & $0.00000 \mathrm{E}+00$ & & $37108-02$ & 3.2 & $710 \mathrm{E}-02$ & 1.7 & $00 E-01$ & 1.00000 & & $\begin{array}{l}0.00000 E \\
0.000008\end{array}$ \\
\hline 56002 & $0.00000 \mathrm{E}+00$ & & $15225 \mathrm{E}-02$ & 4,8 & $225 E-02$ & $1+7$ & $00 E-01$ & 1.00000 & & $\begin{array}{l}0.00000 \mathrm{E} \\
0.00000 \mathrm{E}\end{array}$ \\
\hline 56003 & $0.00000 \varepsilon+00$ & & $2920 \mathrm{E}-02$ & 9.9 & $920 \varepsilon-02$ & 1.5 & $500 \mathrm{E}-01$ & 1.000001 & & $\begin{array}{l}0.00000 \mathrm{E} \\
0.00000 \mathrm{E}\end{array}$ \\
\hline 56004 & $0.00000 z+00$ & & $6121 \mathrm{E}-01$ & $\begin{array}{l}1.1 \\
6.1\end{array}$ & $\begin{array}{l}121 E-01 \\
915 \mathrm{E}-05\end{array}$ & 1.5 & $\begin{array}{l}008-01 \\
000 \mathrm{0}-02\end{array}$ & $\begin{array}{l}1.00000 \mathrm{E} \\
1.00000 \mathrm{E}\end{array}$ & & $\begin{array}{l}0.00000 \mathrm{E}+1 \\
0.00000 \mathrm{E}+\end{array}$ \\
\hline $\begin{array}{l}56301 \\
56302\end{array}$ & $0.00000 \mathrm{E}+00$ & & $6402 E-04$ & $\begin{array}{l}0.1 \\
1.0\end{array}$ & $\begin{array}{l}913 E-05 \\
402 E-04\end{array}$ & 3.0 & DOE-02 & $1.00000 \mathrm{E}$ & & $\begin{array}{l}0.00000 \mathrm{E}+0 \\
0.00000 \mathrm{E}+0\end{array}$ \\
\hline 56303 & $0,00000 E+00$ & & $62608-04$ & 1.8 & 260 -04 & 2.0 & $00 \bar{E}-02$ & 1.00000 & & $0.00000 \mathrm{E}$ \\
\hline 56304 & $0.00000 \mathrm{E}+00$ & & $19915 \mathrm{E}-04$ & 2.4 & $915 E-04$ & 2.5 & $000 \mathrm{E}-02$ & 1.000001 & & $0.00000 \mathrm{E}$ \\
\hline 56306 & $.00000 \mathrm{E}+00$ & & $5702 \mathrm{E}-03$ & 2.6 & $702 \mathrm{E}-03$ & 2.7 & $750 \mathrm{E}-01$ & $1.00000 \mathrm{E}$ & & $0.00000 \mathrm{E}$ \\
\hline & 00 & & $20000 \mathrm{E}+00$ & 0.0 & $000 E+00$ & 3.2 & $000 E-02$ & $1.00000 \mathrm{E}$ & & $\begin{array}{l}0.00000 \mathrm{E} \\
0.00000 \mathrm{E}\end{array}$ \\
\hline & .00 & & $10000 E+00$ & 0.0 & $000 E+00$ & 1.2 & $000 \mathrm{E}-02$ & 1.000000 & & $0.00000 E$ \\
\hline 57001 & .0 & & $9075 E-02$ & 3.1 & $075 E-02$ & 1.7 & $0008-01$ & $1.00000 \mathrm{~B}$ & & $\begin{array}{l}0.00000 \mathrm{E} \\
0.00000 \mathrm{E}\end{array}$ \\
\hline $\begin{array}{l}57002 \\
57003\end{array}$ & $\begin{array}{l}0.00000 E+00 \\
0.00000 E+00\end{array}$ & & $\begin{array}{l}8270 E-02 \\
187048-02\end{array}$ & $\begin{array}{l}4.7 \\
9.7\end{array}$ & $\begin{array}{l}278 E-02 \\
704 \mathrm{E}-02\end{array}$ & 1.7 & $\begin{array}{l}500 E-01 \\
500 E-01\end{array}$ & $\begin{array}{l}1.00000 \mathrm{E} \\
1.00000 \mathrm{E}\end{array}$ & & $\begin{array}{l}0.00000 E+0 \\
0.00000 E+0\end{array}$ \\
\hline 57004 & $0.00000 \mathrm{E}+00$ & & $4459 \mathrm{E}-01$ & 1.1 & $459 \mathrm{E}-01$ & 1.5 & $500 \mathrm{E}-01$ & $1.00000 \mathrm{E}$ & & $0.00000 \mathrm{E}+$ \\
\hline 57301 & $0.00000 \mathrm{E}+00$ & & $10395-05$ & 6.1 & $039 \mathrm{E}-05$ & 2.0 & $000 \mathrm{E}-02$ & $1.00000 \mathrm{E}$ & & $0.00000 \mathrm{E}$ \\
\hline 57302 & $0.00000 E+00$ & & $3733 \mathrm{E}-04$ & 1.8 & $7335-04$ & 3.0 & DOOE-02 & 1. $00000 \mathrm{z}$ & & $0.00000 \mathrm{E}$ \\
\hline 57303 & $0.00000 \mathrm{E}+00$ & & $3593 \mathrm{E}-04$ & 1.0 & $593 E-04$ & 2.0 & $000 \mathrm{E}-02$ & 1.000008 & & $00000=$ \\
\hline 57304 & $0.00000 \mathrm{E}+00$ & & $5352 \mathrm{E}-04$ & 2.4 & $352 \mathrm{E}-04$ & & $000 E-02$ & $1.00000 \mathrm{E}$ & & $0.00000 \mathrm{E}$ \\
\hline 5) 306 & $0.00000 E+00$ & & $18980-03$ & 2.6 & $898 E-03$ & 2.7 & $750 \mathrm{E}-01$ & $3.00000 \mathrm{E}$ & & $0.00000 \mathrm{E}+$ \\
\hline 1 evel & total growr & $(\mathrm{kw})$ & q'fromzr & $(\mathrm{kw})$ & $\mathrm{qf}_{\text {f готиu }}$ & $(\mathrm{kw})$ & ave $z x$ & Wik (in) & & uthik (in) \\
\hline & $0.00000 \mathrm{E}+00$ & & $0.00000 \mathrm{E}$ & & 0.00000 & $E+\infty$ & 2.7875 & $E-01$ & & $0000 E+00$ \\
\hline 2 & & & 0.000 & & 0.00000 & & 2.7875 & & & \\
\hline 3 & $0.00000 \mathrm{E} t$ & & $0.00000 \mathrm{E}$ & & 0.000 & +00 & 2.787 & & & \\
\hline 4 & $0.00000 E+$ & & $0.00000 \mathrm{E}$ & 100 & 0.000 & & & & & \\
\hline 5 & $0.00000 \mathrm{E}$ & & 0.000 & +100 & 0.00 & & & & & \\
\hline 6 & $0.00000 E+$ & & 0.000 & & 0.00 & & & & & \\
\hline 7 & $0.00000 \mathrm{E}+$ & & 0.00 & & & & & & & \\
\hline a & $0.00000 \mathrm{E}$ & & 0.00 & & & & & & & \\
\hline 9 & $0.00000 \mathrm{E}$ & & 0.00 & & & & & & & \\
\hline 10 & 0.00 & & 0.0 & & & & 7.475 & & & \\
\hline 11 & 0.00 & & 0.0 & & & & & & & \\
\hline 12 & 0.000 & & & & & & & & & \\
\hline 13 & 0.000 & & 0.0 & & 0.0 & & & & & \\
\hline 14 & 0.00000 & & 0.0 & & & & & & & \\
\hline 15 & $0.00000 \mathrm{E}$ & & 0.00 & & & & & & & \\
\hline 16 & $0.00000 \mathrm{E}$ & & 0.00 & & 0,0 & & & & & \\
\hline 17 & $0.00000 E$ & & 0.00 & & 0.0 & & & 2 & & \\
\hline 18 & $0.00000 \mathrm{k}$ & & 0.00 & & 0.0 & & & & & \\
\hline $\begin{array}{l}19 \\
20\end{array}$ & $\begin{array}{l}0.000000 \mathrm{E}+00 \\
0.0000 \mathrm{E} 10\end{array}$ & & $\begin{array}{l}0.00 \\
0.00\end{array}$ & & $\begin{array}{l}0.0 \\
0.0\end{array}$ & $\begin{array}{l}E+00 \\
E+00\end{array}$ & $\begin{array}{l}5.69 \\
5.69\end{array}$ & $\begin{array}{l}E-02 \\
E-02\end{array}$ & & $6750 E-01$ \\
\hline 21 & $0.00000 \mathrm{E}+00$ & & $0.00000 \mathrm{E}$ & & 0.00000 & $E+00$ & 7.47 & $E-02$ & & $6750 E-01$ \\
\hline 22 & $0.00000 E+00$ & & $0.00000 \mathrm{E}$ & $+\infty$ & 0.00000 & $E+00$ & 7.47 & $E-02$ & & $6750 \mathrm{E}-01$ \\
\hline 23 & $0.00000 \bar{E}+00$ & & 0.000 & $+\infty 0$ & 0.00000 & $E+00$ & 5.69 & $E-02$ & & $6750 \varepsilon-01$ \\
\hline 24 & & & 0.00 & Do & & $E+00$ & 5.6964 & $E-02$ & & $6750 \mathrm{E}-01$ \\
\hline 25 & 0.00 & & & & 0.0 & E +00 & 7.47 & $E-02$ & & $6750 \mathrm{E}-01$ \\
\hline 26 & 0.00 & & 0.000 & $+\infty$ & 0.000 & $E+\infty O$ & 7.47 & $\varepsilon-02$ & & $6750 E-01$ \\
\hline 27 & $0,00000 \mathrm{E}+00$ & & 0.000 & +00 & 0.000 & $E+00$ & 5.69 & $2-02$ & & $6750 \mathrm{E}-01$ \\
\hline 28 & $0.00000 \varepsilon+00$ & & $0.00000 \mathrm{E}$ & +00 & 0.0 & $8+\infty$ & 5.69 & -02 & & $6750 \mathrm{E}-01$ \\
\hline 29 & $0.00000 \overline{0}+00$ & & $0.00000 \mathrm{E}$ & $+\infty$ & & $E+00$ & 7.47 & $8-02$ & & $6750 \mathrm{E}-01$ \\
\hline 30 & $0,00000 \varepsilon+00$ & & $0,00000 \mathrm{E}$ & $+\infty$ & 0.0 & $E+00$ & 2,4 & $5-02$ & & $6750 \mathrm{E}-01$ \\
\hline 31 & $0.00000 \mathrm{k}+00$ & & 0.000000 & +00 & 0.0 & Etoo & 5.6 & & & $6750 \mathrm{~g}-01$ \\
\hline 32 & $.00000 E+00$ & & 0.0 & 100 & & $E+00$ & 5.6 & & & $67506-01$ \\
\hline 33 & $.00000 \mathrm{E}+00$ & & $0.00000 \mathrm{E}$ & 100 & 0.0000 & $E+\infty 0$ & 7.475 & $8-02$ & & $6750 \mathrm{E}-01$ \\
\hline 34 & $0.00000 E+00$ & & $0.00000 \mathrm{E}$ & +00 & 0.00000 & $E+00$ & 7.4750 & $E-02$ & & $6750 E-01$ \\
\hline
\end{tabular}

$0.00000 \varepsilon+00$ 0. $00000 \mathrm{E}+00$ $0.000008+00$ $0.00000 \mathrm{E}+00$ $0.00000 \mathrm{E}+00$ $0.00000 \mathrm{E}+00$ $0.00000 \mathrm{E}+00$ $0.0000 \mathrm{E}+00$ $0.00000 \mathrm{E}+00$ $0.00000 \mathrm{E}+00$ $0.00000 \mathrm{E}+00$ $0.00000 \mathrm{E}+00$ $0.00000 \mathrm{E}+00$
$0.00000 \mathrm{z}+00$ $0.00000 E+00$
$0.00000 E+00$ $0.00000 \mathrm{E}+00$ 


$\begin{array}{ll}35 & 0.00000 E+00 \\ 36 & 0.00000 E+00 \\ 37 & 0.00000 E+00 \\ 38 & 0.00000 E+00 \\ 39 & 0.00000 E+00 \\ 40 & 0.00000 \mathrm{E}+00 \\ 41 & 0.00000 \mathrm{E}+00 \\ 42 & 0.00000 \mathrm{E}+00 \\ 43 & 0.00000 \mathrm{0}+00 \\ 44 & 0.00000 \mathrm{0}+00 \\ 45 & 0.00000 \mathrm{E}+00 \\ 46 & 0.00000 \mathrm{0}+00 \\ 47 & 0.00000 \mathrm{E}+00 \\ 48 & 0.00000 \mathrm{E}+00 \\ 49 & 0.00000 \mathrm{E}+00 \\ 50 & 0.00000 \mathrm{E}+00 \\ 51 & 0.00000 \mathrm{0}+00 \\ 52 & 0.00000 \mathrm{0}+00 \\ 53 & 0.000008+00 \\ 54 & 0.00000 \mathrm{E}+00 \\ 55 & 0.00000 \mathrm{E}+00 \\ 56 & 0.00000 \mathrm{0}+00 \\ 57 & 0.00000 \mathrm{E}+00\end{array}$

$0.00000 \mathrm{E}+00$
$0.00000 \mathrm{E}+00$
$0.00000 \mathrm{E}+00$
$0.00000 \mathrm{E}+00$
$0.00000 \mathrm{E}+00$
$0.00000 \mathrm{E}+00$
$0.00000 \mathrm{E}+00$
$0.00000 \mathrm{E}+00$
$0.00000 \mathrm{E}+00$
$0.00000 \mathrm{E}+00$
$0.00000 \mathrm{E}+00$
$0.00000 \mathrm{E}+00$
$0.00000 \mathrm{E}+00$
$0.00000 \mathrm{0}+00$
$0.00000 \mathrm{E}+00$
$0.00000 \mathrm{0}+00$
$0.00000 \mathrm{E}+00$
$0.00000 \mathrm{E}+00$
$0.00000 \mathrm{0}+00$
$0.00000 \mathrm{E}+00$
$0.00000 \mathrm{E}+00$
$0.00000 \mathrm{E}+00$
$0.00000 \mathrm{E}+00$
$0.00000 \mathrm{E}+00$ $0.00000 \mathrm{E}+000$ $0.00000 \mathrm{E}+00$ $0.00000 \mathrm{E}+00$ $0.00000 \mathrm{E}+00$ $0.00000 \varepsilon+00$ $0.000000+00$ $0.00000 \mathrm{E}+00$ . $0.00000 \mathrm{E}+00$ 0.00000 E t00 .00000Et00 0.00000E+00 $000000+00$ D.00000e+00 $.000008+00$ $0.00000 \mathrm{E}+00$ a hydrogen roleage rate of $0.00000 \mathrm{E}+00 \mathrm{~kg} / \mathrm{sec}$ occured in this timestep
a total of $0.00000 \mathrm{E}+00 \mathrm{~kg}$ of hydrogen have been relsased over the transiant

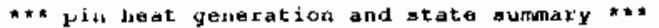

$\begin{array}{ll}\text { pin no. } & \text { powex }(\mathrm{kW}) \\ 1 & 3.90576 \mathrm{E} 100 \\ 2 & 1.04007 \mathrm{E}+01\end{array}$

the total power genurated by the metal-water reaction during this timestep is $0.00000 \mathrm{E}+00$ the tohal power generated by nucluar hoating during this timestep is $1.49696 \mathrm{E}+01 \mathrm{~kW}$ the tolal power genisated by nucluar hodting during this timestep

$x$ x. variable internal thextnal connection ard convection summary *e.

corivective $10580 \mathrm{~s}$ - chantel $401=1.70771 \mathrm{E}+00 \mathrm{~km}$ convective losses - chansel $402=8.52678 \mathrm{E}+00 \mathrm{~km}$ convective losses - channel $403=7.16484 \mathrm{E} 100 \mathrm{kw}$ convective logses - cliannel $404=0.000008100 \mathrm{k}$

\begin{tabular}{|c|c|c|c|c|c|c|c|c|}
\hline modl & nod2 & hint & nodl & $\operatorname{nod} 2$ & hint & nodl & nod 2 & hint \\
\hline 6308 & 6401 & $5.03000 z-0]$ & 8308 & 8401 & $5,03000 \mathrm{E}-01$ & 10308 & 10401 & 5. $83000 \mathrm{E}-01$ \\
\hline $\begin{array}{l}12308 \\
18308\end{array}$ & 32401 & $\begin{array}{l}5.83000 \mathrm{E}-01 \\
5.83000 \mathrm{E}-01\end{array}$ & $\begin{array}{r}14308 \\
6309\end{array}$ & $\begin{array}{r}14401 \\
6402\end{array}$ & $\begin{array}{l}+83000 \mathrm{E}-01 \\
4.97000 \mathrm{E}-01\end{array}$ & $\begin{array}{r}16308 \\
8309\end{array}$ & $\begin{array}{r}10400 \\
8902\end{array}$ & $\begin{array}{l}5.83000 \mathrm{E}-01 \\
4.970000 \mathrm{C}-01\end{array}$ \\
\hline $\begin{array}{l}18308 \\
10309\end{array}$ & $\begin{array}{l}18401 \\
10402\end{array}$ & $4.97000 \mathrm{E}-01$ & 12309 & 12402 & 4. $970000-01$ & 14309 & 14402 & $4.97000 \mathrm{e}-01$ \\
\hline 16309 & 16402 & 4.97000E-01 & 18309 & 28402 & $4.97000 \mathrm{E}-01$ & 6310 & 6402 & $4.97000 \mathrm{E}-01$ \\
\hline 8310 & 8402 & 4.97000E-01 & 10310 & 10402 & $9.97000 \mathrm{E}-01$ & 12310 & 12402 & $4.97000 \mathrm{E}-01$ \\
\hline 14310 & 14402 & $4.97000 \mathrm{E}-01$ & 16310 & 16402 & $4.97000 \mathrm{E}-01$ & 18310 & 18402 & $4.97000 \mathrm{E}-01$ \\
\hline 6311 & 6403 & $4.08000 E-01$ & 8313 & 8403 & $4.080008-01$ & 80311 & 10403 & 4. $00000 \mathrm{E}-01$ \\
\hline 12311 & 12403 & 4.08000E-01 & 14311 & 14403 & $4.08000 \mathrm{E}-01$ & 16311 & 16403 & 4.08000E-01 \\
\hline 18311 & 18403 & $4.08000 \mathrm{E}-01$ & 6305 & 6403 & $4.0 B 000 E-01$ & घ305 & 8403 & $4.08000 \mathrm{E}-01$ \\
\hline
\end{tabular}




\begin{tabular}{|c|c|c|c|c|c|}
\hline & & 4. OBO000E-OD & 12305 & 12403 & $4.08000 \mathrm{E}=0$ \\
\hline $\begin{array}{r}16305 \\
\text { ควก7 }\end{array}$ & $\begin{array}{r}16403 \\
\text { B1nn }\end{array}$ & $\begin{array}{l}4.06000 \mathrm{C}-01 \\
2.4 \text { ARGAR-01 }\end{array}$ & $\begin{array}{l}18305 \\
10707\end{array}$ & $\begin{array}{l}16403 \\
10100\end{array}$ & $\begin{array}{r}400000 E-01 \\
? \quad 5496 \mathrm{AE}-01\end{array}$ \\
\hline 14307 & 14100 & $2.63243 \mathrm{E}-01$ & 16307 & 16100 & $2.67101 \mathrm{E}-01$ \\
\hline 7308 & 7401 & $5.83000 \mathrm{E}-01$ & 9300 & 9401 & $5.83000 \mathrm{E}-01$ \\
\hline 13300 & 13401 & $5.83000 \mathrm{E}-01$ & 15300 & 15401 & $5.83000 \mathrm{~B}-0$ \\
\hline 7309 & 7402 & $4.97000 \mathrm{-}-01$ & $\$ 309$ & 9402 & $4,97000 \mathrm{E}-0$ \\
\hline 13309 & 13402 & $4.97000 \mathrm{E}-01$ & 15309 & 15402 & $4.97000 \mathrm{E}-01$ \\
\hline 7310 & 7402 & $4.97000 \mathrm{E}-01$ & 9310 & 9402 & 4.97000 E-01 \\
\hline 13310 & 13402 & 4.97000E-01 & 15310 & 15402 & $4.97000 \mathrm{E}-01$ \\
\hline 7311 & 7403 & 4.06000E-01 & 9311 & 9403 & 4.00000E-C \\
\hline 13311 & 13403 & $4.08000 \mathrm{E}-01$ & 15311 & 15403 & 4.00000E-C \\
\hline 7305 & 7403 & $4.08000 \mathrm{E}-01$ & 9305 & 9403 & $4.08000 E^{-01}$ \\
\hline 13305 & 13403 & $4.00000 \mathrm{E}-01$ & 15305 & 15403 & $4.00000 \mathrm{E}-01$ \\
\hline 7307 & 7100 & $2.4561 \mathrm{gz}-01$ & 9307 & 9100 & $2.52908 \mathrm{E}-01$ \\
\hline 13307 & 13100 & $2.616008-01$ & 15307 & 15100 & $2.65572 \mathrm{E}-01$ \\
\hline 22308 & 22401 & $5.830008-01$ & 26308 & 26401 & $5.830000-01$ \\
\hline 34308 & 34401 & $5.030008-01$ & 38308 & 39401 & 5. $83000 \mathrm{E}-\mathrm{C}$ \\
\hline 46308 & 46401 & $5.03000 \mathrm{E}-01$ & 50308 & 50401 & 5. $03000 \mathrm{E}-\mathrm{C}$ \\
\hline 22309 & 22402 & $4.97000 \mathrm{E}-01$ & 26309 & 26402 & 4.97000E-0 \\
\hline 34309 & 34402 & $4.97000 \mathrm{E}-01$ & 30309 & 38402 & $4.97000 E-0$ \\
\hline 46309 & 46402 & $4.97000 \mathrm{E}-01$ & 50309 & 50402 & 4.97000E- \\
\hline 22310 & 22402 & $4.97000 \mathrm{E}-01$ & 26310 & 26402 & 4. $97000 \mathrm{E}-$ \\
\hline 34310 & 34402 & $4.97000 E-01$ & $\exists 8310$ & 39402 & 4. $97000 \mathrm{E}$ \\
\hline 46310 & 46402 & $4.97000 \mathrm{E}-01$ & 50310 & 50402 & 4. $97000 \mathrm{E}-$ \\
\hline 22311 & 22403 & $4.08000 \mathrm{E}-01$ & 26311 & 26403 & 4. OBOOOE- \\
\hline 34311 & 34403 & 4.08000E-01 & 38311 & 38403 & $4.08000 \mathrm{E}-$ \\
\hline 46311 & 46403 & 4.00000E-01 & 50311 & 50403 & $4.08000 \mathrm{E}-$ \\
\hline 22305 & 22403 & $4.00000 \mathrm{E}-01$ & 26305 & 26403 & $4.08000 \mathrm{E}-$ \\
\hline 34305 & 34403 & $4.00000 \mathrm{E}-01$ & 38305 & 38403 & $4.08000 \mathrm{E}$ \\
\hline 46305 & 46403 & $4.08000 \mathrm{E}-01$ & 50305 & 50403 & $4.08000=-$ \\
\hline 22307 & 22100 & $2.76262 \mathrm{E}-01$ & 26307 & 26100 & $2.04273 \mathrm{E}-01$ \\
\hline 34307 & 34100 & $2.94962 \mathrm{E}-01$ & 38307 & 38100 & $2.98306 \mathrm{E}-\mathrm{C}$ \\
\hline 46307 & 46100 & $3.04442 E-01$ & 50307 & 50100 & $3.22001 \mathrm{E}-01$ \\
\hline 21708 & 21401 & $5,83000 \mathrm{E}-01$ & 25308 & 25401 & $5.83000 \mathrm{E}-$ \\
\hline 33308 & 33401 & $5.83000 \mathrm{E}-01$ & 37308 & 37401 & 5.8300 \\
\hline 45308 & 45401 & $5,83000 E-01$ & 49300 & 49401 & 5.8 \\
\hline 57308 & 57401 & $5,83000 E-01$ & 21309 & 21402 & 4.9 \\
\hline 29309 & 29402 & $4.97000 \mathrm{E}-01$ & 33309 & 33402 & 4.97 \\
\hline 41309 & 41402 & $4.97000 \mathrm{E}-01$ & 45309 & 45402 & $E-01$ \\
\hline 53309 & 53402 & $4.97000 \mathrm{E}-0.1$ & 57309 & 57402 & 4.9 \\
\hline 25310 & 25402 & $4.97000 E-01$ & 29310 & 29402 & -01 \\
\hline 37310 & 37402 & 4.97000 & 41310 & 41402 & $2-01$ \\
\hline 49310 & 49402 & 4.97000 & 53310 & 5340 & $=01$ \\
\hline 21311 & 21403 & $4,00000 \mathrm{E}-01$ & 25311 & 25403 & $8-01$ \\
\hline 33311 & 33403 & $4.08000 \mathrm{E}-01$ & 37311 & 37403 & OE-O1 \\
\hline 45311 & 45403 & $4.00000 E-01$ & 49311 & 49403 & 81 \\
\hline 57311 & 57403 & $4.00000 E-01$ & 21305 & 21403 & $8-01$ \\
\hline 29305 & 29403 & $4.08000 E-01$ & 33305 & 33403 & -01 \\
\hline 41305 & 41403 & $4,00000 \mathrm{~B}-01$ & 45305 & 15403 & $00000 \mathrm{E}-01$ \\
\hline 53305 & 53403 & 4.00000E-01 & 57305 & 57403 & $08000 E-01$ \\
\hline 25307 & 25100 & $2.825775-01$ & $2930 \%$ & 29100 & $90793 \mathrm{E}-01$ \\
\hline $\begin{array}{l}37307 \\
49307\end{array}$ & $\begin{array}{l}37100 \\
49100\end{array}$ & $\begin{array}{l}3.03879 \mathrm{E}-01 \\
3.20899 \mathrm{E}-01\end{array}$ & $\begin{array}{l}41307 \\
53307\end{array}$ & $\begin{array}{l}41100 \\
53100\end{array}$ & 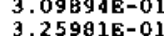 \\
\hline 19308 & 19401 & $5.83000 \mathrm{E}-01$ & 23308 & 23401 & $5.83000 \mathrm{E}-01$ \\
\hline 31308 & 31401 & $5.83000 E-01$ & 35308 & 35401 & $5.83000 E-1$ \\
\hline 43308 & 43401 & $5.83000 \mathrm{E}-01$ & 47308 & 47401 & $5.83000 \mathrm{E}-\mathrm{c}$ \\
\hline 55308 & 55401 & $5.83000 \mathrm{E}-01$ & 19309 & 19402 & $4.93000 \mathrm{E}-\mathrm{C}$ \\
\hline 27309 & 27402 & $4.97000 E-01$ & 31309 & 3) 402 & $4.97000 \mathrm{E}-\mathrm{C}$ \\
\hline 39309 & 39402 & $4.97000 \mathrm{E}-01$ & 43309 & 43402 & $4.970000-1$ \\
\hline 51309 & 51402 & $4.97000 \mathrm{E}-01$ & 55309 & 55402 & $4.97000 \mathrm{E}-\mathrm{C}$ \\
\hline 23310 & 23402 & $4.97000 \mathrm{E}-01$ & 27310 & 27402 & $4.97000 \mathrm{E}-0$ \\
\hline 35310 & 35402 & $4.97000 \mathrm{E}-01$ & 39310 & 39402 & $4.97000 \mathrm{E}-\mathrm{C}$ \\
\hline 47310 & 47402 & $4.97000 \mathrm{E}-01$ & 51310 & 51402 & $4.97000 \mathrm{E}-\mathrm{c}$ \\
\hline 19311 & 19403 & $4.08000 \mathrm{E}-01$ & 23311 & 23403 & .00000 \\
\hline & & & & & \\
\hline
\end{tabular}

\begin{tabular}{|c|c|c|}
\hline $\begin{array}{r}r 4305 \\
6307\end{array}$ & $\begin{array}{r}14403 \\
6100\end{array}$ & $\begin{array}{l}4.08000 \mathrm{E}-01 \\
2.37671 \mathrm{E}-01\end{array}$ \\
\hline $\begin{array}{l}19303 \\
18307\end{array}$ & $\begin{array}{l}1,1 \mathrm{nn} \\
18100\end{array}$ & $\begin{array}{l}29777 \mathrm{~F}-01 \\
2.69836 \mathrm{E}-01\end{array}$ \\
\hline 11308 & $\begin{array}{l}11401 \\
11400\end{array}$ & $\begin{array}{l}2.69836 \mathrm{E}-01 \\
5.83000 \mathrm{E}-01\end{array}$ \\
\hline 17300 & 17401 & $5.830000-01$ \\
\hline 11309 & 11402 & $4.970000-01$ \\
\hline 17309 & 17402 & $.97000 \mathrm{E}-01$ \\
\hline 11310 & 11402 & $4.97000 \mathrm{E}-01$ \\
\hline 17310 & 17402 & $.97000 \mathrm{E}-01$ \\
\hline 11311 & 11403 & $00000 \mathrm{E}-01$ \\
\hline 17311 & 17403 & $09000 \mathrm{E}-01$ \\
\hline 11305 & 11403 & 4.00000E-01 \\
\hline i7 305 & 17403 & $4.08000 \mathrm{E}-01$ \\
\hline 11307 & 11100 & $2.57622 \mathrm{E}-01$ \\
\hline 17307 & 17100 & $2,69740 \mathrm{E}-01$ \\
\hline 30308 & 30401 & $5.83000 \mathrm{E}-01$ \\
\hline 42308 & 42401 & $5.830000-01$ \\
\hline 54308 & 54401 & $5.830000-01$ \\
\hline 30309 & 30402 & $4.97000 \mathrm{E}-01$ \\
\hline 42309 & 42402 & 4.97000E-01 \\
\hline 54309 & 54002 & $0.97000 \mathrm{E}-01$ \\
\hline 30310 & 30402 & $\uparrow .97000 \mathrm{E}-01$ \\
\hline 42310 & & $1.97000 \mathrm{E}-01$ \\
\hline 54310 & 54402 & $4.93000 \mathrm{E}-01$ \\
\hline 30311 & 30403 & $4.000000 \mathrm{E}-01$ \\
\hline 42311 & & \\
\hline 54311 & 54403 & \\
\hline & & \\
\hline 223 & & \\
\hline & & \\
\hline & & $2.91449 \mathrm{E}-01$ \\
\hline & & $\begin{array}{l}3.01458 \mathrm{~B}-01 \\
3.26976 \mathrm{E}-01\end{array}$ \\
\hline & & \\
\hline $\begin{array}{l}\begin{array}{l}29300 \\
41308\end{array} \\
4130\end{array}$ & $\begin{array}{l}29401 \\
41401\end{array}$ & $\begin{array}{l}5.83000 \mathrm{E}-01 \\
5.83000 \mathrm{E}-01\end{array}$ \\
\hline & 53401 & $5.83000 \mathrm{E}-01$ \\
\hline & 25402 & $.97000 \mathrm{E}-01$ \\
\hline & & \\
\hline $\begin{array}{l}99309 \\
21310\end{array}$ & $\begin{array}{l}49402 \\
21402\end{array}$ & $\begin{array}{l}4.97000 \mathrm{E}-01 \\
4.97000 \mathrm{E}-01\end{array}$ \\
\hline & 33002 & $\begin{array}{l}4.97000 E-01 \\
\end{array}$ \\
\hline & 4540 & $4.97000 \mathrm{E}-01$ \\
\hline & & $4.97000 \mathrm{E}$ \\
\hline & & \\
\hline & 4140 & 01 \\
\hline & 534 & 4. \\
\hline & 254 & 180 \\
\hline & 3740 & aoc \\
\hline & 4940 & 4,0 \\
\hline & 2110 & $2.74707 \mathrm{E}-01$ \\
\hline & 332 & $2.97482 \mathrm{E}-01$ \\
\hline $4530 ?$ & 4516 & $3.15600 \mathrm{E}-01$ \\
\hline 57307 & 571 & $3.29997 \mathrm{E}-01$ \\
\hline & & 5.8300 \\
\hline & & 5.8300 \\
\hline & & $5.83000 \mathrm{E}-01$ \\
\hline & & $4.97000 E-01$ \\
\hline & 354 & $4.97000 \mathrm{E}-01$ \\
\hline & 474 & 4.970 \\
\hline & 194 & 4.970 \\
\hline 313 & 31402 & $4.97000 \mathrm{E}-01$ \\
\hline 4337 & 43402 & $4.97000 \mathrm{E}-01$ \\
\hline 553 & 55402 & $4.97000 \mathrm{E}-01$ \\
\hline & & 4.00000E-01 \\
\hline & & \\
\hline
\end{tabular}




\begin{tabular}{|c|c|c|c|c|c|c|c|c|}
\hline 43311 & 43403 & 4.090000 -01 & 47311 & 47403 & $4.08000 E-01$ & 51311 & 51403 & 4.08000E-01 \\
\hline 55311 & 55403 & $4.08000 \mathrm{E}-01$ & 19305 & 19403 & $4,08000 E-01$ & 23305 & 23403 & 4.08000E-01 \\
\hline 27305 & 27403 & $4.08000 E-01$ & 31305 & 31403 & $4.08000 E-01$ & 35305 & 35403 & 4.00000E-01 \\
\hline 39305 & 39403 & $4.080008-01$ & 43305 & 43403 & $4.000008-01$ & 47305 & 17403 & $4,080008-01$ \\
\hline 51305 & 51403 & $4.08000 \mathrm{E}-01$ & 55305 & 55403 & $4.00000 \mathrm{E}-01$ & 19307 & 19100 & $2.70972 \mathrm{E}-01$ \\
\hline 23307 & 23100 & $2.79256 \mathrm{E}-01$ & 27307 & 27100 & $2.86390 \mathrm{E}-01$ & 31307 & 31100 & $2,93931 \mathrm{E}-01$ \\
\hline 35307 & 35100 & $3.00497 \mathrm{E}-01$ & 99307 & 39100 & $3.06696 \mathrm{E}-01$ & 43307 & 43100 & $3.12560 \mathrm{E}-01$ \\
\hline 47307 & 47100 & 3.180868-01 & 51307 & 51100 & $3.23264 \mathrm{E}-01$ & 55307 & 55100 & $3.279098-01$ \\
\hline 19125 & 19126 & $9.01747 \mathrm{E}-0.2$ & 23125 & 23126 & $9.12761 E-01$ & 23125 & 27126 & $9.21157 \mathrm{E}-01$ \\
\hline 31125 & 31126 & $9.29367 \mathrm{E}-01$ & 35125 & 35126 & $9.37109 \mathrm{E}-01$ & 39125 & 39126 & $9.4437 a E-01$ \\
\hline 43125 & 43326 & $9.51163 \mathrm{E}-01$ & 47125 & 47126 & $9-76025 \mathrm{E}-01$ & 51125 & 51126 & $1.012468+00$ \\
\hline 55125 & 55126 & $1.0217 \theta E+00$ & 20308 & 20401 & $5.83000 \mathrm{E}-01$ & 24308 & 24401 & $5.03000 \mathrm{E}-01$ \\
\hline 28308 & 28401 & $5.830002-01$ & 32308 & 32401 & $5.93000 E-01$ & 36308 & 36401 & $5.83000 \mathrm{E}-01$ \\
\hline 40300 & 40401 & $5.83000 \mathrm{E}-01$ & 44300 & 44401 & $5,03000 \mathrm{E}-01$ & 40308 & 48401 & 5.830000E- 01 \\
\hline 52300 & 52401 & $5.83000 \mathrm{E}-01$ & 56308 & 56401 & $5.83000 E-01$ & 20309 & 20402 & 4. $970008-01$ \\
\hline 24309 & 24402 & $4,97000 E-01$ & 28309 & 28402 & $4.97000 \mathrm{E}-01$ & 32309 & 32402 & $4.97000 \mathrm{E}-01$ \\
\hline 36309 & 36402 & $4.97000 \varepsilon-01$ & 40309 & 40402 & $4.97000 E-01$ & 44309 & 44402 & $4.97000 \mathrm{E}-01$ \\
\hline 48309 & 40402 & $4.970008-01$ & 52309 & 52402 & $4.970008-01$ & 56309 & 56402 & $4.97000 \mathrm{E}-02$ \\
\hline 20310 & 20402 & $4.97000 E-01$ & 24310 & 24402 & A. $970008-01$ & 28310 & 28402 & 4.97000E-01 \\
\hline 32310 & 32402 & $4.97000 \mathrm{E}-01$ & 36310 & 36402 & $4.97000 \mathrm{E}-01$ & 40310 & 40402 & $4.97000 \mathrm{E}-01$ \\
\hline 44.310 & 44402 & $4.97000 \mathrm{E}-01$ & 48310 & 48402 & $4 \cdot 91000 E-0\}$ & 52310 & 52402 & $4.97000 \mathrm{E}-01$ \\
\hline 56310 & 56402 & $4.97000 \mathrm{E}-0]$ & 20311 & 20403 & $4.08000 \mathrm{E}-01$ & 24311 & 24403 & A.08000E-01 \\
\hline 20311 & 28403 & $4.08000 E-01$ & 32311 & 32403 & $4.08000 \mathrm{E}-01$ & 36311 & 36403 & 4.08000E-01 \\
\hline 40311 & 40403 & $4.08000 E-01$ & 44311 & 44403 & $4.080000-01$ & 46311 & 48403 & A. $08000 \mathrm{E}-01$ \\
\hline 52311 & 52403 & 4.08000E-01 & 56311 & 56403 & $4.08000 E-01$ & 20305 & 20403 & 4.00000E-01 \\
\hline 24305 & 24403 & $4,00000 \mathrm{E}-01$ & 28305 & 28403 & $4.08000 \varepsilon-01$ & 32305 & 32403 & $4.08000 E-01$ \\
\hline 36305 & 36403 & $4.00000 E-01$ & 40305 & 40403 & $4.00000 \mathrm{E}-01$ & 44305 & 44403 & $4.08000 E-01$ \\
\hline 48305 & 48403 & 4.080008-01 & 52305 & 52403 & $4,08000 E-01$ & 56305 & 56403 & $4.08000 \mathrm{E}-01$ \\
\hline 20307 & 20100 & $2.72323 \mathrm{E}-01$ & 24307 & 24100 & $2.798848-01$ & 20307 & 28100 & $2.80103 E-01$ \\
\hline 32307 & 32100 & $2.95307 \mathrm{E}-01$ & 36307 & 36100 & $3.018178-01$ & 40307 & 40100 & $3.079395-01$ \\
\hline 44307 & 44100 & $3.13749 \mathrm{E}-01$ & 48307 & 48100 & 3.19184E-01 & 52307 & 52100 & 3.24320E-01 \\
\hline 56307 & 56100 & $3.28837 \mathrm{E}-01$ & 20125 & 20126 & $9.02497 E-01$ & 24125 & 24126 & $9+13255 \mathrm{z}-01$ \\
\hline 28125 & 28126 & $9.21662 \mathrm{E}-01$ & 32125 & 32126 & $9.290738-01$ & 36225 & 36126 & 9. $37576 \mathrm{E}-01$ \\
\hline 40125 & 40126 & $9.447800-01$ & 44125 & 44126 & $9.51579 \mathrm{E}-01$ & 49125 & 48126 & $9,82562 E-01$ \\
\hline 52125 & 52126 & $1.01315 \mathrm{E}+00$ & 56125 & 56126 & $1.022268+00$ & 4307 & 4100 & $2+34537 \mathrm{E}-01$ \\
\hline 3307 & 3100 & $2.34543 E-01$ & $\begin{array}{l}2307 \\
5530\end{array}$ & 2100 & $1.47100 \mathrm{e}-02$ & 1307 & 1100 & $7.27020 \mathrm{E}-02$ \\
\hline 1102 & 3103 & $1.52832 \mathrm{E}-02$ & 5300 & 5401 & $5.83000 E-01$ & 5309 & 5402 & $4.97000 E-01$ \\
\hline 5310 & 5402 & $\begin{array}{l}4.97000 E-01 \\
2.33837 \varepsilon-01\end{array}$ & 5311 & 5403 & $4.08000 \mathrm{E}-01$ & 5305 & 5403 & $4.000000-01$ \\
\hline 5307 & 5100 & $2.33837 \varepsilon-41$ & & & & & & \\
\hline
\end{tabular}

*** axial and radial heat logs sumrnary ***

\begin{tabular}{|c|c|c|}
\hline & 年 & ל thes \\
\hline 5305 & 1000 & $0.00000 \mathrm{E}+00$ \\
\hline 5311 & 1000 & $0.00000 E+00$ \\
\hline 5310 & 1050 & $00000 E+00$ \\
\hline 5309 & 1000 & $0.000000+00$ \\
\hline 5308 & 1000 & $00000 \mathrm{E}+00$ \\
\hline 6305 & 1000 & $0.00000 \mathrm{x}+00$ \\
\hline 7305 & 1000 & $0.00000 \mathrm{E}+00$ \\
\hline $\begin{array}{l}8305 \\
9305\end{array}$ & 1000 & $0.000000+00$ \\
\hline $\begin{array}{r}9305 \\
10305\end{array}$ & 1000 & $0.00000 \mathbf{E}+00$ \\
\hline $\begin{array}{l}10305 \\
10305\end{array}$ & 1000 & $0.00000 E+00$ \\
\hline $\begin{array}{l}11305 \\
12305\end{array}$ & $\begin{array}{l}1000 \\
1000\end{array}$ & $\begin{array}{l}0.00000 E+00 \\
0,00000+00\end{array}$ \\
\hline $\begin{array}{l}13305 \\
13305\end{array}$ & 1000 & $0.00000 \mathrm{E}+00$ \\
\hline $\begin{array}{l}14305 \\
305\end{array}$ & 1000 & 0.00000 too \\
\hline $\begin{array}{l}15305 \\
15305\end{array}$ & 1000 & $0,00000 \mathrm{E}+00$ \\
\hline $\begin{array}{l}16305 \\
16305\end{array}$ & 1000 & $0.00000 \mathrm{E}+00$ \\
\hline $\begin{array}{l}17305 \\
17305\end{array}$ & 1000 & $0.00000 \mathbf{E}+\infty$ \\
\hline $\begin{array}{l}18305 \\
1805\end{array}$ & 1000 & $0.00000 E+00$ \\
\hline 19305 & 1000 & $0.000000+00$ \\
\hline 20305 & 1000 & $0.00000 \mathrm{E}+00$ \\
\hline 305 & 1000 & $0.00000 \varepsilon+00$ \\
\hline
\end{tabular}




\begin{tabular}{|c|c|c|}
\hline $\begin{array}{r}22305 \\
3 \geq 306\end{array}$ & 1000 & $0.00000 E+00$ \\
\hline 24305 & 1000 & $0.00000 E+00$ \\
\hline 25305 & 1000 & $0.00000 \varepsilon+00$ \\
\hline 26305 & 1000 & $0.00000 \mathrm{E}+00$ \\
\hline 27305 & 1000 & $0.00000 \mathrm{E}+00$ \\
\hline 28305 & 1000 & $0.00000 \mathrm{E}+00$ \\
\hline 29305 & $\$ 000$ & $0.00000 \mathrm{E}+00$ \\
\hline 30305 & 2000 & $0.00000 E+00$ \\
\hline 31305 & 1000 & $0.00000 \mathrm{E}+00$ \\
\hline 32305 & 1000 & $0.00000 \mathrm{E}+00$ \\
\hline 33305 & 1000 & $0.00000 \varepsilon+00$ \\
\hline 34305 & 1000 & $0.00000 \mathrm{E}+00$ \\
\hline 35305 & 1000 & 0.00000 E t00 \\
\hline 36305 & 2000 & $0.00000 E_{100}$ \\
\hline 37305 & 2000 & $0.00000 \mathrm{E}+00$ \\
\hline 30305 & 1000 & $0.00000 E+00$ \\
\hline 39305 & 1000 & $0,00000 \mathrm{E}+00$ \\
\hline 40305 & 1000 & $0.00000 \mathrm{E}+00$ \\
\hline 41305 & 1000 & $0.00000 E+00$ \\
\hline 42305 & 1000 & $0.00000 E+00$ \\
\hline 43305 & 1000 & $0.00000 E+00$ \\
\hline 44305 & 1000 & $0.00000 \mathrm{E}+00$ \\
\hline 45305 & 1000 & $0.00000 \mathrm{E}+00$ \\
\hline 46305 & 1000 & $a, 00000 E+00$ \\
\hline 47305 & 1000 & $0.00000 E+00$ \\
\hline 48305 & 1000 & $0.00000 E+00$ \\
\hline 49305 & 1000 & $0.00000 \mathrm{E}+00$ \\
\hline 50305 & 1000 & $0.000008+00$ \\
\hline 51305 & 1000 & $0.00000 \mathrm{E}+00$ \\
\hline 52305 & 1000 & $0.00000 \mathrm{E}+00$ \\
\hline 53305 & 1000 & \\
\hline 54305 & 1000 & $0,00000 E+00$ \\
\hline 55305 & 1000 & $0,00000 E+00$ \\
\hline 56305 & 1000 & $0.00000 E+00$ \\
\hline 57305 & 1000 & $0.00000 E+00$ \\
\hline 6311 & 1000 & $0.00000 E+00$ \\
\hline 7311 & 1000 & $0.00000 \mathrm{E}+00$ \\
\hline 8311 & 1000 & $0.00000 E+00$ \\
\hline 9311 & 1000 & $0.00000 \mathrm{E}+00$ \\
\hline 10311 & 1000 & $0.00000 E_{100}$ \\
\hline 11311 & 1000 & $0.00000 \mathrm{E}+00$ \\
\hline 12311 & 1000 & $0.00000 \mathrm{E}+00$ \\
\hline 13311 & 1000 & $0.00000 \mathrm{E}+00$ \\
\hline 14911 & 1000 & $0.00000 \mathrm{E}+00$ \\
\hline 15311 & 1000 & $0.00000 E+00$ \\
\hline 16311 & 1000 & $0.000008+00$ \\
\hline i) 311 & 2000 & $0.00000 \mathrm{e}+00$ \\
\hline 10311 & 1000 & $0.00000 \mathrm{E}+00$ \\
\hline 19311 & 1000 & $0.00000 \mathrm{E}+00$ \\
\hline 20311 & 1000 & $0.000000_{100}$ \\
\hline 21311 & 1000 & $0.00000 E+00$ \\
\hline 22311 & 1000 & $0.00000 E+00$ \\
\hline 23311 & 1000 & $0.00000 \mathrm{E}+00$ \\
\hline 24311 & 1000 & $0.000000+00$ \\
\hline 25311 & 1000 & $0.00000 E+00$ \\
\hline 26311 & 1000 & $0.00000 \varepsilon+00$ \\
\hline 27311 & 1000 & $0.00000 E+00$ \\
\hline 28311 & 1000 & $0.00000 E+00$ \\
\hline 29311 & 1000 & $0,00000 E+00$ \\
\hline 30311 & 1000 & $0.00000 E+00$ \\
\hline 31311 & 1000 & $0.00000 E+00$ \\
\hline 32311 & 1000 & $0.00000 E+00$ \\
\hline 33311 & 1000 & $0.00000 E+00$ \\
\hline 34311 & 1000 & $0,00000 E+00$ \\
\hline 35111 & 1000 & $0.00000 \mathrm{E}+00$ \\
\hline
\end{tabular}




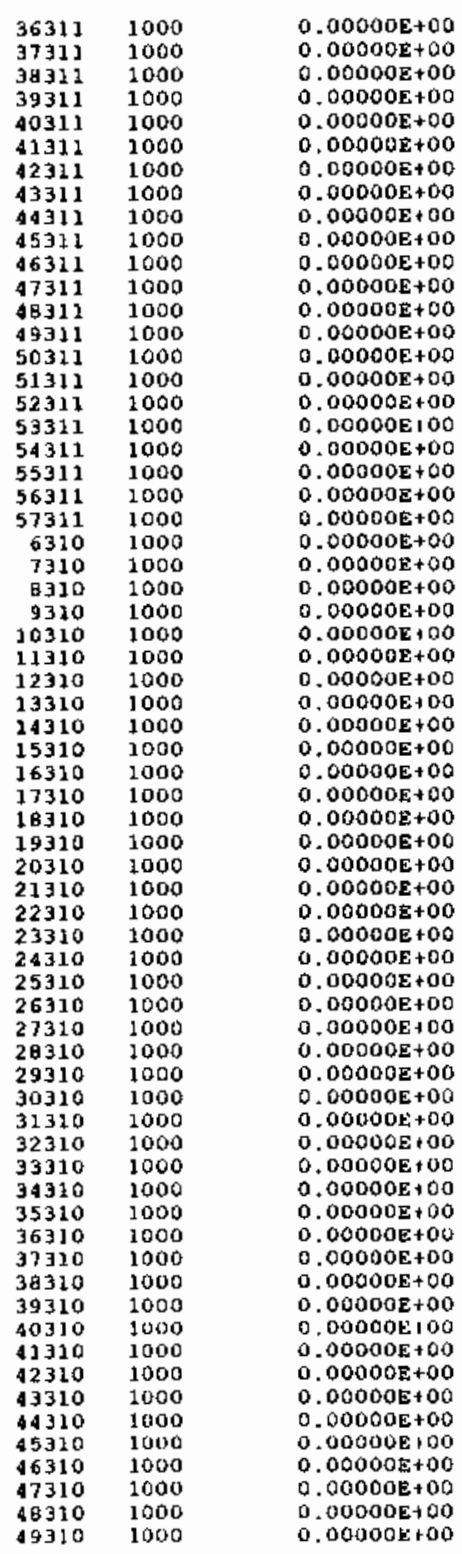




\begin{tabular}{|c|c|c|}
\hline & & \\
\hline & $\begin{array}{l}1000 \\
1000\end{array}$ & $\begin{array}{l}.000000 \mathrm{E}+00 \\
0.00000 \mathrm{E}+0\end{array}$ \\
\hline 310 & 1000 & 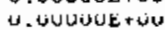 \\
\hline 33310 & 1000 & $0.000008+00$ \\
\hline 4310 & 1000 & $0.00000 E+00$ \\
\hline 310 & 1000 & $0.000000+00$ \\
\hline 6310 & 1000 & $0,00000 E+00$ \\
\hline 57310 & 1000 & $0.000000+00$ \\
\hline 6309 & 1000 & $0.00000 E+00$ \\
\hline 7309 & 1000 & $0.00000 E+00$ \\
\hline 8309 & 1000 & $0.00000 E+00$ \\
\hline 9309 & 1000 & $0.00000 E+00$ \\
\hline 10309 & 1000 & $0.00000 \mathrm{E}+00$ \\
\hline 11309 & 1000 & $0.00000 E+00$ \\
\hline 2309 & 1000 & $0.00000 E+00$ \\
\hline 13309 & 1000 & $0.00000 E+00$ \\
\hline 14309 & 1000 & $0.00000 E+00$ \\
\hline 15309 & 1000 & $0.00000 \mathrm{E}+00$ \\
\hline 16309 & 1000 & $0.000000+00$ \\
\hline 27309 & 1000 & $0.00000 \mathrm{E}+00$ \\
\hline 18309 & 1000 & $0.00000 \mathrm{E}+00$ \\
\hline 19309 & 1000 & $0,000000+00$ \\
\hline 20309 & 1000 & $0.00000 \mathrm{E}+00$ \\
\hline 21309 & 1000 & $0.00000 E+00$ \\
\hline 22309 & 1000 & $0.00000 E+00$ \\
\hline 23309 & 1000 & $0.00000 E+00$ \\
\hline 24309 & 1000 & $0.00000 \mathrm{E}+00$ \\
\hline 25309 & 1000 & $0.00000 \mathrm{E}+00$ \\
\hline 26309 & 1000 & $0.00000 \mathrm{E}+00$ \\
\hline 27309 & 1000 & $0.00000 E+00$ \\
\hline 28909 & 1000 & $0.00000 \mathrm{z}+00$ \\
\hline 29309 & 1000 & $0.00000 \mathrm{E}+00$ \\
\hline 30309 & 1000 & $0.00000 E+00$ \\
\hline 31309 & 1000 & $0.00000 E+00$ \\
\hline 32309 & 1000 & $0.00000 E+00$ \\
\hline 33309 & 1000 & $0.000008+00$ \\
\hline 34309 & 1000 & $0.00000 \mathrm{E}+00$ \\
\hline 35309 & 1000 & $0.00000 \mathrm{E}+00$ \\
\hline 36309 & 1000 & $0.00000 \mathrm{E}+00$ \\
\hline 37309 & 1000 & $0.000008+00$ \\
\hline 38309 & 1000 & $0.00000 E+00$ \\
\hline 39309 & 1000 & $0.00000 \mathrm{E}+00$ \\
\hline 40309 & 1000 & $0.00000 E+00$ \\
\hline 41309 & 1000 & $0.00000 \mathrm{E}+00$ \\
\hline 42309 & 1000 & $0.00000 \Sigma+00$ \\
\hline 43309 & 1000 & $0.00000 E+00$ \\
\hline 44309 & 1000 & 0,00000 E 1.00 \\
\hline $\begin{array}{l}45309 \\
46309\end{array}$ & 1000 & $0-60000 E+00$ \\
\hline $\begin{array}{l}46309 \\
47309 \\
473\end{array}$ & 1000 & $0.00000 E+00$ \\
\hline $\begin{array}{l}47309 \\
48309\end{array}$ & $\begin{array}{l}1000 \\
1000\end{array}$ & $\begin{array}{l}0.00000 E+00 \\
0.0000 E+100\end{array}$ \\
\hline 49309 & 1000 & $0,00000 E+00$ \\
\hline 50309 & 1000 & $0.00000 \bar{x}+00$ \\
\hline 51309 & 1000 & $0.00000 E+00$ \\
\hline 52309 & 1000 & $0.00000 \varepsilon+00$ \\
\hline 53309 & 1000 & $0.00000 \mathrm{E}+00$ \\
\hline 54309 & 1000 & $0.00000=100$ \\
\hline 55309 & 1000 & $0.00000 \mathrm{E}+00$ \\
\hline 56309 & 1000 & $0.000008+00$ \\
\hline 57309 & 1000 & $0.00000 \mathrm{E}+00$ \\
\hline 6308 & 1000 & 0.00000 E 100 \\
\hline 7308 & 1000 & $0.00000 \mathrm{E}+00$ \\
\hline 8300 & 1000 & $0.00000 \mathrm{E}+00$ \\
\hline 9308 & 1000 & $0.00000 \mathrm{E}+00$ \\
\hline 10308 & 1000 & $0.00000 E+00$ \\
\hline 11308 & 1000 & $0,00000 \mathrm{E}+00$ \\
\hline
\end{tabular}




\begin{tabular}{|c|c|c|}
\hline 12308 & 1000 & $0.00000 \mathrm{E}+00$ \\
\hline 13300 & 1000 & $0.00000 \varepsilon+00$ \\
\hline 14300 & 1000 & $0.00000 \mathrm{E}+00$ \\
\hline 15300 & 1000 & $0.00000 \mathrm{E}+00$ \\
\hline 16308 & 1000 & $0.00000 \mathrm{E}+00$ \\
\hline 17308 & 1000 & $0.00000 E+00$ \\
\hline 18308 & 1000 & $0.00000 \mathrm{E}+00$ \\
\hline 19300 & 3000 & $0,00000 \mathrm{E}+0$ \\
\hline 20308 & 1000 & $0.00000 \varepsilon+00$ \\
\hline 21300 & 1000 & $0.00000 E+0$ \\
\hline 22300 & 1000 & $0.00000 E+0$ \\
\hline $2330 B$ & 1000 & $0.00000 \mathrm{E}+00$ \\
\hline $2430 B$ & 1000 & $0.00000 \varepsilon+0$ \\
\hline 25308 & 1000 & $0.00000 \mathrm{E}+0$ \\
\hline 26300 & 1000 & $0.00000 E+0$ \\
\hline 27308 & 1000 & $0.00000 \mathrm{E}+0$ \\
\hline 28300 & 1000 & $0.00000 E+0$ \\
\hline 29300 & 1000 & $0.00000 \mathrm{E}+0$ \\
\hline 30308 & 1000 & $0.00000 E+0$ \\
\hline 31308 & 1000 & $0.000002+00$ \\
\hline 32308 & 1000 & $0,00000 \mathrm{E}+00$ \\
\hline 33308 & 1000 & $0.00000 \varepsilon+00$ \\
\hline 34308 & 1000 & $0.00000 \mathrm{E}+00$ \\
\hline 35300 & 1000 & $0.00000 \mathrm{E}+00$ \\
\hline 36308 & 1000 & $0.00000 \mathrm{E}+00$ \\
\hline 37308 & 1000 & $0.00000 \mathrm{E}+0$ \\
\hline 38308 & 1000 & $0.00000 \mathrm{E}+0$ \\
\hline 39308 & 1000 & $0.00000 E+0$ \\
\hline 40308 & 1000 & $0.00000 \mathrm{E}+0$ \\
\hline $4130 a$ & 1000 & $0.00000 \mathrm{E}+00$ \\
\hline 42300 & 1000 & $0.00000 E \div 00$ \\
\hline 43300 & 1000 & $0.00000 \mathrm{E}$ + 00 \\
\hline 44308 & 1000 & $0.00000 \mathrm{E}+0$ \\
\hline 45308 & 1000 & $0.00000 \mathrm{E}+00$ \\
\hline 46308 & 1000 & $0.00000 \mathrm{E}+00$ \\
\hline 47308 & 1000 & $0.00000 \mathrm{E}+0$ \\
\hline 48300 & 1000 & $0.00000 \mathrm{E}+00$ \\
\hline 49300 & 1000 & $0.00000 E+00$ \\
\hline 50308 & 1000 & $0.00000 E+00$ \\
\hline 51308 & 1000 & $0.00000 E+00$ \\
\hline 52308 & 1000 & $0.00000 E+00$ \\
\hline 53308 & 1000 & $0.00000 E+00$ \\
\hline 54308 & 1000 & $0,00000 \mathrm{E}+\mathrm{D} 0$ \\
\hline $\begin{array}{l}55300 \\
56309\end{array}$ & 1000 & $0.00000 \mathrm{E}+00$ \\
\hline 56300 & 1000 & $0.00000 \mathrm{E}+00$ \\
\hline 57308 & 1000 & $0.00000 \mathrm{E} P 0$ \\
\hline 401 & 3000 & -. 00000 e 100 \\
\hline 402 & 3000 & $0.00000 z+00$ \\
\hline & & \\
\hline
\end{tabular}

the total radial heat loss is $0.00000 \mathrm{e}+00 \mathrm{~km}$

the total axial heat loss is $0.00000 \mathrm{E}+00 \mathrm{~kW}$
the total migellaneous heat loss is $0.00000 \mathrm{k}+00 \mathrm{~kW}$

stration $1.00000 \mathrm{E}+00$

$\begin{array}{lll}\text { cotal g zrb2u reactions } 0.00000 \mathrm{E}+00 \mathrm{~km} & \\ \text { total g from fission } & 1.49696 \mathrm{E}, 01 \mathrm{kw}\end{array}$ total q input $=1.49696 \mathrm{E}+01 \mathrm{~km}$

tolal q lost radtally $=0.00000 \mathrm{E}+00 \mathrm{kw}$
tolal q lost axially $=0.00000 \mathrm{E}+00 \mathrm{kw}$ 
total y lost vaporize $=0,00000 \mathrm{z}+00 \mathrm{kw}$

$\begin{array}{ll}\text { total q lost convect } & =1.13993 \mathrm{E}+01 \mathrm{~kW} \\ \text { total } \mathrm{q} \text { out } & =1.00000 \mathrm{E}-12 \mathrm{kw}\end{array}$

percent q 2 rh 20 react $=0.000$

percent q loss radial $=0.000$

percent q loss convec = $=0.0 \%$.

percent $q$ Joss misc $=0.000$
percent $q$ loss axially 0.000

energy balance:

regidual (qout

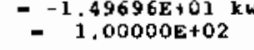

time

$=2886.00$ seconds

$\stackrel{\square}{i}$

$8.01667 E-0$

$3.16655 \mathrm{E}-02$

$1.61524 \mathrm{E}-02$

$3.39333 \mathrm{E}-02$

$1.68746 \mathrm{E}-15$

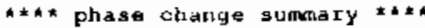

\begin{tabular}{|c|c|c|c|c|c|}
\hline node & temp & $d a$ & dda & spe & a \\
\hline 6001 & $3.4946 \mathrm{E}+02$ & $0.0000 E+00$ & $0.0000 \mathrm{E}+00$ & $i$ & $1.0000 E+00$ \\
\hline 8001 & $3.7576 \mathrm{E}+02$ & $0.0000 E+00$ & $0.0000 \varepsilon+00$ & 1 & 1. $.0000 \mathrm{E}+00$ \\
\hline 10001 & $3.9808 E+02$ & $0.0000 \mathrm{E}+00$ & $0.0000 \mathrm{E}+00$ & 1 & $1.0000 \varepsilon+00$ \\
\hline 12001 & $4.1471 E+02$ & $0.0000 E+00$ & $0.0000 \mathrm{E}+00$ & 1 & $1.0000 E+00$ \\
\hline 14001 & 4. $3718 E+02$ & $0.0000 E+00$ & $0.0000 E+00$ & 1 & $0000 E+00$ \\
\hline 16001 & $4.6431 E+02$ & $0.0000=100$ & $0.0000 E+00$ & 1 & $1.0000 E+00$ \\
\hline 10001 & 4. $7547 E+02$ & $0,0000 \mathrm{E}+00$ & $0.0000 \mathrm{E}+00$ & 1 & $1.0000 \mathrm{E}+00$ \\
\hline 6002 & $3.4922 E+02$ & $0.0000 E+00$ & $0.0000 \varepsilon+00$ & 1 & $1.0000 \mathrm{E}+00$ \\
\hline 8002 & $3.7537 \mathrm{E}+02$ & $0.0000 \mathrm{E}+00$ & $0.0000 \varepsilon+00$ & 1 & 1. $.0000 \mathrm{E}+00$ \\
\hline 10002 & 3. $9763 E+02$ & $0.0000 \mathrm{E}+00$ & $0.0000 \mathrm{E}+00$ & 1 & $1.0000 E: 00$ \\
\hline 12002 & $4,1430 E+02$ & $0.0000 \mathrm{E}+00$ & $0.0000 E+00$ & 1 & $1.0000 \mathrm{E}+00$ \\
\hline 14002 & $4.367 a E+02$ & $0.0000 \mathrm{E}+00$ & $0.0000 \mathrm{E}+00$ & 1 & $1.0000 E+00$ \\
\hline 16002 & $4.6391 \mathrm{E}+02$ & $0.0000 \mathrm{E}+00$ & $0.0000 E+00$ & 1 & $1.0000 E+00$ \\
\hline 18002 & $4.75258+02$ & $0.0000 E+00$ & 0.00005100 & 1 & $1.0000 \mathbf{E}+00$ \\
\hline 6003 & 3. $6150 \mathrm{E}+02$ & $0.0000 \mathrm{E}+00$ & $0.0000 \mathrm{z}+00$ & 1 & 1.0000E+00 \\
\hline 8003 & $4.0106 E+02$ & $0.0000 E+00$ & $0.0000 E+00$ & 1 & $1.0000 \varepsilon+00$ \\
\hline 10003 & $4.3470 E+02$ & $0.0000 \mathrm{E}+00$ & $0.0000 E+00$ & 1 & $1.0000 \mathrm{E}+00$ \\
\hline 12003 & $4.5993 E+02$ & $0.0000 z+00$ & $0.0000 \mathrm{E}+00$ & 1 & $1.0000 E+00$ \\
\hline 14003 & 4. $9209 \mathrm{E}+02$ & $0.0000 E+00$ & $0.0000 E * 00$ & 1 & $1.0000 \mathrm{E}+00$ \\
\hline 16003 & $5.2934 E+02$ & $0.0000 \mathrm{E}+0.0$ & $0,0000 E+00$ & 1 & $1.0000 \mathrm{E}+00$ \\
\hline $\begin{array}{l}18003 \\
6004\end{array}$ & $\begin{array}{l}5.4437 \mathrm{E}+02 \\
6.67 \mathrm{E}+02\end{array}$ & $\begin{array}{l}0.0000 \mathrm{E}+00 \\
0.0000 \mathrm{E}+00\end{array}$ & $\begin{array}{l}0.00008+00 \\
0.0000 \mathrm{E}+00\end{array}$ & 1 & $\begin{array}{l}1.0000 \mathrm{E}+00 \\
0000 \mathrm{O}+00\end{array}$ \\
\hline 6004 & $\begin{array}{l}3.6173 \mathrm{E}+02 \\
4.0157 \mathrm{E}+02\end{array}$ & $\begin{array}{l}0.0000 \mathrm{E}+00 \\
0.000 \mathrm{r}\end{array}$ & $0.0000 \mathrm{E}+00$ & 1 & $\begin{array}{l}1.0000 E+00 \\
1.0000 \varepsilon+00\end{array}$ \\
\hline 10004 & $4.3549 E+02$ & $0.0000 \varepsilon+00$ & $0.0000 \mathrm{E}+00$ & 1 & $1.0000 E+00$ \\
\hline 12004 & $4.6095 E+02$ & $0.0000 \mathrm{E}_{100}$ & $0.0000 \mathrm{E}+00$ & 1 & $1.0000 E+\infty$ \\
\hline 14004 & $4.9333 E+02$ & $0.0000 E+00$ & $0.0000 E+00$ & 1 & $1.0000 \mathrm{E}+00$ \\
\hline 16004 & $5.3077 \mathrm{E}+02$ & $0.0000 E+00$ & $0.0000 \varepsilon+00$ & 1 & $1.0000 E+00$ \\
\hline 18004 & $5.4595 \mathrm{E}+02$ & $0.0000 E+00$ & $0.0000 E+00$ & 1 & $1.0000 \mathrm{0}+00$ \\
\hline 22001 & $5.1824 E+02$ & $0.0000 E+00$ & $0.0000 E_{100}$ & 1 & 1.0000 r roo \\
\hline 26001 & $5,6963 \mathrm{E}+02$ & $0.0000 \varepsilon+00$ & $0.0000 E+00$ & $\mathbf{1}$ & $1,0000 \mathrm{E}+00$ \\
\hline 30001 & $6.2455 E+02$ & $0.0000 E+00$ & $0.0000 \mathrm{E}+00$ & 1 & $00 E_{1}+00$ \\
\hline 34001 & $6.8212 E+02$ & $0.0000<100$ & $D .0000 \mathrm{E}+00$ & 1 & $1.0000 E+\infty 0$ \\
\hline 38001 & $3.3968 \mathrm{E}+02$ & $0.00008+00$ & $0.0000 \varepsilon+00$ & 1 & 1.0000E+ \\
\hline 42001 & $7.9742 E+02$ & $0,0000 E+00$ & $0.0000 E+00$ & 1 & $000 \mathrm{E}+00$ \\
\hline 46007 & $0.5419 \mathrm{E}+02$ & $0.0000 \mathrm{E}+00$ & 0.0000 E 100 & 1 & $1.0000 \mathrm{E}+00$ \\
\hline & & & & npe & \\
\hline & $9.07408+02$ & $0.0000 \mathrm{E}+00$ & $0.0000 \mathrm{E}+\mathrm{C}$ & 1 & \\
\hline 001 & $9.5490 \mathrm{E}_{102}$ & $0.0000 E_{100}$ & $0.0000 \mathrm{E}+00$ & 1 & $00 \mathbf{E}+00$ \\
\hline
\end{tabular}




\begin{tabular}{|c|c|c|c|c|c|}
\hline & & & & 1 & $E+00$ \\
\hline 26002 & $5.6975 E+02$ & $0.0000 \mathrm{E}+00$ & $0.0000 E+00$ & 1 & $3.0000 E+00$ \\
\hline 30002 & $6.2406 E+02$ & $0.0000 E+00$ & $0.0000 E+00$ & 1 & $1.0000 \mathrm{E}+00$ \\
\hline 34002 & $6+B 266 E+02$ & $0.0000 E 100$ & 0.0000 E r 00 & 1 & $1.0000 \mathrm{E}+00$ \\
\hline 38002 & $7.4041 E+02$ & $0.00008+00$ & $0.0000 \mathrm{E}+00$ & 1 & $1.0000 \mathrm{E}+00$ \\
\hline 42002 & $7.98218+02$ & $0.00002+00$ & $0.0000 \mathrm{E}+00$ & 1 & $1,0000 \mathrm{E}+00$ \\
\hline 46002 & 8. $5501 \varepsilon+02$ & $0.0000 E+00$ & $0.0000 \mathbf{E}+00$ & 1 & $1.0000 E+00$ \\
\hline 50002 & $9.0024 \Sigma+02$ & $0.0000 E+00$ & $0.0000 \mathrm{E}+00$ & 1 & $1,0000 \mathrm{E}+00$ \\
\hline 54002 & $9.55758+02$ & $0.0000 E+00$ & $0.00008+00$ & 1 & $1.0000 \mathrm{E}+00$ \\
\hline 22003 & 5.9913E+02 & $0.0000 E 100$ & $0.0000 \mathrm{z}+00$ & 1 & $1.0000 \mathrm{E}+00$ \\
\hline 26003 & $6.6200 \mathrm{E}+02$ & $0.0000 E+00$ & $0.0000 \mathrm{E}+00$ & 1 & $1.0000 \mathrm{E}+00$ \\
\hline 30003 & $3.2596 \mathrm{E}+02$ & $0.0000 \mathrm{E}+00$ & $\begin{array}{l}0.0000 \mathrm{E}+00 \\
0.0000 \mathrm{E}+00\end{array}$ & 2 & $1.00000+00$ \\
\hline 34003 & $7.8841 E+02$ & $0.0000 \mathrm{E}+00$ & $0.0000 E+00$ & 3 & $1.0000 \mathrm{E}+00$ \\
\hline 38003 & $8.4637 E+02$ & $0.0000 \mathrm{E}+00$ & $0.0000 E_{1} 00$ & 1 & $1.0000 \mathrm{E}+00$ \\
\hline 42003 & $9.0174 \mathrm{E}+02$ & $0.0000 \mathrm{E}+00$ & $0.0000 \mathrm{E}+00$ & 1 & $1.0000 \mathrm{E}+00$ \\
\hline 46003 & $9.5044 E+02$ & $0.0000 \varepsilon+00$ & $0.0000 \mathrm{E}+00$ & 1 & $1.0000 \mathrm{E}+00$ \\
\hline 50003 & $1.0017 \mathrm{E}+03$ & D.0000E +00 & $0.0000 \mathrm{t}+00$ & 1 & $1,0000 \mathrm{E}+00$ \\
\hline $\begin{array}{l}54003 \\
22004\end{array}$ & $1,0413 E+03$ & $0,0000 E+00$ & $\begin{array}{l}0.0000 \mathbf{z}+00 \\
0.0000 \varepsilon+00\end{array}$ & $\begin{array}{l}1 \\
1\end{array}$ & $1,0000 \mathrm{E}+00$ \\
\hline $\begin{array}{l}22004 \\
26004\end{array}$ & $\begin{array}{l}6.0094 E+02 \\
6.6395 E+02\end{array}$ & $\begin{array}{l}0.0000 \mathrm{E}+00 \\
0.0000 \mathrm{E}+00\end{array}$ & $\begin{array}{l}0.00008+00 \\
0.0000 E+00\end{array}$ & 1 & $1.0000 \mathrm{E}+00$ \\
\hline 30004 & $7.279 \mathrm{\theta E}+02$ & $0.0000 E+00$ & $0.0000 \varepsilon+00$ & i & $1.0000 \mathrm{E}+00$ \\
\hline 34004 & $7.9036 \mathrm{z}+02$ & $0.0000 \bar{E}+00$ & $0.0000 E+00$ & 1 & $1.0000 \mathrm{E}+00$ \\
\hline 38004 & $8.4817 E+02$ & $0.0000 \mathrm{E}+00$ & $0.0000 \mathrm{E}+00$ & $i$ & $1.0000 E+00$ \\
\hline 42004 & $9.033 S_{102}$ & $0.0000 E+00$ & $0.0000 E+00$ & 1 & $1,0000 \mathbf{E}+00$ \\
\hline 46004 & $9.5584 E+02$ & $0.0000 E+00$ & $0.0000 E+00$ & 1 & $1.0000 \varepsilon+00$ \\
\hline 50004 & $1.0029 \mathrm{E}+03$ & $0.0000 E+00$ & $0.0000 \mathrm{E}+00$ & 2 & $1,00008+00$ \\
\hline 54004 & $1.0423 \mathrm{E}+03$ & $0.0000 E+00$ & $0.0000 E+00$ & $i$ & $1,0000 \mathrm{E}+00$ \\
\hline 7001 & $\$ .6635 \mathrm{E}+02$ & $0.0000 E+00$ & $0.0000 E+00$ & 1 & $1.0000 \mathrm{E}+00$ \\
\hline 9001 & $3.0674 E+02$ & $0.0000 E+00$ & $0.0000 E+00$ & 1 & $1,0000 E+00$ \\
\hline 11001 & $4.0705 E+02$ & $0.0000 E+00$ & $0.0000 \mathbf{E}+00$ & 1 & $1.0000 E+00$ \\
\hline 13001 & $4.24035+02$ & $0.00008+00$ & $0,0000 E+00$ & 1 & $1.0000 E+00$ \\
\hline 35001 & $4.5098 E+02$ & $0.0000 E+00$ & $0.0000 E+00$ & 1 & $1.0000 E+00$ \\
\hline 17001 & $4.7292 \mathrm{E}+02$ & $0.0000 E+00$ & $0.0000 E+00$ & 1 & $1.0000 \mathrm{E}+00$ \\
\hline nodu & & da & dda & & $\mathbf{a}$ \\
\hline 7002 & $3.6599 \varepsilon+02$ & $0.0000 E+00$ & $0.0000 E+00$ & $i$ & $.0000 \mathrm{E}_{t}$ \\
\hline 9002 & 3. $9632 \mathrm{E}+02$ & $0.0000 \mathrm{E}+00$ & $0.00 D O E$ ROO & 1 & $1.0000 \mathrm{E}+00$ \\
\hline 11002 & $0.0740 E+02$ & $0.0000 E+00$ & 0.0000 E rOO & 1 & $1.0000 \mathrm{E}+00$ \\
\hline 13002 & $4.2443 E+02$ & $0.0000 E+00$ & $0.0000 E+00$ & 1 & $1.0000 \mathrm{E}+00$ \\
\hline 15002 & $4.5058 \mathrm{BE}+02$ & $0.0000 E+00$ & $0.0000 E+00$ & 1 & $1.0000 E+00$ \\
\hline 17002 & 1. $7259 \mathrm{~g}+02$ & $0.0000 E+00$ & $0.0000 \varepsilon+00$ & 1 & $1.0000 \mathrm{E}+00$ \\
\hline 7003 & $3.0645 E+02$ & 0.00008100 & $00 E+00$ & 1 & $0 E+00$ \\
\hline 9003 & $4.1788 \mathrm{E}+02$ & $0.0000 E+00$ & 0.00 & J & 1.00 \\
\hline 11003 & $4.4944 E+02$ & $0.0000 \mathrm{E}+00$ & & 1 & $E+00$ \\
\hline 13003 & $4.7474 E+02$ & $0.0000 E+00$ & 0.00 & 1 & $E+\infty$ \\
\hline 15003 & $5,1127 \mathrm{E}+02$ & $0,0000 k+00$ & & 1 & $2+00$ \\
\hline 17003 & $5.4099 E+02$ & $0.0000 E+00$ & 0,0 & 1 & 1.0 \\
\hline 7004 & $3.8683 z+$ & 0.00 & & 1 & 1.0 \\
\hline 9004 & 4.18538 & 0.0 & & 1 & $E+00$ \\
\hline 11004 & $4.5035 \mathrm{E}$ & 0.0 & & 1 & 1.0 \\
\hline 13004 & $4.7587 E+$ & 0.0 & 0.0 & 1 & $E+00$ \\
\hline 15004 & $5.1261 E+c$ & $20 E+00$ & 0.00 & 1 & $1.0000 \mathrm{E}+00$ \\
\hline 17004 & $5.4251 \mathrm{E}+02$ & $0.0000 E+00$ & 0.000 & 1 & $2.0000 \mathrm{E}+00$ \\
\hline 21001 & $5.0692 \mathrm{E}+$ & $0.0000 E+00$ & 0.000 & 1 & $1.0000 E+00$ \\
\hline 25001 & $5,5601 \mathrm{E}+02$ & $0,0000 \mathrm{E}+00$ & $0.0000 \varepsilon$ & 1 & $1.0000 E+00$ \\
\hline 29001 & $6.1102 E+02$ & $0.0000 E+00$ & $0.0000 E$ & 1 & $1,6000 E+00$ \\
\hline 33001 & $6.6800 E+02$ & $0.0000 E+00$ & 0.0000E 100 & 1 & $1.0000 E+00$ \\
\hline 37001 & $7.2632 \mathrm{E}+02$ & $0.0000 E+00$ & $0.0000 \mathrm{E}+00$ & 1 & $1.0000 \mathrm{E}+00$ \\
\hline 41001 & $7.8343 B+02$ & $0.0000 \mathrm{E}+00$ & $0.0000 \mathrm{E}+00$ & 1 & $1.00000+00$ \\
\hline 45001 & $9.40758+02$ & $0.0000 \mathrm{E}+100$ & $0.0000 \mathrm{E}+00$ & 1 & $1.0000 \pm+00$ \\
\hline 49001 & 9.9501E102 & $0.0000 E+00$ & $0.0000 E+00$ & 1 & $3.0000 \mathrm{E}, 00$ \\
\hline 53001 & $9.4415 \varepsilon+02$ & $0.0000 \mathrm{E}+00$ & $0.0000 E+00$ & 1 & $1,0000 E+00$ \\
\hline 57001 & $\begin{array}{l}9.8527 E+02 \\
5.0684 E+02\end{array}$ & $\begin{array}{l}0.0000 E+00 \\
0.0000 E+00\end{array}$ & $\begin{array}{l}0.00000+00 \\
0.0000 E+00\end{array}$ & $\frac{1}{1}$ & $1.0000 \mathrm{E}+00$ \\
\hline $\begin{array}{l}21002 \\
25002\end{array}$ & $5.56 \mathrm{BBE}+02$ & $0.0000 E+100$ & 0.0000 E +00 & $i$ & $1.0000 E+00$ \\
\hline 29002 & $6.112 \mathrm{EE}+02$ & $0.0000 k=100$ & 0.0000 tion & 1 & 1.0600E +00 \\
\hline
\end{tabular}




\begin{tabular}{|c|c|c|c|c|c|}
\hline $\begin{array}{l}33002 \\
37002 \\
614004 \\
45002\end{array}$ & $\begin{array}{l}6.684 \mathrm{BE}+02 \\
7.2700 \mathrm{02} \\
.4421 \mathrm{Q}+02 \\
8.4157 \mathrm{Q}+02\end{array}$ & $\begin{array}{l}0.0000 E+00 \\
0.0000 E+00 \\
0.0000 E+00 \\
0.0000 E+00\end{array}$ & $\begin{array}{l}0.0000 E+00 \\
0.0000 \mathrm{E}+00 \\
0.0000 \mathrm{t}+00 \\
0.0000 \mathrm{0}+00\end{array}$ & $\begin{array}{l}1 \\
1 \\
1 \\
1\end{array}$ & $\begin{array}{l}1.0000 E+00 \\
1.0000 E+00 \\
1.0000 E+00 \\
1.0000 E+00\end{array}$ \\
\hline node & & & & & \\
\hline 49002 & $8.9584 E+02$ & $0.0000 E+00$ & $0.0000 \mathrm{E}+00$ & 1 & $1.0000 \mathrm{E}+00$ \\
\hline 53002 & $9.4500 E+02$ & 0.0000 E +00 & $0.0000 \mathrm{E}+00$ & 1 & ] $.0000 \mathrm{E}+00$ \\
\hline 57002 & $9.8613 E+02$ & & $\begin{array}{l}0.0000 E+00 \\
0.00008+00\end{array}$ & $\frac{1}{1}$ & \\
\hline 21003 & $5.8493 \mathrm{E}+02$ & $\begin{array}{l}0.0000 E+00 \\
0.0000 E+00\end{array}$ & & 1 & $\begin{array}{l}1.0000 \mathrm{E}+00 \\
1.0000 \mathrm{E}+00\end{array}$ \\
\hline $\begin{array}{l}25003 \\
29003\end{array}$ & $\begin{array}{l}6.4663 E+02 \\
7.3064 E+02\end{array}$ & $\begin{array}{l}0.0000 E+00 \\
0.0000 E+00\end{array}$ & $0.0000 \mathrm{E}+00$ & 1 & $\begin{array}{l}1.0000 E+00 \\
1.0000 E+00\end{array}$ \\
\hline 33003 & $7.7350 \mathrm{0}+02$ & $0.00008+00$ & $0.0000 E+00$ & i & $1.0000 \varepsilon+00$ \\
\hline 37003 & $8.3342 E+02$ & $0.0000 E+00$ & $0.0000 \mathrm{E}+00$ & i & $1.0000 E+00$ \\
\hline 41003 & $8.8553 \mathrm{E}+02$ & $0.0000 E+00$ & $0.0000 E+00$ & 1 & $1,0000 E+00$ \\
\hline 45003 & $9.4219 \mathrm{E}+\mathrm{OZ}$ & $0.0000 E+00$ & $0.0000 E+00$ & 1 & $1,0000 E+00$ \\
\hline 49003 & $9.9096 E+02$ & $0.0000 E+00$ & $0.0000 \mathrm{E}+00$ & 1 & $1.0000 \mathrm{E}+00$ \\
\hline 53003 & $1.03278+03$ & 0.0000 E 100 & $0.0000 E+00$ & $i$ & $1.0000 \mathrm{E}+00$ \\
\hline 57003 & $1.0643 \Sigma+03$ & $0.0000 E+00$ & $0.0000 z+00$ & 1 & $1.0000 x+00$ \\
\hline 21004 & $5,0669 \mathrm{E}+02$ & $0.0000 \varepsilon+00$ & $0.0000 E+00$ & 1 & $1.0000 E+00$ \\
\hline 25004 & $6.4855 E+02$ & $0.0000 \mathrm{E}+00$ & $0.0000 \mathrm{E}+00$ & 1 & $1.0000 \varepsilon+00$ \\
\hline 29004 & $7.1264 E+02$ & $0.0000 k+00$ & $0.0000 E+00$ & 1 & $1.0000 \mathrm{E}+00$ \\
\hline 33004 & $7.7556 \mathrm{E}+02$ & $0.0000 E+00$ & $0.0000 E+00$ & 1 & $1.0000 \mathrm{E}+00$ \\
\hline 37004 & 8. $3525 \mathrm{E}+02$ & $0.0000 E+00$ & $0.0000 E+00$ & 1 & $1.0000 E+00$ \\
\hline 41004 & $8.9019 E+02$ & $0.0000 E+00$ & $0.0000 E+00$ & 1 & $1.0000 E+00$ \\
\hline 45004 & $9.4365 E+02$ & $0.0000 E+00$ & $0,0000 \mathrm{E}+00$ & 1 & $1.0000 x+00$ \\
\hline 49004 & $9.92218+02$ & $0.0000 \mathrm{t}+00$ & $0.0000 E+00$ & 1 & $1.0000 E+00$ \\
\hline 53004 & $1.0337 \mathrm{E}+03$ & $0.00008+00$ & $0.0000 \varepsilon+00$ & 1 & $1.0000 E+00$ \\
\hline 57004 & $1.0651 E+03$ & $0,0000 E+00$ & $0.0000 E+00$ & 1 & $1.0000 \mathrm{E}+00$ \\
\hline 19001 & $4, B 204 E+02$ & $0.0000 \mathrm{~B} 100$ & $0.0000 \mathrm{E}+00$ & i & $1.0000 \mathrm{E}+00$ \\
\hline 23001 & $5.3090 \mathrm{E}+02$ & $0.0000 E+00$ & & 1 & $1.0000 \mathrm{E}+00$ \\
\hline 27001 & $5.8354 \varepsilon+02$ & $0.0000 E+00$ & & 1 & $1.0000 \mathrm{E}+00$ \\
\hline 31001 & $6.3919 E+02$ & $0.0000 \mathrm{E}+00$ & $0.0000 \mathrm{E}+00$ & 1 & $1.0000 \mathrm{E}+00$ \\
\hline 35001 & $6.9736 \bar{E}+02$ & 0.00000400 & $0.0000 \mathrm{E}+00$ & 1 & $1.0000 \mathrm{E} 100$ \\
\hline 39001 & $1.5435 E+02$ & $0.0000 E+00$ & & 1 & $3.0000 E+00$ \\
\hline 43001 & $8.1233 \mathrm{E}+02$ & $0.0000 E+00$ & & 1 & $1.0000 E+00$ \\
\hline 47001 & 8. $6839 \mathrm{E}+02$ & $0.0000 \mathrm{E}+00$ & $0.0000 E+00$ & 1 & $1.0000 E+00$ \\
\hline 51001 & $9.2037 \mathrm{E}+02$ & $0.0000 E+00$ & $0.0000 E+00$ & 1 & $1.0000 E+00$ \\
\hline 55001 & $9.6565 E+02$ & $0.0000 E+00$ & $0.0000 E+00$ & 1 & $1.0000 \mathrm{E}+00$ \\
\hline 19002 & 4.8270s+02 & $0.0000 \mathrm{E}+00$ & $0.0000 E+00$ & 1 & $1.0000 E+00$ \\
\hline 23002 & $5.3090 \bar{E}+02$ & $0.0000 \mathrm{E}+00$ & $0.0000 E+00$ & 1 & $1.0000 \mathrm{E}+00$ \\
\hline & & & & npe & \\
\hline 270 & & $00 E+00$ & $0.0000 E+00$ & 1 & 1. $.0000 x+00$ \\
\hline 31002 & & $0.0000 E+00$ & $0.0000 E+00$ & 1 & $1.00008+00$ \\
\hline 35002 & $6.9794 \mathrm{E}+02$ & $0.0000 E+00$ & $0.0000 E+00$ & 1 & $1,0000 \mathrm{z}+00$ \\
\hline 39002 & $7.5510 \mathrm{E}+02$ & $0.0000 E+00$ & $0.0000 E+00$ & 1 & 1.0000E+00 \\
\hline 43002 & B. $13148+02$ & $0.0000 E+00$ & $0.0000 E+00$ & 1 & 1. $0000 \mathrm{E}+00$ \\
\hline 47002 & $8.6922 E+02$ & $0.0000 E+00$ & $0.0000 \mathrm{E}: 00$ & 1 & $1.0000 \mathrm{E}+00$ \\
\hline $\begin{array}{l}51002 \\
55002\end{array}$ & $9.2121 E+02$ & $0.0000 E_{100}$ & $0.0000 \varepsilon+00$ & 1 & $1.0000 \mathrm{E}+100$ \\
\hline $\begin{array}{l}55002 \\
19003\end{array}$ & $\begin{array}{l}9.6651 \mathrm{E}+02 \\
5.5398 \mathrm{E}+02\end{array}$ & $\begin{array}{l}0.0000 E+00 \\
0.0000 E+00\end{array}$ & $\begin{array}{l}0.0000 \mathrm{E}+00 \\
0.0000 \mathrm{E}+00\end{array}$ & 1 & $\begin{array}{l}1.0000 \mathrm{E}+1.0000+00 \\
0\end{array}$ \\
\hline 23003 & $6.1492 E+02$ & $0,0000 E+00$ & 0.0000 E 100 & i & $1.0000 E+00$ \\
\hline 27003 & $6.785 \theta \bar{x}+02$ & $0.0000 E+00$ & 0.0000 t 100 & i & $1.0000 E+00$ \\
\hline 31007 & $7.4235 \mathrm{E}+02$ & $0.0000 E+00$ & $0.0000 \mathrm{E}+00$ & 1 & $1.0000 \mathrm{E}+00$ \\
\hline 3500 & B. $04238+02$ & $0.00000+00$ & 0.0000 e +00 & i & $1.0000 E+00$ \\
\hline 39003 & $8.6062 E+02$ & $0.0000 E+00$ & $0.0000 E+00$ & 1 & $1,0000 E+00$ \\
\hline 43003 & $9.1501 E+02$ & $0.00008+00$ & $900 \varepsilon+00$ & 1 & $1.0000 \mathrm{E}+00$ \\
\hline 47003 & $9.6732 E+02$ & $0.0000 E+00$ & $600 E+$ & i & $1.0000 \mathrm{E}+00$ \\
\hline 51003 & $1.0129 \mathrm{E}+03$ & DOE 100 & $0.0000 \mathrm{E}+00$ & 1 & $2.0000 \mathrm{E}+00$ \\
\hline 55003 & $1.0496 \mathrm{E}+03$ & $000 \mathrm{E} \cdot 1$ & $0,0000 \mathrm{E}$ & 1 & $00 \mathrm{E}+00$ \\
\hline 19004 & $5.5562 \mathrm{E}+02$ & 0.0 & OOOE & 1 & 1.0 \\
\hline 23004 & $6.1677 E+02$ & $0.0000 E+$ & $0.0000 \mathrm{E}$ & 1 & $0 E+00$ \\
\hline 27004 & $6.0056 \mathrm{E}+02$ & $0.0000 E+00$ & $0.0000 \mathrm{E}+00$ & 1 & $1.00008+00$ \\
\hline 31004 & $7.44368+02$ & $0,0000 E+00$ & $0.0000 E+00$ & 1 & $1.0000 \varepsilon+00$ \\
\hline 35004 & $0.0615 E 102$ & $0.0000 \varepsilon+00$ & 0.0000 too & 1 & $1.0000 E+00$ \\
\hline
\end{tabular}




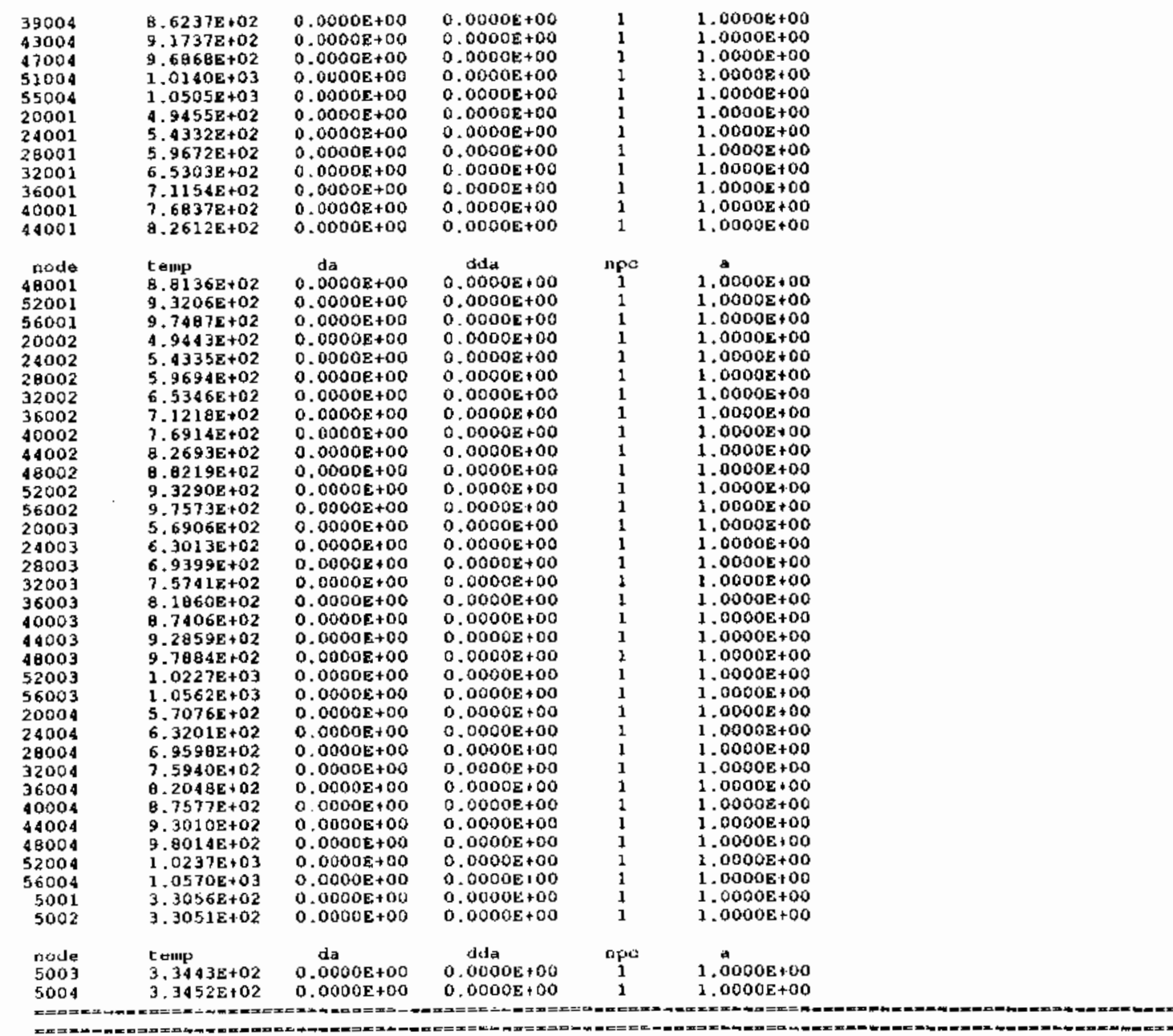

restart file cruated at $8.01667 \mathrm{~g}-01$ hrs munber of riodes

tupes fije contains speclal output nodes:
5001 10001 14001 19001 2200130001 39001 440014600154001 
$500310003 \quad 14003 \quad 18003220033000338003440034600354003$

$\begin{array}{llllllllllll}5306 & 10306 & 14306 & 18306 & 22306 & 30306 & 38306 & 44306 & 46306 & 54306 \\ 5101 & 10101 & 57003 & 57101 & 57003 & 53001 & 50001 & 50003 & 42001 & 42003\end{array}$

number of wirleg to tape 5 file $=$

1. final system sumory *n*

Lemp

axthix

oxarea

zxtikik

6001

10001

16001

6002

6002
10002

14002

16002

6003

1000

12003

[D

16003
30003

os 4. $371 \mathrm{BOE}+02 \quad 0.00000 \mathrm{E}+00 \quad 3.70000 \mathrm{E}-02 \quad 1.75000 \mathrm{E}-01 \quad 7.66692 \mathrm{E}+01$ $4.75465 \mathrm{E}+02 \quad 0.000008+00 \quad 3.70000 \mathrm{E}-02 \quad 1.75000 \mathrm{E}-01 \quad 0.45424 \mathrm{E}+01$ $4.14299 \mathrm{E}+02$ 2.00000E+00 $1.00000 \mathrm{E}-01 \quad 1.75000 \mathrm{E}-01$ 9.86340E+01 4. $34704 \mathrm{E}+02 \quad 0.00000 \mathrm{E}+00 \quad 1.34600 \mathrm{E}-01 \quad 1.55500 \mathrm{E}-01 \quad 1.83309 \mathrm{E}+02$ 4.9203E $0.00008+00$ 1.3400E-01 1.59500E-01 2. $35169 \mathrm{E}+02$ 3.6172BE+02 $0.00000 \mathrm{E}+00 \quad 1.91000 \mathrm{E}-01 \quad 1.58500 \mathrm{E}-01 \quad 0.75717 \mathrm{E}+0$ 4.01573E+02 $0.00000 \mathrm{E} 100 \quad 1.91000 \mathrm{E}-01 \quad 1.50500 \mathrm{E}-01 \quad 1.62630 \mathrm{E}+02$

$3.49456 E+02 \quad 0.00000 E+00 \quad 3.70000 E-02 \quad 1.75000 E-012.44123 E+01$ $3.75356 \mathrm{E}+02 \quad 0.00000 \mathrm{E}+00 \quad 3.70000 \mathrm{E}-02 \quad 1.75000 \mathrm{E}-01 \quad 01.53361 \mathrm{E}+01$ $\begin{array}{lllll}3.98081 E+02 & 0.00000 E+00 & 3.7000 E-02 & 1.75000 E-01 & 5.97621 \mathrm{E}+0 \\ 4.14707 \mathrm{E}+02 & 0.00000 \mathrm{E}+00 & 3.70000 \mathrm{E}-02 & 1.75000 \mathrm{E}-01 & 6.58020 \mathrm{E}+01\end{array}$ $4.64305 E+02 \quad 0.00000 \mathrm{E}+00 \quad 3.70000 \mathrm{E}-02 \quad 1.75000 \mathrm{E}-01 \quad 8.99097 \mathrm{E}+01$ $3.75365 \mathrm{E}+02$ 0.00000E+00 $1.00000 \mathrm{E}-01$ 1.75000E-01 $6.79567 \mathrm{E}+01$ $3.97631 \mathrm{E}+02 \quad 0.00000 \mathrm{E}+00 \quad 1.00000 \mathrm{E}-01 \quad 1.75000 \mathrm{E}-01 \quad \mathrm{~B} .95 \mathrm{~B} 05 \mathrm{E}+01$ $4.367 \theta 0 \mathrm{E}+02 \quad 0.00000 \mathrm{E}+00 \quad 1.00000 \mathrm{E}-01 \quad 1.75000 \mathrm{E}-01 \quad 1.14923 \mathrm{E}+01$

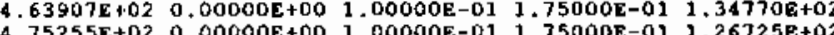

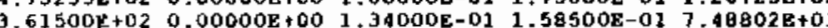
4.01060E+02 $0.00000 E+00 \quad 1.34000 E-01 \quad 1.58500 E-01 \quad 1.39060 E+02$ $4.59932 E+02 \quad 0.00000 E+00 \quad 1.34000 \mathrm{R}-01 \quad 1.59500 \mathrm{E}-01 \quad 2.01835 \mathrm{E}+02$

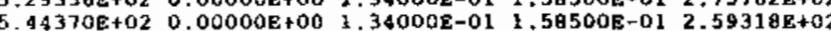
4.35466E+02 $0.00000 \mathrm{E}+00 \quad 1.91000 \mathrm{E}-01 \quad 1.58500 \mathrm{E}-01 \quad 2.143798+02$ 4.60951E+02 $0.00000 E+00$ 1.91000E-01 $1.58500 \mathrm{E}-012.36045 \mathrm{E}+02$ 5. $30769 \mathrm{E}+02 \quad 0.00000 \mathrm{E}+00 \quad 1.91000 \mathrm{E}-01 \quad 1.58500 \mathrm{E}-01 \quad 3.22524 \mathrm{E}+02$

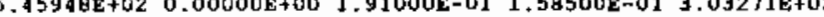
$3.48511 E+020.00000 E+00 \quad 3.76000 E-01 \quad 2.00000 E-02 \quad 4.67503 E-02$

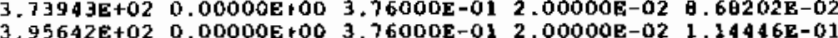
$4.11931 E+02 \quad 0.00000 E+003.76000 E-012.00000 \mathrm{E}-021.26013 \mathrm{E}-01$ $\begin{array}{llll}133895 \mathrm{E}+02 & 0.00000 \mathrm{E}+00 & 3.76000 \mathrm{E}-01 & 2.00000 \mathrm{E}-02 \\ 1.46824 \mathrm{E}-01\end{array}$ $\begin{array}{lllll}4.60416 \mathrm{E}+02 & 0.00000 \mathrm{E}+00 & 3.76000 \mathrm{E}-01 & 2.00000 \mathrm{E}-02 & 1.72180 \mathrm{E}-01\end{array}$ 4.71624E+02 $0.00000 \mathrm{E}+00 \quad 3.76000 \mathrm{E}-01 \quad 2.00000 \mathrm{E}-02 \quad 1.61901 \mathrm{E}-01$ 3.732615E2020.000E 3.95371E+02 $0.00000 E+00 \quad 1.00500 E+00 \quad 3.00000 E-02 \quad 3.4412 \mathrm{BE}-01$ 4.11日56E $02 \quad 0.00000 \mathrm{E}+00 \quad 1.00500 \mathrm{E}+00$ 3.00000E-02 3.78907E-0 $4.33991 E+02 \quad 0.00000 E+001.00500 E+00 \quad 3.00000 E-02 \quad 4.41484 E-0$ 4. $60700 \varepsilon+02 \quad 0.00000 \varepsilon+00 \quad 1.00500 E+003.00000 \varepsilon-025.17727 E-01$

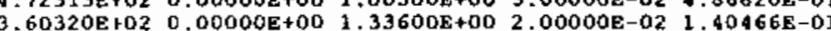
$3.99794 \mathrm{E}+02 \quad 0.00000 \mathrm{E}+00 \quad 1.33600 \mathrm{E}+002.00000 \mathrm{E}-02 \quad 2.60861 \mathrm{E}-01$ $4.31662 \mathrm{E}+02 \quad 0.00000 \mathrm{E}+00 \quad 1.33600 \mathrm{E}+00 \quad 2.00000 \mathrm{E}-02 \quad 3.43666 \mathrm{E}-01$ $4.56470 \mathrm{E}+02 \quad 0.00000 \mathrm{E}+00 \quad 1.33600 \mathrm{E}+00 \quad 2.00000 \mathrm{E}-02 \quad 3.7861 \mathrm{gE}-01$ $4.24658 E+02 \quad 0.000000+001.336000+0022.00000 E-02 \quad 5.17333 E-01$ $5.39789 \mathrm{E}+02 \quad 0.00000 \mathrm{E}+00 \mathrm{l} .33600 \mathrm{E}+002 \mathrm{2}, 00000 \mathrm{E}-02 \quad 4.06450 \mathrm{E}-0$ $3.60955 \mathrm{E}+02 \quad 0.00000 \mathrm{E}+00 \quad 1.90500 \mathrm{E}+002,50000 \mathrm{C}-02 \quad 1.87717 \mathrm{E}-0$ $4.00186 E+02 \quad 0.00000 \mathrm{E}+00 \quad 1.90500 \mathrm{E}+00 \quad 2.50000 \mathrm{E}-02 \quad 3.48611 \mathrm{E}-01$

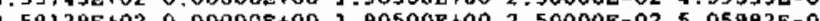
$4.91262 \mathrm{E} 102$ 0.00000E+00 2.90500E+00 2.50000E-02 5. $99545 \mathrm{E}-01$ 


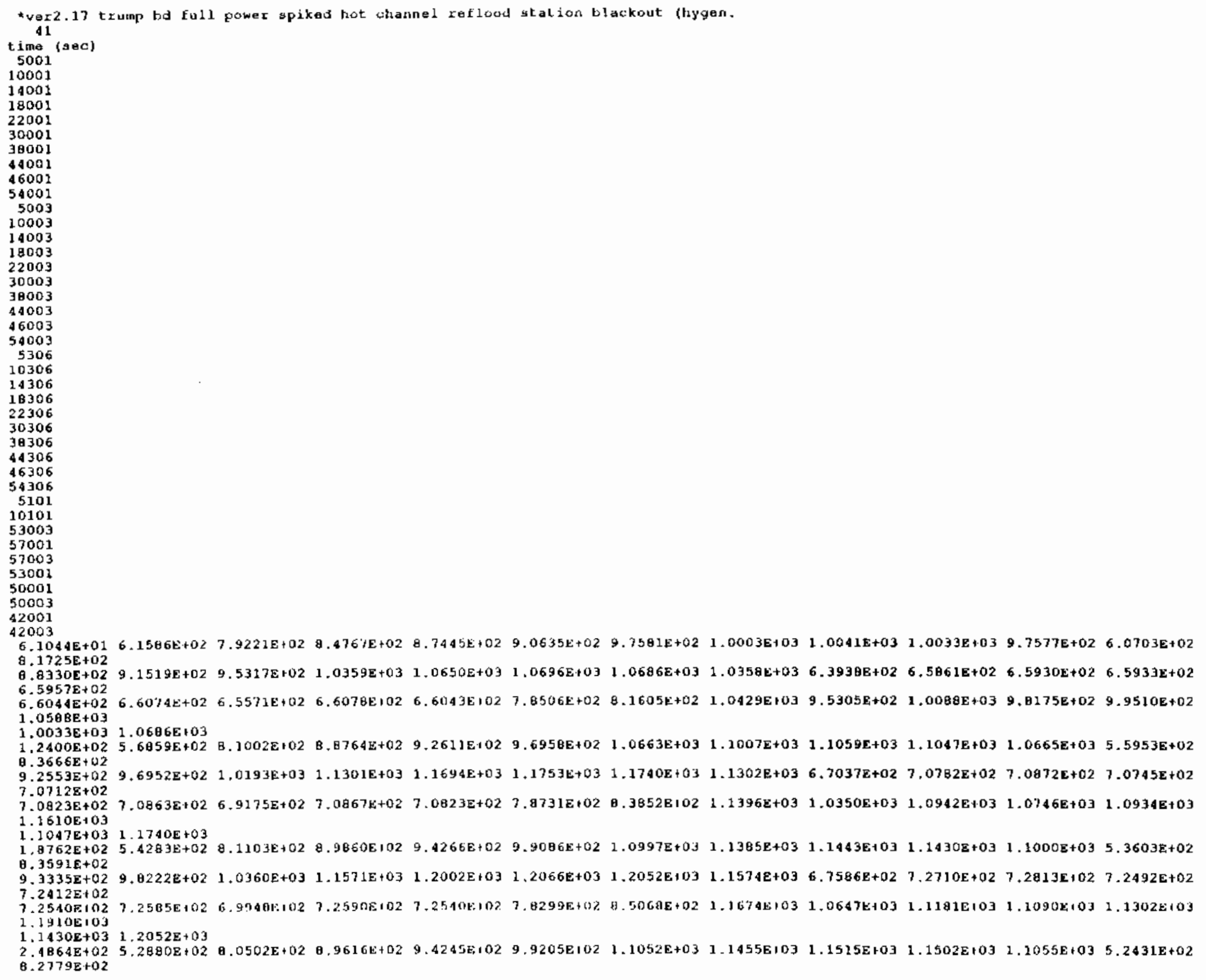


$9.2721 E+02 \quad 9.7743 E+02 \quad 1.0918 E+03 \quad 1.1552 \mathrm{E}+03 \quad 1.1991 \mathrm{E} 103 \quad 1.2057 E+071.2042 \mathrm{E}+09 \quad 1.1555 E+03 \quad 6.7367 E+02 \quad 7.3555 E+02 \quad 7.3669 E+02 \quad 7.31608+02$

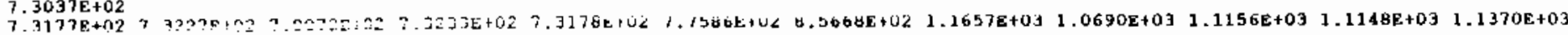
$1.189 \mathrm{BE}+03$

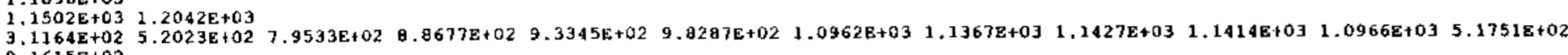

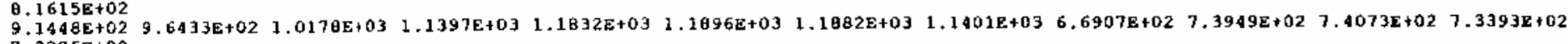

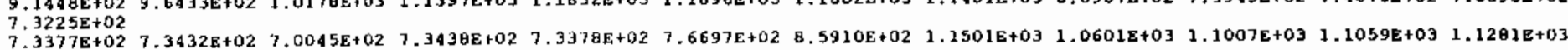

$1.1740 E+03$
$1.1414 E+03$
$1.18 B 2 E+03$

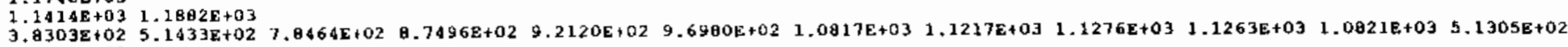
$3.8303 E+02$
$8.0412 E+02$

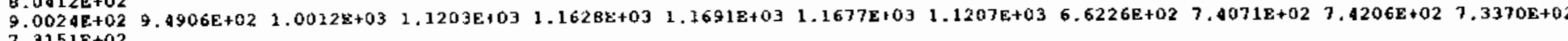

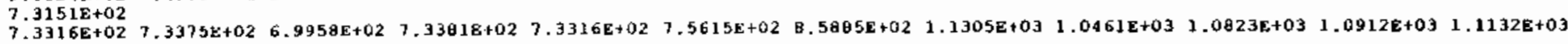
$1.153 \mathrm{BE}+03$

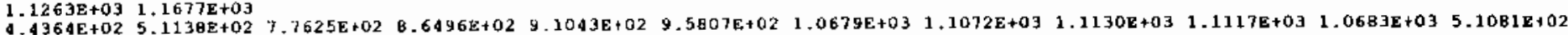

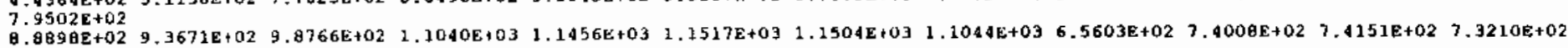

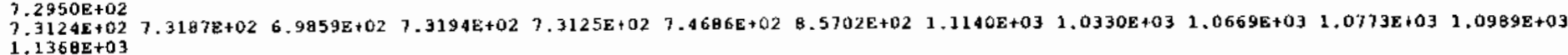

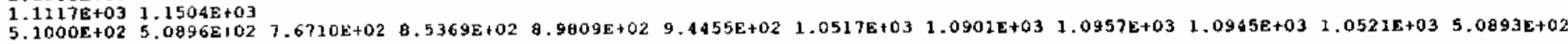

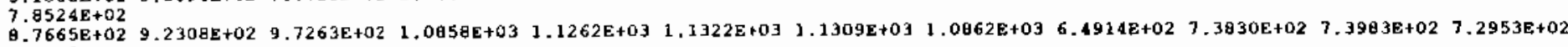

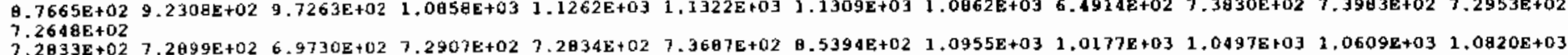

$1.1176 \varepsilon+03$

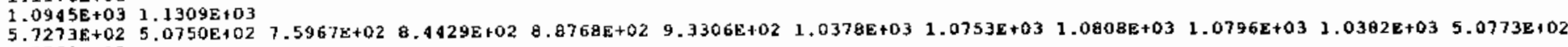

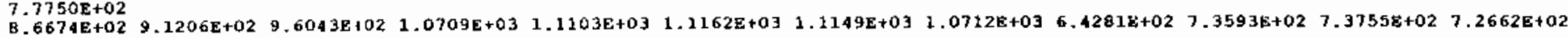
$7.2512 \mathrm{E}+027.2583 \mathrm{E}+02 \quad 6.8593 \mathrm{E}+02 \quad 7.2590 \mathrm{E}+02 \quad 7.2514 \mathrm{E}+02 \quad 7.2776 \mathrm{E}+02 \quad 0,5037 \mathrm{E}+02 \quad 1.0803 \mathrm{E}+03 \quad 1.0045 \mathrm{E}+03 \quad 1.0356 \mathrm{E}+03 \quad 1.0467 \mathrm{E}+03 \quad 1.0673 \mathrm{E}+03$ $1.1020 \varepsilon+03$

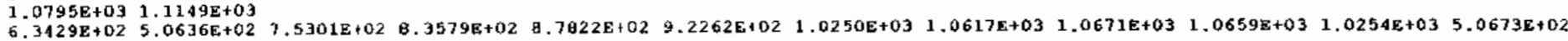

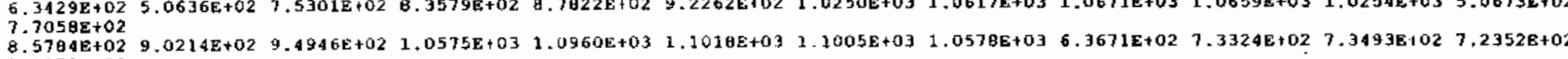

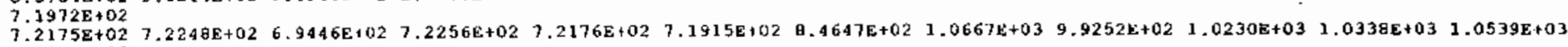
$7.2175 E+02$
$1.0979 E+03$
$1.0659 E+03$
$1.062005 E+103$

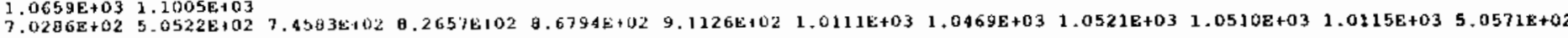

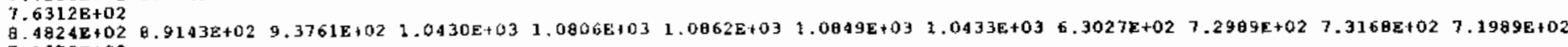

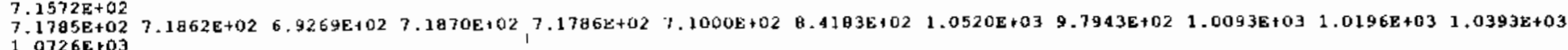

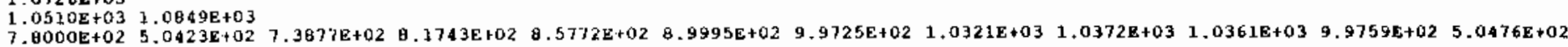

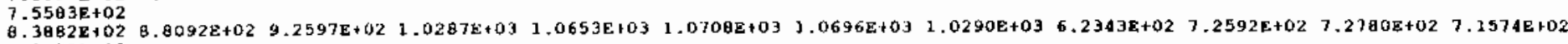

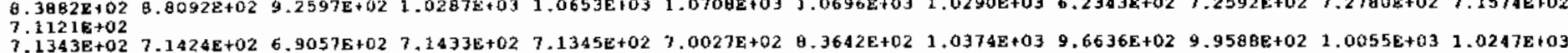
$1.0576 \mathrm{E}+03$

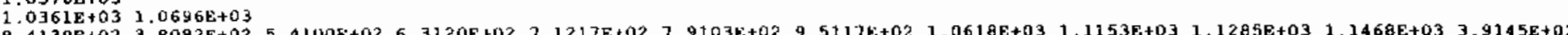

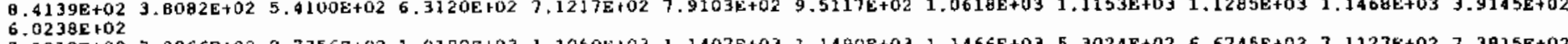
$7.1212 E+02 \quad 7.98668+02 \quad 8.7356 E+02 \quad 1.0180 E+03 \quad 1.1050 E+03 \quad 1.1407 E+03 \quad 3.14908+03 \quad 1.1466 E+03 \quad 5.3024 E+02 \quad 6.6745 E+02 \quad 7.1127 \varepsilon+02 \quad 7.3815 E+02$ $7.5019 E+02$

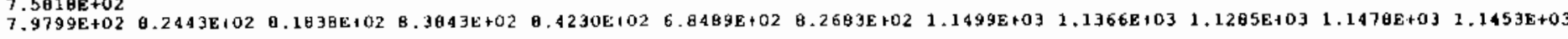




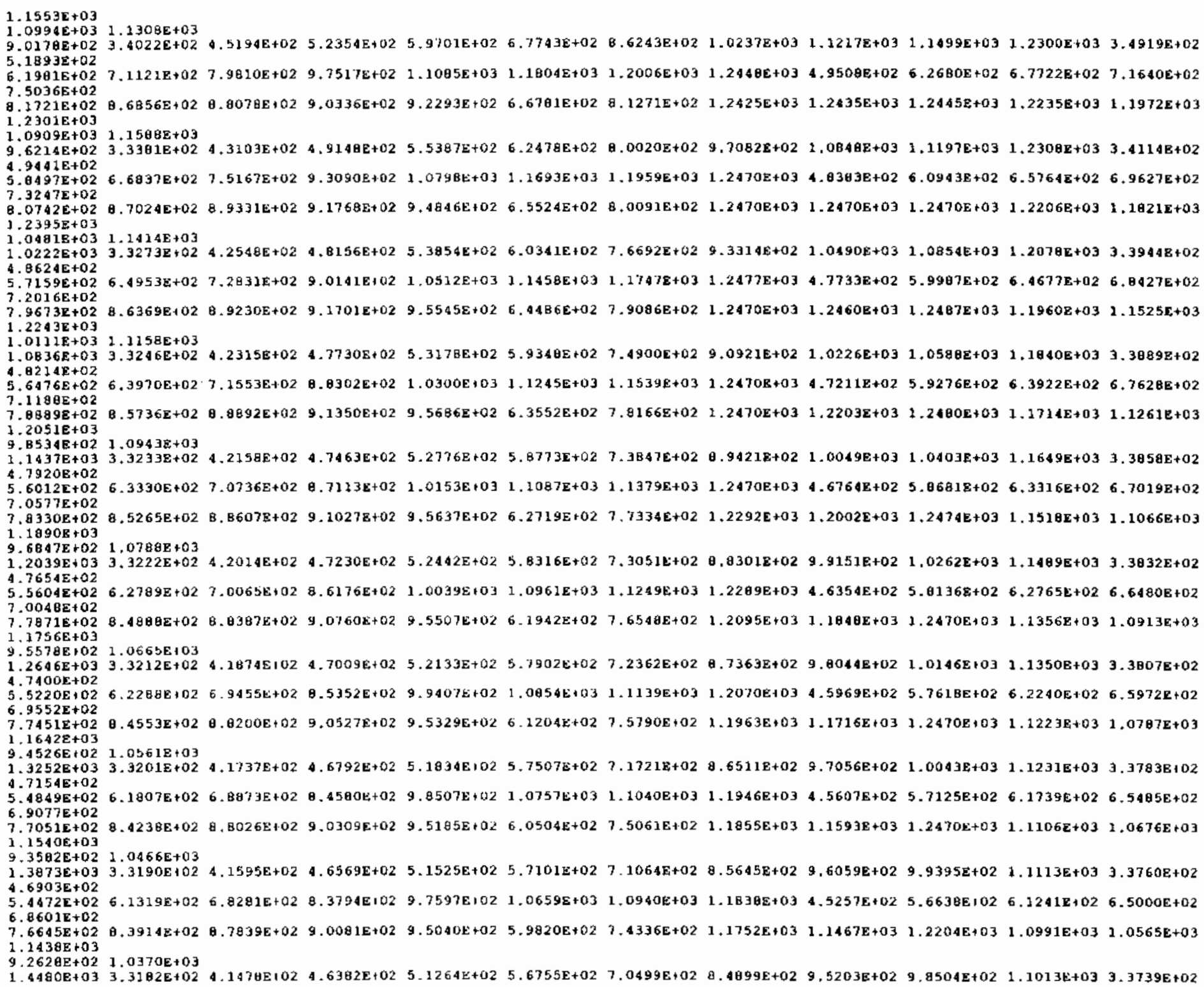

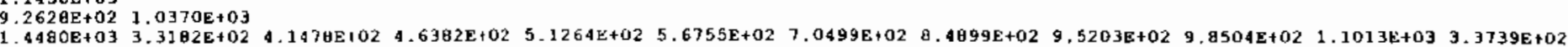




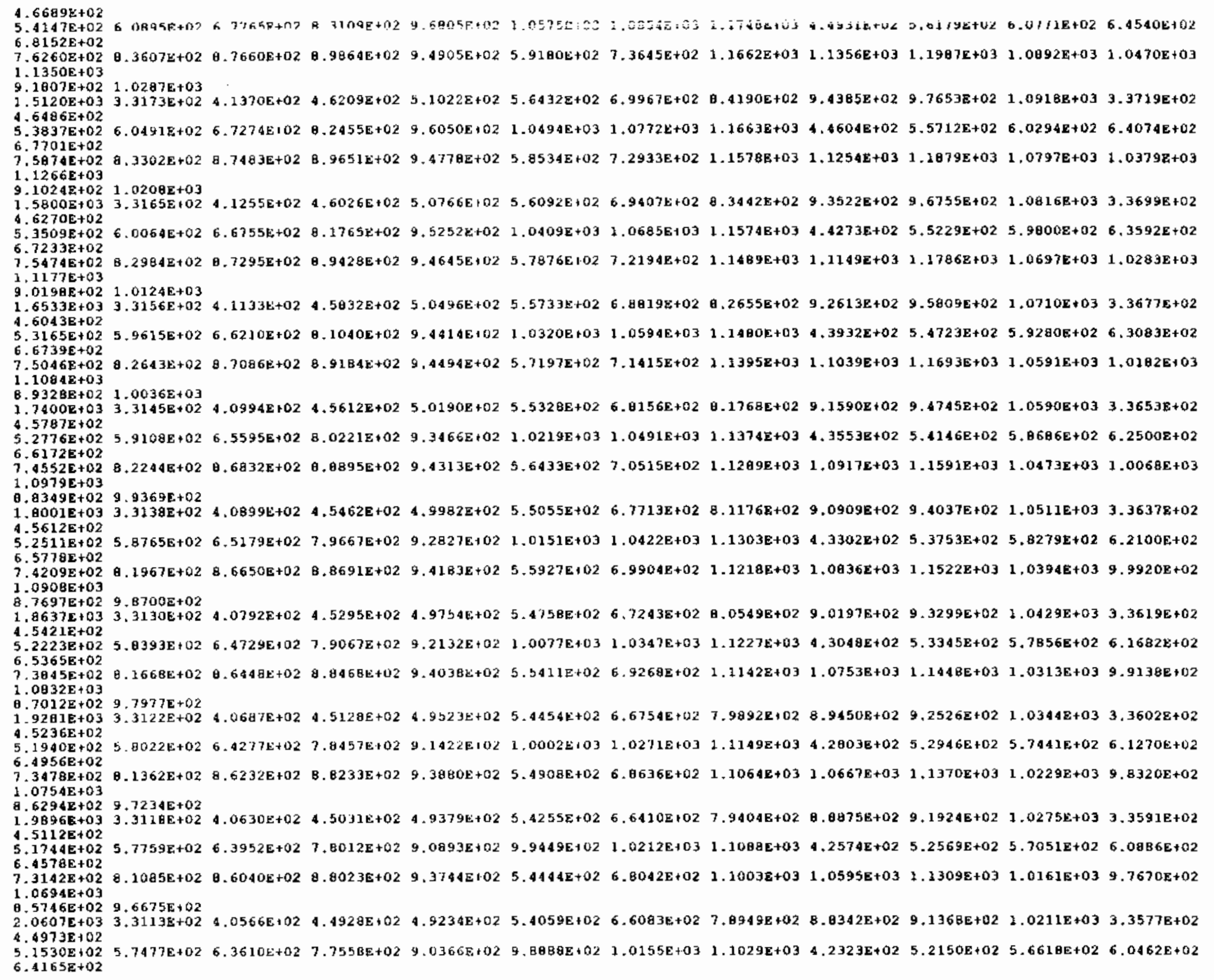




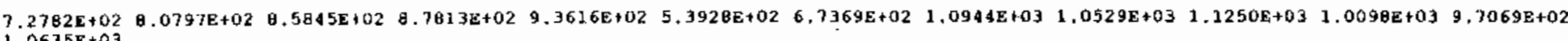
$1.0635 \mathrm{E}+03$

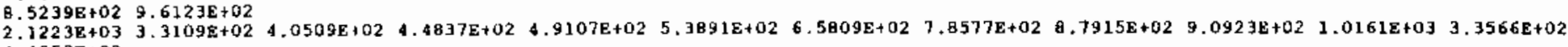
$4.48538+02$

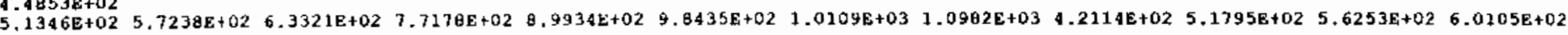

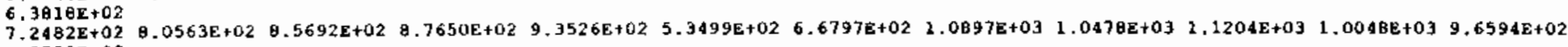
$1.0589 \mathrm{E}+03$

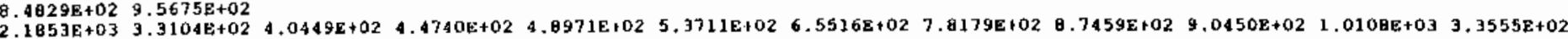

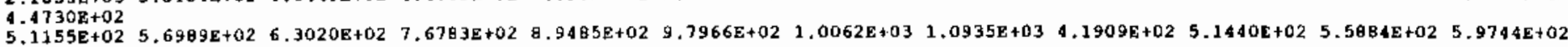

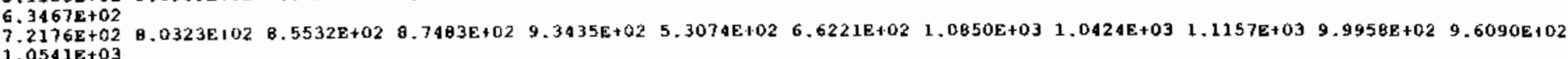
$\begin{aligned} & 1,0541 E+03 \\ & 8.4392 E+02\end{aligned} 9.5211 z+02$

$2.2615 \mathrm{E}+03 \quad 3.3099 \mathrm{E}+02 \quad 4.03 B 1 E+02 \quad 4,4632 \mathrm{E}+02 \quad 4.8819 \mathrm{E}+02 \quad 5.3509 \mathrm{E}+02 \quad 6.5188 \mathrm{E}+02 \quad 7.7732 \mathrm{E}+02 \quad 0.6950 \mathrm{E}+02 \quad 8.9922 E+02 \quad 1.0050 \mathrm{E}+03 \quad 3.3542 \mathrm{E}+02$

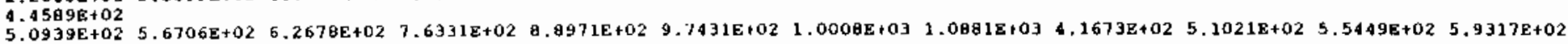

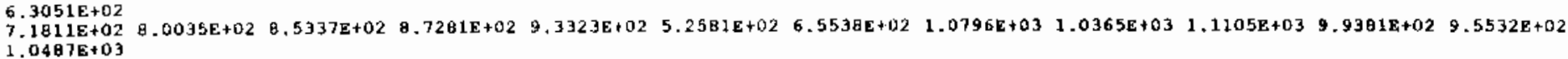

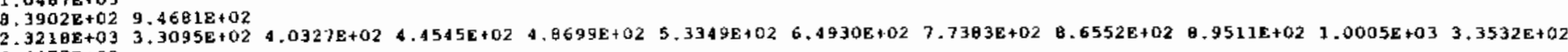

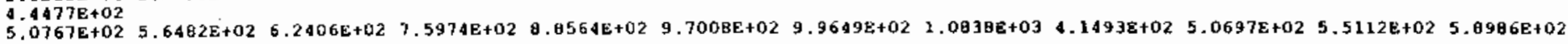

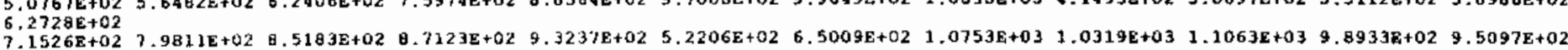
$1.0444 \mathrm{E}+03$

a. $3519 \mathrm{E}+02 \quad 9.42628+02$

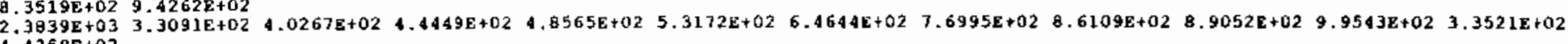

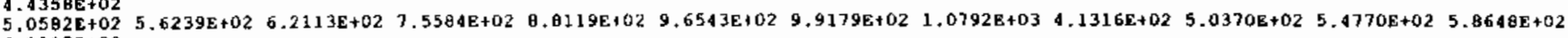

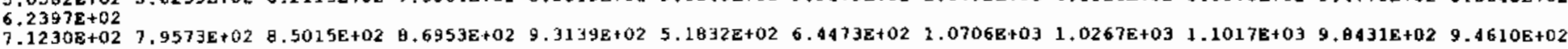
$1.0396 \mathrm{E}+03$

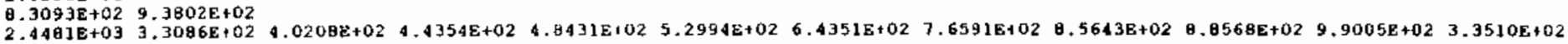
$2.441 E+03$
$4.4240 \mathrm{E}+02$ $5.0400 E+02 \quad 5.6000 E+02 \quad 6.1821 E+02 \quad 7.5191 E+02 \quad 8.7664 E+02 \quad 9.6063 E+02 \quad 9.8693 E+02 \quad 1.0743 E+03 \quad 4.2130 E+02 \quad 5.003 \theta E+02 \quad 5.4422 E+02 \quad 5.0303 E+02$ $\begin{aligned} & 6.2058 \mathrm{E}+02 \\ & 7.0922 \mathrm{E}+02 \\ & 1.0347 \mathrm{E}+03\end{aligned} 7.9322 \mathrm{E}+02 \quad 8.4831 \mathrm{E}+02 \quad 8.6768 \mathrm{E}+02 \quad 9.3025 \mathrm{E}+02 \quad 5.1459 \mathrm{E}+02 \quad 6.3927 \mathrm{E}+02 \quad 1.0657 \mathrm{E}+03 \quad 1.0212 \mathrm{E}+03 \quad 1.0969 \mathrm{E}+03 \quad 9.7898 \mathrm{E}+02 \quad 9.9096 \mathrm{E}+02$ $\begin{aligned} & 1.0347 E+03 \\ & 0.2647 E+02\end{aligned} 9.3329 E+122$

$2.5005 \mathrm{E}+03$ 3.3082E+02 $4.0153 \mathrm{E}+02 \quad 4.4267 \mathrm{E}+02 \quad 4.8309 \mathrm{E}+02 \quad 5.2832 \mathrm{E}+02 \quad 6.4097 \mathrm{E}+02 \quad 7.6226 \mathrm{E}+02 \quad \mathrm{~B} .5222 \mathrm{E}+02 \quad 8.8130 \mathrm{E}+02 \quad 9.8515 \mathrm{E}+02 \quad 3.3501 \mathrm{E}+02$

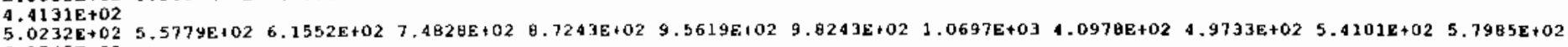

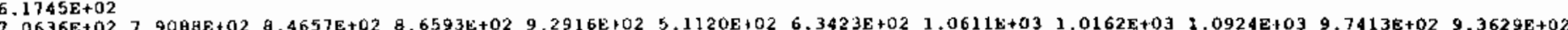
$7.0636 \mathrm{E}+02$ B.2243E+02 $9.2891 \mathrm{E} 102$

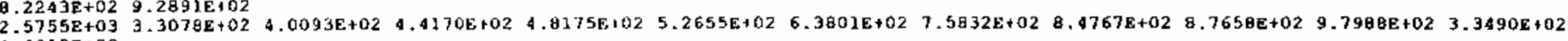

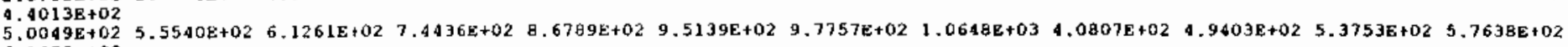

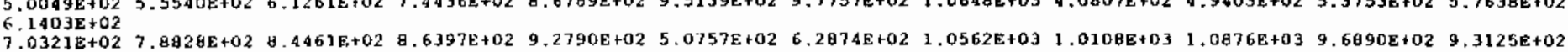

$3.0252 \mathrm{E}+03$

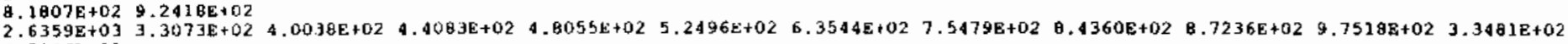

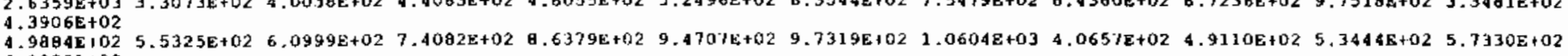
6. $1098 \mathrm{E}+02$

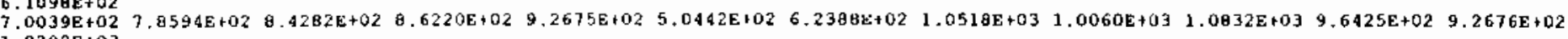

$1.1417 \mathrm{E}+02 \quad 9.1992 \mathrm{E}+02$ 


\begin{abstract}
$2.6960 E+03 \quad 3.3069 E+02 \quad 3.9982 E+02 \quad 4.3995 E+02 \quad 4.7932 E+02 \quad 5.2334 E+02 \quad 6.32 \theta 3 E+02 \quad 7.5119 E+02 \quad 8.3947 E+02 \quad 8.6807 E+02 \quad 9.7042 E+02 \quad 3,3471 E+02$

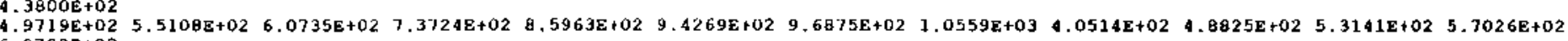

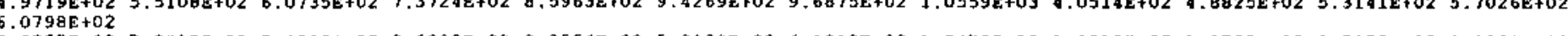

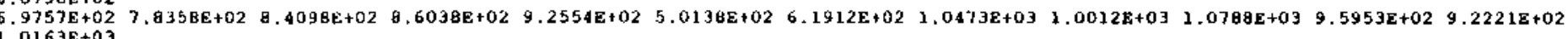
B. $1020 \mathrm{E}+02 \quad 9.1560 \mathrm{E}+02$

$2.7664 \mathrm{E}+03 \quad 3.3065 \mathrm{E}+02 \quad 3.9919 \mathrm{E}+02 \quad 6.3895 \mathrm{E}+02 \quad 4.7793 \mathrm{E}+02 \quad 5.2151 \mathrm{E}+02 \quad 6.2966 \mathrm{E}+02 \quad 7.4711 \mathrm{E}+02 \quad 0,3477 \mathrm{E}+02 \quad 8.6319 \mathrm{E}+02 \quad 9.6501 \mathrm{E}+02 \quad 3.3461 \mathrm{E}+02$

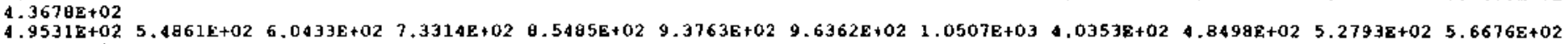
$6.0450 \mathrm{E}+02$ 2

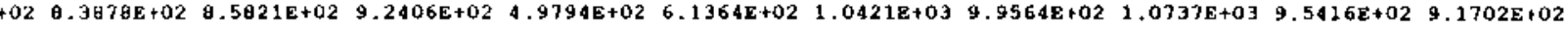
B. $0569 \mathrm{E}+02 \quad 9.1062 \mathrm{E}+02$

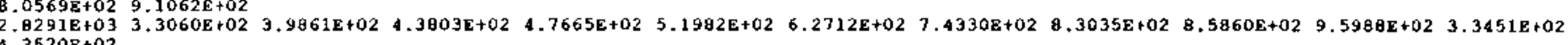

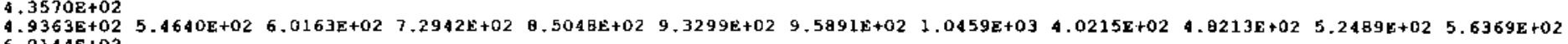

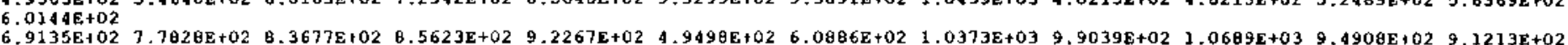
$1.0063 \mathrm{E}+03$

Q.0146E+02 $9.0605 \mathrm{E}+02$
\end{abstract}


-var2.17 trurng bd full power spiked thot chamnel reflood station blackout fhygen.

40

height $(i n)$
node $i t=0.08333 \mathrm{~h}$

node $\quad+t=0.08333 \mathrm{~h}$

node $306 t=0.08333$ h

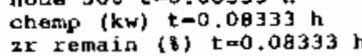

$\begin{array}{ll}2 x & \text { remain (b) } t \times 0.08333 \mathrm{~h} \\ \text { ux } & \text { remain (b) } \mathrm{t}=0.08333 \mathrm{~h}\end{array}$

$h 2$ fraction, flow region- 1 at $t-0.08333 \mathrm{~h}$

h2 fraction, flow region- 2 at $t=0.08333 \mathrm{~h}$

h2 fraction, flow region- 3 at $t=0.08333 \mathrm{~h}$

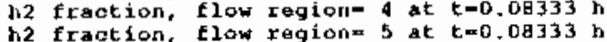

hit fraction, flow region= 5 at $t=0$

node $1 \mathrm{t}=0.2777 \mathrm{~h}$

node $3 t=0.27770 \mathrm{~h}$

node $306 \mathrm{t}-0.27778 \mathrm{~h}$
chemp $(\mathrm{kw}) \mathrm{t}-0.2777 \mathrm{~g}$ h

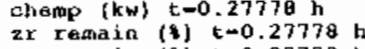

ur remain (8) $t-0.2777 \mathrm{~h}$

h2 fraction, flow region- 1 at $t=0.27770$ h

$h 2$ Exaction, flow region- 2 at $t=0.2777 \theta$

h2 fxaction, flow region ot at $t=0.2777$ h

h2 traction, flou reglon 5 t

axial level h2 fraction $t=0.27778$ b

node $1 \mathrm{t}-0.00166 \mathrm{~h}$

nade $3 t=0.80366$ th

node $306 \mathrm{t}$ to.

zr remain (8) $t=0.80166$

ur remain (z) $t=0.80166$

Fad loss (kw) $t=0.80166 \mathrm{~h}$

h2 fraction, flow region- 1 at $t-0.00166 \mathrm{~h}$

h2 fraction, flow reglon= 2 at $t=0.00366$ h

fration, flow ragion- at $t=0.80166 \mathrm{~h}$

2 fraction, flow region- 5 at $t-0 . B 0166 \mathrm{~h}$

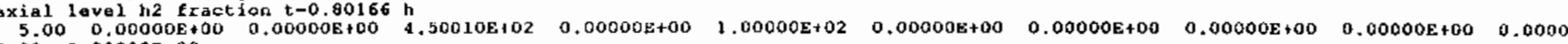
$\begin{array}{lllllllllll}0.00000 \mathrm{E}+00 & 0.00000 \mathrm{E}+00 & 0.00000 \mathrm{E}+00 & 0.00000 \mathrm{E}+00 & 4.50167 \mathrm{E}+02 & 0.00000 \mathrm{E}+00 & 1.00000 \mathrm{E}+02 & 0.00000 \mathrm{E}+00 & 0.00000 \mathrm{E}+00 & 0.00000 \mathrm{E}+00\end{array}$ $\begin{array}{lllllllll}0.00000 \mathrm{E}+00 & 0.00000 \mathrm{E}+00 & 1.00000 \mathrm{E}+02 & 0.00000 \mathrm{E}+00\end{array}$

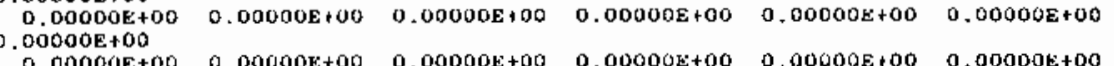

$0.00000 \mathrm{E}+00 \quad 0.00000 \mathrm{E}+00 \quad 0.00000 \mathrm{E}+00 \quad 0.00000 \mathrm{E}+00 \quad 0.00000 \mathrm{E}+00 \quad 0.00000 \mathrm{E}+00$

$\begin{array}{lllllllllll}14.75 & 0.00000 \mathrm{E}+00 & 0.00000 \mathrm{E}+00 & 4.50432 \mathrm{E}+02 & 0.00000 \mathrm{E}+00 & 1.00000 \mathrm{E}+02 & 0.00000 \mathrm{E}+00 & 0.00000 \mathrm{E}+00 & 0.00000 \mathrm{E}+00 & 0.00000 \mathrm{E}+00 & 0.0000\end{array}$ $\begin{array}{lllllllllll}0.00000 E+00 & 0.00000 E+00 & 0.00000 E+00 & 0.00000 E+00 & 4.52122 E+02 & 0.00000 E+00 & 1.00000 E+02 & 0.00000 E+00 & 0.00000 E+00 & 0.00000 E+00\end{array}$ $\begin{array}{lllllllllll}0.00000 \mathrm{E}+00 & 0.000008100 & 0.00000 \mathrm{E}+00 & 0.00000 \mathrm{E}+00 & 0.00000 \mathrm{E}+00 & 0.00000 \mathrm{E}+00 & 4.53251 \mathrm{E}+02 & 0.00000 \mathrm{E}+00 & 1.00000 \mathrm{E}+02 & 0.00000 \mathrm{E}+00\end{array}$

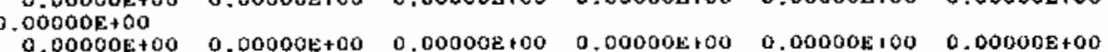

$\begin{array}{lllllllllll}21.00 & 0.00000 \mathrm{E}+00 & 0.00000 \mathrm{E}+00 & 4.53327 \mathrm{E}+02 & 0.00000 \mathrm{E}+00 & 1.00000 \mathrm{E}+02 & 0.00000 \mathrm{E}+00 & 0.00000 \mathrm{E}+00 & 0.00000 \mathrm{E}+00 & 0.00000 \mathrm{E}+100 & 0.0000\end{array}$ $\begin{array}{cccccccccc}0 \mathrm{E}+00 & 0.00000 \mathrm{E}+00 \\ 0.00000 \mathrm{E}+00 & 0.00000 \mathrm{E}+00 & 0.00000 \mathrm{E}+00 & 0.00000 \mathrm{E}+00 & 4.52063 \mathrm{E}+\mathrm{O} 2 & 0.00000 \mathrm{E}+00 & 1.00000 \mathrm{E}+02 & 0.00000 \mathrm{E}+00 & 0.00000 \mathrm{E}+00 & 0.00000 \mathrm{E}+00\end{array}$ $\begin{array}{llllllllll}0.00000 E+00 & 0.0000 E+00 & 0.00000 E+100 & 0.00000 E+00 & 0.00000 E+00 & 0.00000 E+00 & 4.50061 E+02 & 0.00000 E+00 & 1.00000 E+02 & 0.000008+00\end{array}$

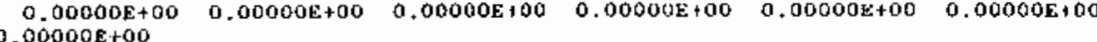

$\begin{array}{llllll}0.00000 \mathrm{E}+00 & 0.00000 \mathrm{E}+00 & 0.00000 \mathrm{E}+00 & 0.00000 \mathrm{E}+00 & 0.00000 \mathrm{E}+00 & 0.00040 \mathrm{E}+00\end{array}$ 
$\begin{array}{lllllllllll}24.00 & 0.000008+00 & 0.000008+00 & 4.82270 E+02 & 0.00000 E+00 & 1.00000 E+02 & 0.00000 E+00 & 0.00000 E+00 & 0.00000 E+00 & 0.00000 E+00 & 0.0000\end{array}$

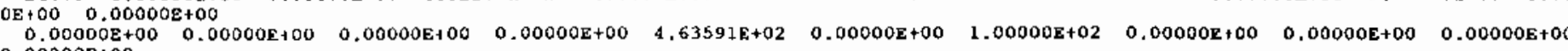

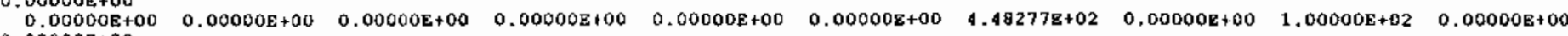
$0.00000 \mathrm{E}+00$

$0.00000 \mathrm{E}+00 \quad 0.00000 \mathrm{E}+00 \quad 0.00000 \mathrm{E}+000.00000 \mathrm{E}+00 \quad 0.00000 \mathrm{E}+00 \quad 0.00000 \mathrm{E}+00$

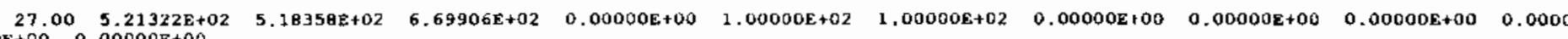
$\begin{array}{llllllllll}0.00000 \mathrm{E}+00 & 0.00000 \mathrm{E}+00 & 3.32936 \mathrm{E}+02 & 3.39 \mathrm{~B} 06 \mathrm{E}+02 & 4.79405 \mathrm{E}+02 & 0,00000 \mathrm{E} 100 & 1.00000 \mathrm{E}+02 & 1.00000 \mathrm{E}+02 & 0.00000 \mathrm{E}+00 & 0.00000 \mathrm{E}+00\end{array}$

$0.00000 \mathrm{E}+00$

$\begin{array}{llllllllll}0.00000 \mathrm{E}+00 & 0.00000 \mathrm{E}+00 & 0.00000 \mathrm{E}+00 & 0.00000 \mathrm{E}+00 & 3.30562 \mathrm{E}+02 & 3.34427 \mathrm{E}+02 & 4.00936 \mathrm{E}+02 & 0.00000 \mathrm{E}+00 & 1.00000 \mathrm{E}+02 & 1.00000 \mathrm{E}+02\end{array}$

$\begin{array}{cccccc}0.00000 \mathrm{E}+00 & 0.00000 \mathrm{E}+00 & 0.00000 \mathrm{E}+00 & 0.00000 \mathrm{E}+00 & 0.00000 \mathrm{E}+00 & 0.00000 \mathrm{E}+00\end{array}$

$\begin{array}{lllllllllll}30.50 & 6.06260 \mathrm{E}+02 & 6.12138 \mathrm{E}+02 & 7.25089 \mathrm{E}+02 & 0.00000 \mathrm{E}+00 & 1.00000 \mathrm{E}+02 & 1.00000 \mathrm{E}+02 & 0.00000 \mathrm{E}+00 & 0.00000 \mathrm{E}+00 & 0.00000 \mathrm{E}+00 & 0.0000\end{array}$

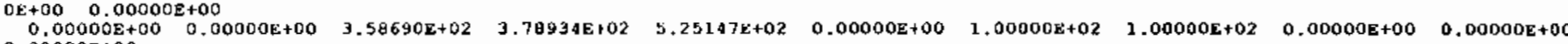

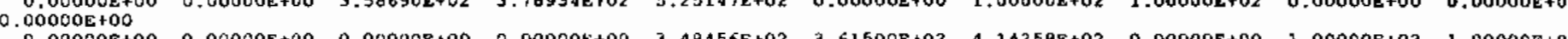

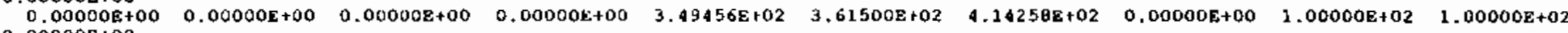

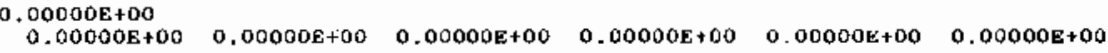

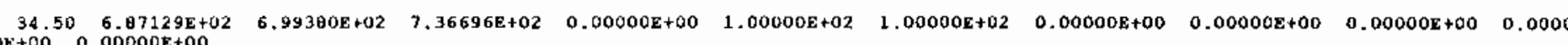
$\begin{array}{ccccccccc}0.0000 \mathrm{E}+00 \mathrm{E}+0.00000 \mathrm{E}+00 & 3.01972 \mathrm{E}+02 & 4.15581 \mathrm{E}+02 & 5.61428 \mathrm{E}+02 & 0.00000 \mathrm{E}+00 & 1.00000 \mathrm{E}+02 & 1.00000 \mathrm{E}+02 & 0.00000 \mathrm{E}+00 & 0.00000 \mathrm{E}+00\end{array}$

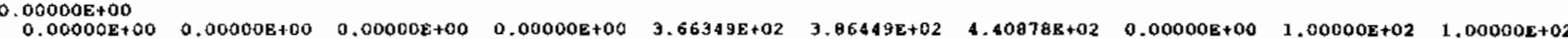
$0.00000 \mathrm{E}+00$
$0.0000 \mathrm{E}+00$

$0.000008+00 \quad 0.000000+00 \quad 0.00000$

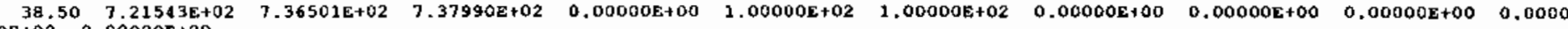

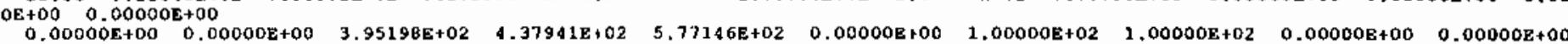

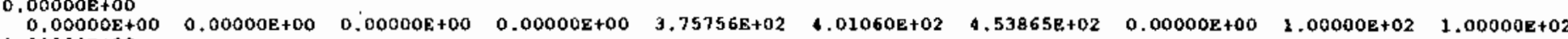
$\begin{array}{cccccc}0.00000 \mathrm{E}+00 & 0.00000 \mathrm{E}+00 & 0.00000 \mathrm{E}+00 & 0.00000 \mathrm{E}+00 & 3.75756 \mathrm{E}+02 & 6.01060 \mathrm{E}+02 \\ 0.000 & 0.00000 \mathrm{E}+00 & 0.00000 \mathrm{E}+00 & 0.00000 \mathrm{E}+00 & 0.00000 \mathrm{E}+00 & 0.00000 \mathrm{E}+00\end{array}$

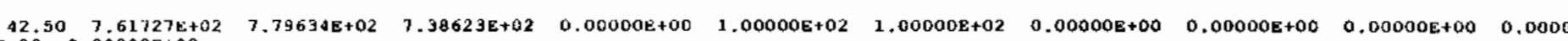
$\begin{array}{cccccccccc}0 E+00 & 0.000000 \\ 0.0000 E+00 & 0.00000 E+00 & 4.10746 E+02 & 4.63296 E+02 & 5.9103 \theta E+02 & 0.00000 \mathrm{E}+00 & 1.00000 \mathrm{E}+02 & 1.00000 \mathrm{E}+02 & 0.00000 \mathrm{E}+00 & 0.00000 \mathrm{E}+00\end{array}$ $\begin{array}{cccccccccc}0.00000 \mathrm{E}+00 & 0.00000 \mathrm{E}+00 & 0.00000 \mathrm{E}+00 & 0.00000 \mathrm{E}+00 & 3.86740 \mathrm{E}+02 & 4.17981 E+02 & 4.69537 \mathrm{E}+02 & 0.00000 \mathrm{E}+00 & 1.00000 \mathrm{E}+02 & 1.00000 \mathrm{E}+02\end{array}$ $0.00000 \mathrm{E}+00$
$0.0000 \mathrm{E}+00$

$0.00000 \mathrm{E}+00 \quad 0.00000 \mathrm{E}+00 \quad 0.00000 \mathrm{E}+00 \quad 0.00000 \mathrm{E}+00 \quad 0.00000 \mathrm{E}+00 \quad 0.00000 \mathrm{E}+00$

$46.50 \quad 7.96972 \mathrm{E}+02 \quad 8.17953 \mathrm{E}+02 \quad 7.39097 \mathrm{E}+02 \quad 0.00000 \mathrm{E}+00 \quad 1,00000 \mathrm{E}+02 \quad 1.00000 \mathrm{E}+02 \quad 0.00000 \mathrm{E}+00 \quad 0.00000 \mathrm{E}+00 \quad 0.00000 \mathrm{E}+00 \quad 0.0000$

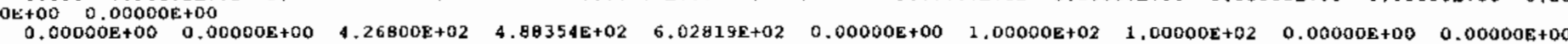

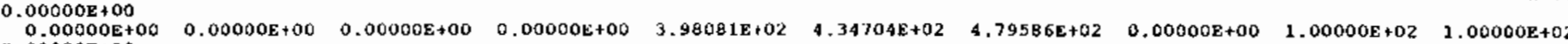

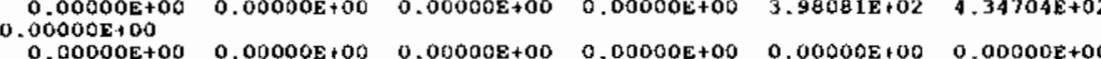

$\begin{array}{lllllllllll}50.50 & 0.22945 E+02 & B .45926 \mathrm{E}+02 & 7.39447 \mathrm{E}+02 & 0.00000 \mathrm{E}+00 & 1.00000 \mathrm{E}+02 & 1.00000 \mathrm{E}+02 & 0.00000 \mathrm{E}+00 & 0.00000 \mathrm{E}+00 & 0.00000 \mathrm{E}+00 & 0.0000\end{array}$ $\begin{array}{cccccccccc}O E E+00 & 0.00000 E+00 \\ 0.00000 \mathrm{E}+00 & 0.00000 E+00 & 4.40 y 57 E+02 & 5.10729 \mathrm{E}+02 & 6.151 \theta 2 \mathrm{E}+02 & 0.00000 \mathrm{E}+00 & 1.00000 \mathrm{E}+02 & 1.00000 \mathrm{E}+02 & 0.00000 \mathrm{E}+00 & 0.00000 \mathrm{E}+00\end{array}$ $\begin{array}{lllllllllll}0.00000 \mathrm{E}+00 & 0.0000 \mathrm{E}+00 & 0.00000 \mathrm{E}+00 & 0.00000 \mathrm{E}+00 & 0.00000 \mathrm{E}+00 & 4.07850 \mathrm{E}+02 & 4.49439 \mathrm{E}+02 & 4.91809 \mathrm{E}+02 & 0.00000 \mathrm{E}+00 & 1.00000 \mathrm{E}+02 & 1.00000 \mathrm{E}+02\end{array}$ $0.00000+00$

$0.00000 \mathrm{E}+00 \quad 0.00000 \mathrm{E}+00 \quad 0,00000 \mathrm{E}+00 \quad 0.00000 \mathrm{E}+00 \quad 0,00000 \mathrm{E}+00 \quad 0.00000 \mathrm{E}+00$

$\begin{array}{lllllllllll}54.50 & 0.326 \theta 5 \mathrm{E}+02 & 8.56295 \mathrm{E}+02 & 7.39577 \mathrm{E}+02 & 0.00000 \mathrm{E}+00 & 1.00000 \mathrm{E}+02 & 1.00000 \mathrm{E} 102 & 0.00000 \mathrm{E}+00 & 0.00000 \mathrm{E}+00 & 0.00000 \mathrm{E}+00 & 0.0000\end{array}$ $0 E+000.00000 \mathrm{E}+00$ 
$\begin{array}{clllllllll}0.00000 E+00 & 0.00000 \mathrm{E}+00 & 4.51197 \mathrm{E}+02 & 5.27143 \mathrm{E}+02 & 6.26354 \mathrm{E}+02 & 0.00000 \mathrm{E}+00 & 1.00000 \mathrm{E}+02 & 1.00000 \mathrm{E}+02 & 0.00000 \mathrm{E}+00 & 0.00000 \mathrm{E}+00\end{array}$

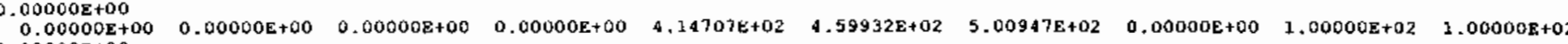

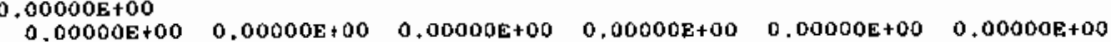

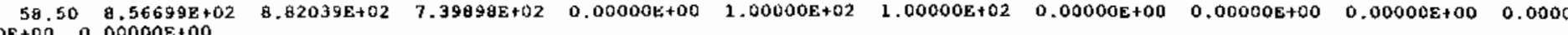
$\begin{array}{cccccccccc}0 \mathrm{E}+00 & 0.00000 \mathrm{E}+00 \\ 0.00000 \mathrm{E}+00 & 0.00000 \mathrm{E}+00 & 4.66086 \mathrm{E}+02 & 5.49533 \mathrm{E}+02 & 6.38470 \mathrm{E}+02 & 0.00000 \mathrm{E}+00 & 1.00000 \mathrm{E}+02 & 1.00000 \mathrm{E}+02 & 0.00000 \mathrm{E}+00 & 0.00000 \mathrm{E}+00\end{array}$ $\begin{array}{cccccccccc}0.00000 E+00 & 0.00000 E+00 & 0.00000 E+00 & 0.00000 E+00 & 4.2482 \theta E+02 & 4.74742 E+02 & 5.12682 E+02 & 0.00000 E+00 & 1.00000 E+02 & 1.00000 E+02\end{array}$ $\begin{array}{ccccc}0.00000 \mathrm{E}+00 \\ 0.0000 \mathrm{x}+00 & 0.00000 \mathrm{E}+00 & 0.00000 \mathrm{E}+00 & 0.00000 \mathrm{E}+00 & 0.00000 \mathrm{E}+00 \quad 0.00000 \mathrm{E}+00\end{array}$

$\begin{array}{lllllllllll}62.50 & 8.88377 E+02 & 9.16535 E+02 & 7.40321 E+02 & 0.00000 E+00 & 1.00000 E+02 & 1.00000 E+02 & 0.00000 E+00 & 0.00000 E+00 & 0.000008+00 & 0.0000\end{array}$

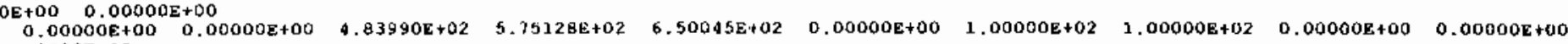
$\begin{array}{llllllllll}0.00000 \mathrm{E}+00 & 0.00000 \mathrm{E}+00 & 0.00000 \mathrm{E}+00 & 0.00000 \mathrm{E}+00 & 4.37180 \mathrm{E}+02 & 4.9208 \mathrm{EE}+02 & 5.22173 \mathrm{E}+02 & 0.00000 \mathrm{E}+00 & 1.00000 \mathrm{E}+02 & 1.00000 \mathrm{E}+02\end{array}$ $\begin{array}{cccc}0.00000 \mathrm{E}+00 & 0.00000 \mathrm{E}+00 & 0.00000 \mathrm{E}+00 & 0.00000 \\ 0.000 \mathrm{E}+00 & 0.00000 \mathrm{E}+00 & 0.000008+00 & 0.00000\end{array}$

$0.00000 \mathrm{E}+00 \quad 0.00000 \mathrm{E}+00 \quad 0.000008+00 \quad 0.0000 \mathrm{E}+00 \quad 0.00000 \mathrm{E}+00 \quad 0.00000 \mathrm{E}+00$

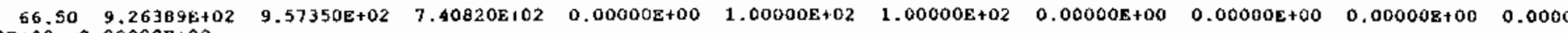

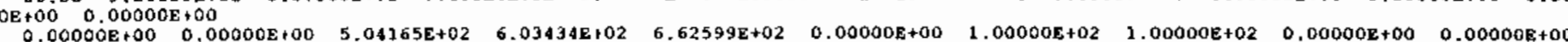
$\begin{array}{lllllllllll}0.00000 \mathrm{E}+00 & 0.00000 \mathrm{E}+00 & 0.00000 \mathrm{E}+00 & 0.00000 \mathrm{E}+00 & 4.509838+02 & 5.11269 \mathrm{E}+02 & 5.34135 \mathrm{E}+02 & 0.00000 \mathrm{E}+00 & 1.00000 \mathrm{E}+02 & 1.00000 \mathrm{E}+02\end{array}$ $\begin{array}{lllllll}0.00000 \mathrm{E}+00 & 0.00000 \mathrm{E}+00 & 0.00000 \mathrm{E} r 00 & 0.00000 \mathrm{E}+00 & 0.00000 \mathrm{E}+00 & 0.00000 \mathrm{E}+00\end{array}$

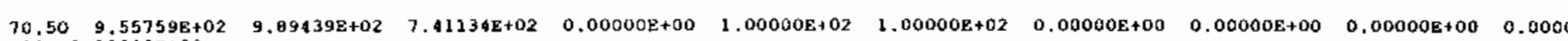
$\begin{array}{cccccccccc}0 \mathrm{E}+00 & 0.00000 \mathrm{E}+00 \\ 0.00000 \mathrm{E}+00 & 0.00000 \mathrm{E}+00 & 5.2367 \mathrm{BE}+02 & 6.30003 \mathrm{E}+02 & 6.73943 \mathrm{E}+02 & 0.00000 \mathrm{E}+00 & 1,00000 \mathrm{E}+02 & 1.00000 \mathrm{E}+02 & 0.00000 \mathrm{E}+00 & 0.00000 \mathrm{E}+00\end{array}$

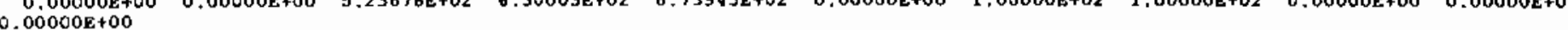
$\begin{array}{llllllllll}0.00000 \mathrm{E}+00 & 0.00000 \mathrm{E}+00 & 0.00000 \mathrm{E}+00 & 0.00000 \mathrm{E}+00 & 4.64305 \mathrm{E}+02 & 5.29336 \mathrm{E}+02 & 5.43529 \mathrm{E}+02 & 0.00000 \mathrm{E}+00 & 1.00000 \mathrm{E}+02 & 1.00000 \mathrm{E}+02\end{array}$ $0.00000 \mathrm{E}+00$

$\begin{array}{llllll}0.00000 \mathrm{E}+00 & 0.00000 \mathrm{E}+00 & 0.00000 \mathrm{E}+00 & 0.00000 \mathrm{E}+00 & 0.00000 \mathrm{E}+00 & 0.00000 \mathrm{E}+00\end{array}$

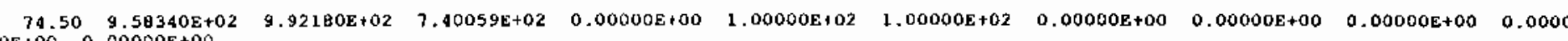
$\begin{array}{cccccccccc}0.00000 \mathrm{E}+00 & 0.00000 \mathrm{E}+00 & 5.37162 \mathrm{E}+02 & 6.49092 \mathrm{E}+02 & 6.02729 \mathrm{E}+02 & 0.00000 \mathrm{E}+00 & 1.00000 \mathrm{E}+02 & 1.00000 \mathrm{E}+02 & 0.00000 \mathrm{E}+00 & 0.00000 \mathrm{E}+00\end{array}$ $0.00000 \mathrm{E}+00$

$\begin{array}{llllllllll}0,00000 \mathrm{E}+00 & 0.00000 \mathrm{E}+00 & 0.00000 \mathrm{E}+00 & 0.00000 \mathrm{E}+00 & 4.72921 \varepsilon+02 & 5.40994 \varepsilon+02 & 5.53324 \mathrm{E}+02 & 0.00000 \mathrm{E}+00 & 1.00000 \mathrm{E}+02 & 1.00000 \mathrm{E}+02\end{array}$

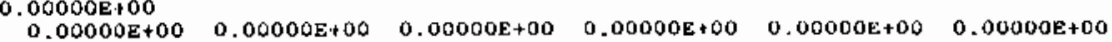

$\begin{array}{lllllllllll}78.50 & 9.35062 \mathrm{E}+02 & 9.66499 \mathrm{E}+02 & 7.33768 \mathrm{E}+02 & 0.00000 \mathrm{E}+00 & 1.00000 \mathrm{E}+02 & 1.00000 \mathrm{E}+02 & 0.00000 \mathrm{E}+00 & 0.00000 \mathrm{E}+00 & 0.00000 \mathrm{E}+00 & 0.0000\end{array}$

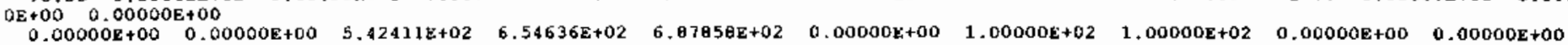

$\begin{array}{cccccccccc}0.0000000 E+00 & 0.00000 E+00 & 0.00000 E+00 & 0.00000 E+00 & 4.75465 E+02 & 5.44370 E+02 & 5.60931 E+02 & 0.00000 E+00 & 1.00000 E+02 & 1.00000 E+02\end{array}$

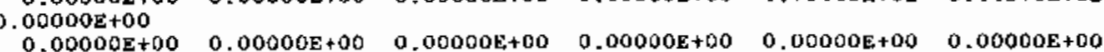

$\begin{array}{lllllllllll}82.50 & 9.31140 \mathrm{E}+02 & 9.62259 \mathrm{E}+02 & 6.97757 \mathrm{E}+02 & 0.00000 \mathrm{E}+00 & 1.00000 \mathrm{E}+02 & 1.00000 \mathrm{E}+02 & 0.00000 \mathrm{E}+00 & 0.00000 \mathrm{E}+00 & 0.00000 \mathrm{~B}+00 & 0.0000\end{array}$

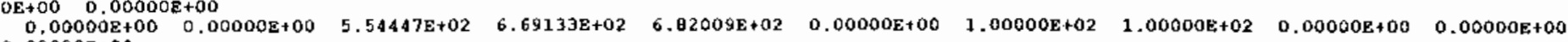
$\begin{array}{llllllllll}0.00000 \mathrm{E}+00 & 0.00000 \mathrm{E}+00 & 0.00000 \mathrm{E}+00 & 0.00000 \mathrm{E}+00 & 4.8283 \theta \mathrm{E}+02 & 5.53976 \mathrm{E}+02 & 5.6 \mathrm{a} 759 \mathrm{E}+02 & 0.00000 \mathrm{E}+00 & 1.00000 \mathrm{E}+02 & 1.00000 \mathrm{E}+02\end{array}$ $0.0000 \mathrm{E}+00$

$\begin{array}{lllllll}0.00000 E+00 & 0.00000 E+00 & 0.00000 E+00 & 0.00000 E+00 & 0.00000 E+00 & 0.00000 E+00\end{array}$

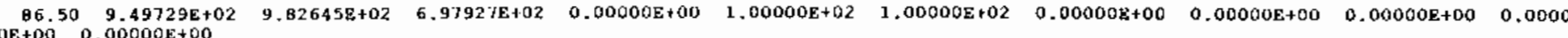

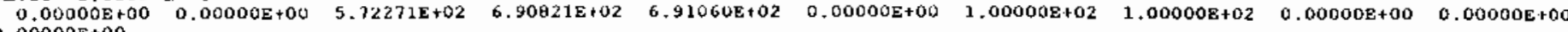
$0.00000 \mathrm{E}+00$ 
$\begin{array}{cccccccccc}0.00000 E+00 & 0.00000 E+00 & 0.00000 E+00 & 0.00000 E+00 & 4.94549 E+02 & 5.69062 E+02 & 5.77217 E+02 & 0.00000 E+00 & 1.00000 E+02 & 1.00000 E+02\end{array}$

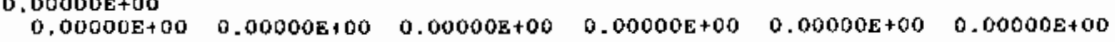

$\begin{array}{rllllllllll}90,50 & 9.70259 \mathrm{E}+02 & 1.00469 \mathrm{E}+03 & 7.33017 \mathrm{E}+02 & 0.00000 \mathrm{E}+00 & 1.00000 \mathrm{E}+02 & 1.00000 \mathrm{E}+02 & 0.00000 \mathrm{E}+00 & 0.00000 \mathrm{E}+00 & 0.00000 \mathrm{E}+00 & 0.0000\end{array}$ $\begin{array}{cccccccccc}0 \mathrm{E}+00 & 0.00000 \mathrm{E}+00 \\ 0.00000 \mathrm{E}+00 & 0.00000 \mathrm{E}+00 & 5.91377 \mathrm{E}+02 & 7.14143 \mathrm{E}+02 & 7.14321 \mathrm{E}+02 & 0.00000 \mathrm{E}+00 & 1.00000 \mathrm{E}+02 & 1.00000 \mathrm{E}+02 & 0.00000 \mathrm{E}+00 & 0.00000 \mathrm{E}+00\end{array}$

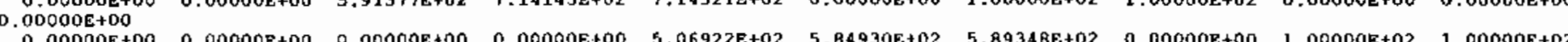
$\begin{array}{llllll}0.00000 \mathrm{E}+00 & 0.00000 \mathrm{E}+00 & 0.00000 \mathrm{E}+00 & 0.00000 \mathrm{E}+00 & 5.06922 \mathrm{E}+02 & 5.84930 \mathrm{E}+02\end{array}$

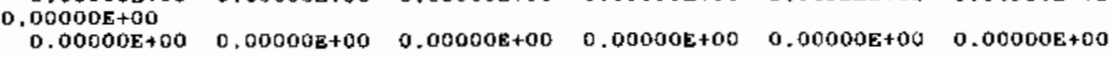

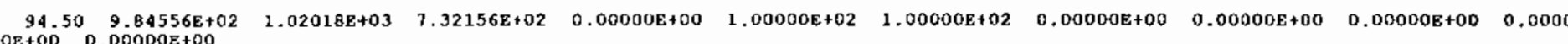
$\begin{array}{llllllllll}0.00000 E+00 & 0.00000 E+00 & 6.08992 E+02 & 7.34945 E+02 & 7.23902 E+02 & 0.00000 E+00 & 1.00000 E+02 & 1.00000 E+02 & 0.00000 E+00 & 0.00000 E+00\end{array}$

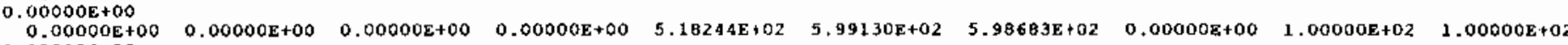

$\begin{array}{cccccc}0.00000 E+00 & 0.00000 E+00 & 0.00000 E+00 & 0.00000 E+00 & 0.00000 E+00 & 0.00000 E+00\end{array}$

$\begin{array}{lllllllllll}98.50 & 1.00229 E+03 & 1.03918 E+03 & 6.98607 \mathrm{E}+02 & 0.00000 \varepsilon+00 & 1.00000 E+02 & 1.00000 \mathrm{E}+02 & 0.00000 \mathrm{E}+00 & 0.00000 \mathrm{E}+00 & 0.00000 \mathrm{E}+00 & 0.0000\end{array}$

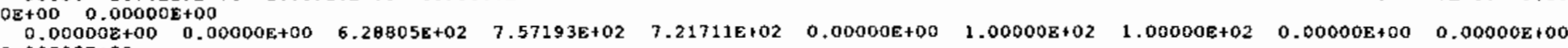

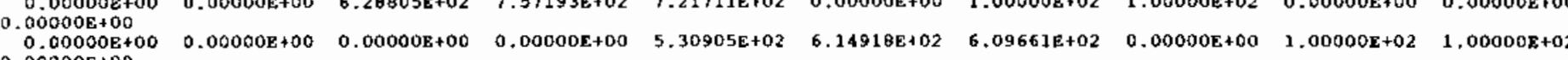

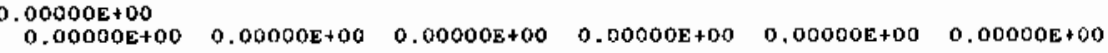

$\begin{array}{lllllllllll}102.50 & 1.01791 E+03 & 1.05615 E+03 & 6.98833 E+02 & 0.00000 E+00 & 1.00000 E+02 & 1.00000 E+02 & 0.00000 E+00 & 0.00000 E+00 & 0.00000 E+00 & 0.0000\end{array}$ $\begin{array}{cccccccccc}0.00000 \mathrm{E}+00 & 0.00000 \varepsilon+00 & 6.49180 \mathrm{E}+02 & 7.78472 \mathrm{E}+02 & 7.30935 \mathrm{E}+02 & 0.00000 \mathrm{E}+00 & 1.00000 \mathrm{E}+02 & 1.00000 \mathrm{E}+02 & 0.00000 \mathrm{E}+00 & 0.09000 \mathrm{E}+00\end{array}$

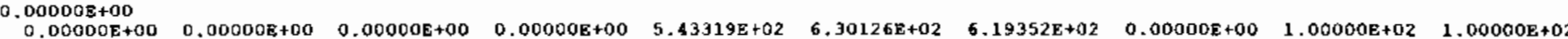

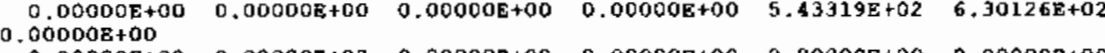

$0.000008+00 \quad 0.000000+00 \quad 0.000000+00+0.00000$

$\begin{array}{lllllllllll}106.50 & 1.03548 \mathrm{E}+03 & 1.07496 \mathrm{E}+03 & 7.33889 \mathrm{E}+02 & 0.00000 \mathrm{E}+00 & 1.00000 \mathrm{E}+02 & 1.00000 \mathrm{E}+02 & 0.00000 \mathrm{E}+00 & 0.00000 \mathrm{E}+00 & 0.00000 \mathrm{E}+00 & 0.0000\end{array}$

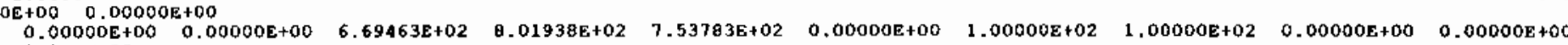
$\begin{array}{llllllllll}0.00000 \mathrm{E}+00 & 0.00000 \mathrm{E}+00 & 0.00000 \mathrm{E}+00 & 0.00000 \mathrm{E}+00 & 5.56 \mathrm{~B} 09 \mathrm{E}+02 & 6.46630 \mathrm{E}+02 & 6.32778 \mathrm{E}+02 & 0.00000 \mathrm{E}+00 & 1.00000 \mathrm{E}+02 & 1.00000 \mathrm{E}+02\end{array}$ $\begin{array}{lllllll}0.0000 E+00 & 0.0000 E+00 & 0.00000 E+00 & 0.00000 E+00 & 0.00000 E+00 & 0.00000 E+00 & 0.00000 E+00\end{array}$

$\begin{array}{lllllllllll}110.50 & 1.04917 E+03 & 1.08982 E+03 & 7.33013 E+02 & 0.00000 E+00 & 1.00000 E+02 & 1.00000 E+02 & 0.00000 E+00 & 0.00000 E+00 & 0.00000 E+00 & 0.0000\end{array}$

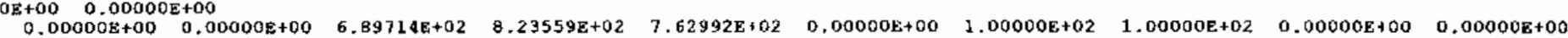
$\begin{array}{lllllllllll}0.00000 \mathrm{E}+00 & 0.00000 \mathrm{E}+00 & 0.00000 \mathrm{E}+00 & 0.00000 \varepsilon+00 & 5.69630 \mathrm{E}+02 & 6.62004 \mathrm{E}+02 & 6.42847 \mathrm{E}+02 & 0.00000 \mathrm{E}+00 & 1.00000 \mathrm{E}+02 & 1.00000 \mathrm{E}+02\end{array}$

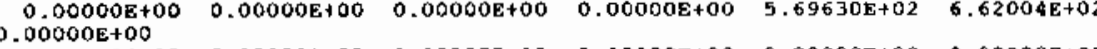

$0.00000 \mathrm{E}+00 \quad 0.00000 \mathrm{E}+00 \quad 0.00000 \mathrm{E}+00 \quad 0.00000 \mathrm{E}+00 \quad 0.000008+00 \quad 0$

$\begin{array}{lllllllllll}114.50 & 1.06427 \mathrm{E}+03 & 1.10597 \mathrm{E}+03 & 6.99430 \mathrm{E}+02 & 0.00000 \mathrm{E}+00 & 1.00000 \mathrm{E}+02 & 1.00000 \mathrm{E}+02 & 0.00000 \mathrm{E}+00 & 0.00000 \mathrm{E}+00 & 0.00000 \mathrm{E}+00 & 0.0000\end{array}$

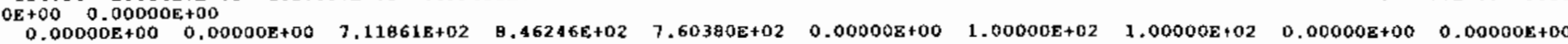
$\begin{array}{llllllllll}0.00000 \mathrm{E}+00 & 0.00000 \mathrm{E}+00 & 0.00000 \mathrm{E}+00 & 0.00000 \mathrm{E}+00 & 5.83536 \mathrm{E}+02 & 6.79584 \mathrm{E}+02 & 6.54542 \mathrm{E}+02 & 0.00000 \mathrm{E}+00 & 1.000008+02 & 1.00000 \mathrm{E}+02\end{array}$ $\begin{array}{lllllll}0.00000 \mathrm{E}+00 & 0.00000 \mathrm{E}+00 & 0.00000 \mathrm{E}+00 & 0.00000 \mathrm{E}+00 & 0.00000 \mathrm{E}+00 & 0.00000 \mathrm{E}+00\end{array}$

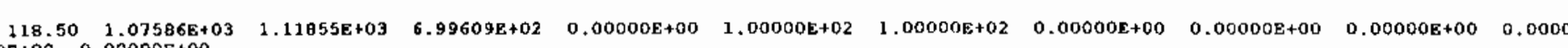
$0 \mathrm{E}+00 \quad 0.00000 \mathrm{E}+00$

$\begin{array}{lllllllllll}0.00000 \mathrm{E}+00 & 0.00000 \mathrm{E}+00 & 7.32739 \mathrm{E}+02 & \mathrm{~B} .67039 \mathrm{E}+02 & 7.69151 \mathrm{E}+02 & 0.00000 \mathrm{E}+00 & 1.00000 \mathrm{E}+02 & 1.00000 \mathrm{E}+02 & 0.00000 \mathrm{E}+00 & 0.00000 \mathrm{E}+00\end{array}$ $\begin{array}{llllllllll}0.00000 E+00 & 0.00000 E+00 & 0.00000 E+00 & 0.00000 E+00 & 5.96725 E+02 & 6.93992 E+02 & 6.64727 E+02 & 0.00000 E+100 & 1.00000 E+02 & 1.00000 E+02\end{array}$ $0.00000 \mathrm{E}+00$ 
$0.00000 E+00 \quad 0.00000 E+00 \quad 0.00000 E+00 \quad 0.00000 E+00 \quad 0.00000 E+00 \quad 0.00000 E+00$

$\begin{array}{lllllllllll}122.50 & 1.08847 E+03 & 1.13206 E+03 & 7.34594 E+02 & 0.00000 E+00 & 1.00000 E+02 & 1.00000 E+02 & 0.00000 E+00 & 0.00000 E+00 & 0.00000 E+00 & 0.0000\end{array}$ $\begin{array}{llllllllll}0.00000 \mathrm{E}+00 & 0.00000 \mathrm{E}+00 & 7.55267 E+02 & 8.89684 \mathrm{E}+02 & 7.91374 \mathrm{E}+02 & 0.00000 \mathrm{E}+00 & 1.00000 \mathrm{E}+02 & 1.00000 \mathrm{E}+02 & 0.00000 \mathrm{E}+00 & 0.00000 \mathrm{E}+00\end{array}$ $\begin{array}{llllllllll}0.00000 E+00 & 0.00000 E+00 & 0.00000 E+00 & 0.00000 E+00 & 6.11016 E+02 & 1.10636 E+02 & 6.78504 E+02 & 0.00000 E+00 & 1.00000 E+02 & 1.00000 E+02\end{array}$

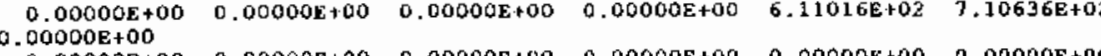

$0.00000 \mathrm{E}+00 \quad 0.00000 \mathrm{E}+00 \quad 0.00000 \mathrm{E}+00 \quad 0.00000 \mathrm{E}+00 \quad 0.00000 \mathrm{E}+00 \quad 0.00000 \mathrm{E}+0$

$\begin{array}{lllllllllll}126.50 & 1.09801 E+03 & 1.14240 E+03 & 7.33660 E+02 & 0.00000 E+00 & 1.00000 E+02 & 1.00000 E+02 & 0.00000 E+00 & 0.00000 E+00 & 0.00000 E+00 & 0.0000\end{array}$ $\begin{array}{lllllllllll}0.00000 E+00 & 0.00000 E+00 & 7.76282 E+02 & 9.10242 E+02 & B .00191 E+02 & 0.00000 E+00 & 1.00000 E+02 & 1.00000 E+02 & 0.00000 E+00 & 0.00000 E+00\end{array}$

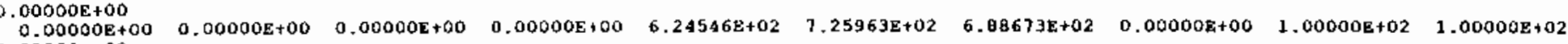
$\begin{array}{cccccc}0.00000 \mathrm{E}+00 & 0.00000 \mathrm{E}+00 & 0.00000 \mathrm{E}+00 & 0.00000 \mathrm{E}+00 & 6.24546 E+02 & 1.25963 E+02 \\ 0.00000 \mathrm{0}+00 & 0.00000 \mathrm{E}+00 & 0.00000 \mathrm{E}+00 & 0.00000 \mathrm{E}+00 & 0.00000 \mathrm{E}+00 & 0.00000 \mathrm{E}+00\end{array}$

$\begin{array}{lllllllllll}130.50 & 1.10819 \varepsilon+03 & 1.15332 E+03 & 7.00026 \mathrm{E}+02 & 0.00000 \mathrm{E}+00 & 1.00000 \mathrm{E}+02 & 1.00000 \mathrm{E}+02 & 0.00000 \mathrm{E}+00 & 0.00000 \mathrm{E}+00 & 0.00000 \mathrm{E}+00 & 0.0000\end{array}$

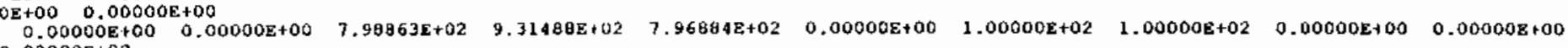
$\begin{array}{llllllllll}0.00000 \mathrm{E}+00 & 0.000008+00 & 0.000008+00 & 0.00000 E+00 & 6.39194 \mathrm{E}+02 & 7.42352 \mathrm{E}+02 & 7.00319 \mathrm{E}+02 & 0.00000 \mathrm{E}+00 & 1.000008+02 & 1.00000 \mathrm{E}+02\end{array}$ $\begin{array}{lllll}0.00000 E+00 & 0.000008+00 & 0.00000 E+00 & 0.00000 E+00 & -6.3915\end{array}$

$\begin{array}{lllllll}0.00000 \mathrm{E}+00 & 0.00000 \mathrm{E}+00 & 0.00000 \mathrm{E}+00 & 0.00000 \mathrm{E}+00 & 0.00000 \mathrm{E}+\mathrm{EO} & 0.00000 \mathrm{E}+00 & 0.00000 \mathrm{E}+00\end{array}$

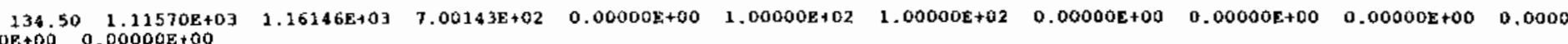
$\begin{array}{lllllllllll}0.00000 \mathrm{E}+00 & 0.00000 \mathrm{E}+00 & 0.19 \mathrm{~B} 2 \mathrm{BE}+02 & 9.50710 \mathrm{E}+02 & 8.05052 \mathrm{E}+02 & 0.00000 \mathrm{E}+00 & 1.00000 \mathrm{E}+02 & 1,00000 \mathrm{E}+02 & 0.00000 \mathrm{E}+00 & 0.00000 \mathrm{E}+00\end{array}$

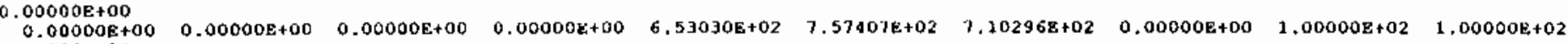

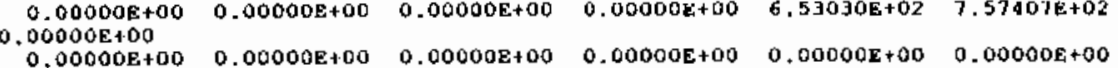

$\begin{array}{llllllllllll}136.50 & 1.12353 \mathrm{E}+03 & 1.16982 \mathrm{E}+03 & 7.35067 \mathrm{E}+02 & 0.00000 \mathrm{E}+00 & 1.00000 \mathrm{E}+02 & 1.00000 \mathrm{E}+02 & 0.00000 \mathrm{E}+00 & 0.00000 \mathrm{E}+00 & 0.00000 \mathrm{E}+00 & 0.0000\end{array}$

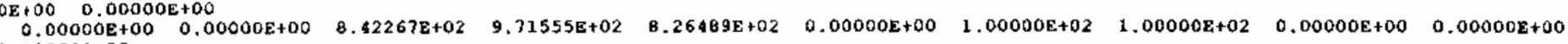

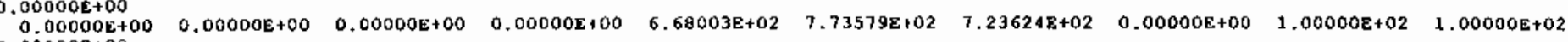

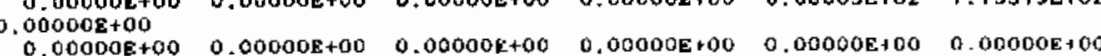

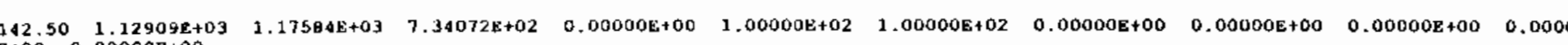

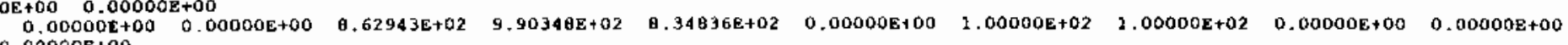
$\begin{array}{llllllllll}0.00000 \mathrm{E}+00 & 0.00000 \varepsilon+00 & 0.00000 E+00 & 0.00000 E+00 & 6.02119 \mathrm{E}+02 & 7.08406 \mathrm{E}+02 & 7.33310 \mathrm{E}+02 & 0.00000 \mathrm{E}+00 & 1.00000 \mathrm{E}+02 & 1.00000 \mathrm{E}+02\end{array}$

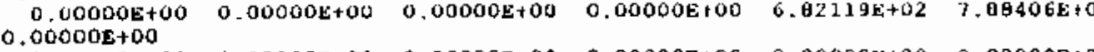

$0.00000 \mathrm{E}+00 \quad 0.00000 \mathrm{E}+00 \quad 0.00000 \mathrm{E}+00 \quad 0.00000 \mathrm{E}+00 \quad 0.00000 \mathrm{E}+00 \quad 0.00000 \mathrm{E}+00$

$\begin{array}{lllllllllll}146.50 & 1.13460 E+03 & 1.181 \% 4 E+03 & 7.00380 E+02 & 0.00000 E+00 & 1.00000 E+02 & 1.00000 E+02 & 0.00000 E+00 & 0.00000 E+00 & 0.00000 E+00 & 0.0000\end{array}$

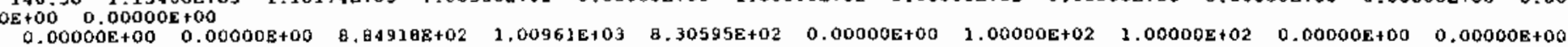

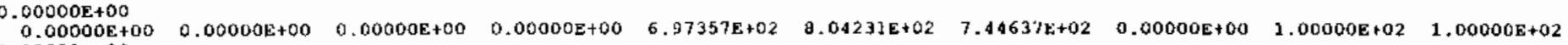
$\begin{array}{cccccc}0.00000 \mathrm{E}+00 & 0.00000 \mathrm{E}+00 & 0.00000 \mathrm{E}+00 & 0.00000 \mathrm{E}+00 & 6.07357 \mathrm{E}+02 & 0.042 \mathrm{~J} E+002 \\ 0.00000 \mathrm{E}+00 & 0.00000 \mathrm{E}+00 & 0.00000 \mathrm{E}+00 & 0.00000 \mathrm{E}+00 & 0.00000 \mathrm{E}+00 & 0.00000 \mathrm{E}+00\end{array}$

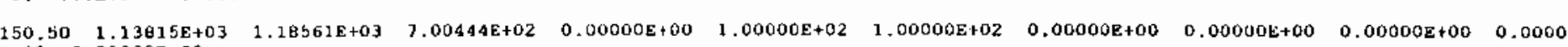

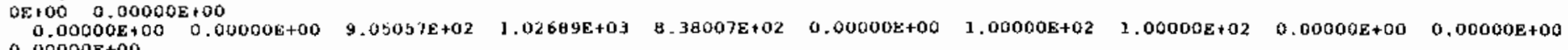
$\begin{array}{lllllllll}0.00000 \mathrm{E}+00 & 0.000000 \mathrm{E}+00 & 0.00000 \mathrm{E}+00 & 7.11536 \mathrm{E}+02 & \mathrm{~g} .19600 \mathrm{E}+02 & 7.54219 \mathrm{E}+02 & 0.00000 \mathrm{E}+00 & 1.00000 \mathrm{E}+02 & 1.00000 \mathrm{E}+02\end{array}$

$\begin{array}{lllllll}0.00000 \mathrm{E}+00 & 0.00000 E+00 & 0.00000 E+00 & 0.00000 E+00 & 0.00000 E+00 & 0.000008+00\end{array}$ 


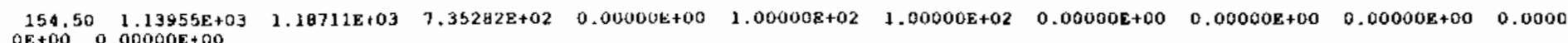

$0 E+00 \quad 0.00000 E+00$
$0.00000 E+00$
0.00000 t

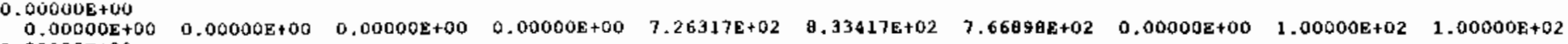

$0.00000 \mathrm{E}+00$

$\begin{array}{llllll}0.00000 \mathrm{E}+00 & 0.00000 \mathrm{E}+00 & 0.00000 \mathrm{E}+00 & 0.00000 \mathrm{E}+00 & 0.00000 \mathrm{E}+00 & 0.00000 \mathrm{E} * 00\end{array}$

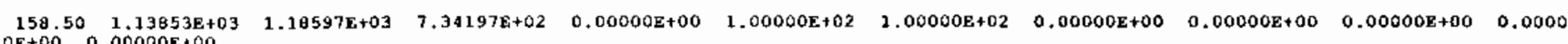

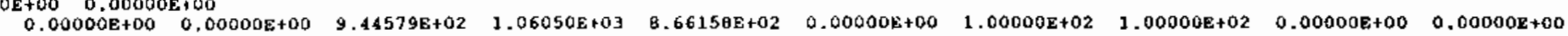
$\begin{array}{ccccccccccc}0.00000 \mathrm{E}+00 & 0.00000 \mathrm{E}+00 & 0.00000 \mathrm{E} 100 & 0.00000 \mathrm{E} 100 & 7.39600 \mathrm{E} 1.02 & 8.46372 \mathrm{E}+02 & 7.75963 \mathrm{E}+02 & 0.00000 \mathrm{E}+00 & 1.00000 \mathrm{E}+02 & 1.00000 \mathrm{E}+02\end{array}$

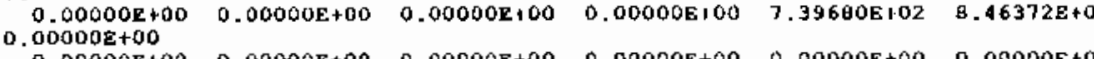

$\begin{array}{lllllll}0.00000 \mathrm{E}+00 & 0.00000 \mathrm{E}+00 & 0.00000 \mathrm{E}+00 & 0.00000 \mathrm{E}+00 & 0.00000 \mathrm{E}+00 & 0.00000 \mathrm{E}+00\end{array}$

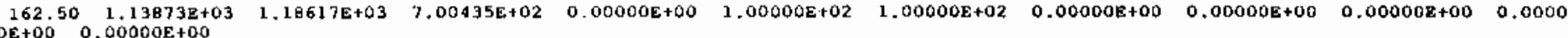
$\begin{array}{cccccccccc}0.00000 \mathrm{E}+00 & 0.00000 \mathrm{E}+00 & 9.64824 \mathrm{E}+02 & 1.07695 \mathrm{E}+03 & \mathrm{a} .60703 \mathrm{E}+02 & 0.00000 \mathrm{E}+00 & 1.00000 \mathrm{E}+02 & 1.00000 \mathrm{E}+02 & 0.00000 \mathrm{E}+00 & 0.00000 \mathrm{E}+00\end{array}$

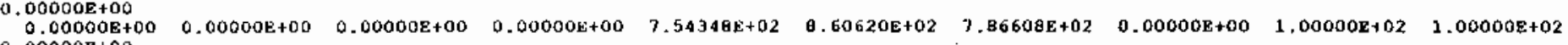

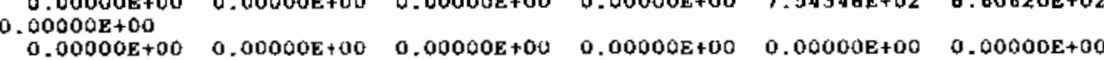

$\begin{array}{lllllllllll}166.50 & 1.14024 \mathrm{E}+03 & 1.10783 \mathrm{E}+03 & 7.00471 \mathrm{E}+02 & 0.00000 \mathrm{E}+00 & 1.00000 \mathrm{E}+02 & 1.000008+02 & 0.00000 \mathrm{E}+00 & 0.00000 \mathrm{E}+00 & 0.00000 \mathrm{E}+00 & 0.0000\end{array}$

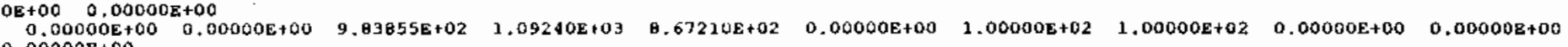

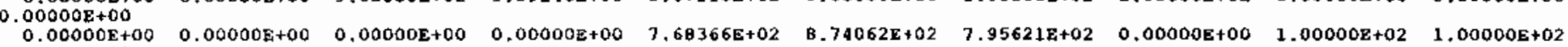

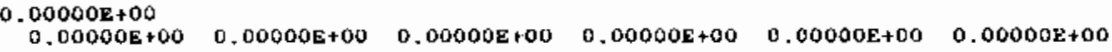

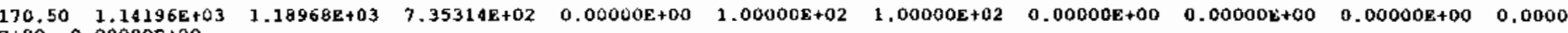

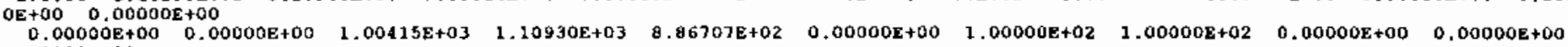

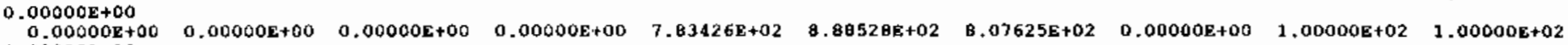

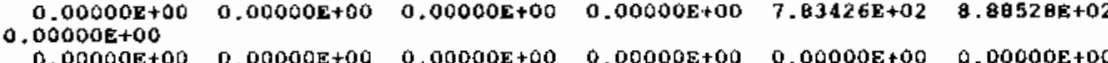

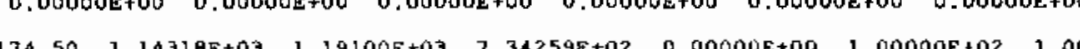

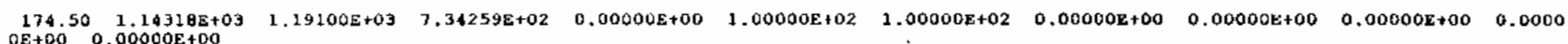

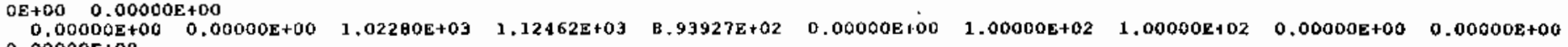
$\begin{array}{lllllllllll}0.000000 \mathrm{E} 100 & 0.00000 \mathrm{E}+00 & 0.00000 \mathrm{E}+00 & 0.00000 \mathrm{E}+00 & 7.97416 \mathrm{E}+02 & 9.01730 \mathrm{E}+02 & \mathrm{a} .16225 \mathrm{E}+02 & 0.00000 \mathrm{E}+00 & 1.00000 \mathrm{E}+02 & 1.00000 \mathrm{E}+02\end{array}$ $0.00000 \mathrm{E}+00$

$0.00000 \mathrm{E}+00 \quad 0.00000 \mathrm{E}+00 \quad 0.00000 \mathrm{E}+00 \quad 0.00000 \mathrm{E}+00 \quad 0.00000 \mathrm{E}+00 \quad 0.00000 E+00$

$\begin{array}{lllllllllllll}178.50 & 1.14415 E+03 & 1.19204 E+03 & 7.00508 \mathrm{E}+02 & 0.00000 \mathrm{E} 100 & 1.00000 \mathrm{E}+02 & 1.00000 \mathrm{E}+02 & 0.00000 \mathrm{E}+00 & 0.00000 \mathrm{E}+00 & 0.00000 \mathrm{E}+00 & 0.0000\end{array}$ $\begin{array}{cccccccccc}0.00000 \mathrm{E}+00 & 0.00000 \mathrm{E}+00 & 1.0425 \mathrm{SE}+03 & 1.14017 \mathrm{E}+03 & 8.87471 \mathrm{E}+02 & 0.00000 \mathrm{E}+00 & 1.00000 \mathrm{E}+02 & 1.00000 \mathrm{E}+02 & 0.00000 \mathrm{E}+100 & 0.00000 \mathrm{E}+00\end{array}$ $\begin{array}{cccccccccc}0.00000 \mathrm{E}+00 \\ 0.0000 \mathrm{E}+00 & 0.00000 \mathrm{E}+00 & 0.00000 \mathrm{E}+00 & 0.00000 \mathrm{E}+00 & 0.12334 \mathrm{E}+02 & 9.15 \mathrm{~B} 11 \mathrm{E}+02 & \mathrm{~B} .26316 \mathrm{E}+02 & 0.00000 \mathrm{E}+00 & 1.00000 \mathrm{E}+02 & 1.00000 \mathrm{E}+02\end{array}$

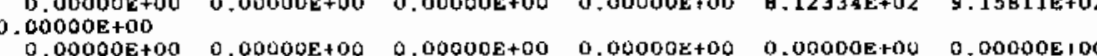

$182.50 \quad 1.14452 E+03 \quad 1.19244 E+03 \quad 7,00529 E+02 \quad 0.00000 E+00 \quad 1.00000 E+02 \quad 1.00000 E+02 \quad 0.00000 E+00 \quad 0.00000 E+00 \quad 0.00000 E+00 \quad 0.0000$

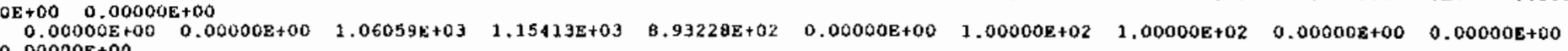

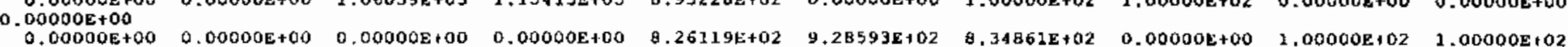
$0.00000 \mathrm{E}+00$

$0.00000 \mathrm{E}+00 \quad 0.00000 \mathrm{E}+00 \quad 0.00000 \mathrm{E}+00 \quad 0.00000 \mathrm{E}+00 \quad 0.00000 \mathrm{E}+00 \quad 0.00000 \mathrm{E}+00$

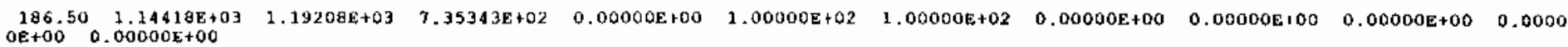




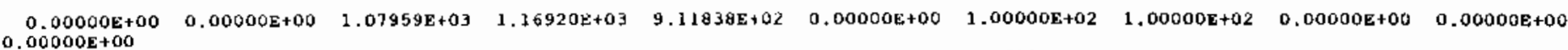
$\begin{array}{cccccccccc}0.00000 \mathrm{E}+00 & 0.00000 \mathrm{E}+00 & 0.00000 \mathrm{E}+00 & 0.000008+00 & 8.40753 \mathrm{E}+02 & 9.4219 \mathrm{E}+02 & 8.46221 \mathrm{E}+02 & 0.00000 \mathrm{E}+00 & 1.00000 \mathrm{E}+02 & 1.00000 \mathrm{E}+02\end{array}$ $\begin{array}{cccccc}0.00000 \mathrm{E}+00 \\ 0.00000 \mathrm{E}+00 & 0.00000 \mathrm{E}+00 & 0.00000 \mathrm{E}+00 & 0.00000 \mathrm{E}+00 & 0.00000 \mathrm{E}+00 & 0.00000 \mathrm{E}+00\end{array}$

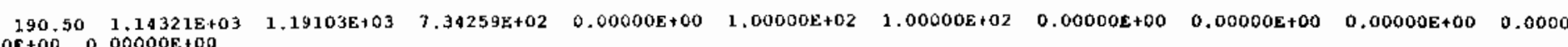
$\begin{array}{cccccccccc}0.00000 \mathrm{z}+00 & 0.00000 \mathrm{E}+00 & 1.096 \mathrm{AE}+03 & 1.18261 \mathrm{E}+03 & 9.17804 \mathrm{E}+02 & 0.00000 \mathrm{E}+00 & 1.00000 \mathrm{E}+02 & 1.00000 \mathrm{E}+02 & 0.00000 \mathrm{E}+00 & 0.00000 \mathrm{E}+00\end{array}$ $\begin{array}{lllllllllll}0.00000 \mathrm{E}+00 & 0.00000 \mathrm{E}+00 & 0.00000 \mathrm{E}+00 & 0.00000 \mathrm{E}+00 & \mathbf{0 . 5 4 1 B 9 E + 0 2} & 9.54436 \mathrm{E}+02 & 8.54349 \mathrm{E}+02 & 0.00000 \mathrm{E}+00 & 1.00000 \mathrm{E}+02 & 1.00000 \mathrm{E}+02\end{array}$ $0.00000 \mathrm{E}+00$
$0.00000 \mathrm{E}+00$

$0.00000 \mathrm{E}+00 \quad 0.000008+00 \quad 0.00000 \mathrm{E}+00 \quad 0.00000 \mathrm{E}+00 \quad 0.000008+00 \quad 0.00000 \mathrm{E} 100$

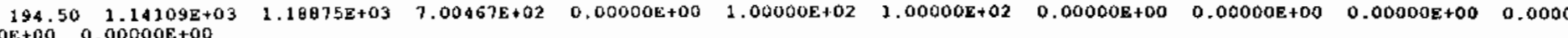
$\begin{array}{llllllllll}0.00000 \mathrm{E}+00 & 0.00000 \mathrm{E}+00 & 1.11486 \mathrm{E}+03 & 1.19589 \mathrm{E}+03 & 9.11003 \mathrm{E}+02 & 0.000008+00 & 1.00000 \mathrm{E}+02 & 1.00000 \mathrm{E}+02 & 0.00000 \mathrm{E}+00 & 0.00000 \mathrm{E}+00\end{array}$

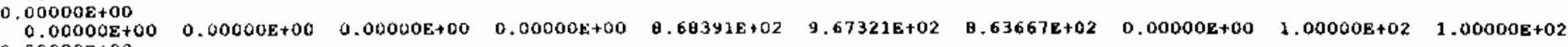

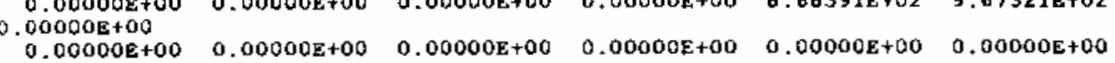

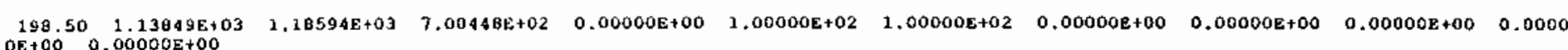

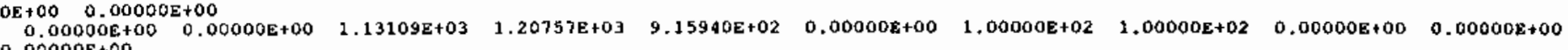
$\begin{array}{lllllllllll}0.00000 \mathrm{E}+00 & 0.00000 \mathrm{E}+00 & 0.00000 \mathrm{E}+00 & 0.00000 \mathrm{E}+00 & 0.00000 \mathrm{E}+00 & 8.81356 \mathrm{E}+02 & 9.78839 \mathrm{E}+02 & 0.71616 \mathrm{E}+02 & 0.00000 \mathrm{E}+00 & 1.00000 \mathrm{E}+02 & 1.00000 \mathrm{E}+02\end{array}$

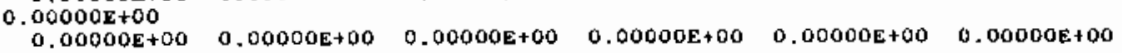

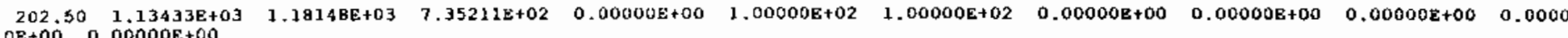
$\begin{array}{cccccccccc}0 \mathrm{E}+00 \quad 0.00000 \mathrm{E}+00 & 0.00000 \mathrm{E}+00 & 1.74794 \mathrm{E}+03 & 1.21996 \mathrm{E}+03 & 9.33553 \mathrm{E}+02 & 0.00000 \mathrm{E}+00 & 1.00000 \mathrm{E}+02 & 1.00000 \mathrm{E}+02 & 0.00000 \mathrm{E}+00 & 0.00000 \mathrm{E}+00\end{array}$

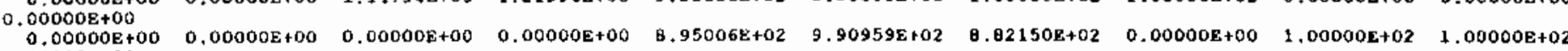

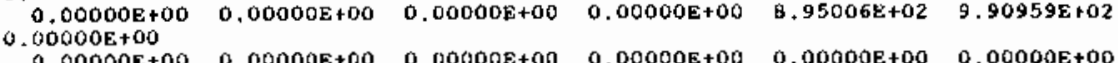

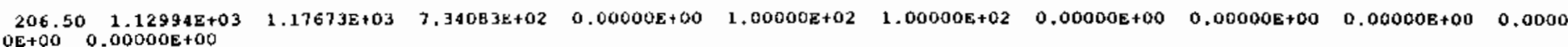

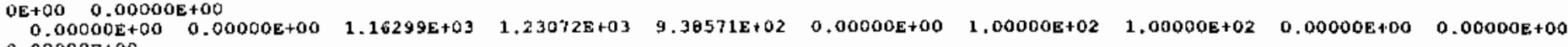

$\begin{array}{ccccccccccc}0.00000 E+00 & 0.00000 E+00 & 0.00000 E+00 & 0.00000 E+00 & 9.07399 \varepsilon+02 & 1.00132 E+03 & 0.89606 E+02 & 0.00000 E+00 & 1.00000 E+02 & 1.00000 E+02\end{array}$

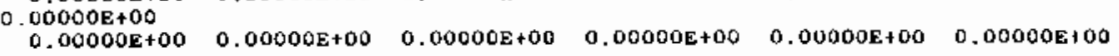

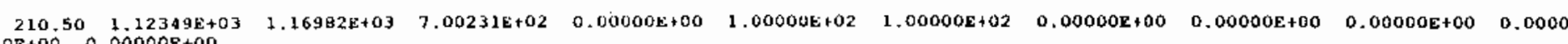
$\begin{array}{cccccccccc}0.00000 \mathrm{E}+00 & 0.00000 \mathrm{E}+00 & 1.17843 \mathrm{E}+03 & 1.24117 \mathrm{E}+03 & 9.30838 \mathrm{E}+02 & 0.00000 \mathrm{E}+00 & 1.00000 \mathrm{E}+02 & 1.00000 \mathrm{E}+02 & 0.00000 \mathrm{E}+00 & 0.00000 \mathrm{E}+00\end{array}$

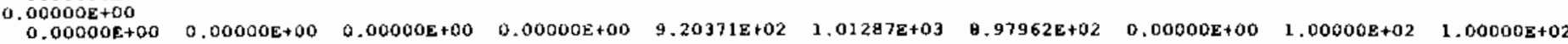

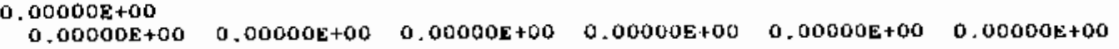

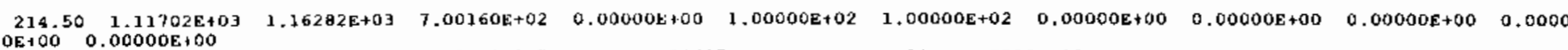
$\begin{array}{llllllllll}0.00000 E+00 & 0.00000 E+00 & 1.19189 E+03 & 1.24700 E 103 & 9.34607 E+02 & 0.00000 E+00 & 1.00000 E+02 & 1.00000 E+02 & 0.00000 E+00 & 0.00000 E+00\end{array}$ $\begin{array}{lllllllllll}0.00000 \mathrm{E}+00 & 0.00000 \mathrm{E}+00 & 0.00000 \mathrm{E}+00 & 0.00000 \mathrm{E}+00 & 9.32058 \mathrm{E}+02 & 1.02265 \mathrm{E}+03 & 9.05130 \mathrm{E}+02 & 0.00000 \mathrm{E}+00 & 1.000008+02 & 1.00000 \mathrm{E}+02\end{array}$ $\begin{array}{llllll}0.00000 \mathrm{E}+00 & 0.00000 \mathrm{E}+00 & 0.00000 \mathrm{E}+00 & 0.00000 \mathrm{E}+00 & 0.00000 \mathrm{E}+00 & 0.00000 \mathrm{E} 100\end{array}$

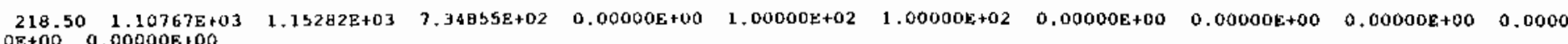

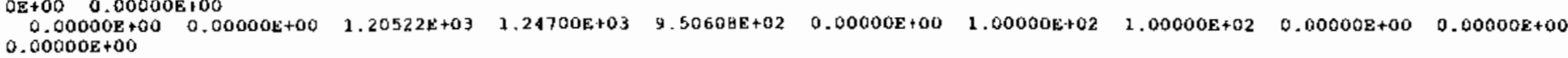


$\begin{array}{llllllllll}0.00000 E+00 & 0.00000 E+00 & 0.00000 \mathrm{E}+00 & 0.00000 \mathrm{E}+00 & 9.44154 \mathrm{E}+02 & 1.03260 \mathrm{E}+03 & 9.14574 \mathrm{E}+02 & 0.00000 \mathrm{E}+00 & 1.00000 \mathrm{E}+02 & 1.00000 \mathrm{E}+02\end{array}$

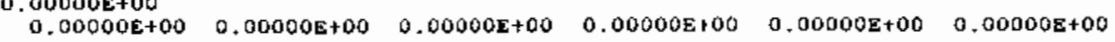

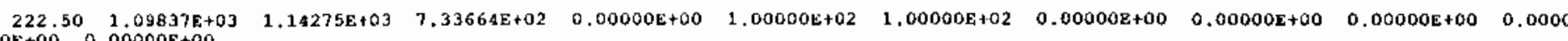

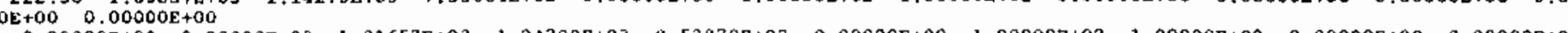
$\begin{array}{llllllll}24700 \mathrm{E}+03 & 9.53970 \mathrm{E}+02 & 0.00000 \mathrm{E}+00 & 1.00000 \mathrm{E}+02 & 1.00000 \mathrm{E}+02 & 0.00000 \mathrm{E}+00 & 0.00000 \mathrm{E}+0\end{array}$ $\begin{array}{llllllllll}0.00000 E+00 & 0.00000 E+00 & 0.00000 E+00 & 0.00000 E+00 & 9.54897 E+02 & 1.04129 E+03 & 9.21305 E+02 & 0.00000 E+00 & 1.00000 E+02 & 1.00000 E+02\end{array}$

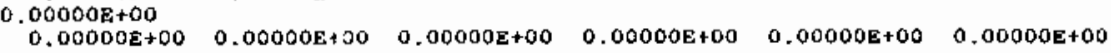

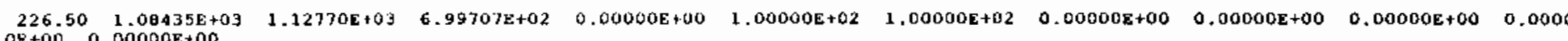
$\begin{array}{llllllllll}0.00000 \mathrm{E}+00 & 0.00000 \mathrm{E}+00 & 1.22734 \mathrm{E}+03 & 1.24 \mathrm{~B} 39 \mathrm{E}+03 & 9.44369 \mathrm{E}+02 & 0.00000 \mathrm{E}+00 & 1.00000 \mathrm{E}+02 & 1.00000 \mathrm{E}+02 & 0.00000 \mathrm{E}+00 & 0.03000 \mathrm{E}+00\end{array}$

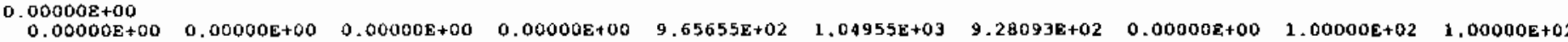

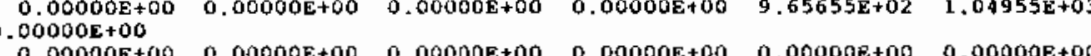

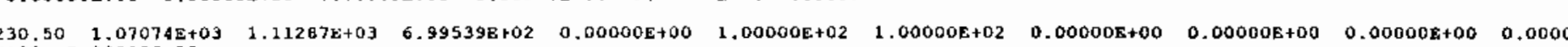

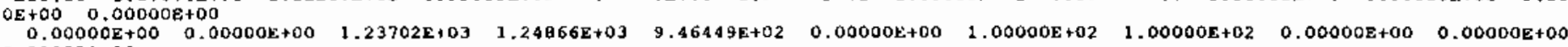

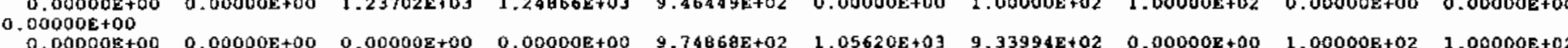
$\begin{array}{rlllllllll}0.0000 \mathrm{E}+00 & 0.00000 \mathrm{E}+00 & 0.00000 \mathrm{E}+00 & 0.00000 \mathrm{E}+00 & 9.74868 \mathrm{E}+02 & 1.05620 \mathrm{E}+03 & 9.33994 \mathrm{E}+02 & 0.00000 \mathrm{E}+00 & 1.00000 \mathrm{E}+02 & 1.00000 \mathrm{E}+02\end{array}$ $\begin{array}{cccccc}0.00000 \mathrm{E}+00 & 0.00000 \mathrm{E}+00 & 0.00000 \mathrm{E}+00 & 0.00000 \mathrm{E}+00 & 0.00000 \mathrm{E}+00 & 0.00000 \mathrm{E}+00\end{array}$

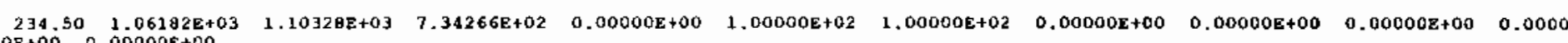

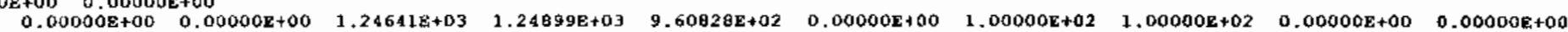

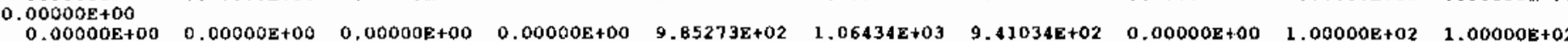

$\begin{array}{cccccc}0.00000 \mathrm{E}+00 & 0.00000 \mathrm{E}+00 & 0.00000 \mathrm{E}+00 & 0.00000 \mathrm{E}+00 & 9.85273 \mathrm{E}+02 & 1.06434 \mathrm{E}+03 \\ 0.00000 \mathrm{E}+00 & 0.00000 \mathrm{E}+00 & 0.00000 \mathrm{E}+00 & 0.00000 \mathrm{E}+00 & 0.00000 \mathrm{E}+00 & 0.00000 \mathrm{E}+00\end{array}$ 


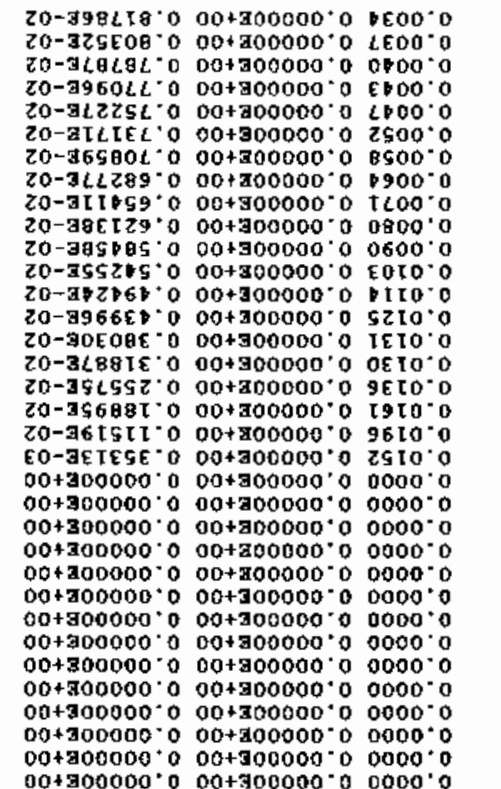

$00+900000^{\circ}: 00+3000000^{\circ} 00000 \cdot 0$
$00+900000^{\circ} 00+300000^{\circ} 0000.0$

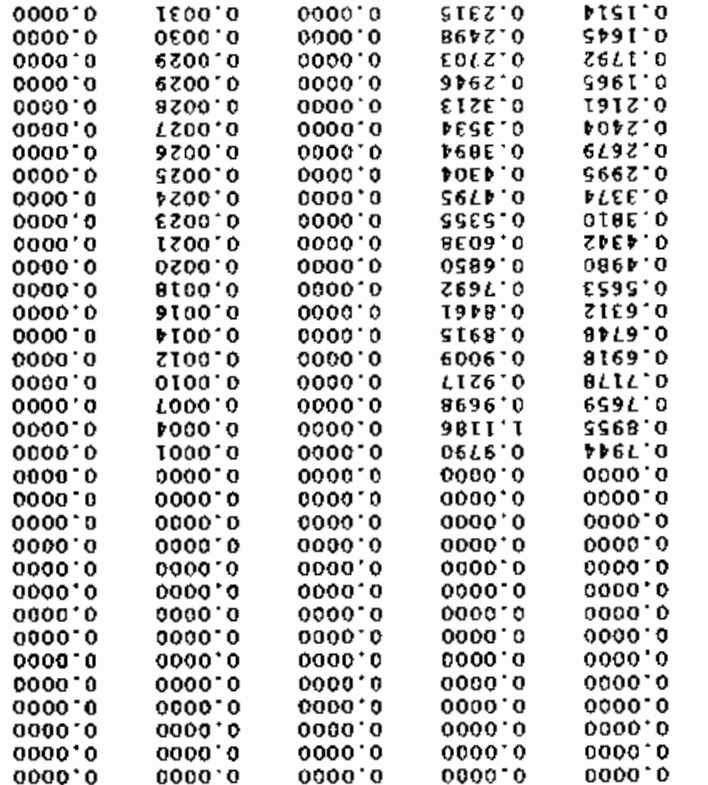

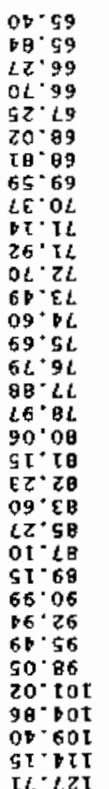

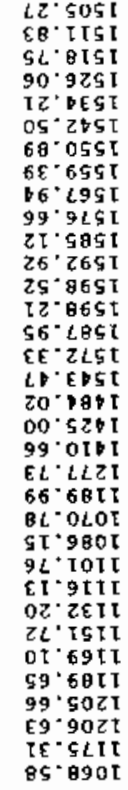

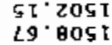

$76.60 \mathrm{tz}$

09.515

$5 Z \cdot 886 \mathrm{I}$
$Z 6 \cdot 2 Z 6 \mathrm{t}$

LO. TEST $E E^{\circ} \angle 98 \mathrm{I}$

$\angle L-\angle V 5 T$ ot $90 L T$

I.

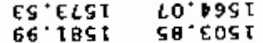

$88.685 T$ OS. EPOT

$05.565 T$ OQ. $28 E T$

$00.505 \mathrm{t} \quad \mathrm{Bg} \cdot 19 \mathrm{ZI}$

DO OLG $2 \mathrm{E}$ '.

¿t. tBUt

ES.

$80^{-9202} \quad 49.006$

$00^{\circ} .990 t \quad 00.082$

$\angle Z \cdot 1 \theta 0 t \quad 98 \cdot z O L$

$6 L .950 \mathrm{r} \quad 6 Z \cdot 7 \varepsilon 9$

$20 \cdot 2 z \mathrm{tt} \quad 00.015$

हgI हo.

II. $68 \mathrm{II} \quad b-\mathrm{tIE}$

$20.00 z 1 \quad k 908 z$

$86.691 \mathrm{t} \quad 00.5 Z \mathrm{~L}$

$95^{\circ} \mathrm{EgOr}$ EL

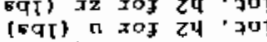

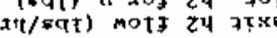

$547 t x$

(M) EeEsot 7804 PE

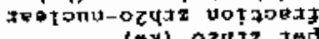

(ix) xxd to tonu

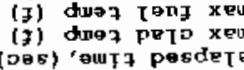

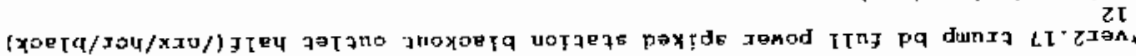


APPENDIX C

BOUNDARY CONDITIONS FOR THE TRUMP-BO N REACTOR STATION BLACKOUT

ACCIDENT ANALYSIS RELAP5 PREDICTIONS 


\begin{abstract}
APPENDIX C
BOUNDARY CONDITIONS FOR THE TRUMP-BD N REACTOR STATION BLACKOUT ACCIDENT ANALYSIS RELAP5 PREDICTIONS
\end{abstract}

FIGURE C.1. RELAP5--Vapor Void Fraction Vs. Time--Inner Flow Channel

FIGURE C.2. RELAP5--Vapor Void Fraction Vs. Time--Middle Flow Channel

FIGURE C.3. RELAP5--Vapor Void Fraction Vs. Time--Outer Flow Channel

FIGURE C.4. RELAP5--Mass Flow Rate Vs. Time--Inner Channe]

FIGUPE C.5. RELAP5--Mass Flow Rates Vs. Time--Middle Channel

FIGUFE C.6. RELAP5--Mass Flow Rate Vs. Time--Outer Channel

FIGURE C.7. RELAP5--Pressure Vs. Time

FIGURE C.8. RELAP5--Void Fraction Vs. Time--Inner Channe T

FIGURE C.9. RELAP5--Void Fraction Vs. Time--Middle Channel

FIGURE C.10. RELAP5--Void Fraction Vs. Time--Outer Channel 


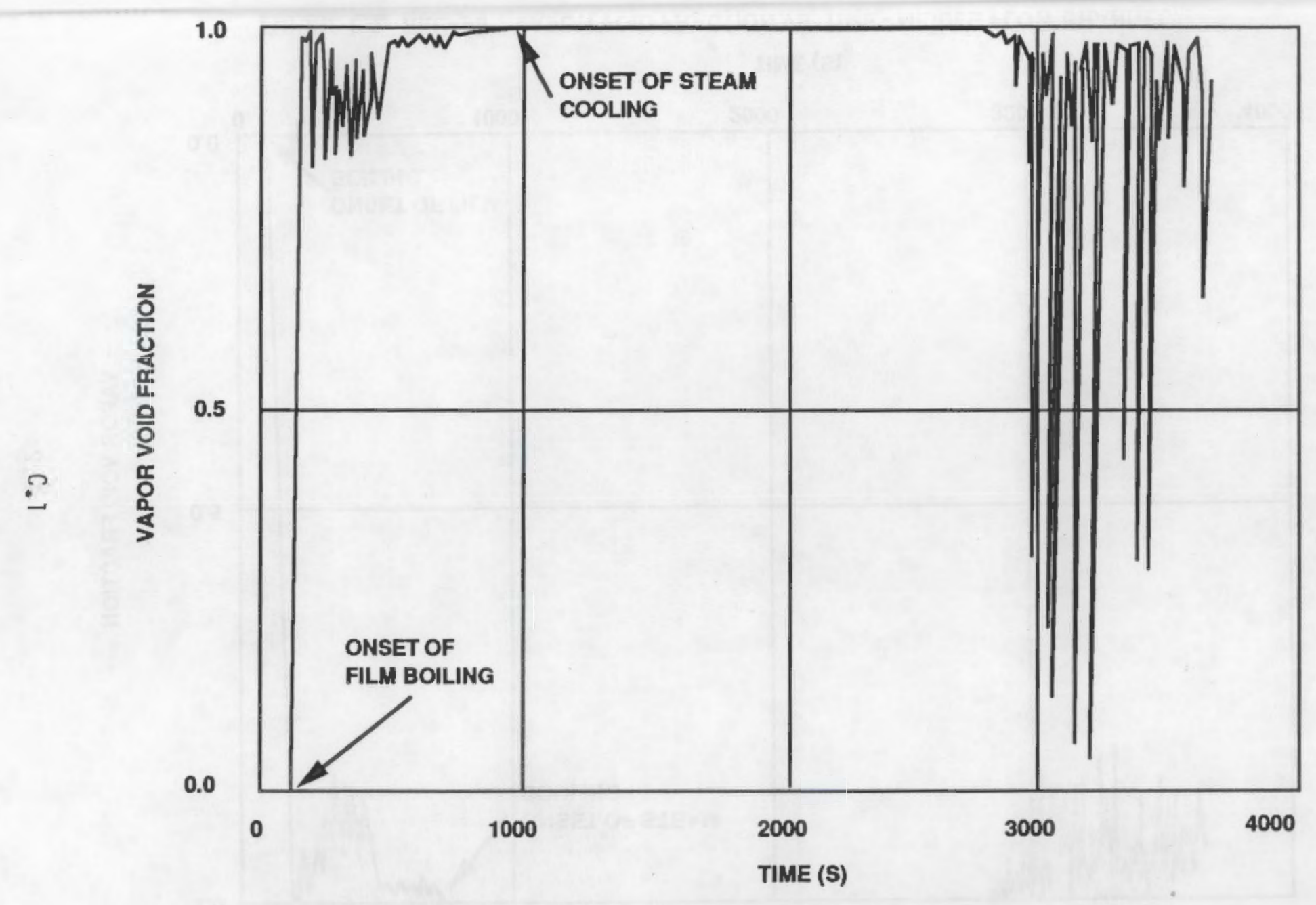

FIGURE C.1 RELAP5 - VAPOR VOID FRACTION VS. TIME - INNER FLOW CHANNEL 


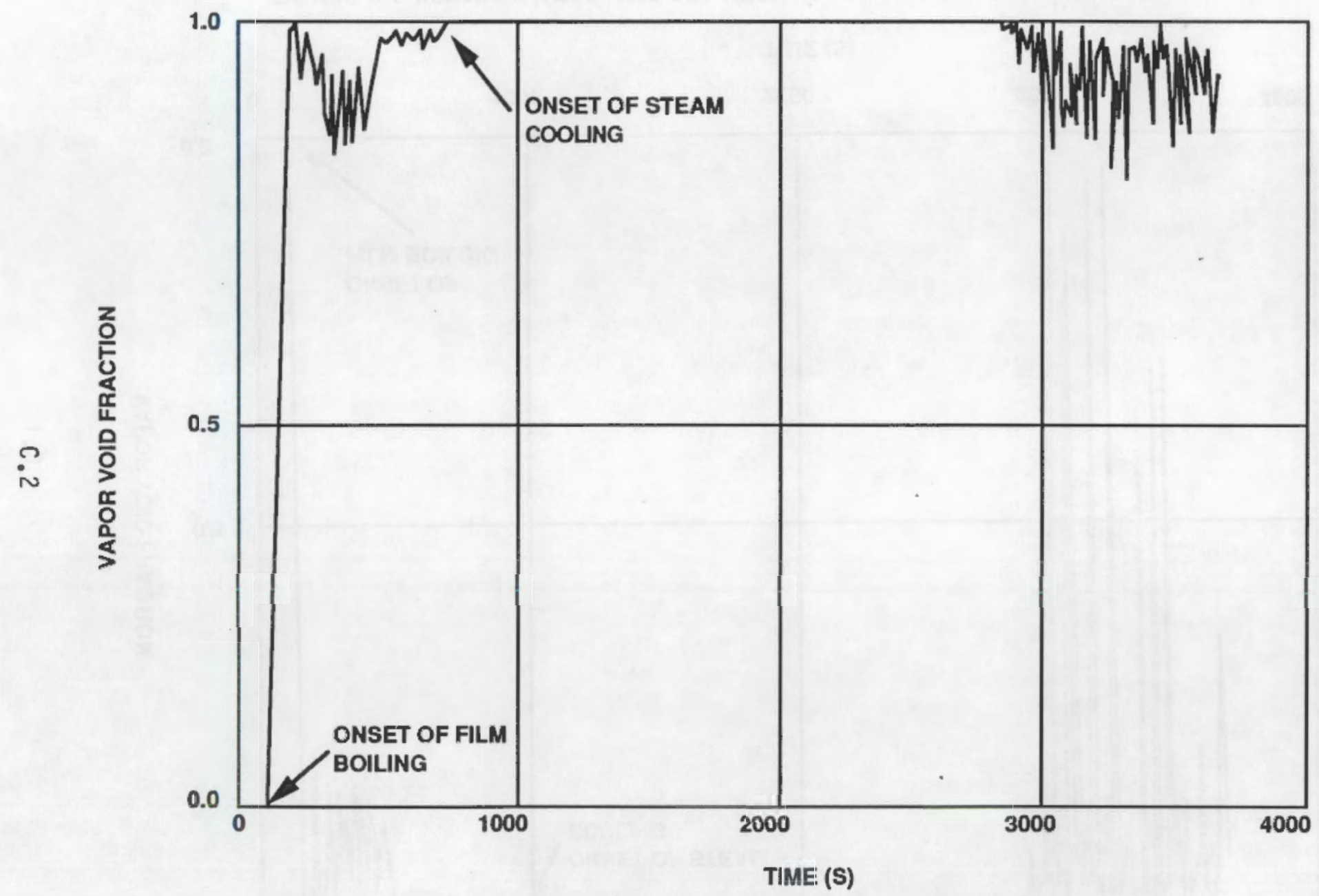

EIGURE C.2, RELAP5 - VAPOR VOID FRACTION VS. TIME - MIDDLE FLOW CHANNEL 


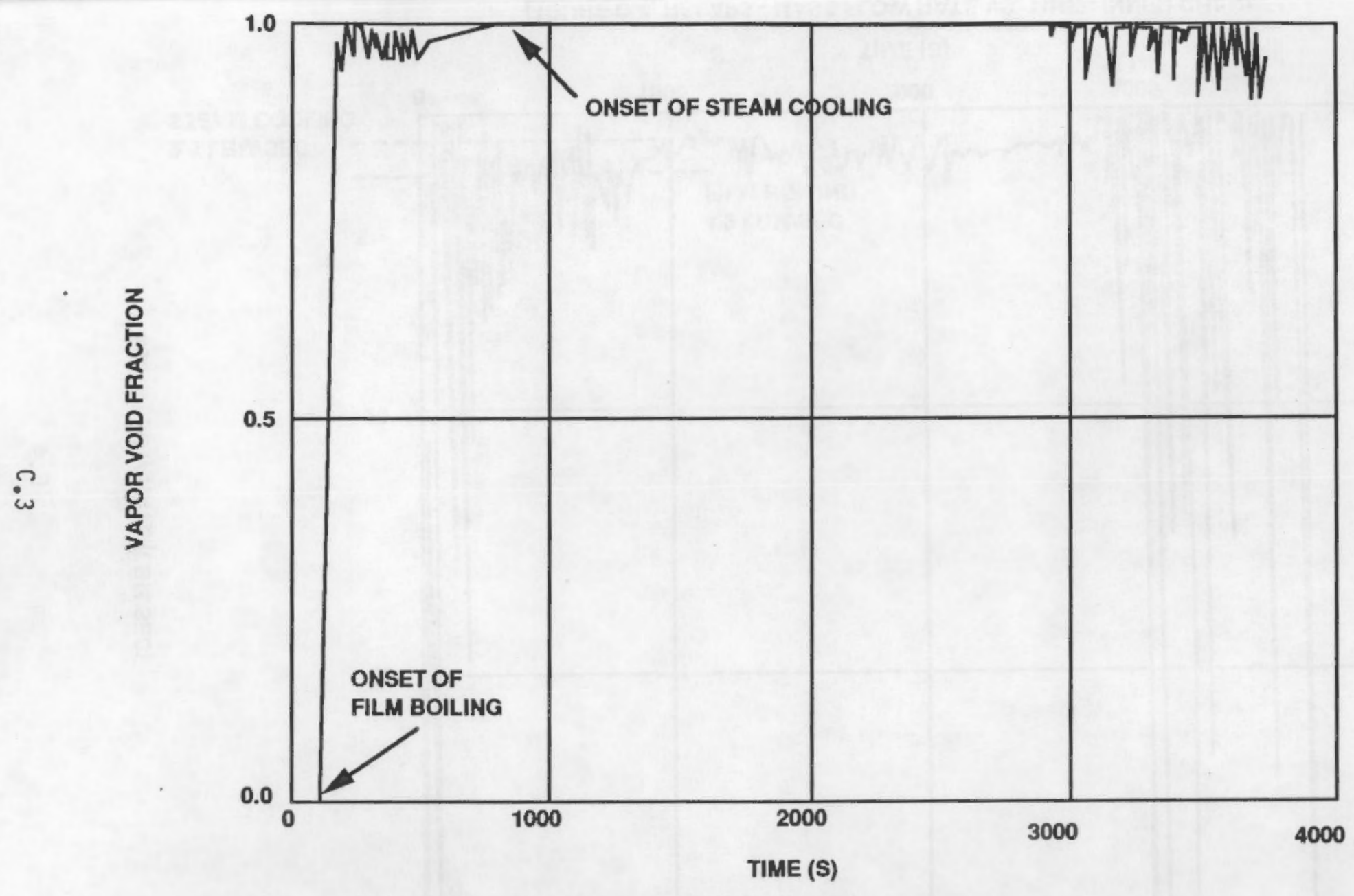

FIGURE C.3. RELAP5 - VAPOR VOID FRACTION VS. TIME - OUTER FLOW CHANNEL 


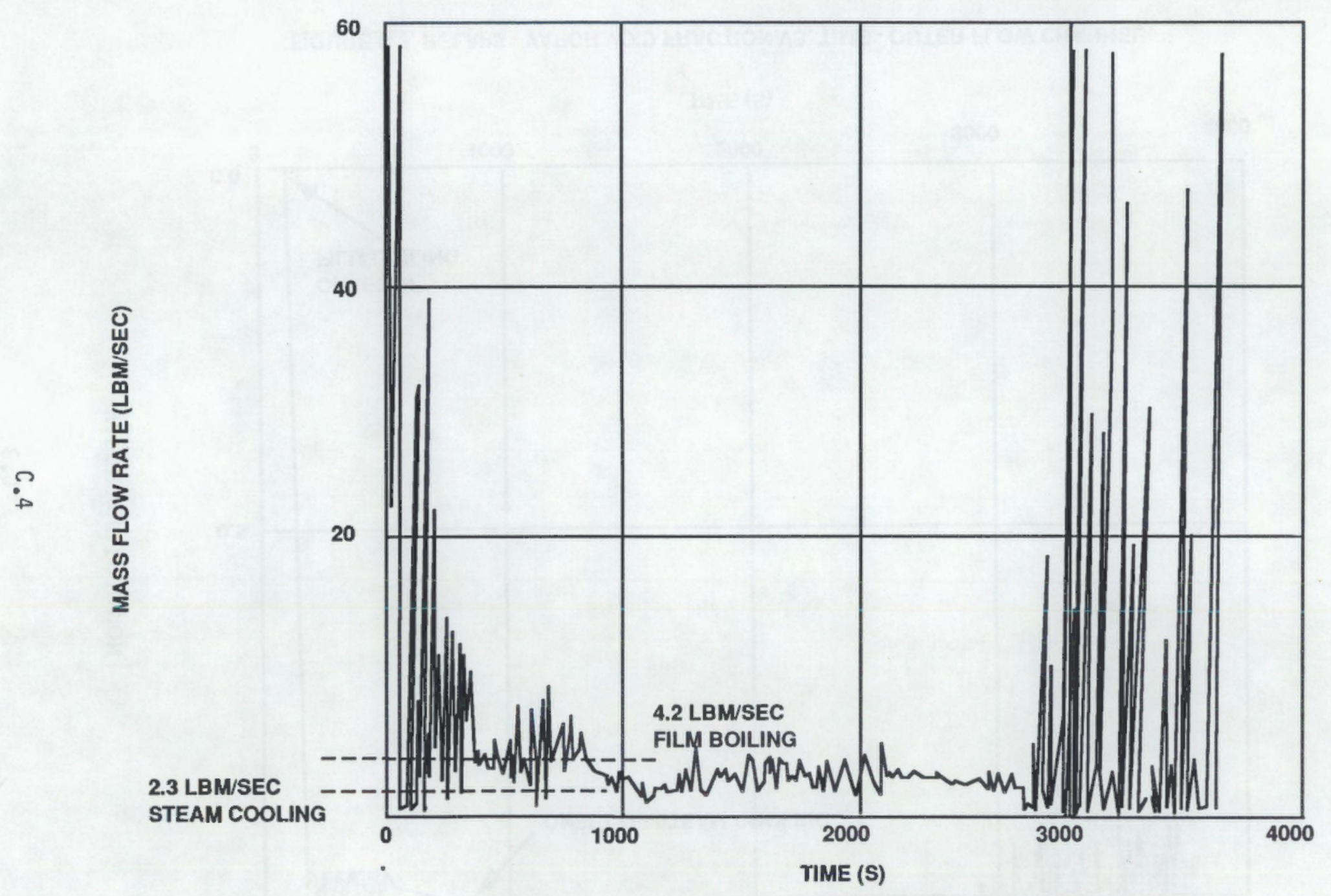

FIGURE C.4.RELAP5 - MASS FLOW RATE VS. TIME - INNER CHANNEL 


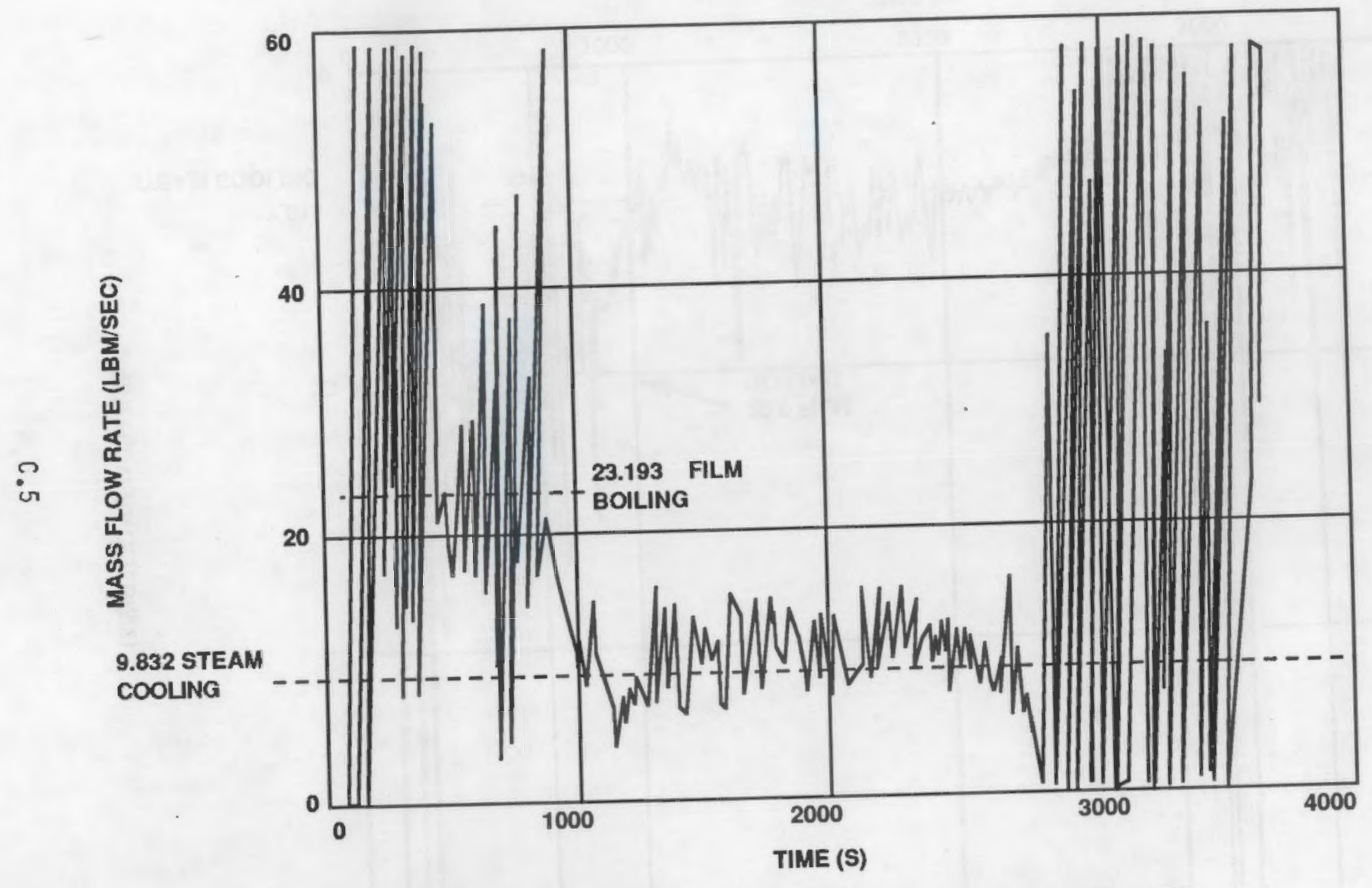

EIGURE C.5. RELAP5 - MASS FLOW RATE VS. TIME - MIDDLE CHANNEL 


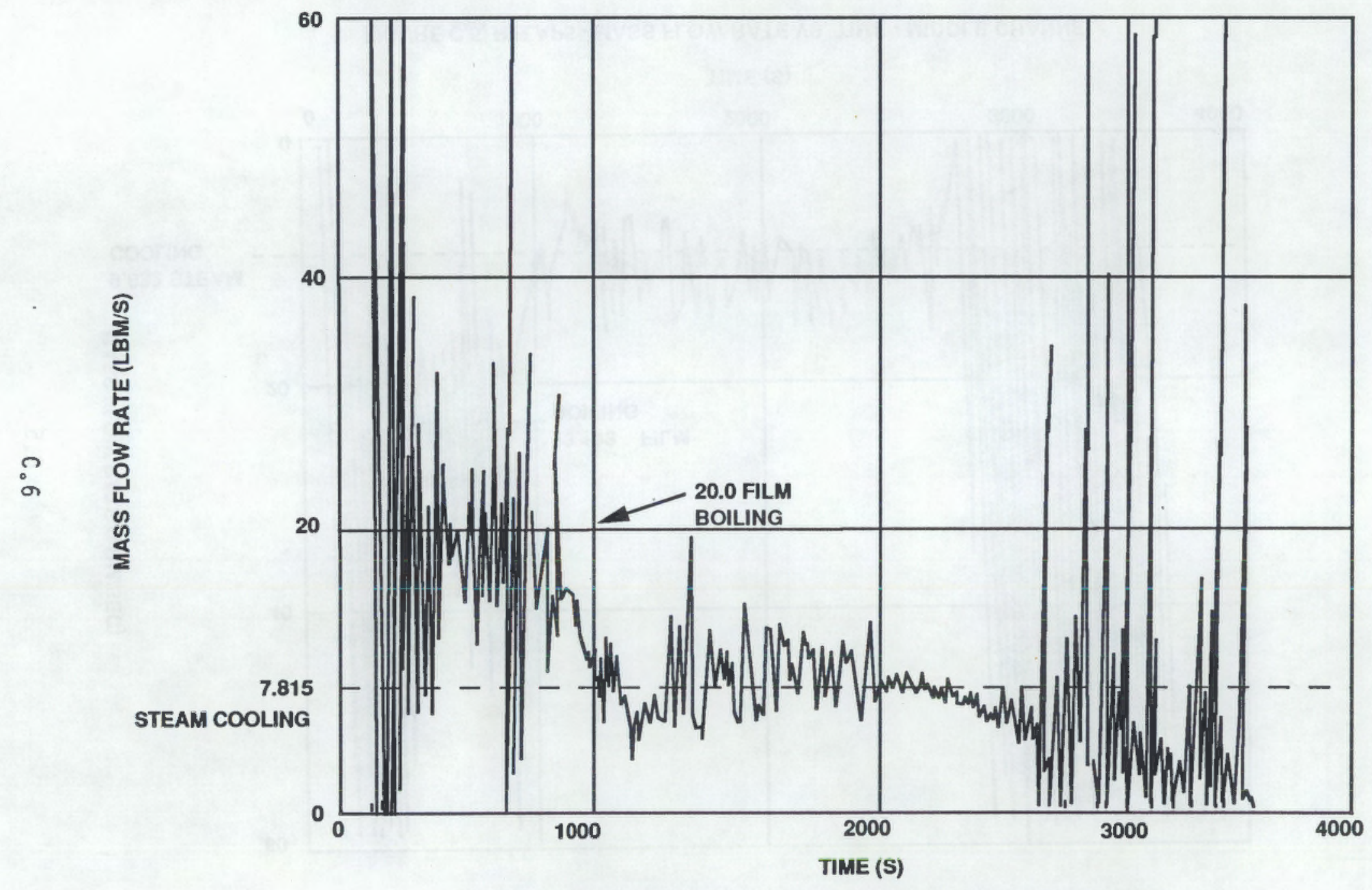

FIGURE C.6. RELAP 5- MASS FLOW RATE VS. TIME - OUTER CHANNEL 


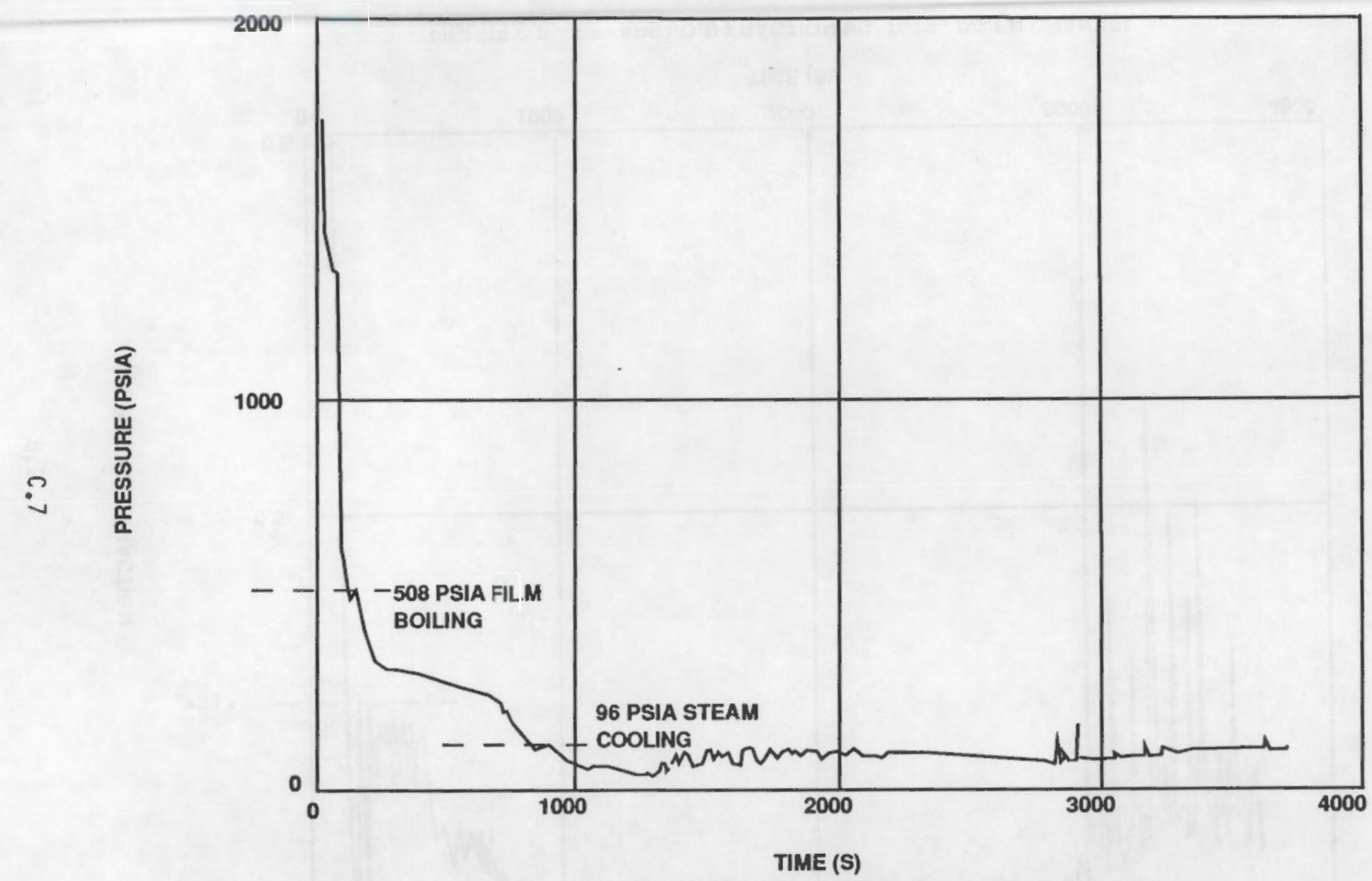

FIGURE C.7, RELAP5 PRESSURE VS. TIME 


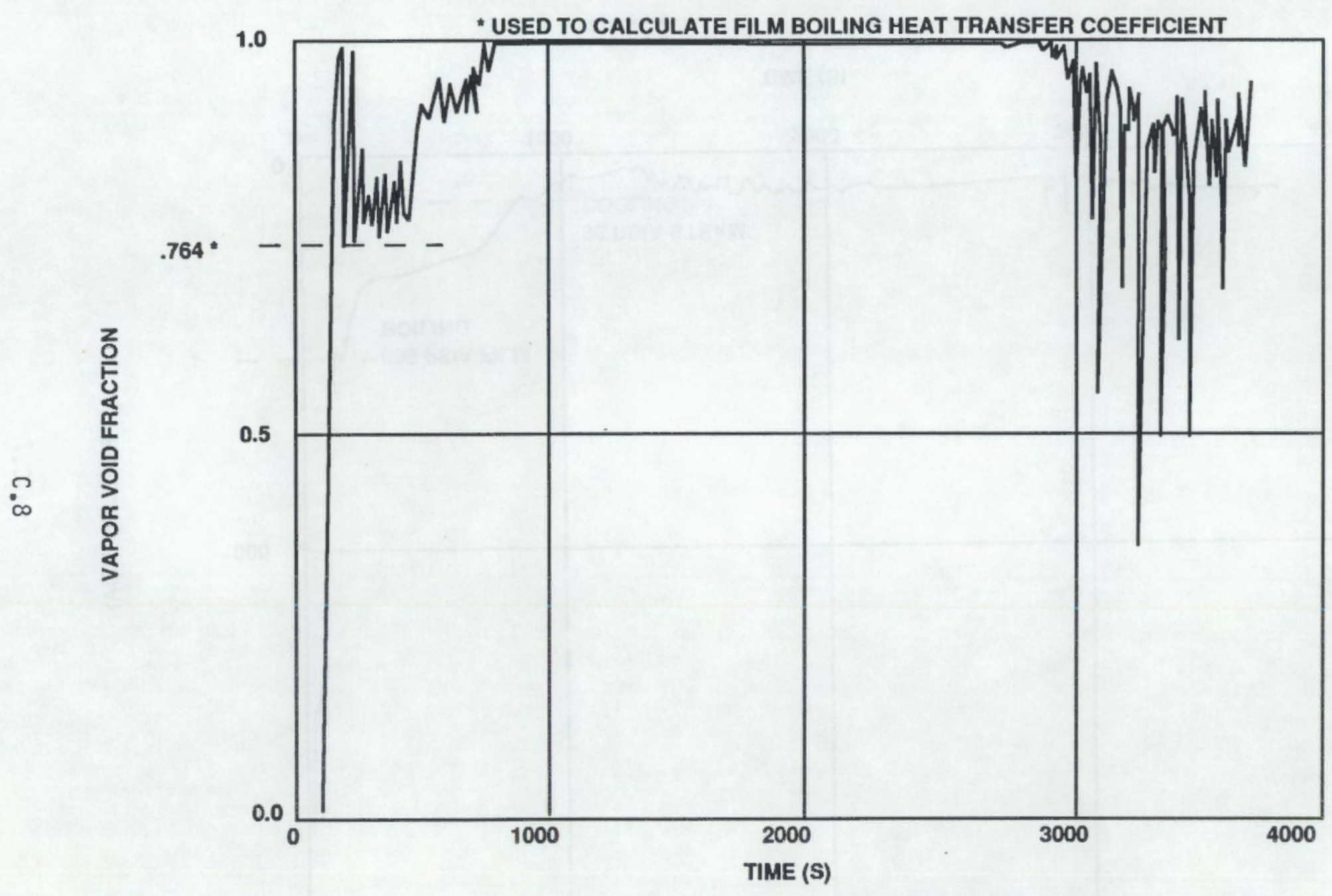

FIGURE C.8 - RELAP5 VOID FRACTION VS. TIME - INNER CHANNEL 


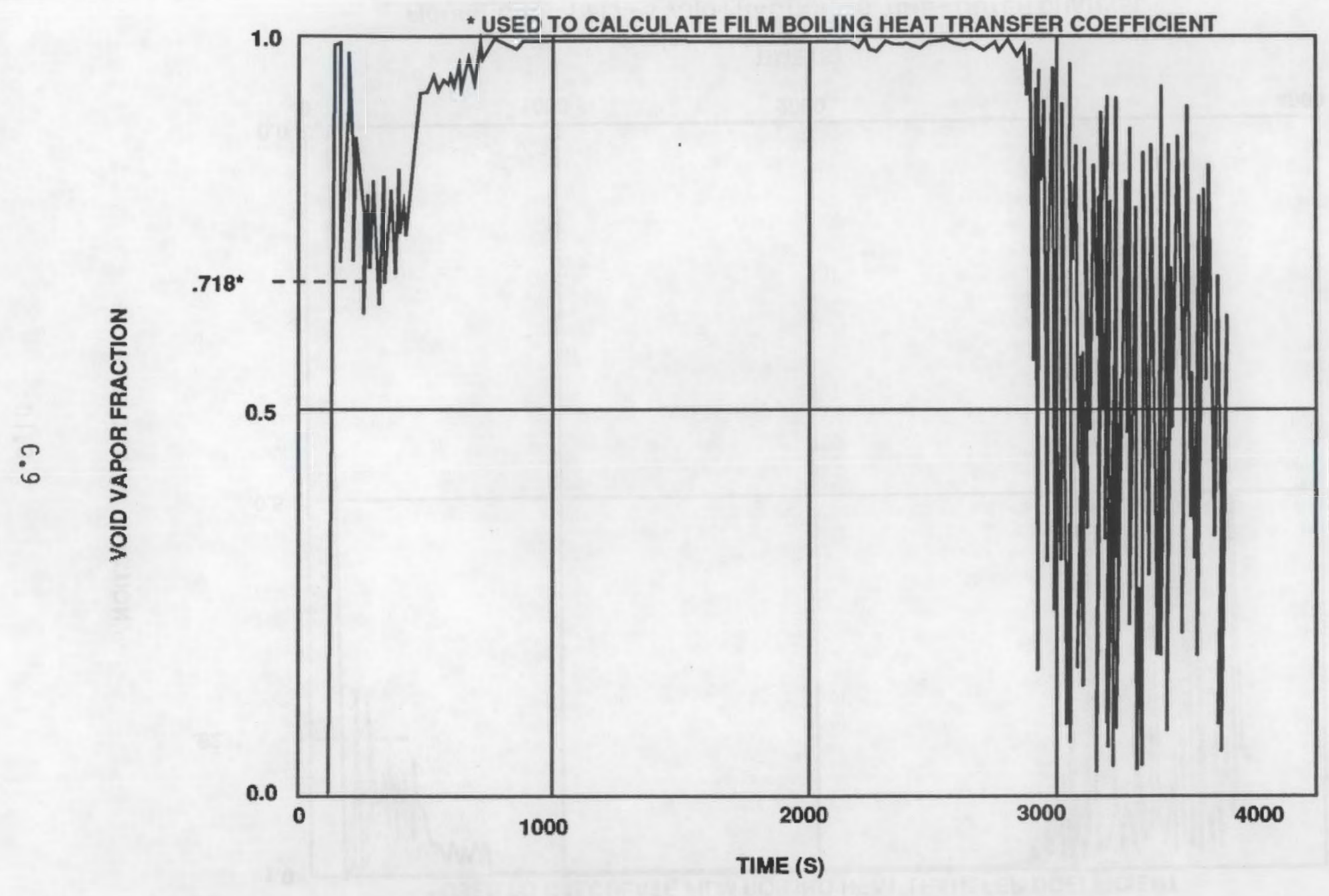

EIGURE C.9 - RELAP5 VOID FRACTION VS. TIME - MIDDLE CHANNEL 


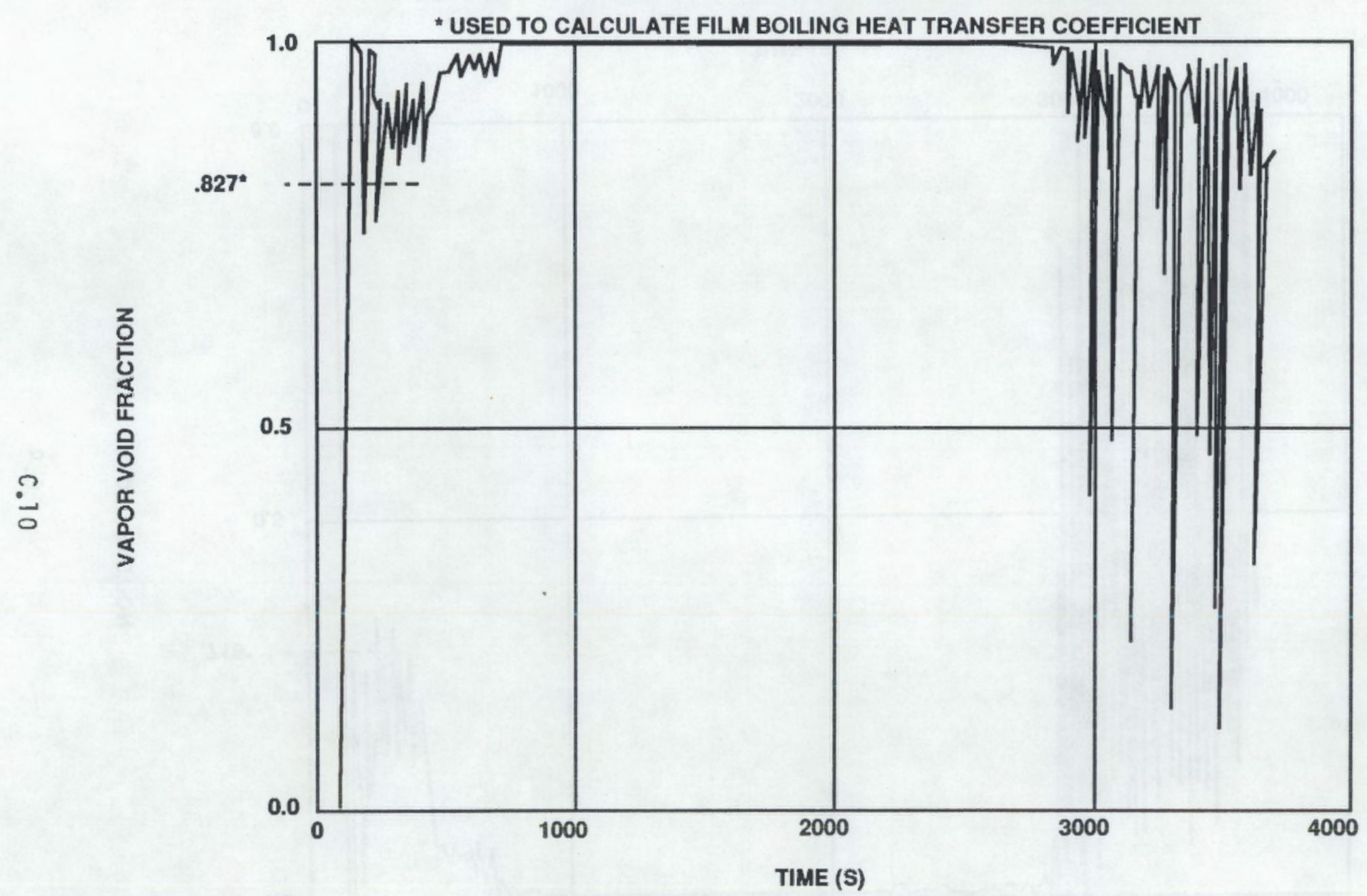

FIGURE C.10 - RELAP5 VOID FHACTION VS. TIME - OUTER CHANNEL 
PNL -7353

UC-706

\section{DISTRIBUTION}

No. of
Copies

OFFSITE

2 DOE/Office of Scientific and Technical Information Center

\section{ONSITE}

DOE Richland Operations Office

E. C. Norman

6 Westinghouse Hanford Company

F. J. Heard

D. M. Ogden (5)

12 Pacific Northwest Laboratory

N. J. Lombardo

T. J. Marseille

(3) $\mathrm{K} 5-17$

F. E. Panisko

K5-19

M. D. White

P8-35

K5-17

Publishing Coordination

Technical Report Files (5) 
